
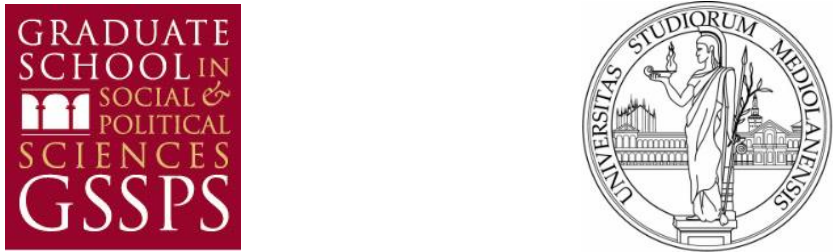

UNIVERSITY OF MILAN

Graduate School of Social and Political Sciences (GSSPS)

Doctoral Thesis in Economic Sociology and Labor Studies

\title{
THESIS DISSERTATION
}

\author{
Ethos at Stake:
}

Roads to Success among Chinese Small Businesses in Milan, Italy

Supervisor:

Prof. Gabriele Ballarino

Co-supervisor:

Prof. Diego Coletto

Phd Candidate:

Ottavio PALOMBARO

Matriculation n. R10424 - R37

A.Y. 2016 / 2017 
S. D. G. 


\section{INDEX:}

INDEX OF TABLES

$\gg$ p. 7

ABSTRACT

$\gg$ p. 9

ACKNOWLEDGEMENTS

$\gg$ p. 10

INTRODUCTION

$\gg$ p. 11

PART ONE

I. ENTREPRENEURSHIP AND ECONOMIC SUCCESS

.p. 23

1. 1 Sociological Theories on Entrepreneurship and Economic Success

1.1.1 Classical Contributions to the Topic

p. 23

1.1.2 The Role of Personality, Culture and Networks

p. 25

1. 2 The Place of Values in the Picture

$\gg$ p. 29

1.2.1 What if Something is Missing?

p. 29

1.2.2 One Example Pointing toward This Direction

p. 31

II. PROTESTANTISM AND ECONOMIC SUCCESS......................p. 33

2. 1 Weber's Thesis on the Protestant Ethic

$\gg$ p. 33

2.1.1 The Critics and Their Fallacies

p. 33

2. 2 The Reality of Calvinism

2.2.1 Predestination contra Anxiety

» p. 46

2.2.2 Assurance of Salvation as the Logic Alternative and other Preconditions

p. 46

p. 48

III. ACTUALIZATION OF THE PROTESTANT ETHIC.

p. 55

3.1 The Puritan Ethic in America

3.1.1 Evolution and Actualization of the Matter

$\gg$ p. 55

3.1.2 The 'Americanization' of Protestantism

p. 55

p. 57

3.1.3 Consequences on the System of Beliefs

p. 67

3.2 China and Its Spirit of Capitalism

3.2.1 Protestant Revival and the Economic Boom

$\gg$ p. 75

3.2.2 The Case of Wenzhou: the Jews of China's Jerusalem

p. 75

p. 79

PART TWO

IV. METHODOLOGY OF THE RESEARCH. .p. 87

4.1 Discussion on the Method

4.1.1 Prolegomena

4.2 History of the Research

4.2.1 Connecting the Dots

4.2.2 Recapitulation of the Steps of Entrance into the Field

4.2.3 Sample, Techniques and Focus

4.2.4 The second Phase of Case-Control 
5.2.1 Chinese Small Businesses in Milan and their Ideal-types

p. 116

5.2.2 The Visionary Investor

p. 122

5.2.3 The Autonomous Buyer

p. 137

5.2.4 The Organized Jeweler

p. 145

5.2.5 The Apprentice Salesman

p. 150

5.2.6 The Creative Barman

p. 155

5.2.7 The Italian-friendly Chinese Boss

p. 160

5.2.8 A Process of Financial Network

p. 163

\section{PART THREE}

VI. THE CASE FOR A PROTESTANT CHINESE WORK ETHIC. p. 171

6.1 The role of Chinese Protestant Beliefs in Business

» p. 171
p. 171
p. 174
p. 177
p. 180
p. 189
p. 203
p. 205
p. 213
» p. 219
p. 219

6.1.1 Introduction to the two Sets of Interviews

6.1.2 The Assistants to the Preconditions in the Field

VII. THE COUNTERPART FOR A PURELY CHINESE WORK ETHIC....p. 226

7.1 The other Side of the non-Christian Chinese Entrepreneurship

$\gg$ p. 226

7.1.1 Inheritance of Materialism

p. 226

7.1.2 The Power of the Chinese Network

p. 234

7.1.3 Cultural Basis for the Exaltation of Work

p. 240

7.2 The Chinese Common Denominator

$\gg$ p. 248

7.2.1 Direct Causality vs. Justification Logic

p. 248

7.2.2 Brief Excursus on a Non-Chinese Entrepreneur

p. 253

CONCLUSIONS.

p. 257

APPENDIX

p. 269

BIBLIOGRAPHY

p. 289

WEB SOURCES.

p. 302

CASE REPORT.

..p. 303 


\section{Index of Tables:}

Table 1 - Relationship between Protestant beliefs and economic ethos according to Max Weber theory.

»p. 39

Table 2 - Critical Approaches to Weber's thesis on Protestant ethic and the genesis of the spirit of capitalism.

$\gg$ p. 45

Table 3-Dynamics of the relationship between the Protestant beliefs and the economic ethos according to the theoretical argument.

»p. 53

Table 4 -Timeline that summarize the evolution of the spirit of capitalism according to the analysis.

»p. 66

Table 5-Evolution of Protestantism in United States and their contribution to the American capitalist spirit.

»p. 73

Table 6 - Dynamics of the relationship between the Chinese Protestant entrepreneurs beliefs and the economic ethos according to the theoretical argument in its empirical application.

$»$ p. 93

Table 7 - Scheme of the typical biographical journey of the Protestant believer.

$»$ p. 100

Table 8 - Part of the interview chart that refers to the beliefs that I wanted to measure among the Chinese Christian entrepreneurs.

$\gg$ p. 101

Table 9 - Part of the questionnaire that I submitted to respondents in order to test the presence of self-efficacy.

$»$ p. 103

Table 10 - Different options of outcomes related to the theoretical argument and sample composition for gender, age and religion.

$\gg$ p. 106

Table 11 - Part of the interview chart that refers to the explanations that I want to check among the Chinese non-Christian entrepreneurs.

$»$ p. 109

Table 12 - Evaluation chart for the first three Chinese entrepreneurs under shadowing.

$»$ p. 122

Table 13 - Evaluation chart for the second group of Chinese entrepreneurs under shadowing.

Table 14 - Illustration of the role of network in business among Chinese entrepreneurs under job-shadowing. In red the family, green the house church and blue external connections. Lastly the typical financial circuit behind business multiplication through network in the China town according to Ah Cy. $\quad$ p. 167-168

Table 15 - List of the Christian entrepreneurs under investigation. The ones with the grey line were part of the job-shadowing activity and Mario is the Italian outsider.

\section{$»$ p. $172-174$}

Table 16 - Peculiar organizational structure of the Chinese evangelical church under my ethnographic investigation.

p. 200

Table 17 - Results from the questionnaire on the presence of self-efficacy for both first and second group. It is possible to see a higher presence of self-efficacy among the first group particularly from the area of Wenzhou. It becomes more than double considering the belief in PAS. Regardless of the belief however self-efficacy tends to be prominent among young male small business owners.

p. 218

Table 18 - List of the non-Christian entrepreneurs under investigation. The ones with the grey line were part of the job-shadowing activity.

p. 226-227

Table 19 - Comparison between the list of religious values corresponding to Confucianism and Protestantism. In grey are the areas of overlapping between the two systems of beliefs. The list has no intention to be exhaustive but it points out the connections between the two sets of beliefs and business according to the main features of the model.

p. 244

Table 20 - Synthetic table representing the dynamics of the model for the case of Wenzhou in light of the results from ethnographic observations and the interviews. 
Dr. Ottavio Palombaro

Department of Social and Political Sciences, University of Milano - Statale

\begin{abstract}
:
Certain values are at stake for the success of economic behavior. Since the genesis of modern capitalism a set of beliefs proper of Calvinism (mainly Predestination but also Beruf, Innerworldly Asceticism, role of Sects...) was said by Max Weber to cause an anxiety about salvation and generate a propensity to economic success as a sign of election. I argue on the contrary that the Calvinist belief in the Perpetual Assurance of Salvation might cause a sense of self-efficacy able to favor economic success. In order to observe this in action today it is crucial to consider the evolution that the Protestant ethic went through migrating first in north America and lastly through the Protestant revival of China. Wenzhou is called 'Jerusalem of China' for its large Protestant community that is also strongly involved in business. Some scholar already pointed out the presence among those entrepreneurs of this Protestant ethic (Yi Xiang, Boss-Christian...). The data presented in this comparative qualitative study pertain to ethnographic observations, jobshadowing and interviews done among Chinese Christian and non-Christian entrepreneurs from Wenzhou living in Milan, Italy. The results show with some adjustments the presence of a Chineseversion of the Protestant ethic overlapping with several values proper to the Chinese context (Confucianism, lineage, social network). The extension of the study to other cases must be done with caution considering the non-causal justificatory role of the belief. Regardless: successful entrepreneurship involves specific social, cultural and even religious aspects that move beyond mere business strategies.
\end{abstract}

Keywords:

Capitalism - Work Ethic - Weber - China - Entrepreneurship 


\section{Acknowledgements:}

My first thanks goes to all the people who took part to this research among the Chinese entrepreneurs and economic players. The contributions contained in this work were not possible without the help of several Scholars and Professors to whom my personal gratitude goes. I thank here for the help, correction and useful directions received from Prof. Gabriele Ballarino during the whole duration of this research. I also want to thank here Prof. Marco Maraffi for his useful comments and encouragement in pursuing this topic with passion and perseverance. Another special thanks goes to Prof. Diego Coletto for his methodological help and consistent support in adopting the right strategy into the field of my research. I personally thank also Prof. Fenggang Yang for his inspiring work, his important inputs and all the help that the Purdue Center of Studies on Religion and Chinese Society has provided to my research. Particularly I thank Joy Tong Kooi for her interesting suggestions and visionary research, Xiangping Li from East China Normal University in Shanghai and Professor Feng Li from the East China University of Law and Politics in Shanghai for their help during my permanence in China. My personal tanks also goes to Xiao Yunze for all his help during my ethnographic observations in Wenzhou. Another thanks goes to Prof. Daniele Cologna for his interesting contributions to my work on understanding more the Chinese culture and context under my investigation and Prof. Patrizia Farina for her help. Thanks also to Tyndale Theological Seminary and the Vrije Universiteit of Amsterdam for their contribution and opening their doors to their documentation centers in order to do this research. 


\section{Introduction:}

How can someone's thoughts about something change the way reality is shaped? When can the view of self lead someone to become a social agent of change? Objects can be perceived in contrasting ways in the well-known example of the optical illusions, when a face becomes a glass or a rabbit becomes a duck. The reality stays the same but the perception of the individual makes all the difference in the world. Back in 1928, some sociologists (see the Thomas theorem in Merton K. R., 1995) conceived what became known as the Thomas theorem, which states: "If men define situations as real, they are real in their consequences." It is possible to put it this way: if someone believes that little green goblins are hiding in the woods and change his route to avoid them, then his fantasy has affected his experience. And this becomes more than a psychological cliché when the social power of those mechanism is taken into consideration. In this regard when Adam Smith's major economic idea on the invisible hand was embraced at large, it changed the whole direction and shape of modern society. The power of ideas, the view about self, as immaterial as they are, tend to go beyond the naturalistic realm and still influence individuals, societies and economies.

But some may ask: what difference does it makes to take those aspects into consideration when adventuring in the field of economic sociology? For endless decades scholars had tried to come up with an answer on what are the determinants for economic success. Some relied only on economic formulas others pushed more on the sociological side and pointed out the role of innovation, others just relied on the influence of personality, others listed culture or networking, others simply trusted that chance will do its work. Yet despite the fact that all those contributions are instructive and important, they never seem to grasp the power of ideas in shaping economic success for individuals and then at large for the whole society. Are those element in and of themselves able to pass the test of empiric validity? Success, as I will show in this study, is in fact to be defined in relation with its opposite: failure and crisis. And that's where certain ideas can come in and really make the difference.

The concept of self-esteem to start with, has some clear significance for the achievement of economic success. Surprisingly, even for the social actors, this success finds its origin in certain beliefs. Among Christian teachings in particular, I found that ideas such as the one of 'loving oneself', a self-image as 'uniquely wonderful' and 'intrinsically valuable' results to have a powerful influence in shaping the daily life of an individual. Those self-worth teachings based on the idea of man as made in the 'image of God', conceive the individual in this case to have an infinite worth, becoming 'glorious', ‘dignified', having ‘worth', 'beauty' (Adams J. E., 1986). Despite undergoing 
many critics inside the same 'religious' entourages, I argue here that those powerful ideas can really in fact influence and shape the life of the individuals, even their work-life.

The purpose of this writing is primarily one of building a closer bridge between the disciplines of economic sociology and sociology of religion. This will be done through an explorative analysis of the relationship between capitalism and Calvinism, between economic behavior and a peculiar set of religious beliefs. Entrepreneurship will here display its sociological significance in its relationship with an etherogeneus set of public forms of religiosity. When I refer to religiosity, as it will become more clear during the progress of the analysis, I refer to something far broader than religious affiliation or church attendance. So, since this study intends to go deeper than a description of nominal religious identification, the question on the legitimacy of such move immediately comes to the surface. Is it allowed for a study that intends to reach a certain degree of objectivity to appeal to a set of ideas of religious connotation? Such question challenged my study from the primary stages of this research to its conclusions. In fact the scientific study of religion has a way to represent a challenge for many of the different ramifications of the discipline of sociology and beyond: positivism, biologism, Marxism, neo-classical economics, structural functionalism, world system theories, rational choice theory, etc., ... I argue here that there's many practical reasons why the discipline of economic sociology need to confirm its efforts for such topic. Chief among them is the central relevance, as I shall express in details ahead, of an individual set of religious beliefs for the formation of a specific economic behavior that indirectly is able to affect the presence or absence of economic success.

Yet the modern and secular worldview of today has somehow neglected the centrality of certain concepts simply because they are somehow connected to the idea of the supernatural. To introduce such dimension would force the discipline of sociology to rethink the very foundations of how somebody looks at human behaviors. Many sociological approaches to this topic came with a baggage of assumptions mainly on how somebody must view science. The task of any science and discipline is said to be the one of observing and analyzing phenomena objectively without making 'religious assumptions'. But if any reference to the supernatural is left out at the foundation of any theory, the same goes also for any of its conclusion. This bias might force any scholar to rethink all sociology, its foundational assumptions, and its effects in the free progress of the discipline as a whole. Even if today the majority of scholar would tend to dissociate themselves with many of the positivist claims of the origin of sociology they would still indirectly agree with its naturalistic and empiricist claims. Religion as a result is somehow 'disqualified' from the possibility of having any sociological relevance. But how can someone count for the myriads of social phenomena of extreme significance today for the foundations of Western civilization which have their roots in 
religion? Among the many examples I here focus on the many economical, political, cultural and sociological benefits that the spread of the Protestant Reformation had for the progress of Western civilization. This case was notoriously defined by the Dutch politician, journalist, stateman and Neo-Calvinist theologian Abraham Kuyper in his Lectures on Calvinism (Kuyper A., 1931). Reading through those pages allows anybody to see how clearly certain ideas (mainly the belief in Calvinism), regardless of their spiritual origin, are able to transform the way people act as individuals and in society having an influence that extends to every area of life: religion, politics, science and art (Bratt D. J., 1998; pp. 279-322).

But as I said the present status of humanities and social sciences seems to be quite allergic to the inclusion of non-material terminology such as the 'spirit' (Geist) of capitalism which I will later describe in details. In this respect is remarkable to mention Vern Sheridian Poythress own's words about the fallacies of modern approaches to societies:

\begin{abstract}
In the twentieth century sociological and anthropological study of human societies has assumed, as a foundation for the discipline that God can be left out of the account. Sociology and anthropology may of course study 'religion' as one aspect of society. But this study focuses on human practice of religion not on God himself. Why this exclusion of God? One response would be that only by such an exclusion could these disciplines hope to be scientific. But the aspiration to be scientific is itself loaded. To begin with it may be loaded with the assumption that somehow human beings can be treated exactly as if they were on the same level as animals or rocks or other creatures $[\ldots]^{1}$
\end{abstract}

Beyond the methaphysics and the specific personal view of this author, here lies a crucial perennial problem in the discipline of sociology when establishing the degree in which certain ideas unavoidably connected with the supernatural can be legitimely analyzed. The broad discipline of religious studies, and inside it the field of sociology of religion, in the past century has, despite some empirical studies, ${ }^{2}$ often undermined the factual determinants of religious beliefs as an aspect worthy of intentional study. The positivist root of this approach has instead labeled beliefs as 'illusion', opposing the study of beliefs not from purely scientific motives but because those scholars themselves entertain other 'convictions' (paraphrased but still forms of beliefs), which they replaced to the others (Bavinck H., 2003; Vol. I, p. 51-52). Later on Vern Sheridian Poythress continues pointing out the intellectual fallacy of this prevailing interpretation:

[...] But even more seriously the label scientific ignores the possibility that our modern conception of science, taken from the existing state of the natural sciences, has already been distorted by a systematic human flight from recognizing the presence of God in science. The aspiration to be scientific may already have introduced biases. [...] But from a biblical point of view, the move to exclude God ignores the single most important fact about communication and the most weighty ontological fact about language. When we exclude God we distort the subject matter that we study, so we can anticipate a multitude of ripercussions when it comes to the detailed analysis of the subject. ${ }^{3}$

\footnotetext{
${ }^{1}$ Poythress V. S., 2011, Redeeming Sociology. A God-Centered Approach, CROSSWAY, Wheaton, p. 47.

${ }^{2}$ For our case of Protestant migrants see for example: Light, Ivan, and Edna Bonacich, 1991, Immigrant Entrepreneurs. Koreans in Los Angeles. 1965-1982, University of California Press, Los Angeles.

${ }^{3}$ Poythress V. S., 2011, Redeeming Sociology. A God-Centered Approach, CROSSWAY, Wheaton, p. 47.
} 
By saying this the author is not suggesting a re-introduction of theology in humanistic sciences but only pointing out a logical problematic biased conclusion coming out from this drastic separation. In the same way an approach of 'religious defense' of a certain topic is to be discouraged in the scientific study of religion, also a complete rejection of religious explanations in the name of objectivity is to be avoided. Francis Shaeffer once said: 'if there's no absolute by which to judge society, society becomes absolute' (Shaeffer F., 2009). So the point made by Poythress apart from its rethoric is that first through the humanistic view centered on man then with the positivist shift that gave birth to sociology, man so far was not able to give a final fundamental solution to the problems of society by intentionally replacing God from any objective sociological discussion. It is possible to conclude that from both sides of the debate no determinism whatsoever is compatibile with the scientific study of religion. As the reader will go through the pages of this work it will be clearer why this methodological point is so crucial and what type of problematic ripercussions there are when somebody adventures in the analysis of such topic.

Having set this premise and coming to the heart of the matter the area of research of the present study has to do mainly with the economic and sociological relevance of certains religious elements. To better comprehend what this mean someone has to go back to the classics of sociology that understood well what is at stake here, what today is somehow the big 'elephant in the room' of contemporary sociology. The starting point of this study is the famous work of Max Weber on the Protestant Ethic and the Spirit of Capitalism (Weber M., 1930 [1905]). Together with subsequent analysis this seminal work basically set the foundations for the analysis of the role of religion for the economy and society. Weber identifies a specific set of religious beliefs proper of Protestantism (Beruf, Inner-worldly Asceticism, Role of Sects, etc., ...) as the spark able to ignite the fire of modern capitalism. The Protestant ethic therefore has nothing to do with love of money or desire to be rich common to all ages and men. The function of those religious beliefs, sometimes even accidentally, was the one of shaping a specific conduct and way of life that resulted in succesfull economic behaviors and crucial for the advent of modern capitalism. By doing this it must immediately be clarified that Weber was not equating the spirit of capitalism with capitalism itself, nor he intended to say that Protestantism was the ultimate cause for capitalism.

This conduct and way of life is what later I will better describe as ethos ${ }^{4}$, a variety of individual systems of values different according to time and space. Among them I focus on a specific economic ethos that lies behind what even Adam Smith perceived as a turningpoint in the worldview of modern economy. At the heart of Weber's thesis was the centrality of the Calvinistic

\footnotetext{
${ }^{4}$ from the Greek word: "ع̋os, ouৎ, tó 'custom' 'habit' 'character' used to describe the guiding beliefs or ideals that characterize a community, nation or ideology. 
belief in predestination as an element causing anxiety about eternal salvation in the believer and therefore leading him to find a solution through economic success as a sign of his personal election. As I was noting the popularity of such thesis in every manual and book of introduction to the matter I was surprised of the absolute neglect of the original sources from the side of scholarly studies. So adventuring in the study of the works of John Calvin as well as successive expressions of Calvinism, mainly in Puritanism, is possible to see no presence of such anxiety about salvation but rather the very opposite: a state of complete and perpetual assurance. After Max Weber intriguing thesis a really fervent and quite intricate field of studies has developed (McKinnon A. M., 2010; Barbalet J.M., 2008; Schaefer R., 2007; Cohen J., 2002; Delacroix J., Nielsen F., 2001; Kalberg S., 1996; Treiber H., 1993; Fisschoff E., 1991; Giorgi L., Marsh C., 1990; Boudon R., 1985; Marshall G., 1980; Collins R., 1980; Razzell P., 1977; Kim H. C., 1977; Bouma G. D., 1973; Roper T. H., 1972; Baechler J., 1971; Mirels H. L., Garrett J.B., 1971, Parsons T., 1968 Bendix R., 1967; Means L. R., 1966). Yet for the most part those critics were not able to deny the validity of the thesis, also due to the sometimes superficial understanding of concepts and historical facts or lack of substantial alternative explanations.

My thesis therefore has the intent to redirect those theoretical conclusions on the basic of documentary theological studies on the sources of such thought pointing out its sociological significance. I argue that the belief in Perpetual Assurance of Salvation together with the other groups of preconditions already identified by Weber is the core of the revolutionary change introduced by Calvinism and is able to impact indirectly economic success. Economic success, among other qualities, has been said by the literature to be already connected with the principle of self-efficacy, mainly someone's belief in his ability to achieve a certain goal (Bandura A., 2001; Zhao H., Seibert S. E., 2006; Laguna M., 2013; Rauch A., Frese M., 2007). Giving the fact that some studies already have shown that certain religious beliefs leads to self-efficacy the question remains on how to check the presence of such correlation between the belief in Perpetual Assurance of Salvation (PAS) and self-efficacy. This can be done of course only by finding a contemporary case of what Weber described when referring to the Protestant Reformation and the genesis of the Spirit of modern Capitalism.

I am not referring to a thing of the past, no longer part of a secularized society, but to a very active principle that can only be traced considering the economic changes in today's world equilibrium. Some studies in fact showed the possibility of the validity of Weber's thesis still in our today's world but under different conditions and places (Merton R. K., 1957; Lenski G., 1961; Willems, 1968; Cowley \& Ballweg, 1971; Kim H. C., 1977; Verba S. K. L., Schlozman H. B., Brady N., 1993; Barker, D. C., Carman C. J., 2000; Feldmann H., 2007; McCleary, R. M., Barro, 
R. J., 2006; 2003). Mainly this evolution that must be taken into account, if someone desires to adventure a re-actualization of the thesis, the crucial passage of Protestantism from Western Europe in the XVI-XVII century to North America. In this respect particularly notorious was the sociological study of another classic cornerstone: Robert K. Merton study of Puritanism (Cohen B. I., 1990). Although Merton focuses more on the impact of Puritanism on modern science this and many other studies point out to the survival of the Protestant ethic in English and successively American Puritanism for the evolution and growth of such spirit of capitalism. Puritanism, Calvinistic in almost all its constitution, was accompanied by a pervasive ethos that worked as a crucial sociological factor for the rise of modern science, technology as well as for the economic development of the Old and New England. Yet today that Puritan heritage seems almost to be lost and substituted by the consumer society and a 'prosperity Gospel' that announces the deat of such ethos or perhaps its further evolution into another geographical and historical context.

Yet a specific case in the far East saw somehow the 'genesis' or rapid change into capitalism during the last half-century. For this reason my eyes were captured by the case of contemporary China and how this country is changing the economic equilibrium of the relationship traditionally viewed between east and west, between the Western world and Asia. Particularly after the economic reforms, China has witnessed the advent of capitalism remaining surprisingly a communist nation. Paralleling the economic shift, a consistent religious revival is taking place in the ricefields as well as in the modern eastern cities of China such as Wenzhou. Among all other religions Protestant Christianity plays a leading role in such context of religious revival coincidentally at the same time as this economic boom. Some scholars already pointed out that Wenzhou, also called China's Jerusalem, because of its growing population of Christian Protestants, is also one of the most rich cities of China with a very high rate of entrepreneurship. Wenzhou has also witnessed the presence of a 'Boss-Christian phenomenon' where many Protestant believers are also strongly involved in business entrepreneurship (Hefner R. W., 2010; Cao N., 2008; Wenger J. E., 2004; Bays D. H., 2003; Fried M. H., 1987; Masland J. W., 1952). As I was approaching the literature on this interesting case (Yang F., 2006) I've found that many ideas present on Weber's treatise about western-Europe during the times following the Protestant Reformation were surprisingly 'resurrected' among those contemporary Chinese businessmen of Wenzhou. So at the same time of this advent of contemporary capitalism, China today is interestingly enough witnessing the presence of such ethos from a variety of influences that could apparently include Protestantism as a crucial factor. This was then leading me to elaborate a research question that flows from the pages and years spent investigating the roots, characteristics and economic influence of such Chinese economic ethos in many ways reflecting and overlapping the ideal-types described by Weber ( $Y i$ 
Xiang, Boss-Christian phenomenon, House Churches, etc., ...). This initial connection is what gave a starting point to my quest for the understanding of how this theoretical argument that affected the discipline of sociology from its early stages could find an evident interplay in today's real life.

As I was listening to stories from my Chinese friends it became apparent that it was not something just confined to the borders of the Public Republic of China but it was transported in many country of the Western world including my own. Italy like much of Western Europe was witnessing a massive Chinese migration that was contributing consistently to the advancement of their economy. In Italy big cities like Milan or Prato as well as many other cases like Paris, London and other places in Western Europe experienced in the past 30 years a strong involvement in business among Chinese entrepreneurs migrating mainly from the Chinese city of Wenzhou. Having found this theoretical connection between the system of beliefs described by Weber and the contemporary case of Protestant China's spirit of capitalism I decided to apply the theoretical verification of Weber's model to this specific sociologically relevant case. So I thought that with the contacts I had and the context I was living in the city of Milan this was enough to advance in an investigation. It came into my mind that if under the constraint of an heavy and long period of economic crisis in Italy the Chinese community was doing exceedingly well in their business above many other migrant communities then there was a need to discover a reasonable explanation for it.

Mainly because of the nature of what was required to be observed (religious beliefs and social behaviors in the workplace) I decided to proceed with a case-control comparative holistic qualitative design in the shape of an ethnography. The study presented here was done among Chinese entrepreneurs migrated from Wenzhou involved in different ways in small business activities in Milan, Italy. The research that I present here is the result of two primary strategies: first the submission of interviews and questionnaires to 85 Chinese entrepreneurs mainly in Milan, Italy. The group was etherogeneous, composed by both Chinese Protestant and non Protestant entrepreneurs to check the validity and presence of my original theoretical model. The intention was to identify the presence and role in business of the set of beliefs among the Protestant entrepreneurs (belief in the Perpetual Assurance of Salvation, House Churches, Yi Xiang, Boss-Christian Phenomenon, presence of a Charismatic Leader, etc., ....) and to compare those results with non Christian entepreneurs to see the difference through a series of potential alternative explanations to the religious ones for the presence of economic success (Economic explanation, Cultural explanation, Network explanation, Minority explanation, Constriction explanation, Communist explanation, etc., ...). The study however was also open toward different interpretations not necessarily connected with the original theoretical framework as they arose from the field. 
At the same time I was contacting Chinese entrepreneurs and submitting interviews with them, I also started a more focused qualitative analysis of repeated participatory observation through the technique of Job-shadowing. I basically was weekly following a group of six entrepreneurs in their daily work-life observing their behavior at work in an informal setting and following after them in the less invasive way as possible. The group was composed by two separate samples: one made of Chinese Protestant entrepreneurs and the other made of Chinese entrepreneurs with no relationship at all with the Protestant faith. This was done in order to guarantee a somehow reliable comparison between the two samples and in order to observe the real features of this economic ethos. As it will be further explained in the methodological section, the access to the field was particularly challenging and not void of problematics in the application of it to the theory of origin of the study.

The main problematic questions that the following study tries to answer to can be expressed this way: how can we define properly and understand the practical significance of concepts such as the 'spirit of capitalism' or economic 'ethos'? What are the specific features and historical origins of the relationship between religious belief and economic success? Why is the case of Wenzhou relevant in the understanding of this relationship and how the theoretical enunciation on the Protestant ethic can relate to our contemporary societies? What significance has for contemporary economic sociology and sociology in general the scientific study of religion? If I was to formulate those questions in the form of specific objectives I would define the objectives of this present thesis as follows:

- Identify and define the relationship between Protestantism and the spirit of capitalism in a contemporary setting.

- Identify and analyze the economic, psychological and sociological significance of the concepts of beliefs, ethos, values, ideas, rituals, etc., ....

- Establish their determinants for economic success among Chinese small businesses in Milan, Italy.

- Analyze the historical origins of the theoretical debate in light of the more contemporary religious evolutions.

- Produce an exhaustive ethnography of the Wenzhou entrepreneurship model overseas in the specific migratory contextual environment of Milan, Italy.

- Promote a case of entrepreneurial success among migratory communities in the contemporary world.

- Promote and develop the centrality of a scientific study of religion in sociology of religion and contemporary economic sociology. 
Concerning the first point which is the main central objective of this study the method, the practical steps or the road with which I attempt to achieve such objective can be listed as follows together with the expected foreshadowed results:

Check the presence of the model as reformulated here on the basis of Weber's original argument among Chinese Wenzhouren Protestant entrepreneurs today.

a) Survival of the Weber's thesis, andacknowledgment of its validity still in today's contemporary societies.

b) Necessary adjustment of Weber's original claims in light of this fieldwork and other contemporary findings that go in a different direction.

c) Possible inclusion, or even complete replacement, by other intervening factors such as a 'Chinese Profit-Oriented Mentality' or a 'Chinese Common Denominator'.

In the following pages the reader will find a reconstruction of the three years I spent among Chinese entrepreneurs and small businesses in the area of Milan, Italy. The observations of the qualitative research are preceded and accompanied by the theoretical framework that originated such investigation. My expectation is that at the end of this sociological journey the reader will at least have an idea of the reasons why successful entrepreneurship involves specific social and cultural aspects that move beyond mere business strategies. This study furtheremore demonstrate the reality of a lesson: economic success in a situation of economic crisis like today is for the one creatively exploiting it, not for the one desperately fleeing it. 


\section{PART ONE}

\section{ENTREPRENEURSHIP, PROTESTANTISM AND ECONOMIC SUCCESS}

«ON THE SOCIAL DETERMINANTS OF ECONOMIC SUCCESS IN ENTREPRENEURSHIP AND THE NEGLECT OF VALUES AS A SIGNIFICANT DIMENSION IN PUSHING THE INDIVIDUAL TOWARD SUCCESS. FROM WEBER SOCIOLOGICAL CLASSIC ANALYSYS OF THE PROTESTANT ETHIC TO ITS EVOLUTION IN NORTH AMERICA AND CONTEMPORARY CHINA. THE ROLE OF THIS SET OF VALUES ON THE GENESIS AND DEVELOPMENT OF THE SPIRIT OF CAPITALISM.» 


\section{Chapter I}

"You were designed for accomplishment, engineered for success and endowed with the seeds of greatness"

Zig Ziglar

\subsection{Sociological Theories on Entrepreneurship and Economic Success}

\subsubsection{Classical Contributions to the Topic}

When faced with the question on how to become a successful entrepreneur someone is not be able to avoid the consideration of a large amount of principles that are inherently social. Entrepreneurship can be defined in economic sociology as the creation of new organizations, which occurs as a context-dependent social and economic process (Thornton P. H., 1999; p. 20). Entrepreneurs provide the economy with new ideas, products and ways of doing things (Iyigun M. F., Owen A. L., 1998). But apart from their features and characteristics, what are the determinants of their eventual economic success? Is it dependent on family background? Environment? Cognitive skills? Level of education? Ethnicity? Personality? I define here economic success on a personal level (not company or national level) in the sense of an accomplishment of an aim or purpose from the side of the entrepreneur related with the attainment of a profit (Halsey A. H., 1982). The Oxford dictionary simply defines it as the accomplishment of an aim or purpose, in particular as the attainment by the individual of fame, wealth or social status (Soanes C., Stevenson A., 2010). In this sense from the side of successful entrepreneurship in the XXI century this means the achievement of the results wanted or hoped for, mainly the making of profit. Therefore the measurement of economic success is not just dependent upon GDP, overall profit or economic growth of whole entreprises as traditionally considered in industrial capitalism. It is the case of relatively small businesses that today has come into the scene as a key player in the quest for economic success in the XXI century. Economic success is always related with the measurement of several indicators such as number of employees, profit, turnover, working capital, capacity utilization, years of operation, etc., ... The definition of economic success can also vary depending on the context of reference and the surrounding standard of economic life. Among the many aspects able to bring an entrepreneur to achieve economic success it is my intention to emphasize here the social aspects. By doing so I am not neglecting the centrality of other aspects for the achievement of economic success in entrepreneurship, starting with the economic to any other aspect such as technological, environmental and more. This will open the door in the next chapters to evaluations concerning the role of business ethics (not without controversy) in economic success. I am not 
necessarily referring to success on a mere social level that substitutes the quest for profit with the benefits to the community (like NGO's) nor I am denying the possibility of economic influence coming from ethics different than those that will be considered in the next chapters, although already hetherogeneous. To better understand this, it is crucial to reflect first on the main suggestions that have been proposed in the field of sociology about entrepreneurship, and in particular its connection with economic success.

The field of studies on entrepreneurship in sociology has focused mainly on two dimensions: willingness to take risk and ability to promote innovation. Risk-taking, the willingness to accept the risk and uncertainty involved in entrepreneurship has been a defining aspect of the study of entrepreneurship since the first reflections on this matter by Adam Smith and John Stuart Mill. Capitalism from its beginning involves economic activities where profit is under constant threats specially because of competition, therefore this creates a dynamic of constant anxiety. Apart from some circumstantial reflections by Karl Marx on the historical pattern that led merchants to transform into entrepreneurs through the advent of the industrial capitalism, no classical sociologist has analyzed deeply entrepreneurship in cultural and social terms as Max Weber. I will treat in details Weber in next chapters so I will not dwell much on his contributions here.

Later on with Joseph Schumpeter the second element of innovativeness was introduced as a defining dynamic quality of successful entrepreneurship. Schumpeter is considered as the theorist of entrepreneurship par excellence. Schumpeter defines innovation as a combination of factors of production that when combined with credit, breaks into the static equilibrium of the circular flow of economic life and raises it to a new level (Schumpeter J. A., 2010 [ed. orig. 1947]). The entrepreneur has in his DNA then a revolutionary character, a specific function of innovating through an ability to change, to combine elements and to create new production functions. The role of the entrepreneur is to reform or revolutionize the routine of production through the exploitation of an invention or in a broader sense through the introduction of a novel technical possibility (Breton Y., 1984).

According to Schumpeter the entrepreneur is a deviant that develops non-rational attitudes in a rational environment and through his anti-conformism he brings innovation into the picture (Stark D., 2011). Another interesting contribution from Schumpeter was the idea that the entrepreneur holds a specific type of personality, specific traits: will to power (wille zur macht), desire for action in order to build, to create, to gain, as well as other personality trait such as: flair, intuition, creativity, boldness in leadership, strong will, break social resistance in his own sphere of action, etc., ... This entrepreneurial type must face strong and multiple social, political and psychological resistances, and with all those different elements combined he can be crowned with 
economic success (Breton Y., 1984). More than for his financial resources the entrepreneur is qualified by his stand as a leader. It is upon this economic agent that capitalism is centered (Breton Y., 1984, p. 255).

\subsubsection{The Role of Personality, Culture and Networks}

Applying the reflections of Schumpeter several studies on social psychology have focused on the psychological traits of the entrepreneurial personalities, their background characteristics or cognitive schemas (Åstebro T., Herz H., Nanda R., Weber R., 2014; AA. VV., 1990). Those studies of the supply-side school focused on the individual characteristics of entrepreneurs, their potential for agency and change as well as the social context that affects their behavior (Thornton P. H., 1999). There is a specific type of personality and conduct according to this view that surprisingly differs from the simple, rational conduct of the economic man. Entrepreneurship is then permeated with an ideological element of passionate individualism, independence, laissez-faire competition and even a moral evaluation of someone's work. According to these scholars special types of individuals create entrepreneurship, individuals with high need for achievement, clear locus of control, strong risk-taking and risk-seeking propensity, problem-solving style, innovativeness, evident leadership style, continuous socialization experience as well as strong values. An entrepreneur in his quest to venture new activities must display: tolerance of failure, flexible planning in order to manage uncertainty and ability to hold a good reaction to changes (Thornton $\mathrm{P}$. H., 1999). Entrepreneurs enter and persist for long periods of time in their business despite low returns. First of all the entrepreneur values the non-pecuniary benefits of being self-employed even if this means lower earning sometimes. Because of this motivation he works longer hours than the average employee, in autonomy and independence, with no pressure of being interfered by other parties, or having to rely on others. The entrepreneur enjoys having control over his life and over the decision-making process. He tends to have also a sense of purpose for his life.

Added to this the entrepreneur achieves economic success because he is constantly looking for new challenges or he is ready to manage them when they involve his business. This once again is linked to the entrepreneur's affection for risk, being risk-tolerant, getting utility out of risk itself. The element of risk and relative return is essential for successful entrepreneurship because in its nature entrepreneurship is risky, characterized by activities that probably can result in failure. The pay-off of skills and investments, as high and consistent as they can be, remain always uncertain and possibly can lead to zero returns (Iyigun M. F., Owen A. L., 1998). For these reasons skills, human capital, economic resources are really not all the heart of the matter. If even the most 
brilliant entrepreneur with all those prerequisites misses this element of risk-taking and riskmanagement, the economic success of his business remains unreachable.

What is therefore the motivation behind it and the originating source that enable somebody to become a risk-taker? The management of risk is strictly correlated with an attitude of overconfidence and endemic optimism (Åstebro T., Herz H., Nanda R., Weber R., 2014). Concerning overconfidence it is important to consider the tripartite difference between: i) overestimation of one's ability or performance, ii) over-placement, too high assessment of one's skill relative to other competitors and iii) over-precision, the excessive certainty regarding the accuracy of one's belief (Åstebro T., Herz H., Nanda R., Weber R., 2014, p. 58). It is precisely this last element that, as I will point out in the next chapters, is a crucial force for the enhancement of economic success. Optimism on the other hand in entrepreneurship tends to revise up the probability of favorable events. When this optimism is led to the extreme by forces that I will later on describe, the entrepreneur is more likely to make risky and even imprudent financial choices. Those are the features of the persisting vitality of entrepreneurship without which entrepreneurship loses the propensity toward economic success. Following this interpretation other studies pursued a more situational approach to entrepreneurship, focusing on what an individual actually does as an entrepreneur. Mainly an entrepreneur has the unique ability to recognize new opportunities and to take advantage of them. However the studies on the individual traits of entrepreneurs fail to provide information on the environment and surrounding context within which the entrepreneur interpret and make sense of his actions (Thornton P. H., 1999). But what is the source that causes the presence of such personality traits? Is it just dependent on the single individual or are there certain contextual, social or cultural inputs able to generate such propensity and to favor economic success?

In order to respond to this question emphasis must be given on a more socio-cultural level to other dimensions resulting to be interesting when examining entrepreneurship: ethnic groups, social classes, economic sectors, cultural logics. Other sociological studies on entrepreneurship have been focusing therefore, like for the study that follows, on the formation of entrepreneurship among specific social groups, classes or ethnicities (raise of new firms and small business). Contrary to the traditional approach to capitalism where family-based economy was supposed to leave room to industrial and managerial forms of business, today small business is growing and it is a field of studies largely undeveloped. Markets are developing in countries and continents previously thought to have non entrepreneurial cultures as in the case of Asia that I will discuss later. According to those scholars the reason why somebody gets involved in entrepreneurship is also due to their social group of origin. 
The fact of being a minority group in a certain society, mainly a group that is deviant from the cultural norms of the larger society, a group that tends to suffer from a withdrawal of status, it pushes the individuals of those social group to get involved in entrepreneurship. Usually according to those theories, whether in the case of ethnic or religious minorities, as I will point out in next chapters, the purposes and values in life of those minorities are not respected by groups in the society where they live as migrants. Those groups on the other hand usually respect and esteem the values of the society around them. The desire of being accepted lead those people to seek the approval of the community through achievement of economic success in their business. For this reason many of those minorities tend to foster individualism and the development of a creative selfreliant personality. They tend to create bounded solidarity with their migrant customers, workers and investors because they are treated as foreigners.

Some scholars concerning this matter have noted how migrants within metropolitan areas tend to locate in ethnic 'enclaves' as they were evaluating the effect of living inside ethnic enclaves for the labor market (Edin P. A., Fredriksson P., Åslund O., 2003). Once arriving into a big city (as for example the China town in Milan that I will describe in next chapters) those migrants tend to be spatially concentrated in a state of semi-segregation. There are economic consequences of living inside those enclaves that for some entrepreneurs members of those enclaves lead them on high or low benefit. This is depending also on the position in the enclaves: being rich or poor, being part of an high or low quality of enclaves. For example entrepreneurs with high earning and self-employed have larger benefits through the identification with the enclaves (Edin P. A., Fredriksson P., Åslund O., 2003). Other studies however (McAllister I., 1995) go in the opposite direction pointing out how the condition of being a migrant entrepreneur has negative effects on economic success. Migrants perform far worse economically than individuals born in the country, because of economic disadvantages caused by the act of migration itself. This is true especially in the case of migrants from a drastically different cultural and linguistic context. Such disadvantage may often result in persisting and lifelong inferiority (McAllister I., 1995). Immigrants in fact very often are discriminated within the labor market because of their ethnicity resulting in the long term into a labor market segmentation and other structural major disadvantages. Moreover those disadvantages deriving from the fact of being migrant (difficulty on the language, problems in the recognition of academic titles, low access to information...) must be distinguished from the disadvantages deriving from discrimination itself (statistical vs. ethnic discrimination).

Another branch of studies in line with this perspective considers how economic environments are embedded in specific social and structural relationships. This approach underlines in particular the centrality of family as a social network source in entrepreneurship. The connection 
work-family and economic success among small business owners has been interestingly investigated (Loscocco K. A., Leicht K. T., 1993). In this picture gender and the family background result to have a decisive impact for the owner's business success. Family characteristics have different effects on the earnings and business revenues and even in work-related attitudes such as commitment, which ultimately affect economic success. Commitment to one's business, willingness to work long hours, seeing business as an important part of life are all crucial elements to achieve success (Loscocco K. A., Leicht K. T., 1993). The greater is the economic need in the family the greater the entrepreneur tends to work harder, especially in the case of men. The study shows that the difference in how hard the entrepreneur wants to push sales growth depends also on the presence of children, the fact to be a man (breadwinner) and the presence of certain family responsibilities. More and more small businesses are funded informally through personal savings, family or network of friends as primary sources for the establishment of new ventures (Thornton P. H., 1999).

Some studies on the growth of entrepreneurs firms in China considered for example how family members or close friends were of great importance, especially to nascent entrepreneurs (Zhao L., Aram J. D., 1995). The family background in fact is a significant predisposing factor to entrepreneurship. Individuals are more likely to become entrepreneurs if somebody in their family has previously been an entrepreneur (Åstebro T., Herz H., Nanda R., Weber R., 2014). In this case it is also of particular interest to consider the succession of businesses among those families of entrepreneurs in second, third and fourth generations of entrepreneurship. The extended family however not only can have positive effects on entrepreneurship but it is often a burden, because of the financial needs that come with the extended family.

On the role of social networks in entrepreneurship, not to be confounded with professional networks (interfirm cooperation or business linkage), some of the literature tried to point out the role of networking in achieving economic success. Some scholar in particular have shown how Asian sub-cultures have a better standing for entering and thriving in business due to group cohesion, mobility and level of education (Kristiansen S., 2004; p. 1149). High quality social networks, not therefore any kind of network, are able to provide the needed motivation, ideas, information, capital and trust. Those elements are the necessary resources in terms of social capital for business start-up, growth and success. This is important especially in the first phase of business start-up with high risk-taking. In this way for example the entrepreneur is able to reduce the transaction costs and risks as well as to receive useful information and new learning skills.

Furthermore the subculture carried about by those networks is important for the development of value systems, motivation, initiatives, ideas for new businesses expansion and trust 
that facilitates cooperation between entrepreneurs (Kristiansen S., 2004). The lack of trust in fact clearly hinders cooperation between entrepreneurs and increases transaction costs. Yet other scholars challenged this one-sided view that sees social networks as an essential factor for economic success (Egbert H., 2009). More than often in fact social networks have negative or restrictive effects on entrepreneurial success. Social networks according to this opposite logic may be considered as institutions and because of that they are not cost-free, they can sometimes result to be a constraint to entrepreneurial success. This perspective agrees on the fact that social networks at particular stages of the development process (whether for business start-up or survival as I shall point out later) can provide essential resources for the enterprise in the form of religious communities, circle of friends or co-ethnicity. However, in and of itself the social network can in the long term impede market development and also constitute a constraint to success, as much as it can foster it, through social obligations or boundaries of mutual responsibilities.

At times a network can cause serious problems to the economic growth or can lead to a business failure resulting to be the number one impediment to the economic success (Egbert $\mathrm{H}$., 2009). Because of their exclusive nature networks tend to be self-enforcing, preventing market structures from establishing themselves. This has negative effects on the economy as a whole that cannot be ignored. Sometimes even what may sound as a positive effect from the side of the entrepreneur, from a different viewpoint can be regarded as corruption where access to the benefits of the network is a privilege only for members (as it is the case of Chinese mafia that I will later mention more in details).

\subsection{The Place of Values in the Picture}

\subsubsection{What if Something is Missing?}

But if all those social element can only partially count for the presence of economic success in the entrepreneur, where does the ultimate motivational source lies? What is for instance the place of values, in the sense of personal virtues, subjective principles and ideals, for the achievement of successful entrepreneurship? Those who are interested in the economic behavior may have no particular interest in the role of values. Yet the economic behavior is an analytic dimension of virtually all social behavior, including values, that are able to create meaning, order and to influence and channel the economic behavior along certain tracks. Values continue to provide internalized sets of moral assumptions about human behavior that add a sense of rationality and order to the economic relations inherently uncertain in themselves. 
The market system in other words is embedded within a cultural sphere of which values are a significant part. Some scholars have pointed out the role of business ethics and social approval of economic activities among the cultural factors (AA. VV., 1990). What really interests me here is to point out that entrepreneurship is in and of itself deeply embedded in certain societies and cultures. Forces of rationalization so crucial in entrepreneurship don't simply generate out of business models but are strictly embedded in specific traditions, cultural, and even religious traits at times, that continue to shape the economic growth and social modernization. Therefore the cultural norms and the related role of expectations and social sanctions can either favor or hinder the innovation I've described above.

The economic category must be considered somehow subject to some cultural construction and is not exclusively guided by an attainment of utilities. Even elements such as beliefs or the analysis of trust, as well as the marginality status or the motivations for achievement have become central in many studies. There is an inculcation of the achievement motive, a standard of excellence and self-reliance in the entrepreneur that goes far beyond the mere economic activity or external structural influences. As crucial as they may be, they are not able to exhaust all the possible options. In particular values in entrepreneurship result to play a therapeutic role, helping the individual to feel better about himself, his work and his wealth. Values provide several important contributions to entrepreneurship and especially in allowing the display of economic success. Values among other things are able to provide:

- legitimation for the ways in which economic resources are distributed;

- maintenance of norms on which ordinary economic relations depend;

- encode and preserve knowledge useful for technical adaptation to a specific environment;

- explanations and comfort in face of economic activities that fall short or produce unexpected consequences.

In the next chapters I will show how those principles find detailed and specific examples for the case under my analysis that I will later introduce. In this present study therefore I will follow the theoretical argument that state clearly that culture, as well as values and religion or politics and economics should not be seen as separate entities with a reality of their own. On the other hand what is sociologically relevant for me is to observe the interaction of those dimensions in a specific social context and how this produces distinctive ambitions and behaviors. But the new economic sociology, perhaps under suspicious instances, with some exception (Light, I., 1991), has usually paid little attention to the relationship between economic life and values or religious beliefs. Some have argued that values or religious beliefs in a secularized context find functional alternatives and therefore they can exert only a passive and reactive role in the economic life. 
According to this view values and religion are epiphenomenal to the economic activity. The latter is said to operate according to its own laws rather than being significantly affected by anything like personal values or even a religious belief. Market behaviors in economics traditionally have been, in the words of John Stuart Mill, operating according to their own laws and considered therefore as a domain separate from ethical considerations. Yet the fundamental question remains on how the economic action is constructed and what interaction there is among the different spheres of actions. This process inevitably involves cultural, psychological as well as ethical dimensions. It is crucial therefore once again to reintegrate the ethical concerns into the economic realm.

\subsubsection{One Example Pointing toward This Direction}

To give an example concerning the role that for example religious networks can have on business some scholars found that among the social groups mentioned in the previous paragraph, the ethnic-religious communities of migrants in a new area result to play a strong leading role in business. Closely knit networks based on religious sectarianism and ethnicity offer financial support to their members fostering a form of business where the entire community contributes directly to entrepreneurial success. In those cases a severe form of social control limits deviant behavior in private as well as in intra-community business affairs. Also, the identification with those ethnicreligious communities provides an interest-free loan scheme that allows taking credit for business investments (Egbert H., 2009).

Ethical systems are proven to provide still today restraints in economic affairs and are central to the understanding of the socio-economic action of the individual. It is important therefore to bring more directly in the picture social, institutional as well as ethical and normative questions in order to advance the study of the economic behavior in our present society. Saying this I am not advocating a perfect harmony in such matter. In fact many times general religious beliefs can and do conflict with the economic action. However, as Durkheim pointed out, there are social sources and functions of religion even for the economic action, that should never be considered in isolation from a consideration of ends and sometimes those tensions unexpectedly resolve in greater advancements (Durkheim E., 2005 [ed. orig 1912]). In the next section I will introduce one of the most famous examples in sociology where that connection has been discovered and it will be possible to identify what can be precisely the role of values from an economic sociology perspective. 


\section{Chapter II}

\begin{abstract}
"Lastly, there was another most pestilential error, which not only occupied the minds of men, but was regarded as one of the principal articles of faith, of which it was impious to doubt: that is, that believers ought to be perpetually in suspense and uncertainty as to their interest in the divine favor. By this suggestion of the devil, the power of faith was completely extinguished, the benefits of Christ's purchase destroyed, and the salvation of men overthrown."
\end{abstract}

John Calvin

\subsection{Weber's Thesis on the Protestant Ethic}

\subsubsection{Definition of the Matter}

Several efforts have been made in the past trying to define the relationship between economy and religion. My major starting point for the discipline of sociology remains Max Weber and his masterpiece on the Protestant Ethic and the Spirit of Capitalism (Weber M., 1930 [1905]). The study starts with the question on why in Western civilization only, cultural phenomena attained universal significance and value (Weber M., 1930 [1905], see author's introduction, n. xxviii). The study then provides statistical evidence of the impact of the Protestant religious affiliation on social stratification. Weber was not the first author that made a reflection on that matter (Mel'gunov A. N., [ed. orig. 1875]; Arnold M., [ed. orig. 1878]; Laveleye E., [ed. orig. 1889]; Keats J., [ed. orig. 1899] in Bendix R., 1967).

What makes Weber so unique is that through a precise historical-scientific method he explained how a non-economic element such as a specific religious belief was able to influence the birth of the spirit of modern capitalism. This was done in clear opposition with the dominant interpretations of the time, such as positivism, Marxism, neoclassical economy theory, and with those that did follow after him such as structural functionalism, biologism world system theory. The "spirit of capitalism" is defined by Weber not as mere economic accumulation, but as an economic ethos that appeared at the birth-stage of modern capitalism in Western Europe and new England (Weber M., 1976 [ed. orig. 1905]; p. 132). The concept of "spirit of capitalism" can be understood only in light of the complex of elements associated in the reality of modern history. In this sense this spirit can be united into a conceptual whole from the standpoint of its cultural significance as Weber states:

[...] The peculiarity of this philosophy of avarice appears to be the ideal of the honest man of recognized credit, and above all the idea of a duty of the individual toward the increase of his capital, which is assumed as an end in itself. Truly what is here preached is not simply a means of making one's way in the world, but 
a peculiar ethic. The infraction of its rules is treated not as foolishness but as forgetfulness of duty. That is the essence of the matter. It is not mere business astuteness, that sort of thing is common enough, it is an ethos. This is the quality which interests us [...] (Weber M., 1930 [ed. orig. 1905], pp. 16-17).

The spirit of capitalism therefore can be defined as an individual's system of values (ethos) able to generate an attitude toward life which sees profit as an end to itself, an incessant pursuit of economic gain as an ultimate end to human existence. Such attitude, not to be confused with the mere utilitarian attitude common to all men, it is based on a source of spiritual satisfaction able to provide real purpose in all that someone says and does, including his economic action. This spirit of capitalism is the opposite of traditionalism and was historically present primarily in north-western European and north American capitalism at the time of Weber. He argued at this point that widespread forms of what he defines as 'ascetic' Protestantism inadvertently legitimated the rise of acquisitive capitalism (AA. VV., 1990). As it will be soon explained, the spirit of capitalism was directly generated by several beliefs proper of the Protestant ethic and developed later in contexts that were not necessarily religious. Such religious beliefs can be an explanatory factor because according to Weber's sociology of religion actions, even economic actions, must be understood starting from the idea of the individual and his system of values (ethos).

In order to understand the cultural causes, added to the technical and economic causes, for the advent of modern capitalism it is then extremely important to identify the 'ethic of conviction', of whom the Protestant beliefs are a direct manifestation. In the range of many options the social actor decides which kind of actions he will display: rational with respect to the purpose, traditional, affective or rational with respect to the value. What was intriguing for Weber was that Protestantism and capitalism came to be compatible despite their conflicting ends. As it will be examined the Protestant beliefs are able to push the individual to act according to his conscience and sometimes even with unexpected or unwanted outcomes from the side of the religious founders of Protestantism (Weber M., 2003 [1923]).

Weber here tries to identify the components, not necessarily of economic nature, that led to the formation of what he calls the 'spirit of capitalism', the ethical premise to the advent of modern capitalism (Weber M., 1993 [1920]). This doesn't mean that the ethical premise plays a deterministic role for the advent of modern capitalism. In his lessons on economic history Weber makes an important distinction between 'speculative capitalism', that was present in the ancient times, and 'rational capitalism', a product only proper to the modern era. Weber does not neglect the role that technical conditions, trade, rational organization of work, the advent of modern state, the advent of a mercantile political economy, all played in the formation of 'rational capitalism'. On the other hand, he does not reduce to those elements the advent of modern capitalism. Therefore 
through his study of Sociology of Religion he tries to explore the cultural conditions, mainly the core ethic impulse, that contributed to the advent of 'rational capitalism' (Weber M., 2003 [1923]).

Weber pointed out the presence of a correlation, not a causal relationship, between several religious beliefs peculiar to Protestantism, that here I will call preconditions, and the genesis of a specific economic ethos, the spirit of capitalism. The first precondition that he identifies is the Beruf, a calling from God for someone's life, precisely in the field of worldly work. This concept, fully elaborated only in the Protestant faith, was very crucial in the attribution of purpose and meaning for any type of work. In the following centuries, even in contexts with no relation at all with the Protestant faith, such idea was the background for the development of professions. This idea of Beruf is the starting point in Weber's analysis and the breaking element with the traditional society of the time that Martin Luther, as a seminal prime figure of the Protestant Reformation, promoted in his theology. This concept that can be extrapolated from Luther's writings and sermons had an antecedent already in the Catholic concept of vocatio. But in this last case the calling in terms of a vocatio was considered appropriate and referred only to the realm of the religious structure (mainly the vocatio to priesthood or monasticism), inside the framework of church hierarchy. Luther on the other hand, believing in an 'universal priesthood' of all believers, applied this concept to any aspect of life and to the specific call that each Christian must discover, discern and pursue, whether to become a pastor as well as any specific job. This view not only addresses the 'soul arena' of someone's life but also sees work in and in itself as a form of service to God. Such revolutionary use of the term had profound reflections in all future aspects of society, especially how the common people viewed and performed their work.

Another precondition strictly related to the first one is the Inner-worldly asceticism (Innerweltliche Askese). To be 'ascetic' is defined by Weber as an attitude characterized by a methodical procedure to achieve religious salvation. As it will be clear when I will later treat the subject of the centrality of the belief in the Perpetual Assurance of Salvation in Protestantism, such view can be applied only to the world-rejecting form of monkish asceticism (Weltablehnende Askese). This clarification can be better understood considering Weber's distinction between asceticism and mysticism. Mysticism differs from asceticism in the sense of being the content of salvation, not an active quality of the conduct when having executed the divine will, but a subjective condition in a state of illumination. In this sense it would be more appropriate to talk about a Protestant 'innerworldly active mysticism' as opposed to the Catholic 'world-rejecting asceticism', instead of innerworldly asceticism for say, with its improper salvific connotation. According to this principle, anyway, men can live pleasing God, not through monkish asceticism as in the Catholic tradition, but through the fulfillment of worldly duties (Weber M., 2003 [1923], p. 176). This view pushed 
people to understand their work in strict connection with their spiritual life as something with intrinsic value, as a 'service to Christ'. The very work someone does becomes then part of 'service' and 'ministry'.

Such view promoted by the Protestant Reformers was going openly against the hierarchical importance of social roles so common during the Middle-Ages and inherited by Aristotelic philosophy. According to this last position those that were engaged in contemplative life were to be considered on top of the social class. Luther and all the Protestant Reformers, after their delusion and secession with the traditional order, rejected plainly this idea that monastic life ought to be considered as the highest level of 'Christian service'. On the contrary work in all of its forms was now to be considered as a 'service to Christ' in the world and because of that it had an eternal significance tied to it in the same way, and level, of a preacher ministering in the church. Protestantism in this way restrained people from behaving in an irrational or unsystematic manner, disciplining them in order to consider carefully the relationships among their various social activities (AA. VV., 1990). Among the features of such restraint generated by this inner-worldly asceticism in the workplace there is the crucial restriction from frivolous expenditure of money, from too much dependence on the kin network, from consuming alcohol, from disordered conduct, from taking breaks or walking off a job, all resulting in a saving mentality.

Before the advent of the Protestant Reformation a principle of this kind was almost unconceivable. The Greek-roman culture first of all promoted often a direct exaltation of otium, matched with a daily life devoted to the intellectual and philosophical quest. Work under this era was considered a matter for the slaves or the illiterate, something to be ashamed of and to be relegated among the lowest classes of society. Then, with the widespread diffusion of eremitism and monasticism, in the common mindset of Christians for centuries the only way to fully please God, to really live at best their spiritual demand, was to separate from the world in all of its forms (pleasure, marriage, riches, secular offices, work, etc., ....) and live their lives in isolated places to practice abstinence, self-denial and quiet meditation. Of course such tendency was compensated by a period of transition during which the monks gradually began to be involved in the world (see the ora et labora introduced by Benedict) but it was always confined in the realm and boundaries of the church. Even if the majority of the people did not pursued such drastic choices, they still embraced the idea and work or worldly duties were perceived more as an obstacle to their spiritual life, an acceptance of looming affairs leading to an alienation from God.

When many of the Reformers that were part of such system left the priesthood or the monastery, they almost immediately promoted the counter-idea that the participation within the institutions of the world (even if with a critical attitude) and the use of personal qualifications 
through work becomes the primary arena for the quest to please God. In contrast with the Catholic mystic that supported the view that the believer needed to be passive in order to receive God, the Protestant believer needs now to be active in serving God and his work and professional life becomes the primary divine instrument to make sure he is pleasing God. This cultural transformation obviously did not happened over night but nevertheless it traces back its roots at the origin of Protestantism and later was developed in many branches of the Protestant faith.

The third precondition, formalized by Weber in another of his successive writings (Weber M., 1977 [ed. orig. 1906]) is the role of sects. Such precondition is not only successive in terms of when it was formulated by Weber, but also in terms of its timeframe, that must here be considered (see the shorter arrow in TABLE 1), in reference to a period much later than Luther and Calvin or the early stages of the Protestant Reformation. In this second writing Weber is considering observations done by him during his lifetime among north American Protestant sects. The sect, differently from the official church, is a voluntary-based congregation where the access is possible only after a long period of examinations and tests on the ethical qualification of the individual. Such element has more recently been defined in sociology as the core of the ritual action: 'disciplines', where whoever fits measures and standards dictated by the scheme is recognized as a member of the discipline (Barbera F., Negri N., 2015). This religious context was able to foster auto-affirmation, search for quality, charisma and strive for rewards. For those reasons being part of a sect was very good for someone's reputation and was often used as a business card of the ethical and commercial qualities of the individual. This doesn't mean that the sect was important only because it was able to activate a social network between the entrepreneurs. Although this may had been the case and the network had its delimited role, Weber was here more interested on how the process of selection peculiar of the Protestant sect generated reputation of a good character from the eyes of the outside context and therefore was particularly fruitful in business.

But what was the main element on the micro level about Protestantism able to push, according to Weber, the individual's economic propensity generated by the preconditions toward economic success? The heart of Weber's theory lies on the belief in the doctrine of predestination. This doctrine formulated by John Calvin (2009 [ed. orig. 1559]) in the sense of 'double predestination', stated that God before the foundation of the world predestined some men to eternal life and foreordained others to eternal death (Romans 9, 14-24). The Calvinist believer then, according to Weber, faces the perpetual question on his own eternal destiny: "Am I elected or am I damned?" This creates a vicious cycle of anxiety that indirectly was extremely beneficial in daily life, generating the propensity to work and strive for success. Working for the glory of God, and 
receiving His approval through economic success, is, according to Weber, the instrument through which the Calvinist believer looked for a sign of his status as elect and predestined:

[...] "But since Calvin viewed all pure feelings and emotions, no matter how exalted they might seem to be, with suspicion, faith had to be proved by its objective results in order to provide a firm foundation for the certitudo salutis. It must be a fides efficax [...]. Especially by comparing the condition of one's own soul with that of the elect, for instance the patriarchs, according to the Bible, could the state of one's own grace be known. Only one of the elect really has the fides efficax [...]. It was through the consciousness that his conduct, at least in its fundamental character and constant ideal (propositum oboedientiæ), rested on a power within himself working for the glory of God; that it is not only willed of God but rather done by God that he attained the highest good towards which this religion strove, the certainty of salvation". (Weber M., 1930 [1905]; pp. 67-69).

And later on Weber continues:

"[...] So then, although good works are absolutely incapable to serve as means to obtain the eternal beatitude $[\ldots]$ yet they are essential as sign of election. They are the technical mean not to buy salvation, but to be free from the anxiety of not obtaining salvation". (Weber M., 1930 [1905]; pp. 67$69)$.

Weber arrives here to define the crucial point of his remarks. The Calvinist believer creates his own certainty of salvation through good works, through his continuous work for the glory of God trying to find an answer to the persistent question of election or damnation. A more definitive answer to this anxiety came only with the Puritan successors of Calvin, like Richard Baxter or William Perkins that later I will analize more in detail. According to the Weberian interpretation of those preachers, it is especially through an exam of one's professional work, through the achievement of an effective economic success (as sign of fides efficax and state of grace) that the person can establish his eternal state (Weber M., 1930 [1905]; p. 220). Even though good works (i.e. good deeds) are not useful for salvation, they are still necessary to control the state of the true elect. The believer then, according to Weber, has an internal obligation to strive for professional success in order to avoid this anxiety and be sure of his state of grace. 
TABLE 1: Relationship between Protestant beliefs and economic ethos according to Max Weber theory.

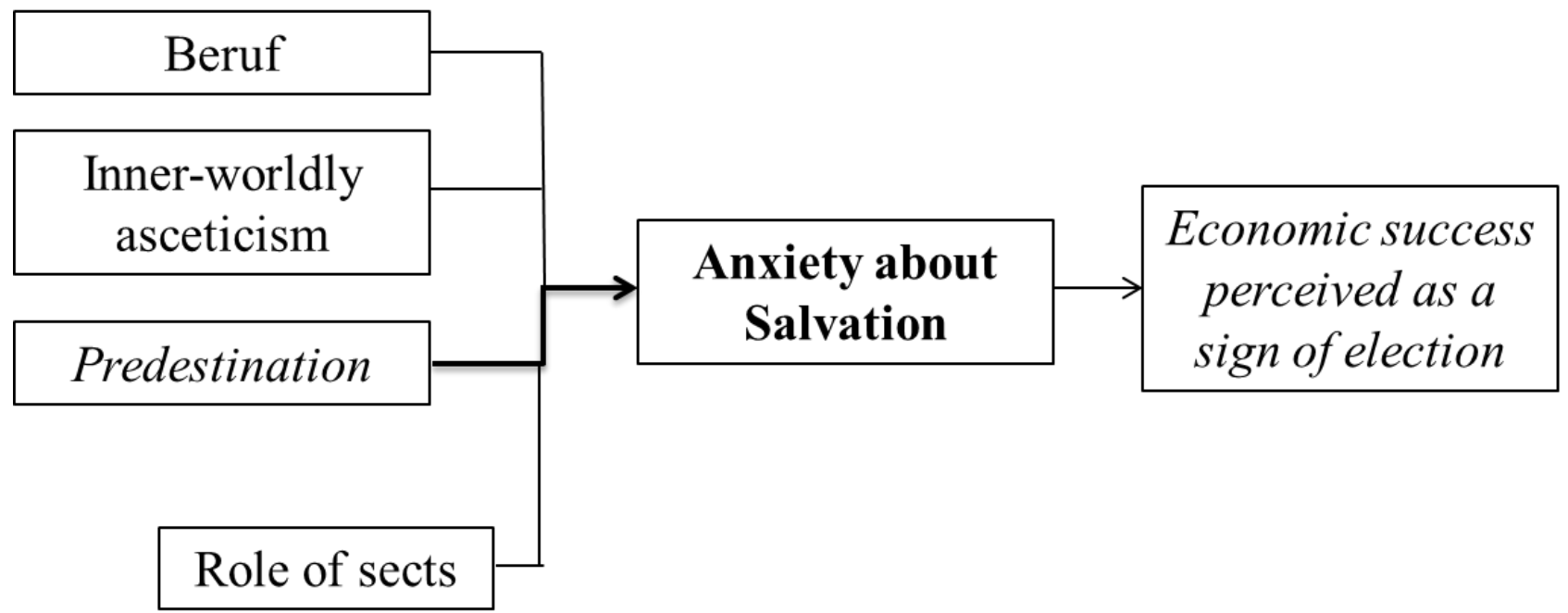

\subsubsection{The Critics and Their Fallacies}

Right after the first publication of the text, first as an article (Weber M., 1904; pp. 176-202; 1905; pp. 554-599) then later on in his comprehensive study of sociology of religion (Weber M., 1920), Weber's thesis generated a great debate. Several important sociologists where motivated to develop further analyses (Troeltsch E., 1906; Simmel G., 1906; Brentano L. 1916; Tawney R. H., 1922, 1926; Groethuysen B., 1927; Sombart W., 1928) and a specific field of studies developed through the critics and suggestions of many scholars (McKinnon A. M., 2010; Barbalet J.M., 2008; Schaefer R., 2007; Cohen J., 2002; Delacroix J., Nielsen F., 2001; Kalberg S., 1996; Treiber H., 1993; Fisschoff E., 1991; Giorgi L., Marsh C., 1990; Boudon R., 1985; Marshall G., 1980; Collins R., 1980; Razzell P., 1977; Kim H. C., 1977; Bouma G. D., 1973; Roper T. H., 1972; Baechler J., 1971; Mirels H. L., Garrett J.B., 1971, Parsons T., 1968 Bendix R., 1967; Means L. R., 1966). The approach of these scholars towards the validity of Weber's theory on the correlation between Protestant ethic and the spirit of modern capitalism tends to vary. I sum up here my personal metaanalysis of four main types of approaches in criticizing the validity of Max Weber's theory:

- Endogenous approach;

- Historical materialistic approach;

- Methodological approach;

- Revisionist approach.

The first approach refers to those scholars who neglect the validity of Weber's theoretical argument basing their critique on their personal belief or identity claims and then they try to bring facts which support their beliefs (Brentano L., 1916; Tawney, R. H., 1922; Groethuysen B., 1927; 
Sombart W., 1927; Robertson H. M., 1933; Fanfani A., 1944; Fischoff E., 1944; George C. H., 1961; Swanson G. E., 1967; Winckelmann J., 1968; Luthy H., 1970; Roper T. H., 1972; Samuelsson K., 1973; Marshall G., 1982; Martello L., 1992; Zaret D., 1992; Novak M., 1993; Burgos J. M., 1996). Those authors tend to conceive Weber's intention as if he was claiming the superiority of a certain religious belief over the other. Max Weber's thesis on the Protestant ethic must be understood in light of his comprehensive attempt of reconstructing the universal economic history. Weber had many cultural interests and his inter-disciplinary approach was always directed by an objective intellectual purpose. Nothing is more ridiculous than isolating the thesis from its original descriptive, explanatory and interpretative role and giving to it the impression as if he was expressing a judgment of value. The critic stands here on a wrong and simplified interpretation of the theoretical argument as if in light of Weber's opinion capitalism is a product of the Reformation or as if only a Protestant mentality can relate to the development of capitalism.

Those scholars move their focus to the economic role of the Catholic Europe in the MiddleAges, the crusades, the reception of the Roman Law, the Renaissance, the counter-Reformation or the doctrinal contribution of Erasmus of Rotterdam as if the key factor can be found ultimately in an alternative "spiritual" cause for capitalism, either Catholicism or some secular spirit of mind. An example of this is the critique by Sombart, that, although coming from an historical methodology similar to Weber, finds a different preceding origin of the spirit of capitalism (Sombart W., 1927). I refer here to his particular emphasis on the role of Jews on an international scale for the birth of modern capitalism, their involvement on credit and their crucial contribution for the birth of entrepreneurship (Sombart W., 1962 [ed. orig. 1911]).

Judaism, grounded in history and Scriptures (particularly the Torah of the Old Testament), had the ability to stimulate the economic performance through a rational, active, self-aware and self-restrained ethos. Sombart considers rabbinic Judaism as the source of this spirit in an evident correlation between the religious ethos and the economic performance (Fishman A., 1989). Sombart in fact made this investigation in light of Karl Marx, that already pointed out before him this role of Judaism in capitalism. Marx, even though on a negative note, talked about the individualistic religious ethic of Judaism as centered on the marketplace and making monetary gain as an ultimate substantially rational goal. The 'practical Jewish spirit' according to Marx's historical materialistic approach conceives religiosity as being composed by merely formal ceremonies encompassing the world of self-interest (Fishman A., 1989). Yet this diffuse world-transformative ethos, rather than a specific economic ethos, was able to generate economic success. It's interesting to notice that many elements of Calvinism are in tune with the previous Jewish and Armenian economic ethic. However, these systems of belief were already in action long time before the genesis of modern 
capitalism and played an ethnic-based role that resulted to be inevitably limited compared with the Calvinist Reformation that took place on the Western world in XVI-XVII centuries.

The case of the Jews nevertheless remains central in understanding how entrepreneurship in its antecedent pre-modern forms of mercantilism was more frequent among members of certain minorities as the Jews, not completely accepted in the societies where they lived, permeated by an acute sense of diversity, living in a marginal status and able to contrast the prevailing attitudes of the society around them against innovation. This point will be crucial as I will consider on a more contemporary level the role of marginal groups as the Chinese migrants in Western Europe (Benton G., Pieke F. N., 1998; Ziegert Van S., 2006) and specifically in Milan. Not all minority groups are able to display such propensity to develop genuine innovations in their social behavior. The Chinese Protestant entrepreneurs from Wenzhou, baptized by the public opinion as 'Jews of China', are, as I will point out in next chapters, particularly suited to make creative adjustments in their situation of change.

Another primary example of this approach remains Tawney in his study of religion and the genesis of capitalism (Tawney R. H., 1926). The author starts defending the economic inheritance of the Middle Ages, then he arrives to question the role of the Reformation, especially that of Calvinism or Puritanism, for the genesis of capitalism, exalting on the other hand the contributions of the church of England, since he himself was Anglican. This approach, largely ideological, remains in general unable to provide explanations that can be valid in the academic arena.

The historical materialistic approach, on the other hand, involves those scholars who believe that all human institutions, including religion, are based on economic foundations (Robertson $\mathrm{H}$. M., 1933; Gordon Walker P. C., 1937; Baechler J., 1971; Lowy M., 1989; Pellicani L., 1993; Grossman H., 2006; Clark G., 2009; Hirschman A. O., 2013). This approach does not refer uniquely to scholars that hold a Marxist view. For example, I find in this category also some evolutionary theorists (Razzell P., 1977; Blum U., Dudley L., 2001). However, they have in common the interpretation of modern capitalism simply as a consequence of gradually increasing economic exchange and they deny therefore that any kind of religion can have a crucial influence in the formation of the capitalistic system. Modern Capitalism then is born uniquely for economic reasons and social norms are always determined by productive structures.

The absolutization of the material dimension can clearly be seen in the effort of those authors to explain the birth of capitalism by only referring to political and economic conditions. For example they mention the price revolution, the pre-existence of usury and speculative practices, or some comprehensive geographical and biological explanations. Even the Reformation, according to them, is just the result of needs created by the advances in the means of production. What those 
authors often misunderstand is that Weber's "spirit of capitalism" is something very different from acquisitive greed. It is an ethos with internalized rules of conduct for which profit maximization is only a by-product (Rimlinger G. V., 1976). This leads those authors to a reductive and erroneous conclusion as if Weber's first objective was to define the causes of the birth of the modern capitalistic economy. Weber's objective instead was to show how a specific religious belief can influence the formation of an economic ethos that led to the foundation of the spirit of modern capitalism. This approach then, is biased by an economic determinism that is equally questionable in his conclusions as the first approach.

Then there is the methodological approach that involves a larger number of scholars. This approach refers to scholars who, rather than focusing on religious or economic aspects, criticize Weber's methodology in his formulation of the theory (Parsons T., 1929; Green R. W., 1959; Hudson W. S., 1961; McClelland D. C., 1961; Hagen E. E., 1962; Nelson B., 1969; Warner R. S., 1970; Trevor-Roper H., 1972; Giddens A., 1973; Glock C. Y., Hammond P. E., 1973; Collins R. 1980; Boudon R. 1985; Laitin, D., 1986; Lehmann H, Roth G. 1995; Kalberg S., 1996; Chalcraft D. J., Harrington A., 2001; Gerhardt U. 2007; McKinnon A. M., 2010). Some of those scholars for example criticize in Weber the use of "ideal types", his concept of rationality, the misunderstanding related to the translation of German concepts, the Weberian difference between "capitalism in general" and "modern capitalism" or the fact that Calvinist doctrine is only a fragment of Weber's full theory that led to the neglect of his diverse theoretical contributions. One of the main concern of those critics was on the neglect of the social aspects in Weber's analysis (Trevor-Roper H., 1972; Boudon R. 1985; Stark R. 2005).

According to this critical position social networks between people of the same religion might more clearly explain the economic success rather than the particular religious belief on salvation. If this were the case I then wonder why the strong social network related to the adherence of faith equally present between other religious minority groups in European past history, such as Quietist, Mystics of XVI and XVII centuries, never led to an economic tendency as for the case of Huguenots or other Protestant sects, but pushed them toward hedonism and radical anti-modern positions. Once again, contrary to the opinion of Boudon, it appears to me that the beliefs of Calvinism tend to play a major role over any social network explanation on the constitution of the spirit of capitalism. Those authors underline also the fact that some of the entrepreneurs in XVI century were not the product of Calvinistic societies as Holland or Switzerland, but of immigrants. What they forget to mention is that those immigrants embraced anyway the Calvinist belief and even though Köln, Antwerp or Liege had their own Catholic entrepreneurs they were an exception compared to the regularities documented by Weber in the ranks of the Protestant economic elite. 
Critics then frequently refer to the exception of Scotland. Even though Scotland was a Calvinist state church from 1560 it remained economically backward until the nineteenth century. Some recent analysis (Marshall G.; 1980) again shows the superficial interpretation of that position based on the strength of largely irrelevant evidence for the case of Scotland. The relatives lowness of the Scottish capitalist development tells me nothing about the modern capitalist ethos that Weber intended to point out. According to Marshall the case of Scotland, examining rather different data, may in the end go against the established opinion and actually be well consistent with Weber's argument (Marshall G.; 1980).

Another example can be found in the use of Weber for the explanation of the 'endogeneity problem' (Laitin D., 1986). According to this interpretation the Europeans who already had an interest in breaking the bonds of pre-capitalist spirit left the church precisely for that purpose. Those scholars, as well as other from the methodological approach tend to emphasize the role of political and economic circumstances such as decline of the imperial legitimacy or the emerging of new mundane obligations already pushing society toward a transformation (Jepperson, R. Meyer, J., 2011). The fact overlooked by those authors is that those who embraced Calvinism did it often under strict persecution apart from any economic interest and guided by motivations that go beyond the simplistic economic considerations. Also, as Weber already pointed out, often the effect of the Reformation on the economic ethic was unintended. However all of those scholars in their critics are well aware that they are not able, nor they intend, to deny the validity of the 'hard core' of Weber's theory.

Finally the revisionist approach includes some scholars who are not directly referring to Max Weber or his thesis. These authors may come from different disciplines and collateral fields of interests such as cultural anthropology or sociology of religion and they may embrace different schools of thought such as the post-modernist or post-colonial perspective which may not be the main focus of this study. However, from their perspective as well as the one of similar studies, I can identify one main logical conclusion that undermine any role that the Western society may had in past history compared with other cultures and societies. What those authors have in common is an anti-ethnocentric perspective and a deconstruction of the concept of modernity as it is known in Western societies (Goody J., 1996; Schluchter W., 1996; 1989; 1985; 1979). The direct consequence of such approach therefore is the inevitable denial of the validity of Weber's theory. As fascinating as it may sound however, the authors that held such a position don't provide many facts and evidence for their position.

Summing up, it is possible to see that those different post-Weberian critics are not able to deny the validity of Weber's theoretical argument, the facts and evidence that he provided in his 
articulated historic, cultural and economic study of religion. Another element that I've noticed with many of those critics is a superficial understanding both of the conceptual background of Weber and of the historical, theological and documental framework of the phenomenon.

This is to say that many critics of Weber's theory don't refer to the original writings of Weber or don't hold a knowledge of the historical sources that Weber was referring to in his analysis ${ }^{1}$. For this reasons the efforts of falsification mentioned above occurred very often in misunderstanding and blatant errors. Therefore, at least from a sociological point of view, they fail to provide an alternative scientific valid description of Weber's theory. Even after examining all those critics, contrary to the established opinion in social sciences, the 'hard core' of Weber thesis on the Protestant ethic remains valid. As it will be analyzed in the next paragraph I'm not suggesting that Weber thesis could not be submitted to falsification, a process that according to the Popperian criteria of scientific investigation is indispensable. I'm just pointing out the fact that the critics fail in giving a valid and alternative interpretation according to sociological criteria. An investigation that results to be already partial or incorrect and that is engaged in solving a sociological problem through its elimination as an end in itself should never be reliable.

\footnotetext{
${ }^{1}$ To better understand max Weber is also important to consider the fact that his life and work were deeply affected by his family traditions. Weber's mother had strong religious Calvinistic convictions that led Max to the decision of doing serious inquiries into religious subjects early in his life (Swatos W. H. Jr., Kivisto P., 1991). From those elements I can deduce the personal interest and intellectual tension of the German sociologist. This doesn't mean that someone can objectively identify some sort of secret religious intention in his sociological work counting his declared breakdown with religion and his strive as a social scientist to always describe, explain and interpret rather than evaluate. 


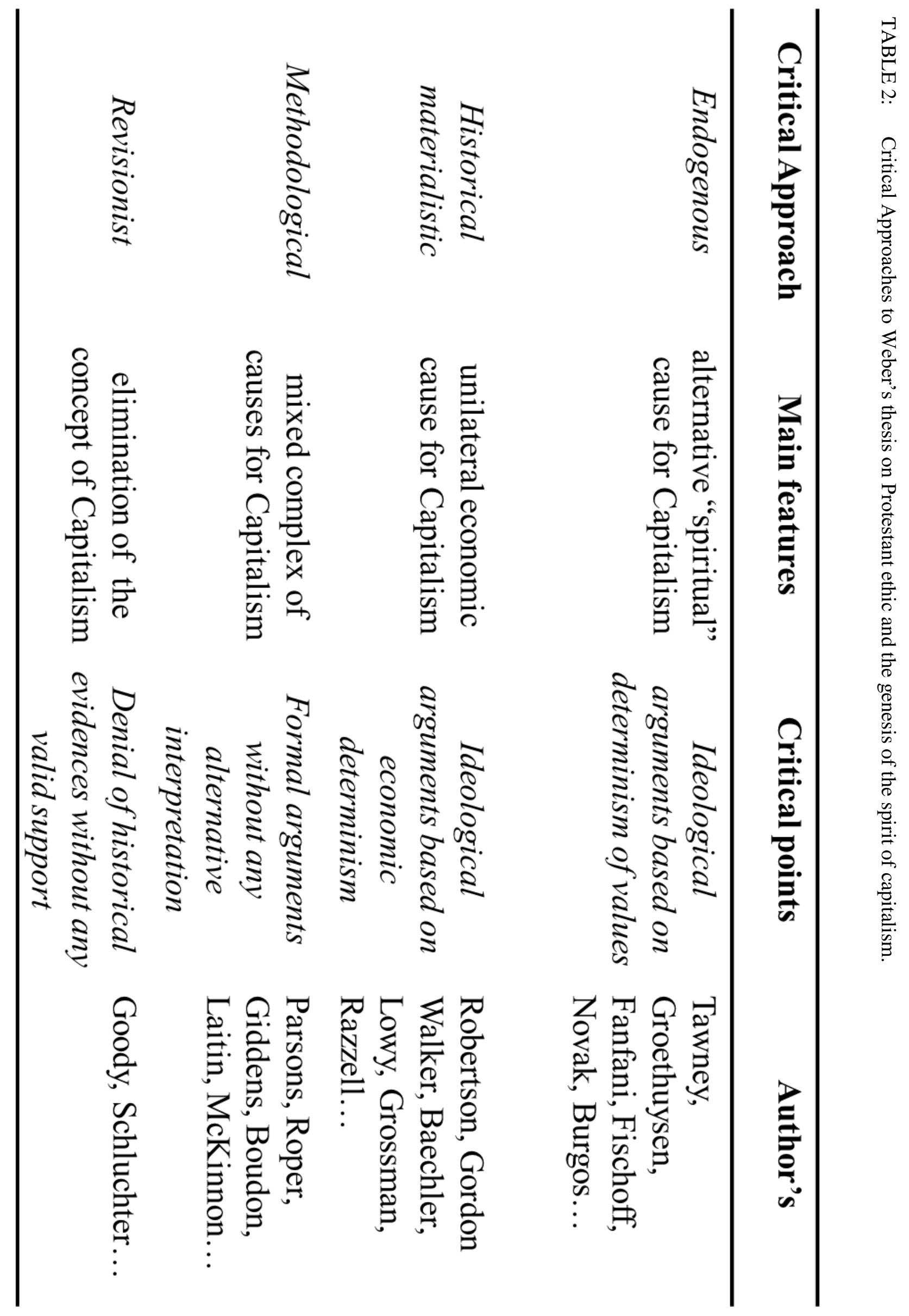




\subsection{The Reality of Calvinism}

\subsubsection{Predestination contra Anxiety}

Two dimensions are involved in Weber's analysis, on one side the history of sociological thought and on the other side the characteristics of the Protestant Reformation. If someone wants to have a clear understanding of this sociological phenomenon however, it is not possible to remain just on the side of sociological thought. The subject involves something else behind the sociological reflection: a particular theological impetus making a way for a moral one (ethos) that is able to influence the conduct and social actions of the individuals. I must necessarily consider the characteristics and dynamics of the particular system of beliefs of Calvinism. In analyzing the facts I can notice several points where Weber's description of Calvinism diverge consistently from my interpretation of it as well as of other experts in the topic. What is interesting to notice is that the doctrine of predestination was a doctrine that already existed in the history of Christianity.

When John Calvin, Martin Luther or Huldrych Zwingli during the Reformation refer to that doctrine they were relating to a concept that was already deeply rooted in the history of Christianity. In particular, many centuries before, Augustine of Hippo (354 a. C. - 430 a. C.) already defined the idea of predestination, and the Catholic church acknowledged the validity of such doctrine. The reformers then were conforming themselves to a long tradition of thought that already believed in the doctrine of predestination: Lucid and Gotelascus for what concern the idea of double predestination and more generally Thomas Aquinas, Duns Scoto, William of Ockham. Among those and other examples (see Gregorio da Rimini) many even believed and preached this doctrine in its more radical implications such as the 'double predestination'. To say therefore, as Weber argues, that Calvin's doctrine was somehow unheard-of or uniquely notable for being totally preordained and completely beyond anything that human can do, doesn't do justice to its multiple and continuous examples in church history that were the basis of Calvin's legitimacy.

Even after the Reformation such doctrine continued to exist in both Catholic and Protestant traditions: Jansenius, Quesnel, Karl Barth, arriving to the second Vatican council. Not only the doctrine of predestination, despite the frequent debates that generated, is then rooted into the history of Christianity but find his ultimate origin into the Sacred Scriptures, the Bible. Particularly Paul of Tarsus in the New Testament clearly defines the doctrine of predestination (Romans 8:29,30; Ephesians 1:5-11). Although not so elaborated as in the New Testament, the doctrine of Predestination is indirectly present in the Old Testament concept of 'election' both to a national and individual level (Jeremiah 49:20 50:45; Micah 4:12; Isaiah 14:24 26-27 19:12 23:9) and therefore in 
the Jewish tradition long before the advent of Christianity. Judaism was always characterized by the awareness of the state of election of Israel, according to which only the Jewish people were God's people, elected and separated from this world. Christianity carried that idea applying it not to the ethnic identity but to anyone who embraces the Christian faith.

When the Apostle Paul introduced the term of predestination in his writings he was defining a concept that was understandable and not new for his Jewish audience. The same belief in predestination can also be found in the Muslim faith and in the Quran, element that with some exceptions (Abbas A., 1988; Turner B. S., 1974; Tyler L. L., 1966) the critics never noticed. This therefore challenges the central idea of Max Weber that predestination played a central role in the genesis of the spirit of capitalism. What was new in the history of Christianity from Reformation and specially with John Calvin is the belief about the assurance of salvation. Assurance is a Christian doctrine present only in Protestantism which states that the inner witness of the Holy Spirit allows the justified disciple to know that he or she is saved (Romans 8, 16). This doctrine was very important in Methodism, Lutheranism and in part of Puritanism. But it is only in Calvin's perpetual interpretation that this doctrine reached the highest implications (John 10, 28-29), through the doctrine of the perpetual assurance of salvation:

[...] but the grace granted to the members of Jesus Christ has a strong pre-eminence of dignity, because, being united to their head, they are never cut off from their salvation.

(Calvin J., 2009 [1559]; Vol. III, C. XXI, p. 1105).

For many centuries Christianity believed with few exceptions in the fact that salvation comes through faith and good works. What was new, or rather back to the origin, in the Reformation was that man can be justified before God and receive this salvation by faith alone, without good works and that he can have absolute assurance in this life of his eternal salvation. All the main reformers, such as Luther or Zwingli before their conversion were Catholic priests while Calvin was an educated scholar of law and humanism. This element surely led his systematic theology to discover the deepest implications of salvation as an eternal state of the soul that nothing in this life can change (Adamo P., 1994). Particularly Calvin, more than the other reformers, put the emphasis on the fact that the doctrine of predestination, because of the belief in perpetual assurance of salvation, leaves no room for anxiety:

\footnotetext{
The most serious and dangerous temptation that the devil has to hit the believers, is to leave them restlessness questioning their election and prompting them to look with absurd lust outside of the Way. [...] This inner turmoil is the most appropriate element able to show how perverse is to imagine predestination in that way. As the spirit of man cannot be infected with something more harmful than this mistake that may distract the conscience from the calm and rest which he should have in God. (Calvin J., 2009 [1559]; Vol. III, C. XIV, p. 1147-1148).
}

In open contrast with the previous Catholic theology that for centuries was characterized by a 'dangerous' and 'demonic' struggle for achieving salvation through all sort of human efforts in 
order to be freed by a state of perpetual anxiety, Calvin proclaims here an opposite message of 'calm' and 'rest' in a perpetual assurance of salvation received by faith, later followed by the next Protestant generations. I can clearly see then that this doctrine does not imply a continuous status of anxiety but a state of peace and confidence caused by the awareness of being saved forever. Although Weber states the presence of a distortion in this doctrine in subsequent developments of Calvinism, there's no trace of such a distortion either in Calvin's theology, nor in subsequent developments of Calvinism. In fact, Calvinism more than any other reformed traditions believed in the total depravity of men, and in the impossibility for a man to come to salvation by any kind of effort, even if is the effort to control his state of grace like Weber had stated (Miegge M., 2010). Faith is a gift from God, sovereignly given by God's grace and dissociated from any meritorious element. Any effort to gain God's favor through human efforts, according to Calvinism, is therefore vain.

\subsubsection{Assurance of Salvation as the Logic Alternative and other Preconditions}

The research question instead of the Weberian anxiety then becomes: is this belief in a "perpetual assurance of salvation", that lead the Calvinist believer to have a positive psychological attitude and therefore enable him to contribute to economic success? This doctrine stated by Calvin, as a completion of Luther's Sola Fide, was the real novelty, or return to the origins, in the history of Christianity. This doctrine states that once a person comes to faith in Christ he is forever sure of his eternal salvation and totally aware of being among the elect not because of works but because of a sovereign call from God. The believer then, instead of living in a state of anxiety about his eternal condition is sure of his salvation. He or she believes that it is impossible to lose salvation. It is this perpetual state of assurance, proper of those particular branches of Protestantism, that is able to enhance what in Social Psychology has been identified as self-efficacy (Bandura A., 2001; Zhao H., Seibert S. E., 2006; Laguna M., 2013; Rauch A., Frese M., 2007). Self-efficacy has been defined as the extent or strength of one's belief in one's own ability to complete tasks and reach goals; which represents a psychological attitude that has been proved to be highly correlated with economic success. Particularly, self-efficacy is a very crucial quality for success in the entrepreneurial process providing several attitudes: a) intention to engage in new firm creation, b) personal choice of the specific entrepreneurial activity, c) actual business start-up, d) propensity towards planned behavior, e) ability to perform various tasks effectively, f) strive for implementation regardless of the obstacles, g) perception of difficult tasks as challenges rather than threats, h) need for achievement, i) stress tolerance, j) proactive personality, k) risk taking, 1) propensity towards perseverance, m) 
openness to new experiences (Laguna M., 2013; Rauch A., Frese M., 2007; Zhao H., Seibert S. E., 2006). What the scholars point out is that the main element that is able to generate all those attitudes is what a person thinks about himself, the person's belief, his consciousness. Also, as the belief tends to be more specific and perpetual, self-efficacy enhances more easily economic success (Bandura A., 2001). Furthermore, I will refer to some literature on how self-efficacy plays a crucial role in situations of risk and uncertainty (Kahneman D., 2003; McLain D. L., Hackman K., 1999; Tversky A., 1995).

What is interesting to notice is that for the case of Calvinism the belief in the perpetual assurance of one's eternal salvation generates in the individual a perpetual state of peace and trust. From my point of view this condition results, together with other elements proper to Calvinism, in the display of all the attitudes proper of self-efficacy mentioned above. The believer, through the perpetual assurance of salvation, can take risks, tolerate stress, reach new experiences, embrace difficulties as good challenges rather than threats, strive for his spiritual growth regardless of the obstacles that he faces because he knows that everything, even difficulties, work for his good and he is sure that one day he is going to heaven. Of course that belief alone does not explain all the economic propensity, although it results in being the foundational principle. Adding to that element, I already said that the Protestant idea of calling (Beruf) helps the believer to choose a specific entrepreneurial activity.

If I look carefully to other elements of Calvin's theology I find that the Calvinistic vision of the glory of God as the ultimate purpose in life enhances the need for achievement. Achievement in this particular case is not intended for the individual but for a much higher cause: God. The believer knows that every single task has an eternal purpose higher than himself. Also the Calvinistic belief in the perseverance of the saints, enhances planned behavior and a general propensity to persevere. This can be, in my opinion, the main element, together with all the other preconditions, bringing those branches of Christianity to develop a particular economic ethos. The perpetual assurance of salvation plays a central role under situations of risk where the believer achieves economic success because of his state of self-efficacy related to this belief despite the challenges. It is the peculiar belief in eternal salvation, and not the anxiety, that explains the correlation generating self-efficacy.

There are also several Calvinist doctrines, apart from predestination, that have been overlooked or only partially analyzed by Weber that need here attention as well. I will include them in the model as "assistants" to the preconditions. In introducing them in the model I will not consider them in a strict causal relationship with my theoretical question as if they are generating the belief in PAS. Instead they are the preconditions without which it is impossible to rightly understand how the belief in PAS generates self-efficacy and therefore favors economic success. 
For example it would be interesting to analyze the negative impact of religious traditionalism for the economic ethos. For this case I will refer to Calvin's anti-superstition. This can be seen clearly in Calvin's treatise on relics (Calvin J., 2010 [ed. orig. 1543]) and in his strong attack on superstition and idolatry proper of many Catholic rituals. Also, very important is his strong attack toward any superstitious view of the sacraments even inside the Protestant tradition (Calvin J., 2009 [ed. orig. 1559], Vol. IV, Cp. XIV, pp. 1490-1519, Cp. XVII,1578-1652). While Luther was supportive of a "sacramental union" of the believer with Christ in the Last Supper, Calvin was challenging this view, together with Zwingli, affirming the mere symbolic function of that rite. The practice of private confession, for example, almost disappeared in Calvinism.

Such anti-traditionalism and anti-superstitious moral stand denies the utility of any kind of means to free the individual from the guilty sense apart from Christ. This change had a huge impact on the daily ethical praxis of the individual (Weber M., 1976 [ed. orig. 1905]; p. 210). Not only that, but if I look at the definition of superstition I can identify it as an irrational belief maintained by ignorance of the laws of nature that an object, an action, or a circumstance not logically related to a course of events influences its outcome (AA. VV., 2001). From this it would seem that a "rational" belief, such as the anti-superstitious moral stand of Calvinism, is the opposite concept to superstition, so important in the eyes of Weber's search for the religious rationality of Calvinism. Once again this anti-traditionalism is incomplete in Calvinism if someone thinks about Calvin's view of the sacrament of pedo-baptism (Op. Cit., Vol. IV, Cp XV-XVI, pp. 1519-1578) or the bondage between state, power and church, elements that only the Anabaptist evolution is able to break (see TABLE 5). Every scholar needs to keep in mind how this bondage, still present in the traditional Protestantism of Calvin, Zwingli or Luther, led them to support the persecution and murder of religious dissidents in Europe such as the Anabaptists of Michael Sattler for more than 200 years.

Another crucial aspect in Calvinism is the role of the Sacred Scriptures. More than any other reformed traditions Calvinism exalted the Holy Bible as the only infallible rule of faith and conduct, the only source for the knowledge of God. This view not only was crucial for the successive development of society fostering writing, rationalization and scientific inquiry, but exalted the biblical principles of business. The Scriptures commands every men to work and consider them responsible before God of its high accomplishment. Financial success is seen here as a result of 'doing the right thing' and obeying the Biblical principles of business. The role of Sacred Scriptures will refer here therefore to the number of principles and teachings contained in the Bible (especially wisdom literature of the Old Testament) concerning business. Protestantism more than any other religious group puts the emphasis on the strict application of those principles in order to 
have a prosperous business. Among other things the Scriptures give no tolerance to idleness, no countenance to carelessness and they emphasize the importance of respecting worldly concerns. Industry is considered as the duty and true happiness of man in a state of innocence (before the fall of mankind). The surest means for the increase of one's property according to the Scriptures requires a wise economy of personal resources rather than rapid gains, in order to promote the greatest promise for long-term success.

Such an economic attitude finds its antecedent only in the Jewish tradition. The Jews or the Armenians are ethnic religious groups of whom role in economic history has already been clearly explained (Sombart W., 1962 [ed. orig. 1911]). Those minorities like the Jews or Protestants highly involved in the European business across the ages, find a correspondence in the Eastern tradition of the Samurais in Japan or the Parsees in India. Those minorities, above others, display a more frequent involvement in entrepreneurship according to Sombart. Because of the lack of acceptance in societies and their subsequent avoidance of traditional values and norms proper of that society they develop an acute sense of diversity and a propensity to innovate in order to survive. Although the Jewish religious tradition, at least after the advent of Christianity, doesn't provide any belief such as the perpetual assurance of salvation, it is still characterized by the faith in the promises of God contained in the Bible able to create a sense of profound assurance and to give the strength to persevere in trials and situations of risk. Anyway it is primarily their status of ethnic minority, as well as for other cases mentioned above, that result to play a major role in enhancing their involvement in entrepreneurial activities together with other more environmental elements.

An equally crucial belief of Calvinism that explains much of Weber's misinterpretation around anxiety is the doctrine of the perseverance of the saints. Such doctrine states that only those who persevere are the true believers. This doesn't mean, as Weber misinterpreted, that is the perseverance that assures salvation, but it means that true believers are kept by the power of God through a firm faith. The perseverance promises that any person who comes to true faith is forever preserved by God from perdition. For this reason, perseverance and assurance are strictly correlated. On one side the assurance promotes perseverance through God's mighty hand preserving and enabling the believer, and on the other side perseverance is the evidence of genuine salvation leading the believer who is saved by grace only through faith to a process of intense vigilance and rigorous discipline. That doesn't mean that perseverance is a pre-requisite for salvation since men are totally depraved and incapable to do anything good but it is rather a consequence of salvation. Perseverance can be illustrated as a race to run. Salvation is the goal of the race and the true believer has already won being already saved by grace through faith. The warnings and admonitions 
in the Calvinist believer call for retrospective and introspective self-examination to assess whether one is already saved or not.

In critical moments the individual is called to go back to the basic teaching of salvation through faith alone in Jesus Christ, making sure to receive Him as Savior and Lord, and, as a consequence, to make fruits worthy of repentance. To abandon the race on the other hand proves one was never saved (Schreiner T. R., Caneday B. A., 2001). Here's what in reformed theology is called the 'practical syllogism' introduced by Theodore Beza. According to this principle one can gain assurance of salvation by observing evidence of faith in his life. However, Beza denied any use of material riches as a sign of justification or election (Muller R. A., 2008). Also, according to reformed theology, good works are the epistemological ground of faith and justification, rather than the ontological ground. In other words the evidence of faith only make faith apparent: it does not create faith. John Calvin particularly warns against inferring election from such signs (Beeke J. R., 2011; p. 273).

Of great importance for the theoretical argument on the perpetual assurance of salvation and the display of self-efficacy it is also the doctrine of the sovereignty of God. This doctrine states that every single element and event of reality is under the control of God and responds only to His will. Although a recent development in reformed theology tried to conciliate such view with human responsibility, the original Calvinistic belief put all the emphasis on God's purpose. This auxiliary aspect, if related to the perpetual assurance of salvation, can explain even more strongly the psychological impact of the system of beliefs on self-efficacy. A man under situation of risk and stress has the certainty that God has the complete control over every circumstance of his life and that everything, even bad experiences, work for his good.

All those auxiliary aspects cannot be understood completely if they are not incorporated within a crucial precondition. Such precondition that cooperate with inner-worldly asceticism, Beruf, and role of sects, is able to prevent the shift in the perpetual assurance of salvation into a mere state of unproductive contentment. This precondition refers to the pursue of the glory of God as the ultimate purpose of life. All aspects of life, specially work and worldly duties, contain therefore a greater spiritual purpose that is able to push the individual to strive for excellence. In this sense every work activity, even the more despised, has its internal dignity, it can be "sanctified" into a legitimate "act of worship" and contain therefore its spiritual purpose also in light of a common good that is lacking in the individualistic reconstruction of Weber (Beeke J. R., 2009; p. 360-361). Therefore both in the theologians thought and its consequences for the common believer it is possible to trace the absence, if not even the presence of the opposite, of anxiety. 
TABLE 3: Dynamics of the relationship between the Protestant beliefs and the economic ethos according to the theoretical argument.

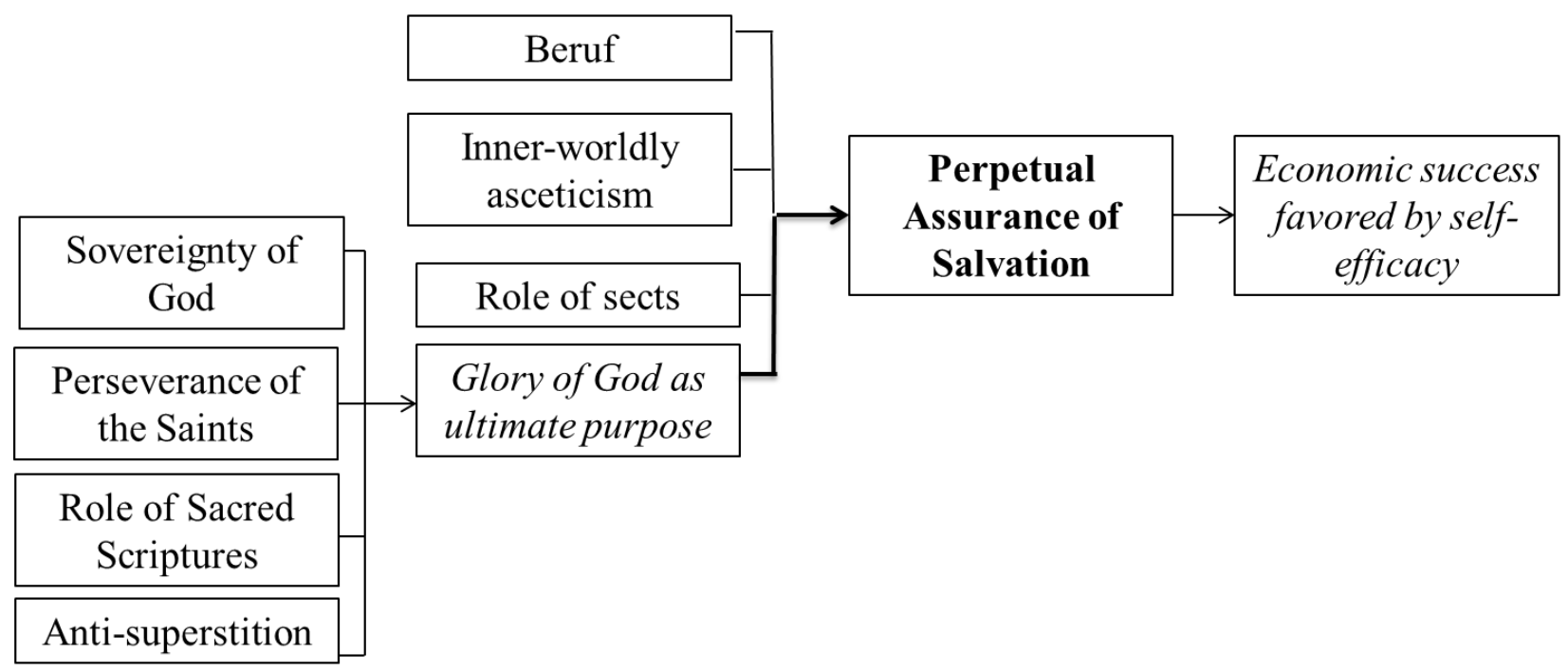

Weber's intuition must be also understood in light of the influence of the neo-Kantian German school, especially through the theological and intellectual influence received by his contemporary Ernst Troeltsch (1865-1923) who put a strong emphasis on the definition of the 'spirit' of thought and the 'forces' of history (see in particular Adair-Toteff C., 2015; Graf F. W., 2013). Troeltsch emphasized particularly the mystical orientation in Western religion and how the ascetic orientation so evident in modern Protestantism is fundamentally compatible with the economic life (AA. VV., 1990). Trying to understand the roots of individualism and instrumental rationality Troeltsch, as Weber, points out the role of Protestantism in its different branches (Calvinism, Anabaptism...) and throughout its different times (paleo-Protestantism, new Protestantism). But differently than Weber, Troeltsch acknowledges the crucial role of the doctrine of perpetual assurance of salvation, and the absence of any form of anxiety. His more accurate interpretation stresses the fact that, in contrast with Lutheranism where grace was revocable, the Calvinist believer possesses an assurance and serenity due to the belief in PAS and his irreversible election to salvation (Troeltsch E., 1987 [Ed. orig. 1906]). 



\title{
Chapter III
}

\author{
"Men are wont to set the highest value on those things \\ upon which they are sensible their interest chiefly \\ depends. And this renders time so exceedingly precious, \\ because our eternal welfare depends on the \\ improvement of it" Jonathan Edwards
}

\subsection{The Puritan Ethic in America}

\subsubsection{Evolution and Actualization of the Matter}

This opens the door to my second main point: could Weber's theory still be valid today? Obviously it was not Weber's intention. His primary aim was to show which role the Protestant ethic played for the genesis of the spirit of capitalism during the XVI-XVII centuries, looking at the first stages of modern capitalism. However, despite his claims, many of the assertions and conclusions contained in his subsequent study on Puritanism, the Protestant sects and the spirit of capitalism were made on the basis of observations among American protestants during the early XX century. Also, both Weber and Tawney were very pessimistic about the role that a "ghost" of the Protestant professional ethic could play in advanced stages of capitalism where religious motivations tend to disappear and work finds no other meaning than the mere satisfaction of personal needs (Weber M., 2002 [ed. orig. 1905]; p. 185). This view assume that modern capitalism, once set in motion, function largely without any continuing influence from religion.

In reality however, as I will point out during this section in tune with all the neo-Weberian approach and the social attitude models, even if the theological basis disappeared, the ethos generated by it can still exert its influence in places and periods with no relation at all with its origin. This tension toward profit tends to prevail even in the present through a dynamic relationship between ethical systems and economic life. For other reasons, some scholars are very skeptical about any effort in favor of the actualization of Weber's theory (Bouma G. D., 1973; Delacroix J., Nielsen F., 2001). Through a quantitative and comparative study of the early accurate data available from late nineteenth century, those authors state that industrial capitalism was not facilitated more in Protestant countries. One of their first mistakes is trying to invalidate Weber's thesis by only focusing on Europe and basing their conclusions on evidence dated from two to three hundred years after the period of time when the Protestant ethic influenced the genesis of the spirit 
of capitalism. Such spirit was an ethic and attitudinal ideal-type that, again, has nothing to do with industrial capitalism or any sort of economic development.

That's also the case of other scholars (Cantoni D., 2012; 2014) who based only on quantitative indicators not entirely congruent with the thesis that they want to falsify ${ }^{1}$ and lacking a clear understanding of Weber's terminology, incurred in serious problems of misinterpretation. But even if I base their conclusions on the actualization of that theory, the features of what they call the "common interpretation" of Weber's theory are a total misunderstanding of his sociological argument. The attitudes and mental predispositions that Weber associates positively with certain behaviors were not common to all Protestant branches. That's why some authors (Kim H. C., 1977) correctly address the fact that religious affiliation is a less adequate measure than the particular religious belief in assessing religion's effect on behavior. Also, the scholars completely leave out the case of United States, a case that by the late nineteenth century must be in my opinion already the center of all the reflections on the Protestant ethic and the spirit of capitalism.

Starting with other evidence, many quantitative and qualitative findings (Merton R. K., 1957; Lenski G., 1961; Willems, 1968; Cowley \& Ballweg, 1971; Kim H. C., 1977; Verba S. K. L., Schlozman H. B., Brady N., 1993; Barker, D. C., Carman C. J., 2000) show that the actualization of Weber's theory can still be supported. It has been clearly observed on a macro level by some scholar (Feldmann H., 2007) that countries in which the largest portion of the population practices Protestant religion have substantially higher labor force participation and higher employment rates, particularly among women. Other studies on religion and economy tell me today that the particular case of Calvinist Protestantism confirms to have a dynamic influence on honesty, work ethic and therefore economic performance (McCleary, R. M., Barro, R. J., 2006; 2003). This then certainly means that, although I have to take in consideration the changes and conflicting evidences, Weber's theory still has an area of authenticity. What those studies fail to identify is the central element of such theory. This, in my view, can be better understood through a clear explanation of the beliefs under my investigation, their evolution in recent history (Miegge M., 2010) and their impact in the spirit of global capitalism rather than relying on mere economic indicators.

\footnotetext{
${ }^{1}$ Cantoni tries to measure the impact of Protestant religious affiliation on economic growth through population figures such as city sizes, city growth or fertility. I am not denying the importance of quantitative methods. Weber for example used quantitative indicator in his introductory stage of the thesis but, according to my point of view, those dimensions cited by Cantoni have little to do with the core thesis of Weber. The German sociologist looked primarily to a specific Calvinistic belief and how such belief impacted the economic ethos. I suggest that, together with appropriate quantitative indicators, including for the US, such as working hours, employment rates, labor force participation, such dynamic may be observable mainly through a critic of the historical evidence provided by Weber and on a micro level primarily through a qualitative research design more appropriate to the objective (Cantoni D., 2014, 2012). 


\subsubsection{The 'Americanization' of Protestantism}

This evolution concerns primarily with the historical passage that gradually led the roots of Protestantism to emigrate from continental Europe to the United States. As I've already mentioned Weber's interest on the American evolution of Protestantism was marginal since his primary purpose was to identify the role of the Protestant ethic in the early stages of the Reformation in western Europe. However, several scholars after him pointed out the absolute relevance of the Protestant ethic for the case of north America from the Puritan era on (Bottum J., 2014; Harrison L. E., 2012; Huntington S. P., 2001; Landes D.; 1998). The historical passage of Protestantism into the new World, that at the times of Weber was not completed, was responsible for two of the major transformations that occurred in Protestantism: i) its de-institutionalization through the breaking of dissident Protestantism with the mainly institutional and national European churches towards the new world seen as a 'Promised Land'; ii) its syncretic development, the inevitable progressive mix of the different branches of the Reformation into an heterogeneous scale of beliefs even inside the same single Calvinist branch (Durston C., Eales J., 1996).

As it was the case of Protestantism spreading in countries of western Europe like the Netherlands, England, part of France or the Scandinavian countries through German traders who brought biblical literature in their trade routes, so it was for the pilgrim fathers and Puritans that came in new England for both economic and religious motives to build a "wilderness Zion" a "New American Israel". One of the main element that characterized Puritanism as a religious movement was the submission of every aspect of life, including work and money, under the higher purpose of bringing glory to God. Puritanism developed first in England through the efforts to reform the official church of England that was going through a decadence of worldliness and compromises. Having experienced dramatic conversions the Puritans felt the need to separate themselves from the mass of the unregenerate to revolutionize human history. Their zeal was displayed into standardized patterns of behavior intended to revive the religion into every aspect of life (Simpson A., 1955). It came to the scene with great Puritan influential preachers like Isaac Watts, John Owen, Richard Sibbes, Thomas Brooks, John Bunyam, John Flavel, Thomas Goodwin, Matthew Henry, Thomas Watson, William Perkins, Richard Baxter, Samuel Rutheford, John Winthrop, etc... Those were brilliant and giants intellectuals that influenced the anglo-saxon world for generations. This movement spread abroad also through the influence of Dutch and Scottish diviners from a Calvinist and Reformed background (Beeke J. R., Pederson R. J., 2007). Yet the king of England and the authorities of the national church of England responded with suppression and persecution which 
culminated with the Uniformity Act of 1662 when many puritans were expelled or forced to compile with the national church directions.

Through this it came the great exodus of the Pilgrim Fathers towards the New World. The Pilgrims and Puritans migrated at Plymouth and the Massachusetts Bay would set about to order their lives in a way that fostered the practice of piety in all that they did. They were zealots who envisioned a theocratic society based on the Testaments who's austere heritage is a vital part of the American history. A good Puritan could had been identified as industrious, thrifty, practicing inflexible integrity in his business dealings, brought up in the pursue of a calling with sober living and purpose, where temperance was considered as a Christian duty, having a propensity to link religious faithfulness with economic prosperity, virtues that were bound to produce plenty in an abundant land (Lambert F., 2003). Hard work perceived and promoted as a duty to be accomplished was a religiously based value toward God. Weber and a vast number of critics after him up until today (Barlow A. J., 2015; Klein, S. 2013; Burg, B. R. 2012; Hewett, R. S. 2012; AA. VV., 2011; Tipson, Jr., L. B. 2010; Le Beau, B. F. 2008; Shulevitz J., 2001; Beder S., 2000; Mulder J. M., 1976; Foster S., 1972; Little D., 1966) identified in this type of Puritan religious experience the historical survival of the Calvinist work ethic (Inner-worldly asceticism, etc., ...) in the New World.

One example of the endurance of the difference between world-rejecting asceticism and inner-worldly asceticism can be found in the change from the external to the internal "spiritual resolutions" of Puritanism. In this sense someone could compare two religious authors that use the same word "spiritual resolution" but they intend it in a totally different way. In the first case of the Catholic monk Brother Lawrence the term refers to exterior practices that a man can display in his monkish life to be closer to God. In the second case of the American Puritan preacher Jonathan Edwards, exponent of the "new light Calvinism", the same term refers to internal practices of selfexamination and commitment that any person can embrace in order to pursue the glory of God in every aspect of the mundane (Piper J., 1974; pp. 59-69). Being among the chief exponents of this Puritan ethic, Jonathan Edwards often put special emphasis on hard work in his sermons like 'The Preciousness Of Time And The Importance Of Redeeming It' (Edwards J., 2003 [ed. orig. 1734]).

Consider what hath been said of the preciousness of time, how much depends upon it, how short and uncertain it is, how irrecoverable it will be when gone. If you have a right conception of these things, you will be more choice of your time than of the most fine gold. Every hour and moment will seem precious to you. ${ }^{2}$

Puritans were pursuing an orderly organized life, an ascetic work behavior, a zeal and diligence against any kind of idleness (Cohen J., 2002). It is enough to go through the pages of

\footnotetext{
${ }^{2}$ Edwards J., 2003, [ed. orig. 1734] The Preciousness Of Time And The Importance Of Redeeming It, A Puritan Mind, Yale.
} 
treatises by William Perkins on the particular calling to see the centrality of the theoretical model of Weber concerning the Beruf even centuries after the Protestant Reformation:

A vocation or calling is a certain kind of life, ordained and imposed on man by God. [...] God is the General, appointing to every man his particular post. God Himself is the author and beginning of callings. [...] There is ambition and envy when we see others placed in better callings and conditions than ourselves. [...] Must we not labor in our callings to maintain our families? I answer: This must be done: but it is not the scope and end of our lives. The true end of our lives is to do service to God in serving man. ${ }^{3}$

It is possible to see here the practicalization of the Weberian Beruf in every aspect of worldly duties through a strong Calvinistic emphasis. In the same way another Puritan, Cotton Mather argues:

A Christian should follow his occupation with contentment. Contentment is no little part of your homage to that God who hath placed you where you are. [...] When God hath called me to a place, He would have His gifts improved to their best advantage. [...] A Christian should not be too ready to fall out with his calling. Many a man, merely from covetousness and discontent, throws up his business. A man ought to pursue a calling so that he may glorify God. [...] We may not aim only at our own, but at the public good. Therefore, faith will not think it hath a comfortable calling unless it will serve, not only its own turn, but the turn of other men. [...] In our occupations, we spread the nets, but it is God who brings into our nets all that come into them. ${ }^{4}$

Again many elements proper of Calvinism (Inner-worldly Asceticism, Beruf, Glory of God, Perseverance of the Saints, Role of Sacred Scriptures, etc....) become the practical guidance and pressure toward working hard and pursuing business success. Particularly interesting are also the intellectual reflections of another great Puritan, Richard Baxter, on the search for the common welfare by the Christian:

The public welfare, or the good of the many is to be valued above our own. Every man, therefore, is bound to do all he can for others, especially for the church and commonwealth. [...] Choose that employment or calling in which you may be most serviceable to God. Choose not that in which you may be most rich or honorable in the world, but that in which you may do most good. [...] In choosing a trade or calling, the first consideration should be the service of God and the public good, and therefore, that calling that most conduceth to the public good is to be preferred. ${ }^{5}$

In a similar direction Thomas Watson invitations on diligence and many other puritans like John Preston or Robert Crowley help us furtheremore to identify such strong emphasis on hard work:

Religion does not seal warrants to idleness. God sets all His children to work. God will bless our diligence, not our laziness. [...] Neither covetousness nor hard work can make men rich, since God alone blesses with success. [...] We must labor, not for our own good, but for the good of others. ${ }^{6}$

All those principles were derived directly from the Sacred Scriptures, particularly from the continuous practical exortations for business contained in the Hebrew Old Testament among the wisdom literature (see for example Proverbs 14, 23 18, 9 19, 15 23, 21). Much of what is now

\footnotetext{
${ }^{3}$ Perkins W., 1603, Treatise of the Vocations or Callings, Princeton, New Jersey, p. 56.

${ }^{4}$ Mather C., 1825, Essays to Do Good, Chalmers and Collins, Glasgow.

${ }^{5}$ AA. VV., 2000, The Practical Works of Richard Baxter, Vol. I-IV, Soli Deo Gloria Publications, Morgan, p. 585.

${ }^{6}$ Phillips M., 2001, Puritan View of Work, Grace Baptist, Fremont.
} 
recognized as distinctively American in thought, culture and tradition is derived from the Puritan temper of the sixtieenth and seventeenth century here displayed. Being Calvinist, Scripturallyoriented, seeing themselves as choosen people the Puritans continually struggled in a fight against any form of sinfulness (Gaer J., Siegel B., 1964).

In fact idleness, luxury and extravagance were considered evil threats that needed to be overcomed through hard work (Pointer R. W., 1988). Individual success and social prosperity was extremely dependent upon virtue whereas American sins were leading the nation as well as the individuals to experience punishment and economic crisis. And religious contentment did not mean inactivity or passive acceptance of the status quo. Rather the Puritan had to exhibit economic ambition and economic satisfaction simultaneously avoiding all forms of luxury. Their piety was considered essential to man's temporal prosperity, enhancing rather than undermining their chances for a happy successful life (Pointer R. W., 1988). Yet those Puritans, contrary to Weber's thought, denied that wealth was a sign of individual salvation instead it was viewed as God's blessing for their lives.

For example the Puritan preacher Richard Baxter, contrary to the total misunderstanding of Weber, in his Christian Directory never relates work to the doctrine of salvation nor does he conceive hard work and economic success as a way to be sure of someone's state of election. On the other hand Baxter opposed work to "idleness" and underlined how diligence put off the dangerous temptations or confusions of a life without an orientation of a calling (Baxter, R., Christian Directory, in Miegge M., pp. 144-146). This message represents an important example for the precondition of the inner-worldly asceticism but has nothing to do with predestination or the Weberian anxiety. Such invitation to embrace the inner-worldly asceticism then is the only intention of Baxter when he talks about the "moral misery" of men that needs to be removed. He does not connect then this invitation to the topic of salvation which causes a state of anxiety among the listeners about their eternal destiny. All this openly contradicts the idea of Weber. The believer could come to salvation only through faith in Jesus Christ apart from any human effort or good works. The good works of a redeemed person are possible only because of the grace of God and they are not the foundation of his eternal salvation, rather they are a consequence of his salvation. The only solution for men then, in the words of another important Puritan, was the establishment of a 'personal relationship with God' (Bunyan J., 2003 [1668]).

It is true that many times prominence in the business world was the primary prerequisite for leadership in the church, encouraging an attachment to business by Puritan believers in a wholehearted but tempered manner. Those principles find their roots in Calvinist theology and can be clearly observed in the collection of Puritan prayers, their emphasis on self-discipline, self- 
restraint, frugality, diligence and freedom from anxiety in the realm of work (Bennett A., 1975). The Congregationalists and Puritans who founded the Plymouth colony and the Massachusetts Bay colony were mainly English Calvinists and the radical Whigs of the American revolution were inspired by ideals that find their ultimate root in Calvinist theology. And without some understanding of Puritanism, it may safely be said there's no understanding of America. Masterpieces in sociological studies of Puritanism like the classic of Robert King Merton on the role of Puritanism for the establishment of modern science show how pervasive and succesfull was such disciplined way of life in every aspect of society (Cohen B. I., 1990 [ed. orig. 1936]).

But what was the main element in the beliefs of the Puritans able to promote such strong work ethic? According to Max Weber such work ethic was due to a series of religious beliefs such as the belief in someone's calling for his life (Beruf) or the inner-worldly asceticism clearly emphasized in many sermons of Puritans such as William Perkins or Richard Baxter (Miegge M., 2010). But the main element that according to Weber identify as able to generate such economic action is once again the anxiety about someone's salvation derived by the belief in predestination proper of Calvinism and internalized strongly by the Puritans. It is true that a core of the Puritan creed was for the individual to work out his own salvation, marshaled as a whole society of regenerated people into one united array. It not merely regulated misconduct but inspired and directed all the conduct of the individuals (Waller G. M., 1973). Yet Puritans being Calvinist were promoters of the doctrines of grace by which man can be saved by grace alone through faith alone. All those efforts in life were not done in in order to find assurance of salvation but in order to 'work out someone's salvation' according to a specific Calvinist doctrine already mentioned that I will explain more in detail here.

In this picture certainly there's no trace of Weber's anxiety about eternal salvation. Possibly it was because of some Puritan experiences or Quaker recollections in diaries of the time that struggled with the assurance of salvation, the reason why Weber was led to his misunderstanding. For example the case has been made by Weber and some of the subsequent critics concerning some puritan writings (for example Bunyan 2013 [ed. orig. 1666]) about the presence of such strong anxiety. But those scholars forget to mention that, in this like in other cases, Bunyan is giving an auto-biography of his life before embracing the Protestant faith. The state of anxiety therefore is precisely the absence of such identification with the Protestant faith and once the individual becomes Puritan he then experiences after his conversion a perpetual state of assurance.

Furthermore, when using some of those writings for his argument, Weber was mistaken in not considering the Puritan distinction between 'assurance of faith', obtainable only believing in Jesus and not through any actions or feelings, and the 'way of faith', the invitation to listen to the Word of 
God and seek God, or to any external manifestations as the conviction of sins. The 'way of faith' by itself never provides the 'assurance of faith' because, as I've already said, evidence of faith cannot create assurance as Weber wrongly assumed. To give an example, according to this Puritan perspective, in a family only God can provide assurance of faith in a son. Parents can address their child to the way of faith, but this does not create saving faith in the child. When Puritans exhort the use of the 'means of grace', they never meant that those means "gave the right" to believe. Once again, this element refers to the doctrine of the perseverance of the saints and not to the general matter of eternal salvation (Hulse E., 2000; part III, C. 6). Contrary to Weber's view, throughout all expressions of Puritanism, more than in any other reformed tradition, there always has been a predominant attention to the work of the Holy Spirit, and not to the efforts of men in their total depravity, in order to produce the obedience to faith (McNeill J. T., 1957).

The cycle of self-examination, repentance, exaltation and good works mentioned often in Puritan writings could strengthen assurance but it was not for this purpose that such set of practices was followed, since the elects already had their assurance through regeneration (Simpson A., 1955). Not only I don't find such evidence of anxiety about someone's salvation all throughout Calvinism but even Puritanism never held such belief. On the other hand what was really unique about Puritanism was again the strong stress on the doctrine of the Perseverance of the Saints. Puritans, in accord with Calvinism, believed that salvation was a work of God, obtained by grace through faith in Christ sacrifice at the cross for the forgiveness of sins. On the other hand true faith in Jesus Christ is necessary followed by good works from a repenting soul as a result, and not a precondition, of salvation. In order to avoid easy commitments and false conversions often Puritan preachers were pointing out that those who claimed to have put their faith in Christ for salvation but lived in a constant lifestyle of sin were never truly converted in the first place. For this reason the doctrine of the perseverance of the saints inherited from Calvin's theology instead of creating anxiety about someone's salvation, which was received only through faith, led the people inside the community into a constant control of their personal conduct, into a diligent and severe display of their faith in every aspect of life. The discipline of self-trial, the perpetual self-accusation so common in Puritan diaries and poems came out of this doctrine. This was done not in order to achieve assurance of salvation but as a result of their belief in the perseverance of the saints.

All those principles present in Calvin's own writings in later Puritan interpretations came increasingly to imply an active commitment to one's career as a service to God, in a progressive practicalization of Calvinism in the New World (AA. VV. 1990; p. 630). It is possible to find some clear example of that in the daily life of those Puritans in the colonies where the religious activity and economic activity were not simply opposites but significantly overlapping. The Puritan 
merchants in their counting houses were able to make an handsome profit as well as receiving through it an assurance of their divine calling (AA. VV., 1990). America was also the land of arrival for all the religious groups of radical Protestantism such as Independents, Separatists, Quakers, Baptists, Waldensians, Huguenots, Methodists and many dissident groups coming from the Protestant Reformation. They composed the wide spectrum of the pilgrim fathers and were guided by the search for religious freedom in the new England.

Hard work, frugality and diligence coming from the Protestantism of continental Europe found their complete and deeper expression in the case of what was becoming the United States of America. Particularly interesting was the concept of impersonality according to which the ethical orientations of the Puritans, Baptists, German and Dutch Pietists were more compatible with the rational economic action than Catholicism, Islam or other religious groups that migrated later on to the New World. This because those Protestant merchants thought ethically virtuous to treat all customers the same. No partiality was to be shown on the basis of personal characteristics other than those dictated by the marketplace (AA. VV. 1990). They developed a work ethic derivated strongly from Calvin's ideas (Bernbaum J. A., Steer S. M., 1986). All those features today so central and common to the American capitalistic spirit of economic rationality, requiring equal and fair treatment according to market principles, find their roots in this religious historical background. Nonetheless at that time in the thirteen colonies there was a large portion of de-Christianized people. Through the revivals and evangelistic preaching of Jonathan Edwards and George Whitefield (both Calvinists) the thirteen colonies experienced unprecedented cases of mass conversion (Latourette K. S., 1975) that gradually led to the first great awakening (1731-1755). The leading force of those awakenings were the religious sects that in less than one-hundred years passed from thousand to billion members (Finke R., Stark R., 2005). In later chapters I will show why such Protestant revivals are crucial in understanding the economic uprising also for the case of China.

Many studies on United States show clearly that the tension between religious orientations and economic growth were recurrent and widespread (AA. VV., 1990; p. 629). Surely this ethical premise didn't stop with the Puritan movement but it involved the future development of the enlightenment in personalities mentioned by Weber more prone to Deism like Benjamin Franklin or Thomas Jefferson. Having been raised in this Puritan context they are debtors to this specific religious set of beliefs for their economic propensity and view of life. Both the Puritan work ethic and Benjamin Franklin's plan of moral perfection were characterized by an emphasis on industry, thrift, frugality, sobriety, honesty, charitableness. The impact of the Puritan ethic on the American society flourished also indirectly from the founding fathers of America such as Patrick Henry, 
George Washington, James Madison, John Adams, Alexander Hamilton, Noah Webster, John Hancock, Francis Scott Key, Andrew Jackson, Abraham Lincoln and many other influential figures that had explicit religious aspirations and where not afraid of showing their belief and ethic that find their ultimate origin in the Protestant faith (Lambert F., 2003).

These were the qualities that brought distinction to a man in the workplace and readied him for success. Their opposite concepts on the other hand: idleness, intemperance, prodigality, sloth, extravagance were said to lead to economic ruin and poverty (Pointer R. W., 1988). Men like Thomas Hooker, John Winthrup, William Bradford, Roger Williams and William Penn are just few examples among those Bible-believers that influenced predominantly the religious, economical and institutional foundations of the United States of America. Such all-encompassing influence of the American religiosity was very important for the shaping of the politics of a "nation under God" and the economy based on the motto: "in God we trust" starting from the founding fathers up until the present time (Moore L. R., 2005; Kosmin B. A., Lachman S. P., 1993). The separation between church and state, the absence of an official religious institution, the general tolerance towards all religious minorities, the public exposition of religion in all the aspects of life such as tribunals, schools or leisure time (Shriver G. H., 2011), together with liberal tendencies towards trade, commerce and taxation were unprecedented examples of how far the Protestant ethic was able to be a good soil for the future developments of the American nation (Wagner H., 1964). And Calvinism among many ideologies, first in Europe then in America, provided new models of social discipline and executive administration. The institutionalization of religious pluralism contributed to the conventionalization of intellectual pluralism (Jepperson, R. Meyer, J., 2011).

Such heritage guided America up until its emergence as the main global economic power during XIX and XX centuries. Frank Chodorov argues that the Protestant ethic was considered for a long time as a crucial element for the success in the campaign of any American political figure. Politicians had to measure up with the standard of a "self-made man" born of poor parents, that made his way up the ladder through sheer ability, self-reliance, perseverance in the face of hardship and responsibility (Duncan A., 2014; Chodorov F., 2011). The influence of the Protestant ethic in America was not only active in the political realm (Mocombe P, 2012; Stevens J. W., 2010) but it had also an impact in the general work ethic of the American population. Interestingly enough some scholars (Pointer R. W., 1988) focused on the example of Philadelphia Presbyterians and their quest for morality, capitalism and economic success during the XVIII century. Many pastors from that area frequently preached that it was a Christian duty to increase one's and one's neighbor worldly prosperity choosing the right calling and pursuing it diligently. The image of the quite orderly and prosperous man with a successful family life and work, was promoted through the correct 
application of the Bible and its philosophy. What Pointer underlines is that through the widespread of Calvinistic ideas in those Presbyterian circles such as: Christian's duty to prosper, self-help as the way to wealth, Christian piety as an asset to temporal success, the ordering and disciplining effects of Christian morality, etc., ... a convergence between Protestant and Middle-class values was possible. Philadelphia then, the most Presbyterian-Calvinist of any of America's major cities, was permeated with the 'true' path to economic success: honest, persistent and toil.

Niall Ferguson looking to the data of working hours and employment by country from the Organization for Economic Co-operation and Development (OECD) confirmed that the experience of north America in the past quarter-century offers an unexpected confirmation of the Protestant ethic thesis. However, as Ferguson argued, during the XIX and XX centuries there has been a decline and fall of the Protestant work ethic in Europe. Together with the triumph of secularization in western Europe, the author points out the simultaneous decline of both Protestantism and its unique work ethic in Europe. The reasons of such decline of working hours and employment rates can explain the misunderstanding of much of the critics of Weber's thesis. Those critics neglected the evolution of the spirit of capitalism in its transmigration to the pious and industrious context of the United States where the Protestant work ethic was alive during all of the XX century (Ferguson N., 2003; Mccloud S., Mirola W. A., 2009). Other scholars stressed this strong relationship between socioeconomic factors and denominational preferences for the more recent American case. They pointed out the compatibility between the rational religious ethic of America and capitalism suggesting a positive relationship between religious faith and such economic measures (Berger P., 1969). 


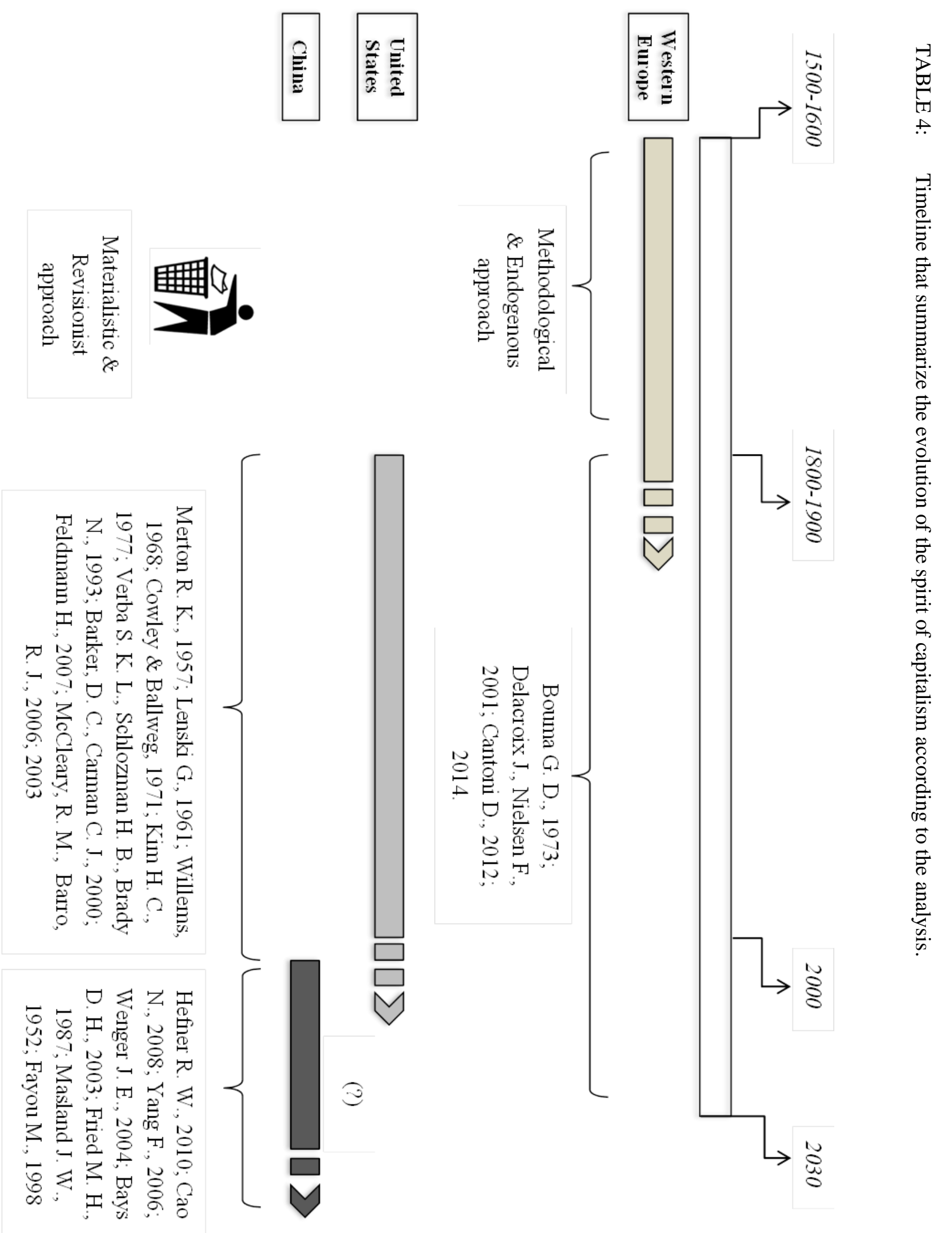




\subsubsection{Consequences on the System of Beliefs}

In this panorama Calvinism played its unique role in shaping the American Protestant ethic. Calvin's concept of God and man with all of its strong elements of freedom was crucial in the development of American liberalism and democracy. Some scholars pointed out that even today among the different religious denominations the Presbyterians, one of the main Calvinist denominations, tended to be considerably wealthier, better educated in terms of degrees pro capita than most of the religious group in America and disproportionately represented in the upper reaches of American business and political elite (Drummond A. B., 2011). However only 5\% of the American population belongs today to religious denominations properly identified as part of the Calvinistic tradition (Rauscher M., 1997). Furtheremore Calvinism has suffered of several splits and fragmentations due to the spread of liberalism such as the case of the Dutch Reformed Church both in Europe and then in parts of United States.

As I've said already, especially in the context of new England, Calvinism was insufficient to break traditionalism. The influence of Baptists, Methodists, and other not official churches was very crucial as well. Although those minority groups faced persecution and were forbidden to preach by the state church at the times of the colonial America, their social impact during the great revivals overtook the state church forcing even traditional churches to adopt religious liberty and to take the road toward a syncretic development. The deregulated separation between church and state, together with the voluntary-based adherence to religious practice, represented for centuries the strength of an American competitive and fervent religiosity (Finke R., Stark R., 2005). An interesting case of syncretic development is the one of Charles Grandison Finney (1792-1875) that although being a Presbyterian minister left the old school of reformed theology, and led the revival phenomenon that is known as the Second Great Awakening in the United States. In any case, Calvinist beliefs and values have nevertheless by now become so diffused among Protestant denominations and sects in America that is no longer easy to isolate them in specific identity-groups (Kim H. C., 1977).

Still today in United States religion remains a potentially important source of guidance in the ways individuals make economic choices. In the U.S. the doctrine of a calling survived in an intrinsic commitment to work and a desire for make it a meaningful experience. Approximatively $30 \%$ of U.S. citizens says they feel that God has called them to their particular like of work and 25 $\%$ says religious values influenced their choice of a career (AA. VV., 1990, p. 635). The foundation for such legitimation of hard work is said to find its root in the Judeo-Christian tradition of teachings. People are in this case considered as 'stewards of the world', having the individual 
responsibility in the budgeting and spending of their money, using their unique talents wisely and responsibly. Having a Protestant religious majority, United States pursue such considerations still today because of its being permeated by this cultural influence.

Particularly Calvinism is still strongly present today. It is possible to find a clear inheritance of the Calvinist beliefs in many of today's evangelical and reformed preaching (Packer J. I., Sproul R. C., Wright N. T., Timothy Keller J., McGrath A., Horton M.). The perseverance of the saints for example is a doctrine that recently came back into the scene of popularity in many American evangelical churches. I find clear examples of that in the current preaching of men like John Piper, Paul Washer, Steve Lawson, David Wilkerson, John MacArthur, in their emphasis on assurance as well as true repentance, holiness, self-examination and sanctification to check the real eternal condition of the soul (Washer P., 2008).

Also, in the United States the influence of such values has gradually opened to a more universal context. It was in the United States that in the XIX century Christianity had its greatest numerical growth. With the advent of the industrial revolution all the different minorities that arrived in the United States during different migration were led to act and behave like the Protestant majority. This created a particular typesetting for the case of United States where such Protestant ethic can be observed today even outside the borders of Protestantism where those element have become part of the 'cultural' traits of society. I find some examples of it in the universalization of work as a "religious duty" for all the American middle-class, in family life, in homeschooling and patriotism. Another example is the view toward individualism. In the American context Individualism has been often conceived as a moral virtue contrary to the traditional European conception of it as incivility and chaos. Those are just few examples of how difficult it is to isolate the American Protestant ethic into specific borders (Wright Mills C., 1951; McClosky Z., 1984).

Also, another consequence of the recent syncretic development of American Protestantism is that is no longer possible to isolate all the Weberian preconditions that I've mentioned above, such as the inner-worldly asceticism or the Beruf. That's why the only solution available for the research is to proceed with a systematization of the different religious traditions through the use of idealtypes. With this procedure I will be able to isolate therefore the inheritance of Calvinism, not in the concept of predestination that only few churches still hold in the original formulation of Calvin, but into the all-encompassing category of the perpetual assurance of salvation that in my view is more able to explain the relationship. What is interesting to notice from the scheme is that all the religious branches holding the belief in the perpetual assurance of salvation are the same branches that generally have higher political participation, support free-market principles or display attitudes of acceptance toward economic individualism (Means L. R., 1966; Verba S. K. L., Schlozman H. B., 
Brady N., 1993; Barker D. C., 2000). Those contemporary American evangelicals, doctrinally conservative, while not always Calvinist in the strictest sense, share much of its preconditions. From the explanatory table that follows it is possible to have a synthetic view of the evolution of reformed traditions into the American context and their contribution to the American spirit of capitalism. I start from the suggestions made by some other scholars (Means L. R., 1966). Every single denomination does not necessarily fit in only one category. An interesting case for that matter is the one of the Southern Baptists, one of the largest Protestant branches in America who tend to mix together the two different traditions of Swiss reformed and Swiss Anabaptist, long time ago very separated. But once again someone can easily identify churches where the perpetual assurance of salvation ('once saved forever saved') is still present, as it is the case for most of the churches of the groups b) and some of the groups c) such as the brethren or Baptists.

On the other hand there are churches where this doctrine of the perpetual assurance of salvation, that came from Reformed theology, is no longer there, such as the case of many British Anglican, liberal churches and Pentecostal churches. The case d), particularly in the example of the Methodists or part of the no longer existing Puritans, represent an interesting case once again able to explain Weber's misunderstanding of the anxiety of salvation. As I've already mentioned before, John Wesley, founder of Methodism, believed in the doctrine of assurance as well as Lutheranism or some branches of Puritanism but that assurance is not perpetual as for the case of Calvinism.

A brief parenthesis on a matter underestimated by Weber, that does not directly concerns my analysis, is the role of Anabaptism and other currents of Christianity apart from Calvinism in shaping the democracy in America. The formation of liberal democracy in United States was possible only through a union between the spirit of freedom and the spirit of religion (Tocqueville A., Democracy in America, [ed. orig. 1835-1840], in Aron R, 1996). This element, together with equality of conditions and abolition of class distinctions was largely inherited from the Anabaptist tradition and other dissident movements. Even though many of those radical groups willingly avoided involvement in politics or worldly professions pursuing a more hedonistic path, their influence in today's strive for freedom of religion, separation between state and church, distrust towards the state, and many other aspects so deeply rooted in the American mentality are undeniable (Adamo P. [et alii], 1994).

Another element underlined by Weber in his study of sects and very important for my research on Chinese Protestantism is the role of a religious belief as a 'business card' of the quality of the subject in developing trust, an element so crucial for the success and development of a capitalistic spirit (Fukuyama, F., 1995). This as I've already pointed out doesn't mean that the sect was 
important simply because it was able to activate a social network but also because through a process of selection it created reputation from the eyes of the outside context and therefore trust.

Furtheremore for the case of United States the connection between free economy and religious liberty can be clearly observed even by looking to some of the contemporary American literature on business. Notions such as the one of "spiritual capital", virtuously successful business and faithbased trust are considered proper of a 'spiritual enterprise' able to achieve the true purpose of business (Roosevelt Malloch T., 2008).Virtues promoted by the American Protestant spirit such as leadership, courage, perseverance, discipline, justice, are more than a set of rules and become here the basis of a successful spiritual enterprise (Roosevelt Malloch T., 2008).

Some contemporary authors underlined the economic impact of some religious belief in the field of business ethics (Quinney R., 1981; Fox R., 1987; Wayne S. F., 1989). Much of this current of writings is directed to American business owners and has more a practical approach on how to achieve a successful business in a certain company (Maxwell J. C., 2003). Ethical dilemmas, moral principles such as the 'golden rule ${ }^{7}$ are displayed in their applications to specific business practices for promoting the way to economic success. A growing number of those writings, mainly from a Protestant background, stresses particularly the centrality of doing business ruled according to the Biblical principles from the Sacred Scriptures (Tam S., 1969). And applying this scriptural perspective to someone's life determines that the realm of work becomes for a Christian a 'waystation of spiritual witness and service', a 'sacred stewardship' with its own special dignity (Henry C. F. H., 1964). Those studies lay out a 'theological view of work' seen no more as a 'necessary evil' or a 'product of human curse' but as a good thing entrusted to humankind, to be understood as a 'calling' and as a 'ministry opportunity' for any Chistian fellow. In this perspective work is seen as a moral duty and an ethical responsibility to be fulfilled with excellency in order to guard someone's spiritual as well as material status (Witherington III B., 2011).

Terms as vocation, calling, working for the Kingdom of God, excellence, importance of savings, being in the world of business, dismanteling the division of labor into 'sacred' and 'secular', are constantly emphasized by this type of contemporary literature on business ethics. Labor is more than a component but it has strong value and purpose, it means being a 'steward of the world from the hands of the highest Boss: the Creator' (Bernbaum J. A., Steer S. M., 1986). The way by which this ethical premise is intended to shape the conduct of the readers involves a motivation that results in a unique workstyle of methods, attitudes, strategies to achieve results. The worker must have a good character and maniacal integrity, respecting the authorities, taking his

\footnotetext{
${ }^{7}$ The golden rule taken from most of major religions invites 'not to do to others what you don't want others to do to you'. Following this strategy is said by literature to lead to a win-win philosophy and trustworthy economic approach able to lead to long-term economic success (Maxwell J. C., 2003). 
responsibilities, seeing work as a service and ministry to be done in excellence and with motivation, being able to face risk, crisis and failures (Sherman D., Hendricks W., 1987). At the same time sobriety, self-discipline, a sense of 'separation from the world' even if 'being involved in the world', gives a crucial balance to the conduct of those that follow this ethical premise (Peabody L., 1974). Many of those contemporary American popular concepts are once again echoing Weber's literature of his times and draw once again a strict connection between the workplace and a series of ethical requisites such as justice, abiding with the law, honesty, agency of contrasting interests, ethical employer-employee relations, etc.,.... All this set of ethical guidelines it is said to be necessary in order to achieve economic success (Hill A., 1997).

Such considerations are also confirmed by several studies in the field of sociology (Harrison L. E., 1992, Fishman A., 1989; Mayer A. J., Sharp H. 1962; Veroff J., Feld S., Gurin G. 1962). Those scholars point out the difference between the traditional Protestant beliefs and our contemporary work ethic due to the secular evolution of society. Yet they witness a survival of such influence from the side of beliefs proper of conservative Protestantism that influenced the emerging of freemarket liberal ideas mainly for the case of the United States. One explanatory example of this survival can be the economic and monetary theorization in its Calvinistic principles such as sovereignty of God, financing the kingdom of God, the role of Sacred Scriptures, present for example in a contemporary Biblical view of economics by Gary North in his interesting analysis (North G., 1973). It is also possible to notice the inheritance of Benjamin Franklin's biblical wisdom in business for example in much of today's American business literature for the general public (Bland G., 1972; Burkett L., 1990; Cook W. H., 1974; Covey S. R., 1990; Devine J. D., 1977; Egli J., Hoerr B., 1984).

To sum up this articulated mixture of religious beliefs I present here a table that synthetizes the evolution of the Protestant ethic in the American context. This over-simplified classification, although very useful for the explanatory purpose through ideal-types, may not be totally respondent to the real much more syncretic evolution of American Protestantism. A clear example of that is the case of infant baptism, that, even though was part of Calvin's and Luther's theology, it is clearly abandoned by many evangelical churches. I observe the same trend for the case of branches coming from Swiss reformed traditions, in favor of adult baptism under the strong influence of Anabaptism. On the other hand Baptist and Southern Baptist traditions, in spite of their Anabaptist inheritance, they generally embrace strongly much of the Calvinistic theology.

A clear demonstration of the heterogeneous set of theological positions in American Protestantism today is the gradual convergence and mixture between what today is known as Covenant theology, inherited from the reformed theological tradition, and Dispensationalist 
theology, inherited from more recent north American theological traditions (Scofield C. I., 1999 [ed. orig. 1909]). Not all the points of Calvinist inheritance, in the famous acronym T.U.L.I.P., survived even inside the reformed tradition, particularly for the case of the belief in limited atonement. This led the panorama of doctrinal positions to be once more fragmented between Amyraldism, hyper-Calvinism, New-Calvinism, five points Calvinism, four point Calvinism, etc... This syncretic development involves also the case of the British Anglican tradition, historically always strongly divided between the national state church and all the British dissident groups (Bainton H. R., 1958; Schorn-Schütte L., 2001). 


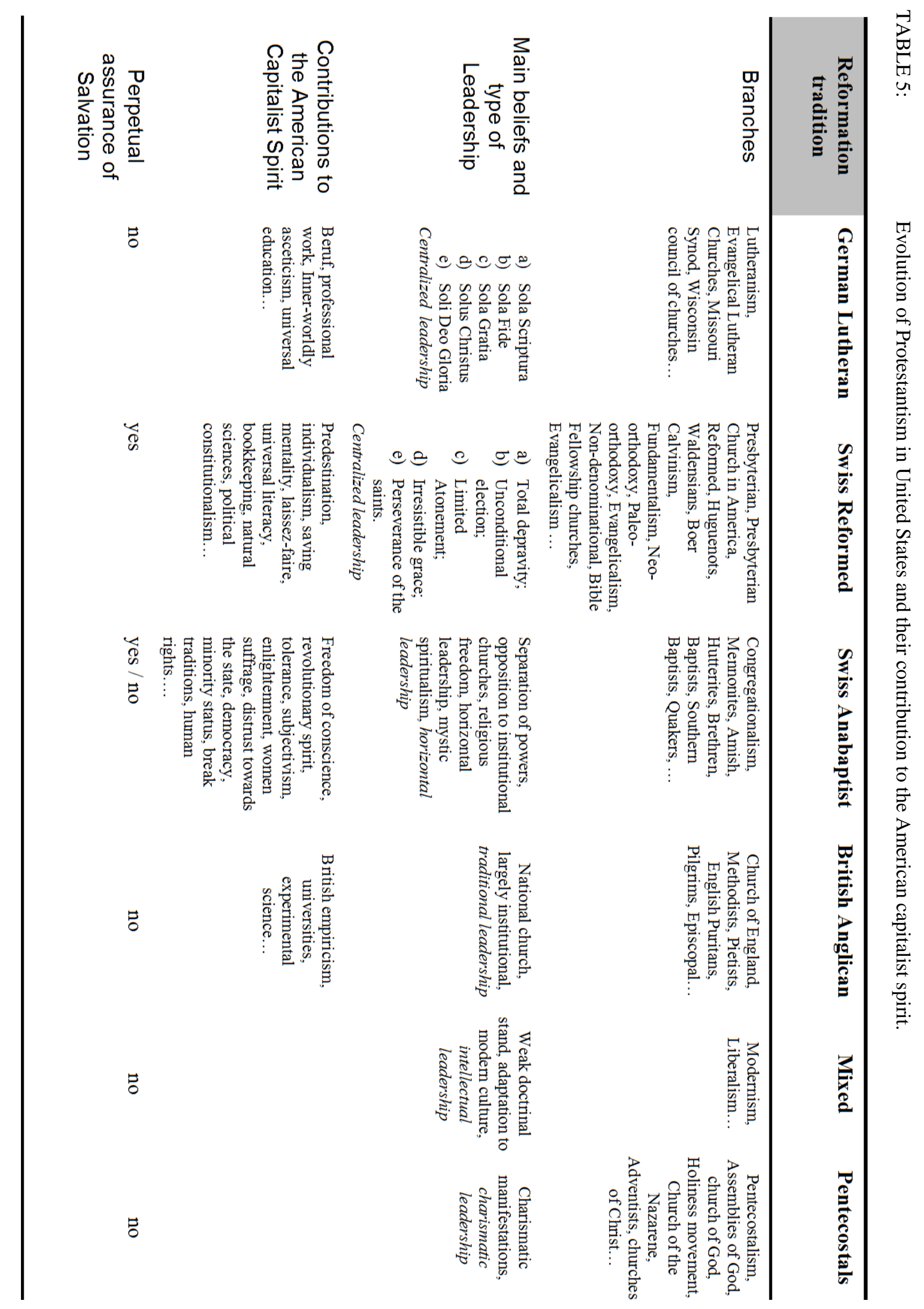


Finally, another important mention must be given about the other side of the coin: the widespread of materialism in American society today. Some scholars argued that American capitalism encountered major difficulties at the end of the 1960's as a result of a growing tension between ways of relating to work based on Protestant asceticism and the blossoming of a mode of existence based on immediate consumer pleasure stimulated by credit and mass production (Bell D, 1976). A trend in the representatives of the sacred overly interested in the material accumulation has been present side-byside with this traditional Puritan ethic. It is the case of television preachers or the phenomenon of the mega-churches in United States, churches where mainly under Pentecostal influences what is commonly known as "prosperity Gospel" or "Gospel of wealth" has spread. One clear example is Lakewood Church of Joel Osteen that with its more that forty-thousand members counts today as the largest church in America in terms of attendance. A strong emphasis is made by these kind of churches on economic success but it has lost almost all references to inner-worldly asceticism, salvation or Beruf.

Some scholars finds that in United States the Protestant ethic has declined in its ascetic work behavior, especially in recent times, losing its characteristics such as frugality or hard work under the pressure of an ever-growing consumption society (Wisman J. D., Davis M. E., 2013). Modern Capitalism it is known to function well because of the specific underlying restraints quoted above that for long time were embraced in Western societies. With the crisis of the prosperity Gospel today the control of the conduct or the display of a work ethic leaves the place to a priceless enjoyment of money. Such love of money common to all ages is not the root of the spirit capitalism which was characterized instead by a control of the conduct, a saving mentality and a frugality that only Calvinism was able to give. Someone may wonder then if this spirit of capitalism suddently died out or where it has moved. 


\section{2 China and Its Spirit of Capitalism}

\subsubsection{Protestant Revival and the Economic Boom}

It is at this point that China find its place in the analysis as the next area maybe destined to play a central role in the development of Protestantism. Recently some analyses have shed light on a large scale unprecedented upsurge in religious attendance and religious association in East Asia (Hefner R. W., 2010). For some cases of religious resurgence the relationship between religion and economic development has already been investigated like for the case of Taiwan that I will later mention more in depth (Lu Y., Johnson B., Stark R., 2008). Also, it will be interesting to see the same with un-explored cases that are experiencing a spiritual revival as South Korea, Indonesia, Malaysia. The comparison, however, should include some double-check cases such as Hong Kong and Japan where economic development took place without any major spiritual resurgence (Constable N., 1994). But what is even more surprising is that the most startling of eastern Asia's revitalizations is taking place in China where together with religion I observe the flourishing of neoliberal economic tendencies.

The reason why I focus on China then is the wide size of the incomparable religious Protestant revival that is taking place together with the rise of capitalism. It is surprising that such religious revitalization is taking place in a country like China where historically monotheism has never been important (Fried M. H., 1987), and high modernist secularism was the predominant voice in the Chinese Marxist Leninism of the recent past (Masland J. W., 1952). Despite the harsh persecution coming from the Chinese Communist Party instead of an extinction of religious belief of any kind the data shows a substantial growth of religion. Not only Christianity in China today is spreading more than any other religious affiliation, but it is in particular the exponential growth of the specific religious affiliation of Protestant Christianity that catches my attention as the prominent part and fastest growth of the religious revival in Communist China. From only 700.000 members in 1949 before the Cultural Revolution, China counts today more than one hundred million Protestants. Some resources report today of 130 to 170 million of Protestant Christians in China (Robertson L., 2009). More accurate analyses speak about 50-80 millions of Protestant Christians (Bays D. H., 2003). This second source, however underestimates largely the enormous number of Christians coming from the 'underground churches'. Even if I take the most prudent estimation the growth is still dramatic: from $0.2 \%$ to $5.7 \%$ of the total population, while Catholicism stays under $2 \%$. 
For the case of Wenzhou the estimation surpasses 12 percent. China is now home to more evangelical believers than any other nation (Baugus B. P., 2014). Some estimates say that by 2030 China could become the biggest Christian nation in the world despite the persecution coming from the CCP (Yiwu L., 2011; Yang F., 2005). The control from the government and the ideological removal of religions created therefore a perverse effect enhancing actually a total emptiness in the individual that finds its response in Christianity. What is interesting to notice is that, together with the spreading of Christianity in China, it is possible to observe the growth of a particular form of capitalism in clear contradiction with the Marxist values of the government (Guthrie D., 1999; 2003; Krug B., 2004; Knight J., Song L., 2005). From the famous 'economic reforms' implemented starting from 1978-79 after the death of Mao, the Chinese Communist Party (CCP) decided to move toward more market oriented policies. That move signified a drastic change in paradigm and a shift in ideology, a fundamental directive that 'cannot be altered for a hundred of years' (Hou J. W., 2011). Out of that shift China's economic success today is evident with a promising average of $8 \%$ in economic growth for more than three decades. The country of China exceeds today the United States in domestic consumption, in both imports and exports even if it is still much lower per capita. China is today the world's fastest growing major economy (AA. VV., 2010; Huenemann R. W., 2015; Kennedy S., 2011). This success in the international trade was surely due to economic and structural features as the presence of a domestic environment favorable to economic success or pressures of national anxieties to win the world acclaim for the Chinese market (Finnane A., 2005). What is not clear, behind those preliminary considerations, is why such major economic development took place in this particular era and under the particular institutional constraints of socialism.

China is just coming out from a Communist era where all the efforts were made to destroy any tension toward profit. Today the majority of Chinese people no longer recognize themselves in the ideology of Communism as it was at the time of the Cultural Revolution (Dorn J. A., 1999; Huang L. J., 1971). Looking further back in time until the modern era, China had a monetary system in decadence, a general economic, political and cultural traditionalism and a perceived environment of segregation. Despite the great realizations in any field of science and technology of the past centuries, sometimes even in anticipation with the Western societies, the Chinese society was not able to systematize those realizations into an elaborated technology and industrial development such as the one that occurred in the West. These barriers were often due to religious beliefs such as for example the occultism of feng shui that forced people's activities on the basis of the flowing of water and wind. Living in harmony with nature was more important than getting caught by the run for economic progress (Mooneyham W. S., 2014). 
From an analysis of Weber's contribution on the study of sociology of religion apart from the Western world (Weber M., 1976 [ed. orig. 1920]; pp. 377-592), I see that Confucianism and Taoism, the main beliefs in China for many centuries, always sustained a vision of society very ranked into classes and ruled by an aristocracy. When the Catholic missionary Matteo Ricci (15521610) went to China it took him 18 years to approach Beijing because the whole country was forbidden to foreigners. That was also the case of many Protestant missionaries such as Hudson Taylor (1832-1905) or Charles Thomas Studd (1860-1931), who were allowed to come to China only by the nineteenth-century (Austin A., 2007). Interesting case is the one of William Edward Soothill (1861-1935) a Methodist missionary to China that spent 29 years in Wenzhou, started more than 150 churches and witnessed close to ten thousand conversions. He translated the New Testament into Wenzhou language, the works of Confucius into English and wrote about Chinese Buddhism. He also started schools and hospitals and is considered the founder of Wenzhou's Christian faith (AA. VV., 2005). So is not that China did not experienced the advent of Christianity prior to the present religious revival (Dunch R., 2001). John Sung Shang Chieh for example played an instrumental role in the revival movement among the Chinese Christians during the 1920s and 1930s. But the proportions of the religious awakenings in China today are far more widespread and permeating every aspect of Chinese society, including its economy.

The events that occurred with the two opium wars or later on with the boxer rebellion show clearly how the relation of China with the outside world and particularly with the Western society was often tumultuous. Meanwhile during past centuries the state religion of China (Confucianism) didn't make any effort to integrate and organize the religion of the lao pai hsing, the common people (Taoism) as part of an unified religious doctrine. In fact it was very common to observe simultaneous religious practices and syncretism of those different traditions. According to Weber the goal of Confucianism was "a cultured status position", an humanistic project of good living and contemplation, while Protestantism's goal was to create individuals who are "tools of God" in every aspect of society. The intensity of belief and enthusiasm for action were rare in Confucianism, but common in Protestantism. Actively working for wealth was perceived as wrong in the eyes of any devout Confucian. Taoism on the other hand promoted ideals such as quietism and passivity that were not beneficial for any professional accomplishment. The "third way" of Chinese ethic was Buddhism, arrived in China in the III century a. C. Not only Buddhism presented a world-rejecting asceticism similar to Catholicism but it also was always perceived as the "teaching from the strangers" and the foreign religion. Therefore, Weber states that it was this set of differences in social attitudes and mentality, shaped by the respective dominant religions, that contributed to the development of capitalism in the West and the absence of it in China (Weber M., 1951 [1916]). 
The advent of Communism in this sense was much rooted inside the history of China. Even after its radical break with the past history during the first years of the Cultural Revolution Communism ended up in the long term supporting a traditionalist anti-capitalistic view. The stateoriented, and socialist project promoted by Mao Tse-tung was always guided by the idea of a future abolition of capitalism. Mao willingly destroyed all the structure of technicians and experts, closed the universities and promoted the idea of a proletariat man living with two dollars a day. Individualism during Communist as well as in past history was never appreciated and rarely thoughts about one's private life were allowed. This anti-innovative ideology of the status quo still promoted in the educational, cultural and social system of China is probably something very far from the Weberian spirit of capitalism. Such ideological baggage leaves today the great void of a closed society that doesn't attract anymore the Chinese masses.

Paradoxically the American capitalism described and condemned as "decadent" by Mao and antithetic to the Chinese revolution seems to be the element that in the end is making the difference in China. The remarkable success of China's economic reforms against all expectation was possible without any political change. Giving the government's onerous exaction on successful enterprises, the absence of security for property rights and many other factors, the expectations of the experts for a Chinese economic boom were very low (Montinola G., Qian Y., Weingast B. R., 1995). Yet because of political decentralization, localities started to embrace this shift in ideology with surprising outcomes. Particularly interesting here is the case of the city of Wenzhou that, from being a little village of fishermen, in the last 20 years has experimented an incredible development becoming a modern center of business for all China. Wenzhou in fact, according to biographical reconstructions of entrepreneurs that I interviewed in my research, three generations ago was a very poor city, the primary activity was the one of fishermen around the islands or rivers. Many people were forced to migrate from Wenzhou into other provinces and cities because there was a state of misery and the people were 'notoriously lazy'. This was quite different from the hard working mentality and modern developed city that it is possible to observe today.

The question remains, then, of where does this profit-oriented mentality, very visible today in Chinese entrepreneurs, come from. Some analysis actually recognized the guiding role of Christianity in enhancing modernity before the advent of Communism, even though in his premature stage compared to today's spiritual revival (Dunch R., 2001). The uncertainty in passing from communism to the market economy has rendered Christianity attractive to the young generations of Chinese people. Especially in the process of violent urbanization, added to several natural disasters and the drastic changes brought about by the Cultural Revolution, all traditional social forms were destroyed over a short period of time and the individual was left in a strong 
search for support and meaning. It is in this period under Western contamination of the Chinese lifestyles that, in my opinion, between all the many American and European models, the Protestant ethic finds its place as an explanatory, even though not exhaustive, component. This present Chinese generation grown without emotional boundaries toward ancient traditions is seeking a way of life that can make you "happy all the time" that "gives you the peace of mind among many difficulties" and that can be observable in the way someone exert his "worldly profession" (Mooneyham W. S., 2014; p. 155). Especially the generation of the 1980's with the 'one child policy' grew without siblings and without any support in life, searching an environment like the church as a community and family of 'brothers and sisters' able to offer a congregational life that other traditional religions were not able to provide. In this sense the anomy and globalization that China had to go through went in favor of the acceptance and growth of Christianity. Furthermore Christianity with the global sense tight to it resulted to be compatible with the values of modernity and democracy, compared with Confucianism or other traditional Chinese sets of values.

Protestantism therefore is not a sufficient condition for the genesis of the spirit of capitalism in China but it is probably a necessary one. It seems to me that without this revival of Protestantism and its consequences in society the passage from a socialist anti-capitalistic project into a market economy would had probably taken a different path. Chinese capitalism is clearly not a direct consequence of Protestantism. It clearly comes from many institutional and technical elements. I am aware moreover that the cultural schemes of Protestantism in XVI century Europe are totally different than those of the China of XXI century. Also I'm not suggesting that wherever capitalism emerged it was always because of this spirit. However, even though the spirit of capitalism is not an universal phenomenon, everywhere it emerges it should emerge for the same reasons. Although I can just take together few pieces of a huge and more complex mosaic there are enough evidence to suggest that the Protestant revival is playing a role that is not marginal for the genesis of a specific Chinese spirit of capitalism clearly observable in Wenzhou's model.

\subsubsection{The Case of Wenzhou: the Jews of China's Jerusalem}

If the investigation moves on to the local and micro level it is possible to see that an increasing proportion of converts today are well educated young people living in urban China (Yang F., 2005). In an historical context of adversity towards Western civilization, Christianity, in clear contrast with traditional Chinese religions as Taoism, Confucianism or ancestors veneration, is clearly perceived as progressive, liberating, modern and universal. In this particular post-Mao market transition the southeast coastal city of Wenzhou is playing a major role. Wenzhou is one of 
the richest cities of China in terms of per capita income and is also known as "China's Jerusalem", the largest urban Christian center in China (Cao N., 2008). Historically Wenzhou was also the stronghold of the national Chinese party (Guomindang) and was particularly reluctant toward the values of the Maoist China. This element, although still under a strong control from the government, in part favored the raise of Christianity in this area.

In Wenzhou, Protestant Christianity, with its over one million Protestants and more than 1.200 churches (Yang F., 2005), has accompanied the economic development of a city that from an impoverished rural town has become a dynamic regional center of global capitalism and the pioneer in developing China's current market economy (Cao N., 2007). In other words for the particular context of Wenzhou evidence tells me of a combination of rapid economic growth and high rate of adherence to Christianity. In this positive turmoil a new entrepreneurial class of Christians known as "Boss Christians" composed by rich successful private entrepreneurs and also influential Christian leaders able to provide funds for church-building, projects, evangelical organizations, and church initiatives, has successfully emerged. One third of Wenzhou's entrepreneurs today is considered to be affiliated somehow with the Protestant faith. Because Protestantism, as I described especially in Calvinism, is a system of beliefs that more than others is able to interfere with the status quo, the CCP makes a continuous effort to control and suppress it. In fact Wenzhou Christian entrepreneurs start to represent a "religious risk" for the Communist government.

But the mobility and commercialism of these so called "Jews of China" cannot be denied by the government as a real success and positive contribution for the economy of China. Attracted by Western civilization, Chinese Christianity took many elements from the religious journey that I have described above first from Western Europe, then more recently from the mainstream American Protestantism applying them in a syncretistic way to the Chinese context. As I will show among those elements I've found also many non-declared Calvinistic beliefs such as the Beruf, the innerworldly asceticism, the role of sects, the glory of God as the ultimate purpose in life, as well as other important preconditions for the case of China such as millenarianism, dramatic conversion, literal reading of the Bible or the presence of a charismatic leader. In fact many churches that I had the chance to visit in the area of Wenzhou are motivated Calvinistic churches. Surely the great majority of Chinese Protestants today live in rural areas outside of the cities and far away from the economic centers of China (Bays D. H., 2003) but if someone look with more attention he may see that the converts are not all marginalized individuals deprived of material and social resources.

As I've mentioned already there is an increasing proportion of converts that are well educated young people living in the urban city of Wenzhou (Yang F., 2005). Evidence shows (Bays D. H., 2003; Wenger J. E., 2004; Yang F., 2005; Cao N., 2008) that a growing number of them is 
involved in economic activity, making a lasting contribution on the economy of the city. Wenzhou, the "Jerusalem of China", is composed by this new generation of entrepreneurs believers that instead of seeing the local government as an enemy of the faith, takes the state as a potential partner that can facilitate the work in spreading the faith. Boss Christians then end up today representing a dominant part of the state development project and holding a certain political influence in local society (Cao N., 2007). Some quantitative analyses (Wang Q., Lin X., 2014) recently studied the effects of religious beliefs on political preference, human capital, work ethic, and therefore economic growth, using provincial panel data from 2001 to 2011 in China. Among the different religions Christianity, particularly Protestant Christianity which is the more numerous, has the most significant effect on economic growth. Coming to qualitative studies on Protestants entrepreneurs it is possible to see the presence of many elements of Weber's theory such as the Beruf (Yi Xiang). Very often when those entrepreneurs are been asked in interviews about their success they acknowledge having been "blessed by God" in their business success and they have little fear of revealing their religious identity in the public arena. Those entrepreneurs demonstrate to have a clear view of their life as a "calling" (Yi Xiang ${ }^{8}$, the Chinese version of the Beruf) stating to have:

[...] the special vision from God. [...] God's power to go ahead in the emerging market economy. [...] (Cao N., 2007; p. 53).

Everything they do, they say, they do it:

[...] for the glory of God and the love of Christ. [...] (Ibidem)

especially in the context of business, perceived as a non-secondary way of serving God. Their job is "arranged by God" and everything they do is seen as "God's special calling" (Cao N., 2007, p. 58). The view of hard work as a calling and the high economic status as God's blessing are then seen as crucial motivation for the ambition of any new member who embraces this faith. Although the traditional Chinese religion of this region and its substrate of magic and miraculous beliefs may have played a certain influence on the perception of the importance of material blessings this is still an unprecedented economic outcome.

The second interesting aspect for my analysis concerns the composition and the characteristics of those Christian communities in China. This refers to the bipartition between the Christian Three-Self Patriotic Movement (TSPM) and the "house churches", quite similar to the distinction between the official church and the sects defined by Max Weber in his review. Protestant Christianity is characterized in China by the presence on one side of the Christian Three-Self

\footnotetext{
8 异象 yì xiàng here means “vision", but yi xiang for the purpose of this analysis also encloses the idea of 意向 yì xiàng, “intention", “purpose”, “disposition”, and is associated also with the word 异想天开 yì xiăng tiān kāi in the sense of "imagine", "indulge in fantasy". From: Manser M. (Eds.), 1999, Concise Chinese-English, English-Chinese Dictionary, Oxford University Press.
} 
Patriotic Movement (TSPM) and the China-related offices of ecumenical church affiliated to the China Christian Council (CCC). Together they form the only state-sanctioned (registered) Protestant church in mainland China. On the other side what is commonly defined as "house church", the specific sector of Protestants not registered by the government (Bays H. D., 2003). Originally the TSPM was established as a government arm of the Communist Party. Many Chinese Christians are distrustful of the TSPM/CCC because of the state control over the church (Wenger J. E., 2004). A "Christian Manifesto" was written in the late 1940s, long before the advent of the cultural revolution, with the attempt to control the Protestant churches.

Since 1979 the TSPM was re-established and in response several Christian leaders went out of the "official church" disagreeing with its prerogative to control worship practices, preaching and behavior. These Christians then began to meet in "underground churches" and acted independently from the official church, refusing to compromise with the atheistic communist government. Because the house churches are not under the CCP control they are within the watchful sight of the government. The result today is that, despite the strong opposition and reputation as criminals of any house church member, more than half of Protestant believers are in autonomous Christian communities (Bays D. H., 2003). In fact the statistical estimates coming from TSPM include only the Christians registered by the government and testify of 15-20 million of Protestants, while it is obvious that the number is much higher if I include the house churches (Yang F., 2006). Even inside this binary subdivision I can identify a more articulated context. Some scholar (Yang F., 2006) proposed a triple-market model of religion in China: a red market (officially permitted religions), a black market (officially banned religions) and a grey market (religions with an ambiguous legal/illegal status). The author points out that an higher restriction and suppression of religious organizations from the Chinese government led to the inverse effect causing its flourishing (Yang F., 2012). The focus of my attention here will be the grey market with its accentuate noninstitutionalized religiosity and the black market. If I exclude the TSPM, those two sections forms the main part of Protestantism in China today and will be here the main object of analysis.

What is then the organizational factor of this particular form of Christianity able to explain in Weberian terms the economic development of those Chinese Christians? An interesting analysis has been done for the case of Taiwan where, after the deregulation of the late 1980s, it has been observed that state suppression of sectarian minorities contributed to the weakness of organized religion while enhancing the popularity of unchurched congregational religions (Lu Y., Johnson B., Stark R., 2008). The scholars found out also that economic de-regulation was associated with the rise of such religious groups while state control had a negative impact disadvantaging economic competition. For the case of China the situation is not so different, and is even more intriguing if I 
consider the higher rate of state control from the CCP. The house church model, very critical of any form of hierarchy, has brought to the flourishing of an entire spectrum of sectarian groups that are the main target of religious persecution. Those religious groups tend to stress a dramatic conversion experience, a literal reading of the Bible, a strong emphasis on millenarianism and the presence of a charismatic leader (Bays D. H., 2003). Also this particular form of sectarian groups has the potential to supply the confidence (see self-efficacy), community and direction so lacking in China's turn into modernization (Wenger J. E., 2004). In other words the autonomous church, as it was among the sects of Weber, is better able to stimulate the believer to the achievement of an economic success for the case of Chinese Christianity.

Those suggestions of scholars may lead me to hypothesize a strong link between Max Weber's thesis and the Protestant revival that is taking place in China (Tong K. J., 2013). The spiritual preconditions to the Protestant ethic, such as the inner-worldly asceticism, the Beruf, the role of sects, the glory of God as the ultimate purpose of life, that seem to be almost totally disappeared for the case of the Western world find then a re-actualization in today's Chinese Protestant revival. But the Chinese Protestant revival doesn't involve only the national and local level in an era of globalization. Much of the success of those Chinese entrepreneurs is related to their massive involvement in the migratory process towards the Western world. Particularly interesting is for me the case of Italy, where the majority of Chinese immigrants, $80 \%$ of all Chinese immigrants (Lisci A., 2011), come exactly from the area of Wenzhou. One third of the people from Wenzhou are actually outside of China, called the Jews of China in diaspora and involved into all sort of businesses. From Wenzhou comes also the majority of the products that China export in Western Europe. My task therefore will be to check empirically the validity of the thesis on the impact of the belief on perpetual assurance of salvation on self-efficacy, a cognitive process that has been proved as an element able to favor economic success. 


\section{PART TWO}

\section{METHODOLOGY AND THE FIELD}

«QUALIFICATION OF THE REASONS FOR THE CHOICE OF THE EMPIRICAL CASE AND DESCRIPTION OF THE STEPS THROUGH WHICH THE OBJECTIVES OF THIS STUDY WERE FOLLOWED.» 


\section{Chapter IV}

"When a truth is necessary, the reason for it can be found by analysis, that is, by resolving it into simpler ideas and truths until the primary ones are reached."

Gottfried Wilhelm Leibniz

\subsection{Discussion on the Method}

\subsubsection{Prolegomena}

After having pointed out the theoretical relevance of the study of values in entrepreneurship and before I move on to the empirical level of analysis the procedure requires that I first make some important clarifications on the methodology of this research. I called this little paragraph prolegomena as to signify its function as an introductory note. With the same word Immanuel Kant wrote the famous essay 'prolegomena to any future of metaphisycs' and prolegomena was the common word for centuries when adventuring a theological dissertation in times and places where theology was still considered to be the 'queen of sciences'. When the discipline of sociology came into the picture and up until now metaphysics, theology and fields of studies related to religion were marginalized or simply forced to be silent. Just for the desire to shed clarity, and not because of any nostalgic instance, I therefore here argue that no determinism whatsoever is compatibile with the scientific study of religion. In order to be objective a study as the one presented here has not to be a mere acritical defence of a set of beliefs but in the same time it has to be free from the other extreme of a secularized determinism that excludes a priori any explanation that involves a religious topic.

What I present here is a comparative qualitative study in the shape of an ethnography. The reason why I chose this specific technique of research is because the object of analysis, behavior of entrepreneurs, requires prolonged and close observations of their daily life in its procedural and contingent display, something that escapes to the eye of mere quantification. The study contains the observation of practices, episodes, meetings, roles and social types as well as social relations, groups, organizations, environments and subcultures observed in three years among Chinese migrants involved in some forms of entrepreneurship in the city of Milan Italy.

In order to understand how this entrepreneurial propensity is developed and pushes toward economic success it is important to have a 'bottom up' strategy of analysis. Any social action, 
including the economic action, according to my perspective works like a cultural artifact that is created by the meaning ascribed to the actions by those who engage in them. It will not be my main focus then to merely observe the characteristics of the action of the individuals but to go beyond it and understand the meaning given by them regardless of the judgement of value that somebody may give to it. However, the subjective perspective of the actor must be taken into account. It is crucial therefore to treat entrepreneurs as ordinary people. It is important to examine their variety of goals, activities, practices, habits and ideas. Then it is important to mediate between those micro-level elements and the more distant, large-scale structures of society. Furthermore my methodological approach in analyzing the social action of the individuals will go beyond an exclusively utilitarian consideration.

\subsubsection{Methodological Background of the Research}

In observing the entrepreneurs as ordinary people, in their subjective dimension, I followed in this study the methodological suggestions of some ethnographers (Duneier M., 1999). In examining the entrepreneurs in their behaviors and interactions I considered their role as idealtypes, the function of 'public character', the symbolic role of places, framing them into a narrative description of their social life as well as their business life (even though not as novelized as Duneier). Yet differently from Duneier I approached the field with a research design that did not come after the access to the field or intuitions as I've observed things even if this was sometimes in a finite set of circumstances the case. Nor my focus was as much on the social position like for the case of sidewalk (Duneier M., 1999) but on the economic behavior of the individual and the role of his social interactions. Furthermore in my connection between macro and micro dimensions differently from Duneier I based the connection not going from case to case through a multi-sited ethnography but focusing on the same case (Chinese entrepreneurs part of the same network) then possibly enlargeable to other cases around the city of Milan and extendable in motherland Wenzhou as well as other metropolis around Western Europe for future studies. The role of places was very crucial in my study considering how important and meaningful was to immerse myself in bars, work-places, stores and shops of China town. Those locations were investigated as a social world, in the lives of its people, in the relationships among regulars, in the different ways in which they interpret and defined community and how did they related with the boss. In this the setting worked for me as a 'laboratory'. A method of seeing places in the city as objects of investigation yet with a greater emphasis on the individual behavior (Ocejo E., 2013). The approach to their work life 
becomes then interested in aspects proper of 'conventional economy', highlighting the role of social rules and moral dimensions of the economic action (Chicchi F., 2006).

My role was the one of a passive observer although sometimes I was actively participating (sometimes in participatory observation) in the daily life of the entrepreneurs. From the beginning it was made clear to any person that asked me my intention of being there as a researcher. Surely this, especially in the initial stages led to a consequential problem of reactivity in the observed individuals modifying their behavior, their way of speaking with me. This was a risk I was willing to take giving the possibility on my part to immerse myself in the point of view of the studied subjects especially for what later on I will describe as first group of entrepreneurs under my analysis. Furthermore giving the social acceptance of such role (mainly for example compared with the role of a journalist or of a public official) inside the context of my study, I decided to follow this premise. In terms of reliability the dynamics in the field were composed by ups and downs. In the case of the first group of entrepreneurs a complete identification of the point of view of the social actors was possible due to my identification with their religious practices. In this case I was able to display what in qualitative research is defined as the 'emic perspective' (Babbie E., 2005) as opposed to a 'etic' and disembodied relationship with the point of view of the social actors. Yet the cultural distance between me and them very frequently was forcing me to dissociate myself from their interpretation with disenchantement specially in the last part of my research. Another aspect of qualitative methodology that was important to take into account is what in literature is defined as the 'reflexivity' issue (Babbie E., 2005). During my time as an observer in the field, it is important to consider the negative effect that my presence was having in the surrounding environment. For example my presence or words were changing the type of answers given to my questions or the specific behavior of the entrepreneur. I even was able to notice this but in some cases it was compensated by the fact that I was deeply involved in the life of the people I was observing (knowing their private life). I then was able to verify when they were faking or being spontaneous.

The ethnography took place mainly into the urban area of Milan in Italy so it borrows several methodological suggestions from the side of urban anthropology, with a special focus on the ethnic community living in the territory of Via Sarpi and other territories that are residential areas of migrants (Hannerz U., 1980). Even though this study is more focused on the cultures of work among Chinese entrepreneurs instead of focusing on the characteristics that are specifically urban, it still needs to take into consideration the methodology followed by those types of studies. For example many of the interactions and circles of relations that I observed on the field may properly be considered as an expression of what in cultural anthropology is referred to as 'urban villages'. Urban villages are cultural realities with their specific features inside a more global urban context. 
The study will try to point out those islands of entrepreneurship in the big city that follows traditional and cultural patterns, that possess their unique features among Chinese entrepreneurs. Instead of thinking of the entrepreneur therefore as an aseptic figure shaped by the economy and with no specific features apart from their profession, I will try to point out the role of the cultural and social dimensions in shaping their business even in a post-modern society and in urban Western realities. Yet differently from the majority of the sociology of culture, this study still follows the more factual, rationalist or functionalist (in cultural anthropology terms) suggestions of the classic theoretical approach to the subject of analysis. I will not apply a mere constructivist interpretation to the matter. In other words, when approaching the field, objects are still to be considered as objects independently from the perception of the single observer.

Even though I took some contributions from this approach in the research I don't identify necessarily with a more naturalistic approach to the social research held by those classical methodologists. On the other hand this research took the shape of a case study, or multiple-case study, focusing on a specific social phenomenon: the case of Chinese entrepreneurs in the city of Milan in Italy and their economic behavior. In many ways what I observed there can be very similar to other realities of Chinese migrant communities from Wenzhou living in big metropolis of Western Europe. The purpose for this study, as I've already pointed out is not just descriptive but explicatory in its nature, trying to discover the role of values in the life of those entrepreneurs. Differently from the grounded theory the field was approached already with theoretical questions $a$ priori and re-elaborated a posteriori in light of the empirical results (Babbie E., 2005). An empirical case was then identified deductively on the basis of its ability to satisfy the theoretical requirements through a series of analythical categories in tune with the existing formulations coming from the academic community. For this reason, as I will explain in more details in next paragraphs the study focused on the relationship between case studies and theory suggested by the extended case method (Burawoy M., 1991). The fieldwork intends to confront somehow the theory gaps pointed out in the previous chapters addressing the need for a refinement or modification of them. It is in fact impossible according to my stand to enter in the field without any form of expectation on what it will be discovered as mistakenly the grounded theory suggested. On the other hand many of the things I expected to observe were somehow challenged by the field. This is a positive element in the quest for reconstruct or improve the theoretical discussion without necessarily having the need to approve it or reject it altogether (Babbie E., 2005). Some of the theories in economic sociology that I've listed in previous chapters will somehow at times crash with the observations in the field while at times surprisingly find a positive validation. What is important to stress here though is that the research started with an in-depth and intentional analysis of the existing literature first with the 
purpose of going to the field with a theoretical question. Certain theoretical interpretations not necessarily in tune with the original theoretical framework were actually added to the study in light of contrasting results coming from the field (justification logic, economy of conventions...).

Relationships and systems of relationships were crucial parts to be considered as I approached and studied the field. It was important, from the very beginning of my entrance into the field, to try to catch as much as possible the entire spectrum of the social relationships of the entrepreneurs: ethnic, social, labor, religious, recreational (Babbie E., 2005). As for the case of the Chicago school I followed several of their suggestions in the importance of considering the 'definition of the situation', the impact of social rules on groups of work, the impact of cultural segregation, the transitory character of relationships from formal to informal, the small isolated worlds as well as the big picture. So it was for me very crucial to follow the contributions of those scholars in enlarging my reflections on the fieldwork. A good example of that is the study of Ghetto in Europe by Louis Wirth (Hannerz U., 1980) almost parallel to the China town of the 'Jews of China' migrated from Wenzhou. The institutionalization of an ethnic border in those areas (whether Jewish ghetto or China town) together with forms of oppositions by the surrounding society, little by little was followed by an identification and quest for success from the individuals that slowly led to an upward mobility from low payed jobs to high payed positions. This in the future generations (as for the case of second generation migrants from Wenzhou) led to a break, from adaptation to assimilation, with the traditional values in favor of economic competition (Hannerz U., 1980).

In terms of network analysis concerning qualitative research I followed the perspective according to which the individual is considered on the basis of the different roles he covers. Actions are considered on the basis of the social purposes that the individual has, the different levels of connections with a specific focus on the individual position and use of it (Hannerz U., 1980). Also findings in the field about the purpose of the network were under my constant interest whether the specific network under my observation was formed by few or more connections. Many times it was due to business reasons but as I will point out later it had its cultural and even religious roots. Also during the times when I was following on a strict level the entrepreneur in specific places, circumstances and contexts of action he was under my constant focus, especially in his role as catalyst for the ramification of several businesses. Also during the whole period of my observations it was crucial to observe the evolution of those networks and changes in the nature of its participants, its purposes and places of influence. 


\subsection{History of the Research}

\subsubsection{Connecting the Dots}

Now, applying what I've mentioned in the previous chapters about Weber's theory, in the next table it is possible to see a synthetic overview of the dynamics of our model applied to the empirical context of Protestant China. The first challenge that I had to face was the identification of the presence and role of something not so tangible such as a religious belief. How can someone use observation to investigate an unobservable idea such as the religious belief? Since the birth of sociology the discipline was characterized by a radical refusal of metaphysics. But such approach on its part neglects the sociological importance of analyzing how phenomena are produced, how certain beliefs (what the actor thinks he can do) give meaning to the social action through intentionality, recognition and social identity. Such approach also neglects the centrality of how individuals often see themselves as 'moral agents', how in Durkheimian terms the 'sacred' gives birth to social interactions that can be seen as 'rituals', where actions have a symbolic, intrinsic and ritual aspect (Barbera F., Negri N., 2015).

According to this view the belief, as an internal state of mind, defines the cause of the action and it express itself in observable behaviors. So in order to establish the influence of those beliefs in an objective way it is important to remember that ideas, frames, meanings and values seem to have an endogenous transformative power, being able to produce effects that are observable over time. This examination of the influence of belief and values in the economic action will be done through induction, the same way someone investigates other things he can't see, by observing their effects mainly in practices, rhetorical discourses, norms and relationships that have their weight in the economic involvement. From those effects I will then make a rational inference for the existence of a sociological relationship. The presence of several beliefs (that I call here preconditions) had already been underlined by recent studies for the case of Protestant China (Cao N., 2007). Some of the beliefs that were crucial in Calvinism, especially among what I call here the assistants to the preconditions (sovereignty of God, anti-superstition), are as I will explain in next pages, marginal for the case of contemporary China, although they may still be present. According to the literature and previous studies I then substituted them with other assistants to the preconditions which are playing a guiding role among protestants in China (mainly Millenarianism and the presence of a charismatic leader).

The following study intends to check the validity of my theoretical argument on the impact of the belief on perpetual assurance of salvation (PAS) on self-efficacy and favoring therefore economic success for the case of Chinese Protestant Christianity. I am not directly interested in 92 
measuring their economic success but the presence of self-efficacy and the impact of PAS on this cognitive process that, among other determinants, has already been proven to be highly correlated with economic success. I am also not denying the strictly social role that those elements display (see for example house churches). From a Weberian methodological individualistic perspective however my main focus remains on the role of a specific belief for the construction of a subsequent socialized ethos that is not strictly psychological. As I've already mentioned several quantitative studies probably lack a clear understanding of Weber's theory on the internalization of a religious belief in someone's life, and how such belief reflects in daily practices and in the formation of a specific economic ethos.

TABLE 6: Dynamics of the relationship between the Chinese Protestant entrepreneurs beliefs and the economic ethos according to the theoretical argument in its empirical application.

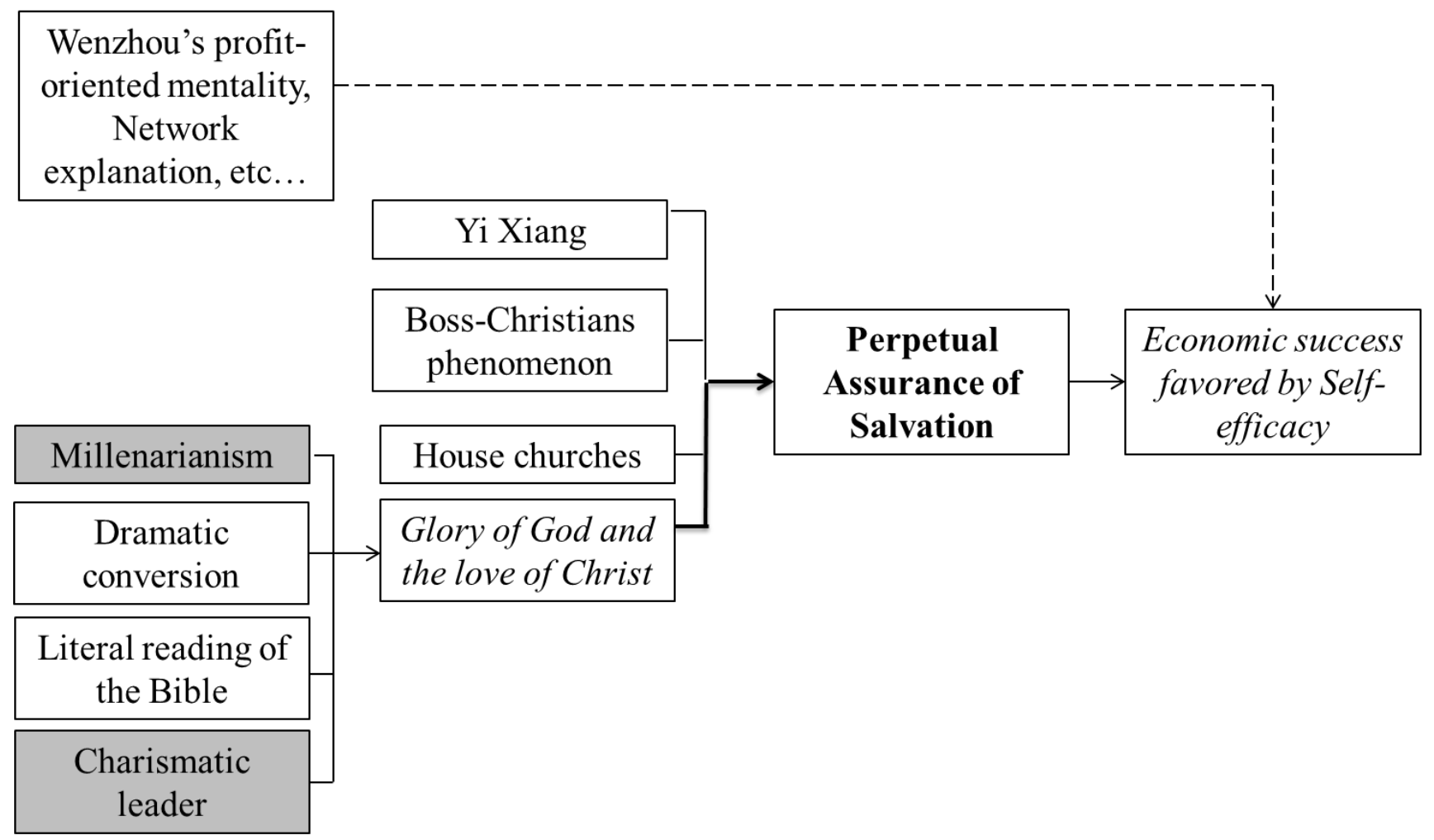

The city of Milan has today an heterogeneous and widespread spectrum of small businesses managed by Chinese hard workers that display economic success despite the ongoing economic crisis. This current situation is accompanied among those Chinese workers by a growing social mobility during the last 30 years (from workers to multiple business owners, from street vendors to large scale buyers, from waiter to graduated business accountants, from machine operator to sales managers). Such a setting provided enough questions and insights to be considered the best candidate for a field of study. That's why I've decided to do a qualitative in-depth study. My target was a group of Chinese Christian entrepreneurs from Wenzhou involved in small businesses 
creation and multiplication living in the city of Milan, Italy. As I've already mentioned, although mainly from a previous rural strata, the majority of the Chinese people that live in Italy come from the city of Wenzhou and the greatest part of them is involved in entrepreneurial activity, running some business and at the same time being part of an evangelical Protestant church. Entrepreneurs from Wenzhou in the past decades have transported in Italy a family-based culture of entrepreneurship, self-reliant, ready to assume economic risks as well as harsh working hours, low profit margins and financial capacity due to their family network. This gave me the opportunity to identify the external influences involved in the migratory process of the "Jews of China" so important in the rise of the recent Chinese entrepreneurship. Milan, after Prato in Tuscany, is the second-largest community of Chinese immigrants in Italy (IDOS, 2014). Chinese entrepreneurs in Prato played a central role for the spread of global supply chains made in China in the past decades (Ceccagno A., 2003). Today however apart from some key examples I will mention in future chapters (wharehouse Il Girasole, wharehouse of AUMAI in Monza...), the most common pattern among Chinese entrepreneurs in Italy is to leave those factories to become small business owners (Wenzhou's model). I have chosen the geographic area of Milan because of the availability of the cases and the economic relevance of the area for the case of Italy.

Since the 1980s economic rise of Wenzhou many migrants from that region arrived in Milan. Some scholars pointed out the interesting evolution of their business activity (AA. VV., 1997). First they started their initiative through the informal economy as peddlers or owners of small shops, focused only on unique products, then, they expanded and diversified their business through bars, restaurants, wholesale shops, financial activities up until having almost a monopoly of certain types of business or managing entire commercial enterprises. In this gradual opening toward economic activities that involves public relations, the contribution of the second generation in knowing the Italian language was crucial. During my ethnographic observations and interviews it was evident that being the son of a Chinese entrepreneur made life easier for the Chinese entrepreneurs of the second generation since the necessary finances and social capital were already circulating for decades. Interesting fact is that, in today's economic realm, those Chinese enterprises represent a parallel and self-sufficient economy in the Italian, and more generally European arena. The Chinese tension toward entrepreneurship is unique or at least peculiar if someone was to compare their entrepreneurial tendencies with other migrant groups present in the same area of Milan and other big cities or even small towns (Ceccagno A., 2014). Many Italian enterprises today depend on Chinese labor force whereas vice-versa Chinese enterprises are gradually infiltrating in businesses that in the past were only managed by the Italian labor force and expand them in new 
ways (Cologna D., 2006). What is then the element, in their specific set of values that led to such evolution and to the rising of an undeniable Wenzhou's profit-oriented mentality?

The approach of the research was from the theory to the fieldwork. Having previously explained my theoretical argument on the impact of the belief in the perpetual assurance of salvation I wanted to check the validity of it through an ethnography of a group of Chinese Protestant entrepreneurs in the city of Milan. The research strategy that I have adopted is a comparative holistic design that focused on the Chinese entrepreneurs attending the evangelical church in Milan together with a second group of Chinese non Christian entrepreneurs in Milan without any contact or adherence to the Protestant faith. The methodological strategy is then similar to the one of an extended-case method (Burawoy M., 1991). This specific perspective in qualitative research conceives methodology as a link between technique and theory and is primarily concerned with the relationship between data and theory. In this case, as well as in other qualitative studies, the extended-case method uses participant observation to reconstruct theories of advanced capitalism, oriented on a macro level of analysis despite the particular significance of the social situation under study. In this the extended case method differs from the ethnomethodology as well as the grounded theory, or from the participatory action research and the institutional ethnography approach (Babbie E., 2005).

Since entrepreneurship and economic success are the elements under my analysis I focus on the particular external forces that shape it among Chinese entrepreneurs both in their motherland and in their migratory journey to western Europe. In other words what I observed on a micro dimension is viewed as an expression of the macro and the particular significance of the social phenomenon is oriented on a more general level of analysis. The fieldwork in this methodological perspective is not less theoretical than the primary analysis that generated it. In fact the field is often seen as an expression of those theoretical questions that still have a preeminent role. What is interesting to analyze through this approach is the construction of genetic explanations of particular outcomes (mainly economic success). In his description of the extended-case method Burawoy mentions Weber's analysis of the motivational component provided by the Protestant ethic as an example of this approach. Weber tried to point out differences between similar cases in order to point out the connection between the elements under analysis. I looked then for the similarities among disparate cases and different social situations such as the Chinese Protestant entrepreneurs and Protestantism in XVI century western Europe in order to evaluate the consistency of the Weberian formal theory (Babbie E., 2005). What is significant for me is what it tells me about the world in which this phenomenon is embedded. At the same time other things are significant such as 
its societal role, what it tells about society as a whole after the aggregation and repetition of those micro interaction I had the chance to observe.

\subsubsection{Recapitulation of the Steps of Entrance into the Field}

The history of the research started with the entrance in the field through a mediator, Delun, that opened the door to the group of entrepreneurs under my investigation. The contact with the community was facilitated by the presence of this informant, a Chinese Christian that had perfect knowledge of Chinese and Italian and that was already linked with the community of my interest. I had a good relationship with my informant since many years before I took the role of a researcher. The problem of the 'first impressions' on him therefore were almost totally out of question, there was no potential hindrance for the successive phases of the investigation. Yet a good amount of diffidence, especially during the first interviews, was present due to the distortion of information, presence of partial points of view on the matter as well as my lack of knowledge at that time of all the different aspects of the phenomenon. At first my entrance in the field caused a high amount of suspect. I incurred several times in breaking cultural rules such as sharing pictures of other people, talking to married women prior to having the authorization from their husband, forge too much ahead the discussion with certain bosses before receiving their complete trust... For this reason I tried to establish a relationship with the subjects, starting with those participants that were more open to my presence, trying to receive their support and cooperation. During the period of my research my involvement in the social life of the entrepreneurs was very intense. I took part to their religious gatherings, meetings in McDonald's, dinners, travels around the city, visits to family members, activity on social media (WeChat...), excursion to China town and even traveling to China to visit people in Wenzhou connected through family and religious relations. In those circumstances I had to be flexible and adapt myself to bear long periods where I was silent and listening them speaking in Chinese, discussing about personal matters, faith, work and family life. In almost all of those occasions I was the only non-Chinese person with them. This captured the curiosity of people but generally, given the fact that after a while they knew me, I became somehow part of the group.

At this point the research took two different paths: on the one hand I decided to do in-depth semi-structured interviews and on the other hand I've started to 'job-shadow' several entrepreneurs in their day at work. Job-shadowing consisted in following silently the entrepreneur in his daily work-routine through a type of observation as invisible as possible, almost 'like a fly in a room'. My data collection strategy was the one of 'being on the job', engaging in their same activities, with 
an experiential type of approach (Ocejo E., 2013). Of course together with this many times those techniques were accompanied by observations and ethnographic surveys. The reason why I decided to introduce job-shadowing in my research was the need to observe the behavior of the entrepreneur in his work, not just through his partial interpretation of it expressed in the interview setting. All the most important aspects of the social process under my analysis and its real nature were possible to be observed only through 'being there' with them. At first I tried to pursue this through a form of participatory observation 'being one of them', working together with them. Since this was not possible I then later decided to pursue the option of job-shadowing. The challenge in the beginning was big, since it was my first experience of this kind and the entrepreneur felt somehow uncomfortable with it. My request faced several rejections even among the closest informants. After this first wall I was able to proceed with it.

In order to avoid the problem of my excessive disturbance in the field both during the jobshadowing and during the interviews I tried to be as invisible as possible in the first case and intervene as less as possible in the conversation during the interview once the dialogue was established. During my job-shadowing I always had my notebook to write down any type of action, what I saw and what I thought with a particular focus on the registration of episodes closer to the research together with unexpected events. Not trusting in my limited memory the transcription of job-shadowing was done almost immediately after a day spent with the entrepreneur even adding more details that came into my mind and that I didn't write. Non important details that I wrote down, later on demonstrated to be crucial for my interpretation of the events. My presence in few cases determined a strong rejection as for example with friends and family members of the person I wanted to job-shadow that were totally opposed to my presence in the store at China town because they thought it to be intrusive. Those and some other rare cases showed a particularly negative rejection. In light of them I was nevertheless able to continue my research and not be excluded nor considered badly by other individuals that I encountered in the field. At times the job-shadowing was particularly tiring because of the high expense of energy of certain working activities done by the entrepreneur, certain days full of stress. Also, when I've started the procedure of job-shadowing, following some entrepreneurs during their work-life, my lack of understanding of the Chinese language represented a big challenge. Giving the language barrier, the presence on the field of the cultural mediator was crucial as well as the use of backtalk during job-shadowing or ethnographic observations. Together with this informant I benefited from other Chinese Protestant who speak fluent English.

Despite being perceived as an external member of a different ethnic origin the access to the community was compensated by the fact that I was already inside a network of evangelicals in the 
city of Milan and therefore I relied on my credibility as an actor inside their network. The study will make no reference to sensible data and I assigned to all the participants a nickname for the respect of their privacy. I've started my investigation with a wide perspective doing observations at church, then I've started later on to focus more on their work activities doing ethnographic observation and interviews at their workplace. After a first explorative stage which served mainly to encourage the building of trust and familiarity with the culture I've alternated moments of participatory observation to 30 semi-structured interviews.

The first interviews that I've done were not prepared in advance, then later on, on the basis of my theoretical argument and also in search of the best way to obtain information in a spontaneous setting and interaction I've developed a series of questions. My talk was very rare, almost all the time the respondent was dominant. Yet, especially in the beginning of my research one of the first challenges was due to their rejection of me as an intrusive Italian foreigner. Therefore at the moment of being asked questions many were silent or gave me only few words. Few times in the beginning I had the respondent answering with only one or two cold sentences, being frustrated for the wall there was between us. My role in the interviews was more the one of a 'miner' rather than a traveler, in the sense that I had enough general information while my goal was to investigate more deeper (Babbie E., 2005). At times I went around having natural spontaneous conversations with the individuals but it was not the prevalent trend in the collection of information for the interviews. Sometimes the interview outline was preceded by an introductory natural conversation about the life and story of the entrepreneur. Accidentally I had the chance to do one focus group in Wenzhou with less than 12 people where I submitted in a less schematic way the interview chart to the people interviewed at the same time. The participants were not chosen according to any probabilistic method of sampling.

\subsubsection{Sample, Techniques and Focus}

The people that I've interviewed are male and female entrepreneurs between 25 and 55 years old. They were first or second generation migrants that came from Wenzhou, living and active in the trade sector and commerce in Milan. My primary focus was to interview Christian entrepreneurs on high role positions as managers. I tried also to identify the economic function of the religious leaders (pastors, elders) as it has been observed to be crucial for the case of Wenzhou. Then I included regular workers focusing more on the perception of their workplace and duties. I did not exclude the option of ethnographic observations and interviews with several individuals from the same family group even on an inter-generational basis, as it is mentioned in the table of further 
techniques. Part of the interview also included a reconstruction of the biographical records of the entrepreneurs in order to see how they started their business, their religious background, if they are a second generation Protestant (Cultural explanation) and their perceived identity as entrepreneurs. Particularly, it was interesting to notice the professional variation from one generation to the other that leaves no room for many of those alternative explanations. All the questions for the interviews progressively (under several major adjustments) followed the procedure of thematising the interview according to purpose and concepts to observe and projecting the whole process of acquisition of information (Babbie E., 2005). The majority of the questions were descriptive with the exception of some structural questions (questions on network). Sometimes, especially in the last part of the study, even 'contrast questions' came out on the spot but that were not specified in the list (Spradley J P., 1979).

Also the reconstruction of the migration project of those Chinese entrepreneurs allowed me in the case of the first generation to understand what was the key element that led them to decide to come in Italy. If the reason was economical, the question aroused if it was done with the idea of starting a new business or to diversify something that already existed. Usually those Protestant groups stressed their focus on the importance of sharing their testimonies of how they became Christians. I took advantage of this element especially in my initial stage trying to enter into the field. Their personal testimonies, added to the biographical records, allowed me to see the impact of the belief in the perpetual assurance of salvation in their daily life, especially through the reconstruction of their past professional life, achievements, failures, risks. All this came out in a natural way, without any need to force the person to provide the information needed on the connection between the belief in PAS and the presence of self-efficacy. Personal testimonies and biographical records allowed me mainly to identify the person's reaction and behavior in situations of economic risk. In order to see the impact of the religious belief in their daily life, the record of testimonies was done in a secular and non religious context.

Also, in order to avoid a process of rationalization ex-post of their reconstruction of events I put a strong emphasis on factual changes that can be verified and that are strongly related to their professional life. Finally in various cases this did not represented a problem since I personally knew them well enough to notice eventual re-interpretations of their stories. 
TABLE 7: Scheme of the typical biographical journey of the Protestant believer.

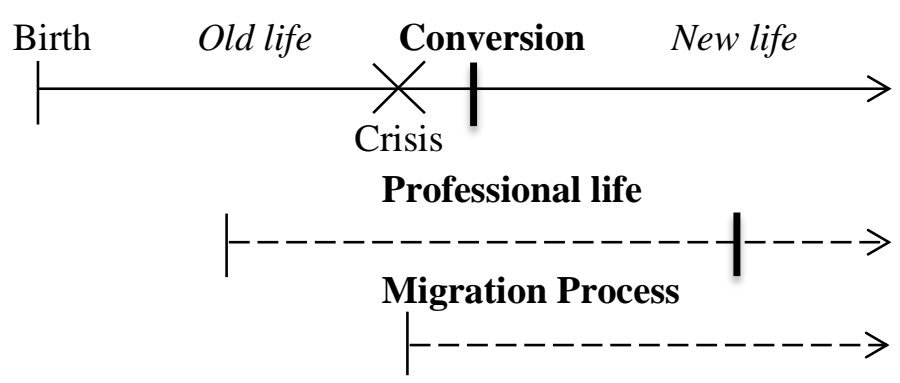

In order to avoid the problem of circular reasoning, which refers in this case to the risk of having certain answers just because I've asked them to give me that exact answer, many of those questions addressed the topic in an indirect way. I submitted the same questions both for the case under primary study and for the second group. The questions of the semi-structured interview worked for me as a guideline, none of them directly referred to religious practices but they all focused on their professional life and business in order to allow the information to come out spontaneously from the entrepreneur's own's words. 


\begin{tabular}{|c|c|c|c|c|c|c|c|}
\hline 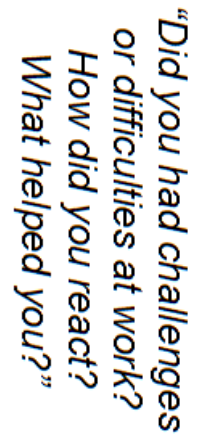 & 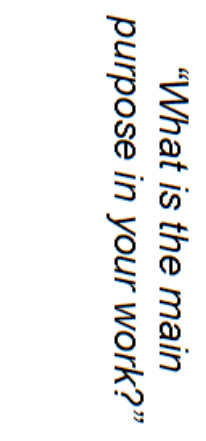 & 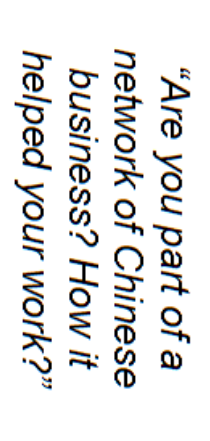 & 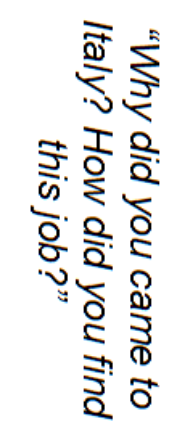 & 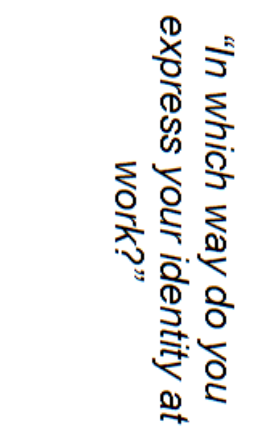 & 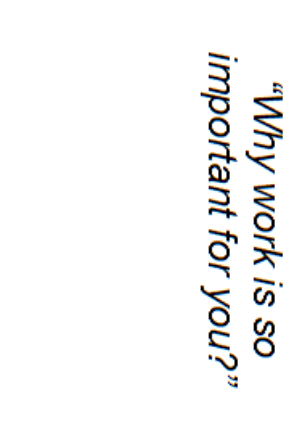 & 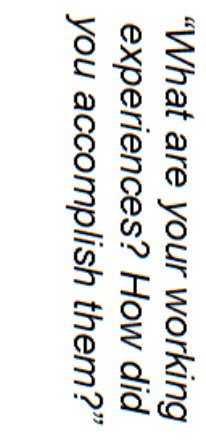 & 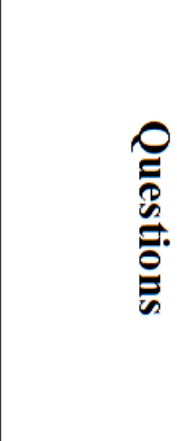 \\
\hline 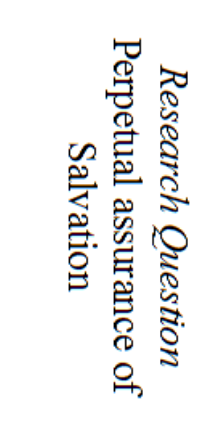 & 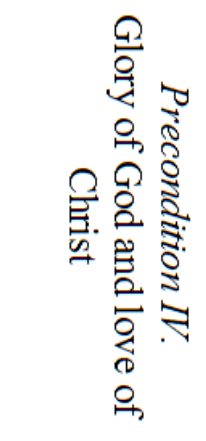 & 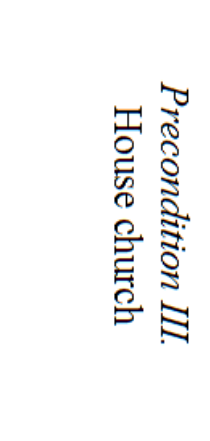 & 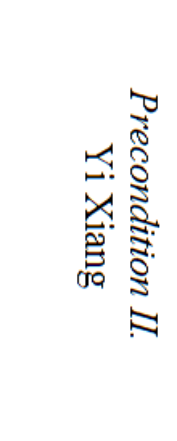 & 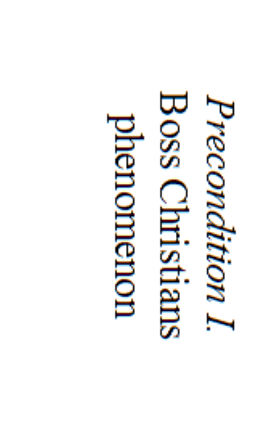 & 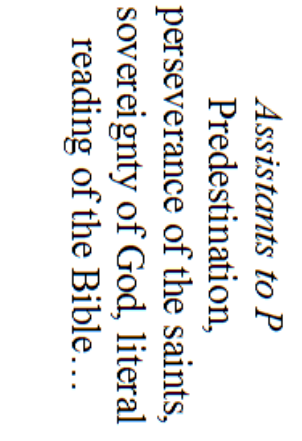 & $\begin{array}{l}\text { 营 } \\
0 \\
0 \\
0 \\
0 \\
0\end{array}$ & 这. \\
\hline 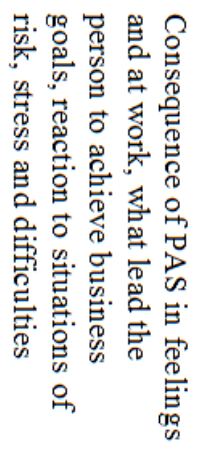 & 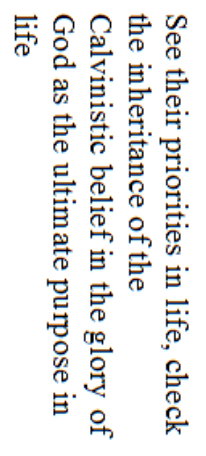 & 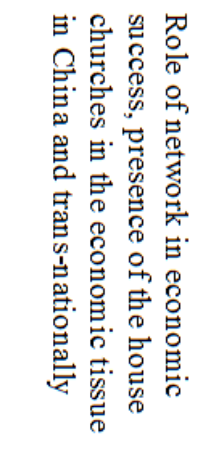 & 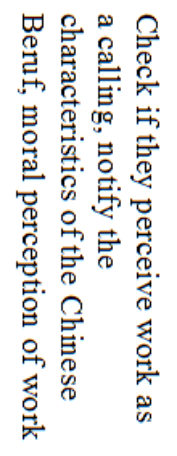 & 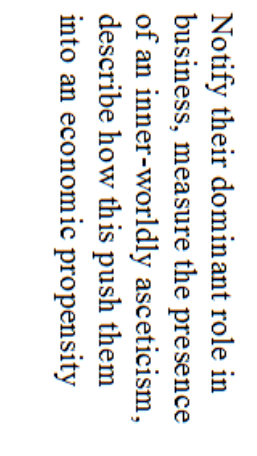 & 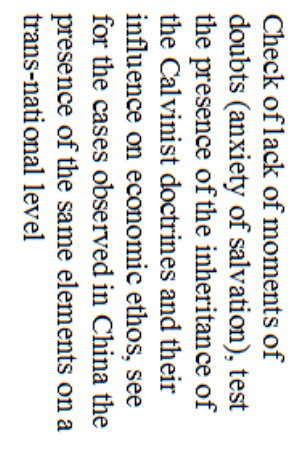 & 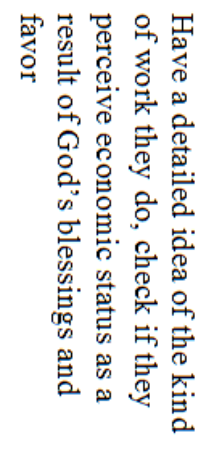 & 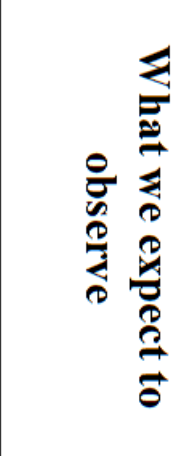 \\
\hline 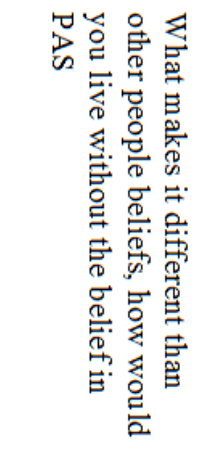 & 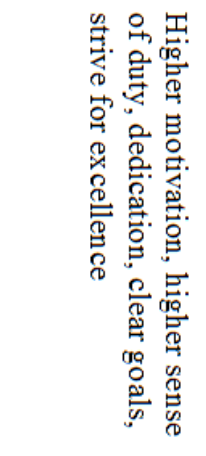 & 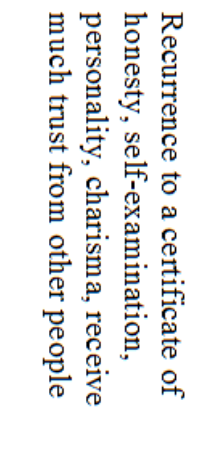 & 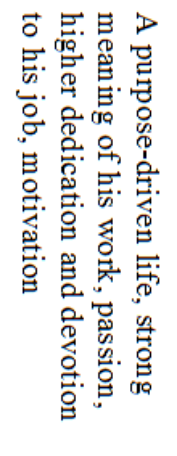 & 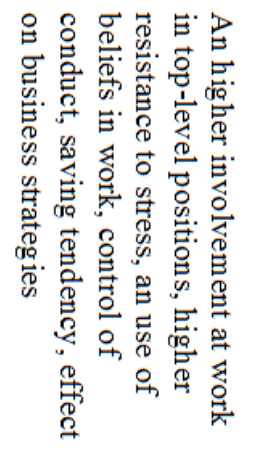 & 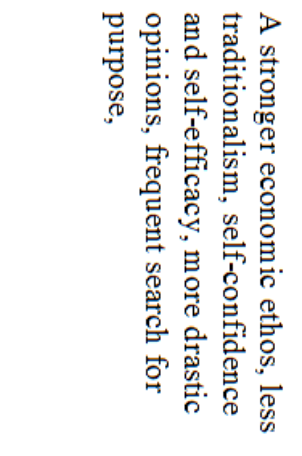 & 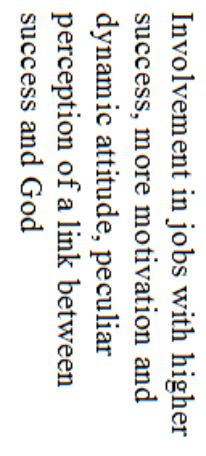 & 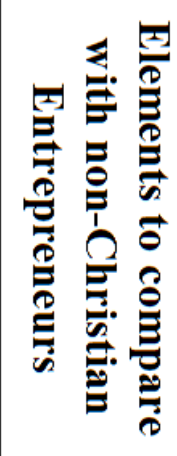 \\
\hline 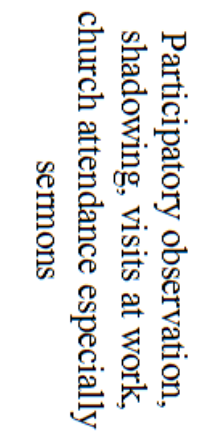 & 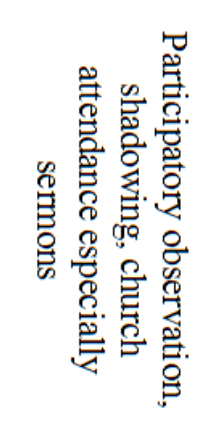 & 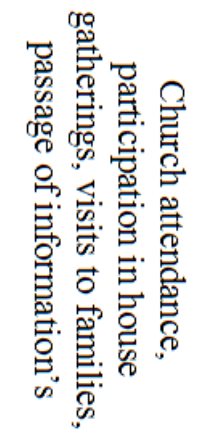 & 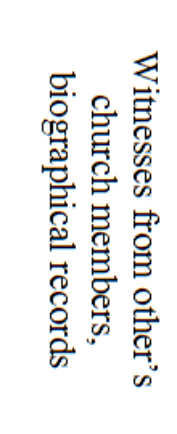 & 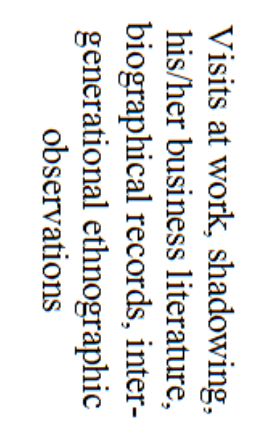 & 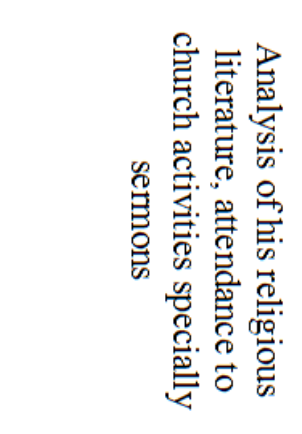 & 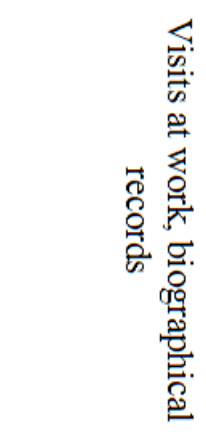 & 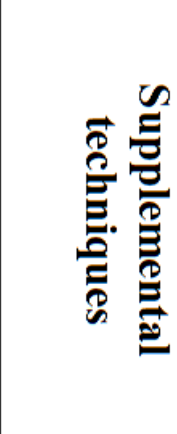 \\
\hline
\end{tabular}


After the interview I've also asked if the respondent had contact with other Christian entrepreneurs that I could include in the research. The main purpose of the interviews, after a general definition of their careers, their professional life, their achievements, was to investigate the validity of my research question on the impact of the belief in the assurance of salvation for the genesis of a particular work ethic able to enhance economic success (see TABLE 8 Introduction and Theoretical Argument). Obviously since my focus was to try to check the presence of a certain religious belief and its impact on self-efficacy the technique of in-depth interviews resulted to be insufficient to check the validity of the sociological relationship. For this reason together with the interviews I spent long periods of time with the Christian entrepreneurs in their daily work life through job-shadowing in order to see how they lived practically their beliefs.

I recurred to the use of several qualitative techniques that allowed me to check the validity of my theoretical argument such as the 'trick of metaphorization', seeing something like something else (in this case seeing the church as an economic enterprise with all its members as entrepreneurs), or the trick of null hypothesis (what would happen if someone tries to subtract from the field the belief in the PAS, as main element under my investigation). Also I recurred several times to the 'trick of unexpressed major premise' and other qualitative techniques (Cardano M. 2011; Emerson R. M., 2001; Ricolfi L., 1997). The 'unexpressed major premise' refers to cultural convictions implicitly held by the people under study that cannot be identified simply by asking them. For example the idea that if an entrepreneur was doing well with his business then he had God's favor, could not be legitimely considered sociologically valid apart from job-shadowing. For the case of Chinese protestants I then invited the respondent to submit a questionnaire with the possibility of adding a Likert scale of items such as the "self-efficacy instrument" (Maurer J. T., 1998) and mainly the General Self-efficacy scale (Sibilia L., Schwarzer R., Jerusalem M., 1995) as a double check. Since I wanted to observe the presence of a psychological attitude, the scale allowed me to check the presence of self-efficacy among the two groups. In the case of Protestant entrepreneurs a second section of the scale together with other techniques was intended to measure the relation between self-efficacy and PAS. 
For the next questions please choose a number $1-4$ and write a number in every statement to identify how you agree with the statement.

\begin{tabular}{|cccc|}
1 & 2 & 3 & 4 \\
\hline Not at all true & Hardly true & $\begin{array}{c}\text { Moderately } \\
\text { true }\end{array}$ & Exactly true
\end{tabular}
1.
I can always manage to solve difficult problems if I try hard enough.
2. If someone opposes me, I can find the means and ways to get what I want.
3. __ It is easy for me to stick to my aims and accomplish my goals.
4. I I am confident that I could deal efficiently with unexpected events.
5. Thanks to my resourcefulness, I know how to handle unforeseen situations.
6. I I can solve most problems if I invest the necessary effort.
7. _ I can remain calm when facing difficulties because I can rely on my coping abilities.
8. When I am confronted with a problem, I can usually find several solutions.
9. If I am in trouble, I can usually think of a solution.
10. I I can usually handle whatever comes my way.

In the case of the Chinese Christian entrepreneurs, I've spent a lot of time observing the rituals and activities at the church and at work through participant observation, job-shadowing and other unobtrusive techniques of measuring. This not only involved the religious gatherings but especially the working days of the entrepreneurs. I proposed to help three entrepreneurs in their work and live with them during their working activities observing the different practices that they displayed. Being an ethnographer my task was from the beginning to describe a specific culture, its expression in the different areas of life: religion, family, circle of relationships, until I then focused more on their business life. The goal of this ethnographic work was to grasp the entrepreneur's point of view, his view of life, his vision of the world (Spradley J. P., 1979) without any specific judgement of value, whether positive or negative on the content of the answers. I spent a long time in continuous ethnographic observation (6-7 months each), entering into all aspects of life of the believer. I did an intense investigation on the daily life of those Christian entrepreneurs, their conversations, through a reconstruction of their routine, through the involvement in their free time activities, through an inquiry of their social environment in their daily life, their cultural schemes, their perception of the outside world...

In the beginning I've used an open and broad strategy of observation (from descriptive observation to focused and more selective observations). I collected information in the field that 
seemed to be not necessarily linked to my topic of interest ('trick to meet the unexpected') with an additional attention to the surrounding environment of the cultural phenomenon under my analysis. Borrowing from ethnomethodology I decided sometimes, especially in the first stages of my research, to ask continually clarifications for every statement in order to discover elements in the conversation that normally I was taking for granted (Babbie E., 2005). I also focused on potential cases of Chinese protestants that were not part of the group of interest, observing in the field their behaviors even if not necessarily linked to my specific interest. The main reason for this strategy, especially for the first period of the research, was to intentionally remove or question my theoretical convictions in order to have the eyes opened toward unknown and different research inputs directly from the fieldwork.

After completing this stage I then did tighten my focus on the aspects under my interest. Two or three entrepreneurs were followed in their work to observe the relationship between their economic transactions and their religious values, how did they declined their beliefs, how did they interpreted their actions directed by those beliefs. I then alternated intense periods of observations to moments of departure from the fieldwork in light of the need to analyze the empirical documentation. Then I came back again into the fieldwork with a different focus and different point of view in the analysis. Many of these Chinese entrepreneurs in Milan were also part of several associations such as the "Association of Chinese Community of Wenzhou in Lombardy" and of the "Association of Chinese enterprises in Italy". The research then included some visits and frequent attendance to events organized by those associations together with the "Chamber of Commerce" of Milan. On the field it was possible to contact some Italian entrepreneurs that were keeping economic transactions with the Chinese entrepreneurs and to see their perception as "outsiders" of the business activity of the Chinese entrepreneurs (mainly Mario, Giulio for the Christian entrepreneurs and Luca for the second group of entrepreneurs ${ }^{1}$ ).

My focus, however, remained on the Chinese entrepreneurs ${ }^{2}$. Prolonged observations were made about the nonentrepreneurial Chinese Protestants in order to see if they still displayed an economic ethic although being involved into different work fields. At the same time, after a first period of the research, I then started another simultaneous group of 20

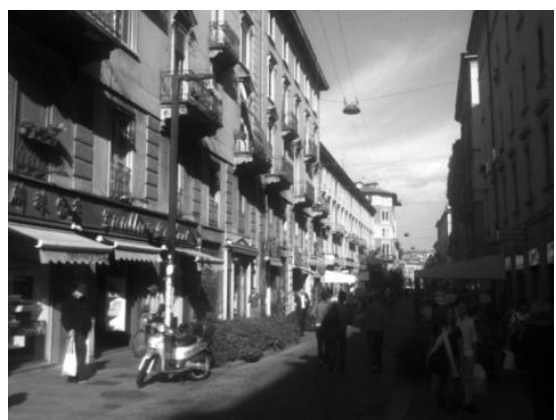

\footnotetext{
${ }^{1}$ Also in this sense Chu Hua not being an entrepreneur and coming from north China somehow gave me an outside view of the phenomenon.

${ }^{2}$ A view of Sarpi avenue, the China town of Milan. Made of Wenzhouren entrepreneurs, the so called 'Jews of China', resemble a Ghetto that has a lot in common with Jews: the ethnic separation, the involvement in businesses, the saving mentality, etc., ... 
interviews of Chinese entrepreneurs with no link with Protestant Christianity that worked in the area of Via Sarpi, the China Town in the city of Milan.

The collection of the sample was done in this second case not through an informant like Delun but through a 'snowball strategy' from a contact list of different Chinese associations of entrepreneurs in the area of Milan. I had in this case the challenge of building trust, facing their suspect, adapting to their busy schedule, postponing very often the meetings. I had several shut doors or negative responses from them but after a first phase I was able to start my investigation. In fact the entrance in the field in Milan was at the beginning particularly challenging especially for the case of the second group giving the lack of integration of many of those Chinese people in the Italian context. I was perceived by many of them as an obstacle, a native Italian that was somehow seeking to take advantage of them. The interviews therefore sometimes suffered of this, being poor in the amount of information that I was able to extrapolate.

My visit in China and Wenzhou on the other hand, as I will later describe more in details (see Cp. 6.2) was much more productive. I was able in the second year of my research to visit Wenzhou and witness with my own eyes the origin of the phenomenon under my analysis. In that circumstance I was perceived by the entrepreneurs as a western foreigner to be welcomed warmly. I received there in both Christian and non Christian interviews their full attention, curiosity and a solemn climate during the interview was common. There the amount of information was very easy to extrapolate and overflowing my own expectations. The visit in the motherland of the entrepreneurs was more an additional confirmation to the already rich ethnographic field overseas in Milan. The second sample of non-Christian entrepreneurs in Milan worked for me as a second group of analysis in order to check the empirical evidence for the relationship that I am studying between a religious belief and economic success, mainly being favored by the self-efficacy associated with the belief in PAS.

The main reason I've introduced this second set of interviews was to check any notifiable difference between two samples of entrepreneurs with similar jobs but different sets of values. The intent was then to confirm or deny the validity of my theoretical argument through the instrument of a case-control study. I wanted to make sure that no intervening factor was present such as social influence, cultural values, network membership or any other element that may lead me to identify an already pre-existing Wenzhou's profit-oriented mentality. Many scholars have pointed out for example that the impact of the institutional context together with the market context are crucial in shaping people's life towards short-minded decisions or long-term decisions (North D., 1989). Therefore I needed to include it in my explanation based on the religious belief. I wanted to shed 
light to the dimensions that may intervene in the relationship between belief and the pursue of economic success through this second sample of interviews.

TABLE 10: Different options of outcomes related to the theoretical argument and sample composition for gender, age and religious identification.

\begin{tabular}{|c|c|}
\hline $\begin{array}{c}\text { Total of People } \\
\text { Interviewed }\end{array}$ & 61 men 22 women - 2 outsiders \\
\hline
\end{tabular}

\begin{tabular}{|c|c|c|}
\hline & $\begin{array}{c}\text { Economic } \\
\text { Success }\end{array}$ & $\begin{array}{c}\text { Economic } \\
\text { Insuccess }\end{array}$ \\
\hline Protestant & i) case study & ii) outcome 2 \\
\hline Non Protestant & iii) case control & iv) outcome 4 \\
\hline
\end{tabular}

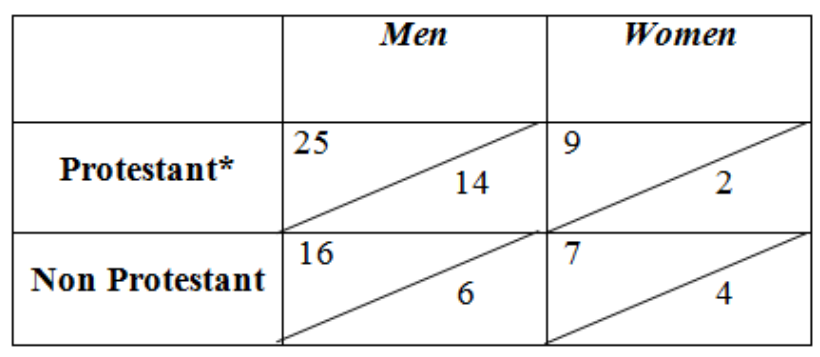

* Focus Group $\begin{aligned} & 1 \text { female Entrepreneur } 27 \text { y.o., } 1 \text { male Banker } 43 \text { y.o., } 1 \\ & \text { Pastor } 44 \text { y.0., } 1 \text { male teacher } 28 \text { y.o., } 1 \text { male Interpreter } \\ & 26 \text { y.0. }\end{aligned}$

Concerning the selection of the sample I considered the case-control study organized in four different options of outcomes, focusing my attention on comparing the case i) and iii) in this sample. Obviously I am not denying the possibility of the existence of cases belonging to the categories ii) and iv). In fact in some cases those entrepreneurs although involved in business they didn't necessarily held high positions nor they were pursuing a kind of activity that someone may define as successful business. Among the Christian entrepreneurs for example I went to visit them at a flea market engaged in selling sashes or glasses and other very low cost merchandises in the middle of the street or at the entrance of the underground of Milan. This type of business, that was more typical of the first generation of migrants when they just arrived 20 or 30 years ago, it is not at all what someone can define as an example of economic success. In any case during my qualitative research in the area of Milan I observed a general tendency toward economic success in terms of number of businesses, new investments, number of clients, etc., ... for both cases of Chinese entrepreneurs under my investigation. More specifically I've found for example in the field that 90\% of the Chinese people attending the Protestant church were involved in entrepreneurial activities.

The cases for the main sample were selected from an ethnic based evangelical church, an immigrant and auto-referential community (Naso P., 2014). I've focused my observations on those Chinese that are somehow involved in an entrepreneurial activity (bar manager, store manager, merchant, supplier, manufacture export, clothing store manager, enterprise employee, farm clothing employee, web designer...) and showed a certain degree of economic success in their business. I did choose to focus on those entrepreneurial activities that symbolically resembled more to the 
merchants of the XVI-XVII centuries under the analysis of Weber. The measurement of success was done where possible on the basis of profit, income, age, number of businesses, history table of work activities, and on the basis of customer, employee and owner's satisfaction, elements that traditionally are treated as indicators of economic success in business.

\subsubsection{The second Phase of Case-Control}

After the first phase of investigation in order to have a more clear and objective understanding of entrepreneurship, regardless of the specific system of values, a second group was introduced that lacked one of the qualities of the first group of entrepreneurs interviewed: they were not Christians. Special attention was given to the selection of this sample of Chinese non-Protestant entrepreneurs avoiding self-selection (interviewing only those who are willing to be interviewed) and enhancing the homogeneity of the sample. As much as possible the interviews in Chinatown were done to a group of non-Protestant entrepreneurs that shared all the parameters of the first group (region of origin, time of arrival and seniority of migration, gender, composition of family migration and lineage tradition, age, level of education, social and economic status) except for the belief in the assurance of salvation.

The majority of those Chinese non-Christian entrepreneurs were atheists, heirs of the postMao project or they displayed an heterogeneous degree of identification with Buddhism. Although it is not a completely representative sample of the whole spectrum of non Christian Chinese entrepreneurs, it nevertheless served successfully for my main theoretical purpose. I recurred to this second group of entrepreneurs in order to clearly identify the absence of any alternative explanations. The aim was not then to do a more general comparison of economic success between the two samples. In other words I am not denying the possibility that non Christian entrepreneurs are able to strive for economic success but I am concerned with the presence/absence of any other element that could demonstrate the fictitiousness of the religious effect. In particular, I wanted to make sure that none of these categories may play the dominant explanatory role: a general attitude to work (Stakhanovism), the lack of awareness on human rights, working hard only because being under constraint, the role of Chinese mafia, a "religion of Communism", family values, education, cultural orientation to work, opening towards the outside world after centuries of segregation, success just based on their involvement in migration process, on their social network, on their duplicating abilities, or on their economic price competition etc.,...

Even counting all of those considerations in trying to consider the possibility of the presence of an intervening factor on the relationship (Wenzhou's profit-oriented mentality), it was still 
difficult to explain where, if present, did this strong profit-oriented and trade-oriented attitude came from. The question was then why Chinese entrepreneurs have a tendency to accept long hours of work, lower payment and still achieve high economic success through their entrepreneurial mindset. My goal here then was to check the consistency of such explanatory component by the 'trick of Wittgenstein' and 'trick of Lindesmith'. These particular techniques in qualitative research consist in a process of subtraction and corresponds in quantitative analysis to the counter-factual control: what will happen to an event $\mathrm{X}$, namely economic success, if I subtract the quality $\mathrm{Y}$, namely the belief in PAS? (Wittgenstein L., 1953; pp. 175-178) Does the work ethic still holds for the case of Chinese entrepreneurs if I subtract the component of the belief in the PAS? This doesn't mean that I've pursued a causal explanation as if no case of economic success would be possible among the Chinese entrepreneurs of the second group. I've rather checked the presence and impact of an association between those Protestant beliefs and economic success, pointing out the subsequent absence of any systematic economic ethos able to push the individual toward economic success. The questions that I've asked to the entrepreneurs in this second group are intentionally identical to those asked to the interest group. This was done in order to identify or detect the role of other possible explanatory elements such as those listed here below: 


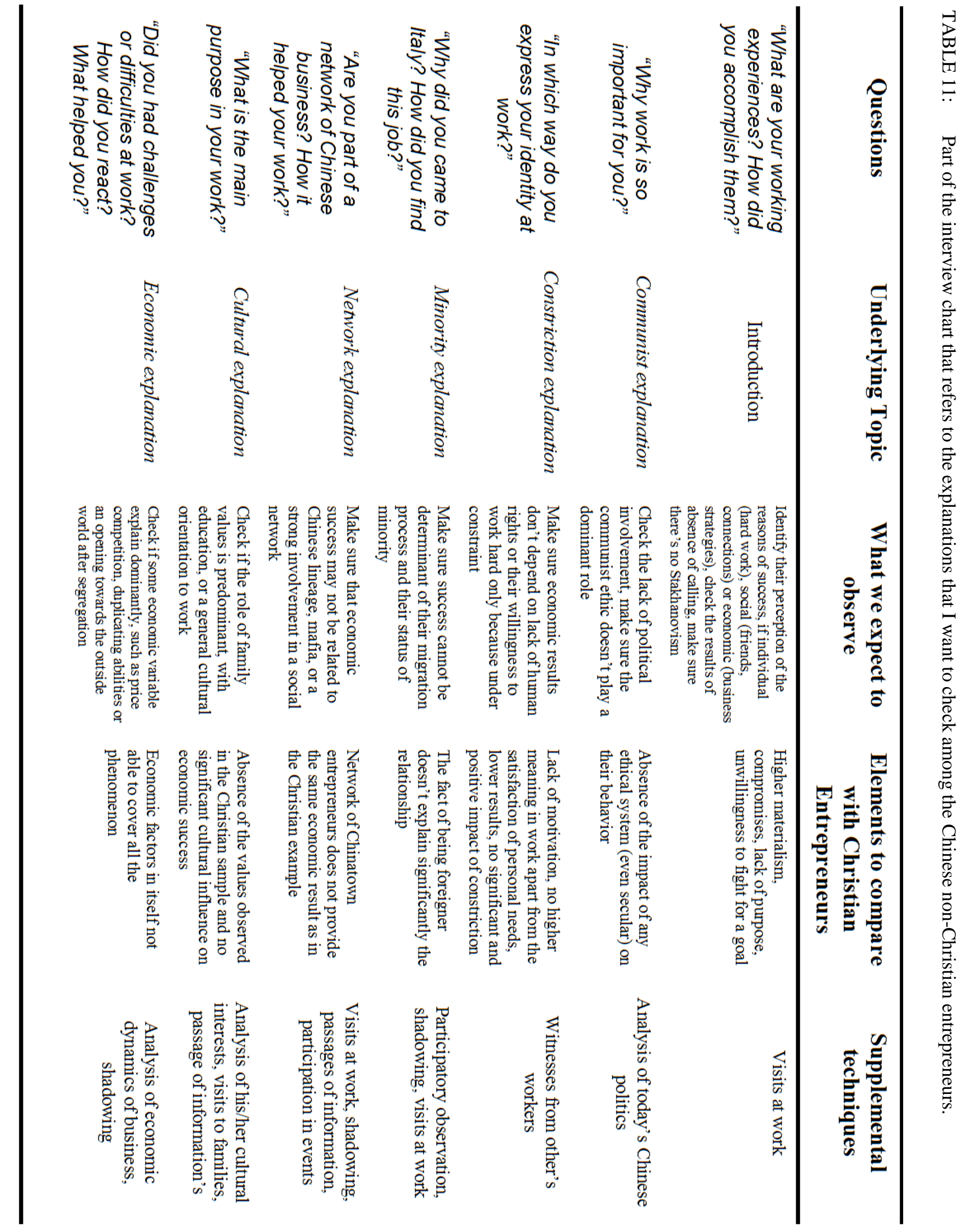


Apart from the interviews once again, for both the samples I've added participant observation to the interviews. For the case of non-Christian entrepreneurs I tested the validity of the research question through a series of interviews with some Chinese non Christian entrepreneurs in Milan as key players. The application of such strategies depended on their reaction to my research interest, giving the fact that migrant communities often are closed toward the outside world. This resulted to be sometimes a concrete obstacle aggravated by the fact that with some exceptions the Chinese community was even more exclusive and unapproachable from an outsider than other migrant communities. At the same time as the interviews I did an analysis of the empirical documentation produced that resulted in a necessary adjustment of the questions of the interview. From initial questions about their beliefs and their relation with business, for reasons of trying to enhance some objectivity I passed then to more neutral questions about work letting the data emerge naturally. This resulted even in an a posteriori re-formulation of the theoretical argument (see TABLE 20). After the interview, I proceeded with the transcription of it into a condensed account (sometimes expanded account) usually no more than 15 days later, analyzing the material and verifying the reliability of the information given by the respondent. Then I proceeded in the presentation of the material in light of the sociological relevance of it (Babbie E., 2005). This strategy went on until the necessary level of theoretical saturation with respect to the cognitive demand of departure was reached. The analysis of the material from the interviews was an activity that covered the entire final phase of the research project.

Some documentary materials on religion and China were collected at the Center on Religion and Chinese Society of the Purdue University in Indiana (USA), as well as during the sojourn in Wenzhou (China) to observe the phenomenon in the original context and visiting some churches and entrepreneurs over there. The visit to Wenzhou was possible through some contacts received both from the academic staff of the Center on Religion and Chinese Society and other contacts received through the Chinese Protestant believers from the evangelical church in Milan under my investigation. Furtheremore the trip was also possible through some of my personal connections with Minzhe and Bingwen that during my job-shadowing were going back to China for a business trip and a visit to their families. My visit in Wenzhou was not void of challenges giving the fact that the topic of my analysis was connected to Christianity and being in contact with TSPM churches as well as house churches. Foreigners are technically not allowed to be in contact with Chinese pastors, church members and church meetings in the area of Wenzhou. My presence therefore resulted to be sometimes a intrusive challenge for the Chinese Protestant believers already at risk of imprisonment because of the controversies on the removal of crosses from their churches and other forms of governmental control over church life. I went to Wenzhou in a critical situation for 
Christian churches and for the people I interviewed in Wenzhou. The fact that the visit was only for two weeks facilitated my position, together with the fact that I had to move continuously from place to place to detect any interception from the police. This visit to Wenzhou and the ethnographic observations that I did allowed me also to compare the mother land with what previously observed overseas in Milan, Italy. The visit in fact was planned during the summer of the second year of my research, at a moment when the data collected in the city of Milan offered a sufficiently clear idea of the phenomena. I was able to witness the significant impact of the migration process in my investigation of Wenzhou entrepreneurs living in Italy. In following chapters (see Cp. 6.2) I will explain some cases that were able to confirm what I previously observed in Milan.

The work of collection and analysis of the empirical documentation reached the necessary level of theoretical saturation. At this point I proceeded then, where possible, establishing a harmonization of the empirical documentation with the fundamental question with which I started the research and through which I constructed the original theory. The research therefore passed through three phases. The first phase was charachterized by an analysis of existing data regarding the theme chosen (Max Weber's theory on Protestantism and Capitalism, history of Christianity, reformed theology, Chinese Christianity, etc., ...). A second phase was composed by the survey and collection of information collected directly in the field through some entrepreneurs involved in business activities. Finally the third phase was the synthesis of what was collected in the field and developed in terms of the sociological theory on the basis of the initial objective.

In case of any problems or drawbacks on the availability of the cases I proceeded with the use of my personal network of other Chinese churches and Chinese entrepreneurs operating in the same area. In some cases the list of questions was not followed rigidly. This gave room for nonstructured and more discursive interviews. The research also had the benefit of giving a better reputation and higher visibility to the communities and entrepreneurs under my analysis. It served also to shed light to a context of analysis sometimes overlooked and characterized by conclusions too often generalized. My description was able to give an account of the complexity and diversity of Chinese entrepreneurship related to values and economic outcomes. Among other elements I treated my data with the necessary respect of the privacy of the people involved in the study, counting the risk, especially in light of the political and ideological control coming from the Communist government. 


\section{Chapter V}

"Today is hard, tomorrow will be worse. But the day after tomorrow will be sunshine."

Jack Ma

\subsection{The Social life of Chinese Migrants in Milan}

\subsubsection{A Particularly Productive Presence}

By looking to the Chinese migration one can rightly so define it as a real diaspora. What I will point out regarding the Chinese presence in the city of Milan in Italy can be extended to what is going on in the rest of Europe (Benton G., Pieke F. N., 1998) and even to other places around the globe where a consistent Chinese presence among migrants is witnessed. Migration from China has reached unprecedented levels of rapid and intense scale. More than any other developing countries. The majority of those migratory flows were historically from the Cantonese and Zhejiangese provinces. As for the rest of Europe the Chinese communities came mainly from the southern Zhejiang hinterland of the port city of Wenzhou and from the rural area around the town of Qingtian. The majority of them came with the intention to find a better life, to start a business and to work. A final wave of Chinese migrants recently came to Milan as well as to other major European metropolis with a background very different from the previous Wenzhounese migratory flows. Today those Wenzhounese migrants are already second or third generation migrants. The last wave on the other hand is composed by well-educated city dwellers from the north part of China of which some examples will be brought through this study.

The substantial difference among those two branches (Wenzhouren entrepreneurs and Northern intellectuals) is in the economic ties that in the first case are much more developed between the Chinese motherland and Milan, as to represent an ethnic niche in the Italian economy. This results in a lack of cohesion and interaction between those two branches. The Wenzhouren migrant sees other Chinese migrants as different. This is accompanied by an innumerable amount of competition and conflicts. An example of this animosity was the conflict between the many Chinese associations and social groups that I came into contact with during my study. Any effort to promote cultural or social activities not beneficial for the community as a whole were seen with suspiciousness. Like in other European urban metropolis, the Chinese community of Milan traditionally located in a Chinatown recently spread its ties into other parts of the city. This reality is 
centered on different businesses and typologies that I will later on classify: restaurant, bar, clothing store, hair shop, phone store, supermarket and traditional food stores (tofu...), massage center, travel agency, tailoring, Chinese bank, Tobacco and betting establishment... Each of them usually is linked with suppliers of Chinese factories sometimes located in Italy sometimes in China. Those different categories are repeated and coined in series and customized through an imitation process ${ }^{3}$.

Even though the Chinatown of Milan has some correspondence with the idea of ghetto, it is also different from it. Chinese workers don't live there and don't necessarily even buy things there. That's why it is more proper to consider it as an 'imaginary ghetto', a core place for certain social, economic and cultural functions that are connecting the migrant to his Chinese homeland. The Chinese workers in the Chinatown of Milan experienced sometimes peaks of hostility and ethnic exclusion. One example of that came when in April 2007, because of tensions with the government of Milan and continuous sanctions on their business, more than 300 Chinese

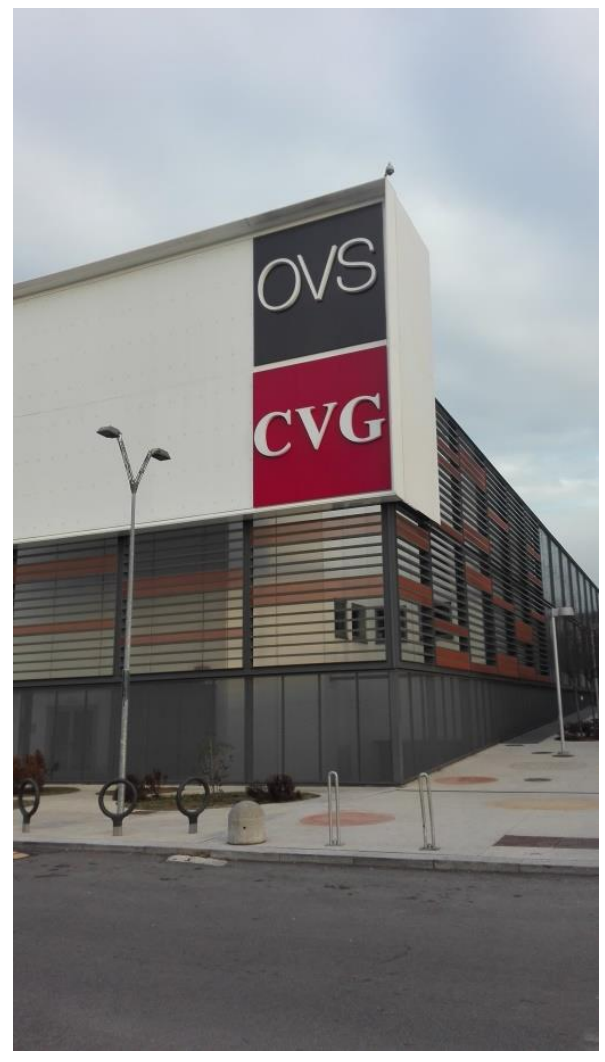
entrepreneurs violently protested in the Chinatown against the Italian police. Another example of this dilemma for example came on December 2013 when in the city of Prato, a Chinese textile factory was on fire causing the death of 7 Chinese workers and the scalding of 2. Many stereotypes related to events like these caused the diffusion of a negative and unbalanced way of seeing the Chinese presence in Italy.

In this vacuum of legitimation many associations and social groups were created (associations made of people coming from the same region, Chinese chambers of commerce, etc., ...). Many of them work as informal networks where resources are concentrated in the hands of few people that allocate access to these resources. The Chinese community and its networks are very closed toward the outside culture and sometimes even toward Chinese migrants of other factions. Being from a different Chinese town or from a different migratory flow caused individuals to be excluded from a network. Even though internally integrated, the Chinese community of Milan is not integrated into the Italian society largely because of linguistic difficulties. But even in the case of the second generation of migrants, although with some major differences, the pressure and

\footnotetext{
${ }^{3}$ An example of how the 'law of imitation' or imitation process works, a practice so common among Chinese businesses in Milan. The Chinese brand CVG just copied the Italian brand OVS competing only on the price.
} 
constraint to remain inside the traditional network is larger than any desire to be assimilated into the Italian society.

After the major economic crisis of 2008 those Chinese communities that focused on business had to work in a hard context. Milan experienced almost 8 consecutive years of downfall in the Italian business where many entrepreneurs were forced to close or sell their small activities. This was due to the high taxation or the lack of finances to keep it going. Entire zones near the center of Milan were, and are still, forced to shut down their shudder. Yet, under this tragic and dramatic spiral of failures and economic crisis the Chinese migrant community of entrepreneurs, above any other migrant community living in Milan, saw its golden opportunity. Instead of failing or decreasing its economic benefits, the Chinese business flourished at the point of almost replacing many segments of the Italian economy. This somehow negatively affects the perception from the Italian public opinion and mass media permeated of jealousy and antagonism. The Chinese community is seen as 'stealing jobs' from the native people and doesn't follow the legal parameters of work. Giving the already critical condition of the economy and the competition over few resources this tension often exasperated. If someone might ask why Chinese entrepreneurs are witnessing this business success despite the surrounding economic crisis it is crucial to consider several factors. First of all the links of obligation in the Chinese society added to the quest for moral superiority and other modes of behavior that are distinctly Chinese (paternalism, nepotism, family ownership) indicate the presence of a certain 'spirit of Chinese capitalism'.

One of the strengths of the Chinese migrants in Milan that immediately stood out in my research was the direct link between business enterprises and family. This was particularly crucial in the first initial stages of their settlement as it was pointed out by the entrepreneurs during the biographical records. Being attached to their traditional values, those migrants were often benefitting from the capital of the family savings and loans involving also future generations. Just to give one example, Ning, one of the entrepreneurs that I've interviewed, almost immediately pointed out how he related his success to some sort of 'moral obligation' toward the family:

\footnotetext{
I worked making money, working hard, in order to ask not [finances] to the parents, for my-self, to grow. [...] I want to make money by myself, to be independent. I am a positive person, I want to be a better man, even if I don't succeed I try hard. First, apart from the family that tells me to study hard, I think on what I want to do, to have the strength and realize my dreams (Ning, Jilin, Milan, 20/01/2016).

Hard work is from culture, since childhood, our parents come after us with a gun on our back [laughing]. My parents own a publishing company. Family pushes a lot to work, there are many people, in order to find a job you need something special (Jing, Chong Ching, Milan, 22/01/2016).
}

Businesses often times are based on a family nucleus. As time went on the Chinese ethnic niche of certain typologies of business was a protective mean in order to rashly achieve economic affirmation. The push for migration comes from deeply introjected cultural patterns, where the individual looks for an opportunity to become quickly rich and he aspires to start an entrepreneurial 
activity on its own. The aspiration to entrepreneurship and self-employment was so strong that capitals and energies inside the family, communities and social networks were quickly mobilized. Powerful ethnic networks favored immediate good employment of Chinese migrants at the arrival in Italy missing among other migrant communities in Italy. And even among Chinese migrants those coming from Wenzhou and Qingtian benefited from the social networks on an international scale more than Chinese migrants coming from other areas.

One of the first features of Chinese small businesses, when compared with the Italian context, is their flexibility, the fact of being able to guarantee a faster production and reduced times of delivery. This competitive factor is able to guarantee the survival and even the good profit in situations of crisis. On the other hand longer working hours, lower payment, tax-avoidance, undeclared work, lack of security, were all recurrent problematics among Chinese entrepreneurs in Milan. Because of personal debts or social pressures from the family the Chinese worker tends to work in extreme conditions. The individual in this circumstance is forced to conform himself to the migratory career of the group, working as much as possible and learning the first elements of the Italian language. An example of this came during my frequent conversations with Minzhe on the matter and it was interesting to hear what she had to say:

\begin{abstract}
Many Chinese work in factories, they spend time only working. They have false passports, they are obligated to come here just to work. The students can go anywhere but the Chinese don't go anywhere, they are forced to work, if they work hard they can make more money. Since they don't have documents they must work in order to buy their documents. Some Chinese have Japanese [fake] documents. In Prato I met a woman that stays in the factory and doesn't talk anymore 'cause her son died inside the factory! She is alone now and doesn't want to come back, her heart broke... [sight] The boss makes pressure but also the workers want to work, they are the same, the majority works in clothing (Minzhe, Shuzhou, Milan, 20/01/2016).
\end{abstract}

The ideal outcome of such a frugal lifestyle, cutting all the possible expenses to the minimal, is the ability to reach the status of entrepreneur. People from Wenzhou see dependent work as a cage, a condition of weakness that goes against their aspirations of becoming self-employed (AA. VV. 1997; p. 135). Once the worker becomes the owner of a store it is like a 'passage of status' in front of the rest of the community. As business grows he can then consider the possibility of multiply his business activities. Sometimes the workers were active even on the week-end and at night, at times working 30 hours of work alternated by brief naps. For this reasons the social life of the Chinese workers tends to be radically compressed, sometimes even forcedly removed as something that can obstacle the production. Marital life, parenthood and family life are all subordinated to the affirmation of work. In this sense someone may properly consider the social life of an entrepreneur as work itself where every sphere of life revolves around it. 


\section{2 Chinese Entrepreneurship in Milan, Italy}

\subsubsection{Chinese Small Businesses in Milan and their Ideal-types}

Here in this section I will examine the results from the job-shadowing conducted among the Chinese entrepreneurs in the city of Milan. The aim of this part will be to give a description of their job, regardless of any reference to religious values or ethics which will be treated in another section of the thesis. From the data of the Chamber of Commerce of Italy and the Italo-Chinese chamber of commerce it emerges that approximately there are 20.000 Chinese resident in the province of Milan (5.9\% of the total population of foreigners). Half of it is composed by women $(9.60047 .7 \%$ of the total). At the third semester of the year 2008 the number of individual Chinese enterprises registered in Milan was of 3.131, $9.8 \%$ of the total Italian number of Chinese enterprises and $68 \%$ of which are active in the city area of Milan (Source: Italian Chamber of Commerce, 2009). The number is much higher because many of those enterprises and small businesses are not necessarily registered at the Italian chamber of commerce. After the Egyptian community the Chinese is the second nonEuropean migrant community involved with entrepreneurship in Milan and its province. The entrepreneurship rate inside this community is high, 1 out of 8 Chinese is an entrepreneur in the city of Milan.

\begin{tabular}{|c|c|c|c|c|c|c|c|c|}
\hline settore & $\begin{array}{c}\text { tot cinesi } \\
\text { III trim } \\
2008 \\
\text { Milano }\end{array}$ & $\begin{array}{c}\text { TOTALE } \\
\text { extracomunitari } \\
\text { Mflano }\end{array}$ & \begin{tabular}{|c} 
tot cinesi \\
III \\
trimestre \\
2007 \\
Milano \\
\end{tabular} & $\begin{array}{c}\text { tot } \\
\text { cinesi } \\
\text { Italia } \\
2008 \\
\end{array}$ & $\begin{array}{l}\text { variazione } \\
\text { cinesi } 08-07\end{array}$ & $\begin{array}{c}\text { peso } \\
\text { settori } \\
\mathbf{2 0 0 8} \\
\end{array}$ & $\begin{array}{l}\text { peso cinesi tu tot } \\
\text { extracomunitari }\end{array}$ & $\begin{array}{l}\text { Cinesi } \\
\text { MI/cinesi } \\
\text { Italia }\end{array}$ \\
\hline Attivita' manifatturiere & 972 & 2.176 & 922 & 13.731 & $5,4 \%$ & $31,0 \%$ & $44,7 \%$ & $7,1 \%$ \\
\hline Costruzioni & 44 & 6.149 & 41 & 248 & $7,3 \%$ & $1,4 \%$ & $0,7 \%$ & $17,7 \%$ \\
\hline Comm.ingr.edett.-rip.beni pers e per la casa & 1.316 & 6.158 & 1.292 & 15.176 & $1,9 \%$ & $42,0 \%$ & $21,4 \%$ & $8,7 \%$ \\
\hline \begin{tabular}{|l|l} 
Alberghi e ristoranti & \\
\end{tabular} & 576 & 927 & 425 & 1.873 & $35,5 \%$ & $18,4 \%$ & $62,1 \%$ & $30,8 \%$ \\
\hline Trasporti,magazzinaggio e comunicaz. & 35 & 1.936 & 38 & 160 & $-7,9 \%$ & $1,1 \%$ & $1,8 \%$ & $21,9 \%$ \\
\hline Intermediaz.monetariae finanziaria & 8 & 121 & 9 & 18 & $-11,1 \%$ & $0,3 \%$ & $6,6 \%$ & $44,4 \%$ \\
\hline $\begin{array}{l}\text { Attiv.immob.,noleggio, informat., ricerca } \\
\text { (servizi alle imprese) }\end{array}$ & 48 & 2209 & 36 & 282 & $33,3 \%$ & $1,5 \%$ & $2,2 \%$ & $17,0 \%$ \\
\hline Altri servizi pubblici, sociali e personali & 90 & 491 & 33 & 162 & $172,7 \%$ & $2,9 \%$ & $18,3 \%$ & $55,6 \%$ \\
\hline Altre imprese & 42 & 424 & 41 & 162 & $2,4 \%$ & $1,3 \%$ & $9,9 \%$ & $25,9 \%$ \\
\hline TOTALE & 3.131 & 20.591 & 2.837 & 31.812 & $10,4 \%$ & $100,0 \%$ & $15,2 \%$ & $9,8 \%$ \\
\hline
\end{tabular}

Elaborazione Camera di commercio di Milano su dati registro imprese al III trimestre 2008

I've already pointed out how Chinese entrepreneurship from the area of Wenzhou represents a significant economic contribution for the case of Italy. In fact as I've already mentioned 80-90\% of the Chinese immigrants living in Italy comes from the city of Wenzhou and $70 \%$ of them are involved in businesses. Many of them are restaurants and bars whereas $20 \%$ of them are involved in

\footnotetext{
${ }^{4}$ Source: Italian Chamber of Commerce, 'In Arrivo l'Anno del Toro', in Camera di Commercio di Milano, (Jan. 2009), Milan, pp. 1-2.
} 
commercial activities. Lombardy, and its regional capital Milan, is very significant for the Chinese business. It is second only to Tuscany in number of enterprises (18\% of the total number of enterprises in the area) and right after Prato and Florence in terms of Chinese presence (15.5\% of the total migrant community). In 2008 the Chinese was the second migrant community living in Milan and it gave the highest economic turnover: 46 million $€$ with an average of $63.000 €$ for business (Bressan N., 2013; Fatiguso R., 2011; AA. VV., 2002).

Classifica nazionalità titolari stranieri di imprese individuali attive a Milano al III trimestre 2008

\begin{tabular}{|c|c|c|c|}
\hline posizioneqnazionalità & \multicolumn{3}{|c|}{ Comune diMIILANO nazionalita|Stato di nascita TOTALE prov Milano } \\
\hline \begin{tabular}{l|l|l|l|l} 
EGITTO \\
\end{tabular} & 3257 & 1|EGITTO & 4932 \\
\hline \begin{tabular}{|l|l|l|l|l|l} 
CINA \\
\end{tabular} & 2085 & \begin{tabular}{|l|l|l|l|} 
CINA \\
\end{tabular} & 3131 \\
\hline 3 MAROCCO & 809 & 3 MAROCCO & 2032 \\
\hline 4 PERU' & 697 & 4 ALBANIA & 1302 \\
\hline 5 BANGLADESH & 669 & 5 PERU & 1074 \\
\hline
\end{tabular}

Elaborazione Camera di commercio di Milano su dati registro imprese al III trimestre 2008

Residenti cinesi a Milano - anno 2007

\begin{tabular}{|l|r|r|r|r|}
\hline & Maschi & Femmine & Totale & peso donn \\
\hline residenti cinesi prov. Mi 2007 & 10.565 & 9.629 & $\mathbf{2 0 . 1 9 4}$ & $47,7 \%$ \\
\hline residenti cinesi prov. Mi 2006 & 10.044 & 9.084 & $\mathbf{1 9 . 1 2 8}$ & $47,5 \%$ \\
\hline variazione 2007-06 & $5,2 \%$ & $6,0 \%$ & $\mathbf{5 , 6 \%}$ & \\
\hline tot stranieri prov. Mi 2007 & 175.344 & 169.023 & $\mathbf{3 4 4 . 3 6 7}$ & $49,1 \%$ \\
\hline peso cinesi su tot stranieri prov. Milano & $6,0 \%$ & $5,7 \%$ & $\mathbf{5 , 9} \%$ & \\
\hline residenti cinesi comune di Milano 2007 & 7.739 & 6.984 & $\mathbf{1 4 . 7 2 3}$ & $47,4 \%$ \\
\hline residenti cinesi comune di Milano 2006 & 7.392 & 6.631 & $\mathbf{1 4 . 0 2 3}$ & $47,3 \%$ \\
\hline variazione 2007-06 & $4,7 \%$ & $5,3 \%$ & $\mathbf{5 , 0 \%}$ & \\
\hline tot stranieri Mi & 88.770 & 87.227 & $\mathbf{1 7 5 . 9 9 7}$ & $49,6 \%$ \\
\hline peso cinesi su tot stranieri comune diMilano & $8,7 \%$ & $8,0 \%$ & $\mathbf{8 , 4} \%$ & \\
\hline
\end{tabular}

Elaborazione della Camera di commercio di Milano su dati Istat 2007

Tasso di imprenditorialità dei residenti a Milano nel 2007

\begin{tabular}{|c|c|c|}
\hline Residenti & Tasso imprenditorialità & Rapporto imprese/residenti \\
\hline cinesi prov. Mi 2007 & 0,14 & 1 su 7 \\
\hline cinesi comune di Milano 2007 & 0,13 & 1 su 8 \\
\hline italiani prov. Mi 2007 & 0,04 & 1 su 27 \\
\hline Totale residenti prov. Mi & 0,09 & 1 su 11 \\
\hline
\end{tabular}

Elaborazione Camera di commercio di Milano su dati registro imprese e dati Istat 2007

More precise statistics show that the Chinese enterprises in Milan and its province at the third semester of 2008 focused mainly in three sectors: trade (1.316 enterprises, $42 \%$ of the total), manufacturing $(972,31 \%$ of the total), restaurants and hotels $(576,18.4 \%$ of the total). Compared to other non-European migrant communities, the Chinese entrepreneurs in Milan are more focused on restaurants and hotels $(62,1 \%$ of the total of enterprises with non-European holder) and in manufacturing (44,7\%). Overall the Chinese enterprises in the Milan province at the third semester

\footnotetext{
${ }^{5}$ Source: Italian Chamber of Commerce, 'In Arrivo l'Anno del Toro', in Camera di Commercio di Milano, (Jan. 2009), Milan, pp. 1-2.
} 
of 2008 were growing of the 10,4\% if compared to the same period of 2007 (Source: Italian Chamber of Commerce, 2009). The biggest growth can be observed in public social and personal services passing from 33 to 90 enterprises, hotels and restaurants (+35,5\%) and services to enterprises $(+33,3 \%)$. From 2008 to the more recent years those numbers are estimated to be exceedingly growing and expanding.

This huge involvement in business of the Chinese community didn't happened over a night. Since their first migratory flows in the 1800 the Chinese people from Wenzhou started to be involved in very low payed jobs as hawker, street vending, domestic work, construction work, loading or unloading in central markets, etc., ... with few specialized skill, without a stable income and living very disintegrated from the European society. Their first consistent involvement in migration started in France after the second world war. Soldiers enrolled from China decided to remain in Europe after the war spreading their connections in other countries like Germany or Belgium (Chee-Beng T., Storey C., Zimmerman J., 2007). In Italy the first presence started from the 1930's, as one of the earliest immigrant community. Their arrival grew more consistently from 1950 's where they started to occupy the sector of restaurants although having a very low economic impact at the time. The first settlement was precisely Milan followed by Bologna, Florence and Rome (Benton G., Pieke F. N., 1998). But their presence for the native Italian society was hardly visible until the mid-1970's. As China became slowly the 'factory of the world' many of those Chinese people started to make connections with their motherland in order to start exporting their merchandises of very low quality at first.

From 1984 Wenzhou benefited of her position as an international harbor for export. The city started to bring trade in Italy during the 1980's, first in the food and leather sectors, later on in the textile sector. At first they worked for Italian retailing companies then with the capital accumulation and exportation of it in China they started their own enterprises. As time went on those initial migrant workers experienced a progressive upward mobility and economic thrive in jobs that required more skills (from worker to multiple boss owners, from street vendors to large scale buyers, from waiter to graduated business accountants, from machine operator to sales managers). This was also due to the introduction of the legal right of families re-union. The request for a residence permit was since then usually driven by the desire to become business owners. Differently from other migrant communities, Chinese workers can benefit from opportunities to work in sectors of the labor marked formed by businesses owned and managed by co-nationals. Many of those migrants arrived or are currently in a condition of 'irregulars' having been involved in 'migrant smuggling' organized by groups specialized in this trade (Ceccagno A., Rastrelli R., 2008). Once 
arrived in Italy the migrant then finds contact with his relatives or family members for housing and work in order to raise the necessary resources to pay back the smugglers.

In thirty years the Chinese presence in the economy of Italy has grown very high and the level of integration into specific sectors of businesses thrived (Zhang Y., Zhang M., 2016). Through family and social networks in the motherland, starting from small productions, those Chinese entrepreneurs arrived to be involved in trades of large scale. Wenzhou counts thousands of factories, mainly family-owned, focused on high production and characterized by long workinghours (7 AM-10 PM). Even though under the pressure of heavy industrialization much of the family business in Wenzhou has transformed into a managerial form of capitalism. That is still not the prevalent case in Italy where small-business has been growing and flourishing. The stress on those types of investments is very high at the point that every company tries at best to survive with no external help. Many of those Italo-Chinese businesses in fact have a factory in motherland China that provides the products (whether clothing, appliances or food) and receives those products from an intermediary company charged for the shipping of those low cost products in Italy, Europe and all the Western countries.

Today what is traditionally known as the 'blue chips' (large-cap companies) left room to what is commonly known as 'red chips' (enterprises more exposed to the Chinese market). The economic sectors more impacted by this 'Chinesization' of the traditional business are those of luxury (for example Minzhe), cars and durable goods. In particular the world of luxury reaches important levels of revenues so that the revenues of the main European fashion houses depends largely on the trend of the Chinese economic market. But what are the features of their businesses and what kind of peculiarity they bring in the context of Milan?

First of all I was able to identify four major categories of different entrepreneurs that I observed in the field: i) property-based business this is often the case all over Italy of Chinese entrepreneurs that work in the clothing sector owning a store, a restaurants, one or several coffee bars (like the case of Delun, Heng, Shaiming, Enlai, etc., ...). This first case is the most common among the Chinese entrepreneurs from Wenzhou living in Milan and represents the majority of their business activity. The people from Wenzhou have this peculiar view passed on from generation to generation that, even when compared with being the employee of a powerful organization gaining a consistent amount of money, it is still better to own a small-medium business created and maintained with their own personal energy and efforts. In the public imagery this finds it's classical example almost everywhere in the typical Chinese restaurant, owned by a family migrated from Wenzhou of whom the father or the mother is the entrepreneur and boss. More recently for the Italian case this has developed into new frontiers where those Chinese entrepreneurs decide to 
invest their profits coming from other businesses in new types of activities such as Japanese (or other Asian) restaurants, Coffee bars, Italian restaurants, etc., ...

Side by side with this involvement in catering services another crucial sector in which this category is flourishing is the clothing industry. Starting from the factories decades ago, first in the motherland then exported to Italy many Chinese entrepreneurs are involved in an intensive mass production of clothes that spread almost everywhere. With the economic growth from those investments many entrepreneurs passed from owning a factory to selling directly the products to the customers without the help of intermediaries. This is how therefore clothing stores or stores specialized in the wholesale of household products spread like wildfire almost everywhere. In several cases due to the big amount of revenue or due to the desire of entering into business partnership, many entrepreneurs were able to develop chain stores. A common trend of this mainline Chinese entrepreneurship is the emphasis on low and competitive price in the market despise the losses in quality. Although representing the larger section of Chinese entrepreneurship, in the next future such form of entrepreneurship under the pressure of increased costs of life in China will inevitably change its shape.

Then there is the: ii) intermediary business, which is the case of firms or group of associations which role is to connect different Chinese enterprises that come in Italy to start an activity and that need partnership (like the case of Boqin, Peng, Yi, etc., ...). A classical example are the estate

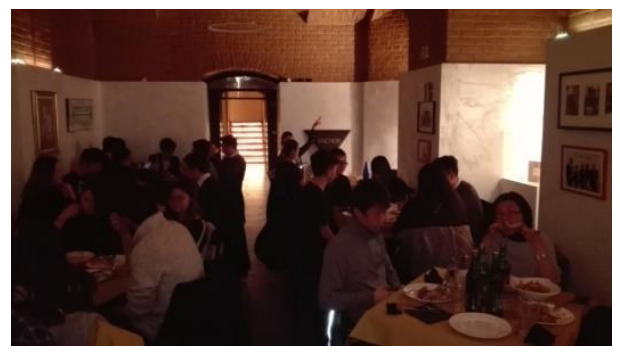
agents, the office accountants or associations for the civic society owned by Chinese and specifically designed to help other Chinese entrepreneurs in their business ${ }^{6}$.

The third category can be defined as iii) self-employed business where on his own the entrepreneur starts a personal business as buyer or freelance and then in due time he grows big enough to open his own firm (like the case of Minzhe). This category differs from the previous one because it lacks its intermediary purpose among different businesses. Here the Chinese entrepreneur basically works on 'solo' many times even without any specific legal recognition. This category, being the same for many other migrant communities, was the most common type of business during the firsts migratory cycles several decades ago. Starting low as mere hawkers many of those Chinese entrepreneurs in few decades were able to grow and discover different and better ways to do business. This can find a correspondent today in the role of Chinese buyers.

\footnotetext{
${ }^{6}$ Dinner of 'fresh Chinese entrepreneurs' living and operating in Milan organized by Peng in his restaurant. Both on an official and unofficial level the Chinese network of businesses is crucial for the acquirement of services and favors of any kind. 
Finally there is the: iv) managerial business, which is the most traditional way of perceiving business. Only through the second generation of Chinese entrepreneurs (like the case of Ya or Biming) this type of business is starting to involve consistent transactions. This include for example the Chinese shareholders involved in international investments or banking. Such classification drawn from some of the literature (Collino A., et alii, 2014; Miranda R., 2014; AA. VV. 2012; AA. VV. 2008; Ceccagno A., 2008; Cologna D., 2004, 2004) and from my empirical investigations for the area of Milan serves only for the purpose of simplification and it does not pretend to be exhaustive of all the different cases of Chinese entrepreneurship today active in Italy or elsewhere.

The typical day of an entrepreneur, category i) being the most common, involves mainly a man and leader of a nuclear family. I will consider here an entrepreneur tipically working at Via Paolo Sarpi, the Chinatown of Milan, although ramification and integration in other parts of the city are often witnessed. His day starts early in the morning leaving his home to go to his workplace usually located far from where he lives (the suburbs or other villages around the city of Milan). Whether in China town or in other parts of Milan each entrepreneur is owner of one or more businesses and starts the day taking the merchandise that arrived the day before early in the morning (6-7 AM). Usually his business is not isolated but is strongly connected with other Chinese firms, so each entrepreneur spends time talking, giving and receiving help in everyday incumbencies. The activities are spent between calls, moving the merchandises, receiving clients and talking to friends and neighbors. Then during lunch break the entrepreneurs gather all together to eat Chinese food sharing their thoughts in close friendship. During the rest of the day he receives more visits from clients and he spends time presenting the merchandise to the potential clients almost always available on wholesale instead of retail.

The entrepreneur receives almost everyday visits from his Chinese suppliers that bring the new merchandise in the warehouse of every store. Some of the stores stay open until late hours and follow a non-stop schedule of work. This raises the question on what could the source of such hard working attitude. The working hours last frequently until 9-10 PM for seven days a week. This rough schedule however changes according to the specific job that the entrepreneur does. For the cases under job-shadowing of entrepreneurs I observed some relevant variations that I will describe in the following pages. 
TABLE 12: Evaluation chart for the first three Chinese entrepreneurs under shadowing. The extension of the dark circle signifies the low/high presence of several key factors of economic success as I observed the entrepreneurs during the job-shadowing.

\begin{tabular}{|c|c|c|c|c|c|c|}
\hline & $\begin{array}{l}\text { Confidence } \\
\text { in his/her } \\
\text { skills }\end{array}$ & $\begin{array}{c}\text { reaction } \\
\text { to } \\
\text { challenges }\end{array}$ & $\begin{array}{l}\text { expression } \\
\text { of values }\end{array}$ & $\begin{array}{l}\text { Hard } \\
\text { work }\end{array}$ & $\begin{array}{l}\text { relationship } \\
\text { with the } \\
\text { customer }\end{array}$ & $\begin{array}{c}\text { Integration } \\
\text { with other } \\
\text { Christians }\end{array}$ \\
\hline Delun & & & & & & \\
\hline Minzhe & & & & & & \\
\hline Heng & & & & & & \\
\hline
\end{tabular}

\subsubsection{The Visionary Investor}

Delun ${ }^{7}$ belongs to the i) case of property-based business, the most common among Chinese entrepreneurs from Wenzhou living in Italy. Delun is part of a family that was already active in business of bar and cafes before him. He first worked with the bar of his parents 8 years ago in San Giuliano Milanese, in the suburbs of Milan. After six years then, having collected the savings he decided to open his own new bar-café. He first started by working 16 hours a day from 5.30 AM to $10 \mathrm{PM}$ at night for one year and a half. Even his brother had a different business of bar and cafes and his aunt was co-partner with Delun's fast food. During my job-

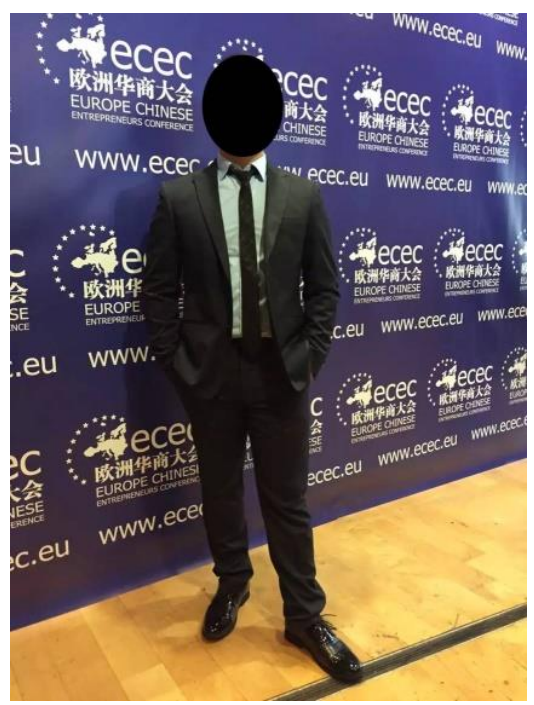
shadowing with Delun that lasted for several continuous periods alternating from 6 to 10 months, I had the chance to observe him passing from owning two businesses in the beginning of our contacts, then back to one business at the end of the first year and opening a new fast food chain and SUSHI bar the third year.

Delun opened then his fourth business and during all the period he was involved in several tenders for the management of several businesses already existing. As I've started my research Delun recalled to me how he got involved in business and entrepreneurship:

$M e$ : Now, coming to your job, what type of work are you doing?

Delun: I am a barman, I manage a bar.

Me: Tell me the trajectory, did you always managed a bar? What type of jobs have you done before?

\footnotetext{
${ }^{7}$ Delun at the 'Europe Chinese entrepreneurs conference'. Delun often takes parts to many of the activities for entrepreneurs organized by the 'Chamber of Commerce Italia-Cina', he is member of the association: 'UNIIC - Unione Imprenditori Italia Cina' for the second generations and active in many other associations for Chinese entrepreneurs. 122
} 
Delun: when I finished the school I decided right away to jump in business. At the time, six years ago, because, before managing a bar of my own, I worked already together side by side with my dad, since we already had a bar.

$M e$ : your father owned the bar?

Delun: he had a bar correct, for this reason I already knew this job and I started to do this.

$M e$ : then you open another bar or you owned the same bar of your father?

Delun: another bar, that, you know... I manage on my own.

$M e$ : and then you also expanded I remember that you had your own bar...

Delun: Then after a couple of years I wanted to buy another bar, ok, it was very stressful.

$M e$ : In short, a lot of work. To what do you attribute this success in your work? That is, you started with business right away, you've joined your father then began your own bar, then you have opened another one... Why do you think you had this success?

Delun: We had this big success because we want to give this contribution, because we are Chinese who have a very strong entrepreneurial will.

$M e$ : ok, and what do you think is the first reason for the success?

Delun: eh .. working hard, the Chinese culture, especially the Chinese culture that encourages us to always run the risk in trade. (Delun, Wenzhou, Milan, 06/08/2014)

Delun mainly started with a bar-café then he hired several Chinese workers for it as he usually spended the day going on errands for the different businesses he owned. When I've observed those workers I clearly saw the absence of any social skills and the lack of warmness that I saw in Delun. This is perhaps one of the black spots that is present in Chinese entrepreneurship in Italy in general. The Italian culture requires a level of warmness that among Chinese worker, especially those first-generation migrants, was completely absent. So, the competitive price and quickness of service was frequently not accompanied by the crucial element of customer service. In those cases even regular attenders to the bar complained and were disappointed for this aspect. The Chinese workers at the bar didn't necessarily follow a rigid working hour, they were flexible according to the circumstance. Delun frequently was late to the appointments because of his busy schedule and therefore the Chinese workers were willing to work extra without any form of complaint. This is another unique aspect of the Chinese workers compared to the Italian counterpart, which caused Delun to have several cultural misunderstanding on the relationship bossworker when he hired Italian workers in his business. During the morning Delun did several calls to the suppliers then he went by car to take the orders in several parts of Milan. The merchandises were bought wholesale, some products were brought directly at the bar some other required more bureaucratic work. Even during his time at the bar Delun received several calls both from his mobile and the landline, mainly to stay in contact and control the other store. Sometimes I spent long hours listening to his phone conversations about a product to buy, problems in clauses of contracts. As he arrived to the bar, in clear contrast with the Chinese workers, Delun brought happiness, warmness, easy talk, and an attitude to serve.

Delun usually had several typologies of clients: regulars, occasional and visitors. Regulars were usually those that standing at the counter bought coffee or some alcoholic drinks, as well as those sitting down at the slot machines. Occasional clients were those who bought bus tickets or 
lottery tickets, and those sitting down at the tables taking beverages or food. Visitors were those clients that didn't live in the area and that probably were just passing by the bar (whether tourists or people from a totally different neighborhood or city). Delun recognized those categories almost immediately and applied a different treatment for every single typology. His relationship with the regulars for instance was totally different than the relationship with visitors and even with the occasional clients. Delun sometimes had to learn how confidentially he could talk with clients. This required Delun to have a strong memory of faces, conversations, names and voices of the people and in cases where this was missing friendship or fidelity of the customer was at stake. At the bar he had a special section where he collected receipts and the credit card machine. During the last part of the day Delun spended time at the counter with a calculator to close it and finish the day of work. The Chinese employees usually were at the bar as he was out buying and transporting some merchandises or meeting some business partners.

Daily, Delun moved between the fast food and his bar. He waked up at 09:00 AM. At 10:00 AM he came out of his house and had a list of things to do during the day. He did 3 or 4 calls from the house to the bar fixing appointments during the day. In-between Delun had to do many bureaucratic things. For example he had to make the economic declarations, visit trade unions, visit the Chinese and Taiwanese embassy for obtaining the VISA for migrant workers, visit the office to hire new workers, visit insurance offices and the lawyer, etc., .... Delun was very busy because of those many administrative tasks and he felt uncomfortable with all the bureaucracy of the Italian government necessary to manage his multiple businesses. By 12 o' clock or 2 PM depending on the day he went to the phone store and controlled the advancement of his job. Sometimes his schedule was so tide up that he arrived at the phone store after 8 PM when it was already closed. There were times when Delun received more than 100 calls in a single day especially when he was hiring new workers for the new businesses. In order to be able to control the progress of work Delun had a system of camera's on his computer, so he could supervise the workers at the other workplace and check the amount of clients entering in the store. He usually checked the back of his bar where he also had a huge refrigerator and a microwave to warm sandwiches and food that the clients asked. Then in the afternoon (around 4.40-5 PM) Delun, or sometimes his wife that worked together with him, came permanently to his bar to open the slot machines, then he controlled the counter, the cash (counting the revenue of the day), giving directions to his Chinese employees always in a warm and kind way. Sometimes only one or two Chinese employees were working at the bar. The workers left the bar around 08:15 PM and then Delun was spending time there speaking with the regular clients until 09:30-10:00 PM before closing the bar. At this point Delun came back home and after having 
dinner with his family he did calculations and a general account of the expenses, planning what he would schedule for the next day.

In some of my job-shadowing at his work I had the chance to observe Delun's wife at work instead of Delun himself. She generally worked there in the morning or on the early afternoon. The same that I've observed concerning Delun was generally valid for his wife. She was professional, fast in her job, kind but differently from Delun she was less extroverted and she didn't speak Italian very well. As Delun she was always at the counter receiving money from the clients, serving coffee or washing the used dishes often speaking with the Chinese workers (2-3 women, one at the counter another cleaning the place, windows, machines...). Delun's wife had a good relationship with the Chinese workers that her husband hired and the environment was always friendly between them. Several times the baby sitter of the kids of Delun came to the bar in order to visit him. Also specially during the last part of the day he was busy washing the dishes used during the day. There was a machine to change coins for the slot that was always crowded with the same people from 5 PM to the closure of the store and when there was some win they went to the counter to collect the money (100-200 coins).

Sometimes there were some arguments at the slots among people, but Delun was always firm in re-establishing the equilibrium. Delun provided for them also drinks and beverages according to their regular tastes and he passed table to table collecting the used items and he quickly threw them in the garbage. The bar also provided scratch and win and lottery tickets. During my period of observations $1.000 €$ were won at the bar through lottery. Delun came usually at that time also to exchange place because one of the Chinese women left the bar and there was a need to have always at least two people working.

I've observed the same dynamic for the case of the fast food where however the amount of employee was greater (7 to 2). The employees were usually well treated by Delun which didn't pressure or threat them. Delun treated them always with respect and understanding. Differently from many other Chinese entrepreneurs Delun was committed to pay the salary to his workers at the end of every month without any delay, even if that would have represented a risk for his business. In one sense Delun didn't want to lose authority but he also was concerned to follow good principles of well treatment with his workers. Also, in both cases, Delun was the boss but during the day at the store he was always surrounded by a group of employees and they worked as a team. The employees were usually warm and kind in an environment of friendship. This however didn't mean that in the workplace the employees under the leadership of Delun were not diligent or not working hard. 
Both places were crossroads of a lot of Italian and Chinese visitors and Delun succeeded in having many clients (5-6 each 10 minutes). Depending on the day, sometimes there were a lot of clients sometimes less. When there were a lot of clients Delun demonstrated to be multi-tasking, being able to

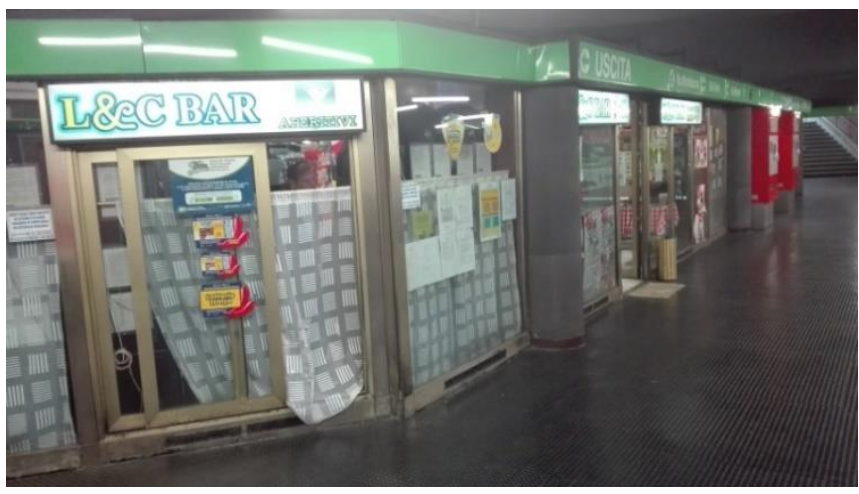
serve 4 or 5 clients simultaneously. Delun's view of the client was very high, clients had the priority over everything. For example if I was speaking with Delun and a client came into his store, then he stopped speaking to me and focused all his attention on the client. I witnessed the presence of many regular Chinese clients that were coming regularly at the bar but also Italian regular clients both in warm and friendly relationship toward Delun. Sometimes the warmness of Delun was invasive with shy clients. Out of three clients at least one knew Delun's name. Delun demonstrated to know about their private life and, vice versa, some clients knew about his trips to China. At times there was a witty environment, some of the clients didn't even pay when they took something because, as regular clients, they had an opened account. Many were the regular clients that came in Delun's stores $^{8}$.

Sometimes the regular clients were coming and going for two or three times to the store. They had a friendship with Delun, they were well treated as clients, but they also received from Delun some friendly nicknames like 'uncle', 'aunt', 'tell me doctor', 'good evening doctor!' 'hi mister!' 'how are you friend?' 'yes Sir!' 'bonsoir!' 'wee..' 'time to eat my children'. In his gestures and words Delun always had confidence, for example in unplugging the receipt or closing the counter. He wanted to give a good impression on the clients. Sometimes it was common to see Delun joking with his clients. Delun's strategy with his clients was to be very friendly, always greeting, being gentle, smiling, knowing all their names and their tastes, laughing, being ironic, seeking respect and empathy, often showing his generosity offering food free of charge, promoting a very warm relation with them. Very often he postponed the payment of the merchandise by regular clients in order to help them and facilitate their day. Even if clients didn't pay back his kindness he didn't let this bother him and kept working. At the same time Delun treated the client like a prince, he tried to be fast and efficient in answering to their needs, giving them fresh beverages or well prepared food. He was fast and kind at the same time.

When preparing coffee Delun was very fast, in a fraction of seconds he already served the drink. Delun was very extroverted and started often conversations with the customers about several

\footnotetext{
${ }^{8}$ One of Delun's bars. Delun is a very succesful businessman and also a man of vision and purpose for his life. 126
} 
topics such as the quality of a certain plate, or wine, the situation at their work, giving details about their personal jobs, the weather, some purchases done (for example phones or articles of the house) in a friendly climate that was absent when Delun, the boss, was away from the workplace. This unique environment often left the clients as I was doing job-shadowing surprised, glad and with a sense of invitation to come back. Everybody knew Delun in the surrounding area of his business and he was highly esteemed. They appreciated to come in his bar or fast food even if there were stores that offered the same type of service around him. Sometimes it was common to hear some clients at the counter say 'you are good people' referring to Delun and his family members. Some clients in their conversations were marveled about the absence of any Chinese accent in Delun, and were considering him at this point as a 'Milanese' because of his experience and ability to relate to the Italian culture. Many times the clients referred to what they ordered adding statements like 'as you know how to do' or 'I take the usual'. Such climate of hospitality and warmness reflected also among the clients themselves that felt like being at home and they were acting like a family. The bar usually stayed opened until 9 PM, he warned the players at the slots that the time was out. He then closed the freezer and the machine of coins for the day and counted the money in the cash. Several clients were marveled to know that his bar stayed open until such a late hour. Sometimes he had the last minute client before he closed the cash, shutting down the lights and closing the door.

In the bar-café Delun selled cafes, drinks, food, etc., ...while in the fast food Delun selled lunches trying to introduce a new style of food in Italy which is quite innovative and still original if compared with some other big chains. After 10 years of working and saving investments working in his bar, Delun created 'Dutch Chips', a fast food producing fried food, vegetables, chickens, sandwiches, burgers... The fast food had several workers (one from Philippines, one Italo-Brasilian, some Italians) and one Italian chook (Giulio). They were organized in two shifts: one in the morning and one in the afternoon, changing turns at 05.30-06.00 PM. It was hard in the beginning for all the workers to get accustomed working with a Chinese boss, so 3 workers during my period of job-shadowing were changed while other 2 were fired. Usually the fast food had more clients on Saturday while Monday it was almost empty. The first months of the business was hard because the workers were not necessarily prepared, Delun was working with them for the initial periods for 1214 hours.

Close to the fast food the aunt of Delun had a bar, so she was responsible for the training of the workers at the fast food, since she was expert and already in direct contact with food. As Delun's bar, his aunt had a bar in front of the entrance of the underground. Putting together all the family members and distant relatives Delun was part of a network of 30 bars. She was very rigid, demanding and very controlling. As time went on Delun was more responsible for the 
administrative aspects while his aunt was managing the place. During my job-shadowing the fast food was in disadvantage because of the summer heat. People preferred to eat ice creams instead of fries. Even as the winter came, the fast food had less movement despite its strategic position in an area of town with the

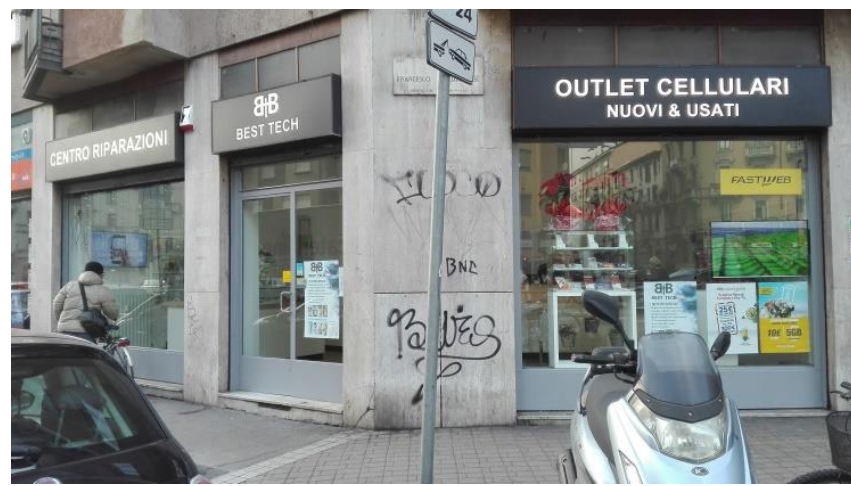
headquarters of large companies attended by rich people. The type of clientele in fact was completely different from the bar or the High-Tech store ${ }^{9}$. He decided to open this new activity after he went to China for a business visit. He went to Shanghai because he had invested into an activity there and he met a business partner for dinner. Delun in fact like many Chinese entrepreneurs, apart from the businesses running in Italy, he had invested 2 years in a pharmaceutical company in China. The company was implementing special treatments in the Zheijiang province near Wenzhou and from there into all China. As he was having his dinner with his business partner, Delun expressed how bad the economic situation was in Italy at that time. The youth unemployment of people and the concern he had for this situation. His friend advice was to use his values and hire those Italians in difficulty. At first his reaction was negative, since working with Chinese people is the norm for the Chinese Boss wherever he goes, since is easier to manage them. This is true because they are more ready to make sacrifices, work extra hours... So as an entrepreneur Delun was thinking about the economic interest but he also thought of how to resolve this thing. He wanted to overcome the partiality and ethnical exclusivism that other Chinese entrepreneurs were displaying in not helping the Italian people.

After the trip Delun had to choose between four business opportunities: to open a fast food, to be a financial broker, to be a retailer of luxury goods or to be a representative for merchandises in the cosmetic sector. Only the first option involved other people and could provide a salary for people. So he decided to pursue this option in order to give a solution to the problem of Italian youth unemployment. It was quite unusual for a Chinese entrepreneur to hire non-Chinese or Italian workers, because the expenses were high, the willingness to work on hard schedules was lower, and the economic risk was big. Even if it was not necessarily convenient or attractive economically Delun took this decision anyway. The fast food in fact had at times seven Italian workers. Delun followed there principles of correct concurrence without corrupting anybody, pursuing an honest earn, respecting fully the rights of the workers according to the law and never abusing them.

\footnotetext{
${ }^{9}$ Outside view of the new High-Technology store of Delun. The logo, as for the Dutch Chips (see Appendix) has the shape of a cross. 
Another example of Delun's interest in establishing business partnerships of social significance was his project to start a new business with Bingwen. Delun started the traditional Chinese bar as many other Chinese entrepreneurs of second generation migration. Then he broke with this traditional way of doing business exclusively with Chinese people first through the transitioning phase of the fast food then changing totally the sector through this business focused on Hi-Tech and other more modern sectors. After working in the engineering sector Bingwen decided to start working in the business sector as a salesman in a fashion company in Milan. Since profits were not expanding for Bingwen, his friend Delun

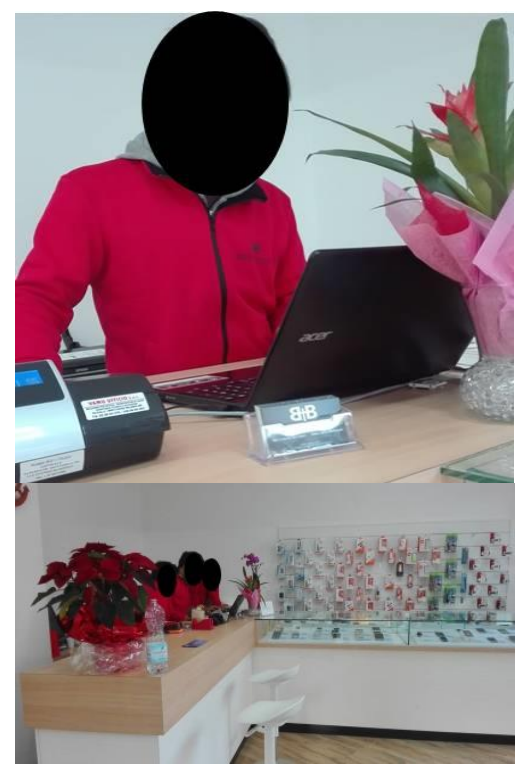
came with the idea to open a new store in business partnership with Bingwen, a store of telephony and new technologies in Milan. Delun realized that everybody needed a cell phone in order to be in contact with people and this need was not going to change in the brief period. I knew both of them before the start of this cooperation and I was surprised in the change of relationship between the two. Since Delun now was his boss, Bingwen was worried about giving a good impression on him, especially during the first months of their relationship. Even though Delun knew that Bingwen did not had skills on the field, he decided to hire him as a business partner for this activity. He wanted to entrust it to somebody he could rely on since he was already very busy with other things. Bingwen recalled how Delun got the idea to start a new business together:

[...] Delun had an idea because there is a market, everyone has a cell phone and will keep having one, if the business is for something that lasts only for ten years is not good. At first [he] tried with two other people but they didn't want to do it, then he though about Bingwen that is available, is connected to what I know, on electronics, we had a dinner together then we said yes, and after two weeks I started to work for the training in Hangzhou (Bingwen, Tonglu, Milan, 18/11/2015).

Bingwen went to China for one month to start a training on new technologies, to learn the basics notion about the field and then he started to work in the store that Delun and Bingwen rented in Milan ${ }^{10}$. There were several training schools in China, more in Guangdong province. Yet the price for that area was too expensive, so Bingwen decided to leave Italy for one month and to go in Hangzhou, an area where the cost was lower and he could have visited his family in Tonglu. Together with Bingwen there were many other Chinese people taking the course and even another Italo-Chinese worker (second generation migrant living in Reggio Emilia) that had the same idea. He wanted to go back to Italy and to start the same type of activity.

\footnotetext{
${ }^{10}$ Bingwen working in the new store of Delun at the counter. Together with him the two other Chinese colleagues that are apprenticed in fixing phones.
} 
This other person at the young age of 21 years old was already first working as a barman then into a factory and now he was involved in training to learn competences in Information Technology as well as other ideas (opening Italian restaurants in China). During the training they taught Bingwen to fix phones and technological items, to study the composition, the circuit, the parts. Practically Bingwen and all the other Chinese workers had to take broken phones and change the screen. If the phone was damaged by water they had to find a solution to fix it. The training was an investment for Bingwen (700 €) but even if he was allowed to attend the training for an unlimited time he decided to do that only for one month and go back to Italy to start the business. This was increasing the challenge for him and Delun since it was a very complex work. At first Bingwen did not have any particular interest on the type of activity nor he had any confidence. After the first challenge he was able to develop his skills. Bingwen was available to Delun that on the other hand knew he could trust Bingwen. Delun encouraged Bingwen and the other Chinese workers to do their best, to assume their responsibility and to work hard.

I followed the initial steps of establishing this new business during my job-shadowing. The store was located in an area of Milan, an area full of foreigners and with plenty of stores that were already doing the same type of business of cell phones and high technology (I-Phones, Samsung, etc., ...). The clients at the store were of all different ethnicities: Italians, Spanish, Latino's, Arabic, French, English, Korean, Chinese... because the area was full of foreigners. Many Chinese friends of Delun were regular customers especially during the first stage of his business. On the video monitor Delun regularly shew pictures of phones but also of the whole group of Chinese Protestant entrepreneurs at the inauguration of the store. They heard of his new store and came presenting their problems with the phones and were involved in Delun's work if he needed help of any sort. The neighborhood of the store was surrounded by similar stores that repaired cell phones, supermarkets, hairdressers. Some of them were Chinese others were Arabic in their ethnicities. People were coming to the store of Delun despite the saturated market of the competitors because of the good customer service provided in Delun's store.

Even if other stores could have been more professional in repairing and had more technical experience with the suppliers, the store of Delun with his more modern looking and good customer service was really giving an added value to the transaction from the side of the client. The design and furnishing were modern and unique if compared with the old-looking and repetitive surrounding stores. Furthermore Delun and Bingwen shew a strong entrepreneurial spirit in the fact that despite the lack of technical knowledge they were able to start and learn the way to manage this business. This was because of their passion and because of their commitment to it. Their dedication led them to be always busy in doing something, never giving up when they couldn't find the 
solution to a problem. This difference was clear when comparing them to the other workers in the store. Sometimes clients came to fix their phones, to change their SIM card, to ask about a specific type of model ( $3 \mathrm{G}, 4 \mathrm{G}$, etc., ...), to place a new phone cover, to sell or to buy. Sometimes clients were staying for a long period of time discussing on what decision to take on their purchases: whether to give the phone and repair it or not due to the high price.

As phones were given to Bingwen, Delun or the other Chinese workers quickly tried to determine what was the problem in it and the amount of approximate costs. Sometimes the fixing required only few minutes, other times days and weeks with an average of one phone repaired each day. Sometimes the customers just came to ask prices and test the area without buying anything. This was done in order to compare the prices and choose afterwards. Then the customer was asked if he wanted to leave the phone to them and if after the repairs he wants to sell it. At times the store was empty and the workers were listening to the music, watching their phones or talking with one another. Delun usually tried to motivate them, always working in team with them almost like a coach. The same pattern that was present at the Dutch Chips was reproduced in this new environment. Sometimes Delun did also delivery and technical support in the homes of people. Customers had problem on the Wi-Fi or other technical issues. It was not always easy to proceed in the price evaluation because mistakes were common. The Italian worker, Giulio, was always at the counter as front office with the clients because of his proficiency in the Italian language. In fact many Italian clients were sometimes suspicious of Chinese people so as soon as they saw an Italian worker they felt more willing to stop and buy. He was also responsible of managing the bureaucratic staff. Giulio was an Italian guy that worked first for 5 months at Delun's Dutch Chips and then he was transferred to the Best-Tech store. As I was doing my job-shadowing at Delun's new Best-Tech store I had many chances to hear his interesting point of view:

\footnotetext{
Since the beginning I worked always for Chinese people, a bar buffet in the Loreto area, the owner was Chinese, the chef was Italian. It is hard to work with Chinese, their view of work, a life based only on work, many hours, the rest doesn't exists. In one sense is hard for the rhythms but they teach you well the job, they can't think outside the lines. They give you a lot of orders, piercing eyes, mr. know it all, no matter what I do is wrong, they like to have the situation under control. Delun compared with my ex-boss is more ready and able to help, it's been a long time since he arrived in Italy. [the previous work] It was hard, the Boss and his mother, it wasn't going good (Giulio, Milan, Milan, 16/01/2016).
}

Giulio was not necessarily always in agreement with all the procedures followed by Delun but he obeyed nevertheless. After the transaction was over Delun and his workers went back speaking in Chinese with one another. The counter must had at least two people together as the others were downstairs repairing phones. Usually they tried not to leave any unfinished work from the night before, but they tried to immediately find the technical solution to the problem.

The choice of suppliers and of prices as well as the way the workers had to proceed were very crucial. There were delicate aspects in this business compared to any professional experiences 
that Delun had up to that point. In this new store Delun had to hire 2 workers at the front office and 2 technicians. His choice in this case, differently from Dutch Chips, was to hire Chinese workers since he recognized that they were more efficient and fast in their job. A Chinese worker, according to Delun, 'is able to do in 30 minutes the same work that an Italian does in a day'. Italian stores around the one opened by Delun were taking a long time in fixing the phones, doing less effort but still having high prices. The Chinese store of Delun on the other hand followed a different strategy: fixing the phone as fast as possible, even under the eyes of the client, with a 'paying and going' approach. The most important task was to be able to fix and repair cell phones of clients in the quickest way. It was almost like a surgery to be done in a delicate situation. The prices furthermore were in accordance to the amount of hours required to fix the problem, trying not being dishonest or not taking advantage of the client. Delun and Bingwen from the beginning were therefore to be directors of the business, sharing $40 \%$ of the investment on the side of Bingwen and $60 \%$ of the investment on the side of Delun. Delun took the majority since the idea was his and he wanted to take control of the company. This was done in order to avoid the battle and conflicts involved in business leadership in cases where the setting was 50-50\% (see Chun). They had simply to compile in making sure that the worker was going to do his job efficiently.

Since the first periods of the opening of the business Delun was coming every day to the new store because his presence was indispensable and he actually enjoyed being there more than being at the bar or at the Dutch chips. Even if he was always busy, he had more interest on this place, he liked new things and not the traditional businesses he was involved at first. Usually Delun did not hire a person that he knew personally since as a Boss Delun needed to be direct in giving suggestions and critics. With a friend this was risky because he was afraid of losing a friend. In fact Delun recalled when that happened as he hired a Chinese woman that was his friend and as soon as he pointed out a critic she was offended and left the job. But with Bingwen the case was different, the two knew each other very well and were in a friendship of mutual trust. Also they shared common values, that I will examine more deeply in next chapter, that really enhanced their common vision for business. Bingwen and Delun were considered the directors in the store, the others were workers. Often Delun was sharing and discussing with Bingwen administrative stuff, asking him his advice. Delun knew that there were a lot of people involved in the market of phones, so he started to contact his first potential clients. Delun during this period spent 18 hours of work a day between those three businesses.

The new store of technology opened at 09.30 A.M. every day. Friday and Saturday were considered as the peak days with 20-30 clients. Some other days the store only had 5 customers. The store closed always around 08:00 P.M. and there were shifts among the different workers. 
Delun usually came to the new store around 11:00 in the morning. Delun arrived always after the workers and Bingwen already started their job. Workers were busy in putting the phones in the window, waiting the clients to come, cleaning the place and starting the works of repair left unfinished the previous day like broken cell phones that needed to be fixed. There was not a specific timetable during the day at the store. It depended on the number of clients. Some clients were just coming in to ask opinion on a phone they already had: if it was a fake or an original phone and how to sell it. Other clients were coming to fix their phone, for example to change the screen (40€ max price) or to buy used phones as well as new ones with a cheaper price or just to receive information about making an ID with I-clouds. The neighborhood was not the best in town and often some of those clients were not honest in their deal. At first many clients were just coming to check the prices of repair. As they came in Delun asked questions on how the work was going in an environment that was still warm and friendly. He usually stood at the front office, the place that he preferred because of his good relationships skills. He also occasionally came downstairs to fix phones, change screens, batteries and camera's. Even if he enjoyed fixing phones in the calm environment of the downstairs room his primary place was at the front office. This somehow perceived by Bingwen as 'his territory'. Delun stayed at the store usually at least for 5 hours a day, but sometimes if the workers had any inconveniences he would remain at the store for 9-10 hours. The store also had a roster to sign entry and leave of the workers for Delun to know their schedule. In the initial stages of any of those businesses Delun always had many workers and apprentices but as time went on he selected only few among them to work for him on a regular basis.

As the client entered the store Delun asked them if they wanted to sell or buy. Two of the Chinese workers were responsible of repairing the phones in the room downstairs. Bingwen usually repaired damages easy to repair leaving the more hard repairs to the two Chinese experts while he was trying to learn from them. Those two Chinese workers were experts because they already worked as apprentices in other stores. Bingwen and Delun needed also to control the workers and to make sure that they were doing what they were supposed to do. In their economic transactions sometimes people brought things that were stolen. In those circumstances Delun tried to maintain the standard and oppose shoplifting. Those situations were easy to discover because the price required by the customer was blatantly lower than its real value. Delun wanted to make profit but not to feel bad about wrong strategies to achieve it. For this reason he followed the standard of refusing to take merchandises under unethical circumstances.

To fix a phone was a delicate operation. Sometimes the damage required an obvious operation while other times it was due to chips, the motherboard of the phone, etc., ... First Delun, Bingwen or the other Chinese workers needed to define what was the problem then they had to 
come up with a solution. This process required experience, knowledge and skills. Some cell phones required only 10 minutes to be repaired, in other cases it was something impossible to fix. In this case some irremediable mistakes were done on fixing the phone or on labeling the price of a certain product. This was causing a loss of profit. For example often a phone was sold for $1.000 €$ but then the workers discovered that the real cost was $1.200 €$ with the addition of taxes, ending up then losing $200 €$ of profit. Another difficult task, especially in the first months was to find suppliers for new phones and parts of the cell phones, machines, computers... Italian suppliers (mainly from Rome or Lecco) resulted to be slow in shipping of the parts needed to repair the phones. Sometimes even wrong pieces were sent instead of the needed things for the repair. This slowness was resulting in the client coming repeatedly to the store even if the merchandise was not ready, waiting for a long time. Almost every Monday Bingwen was receiving at the store deliveries from the suppliers, paying them for the products. Those products were usually spare parts or new phones cheaper than what he could buy online or in other stores. The Italian worker on the other hand was hired because he spoke the language. He was always at the counter, tryng to let the client feel comfortable, building the necessary trust and relationship. He was also trying to get done with all the paperwork, the corrections on the information to publish in the website or at the sign. He also knew how the software of cell phones worked. According to Delun's view of him, he was not the typical Italian, he arrived in time to the appointments, he was opened with Chinese people and it was a person easy to talk with. Delun knew him since two years before they started this business, as he worked for two years at the Dutch Chips before passing to the new business.

As Delun started this new activity slowly the leadership and management of the fast food was given by him to an entrusted Italian worker as he progressively focused his attention to new business. His role then became just the one of owner and overall director of the previous business. This decision required an ability to delegate, trust and not holding on to past successes but constantly aiming for the unknown future developments of business. Sometimes the Italian worker that managed for Delun his fast food business came to visit him at the bar to give a recount of how the business was going: taxes to pay, behavior of workers, use of bricklayers for the new buildings. With him Delun was trying to establish a business partnership still in the framework of a bossworker relationship but somehow more friendly and based on an entrustment and accountability of the business. This Italian worker trusted Leo's leadership, he was friendly and satisfied with their relationship, sharing the contagious commitment of Leo.

Sometimes Delun had to face situations of risk especially with his business at the fast food. Some breakdown in the machines to be repaired (fridge, cash desk...), tablets that stopped working or disconnected cables that were blocking the line of clients at the counter were all sources of 
challenge. I witnessed how even at his bar when clients were having very bad reactions, or were taking advantage of his generosity, especially among the goers to the slot machines, Delun was always kind and confident. For example sometimes regular attenders to the slots were disappointed because they had lost a lot of money (200-300 €) at a particular machine. Yet Delun tried always to answer to their occasional complaints with the friendly attitude of a pacificator and proposing them to change machine if necessary. Sometimes because of the slow bureaucratic process of Italy in receiving a specific documentation Delun had to block the whole work at a store which causes a big amount of challenge. Several conversations at the phone with the suppliers were about those problems, sometimes leading Delun to the necessity to withdraw from the contract.

In light of those multiple problems connected to the lack of professionality of some suppliers, Delun was always confident and focused on his goal. Delun big challenge during my jobshadowing was related to his new fast food chain, Dutch Chips. He had trouble finding some business partners that could join the company. Sometimes he had to deal with cases of plagiarism from other fast food around the city of Milan copying similar brand (like 'Amsterdam Chips'). When Delun started this new fast food he had a lot of revenue, the place was full of clients up until 12.00 AM at night whereas, later on, the place was sometimes almost empty. The problem again was due to the fact that many people just copied the brand and started a similar business stealing his clients. As the business grew Delun had to fire 3 workers at the Dutch Chips because of the taxes and bureaucracy. The reason was for the many expenses, for the suppliers, for the rent and the salaries. The fries and vegetables came directly from special suppliers so their price was more expensive being of higher quality. Delun had to make many efforts in order to pay the workers. Their work was done in a very narrow space and he was not making any profit. This element of risk caused Delun to be bitter at times because of the Italian system that according to his opinion was too full of privileges and protections. Even if in the beginning the store was full of people, after a while because of the competition with the rival Amsterdam Chips, the number of costumers was decreasing. The problem with this type of business was that it was badly oriented, more suitable in other areas of town. For this reason during my period of job-shadowing Delun decided to remodel the Dutch Chips and change it into a Sushi bar (Sushi express) with the business partnership and help from his cousin's husband. Seeing that the business of Dutch Chips was not growing Delun decided to change and innovate again restructuring the whole building. Delun's philosophy was that if a business was not growing he had the option to close it, sell the activity at a low price or like in this case transform the activity in a more strategic way. Sushi was a type of food easy to manage by Chinese entrepreneurs. During the time of preparation for this new business, Delun was very busy collecting all by himself the ideas, the Japanese recipes for food, the bills and facilities. Delun felt 
that his role was the one of 'the living soul' of the firm. Anytime he was trying something new in business with all of its challenges he saw it as a training experience.

Another challenge came when Delun had to manage three businesses because of the new store of high technology. During that period Delun at the same time had the possibility to participate successfully to a tender and indirectly manage a chain of 18 stores in the undergrounds of Milan. Among them, 8 or 9 of those stores were stores to fix phones but there was a lack of specialized personnel. In the area of his business there was high concurrence from more than 19 stores. The unique strategy of Delun in this context was to give trust, good image, professionality and efficiency. In those periods Delun was over-loaded with responsibilities. He appeared to be 'death tired', challenged by the many worries in a situation of high economic risk. To open always a new business causes many bureaucratic problems, it is a bet full of tension and stress. It was hard and difficult for anybody to manage the stress involved in those circumstances yet nevertheless Delun was surprisingly calm. Even though sometimes he was tired, nervous, he was generally optimistic, peaceful and confident, smiling, without tension, trying to maintain the patience in front of the client and the other employees.

Even Bingwen said during our conversations at the job-shadowing that Delun was a model for him because he was able to work the whole day but he still was able to be happy in front of the client adapting to any situation. His determination despite his tiredness in those circumstances was remarkable. Another source of risk in the new business was the recurrence of inconveniences when the cell phone of the client was accidentally broken by the workers. In those cases when the worker, trying to fix the phone, actually broke it, he personally had to share expenses and to compensate the losses of the client with his own budget. To accept the assignment of fixing a phone was therefore always a challenge. Sometimes Delun or Bingwen had to spend the whole day trying to resolve the problem without being able to find any solution. It was a frustrating experience but they did it anyway searching online or through the personal trainer in China explaining him the problem trying to find a solution. Again in those circumstances Delun was determined even though he lacked specific experiences and was discovering an unknown and risky territory. 


\subsubsection{The Autonomous Buyer}

Minzhe $^{11}$ belongs to the iii) type of business, she is self-employed and she works as a buyer in the surrounding area of Milan. The role of buyer in the field of fashion is becoming very common among Chinese entrepreneurs in the area of Milan. She started doing this type of job at first only to help a friend. Then, since twenty years, she is involved in selling and buying products of high fashion from Italy to China. She started just talking with some of her old friends through the Chinese social network WeChat. They noticed how goods of luxury had different prices in different nations and therefore she decided to make a business out of it first opening a market in Malaysia then later expanding it to China. I observed Minzhe in her work and she was very focused and she

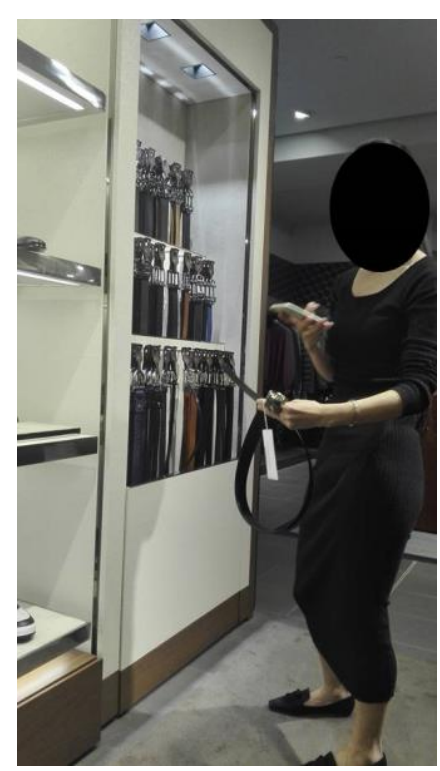
tried to do it with the best of her capabilities.

The target of products for Minzhe was usually luxury goods, high quality clothes, that usually in China may cost $1.800 €$ but that are more convenient to be purchased through a buyer directly from Italy. That's why usually Minzhe chose to buy expensive clothes in order to make more profit. During my job-shadowing observations the Chinese buyers around Minzhe were choosing less expensive merchandises (200-300 €). A big problem was the amount of taxes that the buyer had to pay for the expedition. Many times the company tried to come in help of the buyer offering a taxfree transportation in China passing through Hong Kong. Like for many Chinese entrepreneurs her strategy was not to buy a certain fixed quantity but she bought on demand. First she went to the store and she took pictures of the products, then she immediately sent the pictures to the website ${ }^{12}$ publishing the price declared. This was done in order to see if there was anybody interesteded in purchasing it and on

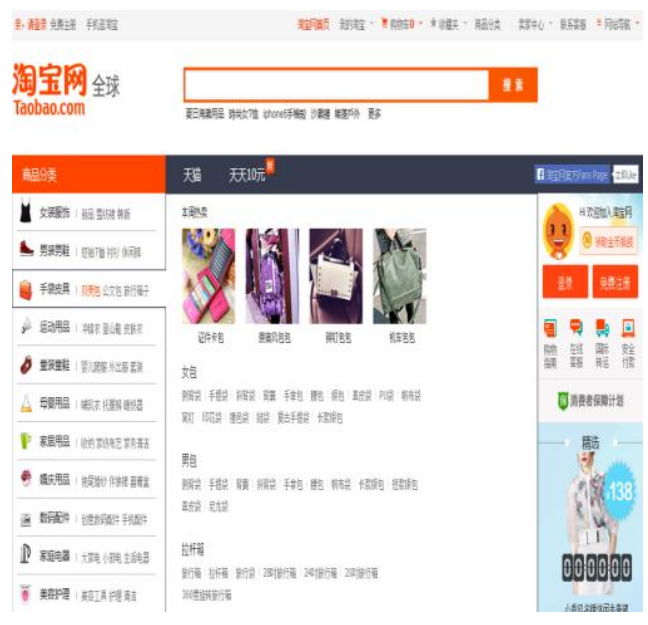

\footnotetext{
${ }^{11}$ Minzhe taking pictures at Rinascente in Milan of a fashion belt in order to sell it on her website.

${ }^{12}$ Homepage of the website that Minzhe as many Chinese buyers uses to sell her products in China. Taobao, a subsection of Alibaba is a very popular and smart online platform to do e-commerce today in China.
} 
the basis of the demand she bought the product. Sometimes the feedback from the client took 3-4 days so Minzhe came back to the same boutique to buy the product she selected before.

The e-commerce represents today a great majority of the business in China and Minzhe was not an exception to that. The Chinese government was not so happy for the spread of this commerce online because of the tax-free market that internet provides. Minzhe started to work as a buyer long time ago and when she first started she initiated a business with Malaysian clients through a Facebook page. Then she decided to start to sell in China through a Chinese friend using a Chinese social network (Weibo, the Chinese version of Twitter), then later on she also started to use the Chinese social network WeChat where she posted pictures of the products and received notice of interest from the clients. For the payment however she used other more trustworthy websites were it was more safe for the payment.

She used frequently websites like E-bay and Alibaba, a popular Chinese website for selling and buying. Particularly Taubau, a sub-group of Alibaba, is dedicated to buyers that sell products and became extremely popular among people under forty years old in China that wanted to buy from that online platform. The founder of this website, Jack Ma from Hangzhou, a city close to Wenzhou, started the company with a budget of only $200.000 €$. Jack Ma is today one of the most rich person in China with 14 billion of dollars. Yet to have a personal page in Taubau was not as easy. Sometimes was a 24 hours work uploading pictures of products, designing, describing every detail for every single picture. Through the chat, people asked questions on the store page that required immediate response unless the client decided to go to another store page and buy there. The same difficulties were present among other Chinese entrepreneurs focused on e-commerce like Lei and his Chinese version of Groupon website (Guua):

What I would like to do is to connect stores and restaurants and put them online. [...] 30-40 years ago China was poor, the basic things of business were not mature, now the e-commerce takes and make you rich, people can spend more money (Lei, Milan, Wenzhou, 21/01/2016).

Lei had to work sometimes up until 4 AM in order to keep in contact with customers in China and update his website yet he found inspiration and strength through imitating famous business figures like Jack Ma or Elon Reeve Musk.

Taubau also resolves the problem involved with e-commerce of possible fraud through a payment from the company. The seller sends the product and the company is involved in the transaction to guarantee that none of the parts is fraud. The buyer then receives his payment that then can be payed to the seller even if the client commits any kind of fraud. In order to avoid suspicion and to have the trust from the clients in China, Minzhe had to go to the different boutiques in Milan and she took pictures of herself with the merchandises to demonstrate that she was personally involved in the purchase. She was known by her clients to be an expert on fashion 
and she had a strong desire to please the desires of the client. To buy in stock was very expensive and since Minzhe just started her business since 5 years she preferred to buy only when the customer in China already expressed his interest on the product and deposited the money on the bank for the payment. Usually the product was not sent in China singularly but after a certain amount of orders from different clients was reached (generally $7.000 €$ of merchandises) the orders were sent to China with a cost of transportation around $150 €$. The merchandise was not sent to China until it reached a total accumulated value enough to make some significant money out of it. So overall Minzhe made an average of $5.000 €$ for month.

During my job-shadowing I was able to follow Minzhe for her different visits in the stores of Milan. Usually she went to famous Italian brands of wholesale stores, as a usual customer. Her primary providers were 8-9 stores in the area of Italy, especially Milan where she was a regular buyer. Among her first choices she went to the Rinascente in the center of Milan. Usually she went there every 2-3 days depending on new arrivals and orders or she went to other stores in small towns close to Milan like Tod's. Tod's was a clothing store close to where she lived. The brand depended for its revenue for the $15 \%$ on the Chinese market. She also went to another store in the surrounding area of Magenta (usually every Tuesday), Serravalle (usually every Monday). Other boutiques around the center of Milan that Minzhe visited were in Via Montenapoleone (Chanel, Pisa Watch...) or in other stores at Rinascente (Miu Miu, Bottega Veneta, Bovary, Chloé, Celine...). She usually went there once a week because there were a lot of stores there. Another place sometimes Minzhe went, every two or three months, was an outlet close to Florence (The More) because she knew a Chinese worker in Prato that introduced her to the products of that store. She usually was focused on the buying and selling of bags, fashion shirts, shoes, wallets, belts and clothes of expensive fashion (Gucci, Prada, etc., ...). As she arrived to the usual store she was introduced by the owner, that knew her very well. She went to the warehouse to see the new arrivals of products together with other Chinese buyers. At Serravalle they sold the same type of products as the other stores but more updated specially for what concerned the new seasonal samples. The best moments of the year for her business were after the Christmas season and the Chinese new year (December-Jannuary) or other holidays when it was time for discounts and there were pre-sales in every store.

When she went to the Rinascente in Milan she usually started with the store of Gucci where she was known to be a regular client. The people at Rinascente usually spoke English since there were a lot of Chinese people that didn't speak Italian. Sometimes I witnessed how Italian workers had trouble understanding the needs of the clients, so it was necessary almost every moment to have a Chinese salesman. Sometimes even for Italian salesmen it was required to speak Chinese, and 
some store had people speaking up to five languages. Another ethnicity that was very strong in the business of buyers at Rinascente were the Russians. Minzhe waited for the regular saleswoman that stayed in contact with her through social networks and gave her all the details about new arrivals. As she waited for the saleswoman at Rinascente or in other stores of Milan her most important duty was to choose among the different products in the warehouse or in exposition, controlling the prices and the quality of the different brands. In stores like Gucci at Rinascente or other boutiques around the city I observed the same process of taking pictures with bag after bag in front of the mirror. At Rinascente not only there were a lot of Chinese buyers going around but even the saleswomen and salesmen were in majority Chinese. Minzhe told me that at least every store at Rinascente had one Chinese salesman, some of them were second generation migrants and the majority of them were from Wenzhou. Sometimes Minzhe had trouble speaking Chinese with them because their Wenzhounese dialect was not easy to understand. Some stores were so crowded (for example Louis Vuitton) that it was hard for her to enter and to find what she was looking for.

Minzhe like other buyers started to take a lot of pictures of the merchandise that she selected to post in the website. The process of taking pictures was very detailed, at least she took two or three pictures for each merchandise, internal and external pictures of the bags or of the clothes, valuation of how many pockets or belts the bag had. Usually she chose the best sample on the basis of what was having trend in the sector, what was currently in fashion, a specific color (pink, red...). Then she took pictures of the merchandises. Minzhe had precise criteria of selection, she looked at the details of the product, the practicality, the use and tastes about fashion, something that required special ability and to have an eye for purchasing. During my job shadowing it was frequent to see Minzhe surrounded by three or four Chinese people, sometimes even entire families. Sometimes they were tourists like for the case of Rinascente, sometime small 'family buyers' like for example a mother and a daughter and they were doing the same type of job. Sometimes they were steering at Minzhe as a witness of the high competition involved in this type of job. When I was doing job shadowing at the Rinascente close to the Duomo of Milan at least one out of three clients was a Chinese buyer like Minzhe going around to visit the different stores, taking pictures and doing calls to check the interest for a product from the clients. Many of them were the same age of Minzhe and one out of two clients was Chinese.

Minzhe went to the store at Rinascente usually to pick up new arrivals. When she came there she generally chose specific fashion brands. The pick was based on the need, names that are popular, that Chinese people loved, depending on the season and the popularity of it in China. For example one time at Gucci store she was informed ahead of time of the arrival of scarves, so she went to pick up the arrived order of 20 scarves since the winter season was coming up. Before the 
period of sales (January and July) Minzhe together with 10 buyers received pre-sales discounts at Rinascente since she was a faithful client there and bought a lot of merchandises. Because of her privileged position Minzhe received pictures of the products and was notified of every new arrival. Minzhe told me about that time that together with those 10 buyers she bought more than 1.000 products at the store of Gucci in the Rinascente. More than 100 products was already a huge quantity for a client in stores of that level of expensiveness. When January came, Minzhe sold many bags from Gucci and since people kept asking for them she stayed there the whole day. Like Gucci every store at Rinascente did pre-sales. This particular company though, allowed to buy only a limited number of samples at their store so several Chinese buyers asked after Minzhe to take her ration if she could use her name to allow other buyers to buy more scarves.

There were many Chinese buyers at Rinascente. They usually were students that started to get involved in it first for purchases to their families and friends then through a larger amount of clients. This was a signal of the competition in selling that was faced by those buyers and of the high request of some specific products that just arrived. Still Minzhe was notified ahead of time by the Chinese saleswoman about it because she was 'friend of a common friend' with Minzhe. They shared their contact of WeChat (Chinese social network) and she notified that the merchandise for Minzhe was set aside because of their friendship.

Another time she went to look for a new brand of shoes in a special store of Rinascente that she knew was doing tax exemption (IVA). For this reason that store was full of Chinese buyers and she was not able to find the sample she was interested in, because it had been sold out already. Those stores allowed only the selling of few samples of the same brand in order to block people from taking advantage in the process of re-selling. She controlled the merchandises, she took out one sample and she quickly took a picture of it to public in her website in order to sell them as soon as possible since she was worried to have merchandises in stock that she was not able to sell. Sometimes she was able to sell the merchandises in few days, sometimes it was a matter of weeks or months. Every boutique had a manager responsible to help the buyers in their selections and purchases. He usually led the buyers in the warehouse and checked the list of prices for the new arrivals (some bags costed 1.500-2.000 € some other $400 €$, but usually the average was always above $1.000 €)$. When Minzhe was at Rinascente she was primarily focused on bags, but she also took pictures of belts, wallets, scarves or shoes of high fashion. Minzhe had a phone with more than 10.000 pictures of products (130 GB of memory), every day she made from 100 to 300 pictures, dedicating 5 to 7 pictures for each sample. Only the $30 \%$ of all the merchandises she photographed was sold, depending if the clients appreciated the product. Sometimes her activity was going from 
one store to the other and then she came back to the same one for her final decision to book a sample from the upcoming arrivals.

The manager of the buyers as well as other workers in the company knew very well Minzhe and the manager was the one that she often talked with for the business more than the owner. After buying a product, for example a brand shirt for $400 €$ she added 20 to $50 €$ and sold it to the customers in China. The competitors around Minzhe did the same type of activity as buyers, they often watched one another, seeing what type of product the other persons was choosing to publish on their websites. As Minzhe was for example choosing a brand at Rinascente, another Chinese buyer was choosing it as well, or simply watching to see which sample Minzhe was taking. This environment of competition was particularly strong in the center of the city of Milan, in big famous stores such as the Rinascente or many other boutiques of fashion. Even if they did the same type of job the buyers at work usually didn't speak with one another, they tended to be unfriendly. For this reason Minzhe tried often to find unfrequented boutiques, outside of the city center, in order to receive a discount, better deals and to maintain it as a secret against other competitors. Minzhe was particularly surprised and disappointed to see many buyers coming at some of her favorite stores doing her same type of business.

In my job-shadowing I was able to witness how in few minutes many products were already sold online and Minzhe arrived too late to sell a certain brand. Several times Minzhe, after having evaluated the products, was immediately at the phone waiting for some quick responses and purchases in order to anticipate the competitors. Her relationship with the clients or with the seller during the transaction was straight to the point. The results generally were very positive compared with other competitors, Minzhe was able to sell the product almost immediately. Many times the competitors were standing around were Minzhe was looking to the different products in order to check which merchandises she would choose. The indecision of the competitors contrasted with the confidence that Minzhe was able to display during the job-shadowing in a current race in order to succeed in selling as much as she could. As soon as she took a picture of one product she was already having her eye to the next one.

Furthermore her reaction to situations of risks was very significant. Sometimes we had to stay in warehouses with hot temperature and uncomfortable settings, yet she never loosed her focus of the selection, evaluation, price comparison... Under the strong pressure of competition Minzhe always demonstrated to be secure of herself and able to handle the difficulty. Other times when there was some sort of inconvenience, like when the owner loosed his patience, a worker did some mistakes, didn't know how to determine the prices, could not identify what was the right color for 
the merchandise, Minzhe was always displaying a strong degree of confidence. Also Minzhe at times felt in a situation of crisis:

I feel tired, I go to work at $10 \mathrm{AM}$ and I come back at 6 PM. Even if I make money it does not satisfy me, I feel like is empty, I don't have time to think on what I am doing. [...] After two years I feel tired, I am not helping people. Use my time is fundamental, in my job I lose time. Sometimes we are lost but then we find the way, even if I'm sad (Minzhe, Shuzhou, Milan, 19/01/2016).

Minzhe sometimes felt the situation was difficult, she wanted to have other people working with her but it wasn't easy. Even in her business partnership with Enlai and Fai, that I will describe more later, she felt it was difficult because they were not living in the same environment (Enlai and Fai were in China at that time). Fai for example was already busy with his 5 online stores and in managing the factory. Enlai on the other hand after he started the business partnership with Minzhe was not reliable, he didn't finish the task he promised to do by Minzhe. This led her to be particularly frustrated because it was difficult to find committed clients. In this kind of job it was crucial to have the right clients. In this situation of high competition Minzhe decided to start a cooperation with Enlai in China in order to find a 'customer niche' in order to survive in situations of economic risk. Enlai tried to find more clients in China, through several websites, and when he cought their interest he went to visit them, he presented the different categories of products that Minzhe could by for them in person in order to give a supplementary tool to what the e-commerce, so common in China today's business, was not able to provide.

During his visit in Italy I had the opportunity to follow Enlai and Minzhe during their beginning of a business partnership. Enlai's wife was owner of a Jewelry store in China but because of the downfall of business and shutting down of some factories, Enlai decided to start this international business partnership with Minzhe. He tried to fix different appointments in order to understand if there were some discounts in the merchandise, and he tried to speak with the managers in order to find a better price of transportation counting the taxes involved. Several times Enlai asked me to translate his e-mails to managers of stores here in Italy, to do some screening of the different websites of the companies and to go for some visits at the boutiques. The surrounding environment of Minzhe and Enlai was an environment of strong emphasis on fashion and my observations demonstrate a sense of sobriety in them that contrasted with the context. After the period Enlai visited Italy for business reasons together with Minzhe, Fai was also involved by Minzhe and another Chinese entrepreneur in China in order to start a cooperative effort and expand the sales. Fai was charged to do the biggest part of the online business for Minzhe since he owned 5 online shops. Fai took pictures from the website of Minzhe and shared them in his online shops. After Minzhe collected the pictures Fai was delegated to collect the pictures and Enlai took all the information about the product and gave them back to Fai that therefore posted them on the 
commercial websites. Apart from them Minzhe also had another business partner in Shanghai to whom she sent the pictures.

Usually Minzhe shared her revenues with them, approximately 10\% Enlai, $10 \%$ Fai and $40 \%$ to this last Chinese business partner from Shanghai and she kept $40 \%$ of the revenue for herself. The end of visits at stores usually ended with several purchases in accordance with all the requests received by the clients added to previous purchases from precedent days. At Rinascente Minzhe went around several stores collecting the booked merchandises that arrived and she payed. Very often there were at this points discussions about exemption from taxes (IVA) and expedition suggestions. The total of the purchases varied (from 1.600-2.000 $€$ to $10.000 €$ depending on the season). Minzhe checked the merchandises once again, making sure that she took the right sample. Then since Minzhe was a regular and trustworthy client the manager gave her a big discount on the merchandises (usually 5.000-6.000€ instead of 7.000-8.000€). To the price of the sample Minzhe adds 20 to $50 €$ for selling it in China. The reason of such low charge on the price was due again to the high competition. If Minzhe raised the price the client went to another buyer, since there were many competitors, therefore she decided to maintain the price low.

The transaction didn't conclude in that day since Minzhe usually went back some days after to do further purchases on the basis of feedback received from clients. Sometime Minzhe had moment of difficulties and risk at work, especially in the last 2 years when the business was not so high like in the past before the financial crisis of Shanghai. The Chinese people, she said, didn't have a lot of money to spend like some years ago. Some of them kept buying but the amount of turnover was going down. Before clients were buying a lot of merchandises without thinking so much about the details, now they bought more selectively and they were more careful with their budget. This required a much higher effort in selling from the side of Minzhe. As a consequence Minzhe had to reduce the amount of stores she was able to reach. Two years ago she was used to go to other boutiques in Switzerland (Fox Town), she had another buyer helping her and doing a lot of work on her behalf. Now on the other hand because of the fall on the demand she had to do it on her own. 


\subsubsection{The Organized Jeweler}

Heng $^{13}$ like Delun belongs to the i) most common category among Chinese entrepreneurs in the city of Milan of property-based businesses. Differently from Delun however Heng is more focused on the clothing sector. I had the chance to observe Heng from managing a clothing store during my visits of the Chinese

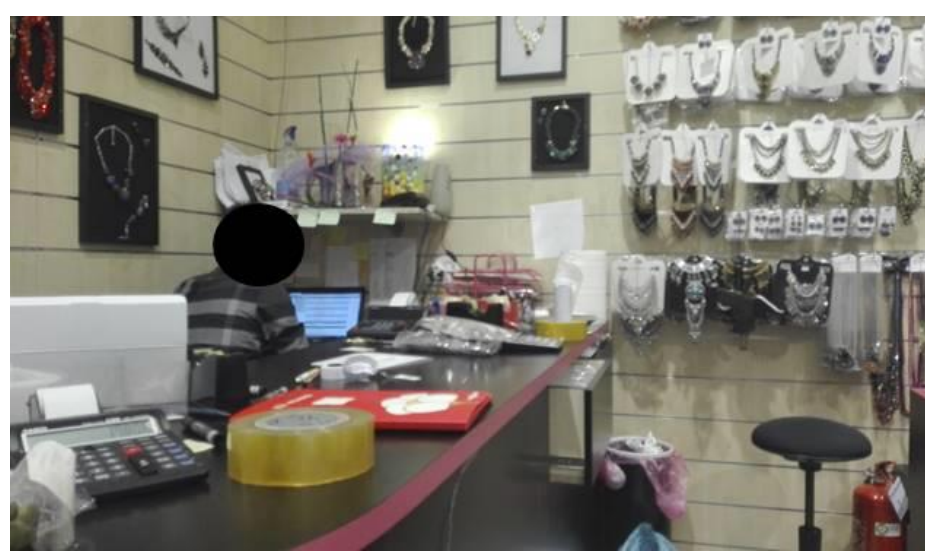
wholesale shopping center 'il Girasole' and after the opening of his new business in Via Paolo Sarpi, the China town of Milan. In his workplace Heng worked together side by side with his wife Nuo and his sister in law (Meixiu), since the first business was inherited from his wife's parents. Therefore Heng was part of a typical Wenzhouren family business in partnership with his in-laws. Heng started working for them in order to send or receive merchandises from China and to control the invoices, the numbers of ordinations, the contracts and the bills. Concerning the electricity, like many Chinese businesses in China town, he was not affiliated with Italian electric companies but with the famous Chinese electric company among Chinese circles (CHINA POWER). The founder of China power (alias Songhe) was friend of Heng, a second generation migrant that graduated at one of the best Universities of Milan, studied the electric sector for several years and then decided to open a company just for Chinese entrepreneurs living in Milan and in the surrounding area of north Italy. Added to this Heng also had a Chinese worker encharged to control, unpack and move the merchandises while Heng was working often at the computer making orders. Heng with his wife Nuo was more focused with this new business on the jewelry, although he already had some experiences in the same field at his first store. His jewelry store in China town compared to other same type of stores was more modern looking and clean. The fact of being a second generation worker helped him to have a more innovative perspective. Sometimes Heng had to exchange place with his sister in law Meixiu (Nuo's sister), going to the store at Girasole while she stayed in the Jewelry because of the absence of her parents traveling in China for business and family visits.

During my job-shadowing at Heng's Jewelry and at his first clothing store I had the chance to observe the same type of products wholesale for individual and companies at a reasonable price. Very often as soon as the client entered the door of the store Heng or Nuo asked always 'wholesale?

\footnotetext{
${ }^{13}$ Heng inside his jewelry store in China town. Heng spends a lot of time at the computer or unpacking the merchandises in the back of the store.
} 
We sell only wholesale!' pointing out to the sign on the window. In case the client was not interested in wholesale but in retail then he left. Nevertheless it was crucial for Heng to do only wholesale in order to have good quantities of sales and to make profit. Heng, differently from many Chinese entrepreneurs in the same area of China town understood that profit on wholesale did not depend on numbers but on the quality of products. The liquidity necessary to open both stores was possible because of the economic support of his mother and father in law, both entrepreneurs of first generation migrants from Wenzhou. Heng did both e-commerce and sold directly at his stores, then he spent a lot of time checking the website of his enterprise, taking elaborate pictures of the jewels with his professional camera to put online. In other occasions Meixiu, Nuo's sister, was responsible to take pictures of the products to post online. Heng used websites like Taubau to buy merchandises from China but unlike Minzhe he didn't sell merchandises in China since it was not convenient for his type of merchandises. On the other hand Heng spent a lot of time organizing and storing the merchandises (more than a thousand each day). His daily working activity started here from 09:00 AM to 07:30 PM while at his other store he decided, as he opened the new one, to have several salesmen in the previous one. Wing, one of them, took care of the clients. Despite his hard work Heng took also breaks for a snack during the day.

Both of the stores always had a lot of new arrivals so Heng spent a lot of time packing and unpacking the merchandises. The store also had 5-6 cameras in order to defect stealing and thieves from breaking in. Very frequently Heng, after booking from websites certain merchandises received calls, answered to some e-mails or visited the 'managing products recalls' to take the merchandises ordered. Heng had several suppliers and more or less the suppliers were the same for both stores. The person delivering the merchandises to the store was usually Chinese. It was an image often seen in the China town where those Chinese workers went from one shop to the other with their car or bicycle taking or delivering merchandises. Recently though, because of the improvement of the working conditions of the Chinese small businesses, this type of task passed on to Arabic migrants. The boxes were opened, Heng controlled the nature of it, its constitution, the reference code of it. Then some of the products that he was able to sell were put together in groups, ready to be shipped to the destination. Every box had a specific reference code that corresponded to a catalog were all the jewels were insered. Rings and necklaces were put inside specific containers in order to be exposed in the window.

His wife Nuo almost always worked together with him. During the period of my jobshadowing Nuo had a baby and in order to keep running the business Heng hired a Chinese worker to do the work of organizing all the merchandises in the store. Some merchandises were lifted with metal rods and hanged on the wall in exposition. Rarely the same merchandise was left hanging for 
a long period of time, in order to give the idea to the client of newness and continuous updating of the store. Part of the time was spend doing calls to providers or receiving calls from potential clients, both in Chinese or in Italian, in order to coordinate the times of delivery or in order to describe the details and prices of certain products. The majority of calls were from Chinese business people and friends to whom Heng passed contacts of Italian business people, gave suggestions for business or proposed some partnership for specific events. Sometimes Heng received voicemails from Italian great distribution clients from Milan interested in buying their products, having noticed the pictures in their online shop. Also, Heng received calls from clients asking for a delivery of the merchandise in several parts of Milan instead of the store. In those cases Heng asked the Chinese worker to bring it to destination by car and usually he tried to be as fast as possible. Generally Heng had a number of regular customers with specific requests. Those regulars (minimum 20) knew Heng's private life, were warm and spent a lot of time talking about the merchandises, coming to visit him, to withdraw new packages. Among them the main clients were simply other Italian store managers that brought Chinese products to their warehouses from Heng, the direct importer. Sometimes they came at his store during the week, asking for new arrivals, details on products of gold and silver, bracelets, new coloured merchandises made of zircon, necklaces, measures, especially during the spring-summer clothing seasons.

January was usually a favorable time of the year for his business because of the change in seasonal products (different colors, light or dark jewels). In this time of the year Heng was particularly busy adjusting all the new arrivals. The new arrival were put inside specific coded closet according to the type of jewels and the prices. The amount of merchandises to put in those closets was regularly very consistent. First the merchandise just arrived was unpacked

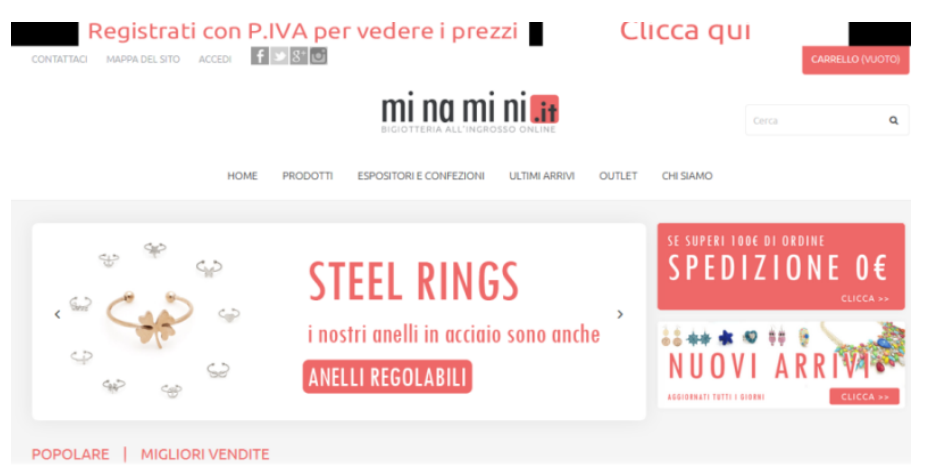
from the boxes to be put inside the shelves, inside specific wardrobes in the case of very precious jewels. Other merchandises were packed and sent to some client that bought them, specially through e-commerce and the website ${ }^{14}$.

Several websites were the target of Heng, websites for his work, websites to sell or websites of the providers. Heng had a specific brand for every type of product of jewelry in his store. Often there was bureaucratic stuff to organize so Heng spent a lot of time looking at the website of the

\footnotetext{
${ }^{14}$ Heng and Nuo's website of their jewelry store with the catalog of all products from both stores. Heng finds clients all around Europe through the new frontier of e-commerce.
} 
national tax office, controlling receipts and bills. Compared to the client face-to-face Heng gained much of his profit through clients online from all over Europe. For example he had clients from Germany that decided to buy from him since the prices were too high in Germany. Sometimes he received sudden visits from Dutch clients from Holland. The majority of his clients though came from Milan or from north Italy. The market was good according to Heng because people were willing to come there even from far away. This was because the products were of a better quality and Heng didn't sell the same kind of products that an European customer could find in other places. This kind of market was the guarantee of a good profit then. Usually the clients found his store through his website or through google maps, or just going around stores in the China town of Milan. There were other jewelry stores in Via Sarpi yet Heng had a modern looking store and high quality products that helped him to attract clients. Yet the outgoing relationship with the client and the friendship with the customer was missing in Heng.

Apart from that, Heng always gave me the impression of being organized and rigid, trying to keep everything in order. The work was done in couple with his wife Nuo, as she made some calls or fixed the prices as he was packing and unpacking the merchandises. The relationship with the client was usually very warm and kind. The client entered into the store and started to observe the different merchandises hanging (necklaces, bracelets...). Sometimes clients came to ask for a specific type of jewelry that was missing. In those cases Heng invited the client to look around to other Chinese stores or to accept to order them in advance. Heng explained the qualities of the products under attention of the client (crystal, silver...), and gave the exact price for each product (usually very cheap, 3-8 €). The store was a warehouse and many exemplars of a single merchandise were usually bought by the client. Usually the client tried to low the price which was already fixed and the ethic of Heng store was to maintain it as it was even if he was giving some discount on the final price. Then after choosing the merchandises Heng packed all the products and gave it to the client with the check-out payment (usually 100-400-1000 €).

Heng tried usually to be efficient, fast in his transactions, kind and thankful to the client. Heng usually had some regular clients that came to buy at his place because he gave a good discount to them. Right after the conclusion of a transaction with the client Heng was quickly back to work, opening more boxes, controlling more packages, checking the materials and cataloging them. The jewelry store also had an upper floor were the merchandise in excess was preserved. On the back of the store Heng had a warehouse where he kept the ordered merchandises. Heng usually moved with a basket to collect special ordered merchandises unpacked and set apart. Usually a time of the day was spent respectively by Heng, Nuo, Meixiu or the saleswoman using the calculator and the ticket machine to check the revenues of the day or to use the price machine to fix the prices that 
needed to be applied to the products. In both the stores of Heng the time was characterized by the sound of envelopes moved from one place to the other.

In specific periods of the year Heng took part to public fairs and exhibitions of his merchandises in the city of Milan. During my job shadowing I had the chance to observe him working four days at a two weeks public exhibition in Rho, a suburb of Milan. This exhibition was repeated twice a year and gave Heng the opportunity to increase his profit, added to the two stores he already managed. During this period Heng abandoned the store and came at the exhibition to work all day long with very little time for a break. It was very tiring for him to assemble and disassemble the merchandises at the exhibition. The part of decorating was very crucial for this type of job in order to attract clients. Because of the high degree of concurrence, Heng was challenged in taking entrepreneurial risk through participating in those events. Often as he worked Heng had a peaceful attitude, he worked with confidence in spite of all the tasks ahead of him. Since the environment in this case was the one of a family business the surrounding was friendly and relaxed.

After this first phase of observations through job shadowing among Chinese entrepreneurs in Milan I then started a second group of observations among others Chinese entrepreneurs from another sample. This second group of entrepreneurs under job-shadowing was composed by entrepreneurs that did not had any contact or affiliation with the first group. This process of selection was done simultaneously with the interviews of my case-control study with some specific contacts in the list of entrepreneurs that after having done the interview showed an interest and willingness to be observed in their work-place. The observations of this second group were done after the end of my first year of research and lasted for several consecutive periods for a time-frame from 6 to 10 months alternated by a period of analysis of the empirical documentation. In the beginning this process of selection of a group of entrepreneurs with no contact at all with the first group was very difficult, generating several rejections or practical impossibilities due to the specific context of work that did not allowed the application of a job-shadowing strategy. For example in public offices with co-workers or direct reports to superiors my presence was considered intrusive and not allowed. This was particularly clear in the case of Biming that openly refused to be involved in this practice. For what concerns the second group of entrepreneurs I was able to do job shadowing with the following Chinese entrepreneurs in a more consistent way 
TABLE 13: Evaluation chart for the second group of Chinese entrepreneurs under shadowing. The extension of the dark circle signifies the low/high presence of several key factors of economic success as I observed the entrepreneurs during the job-shadowing.

\begin{tabular}{ccccccc}
\hline & $\begin{array}{c}\text { Confidence } \\
\text { in his/her } \\
\text { skills }\end{array}$ & $\begin{array}{c}\text { reaction } \\
\text { to } \\
\text { challenges }\end{array}$ & $\begin{array}{c}\text { expression } \\
\text { of values }\end{array}$ & $\begin{array}{c}\text { Hard } \\
\text { work }\end{array}$ & $\begin{array}{c}\text { relationship } \\
\text { with the } \\
\text { customer }\end{array}$ & $\begin{array}{c}\text { Integration } \\
\text { with other } \\
\text { People }\end{array}$ \\
\hline Gho & & & & & &
\end{tabular}

\subsubsection{The Apprentice Salesman}

Ho arrived in Italy as a student and was son of an already successful entrepreneur living in China. Ho compared with many other Chinese immigrants spoke quite good Italian. During my time of interview with him and in the following months he started to work as a salesman in a chain of a multi-national company (Swatch, a company that realizes $20 \%$ of its revenue in China), a job that he was able to find through a work agency. The period of job-shadowing was composed of 6 months of observations during the international annual event of EXPO that took place in the city of Milan in the year 2015. Although his ambition was to become an entrepreneur like his father Ho did not started his career as an entrepreneur. Compared to Chun there was a clear differences in Ho's younger age and in his different migratory condition as a student then as a worker. Ho therefore did not have at the time his own business and he was not an entrepreneur already made up. Nevertheless during my research it was interesting to see his successive evolution as a marketing developer for a widely known Chinese company and boss of his own brand of fashion design. For this reason it was significant to insert him in the investigation and see his trajectory from being a worker to being able to invest his money to realize his own entrepreneurial project. His father in fact in China was boss of an important business in the field of construction in the city of Nanjing and he had a past history of strong involvement in business activities of all kinds: automobile shop, rice production company and several intermediary businesses. After graduating in Fashion Design in Milan Ho decided also to start his own company of fashion clothing together with a colleague living in China. They started their own brand created by Ho (SENZA), then his Chinese colleague was responsible to look for suppliers and potential clients in China. Differently than many Chinese companies of clothing Ho wanted to find a creative and new way of doing this business that didn't look like a typical Chinese 'copy and paste' company. His brand was a brand for high fashion clothing import-export. But on 
the side of this new project Ho was mainly working as a sales assistant, a position that many Chinese migrants of his new generation where acquainted with.

At his workplace ${ }^{15}$ Ho operated inside a team with other colleagues (at least 4-5 for every relay and the store manager all with the same uniform for a total of 13 workers). Some of them were Italian, others Chinese. The team always had a store manager among the more mature people that worked in this shop for a longer period of time. Among them one was a very diligent and hardworking Chinese saleswoman that, although being less outgoing compared with the Italian store manager, she was much more organized and systematic in her work. The store manager often went around and controlled that the salesmen worked efficiently whether in engaging with clients, explaining the product or using properly the checkout.

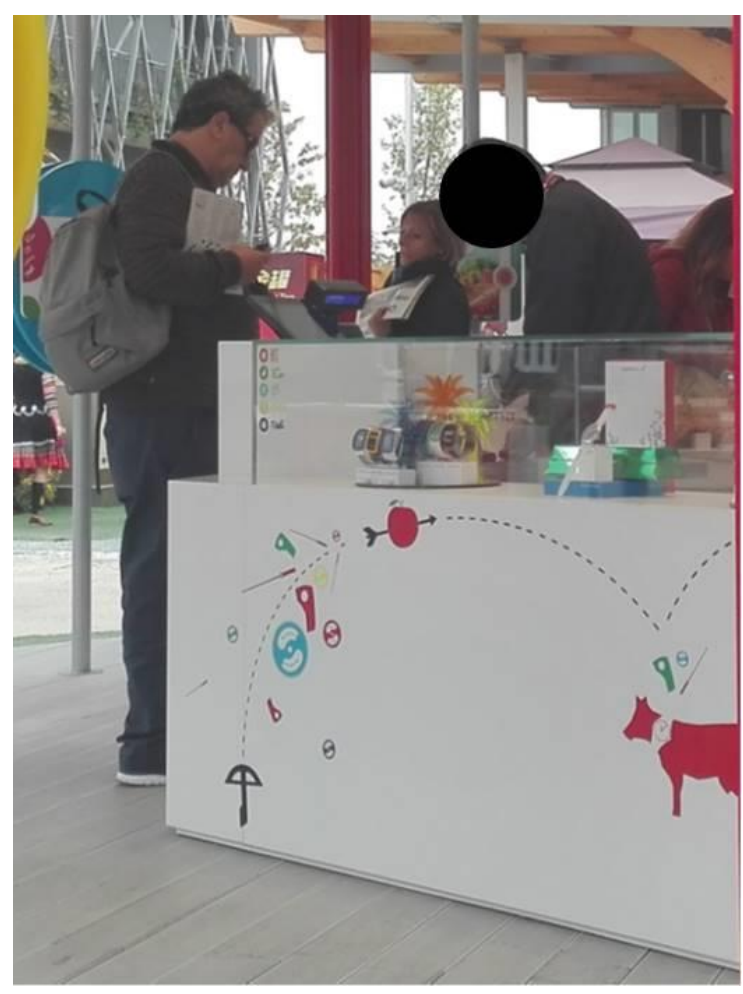

Another important role of the store manager was to encourage the salesmen in moments of challenge especially when a transition with the client didn't reach the conclusion. With new salesmen the store manager had to train them in the use of the store and on how to resolve problems. Ho usually had a good relationship with his store manager (both Italian and Chinese). He was not too rigid but friendly with him and talking often about several topics. The store manager was satisfied with the insistence of Ho with the clients. Compared with other Chinese colleagues Ho was much more effective although being less outgoing than the Italian colleagues. During a typical working day it was frequent to see the salesmen exchanging place with one another, coming and going, making shifts at work. As Ho approached the checkout with a client he talked with him about the guarantee of the product. Many of the people that came inside the store simply went around the store without buying anything.

His turns at work were varying from time to time (10 AM-1 PM, 1 PM-6 PM, 4 PM-11 PM). The store was an almost open place, rounded and at the center there was a column with a small warehouse where the watches were kept together. On the wall of the door there was a table with the working hours and shifts. Working together with Ho there were other Chinese salesmen and saleswomen. Ho often was busy going around the platform of the store, from one side to the other,

\footnotetext{
${ }^{15} \mathrm{Ho}$ at the counter after having exposed the merchandises to the client that decided to buy. Among his team Ho came out as one of the top best salesmen.
} 
stopping every person, with a smile, introducing himself, asking if they needed instructions on the products, showing specific models of watches as if he was involved in some sort of client-hunting. Once the client had interest on the collection of watches, Ho went to the counter and took a copy of the sample from the warehouse. Many times after the choice Ho asked the client if he wanted to see other products before the checkout. The purchasing went on very smoothly, a lot of people took and bought things without much thought. In this case Ho went to the counter, printed the receipt, gave a signature and quickly stamped the invoice with the warranty. Ho was usually very fast in serving the client and right after he finished the transaction with one client he was back at work going nonstop around and seeking new potential clients.

Many times though what created stress was that the clients were potentially interested but after minutes of conversations they decided to leave. This had a negative impact in Ho that was unsatisfied and stressed, moving his arms or scratching his head and chasing the clients with pressure and receiving little response to his offer to give help. In the real life Ho was a very nice person but under the work pressure he tended to have a lot of tension. Sometimes this was due even to the fact that some people didn't like to engage in conversations with Chinese foreigners. Other times the stress in Ho was caused by the high degree of competition among the sellers around him. In several occasions they were fighting over talking to the same client in two, three sellers or sometimes if somebody was introducing the client, the other worker was at the counter stealing the client from his colleague. When the store was crowded Ho went slowly and spoke with groups of people, trying to be friendly. Ho had to smile, he asked if they were interested in anything in particular and he made statements like: 'Good morning!' 'welcome!' 'are you together?' 'how can I help you?' 'do you need help?' 'did you visited the Chinese Pavilion here at EXPO?' 'are you interested?' 'are you looking for something in particular?' 'which one do you like?'. When finally somebody showed interest. Ho became then very excited. As he presented the product (sometimes more than ten different types of watches), its prices, its qualities and features (color, type of material, etc., ...) Ho showed them his watch, praising the qualities of it in order to engage the client in buying it. Ho followed the client around the store, he gave details after details, answering to their doubts and questions with no assurance that the client was finally sure to buy something.

This lack of assurance was creating tension in the side of Ho. If the client had a friend Ho tried to involve him too in the conversation, trying to be warm, joking, but also presenting the product with conviction. Compared with other Italian salesmen Ho was much more incisive. Sometimes people asked specific questions such as 'can I find the same product elsewhere?' or 'how much period of warranty there is?'. To those questions Ho needed to be prepared to answer quickly, he tried to answer in the most convincing ways. However, when a client was asking many 
questions, it didn't necessarily mean that the customer was really interested in buying. Ho in those occasions was frustrated and annoyed by their indecision. In other occasions those same people that left then came back again after 20-30 minutes and decided to buy from Ho, at his surprise. Very often Chinese clients, both young couples and old people, entered the store, since the store was located in front of the Chinese Pavilion at EXPO. This was a strength factor for Ho, since he started to speak Chinese with them. Ho knew their culture, he was able to relate with them and engage them in the purchase. Ho told me that the Chinese clients from Wenzhou were particularly direct and impolite. Ho came from Nanjing and, like many people from other parts of China, he had a low view of people from Wenzhou, as uneducated and focused only on money. Even though he had his suspicion Ho was always in contact with those Chinese people coming out of the Chinese Pavilion. It is for this very reason that Ho and other Chinese people were hired for this specific position.

During those occasions Ho was very anxious, stressed, nervous, his look was impatient as he tried to approach clients. He was trying to be able to stop somebody among the people passing by. Ho was stressed because he was trying to conclude a deal, to have some client that will stop and buy. Like him also the Italian workers demonstrated to display the same stress as sellers. Differently from them though, Ho was much more diligent, without having any break (except for drinking water), without ever checking his phone, spending all of his time trying to engage clients. The Italian sellers on the other hand, although being more outgoing, were chatting with each other, making jokes. Several times I noticed that as all the other sellers were talking with the boss and laughing with irony, or in a state of laziness and low professionality, Ho was the only one that kept on working. He did not associate with them but kept on reaching more clients and trying to do more even during idle times. It was interesting to notice that Ho's hard work disposition was not dependent on the control of the boss. Secondly Ho didn't have any direct economic benefit or commissions for selling to more clients, he could had just done what was enough, but he wasn't satisfied of it, and he felt as his duty to work hard anyway even apart from any direct advantage for him.

During my period of job-shadowing with Ho, he was promoted together with another salesman as 'the best seller of the month'. In few cases there was an exception to this when some Italian saleswomen were better able because of the language proficiency, catching the attention of the client, smiling and being kind, even doing a better job than Ho. Some of his Italian colleagues for example were in few occasions much more engaging than Ho, going even outside of the store to talk with the potential clients and inviting them to come inside and take a look at some watches. In an interesting occasion I had the chance to witness how some clients were interested in the merchandises but none of the team of sellers noticed it, although they were all looking forward to 
talk with customers. This lost opportunity was very significant and endured for several minutes until the store manager noticed them. Many times Ho had to stay at the counter repairing some watches that were damages and needed to be adjusted in measure, cleaned or replaced. In those occasions he often used an hammer, scissors, pliers or screwdrivers. In less than a minute Ho was able to resolve the problem. Sometimes he had to repair several watches at the same time. During this time he showed to be expert and precise in moving the different parts of it. As he was working in this specific task Ho smiled at the client, he had conversation with them, explaining the problem and trying to find a solution. This attracted the clients that often stood in attendance in front of him. It was interesting to notice that among all the salesmen Ho was responsible for this type of task much more frequently. Many times Ho had to serve several clients at the same time.

The store was often crowded, even during regulars days of the week and not just during the week-end. The people were coming at intervals of 40-50 people, since they were coming out of the Chinese Pavilion in different ranges. For this reason the store had a big movement and Ho talked with people of all kinds that were coming and going. In reality trough the working day there were many times were there was not a lot of people. In this situation of continuous change from too many clients to too few, it was not always easy to establish an equilibrium for Ho. Sometimes I witnessed days when Ho was working until the closure time (11 PM). In this occasion Ho was attending at the closure of the counter, in a moment of tension under the supervising of the boss. He had to count the cash and the receipts to estimate the selling of the day and then he had to do the reckon of watches in the warehouse. The economic turnover of this type of business was very high for the company. Sometimes there were situations of difficulties at work, for example when the counter and the tablets were not functioning properly.

After this experience Ho started his own company business in SENZA fashion design called SENZA ${ }^{16}$. The goal of this new brand was to open an import-export company of high fashion in Milan but with a Chinese target. Also Ho started to work as a marketing developer in AUMAI, trying to grow his skills in order to become one day a business owner (see Appendix). Ho once again was a special case for his young age, yet even if not totally formed such entrepreneurial spirit was present in him as well as in Minzhe that among the entrepreneurs of the first case-control group she was involved in a very similar business field.

\footnotetext{
${ }^{16} \mathrm{Ho}$ 's logo of his new business of import-export from Italy to China of high fashion clothing. 154
} 


\subsubsection{The Creative Barman}

Chun is a first generation migrant that came in Italy from Wenzhou to find a job. From 1998 to 2006 he lived together with his cousin. Then they decided to start working together. His cousin before opening this business was a waiter. Chun's wife was the business owner with her brother of a clothing store in Wenzhou. With the advent of e-commerce in Wenzhou however, Chun's wife had to change her business strategy and she started to use ecommerce. The value of stores in Wenzhou were dropping, exporting from China became too common, importing from Italy was no more convenient for her, since students or migrants of the younger generation bought those same products but without taxes (tax-free). As I mentioned before,

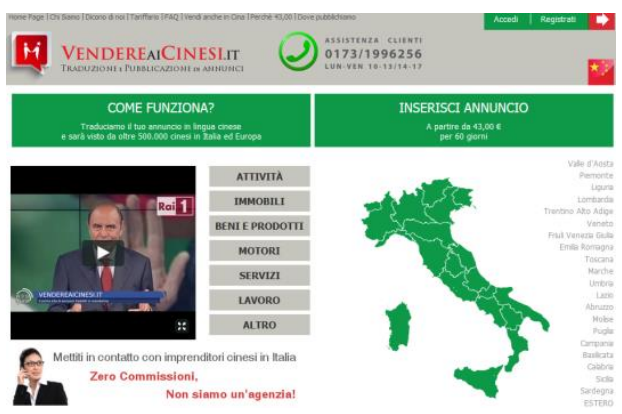
Minzhe in the same way decided to become a buyer. Because of the advent of e-commerce ${ }^{17}$ in fact Minzhe's mom constructions factory, as well as Chun's wife store, had to shut down and other businesses were barely surviving like Bingwen's parents factory. As I've already pointed out Minzhe perceived this change and she was able to adapt her business strategy to the 'internetization' of business. But there were stories of success even in this second group of entrepreneurs, mainly among the youngest generation like Chun, that was able to see the signs of the times and took action for bringing a change. Another example of this passage to e-commerce was the group of Chinese entrepreneurs revolving around Lei and Ning that in Milan invented a Chinese version of Groupon (GUUA) to help Chinese people living in Milan to find restaurants, goods, deals, through an App created by them:

I like creating websites since I was young, I then studied in Turin [city in north Italy near Milan] in a
Chinese company to create and maintain websites. I arrived in Milan in order to expand my business and
I created the Chinese Groupon named Guua. I want to connect stores and restaurants online. O2O (online
2 online) is already developed in China [...] and it will change business (Lei, Wenzhou, Milan,
$21 / 01 / 2016$ ).

Lei played a key role opening the market for business investors as a starting point for Chinese investments in Milan. Yet it required hard work for many hours and stress (sometimes until 4 AM) for him and the other two founders. This was done in order to communicate with clients and technical supporters in China or to respect the deadlines for certain sections of the websites. Even Guiying as an entrepreneur and a photographer had to adjust to those changes in the way business was done so he started to work for an e-commerce agency that sponsored several Italian brands

\footnotetext{
${ }^{17}$ A website recently created for those interested in selling their business to Chinese entrepreneurs living in Italy. In the economic crisis forces many companies to shut down and this system allow the survival and thrive of business entrusting it to Chinese buyers.
} 
(Casa Day, Geox, etc., ...). He found the job because he had a Chinese friend that worked in the ecommerce company. When she needed a photographic team she immediately thought of Guiying and his Chinese friends. Guiying had also to take pictures for superstars and newsletter during the 'fashion week' in Milan for both Chinese and Italian media, posters and collections for shoes, sweaters, etc., ... Guiying also developed a website that as an online platform tried to connect different Chinese people that wanted to sell products. This type of work though was particularly tiring for Guiying because he had to take pictures for more than 50 clothing outfits in one day using Photoshop. Despite Guiying works together with other 7 Chinese workers, it was still very challenging as a photographer while the traditional business of food and beverages sector with his restaurant was much more feasible. In this case, like Chun, Guiying was the owner of a food and beverage store, a Chinese restaurant, making true typical Chinese food, an idea that he got together with his friend.

Chun like many other Chinese entrepreneurs started a traditional business. He was just an observer of those changes and he was forced to change in order to survive. In this situation of difficulty Chun then in July 2011 started his partnership together with his cousin and an Italian businessman. In partnership with Luca, this Italian businessman that I will later introduce as an outsider for the second group of entrepreneurs, Chun opened his own bar and tobacco shop where he was co-boss and where he worked every day. Both of them gained from this business partnership since the Tobacco shop was property of Luca while the rest of the resources were given by Chun. In fact Chun still had to pay back debts to his family members and to his close friends that lend him money. Luca embraced Chun as a friend and business partner, although they were of a different ethnicity and they became to manage together their business despite the cultural challenges. The reality was however that Luca was taking advantage of the fact that Chun was willing to work long hours under any circumstances.

Chun's ${ }^{18}$ daily routine at work started at 07.30 AM when he left home to go and do some commissions buying the products for the bar in the morning. He went to the bank, at the post office and in other public offices like to his business consultant in order to resolve the bureaucratic matters and to pay the suppliers and monopolies. His cousin usually did the morning shift while Luca, the Italian co-boss, stayed in the early afternoon shifts until 5.30 PM. Apart from those family ties Chun didn't have an elaborate network of friends around him, so his daily routine basically rotated around the

\footnotetext{
${ }^{18}$ Chun working at the counter during my job-shadowing. Chun always has a line of clients to serve on a daily basis. 156
} 
bar. Then from 4 PM Chun went to the bar and started to work there until 09.30 PM (10-11 hours a day, sometimes 14 hours). Chun had specific suppliers for the products he sold at the store, he was putting a lot of emphasis on the right management of it. Sometimes people were coming at the bar to present their proposals as suppliers of certain products and Chun needed to evaluate the expenses. Mainly Chun worked at the counter of the bar, then sometimes he worked directly at the machines making coffee when his workers (several alternated in their schedules) needed to take a break for lunch. Compared to Chun the Italian workers were slower at the counter. Together with Chun his Chinese cousin worked every day at the counter with him and the Italian business partner that was boss with him of the store. Chun also has 3 workers that always stayed at the bar while Chun substitute them only in case of an emergency or illness. There was a conspicuous change in manpower. In the past Chun had 4 workers but he had to fire one of them because of the economic crisis. Chun often gave instructions to those workers as a boss together with the Italian business partner. The fact that the business owners were both Italian and Chinese increased the trust dimension for Chun. Even the old people, that usually didn't talk a lot with foreigners, they were very friendly with Chun.

The store was organized in a corner structure, it was a big store, very clean and inviting. One side had the bookies for lottery while the other side was the bar and tobacco shop. The space of the lottery had 3 different monitors to display the results of every extractions. The store also had two other rooms, one for clients to sit on tables and another for slot machines. Chun added also a section with home-made ice-creams while he decided to cut on the number of slot machines. This reduction of the number of slot machines to one third of the original quantity was due to the fact that many people were using online shops or playrooms open twenty-four hours a day. Together with the lottery, the bar, the tobacco shop, the ice cream and the slot machines, Chun also offered happy hours and food service at the tables. As he worked at the lottery Chun was very fast in giving tickets when there were a lot of clients. Especially when there was the extraction lottery the bar was packed otherwise the bar was less crowded. Chun also had to charge for the monthly and yearly pass of public transportation. For this reason at the beginning of the year or at the beginning of the month he had a large crowd of people to manage. For the lottery Chun had a lot to do, keeping the receipts, dividing between payed and booked tickets and sending them to the monopoly. If an accidental mistake was noticed Chun had to pay a fine of 200-300 €. For this reason the task required a lot of attention from his side, he had a lot of people, he needed to rush through his tasks, writing down the exact amount for each client making sure that the word he heard was correct.

The philosophy of Chun's business was that the more services he was able to offer, the more people were coming to buy, higher was then the number of sellings. In order to please the clients 
Chun examined often his merchandises, making sure that he had everything, every type of cigarettes and detailed types of coffee. This intention however had to face the limits of labor costs. Chun at work went around often with whole packages of cigarettes or with a paper list of merchandises that he needs to check. The people that bought cigarettes were often Italian, in few cases they were foreigners, while the lottery was mostly chosen by foreigners rather than Italians. When Chun was at work at the counter he lingered in talking with the clients that came. Sometimes Chun gave advice to his clients, offered favors, helped and gave directions. In some occasions and at certain hours of the day packages of merchandises came, for example cigarettes, fruits, drinks or many packages of products ( 10 or more boxes for each delivery). Chun then took all the merchandises and placed them in specific containers and closets. Chun chose the suppliers on the base of who offered the lowest price. Although being a foreigner Chun had a personal relationship with the client, he had a strong voice, he talked almost all the time and he was very talkative with the regular customers. He knew their names and he tried to put himself at their same level, imitating the dialect of Milan. Some regular customer stayed at the counter speaking with him for a long period of time. Some of the recurrent statements were: 'which one do you want?' 'what do you need?' 'what would you like?' 'I'm coming' 'do you want to play the lottery?' 'this cost...' 'anything else?' 'bye, thank you'. The clients at his bar were people from around the neighborhood that knew each other already and that came at the bar as a social place of gathering.

Chun was usually kind with them, the people knew him and did not just spent few words with him but entire dialogues about their lives. Sometimes he had conversations with them about working hours, expenses at the supermarket, discounts or taxes. He or his cousin changed turns frequently, depending on the number of people in line at the counter or at the betting shop. Chun never left the counter since there were so many clients every day, every minute. For this reason few were the moments of break for Chun at work. In fact Chun's role was the one of working at the counter on a stable basis, giving his best to save time for people and treat well the customer. As he was always at the counter he was very fast to serve the customers that came to him. He used the tablet for the lottery in one hand, then the counter for the bar on the other hand since his activity moved daily from the betting shop to the counter. He was often busy giving the receipts of the betting shop, working in pairs with his cousin even though Chun was the most talkative. When no client was in line at the counter Chun spent time at the phone, reading the newspaper or going to the betting store discussing with the people there and crying out loud the numbers that recently came out at the lottery, counting the lottery tickets. The atmosphere was the one of loud voices, exchange of ideas, resembling more to a community center or a party assembly rather than a regular bar. 
During the day I noticed how sometimes repeatedly the store was full of clients in line at the counter and then almost desert for a while. It was common to see Chun totally forgetting his clients in line especially when he was busy at the betting shop. Sometimes there were more than 5 or 6 clients in line while Chun was absent from the counter. Other times the line grew up to 10-15 people especially on Thursday, since the day of the lottery was drawing near. In those situations Chun tended to be more stressed as he tried to satisfy them. He needed to go straight to the point with the requests from the clients in order to save time of attendance to the other customers behind. As he finished serving one client Chun moved his feet in sign of impatience waiting for the next order. The clients usually were old people both men and women, sometimes families with kids or single young individuals from the neighborhood, living around the bar, on in retirement. It was difficult in this area to find new clients. Some people came for the lottery, some other people came to take a coffee at the bar section.

Chun had to face several situations of economic risk. The first example was when he and Luca took over the bar several years ago. Luca had to do a mortgage on his house while Chun had a lot of difficulties in understanding all the bureaucracy. In the beginning they had to transfer the shop from one side of the street to the other, then they had to face a lot of expenses. During my period of observations they were paying the rent of the place but they could not effort the loan because of the expenses. Chun had to adjust to the Italian culture, even in the way he was doing business, because of some of his bad reactions with the client, because of a lack of warmness with the customers. In particular Chun, like many other Chinese workers, was often very cold in his relationship with the clients. Staying at the counter he didn't even say hello to the people that were coming in, nor he gave any sign of welcome. Among the Chinese entrepreneurs like Chun there was a lack of being proactive, building relationship with the client, describing the characteristics of the products and giving the alternatives. Even if Chun improved from being a silent worker at the counter he still had some trouble in adapting to it. Because of this the clients, not feeling welcomed, or angry because they didn't received greetings, were leaving the bar. This was a big problem also because clients were varying in their requests, some wanted to be greeted, others didn't want too much warmness. Chun unfortunately was impulsive in his reaction to those situations.

Chun's cousin was even worse, almost a-social with the customers. He wasn't able to create that necessary bridge with the clients. The lack of smiles and 'thank you' at the end, which for the worker meant 'thank you for choosing our bar and not another one', it was resulting in the loss of clients. When Chun was explaining some products he was going straight to the point instead of engaging in explanations and social interactions. Luca was lamenting the lack of hard work of Chun, his negligence in cleaning up the place and its consequences on the revenue of the bar. Hard 
choices needed to be taken, especially when they had to fire a worker for the lack of revenue, then low periods of turnover in the clients represented a big threat to the business. Chun lamented the consequences of the economic crisis during the job shadowing. Particularly he blamed on the fact that the workers had the highest turnover, the contributions, the salary while he, as a boss, needed to pay high taxes.

In China Chun pointed out that a boss simply managed a restaurant or a bar without working directly, while in Italy the Chinese boss needed to work together with the workers and even more than the workers. Chun was then expressing his struggle with me concerning the payment of taxes for his business and his workers that were precluding any chance to make profit. Other situations of risk and difficulties for Chun came when difficult clients were around, dunked or hard to talk with. For example sometimes some clients were upset for a word or statement, so the circumstance required to be firm. Many foreign clients didn't speak the language well and this was causing many misunderstandings. Chun was particularly nervous in those circumstances, turning his face away, losing his patience and even if he was trying to interact with them he was still anxious. Several times there were situations of complaining from the side of the clients saying that they didn't received respect or attention. Chun usually didn't take part to the discussion, he didn't wanted to take responsibility for what happened. He had tension and was afraid to be blamed for the misunderstanding.

\subsubsection{The Italian-friendly Chinese Boss}

Guozhi $^{19}$ in many ways resembles Chun or Delun by the fact of being a bar and tobacco store owner of a second generation Chinese migrant from the area of Wenzhou. Guozhi came to Italy when he was only 10 years old. Guozhi's father was an employee of a bar, then after accumulating the necessary capital, he bought his own bar. Before it, his father, like many Chinese entrepreneurs, for 25 years owned a clothing store wholesale at Via Sarpi and Guozhi was working there together with his parents. In this Guozhi was more similar to Heng. A peculiar element in the bar and

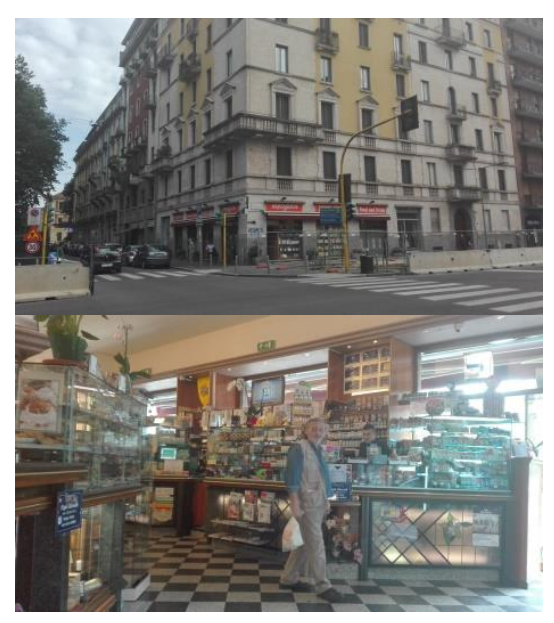
tobacco store of Guozhi was that, after bying the business from Italian entrepreneurs, Guozhi and his father kept the whole equipe of Italian workers. Many Chinese small businesses owner were

\footnotetext{
${ }^{19}$ Outside and inside view of Guozhi bar, Tobacco shop and Betting shop. The Bar is located in a very strategic crossroad of the neighborhood. 
following this stratwegy by simply absorbing Italian businesses in debt but keeping the whole structure as it was:

For me to work good you need the right people, not just saving, to work better you must invest, foreigners or not to have quality you need personnel of quality. The previous owner has selected, we kept them, we added then [a new worker]. Before I was working in the tobacco shop of my exgirlfriend, for my parents, and as an interpreter during exhibitions, then I opened an Italian restaurant in Shanghai but then I gave up and came back here, I sold. Also the clothing store of my parents at Via Sarpi working was different, more free hours, more quiet but it was a differend period, with the crisis everything changed (Guozhi, Zheijian, Milan, 31/05/2016).

Guozhi left his investment in Shanghai and came back to Italy because there was too much concurrence and cheating in his motherland. To have a business investment in Shanghai was very hard, trade was more brutal and it was necessary to be already part of the cycle of acquaintances. To survive in the business of Shanghai it was fundamental to have a joint stock company, a limited company. The market in fact was very different and Guozhi knew that there was no middle way: wether he would had died or won the whole marketplace with a new brand in due time, with the necessary money and connections. This would had meant trying to survive for at least five years of business then all the sudden flourishing and multiplying. Yet Guozhi decided to come back to Italy and to invest with his father in a new business. The work on the tobacco store of his girlfriend was for Guozhi boring, being located in a little small town and attended mainly by older people.

Nevertheless Guozhi tried to connect this professional experience with his family trying to convince them to start this same type of business. Because of the economic crisis in Italy Guozhi and his parents decided to sell their clothing store at Via Sarpi the Chinatown of Milan and started a business in a new field: food and beverages. Having obtained his Italian citizenship Guozhi could had autorization also to manage a tobacco shop and a betting shop. Guozhi started his working day around 6:00-06:30 AM going to open the tobacco and bar store. Then around 12.00 he went back home to eat, rest and then after 4 hours, around 04:00 PM, he came back to the Tobacco and bar store for the closing hours. At 08:30 he closed the store. On Sunday Guozhi only worked half a day. The bar and tobacco shop was located in a very strategic crossroad of two streets in a wealthy neighborhood of Milan. The adobe and furniture of the place was very Italian in its style. Usually the Italian workers were at the counter for coffee or at the tobacco area taking turns with Guozhi while Guozhi's father was at the betting shop. The Italian workers were on average very young in their age, at times they were undisciplined and noisy. Sometimes Guozhi's wife was at the counter with him looking at her phone and just killing the time. Guozhi had a very good Italian pronounciation, better than many other Chinese workers. Guozhi was very opened with the clients even though he was just going through the first months of his business. People already knew him and made friendship with him. 
The tobacco and bar store was just bought by Guozhi and his parents recently so the business, inherited by other Italian owners was already in place and in its initial stages. In order to start the business Guozhi had to ask for a loan from the bank and the big challenge for him was just surviving in order to pay the debts. Since the store was big and had many workers the moment was challenging for Guozhi. He had to learn to know his workers, how to cooperate with one another despite the different culture, how to get advice from them and to know the customers of the area. Guozhi's store had to offer the proper services, trying always to improve them. Guozhi knew that if clients noticed a loss of quality in the change of ownership it could have meant the loss of many clients. For this reason Guozhi always had to offer new and better services to his customers.

Another challenge in Guozhi's business came because of some renovation works right in front of the bar for the construction of a new underground metro. Those works of construction were going on for many months and many stores were loosing clients because of that. Because of the blocking of the street clients could not find a parking spot so they were not attending the bar regularly anymore. Guozhi had to attend a public reunion of traders from the area to signal this problem but he was lamenting how he received very little help from them despite all the expenses he had to bear for new machines and products. Under those circumstances Guozhi was forced to fire some of his workers and this was not an easy decision for him.

Guozhi was well aware of the fact that the generation of his father from Wenzhou was the first generation of Chinese true entrepreneurs and had to make harder efforts. Between the city of Wenzhou and little towns around Wenzhou everybody in the family of Guozhi knew each other wether through family links or friendships. If for example somebody worked well in the family, he brought alongside family members that from their part invited friends to follow the same business idea. In less than a decade the whole neighborhood of Guozhi in Wenzhou was composed by a network of traders involved in some sort of small business ownership. And from there this Wenzhouren model of business reached the rest of the world as many like Guozhi's family decided to emigrate in Italy. Guozhi had a big family of entrepreneurs: 4 uncles and 2 aunts were working in different parts of Italy, some in Bologna others in Rome. Some of them were small business owner of tobacco and bar store like Guozhi, but others had a clothing store. This role of Guozhi's family leads me now to introduce the last point in the analysis of the job-shadowing concerning the financial aid that these Chinese enlarged families, as well as other forms of network, are giving to Chinese business. Wether during difficult times or during special occasions like marriage, family plays an important financial role for Guozhi and other Chinese entrepeneurs. 


\subsubsection{A Process of Financial Network}

But how is the business commonly created among these Chinese entrepreneurs? Why is it possible to observe their rapid and exponential growth in many areas of Italy as well as in other parts of Europe? In order to answer these questions I spent sporadic periods of Job-shadowing among Chinese businesses in the area of Milan. During my ethnographic observations at Via Sarpi, the China town of Milan, Ah Cy pointed out how the enterprises of the area followed a common path in the creation of business. First of all three or more entrepreneurs having a relation of friendship or belonging to a similar network decide to incorporate themselves into a joint venture. Among those one plays the role of a founder (A in TABLE 14) that manages the firm, puts the initial budget and he is followed by other's support to this initial fund. The financial resources that the entrepreneurs put together through loans from family members of China are useful to avoid the use of loans from banks which will slow the process and make it harder. Usually somebody sells his business in China in order to guarantee his relatives in Italy to open a new firm. This was said by Giulio, an Italian worker collaborating with Delun, to be the strength factor of Chinese entrepreneurship in spite of any possible failure:

Their power is that they are many and they cooperate between the family, they give help to one another, they will never fail, it is hard that a Chinese is in loss [economically], they know how to manage the investments. Delun thinks always things in big, he never stops (Giulio, Ibidem).

Such reciprocity based on faith is also enforced by a traditional Chinese cultural pattern of social relationships (Guanxi). I will later further discuss the implications of the Guanxi principle for the thesis when I will analyze the Network explanation in the second case-control group. This structure was basically interchangeable in the sense that sometimes the family lineage was used to accomplish the same purpose like in the case of Jiahao, Yan and many others:

\footnotetext{
Relatives and friends help us a lot, from the weeding we had many gifts from family and friends, many were invited, we received large amounts from relatives and friends. Letters of wedding where high, 500-1000 euros with all the people we invited, we had a great capital, if I didn't invest had to give back to the next wedding. [...] I've found the workers through word of mouth, in the market we are like a family, among friends and family we present people to each other, and the workers themselves help me to find new workers when needed (Jiahao, Milan, Wenzhou, 09/05/2016).

I had a debt, I had to pay my relatives therefore I was working a lot. We continue to grow new businesses, the Italian goes through failure but we work 16-17 hours and we succeed. As the business reaches his autonomy we delegate, we change mentality (Yan, Milan, Wenzhou, 25/01/2016).
}

Yan in fact is the woman boss of two businesses. Like many other entrepreneurs, when her small business reaches a level of autonomy, she decides to turn it over to other Chinese workers as she starts a new one. People are united on the basis of favors and obligations reciprocally exchanged that often take the form of monetary loans (Ceccagno A., Rastrelli R., 2008). 
After a certain degree of development the Boss together with those founders that helped him in the initial stages decides to open a new business as he finds some cooperators that as substitutes will take over the original business (specially members of the second generation of migrants connected through a network) as they plant the new business. This strategy is very important for the first stages of a property-based business of the first type which is the most common form of business among Chinese entrepreneurs in the area of Milan. One of the many examples of it was pursued by Heng that left his clothing store outside of Milan in the hands of Wing and decided to open a jewelry in Via Sarpi leaning on the financial resources from his initial business for the expenses of construction, rent, taxes and lack of clients in the initial phase of the jewelry. It is in fact very hard to make any kind of revenue from a business for the first 5-6 years of activity due to construction expenses, taxes and building up of the portfolio of clients. For this reason every 4-5 years a new business is opened leaning on the profits of the previous business guaranteeing the sustainability in the first years of losses, in times of crisis and most importantly guaranteeing a capillary state of continual multiplication of businesses that leads to economic success. The greatest example of this is Ning's store that is part of 11 other restaurants in the area of Milan (see Appendix) and owned by Jiahao, with few Chinese workers in each of them:

To have a strong working team is crucial power and stability. In every restaurant I have people that I trust, I don't have to carrying it on by myself, I go according to the need, not everyone is new, then the others keep going by themselves. [...] I don't need to contact the suppliers anymore, every restaurant has his own entrusted person, that takes care of it in my place, I just have to manage it in the background, rarely I go visit my restaurants unless it is in the initial stages, but once they can sustain themselves I'm ok. Now the businesses can sustain themselves, I just need to manage them (Jiahao, Milan, Wenzhou, 09/05/2016).

As Jiahao started her business from family saving, every time one business was able to stand on its own she moved on opening a new restaurant as she entrusted somebody in the previous restaurant to manage it in her place. Despite the lack of knowledge of the Italian language and other issues, those networks of Wenzhouren hard workers with their flexibility and adaptation, working every day and sleeping only 4 hours at night, are able to guarantee an easy multiplication, are more prompt to face challenges and avoid failure. Yet Ning also wanted to clarify a change in the times where such quick road to success may be no longer possible:

Since the Laoban [Boss] came early twenty years ago, at the time there weren't as many Chinese as today, it was easy to grow, today is not that easy, everybody is selling and replicating (Ning, Ibidem).

Ning and her network of 11 businesses is not an exception but it clearly comes from investments that started long time ago and that today may be harder to implement because of the market saturation in Chinese entrepreneurship. After the passing of those critical initial stages however if the business results to be fruitful the Boss and founders of the business come back to their initial business and take over the business as Boss employing the cooperators $(\mathrm{D}, \mathrm{E}$, and $\mathrm{F}$ in 
TABLE 14) for the starting of a new business. This is a strategy often used by Chinese entrepreneurs. The number of people involved and timeframe may change but the model is still the same and it is what ultimately helped the Chinese entrepreneurship to develop and thrive in the long term in Italy and in many other European countries. Such results are partially confirmed by the literature on social networks and economic success (Egbert H., 2009; Kristiansen S., 2004; Loscocco K. A., Leicht K. T., 1993). Particularly this goes in line with the theories on 'relational embeddedness' where one cohort of successful companies seeds successive generations providing the financial, human and social capital to start new ventures through a system of cooperation, spatial proximity and transmission of technical and managerial know-how from one generation of firms to the other (Thornton P. H., 1999; p. 32). Such process also is not possible to function without including the family. Members of a family have a propensity to create small productive structures. Once established these structures tend to generate new units on the basis of the development of a new family nucleus. On a geographical level then those groups tend to aggregate closest to the location of the firms (Carchedi F., Ferri M., in Benton G., Pieke F. N., 1998; p. 275).

So this leads me to define here an important cultural principle underlying those economic transactions which is the one of Guanxi. Guanxi is a basic dynamic in personalized networks of influence and it can be best described as the relationships individuals cultivate with other individuals in terms of reciprocity and it is a central idea in Chinese society (Wong M.. 2007). What was possible to witness in Jiahao, Peng, Delun, Yan, Yi, Na's parents, up to big examples on a macro level such as AUMAI is this exact principle in action. Behind those financial circles and change of roles there must be a driving principle that is able to hold together different people and allow a fast and succesful multiplication procedure. Guanxi is the basis for such success in many of the entrepreneurial cyrcles wether they are based on family relationships or on associations. The person inside the network feels a compelling reason to reciprocate and therefore allows the circulation of financial resources and other forms of business investments among Chinese entrepreneurs.

Guanxi is also significant when it comes to estabilish its function as a producer of social capital. This doesn't actually means that Guanxi somehow substitute in all its forms social capital but most of the times it definitely is a producer of important relational social capital. There are definitely similarities and differences between those two concepts but it must be carefully considered how the Chinese guanxi somehow differs from Western preconceptions about social networking (Huang K., Wang K. Y., 2011). Both of them involve social relations but guanxi does not relate exclusively to social capital, it has more to do with interpersonal relationships that are particularly crucial when like in this case the focus is on small business multiplication. Guanxi has 
to do with the relationship between two or more people, direct particularistic ties where relationships are seen as an end in themselves and people are divided into categories, being treated accordingly. It is somehow actionated by gift-giving but then it becomes a long term personal relationship, pervasive in every aspect of life, including business. So guanxi-based business practices are mainly able to produce strong effective networks (Huang K., Wang K. Y., 2011). Within corporate environments this concept is often lost and leave the space to what commonly is defined as social capital (See also: Egbert H., 2009; Kristiansen S., 2004; Loscocco K. A., Leicht K. T., 1993; Thornton P. H., 1999; p. 32; Carchedi F., Ferri M., in Benton G., Pieke F. N., 1998; p. 275.).

So when someone may come to summing up the impact of network in economic success instead of focusing so much on the type of network, as I will later point out, what results to be more effective is first this underlying principle. Regardless of the type of network, if a Chinese entrepreneur is member of an Association, an House Church, Lineage or circles of friends, the field and other studies confirm that what is crucial for the achievement of economic success is the presence of such guiding principle of guanxi. Business multiplication and the activation of an effective network for business purposes is usually not possible, regardless of its ideological origin, without the proper activation of this sociologically relevant specific quality. That is why as it is visible from TABLE 14 the contribution to business tends to be higher in types of networks where relationships are already consolidated from a long time and not necessarly just because of other specific features of the single case. However the concept of guanxi carries its problems since it is mainly based on indirect forms of reciprocity that are often instable and operating in a context often self-interested such as business and carry other clear problems when is connected with destructive circles such as the Chinese mafia. 
TABLE 14: Illustration of the role of network in business among Chinese entrepreneurs under jobshadowing. In red the family, green the house church and blue external connections. Lastly the typical financial circuit behind business multiplication through network in the China town according to Ah $\mathrm{Cy}$.

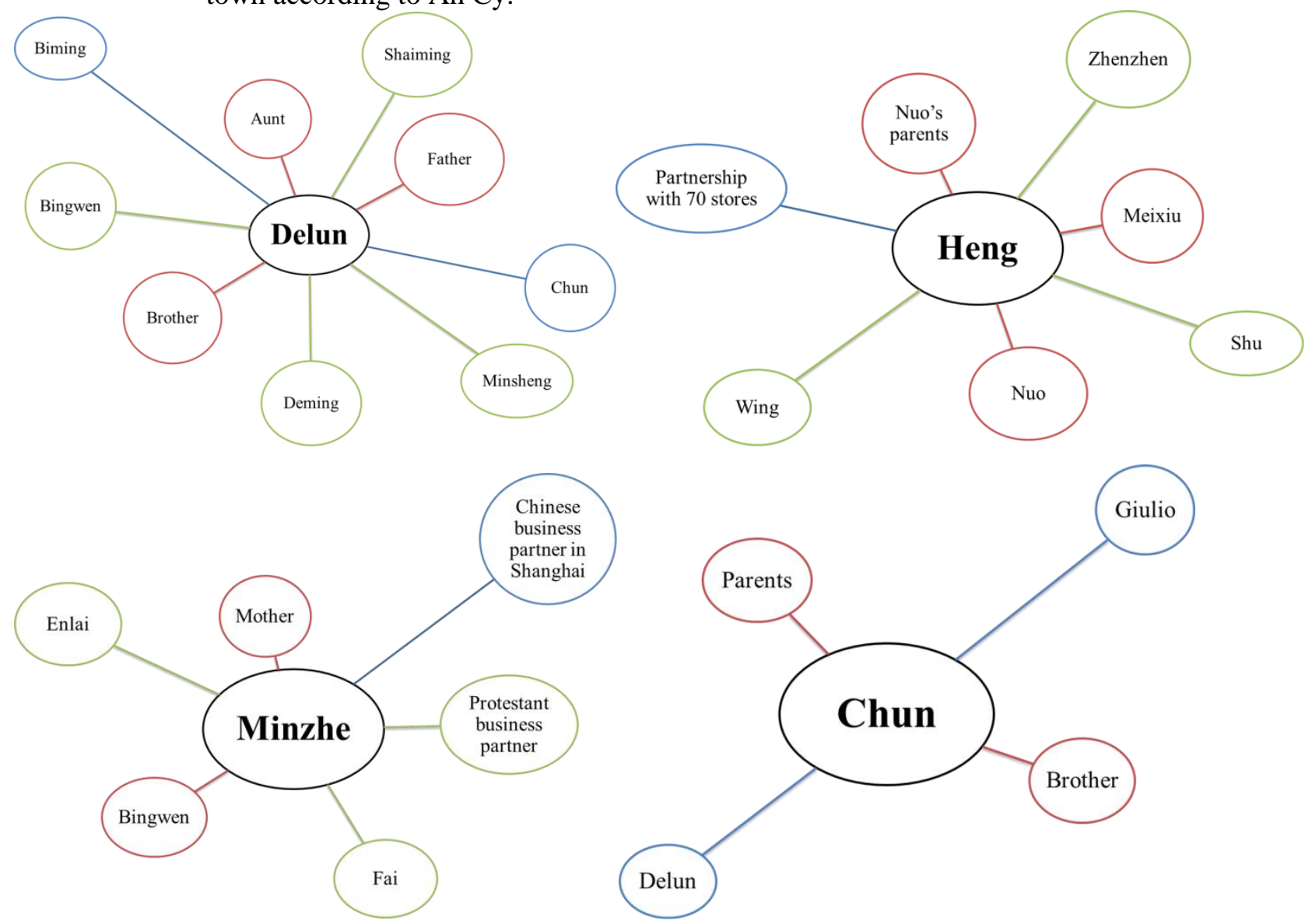



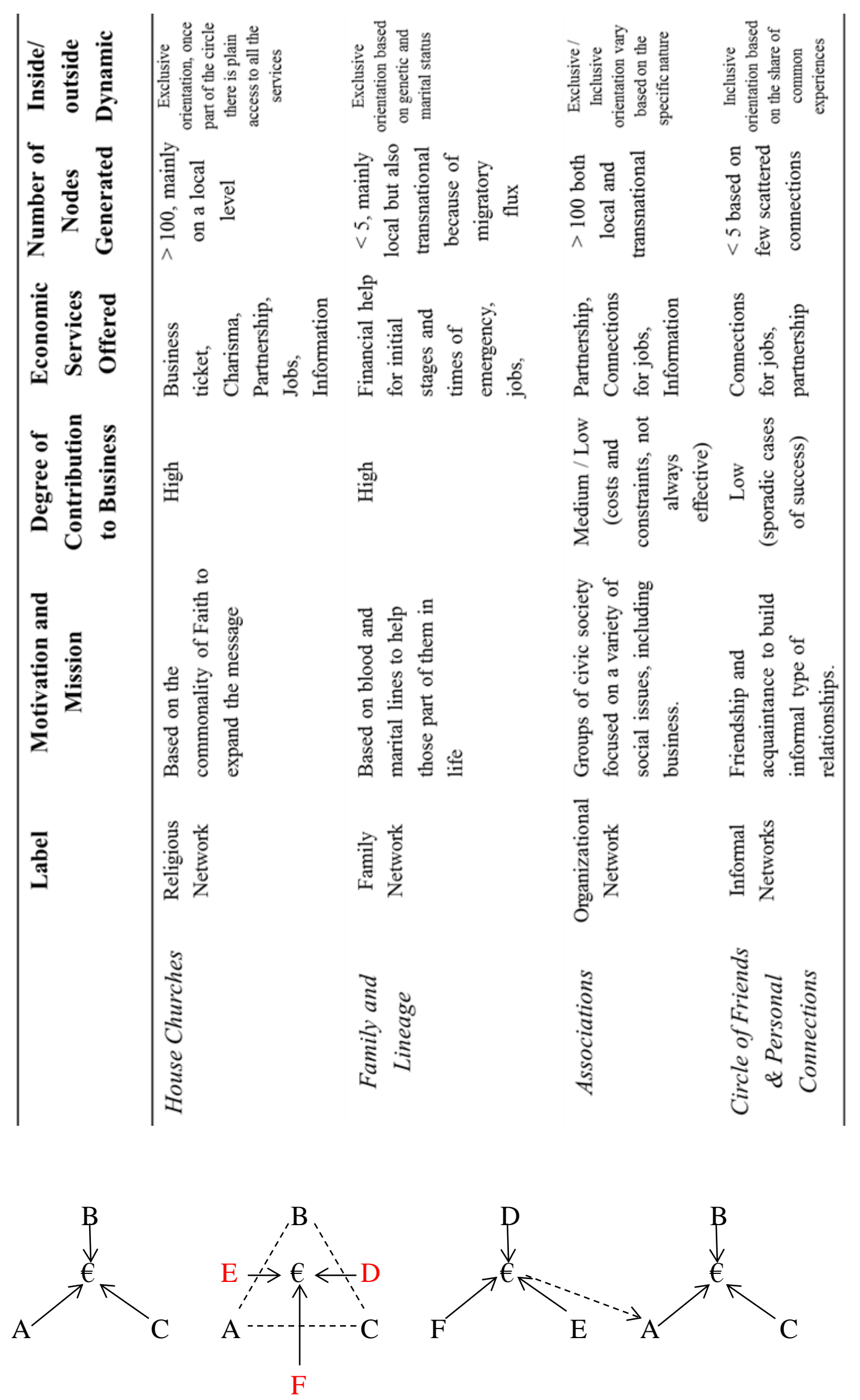


\section{PART THREE}

\section{THE CASE FOR (OR AGAINST) A PROTESTANT CHINESE WORK ETHIC}

«PRESENTATION OF THE RESULTS FROM THE FIELDWORK OF CHINESE ENTREPRENEURS WORKING IN MILAN, ITALY. REPORT OF THE ETHNOGRAPHIC RESULTS FROM OBSERVATIONS, JOB-SHADOWING AND INTERVIEWS IN LIGHT OF ITS PROBLEMATIZATION.» 


\section{Chapter VI}

"I will call them 'my people' who are not my people"

Romans 9, 25

\subsection{The role of Chinese Protestant Beliefs in Business}

\subsubsection{Introduction to the two Sets of Interviews}

During my period of ethnographic observations and job-shadowing there was an important element that needed to be taken into consideration: the fundamental centrality of the religious belief in the business practices. Those Chinese entrepreneurs in Milan apart from their ethnic origin shared something else with one another that was playing a predominant role in their daily work-life: the affiliation and identification with Protestantism. In the previous chapter I pointed out how among the several entrepreneurs under job-shadowing there were some significant differences on the way the business is pursued, on the way they reacted to situations of economic risk as well as on the way work is done. Those differences cannot simply rely on the application of different business strategies, accidental circumstances or mere coincidences.

To better understand how this works it is necessary to consider the personal and private sphere of those entrepreneurs, in particular their social identification with a system of beliefs, whether Protestantism in the case of the first three entrepreneurs under job-shadowing or other types of cultural, social and economic dimensions like in the case of the second group of entrepreneurs under job-shadowing. At first it might sounds strange to introduce such type of an argument in a scientific investigation, especially in the mind of a skeptic, since the economic activity operates according to its own laws rather than being affected by something different such as the religious belief. Taking into account this, because of its primary role in the work-life of those entrepreneurs and because of its deep connections with the business outcome it is crucial anyway to consider it even if it ought to be done as much as possible with a neutral and impartial perspective. As it will be clear from the next pages, the field tells us of the centrality of such argumentation even if it must be considered without question in light of many other explanatory dimensions.

This research in fact started with the enunciation of a theoretical argumentation that dates back to the roots of Sociology and went through major adjustments in the past decades. The question of the validity of my thesis in the contemporary realm requires, as I've already pointed out, the necessity of an investigation with the right method, on the right field, with the right information. 
So many times the reality is very far from the expected theoretical principles and as it will be clear from the field it may require a change in the premises. For what concerns the results on the evaluation of my research questions, after preliminary observations and the first set of interviews that I've already did in the empirical context with the different entrepreneurs, here's a list of the Christian entrepreneurs interviewed:

TABLE 15: List of the Christian entrepreneurs under investigation. The ones with the grey line were part of the job-shadowing activity, Mario and Giulio are the Italian outsiders.

\begin{tabular}{|c|c|c|c|c|}
\hline Nickname & Work Sector & $\begin{array}{l}\text { City/Region of } \\
\text { Origin }\end{array}$ & Age / gender & $\begin{array}{l}\text { Date of the } \\
\text { Interview }\end{array}$ \\
\hline Minzhe & Buyer & Shuzhou & $28 \mathrm{~F}$ & $12 / 09 / 2014$ \\
\hline Bingwen & Engeneer & Hangzhou & $28 \mathrm{M}$ & $12 / 09 / 2014$ \\
\hline Hop & Architect & Shanghai & $28 \mathrm{M}$ & $15 / 11 / 2014$ \\
\hline Heng & $\begin{array}{l}\text { Store Manager in } \\
\text { clothing and } \\
\text { jewelry }\end{array}$ & Wenzhou & $28 \mathrm{M}$ & $08 / 11 / 2014$ \\
\hline Huizhong & $\begin{array}{l}\text { Store Manager in } \\
\text { clothing }\end{array}$ & Wenzhou & $26 \mathrm{M}$ & $14 / 05 / 2015$ \\
\hline Jun & Travel Agency & Wenzhou & $30 \mathrm{M}$ & $08 / 11 / 2014$ \\
\hline Kong & $\begin{array}{l}\text { Shopkeeper in } \\
\text { clothing }\end{array}$ & Wenzhou & $26 \mathrm{M}$ & $14 / 05 / 2015$ \\
\hline Minsheng & $\begin{array}{l}\text { Business } \\
\text { employee }\end{array}$ & Wenzhou & $25 \mathrm{M}$ & $20 / 12 / 2014$ \\
\hline Shaiming & $\begin{array}{l}\text { Cashier in } \\
\text { clothing }\end{array}$ & Wenzhou & $23 \mathrm{M}$ & $29 / 11 / 2014$ \\
\hline Shing & $\begin{array}{l}\text { Boss of lamp } \\
\text { business }\end{array}$ & Wenzhou & $45 \mathrm{M}$ & $30 / 01 / 2015$ \\
\hline Shu & $\begin{array}{c}\text { Store manager for } \\
\text { multiple stores in } \\
\text { clothing }\end{array}$ & Wenzhou & $45 \mathrm{M}$ & $30 / 01 / 2015$ \\
\hline Wing & $\begin{array}{l}\text { Administrative } \\
\text { for multiple } \\
\text { businesses }\end{array}$ & Wenzhou & $23 \mathrm{M}$ & $06 / 12 / 2014$ \\
\hline Bo & $\begin{array}{l}\text { Shopkeeper at } \\
\text { Swatch }\end{array}$ & Wenzhou & $27 \mathrm{M}$ & $22 / 11 / 2014$ \\
\hline Delun & $\begin{array}{c}\text { Store Manager } \\
\text { for multiple bars } \\
\text { and cafe }\end{array}$ & Wenzhou & $24 \mathrm{M}$ & $08 / 06 / 2014$ \\
\hline $\mathrm{Nuo}$ & $\begin{array}{l}\text { Shopkeeper in } \\
\text { clothing }\end{array}$ & Wenzhou & $37 \mathrm{~F}$ & $30 / 01 / 2015$ \\
\hline Deming & $\begin{array}{l}\text { Factory } \\
\text { packaging in } \\
\text { clothing }\end{array}$ & Wenzhou & $27 \mathrm{M}$ & $08 / 11 / 2014$ \\
\hline Yongnian & $\begin{array}{l}\text { Store manager in } \\
\text { clothing }\end{array}$ & Wenzhou & $34 \mathrm{M}$ & $14 / 05 / 2015$ \\
\hline Meixiu & $\begin{array}{c}\text { Shopkeeper in } \\
\text { clothing }\end{array}$ & Wenzhou & $23 \mathrm{~F}$ & $30 / 01 / 2015$ \\
\hline Zhenzhen & Store manager for & Wenzhou & $40 \mathrm{M}$ & $30 / 01 / 2015$ \\
\hline
\end{tabular}




\begin{tabular}{|c|c|c|c|c|}
\hline & $\begin{array}{l}\text { multiple stores in } \\
\text { clothing }\end{array}$ & & & \\
\hline Zixin & $\begin{array}{c}\text { Shopkeeper in } \\
\text { jewelry }\end{array}$ & Wenzhou & $28 \mathrm{M}$ & $14 / 05 / 2015$ \\
\hline Enlai & $\begin{array}{l}\text { Store manager of } \\
\text { multiple stores in } \\
\text { clothing }\end{array}$ & Chong Qing & $28 \mathrm{M}$ & $15 / 11 / 2014$ \\
\hline Fai & $\begin{array}{c}\text { Factory } \\
\text { packaging in } \\
\text { clothing and } \\
\text { export }\end{array}$ & Yun nan & $26 \mathrm{M}$ & $22 / 11 / 2014$ \\
\hline$A h C y$ & $\begin{array}{l}\text { Store manager in } \\
\text { clothing }\end{array}$ & Wenzhou & $26 \mathrm{M}$ & $22 / 11 / 2014$ \\
\hline Ting-Ting & $\begin{array}{l}\text { Shopkeeper in } \\
\text { clothing }\end{array}$ & Wenzhou & $31 \mathrm{~F}$ & $14 / 05 / 2015$ \\
\hline Ah Lam & Trader & Wenzhou & $37 \mathrm{M}$ & $29 / 11 / 2014$ \\
\hline Guang & $\begin{array}{l}\text { Shopkeeper in } \\
\text { clothing }\end{array}$ & Wenzhou & $23 \mathrm{M}$ & $18 / 07 / 2015$ \\
\hline Ling & Neuro-physician & Baoding & $30 \mathrm{~F}$ & $29 / 05 / 2015$ \\
\hline Mario & Relator & Milano & $45 \mathrm{M}$ & $30 / 01 / 2015$ \\
\hline Xiu & $\begin{array}{c}\text { Boss of a factory } \\
\text { of LED }\end{array}$ & Pan Qsiao & $34 \mathrm{M}$ & $28 / 08 / 2015$ \\
\hline$Y i$ & $\begin{array}{c}\text { Store manager of } \\
9 \text { pharmaceutic } \\
\text { stores }\end{array}$ & Wenzhou & $45 \mathrm{M}$ & $23 / 08 / 2015$ \\
\hline Zhong & $\begin{array}{c}\text { Director of } \\
\text { English School }\end{array}$ & Pan Qsiao & $28 \mathrm{~F}$ & $28 / 08 / 2015$ \\
\hline Tai & $\begin{array}{l}\text { Boss manager of } \\
3 \text { kindergarten }\end{array}$ & Tangxia & $47 \mathrm{~F}$ & $26 / 08 / 2015$ \\
\hline Min & $\begin{array}{l}\text { Commercial } \\
\text { designer in a } \\
\text { factory of } \\
\text { furnishing }\end{array}$ & Wenzhou & $27 \mathrm{~F}$ & $23 / 08 / 2015$ \\
\hline$D a$ & $\begin{array}{l}\text { Boss in a factory } \\
\text { of printing and } \\
\text { packing }\end{array}$ & Wenzhou & $36 \mathrm{~F}$ & $25 / 08 / 2015$ \\
\hline Bai & $\begin{array}{l}\text { Boss of multiple } \\
\text { businesses }\end{array}$ & Wenzhou & $28 \mathrm{M}$ & $20 / 08 / 2015$ \\
\hline Chao & $\begin{array}{l}\text { Saleswoman in a } \\
\text { supermarket }\end{array}$ & Geu Xi & $32 \mathrm{~F}$ & $26 / 08 / 2015$ \\
\hline$N a i$ & $\begin{array}{l}\text { Boss of two } \\
\text { factories of } \\
\text { materials for } \\
\text { hospitals }\end{array}$ & Wenzhou & $41 \mathrm{M}$ & $24 / 08 / 2015$ \\
\hline Qiang & $\begin{array}{c}\text { Manager of a } \\
\text { bar/library }\end{array}$ & Wenzhou & $46 \mathrm{M}$ & $26 / 08 / 2015$ \\
\hline Xun & $\begin{array}{l}\text { Manager of } \\
\text { clothing store and } \\
\text { President of } \\
\text { WCMUA }\end{array}$ & Wenzhou & $46 \mathrm{M}$ & $22 / 08 / 2015$ \\
\hline Ning & Boss of 'Thien & Wenzhou & $47 \mathrm{M}$ & $24 / 08 / 2015$ \\
\hline
\end{tabular}




\begin{tabular}{|c|c|c|c|c|}
\hline & Hai' foundation & & & \\
\hline$Y a$ & Banker & Wenzhou & $43 \mathrm{M}$ & $23 / 08 / 2015$ \\
\hline Kun & Teacher & Wenzhou & $28 \mathrm{M}$ & $23 / 08 / 2015$ \\
\hline Zhi & Pastor & Wenzhou & $44 \mathrm{M}$ & $23 / 08 / 2015$ \\
\hline Hung & Pastor & Pingshan & $26 \mathrm{M}$ & $26 / 08 / 2015$ \\
\hline Yong & Pastor & Rui An & $45 \mathrm{M}$ & $27 / 08 / 2015$ \\
\hline$N i u$ & Pastor & Qing Tian & $46 \mathrm{M}$ & $13 / 09 / 2015$ \\
\hline$N a$ & $\begin{array}{l}\text { Worker at a } \\
\text { Clothing Store }\end{array}$ & Wenzhou & $20 \mathrm{M}$ & $14 / 12 / 2015$ \\
\hline Yan & $\begin{array}{l}\text { President of } \\
\text { Association and } \\
\text { Bar Owner }\end{array}$ & Wenzhou & $45 \mathrm{~F}$ & $25 / 01 / 2016$ \\
\hline Fang & $\begin{array}{c}\text { President of } \\
\text { Association and } \\
\text { Pastor }\end{array}$ & Wenzhou & $50 \mathrm{M}$ & $25 / 01 / 2016$ \\
\hline Giulio & $\begin{array}{c}\text { Chook and Store } \\
\text { Manager }\end{array}$ & Milan & $25 \mathrm{M}$ & $16 / 01 / 2016$ \\
\hline
\end{tabular}

Now I proceed examining whether it is possible to trace the presence or absence of the set of beliefs that I previously described in the model and if the identification of an economic success is due to that same ethos or to some other element in the field under my investigation. What will be presented in the following section is a deepest and more detailed definition of the cultural dynamics in light of the intention to check of the presence of any significant intervening element for the case of the Chinese entrepreneurs in the city of Milan, Italy. In other words, if the Protestant belief has some observable effect on the conduct of the individual, as I state, what is the degree of such effect for the case of Chinese entrepreneurs? My main expected result from the research was to see a positive effect after having checked the empirical evidence of the main theoretical argument: is the PAS able to impact significantly self-efficacy and therefore to favor economic success? From a first analysis of the interview materials of Wenzhou's entrepreneurs I may be able to move only in part toward the direction of giving a more answer.

\subsubsection{The Assistants to the Preconditions in the Field}

Those first findings reveal that those Christian entrepreneurs belong to evangelical churches (see group b of TABLE 5) that, first of all, hold the auxiliaries to the preconditions that I've defined in the model for the Chinese case. I was able to see the regular presence and emphasis on a dramatic conversion for any member of the church. This corresponds to the role of precondition on the Perseverance of the Saints typical of Calvinism. Also it involves a literal reading of the Bible with all of its implications in their daily conduct that confirms the role of Sacred Scriptures according to 
the model for the case of Calvinism ${ }^{1}$. One of them common in the explanations given by the entrepreneurs is the literal reading of the Bible and in particular the application of principles of wisdom from the Bible to their business:

From the Bible, the Word of Jesus, it helped me specially in life, first we need to be immersed in the Word of God, it gives you the meaning, because when you don't work you can rest and find directions (Zhenzhen, Ibidem).

During the shadowing and ethnographic observations I was able to see many cases where the entrepreneur takes the time during breaks or when there are not a lot of customers, to read the Bible, to listen to Christian radio, sermons, devotional books for practical application or, in the case of deacons and leaders, sermon preparation. Delun for example always had Christian

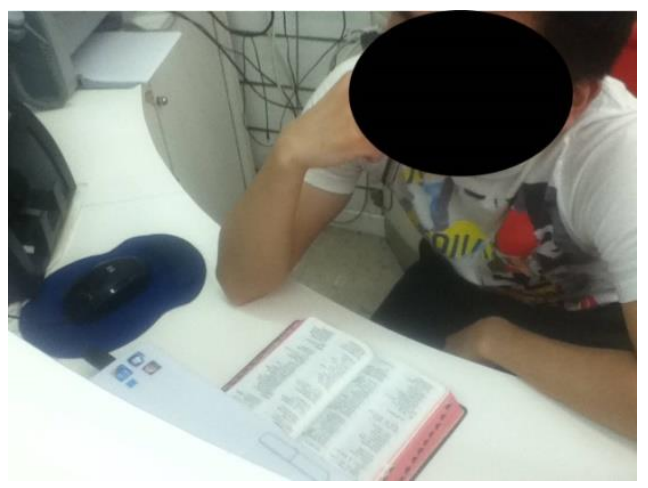
Chinese music playing at his bar as a way to witness through his business. Also Delun during my job-shadowing of his new business not only was very diligent in his work but he also spent 4 hours from 11 PM to 3 AM reading the Scriptures. Bingwen in the same way spent his hours of travel from his house to work listening to the Bible on his phone. All of those activities are ways in which they express indirectly their faith during business activity, something that gives them a meaning and purpose as they accomplish their daily tasks. During my job-shadowing of Heng I witnessed how he passed a lot of time using WeChat, a Chinese social network, inviting people to church events, preparing and posting Bible verses and questions for the weekly Chinese Bible study, listening Christian music at his workplace. Another of the preconditions that I was able to observe during the ethnographic observations is the belief in the doctrine of the perseverance of the saints. As I mentioned already, this belief proper to Calvinism survives today in this section of evangelicalism. Such belief gives the entrepreneur an emphasis on discipline, accomplishment of tasks and hard work, not as a way to control their state of salvation but out of a desire to grow in their faith. During the ethnographic observations at work I've observed this in their stress on striving for the fulfillment of their salvation with fear and trembling. Concerning conversion a dramatic experience is always stressed by the entrepreneurs as a common trend. Of special significance is the identification of the migratory process, with all of its challenges as a crucial element in re-enforcing the faith or causing the individual to embrace the faith in the first place:

I arrived here in 2009 since six years and I've got baptized here in Milan, now I know very well, before [in China] I believed a little bit but never so deep like it is now, I understand and I believe a lot (Zixin, Ibidem).

\footnotetext{
${ }^{1}$ Guang reading his Chinese Bible at work in his desk. The role of Sacred Scriptures is very important in giving the workers direction and purpose during their job's activities.
} 
Many studies have been done in Sociology and Cultural Anthropology on how the migratory process intervenes in the practice of conversion. Specifically for the case of migration and conversion to Protestantism among Chinese communities a study has been conducted for the case of Paris and France (Vendassi P., 2014) confirming such influence. But what I mainly want to underline here is how the dramatic conversion, that starts for Protestants with the acquisition of PAS, relates to the realm of work and, according to their biographical reconstructions, brings a radical change in the way they do business after such event. The entrepreneur sees a clear difference between his past life before acquiring the belief in PAS and his present life, also in the realm of work:

I saw changes at work since I became a Christian, those are things that you can't see but the more you feel them at work and in life, you feel that somebody is protecting you (Kong, Ibidem).

This dramatic conversion permeates every area of life and is perceived as a prerequisite inside the community. In other words if a Chinese entrepreneur attends the community but doesn't have such testimony of a dramatic conversion he can be considered even as an external to the social group regardless of his involvement or family Protestant background. All this emphasis pushes then the individual to activate a process of self-examination that I saw in action even in the realm of work. The entrepreneurs under shadowing, Delun or Heng were particularly concerned on the impression that their business life may have in front of the Christian community, they emphasized their struggles and how their belief in PAS helped them, they frequently shared their testimony of salvation and they were making a strong emphasis on business primarily as a God's blessings on their lives. In order to conform to the other members of the church the entrepreneurs wanted to give an impression of successful business in the eyes of the community. Nevertheless I witnessed some exceptions to this element into the field and also according to previous studies done in Wenzhou about the same topic. The Assistants to the preconditions for the case of Calvinism that I've mentioned before (sovereignty of God and anti-superstition) were present in the field, for example in Xun or Yi, but didn't have such strong role as the one of the belief in Millenarianism (emphasis on the return of Christ to rule one thousand years in Jerusalem) and especially the presence and role of a charismatic leader such as Shu or Zhenzhen, their role of leadership in the church and involvement in business which is nevertheless still included in the role of sects theorized by Weber. Also from several ethnographic observations and interviews I can identify the peripheral position of the belief in predestination, that was instead so crucial in Weber's interpretation:

[...] Many people think that we are predestined I don't think so. We are all sinners and with Jesus we are saved with His blood. I can change the future with the Christian faith (Delun, Wenzhou, Milan, 06/08/2014). 
This doesn't mean that this evangelical church doesn't believe in predestination or election since in my ethnographic explorations I've witnessed the presence of such belief, but it implies the peripheral role of such belief in the daily life of some individual and the absolute disconnection between this belief and a presumed state of perpetual anxiety. In fact concerning the potential effect of the belief in predestination, generally speaking in my ethnographic observations I've noticed a sense of predilection, a clear distinction between the believers and the so called 'pagans', the unbelievers, even when relating to other Chinese immigrants instead of a state of anxiety and frustration. This leads the individual under job-shadowing to feel special, different from the others, better, even when he was confronting with other Chinese people. This therefore reveals the presence of a state of being generated by the belief in predestination if not directly inversed at least very far from the anxiety theorized by Weber.

\subsubsection{Chinese 'Calling' to Work}

Coming to the main preconditions of the model through my interviews the presence of the $Y i$ Xiang, the Chinese Christian version of Weber's Beruf emerged clearly:

[...] If I have to choose a job all things are allowed but not everything is lawful. If you go in difficult places there is God but there are consequences, it is better to do a good work for you and God. To me being a businessmen in trade is lawful and you can obey God. (Bingwen, Hanzhou, Milan, 12/09/2014). To find a job the evidence is that I served in the church always up until today. In the beginning I served teaching students or other services then I felt that I wanted to be a pastor, I took a calling, if I open the bar it will benefit more people, if God opens this bar it is an opportunity to do the Gospel, God guided my steps (Bai, Ibidem).

In the words of Bai it is possible to see the progress of such calling in the life of the entrepreneur. First Bai thought to serve in the church but later, as he was multiplying his businesses he felt the calling to open a new bar, a place where he was able to respond to that calling through the accomplishment of this job. This belief is even sometimes unconsciously related to the realm of work and lead Bingwen to the search to find a job that will fit his spiritual driving-force. The believer, as Bingwen in this case, looks for a job that is in tune with his belief and all that he has to do is to discover where God wants him to work. Then he needs to display God's plan through his work. The job is perceived by those Protestant entrepreneurs as God's calling, it is in other words already arranged by God. The only duty of the believer therefore is to discover which is his particular calling in the worldly professions. During my visit in Wenzhou for example I had the chance to interview Yi a successful boss and also a pastor in a house church. Yi talked about this sense of calling that was fulfilled little by little through the expansion of his business:

I was often in church, I thought I was called to full-time ministry. In 2003 I thought I would spend all the time at church because there was a need for workers for the harvest that would reach out new 
believers, then I decided to transform my business into a multiple company with the help of some brothers from the church [...] (Yi, Ibidem).

[...] Little by little faith help us to know the kind of work to do, the kind of trade to open [...] (Delun, Ibidem).

[...] I'm not saying that I know for sure the purpose of my life, I'm still looking, God will prepare the best for us. (Minzhe, Shuzhou, Milan, 12/09/2014).

[...] I thank God because He found the job for me. [...] when I start anything I pray and think about those things $[\ldots]$ where I work right now is exactly what I was looking for, an international company, a door opened by God. (Hop, Tsinghua, Milan, 15/11/2014).

[...] Something has happened and God prepared the things for Him that He wants me to do. (Jun, Wenzhou, Milan, 08/11/2014).

[...] Before I had the job I prayed always God to tell if choosing that job. (Deming, Wenzhou, Milan, 08/11/2014).

Our life depends on God and what He sends me [...] I hear of people, you can't do too many things, our lives are special, they say 'I want to do this', but at the present how can you know? I've understood that God brings us into existence so that we manage, even at work, He wants that we manage (Zhenzhen, Ibidem).

Since I have the faith I work very hard, God let people have many jobs, some do business but God let me study working in the education and I work very hard for God not for myself (Tai, Ibidem).

How can such a mere metaphysical list of statements relate at all with their profession as entrepreneurs? What really interests me here is not necessarily the factual reconstruction of the event from the entrepreneurs or the validity of it but the interpretation of it. Delun and Minzhe that were under job-shadowing both, as they started their business, they seemed to have a clear idea of their job as something to be discover with the help of faith, something that is already prepared before them. Moreover, Hop, Jun or Deming sense that their job is just a response to a calling, a higher plan in which they are in and that can be disclosed only in trying to understand the kind of profession, the specific environment and the detailed tasks they know to be the clues for such discover. There's certainly no room for casualty here similarily to the deterministic interpretation of events in Calvinism.

There is also no room for a feeling of being forced to do a job that the believer doesn't like contrary to the surrounding context of non Christian Chinese entrepreneurs that will be described later on for the second group. Even when the job is hard or not exactly the best desired by the entrepreneurs I never heard them complaining about it or feeling in the wrong place. This belief, contrary to the case of the non Christian Chinese entrepreneurs helps then to give a purpose to their job and in sociological terms provides a sense of liberation from the Durkheimian alienation that often comes together with work in their post-modern society. The entrepreneur through this $Y i$ Xiang can't remain a passive victim of circumstances but he needs to identify concretely the kind of profession to choose through the personal investigation of a plan for his life ordained from above. The entrepreneur as in the case of Enlai is in a "training process" or in a continuous effort for the excellent accomplishment of his duty, in order to be in "God's schedule" as in the words of Fai:

[...] To sell and boutique was my target that I choose. Then I found the job. God took me as in training. I thank God to let me go in that difficulty. (Enlai, Chong Qing, Milan, 15/11/2014). 
[...] Right now I would like to be a businessman, to open a factory [...] I'm very happy that I am in the right way toward my schedule, answering to what God asked me to do. (Fai, Yun Nan, Milan, 22/11/2014).

[...] In this job I try to serve God [...] we have to grow and feel God how He directs us to what to do. (Ah Lam, Wenzhou, Milan, 29/11/2014).

At work I don't worry if there is or not a job because I know that God will give it to me and set before me according to his purpose (Shaiming, Ibidem).

When we do something we always first pray asking direction to God, if everything goes well we do that work, if some bad sign comes then we don't do that. I was in the retail sector and we prayed then decided to do that job [...] when I have challenges, if I have to choose a product or other things is God that send the client to me, God helps me to choose the right deal (Yongnian, Wenzhou, Milan, 14/05/2015).

Notice how words such as 'schedule', 'target', 'direction', 'purpose', 'choice', are highlighted in their responses to a neutral question such as 'how did you find this job?'. Those words speak of the detailed planning strategy behind their business which is so important in order to achieve economic success. Only later on this planning strategy and sense of calling for the realm of work is loaded with all its spiritual and supernatural interpretation. Nevertheless this belief, which is by definition metaphysical, achieves its factual role in directing the behavior of those entrepreneurs toward a reasoned and rational strategy so important in their business. Every choice in the case of Yongnian or Shaiming is under the complete submission to a plan that comes from above and nothing in business as well as in the daily life is perceived as been just fruit of pure chance. Also, is very important to mention the intensity of such belief in order to avoid a pure static interpretation of its role in their long-term economic activity. Particularly, in the process of trying to understand his calling the entrepreneur demonstrates to never be totally satisfied until he finds and responds to his particular calling as in the case expressed by Wing:

I've found a job first I was a waiter at the bar as service, when I came back to Italy I didn't want to do it then I prayed to Jesus that He could give me another kind of job and I've found it [...] as I came there I didn't know the boss was Christian (Wing, Wenzhou, Milan, 06/12/2014).

As it will be possible to see in the next pages very often the entrepreneur senses a progressive development of his business bottom-up, as was the American case of the self-made man. But the origin of such tension toward success here is not just fruit of some cultural trait or external circumstance, but it finds its ultimate origin in their spiritual interpretation. Wing is striving to find a better job that in his mind already exists, it is perceived to be ordained from high for his future, his only role is to believe and to go forward in his search. This element proper of the Yi Xiang is the great motivational ingredient able to push the entrepreneur to think big about his professional life at whatever level of it he may finds himself at the moment. 


\subsubsection{The Boss-Christian Phenomenon}

Another result of this belief is the constant presence of a vision for someone's life that many entrepreneurs have and that also reflects in the display of a Boss-Christian phenomenon (老板 Lăobăn). This strictly connect the analysis therefore with the second precondition. Delun is a good example of this, through my job-shadowing observations I was following him in the process of opening his third and fourth business. Delun can be apropos be considered a 'man of vision', he often told me of his vision both for his Christian community in China and for the local church in Italy, that he was serving and helping in order to find a building for it, Bibles, making consistent financial donations (over $10.000 €$ each month) for religious purposes. But also Delun has a strong vision for his business that he strongly relates with his faith, as an expression of his faith. At the same time he sees his proliferative business activity as a direct consequence of his answer to a call from above. During our trips with his car he listened to Chinese Christian music, and he showed me Gospel tracks that he shared with the people he came into contact with. All the logo's that he chose for his businesses have Christian underlying symbols or messages (see Appendix).

I also had long conversations with Delun about famous Protestant Chinese preachers like Stephen Tong, a Reformed Calvinist famous Chinese preacher that is responsible for large part of the Christian revival in Asia, and that Delun admires a lot. During his working activity, early in the morning or late at night Delun often had an headphone and as he was working he was listening to sermons of Stephen Tong for more than ten hours. This was said by Delun to give him strength to work harder. Sometimes at work it was common to see Delun praying or reading the Scriptures. When asked by clients if he was open on Sunday Delun answered saying that Sunday is an holy day so he will not stay opened as a sign of Christian identity. This not only gave him strength and motivation during his job but was most importantly a sign of his Calvinist ethic of work that he acknowledges and that leaves the client wondering. An example from my job-shadowing with Delun of the role of Calvinist ethos in his business came when Delun had to choose between several business activities to start. He prayed for a long time, he didn't know what to do, he didn't have any clues. Then he recalled the three questions that Stephen Tong, this famous Chinese Calvinist preacher that he admires shared once in one sermon about making decisions: i) does it glorify God? ii) does it contributes to others? ii) is it under the power of sin? For example Delun and Bingwen in their economic transactions at their new business sometimes had to face situations where people brought things that were stolen. In those circumstances Delun tried to maintain his ethical standard and to oppose robbery. Delun wanted to make profit but not at the price of the loss of integrity so he decided to honor God and he followed the Biblical standard of refusing to make business at 
someone's else expenses. The workers in the same store, compared to Delun and Bingwen, were very different. For example after some operation of trying to fix a phone, if the operation failed they immediately were concerned with their individual losses and refused to do again the job next time for the fear of failure. Delun and Bingwen had on the other hand the willingness to assume their own responsibilities, overcoming the fear of failure. And even if they failed in a job they will keep pressing on being more careful next time on the outcome.

Delun followed those Calvinistic principles and discovered that many people make business damaging others, practicing unfair concurrence, financial fraud or unfulfilled payments. In this case Delun made his personal stand and decided to open his new business with the fast food that from the outside it appears to be a regular store but that follows in reality a Christian agenda. Delun must not however be considered as the average example of a Christian Chinese entrepreneur since I was able to observe a wide range of differences both in terms of economic success and involvement in religious activities among those Christian entrepreneurs. Nevertheless I had the chance to notice that his identity as a 'man of vision', with a plan and direction for his business activity, can be legitimately related to his religious identity if not even consistently being stimulated by it. This attitude can be observed among many other entrepreneurs where the religious faith is by no means perceived to be in contradiction with work. In this particular form of inner-worldly asceticism the entrepreneur, having first identified his calling, pursues an accomplishment of the calling not through religious practices but through his professional life, a quality that for the case of Wenzhou is well known in literature as the Boss-Christians phenomenon:

\footnotetext{
Faith can help the business to progress. [...] The [Communist] government feel threatened by the West. An example of this is Christianity but the principles of the Bible can resolve the economic imbalances. After the economic opening the number of Christians multiplied, at Wenzhou there's a lot of Christians and Laoban [Bosses]. With the help of faith it contributes the business, it gives positive energy to people. [...] Wenzhouren go where other Wenzhouren are, they bring business and the Gospel. They are called Jews because they are good in making business (Niu, Milan, Qing Tian, 13/09/2015).

The clients that are regulars, my old customers, I keep them through friendship, sometimes they come and we speak about religion (Zhenzhen, Ibidem).

Sometimes I express my faith especially with clients who wants to talk but among our clients we have some that trust me and some that don't (Zixin, Wenzhou, Milan, 14/05/2015).
}

From what it is possible to see in those first words from entrepreneurs such as Zhenzhen or Zixin work is seen by them also as a platform to express their religious identity. For example during my job-shadowing of Delun and his wife at work I witnessed how the Chinese workers hired by Delun, although not being Christians were particularly surprised by the kindness, different treatment and quality of work that Delun was pursuing. Something was different in Delun if compared with a regular Chinese boss, something that was attractive to them and that involved his religious belief. In this there may be nothing special or different from a Buddhist or a member of another ideology that shares his personal convictions during his working activities with the social contacts he has. But 
what is behind this generic assessment is more interesting for the sociological argument behind it. Mainly what is interesting for me is first of all the profound connection that this expression of faith has with something profane such as business that usually by mainline religions is considered to be in complete contradiction with religion or at least in conflict with it. The interpretation that Ling, Guang or Wing give about their religious identity goes in the direction of an inner-worldly asceticism that is able to see the accomplishment of their professional life as a fulfilment of the will of God:

I have a boss who is Christian [...] some share the Gospel, help the workers and bring them to Christ. God convinced me about my ethic at work [...] God didn't want me to go out of the world but to stay in the world to know and seek people that are not Christians (Ling, Ibidem).

I work as a warehouseman and I think at work faith is a part, faith.. work is like God says you are in the world but it doesn't mean you don't have to work, it can't be missing (Guang, Ibidem).

I work in a firm and the "grandmother boss" is a Christian. [...] I work for Jesus surely I do my job but I work for Jesus [...] I talk and if there's the opportunity I share (Wing, Ibidem).

$[\ldots]$ therefore the two serve one another, to be a manager is very important in order to be a preacher [...] How to reconcile faith and money? Money can support the church, establish a biblical culture in the company different from companies around me. [...] We help missionaries that are dedicated to churches and foundations. I want that the company has values, I think it is very important to have this mission that very often many don't have. [...] it is an important resource of values, then I share this with other entrepreneurs. The Gospel and my company are balanced, I studied theology, business administration and I don't ask myself which is over or under, I want to meditate the two, some companies don't know the management, I suggest to learn it, I preached this morning about knowing the social, newspapers, web, to understand things (Yi, Wenzhou, Wenzhou, 23/08/2015).

I opened this bar-library [...] the government supported us even if they knew we were Christians. The Christians have big numbers therefore do business. [...] Many Christians don't understand, we want to create a bridge between church and society, influence the world around us. [...] When people enter into our bar-library we share our vision for this library with them, many people are interested to know us. Make it possible that they hear the Gospel is our responsibility. If they accept it or not God knows, we do our best this is our purpose to have this library. [...] Since we do so many social activities even the local TV and the newspapers gave a good report of us, therefore we have a good and big influence. We try to do our best to witness the love of God in a concrete way (Qiang, Wenzhou, Wenzhou, 26/08/2015).

Both Qiang and Yi for example apart from their business are also pastors in their churches. Their strong dedication to their business and the success they have must therefore be framed by necessity inside their personal religious convictions. The bar-library of Qiang has a customer service that many times surprises the customers, he offers often beverages for free and many books of his library have a Christian content. This peculiar interpretation of their religious identity at work can have therefore its effect in encouraging the involvement in business among those Protestant circles. I was able in fact to witness that among the church members the majority, if not the totality of them, both from the first and second generation of immigrants were involved in some sort of entrepreneurial activity. Another effect of this Boss-Christian phenomenon among those entrepreneurs that is important to notice and that is connected with the next precondition of the house churches is the reinforcement of their conduct, a tension toward honesty and to give the imagine of a respectable entrepreneur so important to create trust, respect and creation of a potential portfolio of faithful customers as it is expressed in the words of Minsheng: 
Compared to other colleagues my words are different, the things that they do I don't do them, in difficulties I pray, they don't pray. And my colleagues then know that I'm a Christian and they respect me, they are happy to know me (Minsheng, Ibidem).

God helps you at work but if there are righteous people then there is an intelligent hand, we must work for God, we help the church, the needs, the Gospel the spread of His Word [...] God changed my life even others can know we must share the Gospel for the unbelievers (Shu, Ibidem).

Again it is possible to see this almost 'maniacal' propensity in seeing the accomplishment of worldly duties as a response to their personal mission in Shu's words that differentiates those entrepreneurs from other common Chinese entrepreneurs and that was in fact what Weber defined in his sociological interpretation. Another important impact, perhaps the one that involves the thesis the most, concerning this Boss-Christian phenomenon, can be traced in the strive for economic success, efficiency and accomplishment of objectives, so important for the good result of a business activity and observable in the words of entrepreneurs such as Shaiming or Fai:

The reason for success in business is to have a good relationship with the clients, and in this my faith helps me a lot (Shaiming, Wenzhou, Milan, 29/11/2014).

The strong faith helps me in the job to work efficiently, I have to finish the job and do more. With faith and duty I can have success and passion and accomplishment of the purpose. Especially for Christians they have to set an example for others. [...] I would like to produce and share with them my faith, threat them well, grow together and let them know faith and love in the factory as example. (Fai, Ibidem).

Since some arguments may be brought forth for a gender distinction of such peculiar economic propensity that may explain why those Chinese entrepreneurs are so much involved in business it is therefore important to notice that a quite similar behavior can be observed for the case of women:

At work I try to be honest with the client, smiling, I offer coffee, the others notice that I'm kind and I do what I can. [...] first I was working dependent on others but now I came to Milan and decide to do this entrepreneurial investment. This because we weren't satisfied with our salary [...] Work brings life ahead, you are not a Christian and you don't work, people then think that we are lazy, we work hard but not with deception, even in order to differentiate from other non believers (Nuo, Wenzhou, Milan, 30/01/2015).

Christians [...] don't work on Sunday, they educate more the children through Sunday schools [...] we work as Christians for five days others six days [...] we put our faith in work, if the boss let us work on Sunday we say no, we obey the Bible to work (Chao, Ibidem).

In the past work faith made me honest, righteous with the client, the prices were raising up and going down but I was buying and somebody was having debts but not me, so I acquired the trust from clients. In the past doing business I bought materials and the price was low, the others saw this and they said that they were buying but then they didn't, however if we make a contract as Christians we must fulfill it, we don't act this way. After some years of purchases the prices raised up and we gained a lot of money. Therefore if a Christian does well his work he can gain a lot of money. My company dedicates $10 \%$ to the church, some shareholder are Christians and there is a good environment, the nonbelievers want to join us and then they become Christians [...]. There is a relationship between Christianity and business of Wenzhou, there are many Christian enterprises in Wenzhou [...] while the unbelievers [entrepreneurs] don't pay taxes (Da, Wenzhou, Wenzhou, 25/08/2015).

This I believe that only God can bring success, not me. If God wants then I can have success. (Minzhe, Ibidem).

I try to be more sincere with clients, more honest with the people that come into our business, first I was working in a factory then in a high technology factory and then we opened this store to become autonomous. My grandparents were Christians already so we are all Christians we all went to church and live out our faith (Meixiu, Wenzhou, Milan, 30/01/2015). 
Therefore the behavior of those Chinese women entrepreneurs can be considered to be very unique in their context that I had the chance to witness during the job-shadowing. Another important element to take into consideration is the secondary role of women in the traditional Chinese view of business whereas here I see their direct involvement in business at the same level of men as for the case of Minzhe under job-shadowing. Another interesting fact to notice as a confirmation of this strong inner-worldly asceticism is that very often the entrepreneurs that were not very involved in the activities at church, because of the necessity of staying open on Sunday or because they had unbelievers among their close family members, they indistinctly saw their faith to be in contradiction with their work. On the other hand those entrepreneurs that were strongly involved in church activities even in position of leadership as is the case of Zhenzhen or Shu, they didn't see any contradiction between their faith and their business. Not only that but generally they demonstrate to have better results at work, less difficulties and more economic success in terms of number of business opened, income and number of clients. Delun gave me a good example of the ethos that this Boss-Christian phenomenon was able to build in his life through a Christian association of entrepreneurs in Wenzhou of which he was member. The regulation of the association required to every Christian trade member to follow four 'golden rules' which outdistance the Boss-Christians from the average Chinese entrepreneur:

a) never delay the pay check for the employees. Usually many Chinese entrepreneurs decide to delay the pay chek for their employees of three or four months to have the money necessary to re-invest forcing this way the employee to be unable to leave the company whenever he wants. In this way the entrepreneur is enslaving somehow the people so this practice has been condemned by the Christian entrepreneurs.

b) Pay the taxes justly. Many Chinese businesses usually decide to avoid paying taxes especially in the name of the economic crisis so the Christian entrepreneurs decided to avoid such behavior disrespectful of the institutions.

c) Produce merchandise with equity. Many Chinese businesses produce merchandise at a very low cost so the quality and healthiness of the products is often absent. The Christian entrepreneurs decided therefore to avoid products that damage health, environment, trying to safeguard the origin of the product (against labor exploitation).

d) Don't engage in extra-marital relations. Very often, especially among the richest Chinese entrepreneurs the pressure for extra-marital relations is high, almost as a demonstration to be in step with the times. The consequence is an high rate of divorces and double lives. Therefore the Christian entrepreneurs decided to condemn such behavior. 
Those entrepreneurial practices are an example of good strategies to manage business and give an account for the distinctive identity of the Boss-Christians. In fact before anybody was leaving the place, whether because he was fired or there was some argument, Delun always gave a Bible, sharing his personal testimony of how God saved his life inviting them to read that book. Those were moments where he needed to make hard decisions, yet Delun always wanted to treat them with dignity. In one sense he was ready to rebuke the workers when needed with impartiality but he also did everything in the context of treating people with dignity. This process was particularly challenging when he had to transform several times his business. Also in his time under my job-shadowing Delun never delayed the payment of the salary even if the business was not necessarily doing good because it was a matter of rights of the worker. Many Chinese entrepreneurs in this context of economic crisis on the other hand were delaying payments and even posing threats to the workers.

However, before jumping in a too much romantic and optimistic view of this process it is important to consider the fact that the results were often contrasting. For example Bingwen in opening his new store with Delun was once coming back from China with machines that needed to be declared with customs duties. They almost got fined for this infraction of the international law. Cases like that and even worse came also during my visit in Wenzhou. I had the chance to do a focus group with some entrepreneurs that belong to the house church and to ask the opinion of the pastor on his part of regular counselling with the people he knew:

I saw negative things often among entrepreneurs, I don't notice any difference between believers and
unbelievers. They leave the creditors, they hide their profit before they go bankrupt or they transfer it
into other bank accounts. Many have illegal businesses, they practice usury, they are not sensitive to the
nature of business. Since the economy goes down, they take advantage of it (Zhi, Focus group,
Wenzhou, Wenzhou, 23/08/2015).

The picture that Zhi gives of the phenomenon is far from being optimistic. Even during my job-shadowing at times this contrasting feature came out. For example Minzhe lamented with me that sometimes she had to lie at work in order to make more profit. If she wanted to receive the same merchandises she already took in another store in town she had to lie on her real name because of the limits in the amount of merchandise she could take. It must nevertheless be considered that together with those bad examples Zhi still recognizes that the case still can be made for a positive side of the story:

Some other however are honest they prefer losses and clean the debts, even if they suffer a lot. They think about being righteous even if the local officials try to take advantage of them [...] Then there is a third type that do their job, gain trust and resist. [...] there are cases of Christians that live the faith and are strong in business (Zhi, Ibidem).

Together with these examples also the ethnographic observations during my visits at work show a similar emphasis on the conduct to hold outside the church, how to fulfill their spiritual 
purpose through the different tasks that they have to do at work. Their life-spheres of worship, prayer and work are put all at the same level, in order to be a "living testimony" according to their own words, in front of an outside world. Many of the conversations and interactions that I attended and listened were stressing the idea that there is a divine power working in each one of them, that all the success they accomplish must not be for themselves but for an higher purpose. It is this divine power that, according to their interpretation, does things through them and therefore they must give 'glory to God' through their job. I was also able to witness a strong emphasis on the right and best use of time, against laziness. Those are all elements that I already described before in Jonathan Edward's Puritan ethic and that finds its ultimate origin in the Bible.

This modern version of the inner-worldly asceticism involves therefore a constant selfexamination that, as I shall explain later, is also connected to the next precondition of the house churches. Such process of self-examination and control of the conduct that I will point out here among the house church system, not separately but in addition to the social network, is able to generate trust, respect, honorability from the side of those that buy products from those entrepreneurs, their suppliers. This generates a fertile ground for business transactions:

[...] faith helps me to become more fair, to become a right person in trade, more just [...] the Christian faith compels us to be loyal always correct [...] in Italian trade is not easy because everybody cheat [...] in the beginning I may lose something [...] but after a while you feel more happy inside [...] (Delun, Ibidem).

The people that I work with know that I am a Christian, I don't go directly to share the Gospel, but reacting with my acts and mentality they see it (Heng, Ibidem).

In my behavior and words I try to say to every business company that I am a Christian, my tone is more hearty, this helps me. Directly I share my faith (Xiu, Ibidem).

All my students appreciate my classes, some of them don't believe in God and I take the opportunity to share the Gospel with them. [...] I do my best, if I am efficient in the little things the parents will choose us [...] if a parent choose us he must trust me he must be there (Zhong, Ibidem).

I tried very hard and I wanted to be an example at work to demonstrate the love of God, it was a way of work that was different from others, I didn't curse anybody I didn't do anything nasty, I respected and honored people, I didn't complain. [...] The reason of success at work is God, the power of God, because when I was weak He was strong. For example He gave me wisdom to manage the relationships with colleagues, how to treat people, honor my supervisor and clients, how to succeed with colleagues. (Enlai, Ibidem).

I wanted to build education and connect it with the church we express our faith with the kids, the principles are based on the Bible, we teach them to follow the Bible, and the small kids come and we try to build good men [..] the reason for this business [success] is that God blesses as God blessed the Jews $[\ldots]$ in the kindergarten I can show Christ's culture [...] some people come to the kindergarten and they are not Christians but then they believe, even among the teachers, the families, the kids, we invite them to church I say to everyone that I am Christian [...] if I work hard the people will pass the word in the city (Tai, Ibidem).

In moments when I was doing other jobs there were dishonest clients and I thought this, unfortunately we have this sense of revenge from the devil, you receive something evil and you try to react in a bad and frustrating way [...] but at the end it doesn't happen like the Bible says you forgive the other and somebody will forgive you for the evil you have done (Kong, Ibidem).

For example during my job-shadowing Heng has several suppliers from China for the merchandises he sells in his two stores in Italy. Some of Heng's friends come from the area of the trade city of $\mathrm{Yu}$ and from Guangzhou. Those partners in trans-continental business with Heng find 
suppliers of products and are also there involved in a house church composed of hundreds of migrants from Wenzhou. Their commonality of faith becomes a factor of involvement in business partnership. Once again it is possible to see also its impact on the quality and professionalism with which work is accomplished that ultimately favors the economic success of their entrepreneurial activity:

[...] Success at work is given by the fact that work is acknowledged in its quality. Faith is for every job you do, if you do it for Christ you have success. [...] I don't work for myself, you see many people do less than I do, but I do it with all of my strength because I know that I work for God [...] I do things that my colleagues don't do and I'm different in a positive sense I don't follow the mass (Bo, Ibidem).

Success is related to honesty, if you cheat with a client he knows and don't come back, at Paolo Sarpi there are 300 shops, if he doesn't come to you he goes to another one (Ah Cy, Ibidem).

You need to have courage to open a new business, faith then gave us that courage. [...] you don't have to lose that trust, for us trust is crucial, we can lose money but we can't lose trust. We believe in God if we lose faith then the non Christian think bad: 'those Christians lose faith' (Yongnian, Ibidem).

Part of this inner-worldly asceticism features also a saving mentality that was the real key element for the capitalistic spirit mentioned in Weber's analysis of Protestantism ${ }^{2}$ as opposed to a mere love of money common to all mankind. Those studies, as I pointed out before showed that some of the beliefs proper of Protestantism push the individual toward the necessity of embracing a saving mentality so important for the advent of modern capitalism that the love of money in itself or the desire to be rich, proper of all ages, could not generate by themselves. This will be more clear as I will examine the results for the case of the second group. This saving mentality proper of Protestant Chinese people stands out even when described by the surrounding Chinese people sometimes. A good example that I was able to find is from the side of non Christian Chinese people such as Chu Hua that recalling her perception of Protestant people in China she mentions their saving mentality:

I know some Christians in China, they are different, they always work, they don't work just to have fun like all of us, they don't work to buy a new car, they don't work to buy fancy clothes, in this the Christians in China are different than us (Chu Hua, Heilongjiang, Milan, 28/03/2015).

Chu Hua makes here a very interesting point on the perception of Christians in China as economizers, savers, with their sober way of living and consistent work-centered life that finds its origin in the inner-worldly asceticism that I've described above. Although such statement was significantly made by a Chinese interviewed from the second group, it is still true that from the eyes of the common entrepreneur this is perceived sometimes as part of the Chinese mentality, not so much identified as a conscious result of their faith like for Kong:

We Chinese come from a land that is very realistic concerning money, there it is a land difficult based on money, we come to Italy because we have this mentality, if you move and you don't work, you don't

\footnotetext{
${ }^{2}$ See Weber M., 1930 [1905] for his analysis of it regarding Methodism or Benjamin Franklin and Wisman J. D., Davis M. E., 2013 on the more recent declines of such saving mentality in the American case. Also it is useful to compare it with Burkett L., 1990 works as an example of a contemporary application of those principles of Protestantism into business.
} 
make money, if you want to do less just stay in China. In Italy you find very often racism and we are here for our job, if someone tries to do less, he loses a lot of money [...] (Kong, Ibidem).

Around Wenzhou there's mountains and the ocean, we don't have natural resources, we are not a big city like Shanghai, we must do business if we want to survive (Min, Ibidem).

Among the factors of orientation to profit the geographical position of Wenzhou results to play a decisive role. Like Chu Hua many Chinese students that come from China to study university are not from Wenzhou and are useful in here for the understanding of an outsider perspective on this Wenzhou's business-oriented mentality regardless of the religious identification. A very interesting case during my observations in Milan was when I attended Bible meetings of students in their houses where Chinese students from different parts of China expressed their concern in being able to integrate with the Chinese people living in Italy (mainly from Wenzhou). In their mind the people of Wenzhou had a different way of thinking, more oriented to business, and it was difficult to relate with them for a Chinese person from another area regardless of their religious convictions:

\footnotetext{
The Wenzhouren are rich, traders, more ahead than us, they have basis to do business. Many in quantity. Before they were doing import-export now they do mainly food, and family is very important for them. [...] To me the Wenzhouren are more closed it is easier to enter in their group, I thought they came from another world, the dialect, they are very closed with students. [...] Hard work comes from culture, since I was a child, behind us our parents very insisting. They have a publishing house. Family pushes hard to work there are many people, to find a job you need to have something special (Jing, Milan, Chong Ching, 22/01/2016).
}

People from Wenzhou in Milan were part of the first migratory flow, already consolidated in their networks. The new more recent migratory flow of Chinese students coming from north China like Jie found it very hard to integrate with them and followed a different logic and business strategy:

We don't have a network, we are students, we come after the Wenzhouren, they have a different dialect and mentality, how things work, the culture, they are particular. The worker that works with me goes through a lot of misunderstandings, he doesn't responds, he doesn't understand the question. With other people is easier (Jie, Milan, Hebei, 28/01/2016).

The same was mentioned by Ho during my job-shadowing referring to cultural associations owned by Wenzhouren that were organizing meetings of Chinese entrepreneurs to which Ho was participating. During those meetings Ho felt like a fish out of water and noticed how despite his being a Chinese entrepreneur he was not considered one of them by the already established elite of networks. This is pointing me to the realization, that later I will analyze in details, of the possibility of a Wenzhou Profit-oriented mentality where the economic propensity can be explained not necessarily resorting to the religious factor but on a pre-existent economic propensity due to one or more elements that subsist in bot Christian and non Christian entrepreneurs. 


\subsubsection{The Role of the House Churches in Business}

Another precondition that can be found among those Christian entrepreneurs is the House church, particularly in its influence designed by Weber as the role of sects. The house church is framed in the bipartition of Protestantism in China that I've already mentioned above between the official church (TSPM) and the unofficial churches (house-family churches). Although in the Italian context of relative religious freedom the emphasis tends to be bland, its role in shaping the conduct and the social relationships, which is what interest me here, it is still there. Those entrepreneurs belong to an evangelical church that is basically an house church simply trans-planted in the European context. Their members during my ethnographic observations tended to always emphasize their detachment from the official church of China, perceived as an "apostate" church weak in its doctrine and unable to assure the presence of true converts. This bipartition very close to Weber's distinction between the official church and sects is the object of concerns from the Chinese communist government because the house church is difficult to control and is today spreading everywhere. During my visit in China however I had the chance to visit and interview people belonging both house churches and TSPM. Hung is a pastor of an house church and he travels between several churches in an environment of persecution and threats from the government. He also points out how the Boss-Christians help substantially for the finances of the church:

\footnotetext{
if some businessmen wants to support us we are more than happy, we let them build the church, more people come to church and more people can know God. The building is high and the cross visible, therefore they want to tear it down. [...] I was there when they wanted to destroy the church. They took the car licenses plates and interrogate the Christians [...] every time the government says something different and contradictory. The people are put to jail and beat. [...] They come late at night or early in the morning like thieves to steal the cross (Hung, Pingshan, Wenzhou, 26/08/2015).

The people from the house churches don't speak with us from the TSPM even if now the situation is getting better and we try to defend ourselves. The TSPM church must obey to the rules of government, what you preach must be in harmony with the social dimension. [...] The government wants to do something bad, they will remove crosses by force, they will order to obey to the government, they will make pressures on Christians, if you have a business they will threat you to be fired. [...] Before they were saying that it was a problem of spaces now they destroy everything even if you abide the rules. We have no security, we don't know when the government will come (Yong, Rui An, Wenzhou, 27/08/2015).
}

Yong on the other hand is a pastor of a TSPM church but he suffers the same type of persecution from the government. His church has received threats to remove the cross and he has been several times in jail even during the time of my personal investigation with him. Therefore a climate of persecution was in the background of our conversations. Many Christian bosses are helping financially the church but this creates a potential threat for the Communist government that decides to fire those workers or to damage their business. Because of the silence of the media and the long time of separation from their motherland, the Christian entrepreneurs from Wenzhou living in Milan have only a vague idea of the seriousness of the situation. Delun during my job-shadowing 
recalled how in China many churches have the intention to promote the involvement of Christian bosses in financing building, organizing meetings of commercial fellowship and share business opportunities with its members:

\begin{abstract}
For the Chinese government the Christian church now is a threat, I always have experienced intimidations and even persecutions but the Christian faith even though the Chinese government does not allow us... doesn't want that we grow, we grow anyway incredibly [...] in China there are two kinds of churches, the one recognized from government and the one who's not [...] the one recognized must declare to be independent from foreign associations, they must love the homeland [...] that they don't have any contact with western people and then there are those not recognized from the Chinese government, they call them house churches that are private organizations [...] (Delun, Ibidem).

[...] In Shanghai the same church there are 12 ramifications, it was an house church, family church, 5070 people, not state church, in a private house. And maybe every six months the believers of all churches will get together, 500-1000 people, a wonderful moment [...] I shared my work experiences, we will pray to God and ask God. [...] when I went to church they motivated me shared their experiences, I was encouraged and I came back home that I wanted to grow. (Fai, Ibidem)
\end{abstract}

This last element from Fai about 'motivation' introduces the reflection to the reason why the house church model is significant in sociological terms and not just for religious or political reasons. Those small-group communities function in many ways exactly as the role of sects that I've defined before in Weber's formulation. Apart from the encouragement that Fai received through the adherence to such social groups, in the same way any other social group may work, he was more specifically led to "grow" in his spirituality as well as in his conduct in life and business. The house churches, as the sects at the times of Weber, are crucially important because they uniquely are able to foster a control of the conduct, "being the right person", enhancing a process of auto-affirmation, a strive for quality and charisma in order to receive good reputation (being "trustworthy") and rewards (such as "work together"). As it will be clear in the comparison of this social group with other cases that are able to serve for similar purposes of trust-building regardless of their religious connotation, the house church has among its functions the one of a social network but it is not limited to it. What I intend to emphasize is that this process starts with an internal process in the individual that belongs to this specific type of communities that cannot be replicated in any other type of network and that influences the economic success much more than the social network dimension of it. It is possible to identify the details of this internal process in dynamics such as the self-examination before becoming a member, the support of a common goal, the selfexamination of the individual in order to be the 'right person' but more importantly here it is often brought in their professional life projecting the same qualities in the realm of work:

The church at work helped me to remain calm without anxiety because anxiety can't resolve all the problems. I've always prayed to have Jesus near me. I would like to get baptized but I think I didn't learn enough. When somebody get baptized must understand all the rules and someday I do some mistakes (Shaiming, Ibidem).

Christians really helped me, they come to greet me or they pray for me, when I have some questions they answer me and help me if I don't know how to do something at work (Huizhong, Wenzhou, Milan, 14/05/2015).

Christians helped me at work and in life, in difficulties, we talked with each other, we will get together and I've received counsel from them for major decisions (Zixin, Ibidem). 
I have received no direct help from other Christians but in daily life yes, even just a greeting, will encourage me, it makes me understand that we are multiplying as believers (Kong, Ibidem).

The community of faith [...] in the end helped me a lot to be a right person, to be a just person, the other people understand you when you are trustworthy, that they can work with you, then when they see that you don't want to take advantage of them, that you want to be loyal, you want to be just, for you is a lasting feeling, because you gained their trust, people trust you, then there is a greater approach that push you to start a business with other people that trust you and this help me, because if you say you are a Christian this helps you [...] the people say that they would like to work in business with Christian individuals, nevertheless they will not take advantage of me, they are sincere, they are sincere people [...] (Delun, Ibidem).

Together with this positive influence on the behavior Delun introduces the analysis to the another that the house church also plays. Its role is very important in giving a useful identity mark for the outside world especially in the realm of business. Belonging to an house church results to be like a 'business card' for the entrepreneur, guaranteeing in other words the building of a climate of trust and respectability that is very useful for business, exactly as Weber defined in his analysis. Here it can be found a clear corroboration of the Weberian role of sect from the entrepreneur's own words that can further my understanding of what more practical role their religious identity may have in enhancing the business of Zhenzhen and Shu:

The clients that comes I speak about Bible and religion [...] this helps me at work because they see that is not just the relationship of business but also the friendship, this is my future, is very important, the customer that comes I'm not anxious to sell or earn money (Zhenzhen, Ibidem).

Religion gives you respect, you believe in God and in Jesus Christ then it means you help others in anyway. When I had God helping me I've success, you help others and you live His plan (Shu, Ibidem).

Lastly but not in terms of importance the house church inevitably plays a role in the creation and use of an internal social network, made of strong and weak ties that are very important in the business world. A consistent current of thought already pointed out the absolute centrality of social networks in order to build trust and exchange of information. But if the commonality of faith among those individuals is so often associated with economic interactions someone may say that it is precisely because of the already existing economic interest and motivation to profit that a person decides to instrumentally join the church and embrace those network resources that are able to bring economic success. There is a need to understand whether an entrepreneurial person creates a successful business or a successful business creates an entrepreneurial person. Following this suggestion it is precisely because of the economic interest that someone will embrace the religious belief with a 'justification logic'. In theory of justification propositions and beliefs are understood to certify certain actions by providing a reason for them (AA. VV., 2011). In this sense the religious belief has the purpose to merely justify, not to generate, a behavior that is already in place. I will examine some of the correct implications of the 'justification logic' in the fieldwork later on in the study. The reality of the matter however is that it is a much more dynamic and complex relation across time and space between economic interest and religious affiliation counting also the role of external structural influences. Embracing a rather deterministic view that sees the identification 
with this religious network as only instrumental to profit is to be discouraged. It is true however that in Europe, as in the United States, new waves of immigrants from Asia tend to struggle to improve their economic status by adopting a religiously legitimated ascetic work ethic. Religious groups involved in migration patterns with a distinctive ethnic and regional origin as the Protestant Chinese entrepreneurs from Wenzhou, often occupy different niches in the labor market and at that point it becomes difficult to distinguish between the religious motivation and the motivation for profit.

In the Chinese context the case can be made for the Protestant faith to be in a certain sense a mean of 'rationalization', a source of motivation to economic success that in some cases was already existing in the individual but that neither the traditional cultural values nor communism were ever able to foster. The fact of the matter is that the results of the field and the existing literature on the subject require some clarification. First of all, social networks, as I've already pointed out, do not bring in themselves economic success, on the contrary sometimes even hinder that economic success. The only thing that can be stated, as I will explain later, is that social networks, whether those with religious connotation or those without it, are able to favor the 'survival' of a business but not necessarily the economic success of it. For that specific function individual strategies and personal sources of motivation seem to play a more decisive role. And that's the unique added value of the house church compared to any other generic social network. Secondly, it is not always the case that a person joins this type of network just for the economic benefits that he can get. I've already pointed out how generally those that identify with this type of network do that despite the risks of persecution and sanctions from the communist government. The entrepreneur that join the Christian church may as well lose its business because the Comunist government could decide to confiscate or shut down his business. The identification with the house church network therefore goes far beyond a mere calculation of costs and benefits.

Nevertheless it is true that the social network of the church sometimes may be just an instrumental mean for the flow of business activities. The house church provides several crucial additional network resources that need to be taken in mind. First of all the network of the church results to be crucial in the first stages of someone's professional life or for the start of a new business. Bo testified about members of the church that had the intention to open together a new business, or in other cases one member of the church hired the other and decided to work together with him. This last case has been observed specially for the case of the relationship between the first and the second generation of immigrants. The house church works then as a social organization made by experts that are able to give advices to the entrepreneurs, providing contacts with other Christian entrepreneurs to whom people can talk, meet other companies managed by Christians in Milan that help people living still in Wenzhou. 
Another important role of the network provided by the church involves the stage of development of business. It is possible to see this in the description of Deming about an association of Christian entrepreneurs in Milan of which he is part of and that connects together people that are doing different businesses, or that graft new people arrived in Italy desiring to start a business. Another important case of the role of house churches as a network for business was witnessed during the job-shadowing of Minzhe. Minzhe works as a buyer in Italy of expensive fashion products to sell in China. During our time-frame of observation she decided to connect with Enlai in order to establish a partnership. Enlai, living in China, was able to provide and manage the clients needed for Minzhe in Italy. Minzhe on the other hand had to provide the products from different stores in Italy. Enlai came to Italy during a period of job-shadowing that I was doing with Minzhe. I often had to translate messages and e-mails that Enlai had to send to different managers here in Italy, asking to meet them, see the new merchandise, finding a good deal, find out the eventual possibility to be tax free passing through Hong Kong for the transportation of the goods, etc., ....

All this trust (xinyong) between the two was possible because of their connection with the same house church in Milan. Furthermore during their visits to different stores in Italy they decided to go to Tuscany for a business exploration with another businessmen from the Chinese church in Milan that was in contact with Minzhe since a long time. Here too the commonality of faith given by the house churches was an important element in guaranteeing a bridge useful for their business. This third Christian entrepreneur was a common friend for Minzhe and Enlai and all three persons involved were sharing different contacts with other Chinese stores and Italian stores without which it would have been difficult to grow their business. After their several visits to different suppliers during their daily tours with me, Minzhe and Enlai were having a regular planning meeting in order to structure their business strategies for the future once Enlai would had gone back to China.

After the visit of Enlai in Italy Minzhe also contacted Fai, that at that time was living and working in China. Minzhe decided to involve Fai in his business in order to develop a bigger portfolio of clients in China. Together with Fai and Enlai another Christian entrepreneur was contacted by Minzhe for this reason. The commonality of faith provided by the identification with the house church in the case of Enlai, Fai and this other Christian entrepreneur was for Minzhe the requirement of trust in order to establish her personal network of business partners in China. They all started their business activity through a common conversation through social media in meditation of the Sacred Scriptures, they often pray that their business will be able to follow the spiritual directions of their common faith. The religious identification, as at the time of Weber, is still a 'business ticket', a source of trust and a flow of information among those Chinese 
entrepreneurs, in accordance with the social network explanations from the mainline sociological theories.

Also, from the ethnographic observations with Ah Cy that I introduced before (see TABLE 14) it is very important to mention here that the type of structural strategy oriented to the multiplication of businesses is very similar, if not identical in its form, to the religious strategy proper of the house church model (as opposed to the traditional building-oriented form of church planting). The house church is oriented towards a multiplication of small groups of faith, and goes sometimes hand in hand with entrepreneurial transactions as members of this network are connected through religious interactions. The house church then promotes a circle of information about work vacancies and opportunities, a tension toward multiplication and it becomes an instrument for the establishment of business partnership, very important for the achievement of economic success:

[...] together with other brothers and sisters we created a website for Christians and work. The shareholders of my enterprise are my relatives, 600 workers all Christians, if somebody introduces a Christian he is welcome into my company [...] The Christian enterprises establish social enterprises, they are sensitive to profit but also how to help others. There are many foundations to whom the company is entrusted. (Yi, Ibidem).

The work that I'm doing right now is for a brother of the church, I worked because we got together and agreed with a brother to work together for that person [...] it helps me to be more confident, we are friends other than colleagues (Bo, Ibidem).

I came in Italy to work, I've found it because in Italy there was a lot of Chinese [Christians] (200) my sister has a store and I worked as a saleswoman. The husband of my sister was the first that came to Italy, in Florence, they let them work in a factory then he searched by himself and he found in Trieste, a lot of Chinese, many Chinese arrive there [Prato, Florence] then they go somewhere else. The family helped me to find a job, the church introduces too the job, if somebody is a boss takes and assume workers in church (Chao, Ibidem).

My father is the owner of this business. My parents started 10 years ago here [Chinatown] this year at Cernusco [suburbs of Milan] they opened a new store. [...] The church helps in the first years I arrived and they helped me [...]. Before 2005 we opened factories, difficulties were not on the salary... the church provided help. (Na, Milan, Wenzhou, 14/12/2015).

I started this activity ten years ago with several Christian [business] partners [...] three Christians in particular helped me to build three kindergarten, we work together since six-teen years. In the beginning was difficult but we work well together because we grew, we are very united. The most important thing is that we are Christians and this connects us (Tai, Tangxia, Wenzhou, 26/08/2015).

There is a circle of connections between Christian entrepreneurs, we have the laoban [bosses] fellowship, and our church was doing a fellowship of laoban, connected one with the other (Da, Ibidem).

I'm the president of Thien Hai ('love from heaven') [...] we encounter many people that do business $[\ldots]$ it is time to have integration among different organizations so that Christian can impact society. The mission is to know and collect talents, a social energy to resolve social problems. [...] Many Christian entrepreneurs support our foundations, we as Christian entrepreneurs founded this association, that connects socially several entrepreneurs [...] here in Wenzhou we are very active, we express the Christian culture to the public and to the government, like in a mission (Ning, Wenzhou, Wenzhou, 24/08/2015).

For what concern business and faith there is a group of 40-50 people and a teacher from China that came 40 years ago, he was very rich, now he is very rich spiritually of love to give to the people. We have an office in Milan to help and serve the brothers who are foreigners in Italy. (Deming, Ibidem).

Many customers are Christians and when they are Christians they come to me and they speak because we have the same language [...] as Christians let's say that they helped me they prefer to buy from other Christians (Yongnian, Ibidem). 
The last case of Yongnian reminds the impartial reader of the instrumental role of the house church for the business despite its religious connotation. The commonality of faith becomes a guarantee for the availability of a portfolio of customers and suppliers that are already in the network and therefore can be

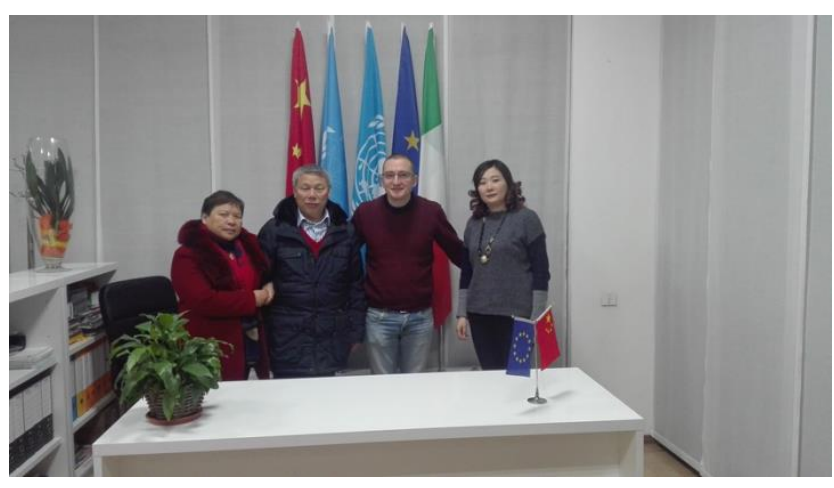
quickly used for business reasons. As it will be clearer through other examples from my visit in Wenzhou like Xun, this overlapping is not just driven by an instrumental reason that pushes the entrepreneurs toward this identification with the house church. Yongnian as Delun is member of the 'East \& West International Cultural Exchange Association'3 (Dong Xi Fang Wen Hua Jiao Liu Xie $\mathrm{Hui}$ ) which purpose is not only to promote the Chinese culture in Italy through social and charitable activities funded by entrepreneurs but also to connect entrepreneurs and evangelize. During my research I had the chance to speak with the president of this association, Yan. Both as a woman entrepreneur with two clothing stores, one at Chinatown of Milan and the other in the city of Alessandria, and as the boss of the association, Yan had a high position in the Protestant Chinese community of Milan. Her association in fact unites together Protestant entrepreneurs from the different Chinese churches in Milan (the main Protestant church of Via Fortunato Stella, the Taiwanese church and the Pentecostal Chinese church). The goal of this association was to integrate the entrepreneurs in the European culture mainly in terms of security, environment and other gaps among the entrepreneurs:

With the Chinese of Milan we don't speak only of money we motivate them to link the business in China or to be more responsible here in Italy in their way of working. In the exchanges we help a lot the local italoChinese businesses, for example a member does twinning between Italian and Chinese cities. We try to create a school for unemployed foreigners, how to hire them in Chinese stores, we do this type of job. [...] We have good relationships with the laoban (Chinese word for boss) among 500 businesses, many are Christians. We have meeting places with them to dialogue and they take to heart what the association does. (Yan, Milan, Wenzhou, 25/01/2016).

The association in fact helps Chinese entrepreneurs in their motherland. They do that by providing useful information about business or contacts of people interested in making business. The $90 \%$ of the members of the association are Christians. Through the association they come into contact with one another and with people of high standing. During conferences they meet managers, public officials, discussing of official matters but also sharing their faith at the table. The association also helps Chinese missionaries or Chinese students that need financial help to pay their

\footnotetext{
${ }^{3}$ From the right: Vittoria Wang (president of the 'East \& West International Exchange Association'), me, Jin Guanchun (Director of the International Ecological Safety Collaborative Organization and pastor at the Chinese church of Milan), and another member of the Associations also part of the Chinese church of Milan.
} 
rent. On the other hand Da told me how in Wenzhou almost every house church has a meeting group of Christian bosses and entrepreneurs connected with one another in business through their commonality of faith. Those 'commerce fellowships' are involved in events and meetings intended to promote their economic success on the basis of Biblical and Christian principles. Another example of this came during the job-shadowing of Heng. Heng's store sometimes was visited by some Chinese people bringing advertises for entrepreneurs of the China town: business consultant or help with the bureaucratic administration. Yet talking with Heng I discovered he already had a business consultant, a 'Christian brother' from the church that started a partnership with an Italian business consultant to assist Chinese Christian entrepreneurs in China town with the Italian bureaucracy. Furthermore the level of personal help through the commonality of faith reaches also the possibility to find a job among family members. Heng's younger brother works today for this Chinese Christian business consultant.

In several of those business cases, it is then already possible to see the presence and role of the church as a network, which positive impact on business I am not neglecting. However in Weberian terms it must be remembered that the role of sect played by the house church is much more than simply being part of a network. As from the words of Shaiming, although being a case of a second generation immigrant, he still feels a lot of pressure and control over his conduct to become a member of the church. Shaiming together with his father also works in a big Chinese store that sells all sort of products, a typology very common among Chinese entrepreneurs today. He has a lot of clients, he speaks a perfect Italian. Because of these skills he could not leave the store for any reason, and during my visits at his work he was always kind and serene, but also very diligent and professional, qualities that he developed through his acquaintance with other Christian Chinese businessmen. This element shows that the simple connection with this network in and of itself, despite providing a strong help for the business activity, does not necessarily substitute all the other possible explanations. To be connected with the network in and of itself does not create any ethos. It is still necessary to be an active part of the house church network to enhance the selfexamination, the stress on Charisma, the identity-trust that according to Weber's model are able to push towards economic success. This element, as I've recalled before, is the most important element, part of the Weberian role of sects and it is peculiar of this type of network.

It is also true that the family plays a role in the dynamic for many of those entrepreneurs over their house church network. Especially in the case of the second generation, the entrepreneurs inherit sometimes their business from their parents or they found their job because some member of their extended family hired them in their business. There is therefore a frequent inter-generational component in those family businesses of Chinese entrepreneurs that needs to be taken into 
consideration for the business-potential added by the presence and accumulation of inherited financial resources. This for example was clear during my job-shadowing of Heng. The business where Heng was working was inherited by his wife and the financial involvement of her family in the opening of Heng's new business was crucial in guaranteeing his growth especially in the initial steps. Engagement celebrations and marriages were very important in the community. Nuo's sister Meixiu was getting engaged during my job-shadowing with another Christian Boss in China town. For those reasons it is not hard to imagine why it was common to mix business and their own lineage.

This may lead me, as I will point out later, toward recognizing the role of a network and especially for the specific case of the Chinese culture the role of the network through family clan and lineage (Network explanation). It is undeniable from the results that the house church as well as any other social network is an exploitable channel, sometimes even apart from the religious reasons, to guarantee the better and faster passage of trust and information. Yet, it has to be remembered that social networks give no guarantee for economic success and the aspects of the church network able to foster success are those that influence the conduct of the individual, not the network in itself. In networks such as the family or the membership to a certain association this key element is absent. This argument will be more clear as I will compare those findings with the case of the second group. In any case, among the many cases I was able to observe, although there is an influence of the family, it is still the larger church network that seems to produce its blatant role in business especially through the provision of job opportunities to its members as it can be seen behind the polite words of Nuo:

Faith helped me, if you are alone is hard to resist, instead with the church you can accomplish more, initially I resist, but then I lose heart, is better to have the church help you. Everybody is seeking for business opportunities here so we talked with one another (Nuo, Ibidem).

My uncle is the owner of the store here in Milan with him we first opened a store at Lake Maggiore [...] we are all believers in our family and the experiences with my uncle. My uncle does the job and I learn from him (Guang, Wenzhou, Milan, 18/07/2015).

Guang is just one of the many examples of a person that belonging to the house church can profit of the membership in a business that is based on the commonality of both faith and family. His uncle is the owner of a store in a very strategic and central part of the China town of Milan. His family arrived in Milan in 1989 after the events of the Tiananmen square, he is third generation Christian. Before arriving in Milan his family had factories of different merchandises to sell in Italy, then they were able to open their first store in 2005, and finally after 15 years, they opened a new store in the suburban area of Milan (Cernusco). It's in fact a common experience for many members of the church to be hired by a boss who is a Christian or whose wife is a Christian part of the same church. The house church then works as a node for their search for a job. Some examples of that 
came into the surface during my job-shadowing activity with Delun and Minzhe, involved in the creation of business activity through their network of Christians. Enlai, Fai, and another member of the house church at Milan are an example of this network. Also Minzhe and Bingwen in the case of Delun were significant. In other words the commonality of faith led Delun to start a business with Bingwen as his Christian business partner and co-Boss:

[...] inside this dynamic I was a brother, that trusts not in himself but in God, we can talk, we have the same basis, secondly I didn't had a job and I was available, and it was right for me, skills linked with my background (Bingwen, Ibidem).

To manage a business with a commonality of faith was said by Bingwen to encourage and positively influence his personal growth. Sometimes during my job-shadowing of Delun it was also common to see business interaction with other members of the house church. One time a brother from the church came at the bar of Delun to discuss the installation of cameras at the new store of Delun. Another brother from the church (Deming) was responsible to help Delun for the fixing of lights and so on. Every single member of the church has a specific skills and use it in reciprocity (bao) to help the other members of the community of faith in their business. This type of network is particularly strong because is based on a common ethnic, religious and relational back-ground, based on their friendship, their commonality of purpose, their mutual 'brotherhood'. All this enables the work to be 100 times easier because of the trust already in place between them. When such a spirit of comrade is present, problems and difficulties are never too big. Conversations about business are alternated then very easily with daily life exchanges of experiences. If I go back looking to the first generation of Christians however, something slightly different happens which is very significant for my thesis. Many of those first generation migrants such as Shing, Zhenzhen or Shu decided to join their enterprises together with some other boss-Christian members of the church regardless of their family background (acting as strong ties). This was done with the specific purpose of strengthening their partnership and vision for business on the basis of their common faith (acting as weak ties). In those cases they started their business bottom-up, they describe a gradual progress in their professional experience where the help of the house church or of the family, which in the case of Zhenzhen corresponds with the church, represents somewhat the positive turning point of their business growth:

Before I was working in the business of shoes, then clothing, then in a store of the brothers from the church, then I've started my own business, from some months I manage this store selling lamps for companies (Shing, Wenzhou, Milan, 30/01/2015).

First I was working into a Chinese restaurant, for two years, I couldn't speak Italian, I was washing dishes, cleaning, then little by little I was helping the cook, then I became the cook, then several other works in the kitchen, then little by little I was helping Chinese students at University, I was preparing learning Italian, I was buying Italian books, then they could study them at home. Then I've changed job into an Italian restaurant, then I became a barman for three years, I was managing the bill and in 1999 I started my own business in clothing, I just tried everything (Shu, Wenzhou, Milan, 30/01/2015). 
Before I was working in a restaurant as an employee with others, I've opened my own restaurant then since five years I work in the clothing business. I can see a growth and God helps me, I don't look for greatness, the things he gives me I'm happy, but God leads me on, this job is to support those of my religion that Jesus tells me. Life is not just for work is working for the faith, as I work we must prepare sermons [...] I started little by little under others, then in a little shop, then I created a pizza place, then a restaurant, the money was growing, and my family helped me and our work prosper more and more as I grow bigger (Zhenzhen, Wenzhou, Milan, 30/01/2015).

As it will be clearer when I will compare those results with the second group of entrepreneurs with no link with the Protestant faith, the house church in this case works just as a functional substitute to what the family lineage, the identification with the same ethnic group or the membership into an associations are for the second case: network generators. Secondly Shing, Zhenzhen or Shu are also what I can call the perfect example of a 'boss Christian' from Wenzhou.

They are all first generation of Chinese immigrants, very successful in their business but also very involved in leadership roles inside their church. Particularly in those cases the element of lineage (strong ties) seems to play a secondary role compared with their image of a 'self made man'. Only in later parts of their life those entrepreneurs started to use the network of the church inside business. It must be also noticed that their belonging to the first generation of immigrants meant the absence of economic support from both church and family in their primordial stages of business life when they arrived in Italy. From ethnographic observations I was also able to see that not only Shing is very involved in business and he has a vision for leading business and start always new activities but he is also very involved in the church, being a core member, a deacon always very active in all the religious activities.

The case of $\mathrm{Shu}^{4}$ is even more interesting for this matter, he perceives and describes his professional life as a continuous and perseverant process of growth toward success, from low paid jobs into independent business ownership, being therefore very visionary toward his economic future. Like Shing and Zhenzhen, his brother Shu is very involved in business, helping other Christians to succeed in their business life,

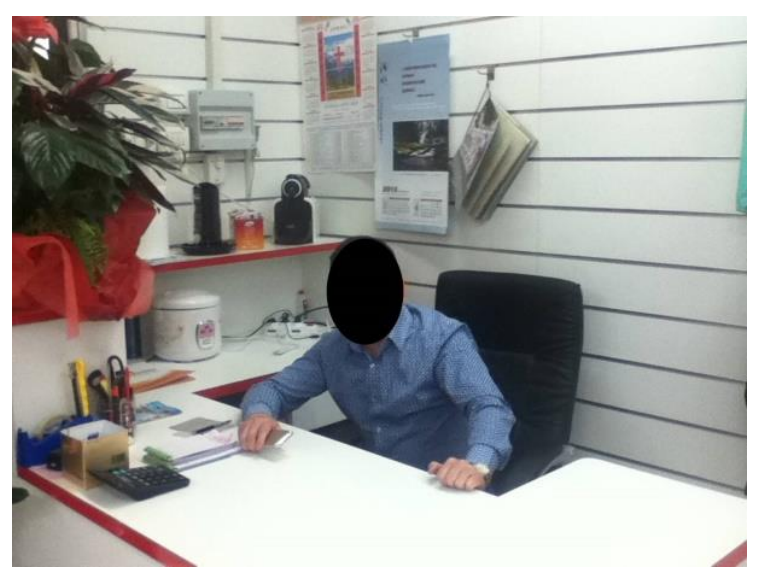
having also a role of key leadership in the church as a deacon, seen and treated as a role-model for younger members and being leader both in church and in business. Sometimes this positive influence comes out of the boundaries of the house church and involves even the non Christian entrepreneurs. One example of that came through interviewing and job-shadowing Chun, a non Christian entrepreneur, in his relationship with Delun, a Boss-Christian. Chun is a first generation

\footnotetext{
${ }^{4}$ Shu in his office. On his back four different Christian calendars. Shu is deacon of the church, very respected Christian involved in ministry as well as a successful entrepreneur.
} 
migrant and at first he had a lot of difficulties integrating in the Italian society. It was at this point that the connection and help received from Delun really gave a turning point for Chun. This characteristic is unusual even among Chinese entrepreneurs:

When there's some problem other entrepreneurs [looking at Delun] will help me. There are few people like Delun, kind that will help you. A lot of people think always about themselves, it is difficult to receive help, before I left to go to Italy I've met Delun (Chun, Ibidem).

It must be noticed that a specific Chinese cultural structure of the church has been developed in this church which is very far from the traditional subdivision between Pastors (also called elders or teachers as leaders) and Deacons. This cultural structure of the Chinese church tends to be very elaborated and it must be taken into consideration in order to understand the role of leadership. The function of the pastor in many of the evangelical churches of Wenzhou seems to take second place due to the frequent cases of persecutions so that the role of deacon as the one of Shu or Zhenzhen becomes the one of actual leadership inside the church.

TABLE 16: Peculiar organizational structure of the Chinese evangelical church under my ethnographic investigation.

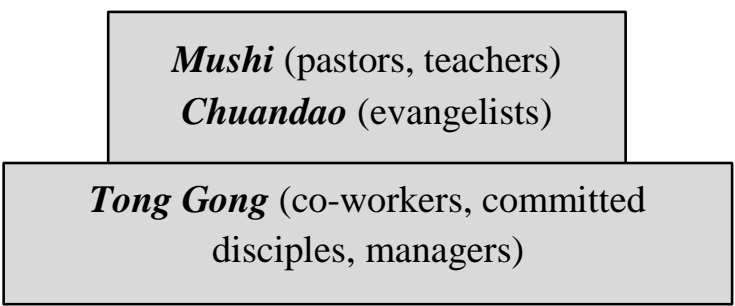

\section{Regular church members}

Because of the frequent persecution coming from the Communist Government specially during the Cultural Revolution many pastors were imprisoned or killed. For this reason the church in Wenzhou developed a specific type of leadership that is present still today. The evangelist (Chuandao) will take the place of the pastor in situations of leadership vacuum caused by his imprisonment. But in this particular situation in the long term the Tong Gong is the real decisionmaker and leader of the church in many of the churches of Wenzhou (see for instance Zhenzhen, Shu or Shing for the case under my analysis). This complex organizational scheme that allows the church to act as a surrogate of the Chinese lineage, overall matriarchal, may re-direct my original theoretical considerations on the different church models of leadership (see TABLE 5) taking into account their further evolution in light of the cultural context of China. This is especially true for the influence of lineage and indigenous forms of government in Wenzhou. China follows the 'descriptive' kinship system of classification or also called 'Sudanese kinship system'. Such system 
is among the most complex and, particularly in the region of Wenzhou where ancestors worship is very important, it results in the centrality of the enlarged family in every aspect of life (Morgan L. H., 1877). For this reason lineage needs to be taken into consideration as a central aspect for its syncretistic influence into the religious practice of Chinese Protestantism and for its application to this structure of leadership inside the Chinese church as well as many other aspects of their daily life, even their business.

Such structural shape of church organization in China was also due for example to the influence of famous Chinese Christian leaders such as Watchman Nee or John Sung that developed a new type of church leadership (the idea of 'older brother' instead of pastors or deacons) which finds no correspondence in the West. This point will become more clear as I will examine the findings on the cultural explanation for the second group. Anyway what is interesting is to see here is the profound influence of lineage and family clan not just on the social structures but also on the economic structure of relations and strategies of those Chinese entrepreneurs. Lineage in other words tends to shape those elements during the migratory process and engagement in business activities. The strong involvement of Wenzhou in the migration process all over the world above any other region of China is in fact also due to the strong role of family networks and lineage. It works like a chain started from singular migrants up to the involvement of entire villages and larger social groups. For example Shu is the first person of his family that came to Italy before Zhenzhen and then all the other members of his extended family decided to move and to start a business in Italy, in France and in Spain. This shows the complex ramification of businesses all over the continent that allows their survival in times of economic crisis because of the lineage ramification. However as I already said, the role of lineage for the case of the Protestant entrepreneurs seems to work inside a more influential context, in terms of the amount of people that can be directly involved in the network, which is the one of the house church. Furthermore, as many studies in economic sociology have shown (AA. VV., 1990, p. 482), during the migratory experience the lineage, as well as any form of

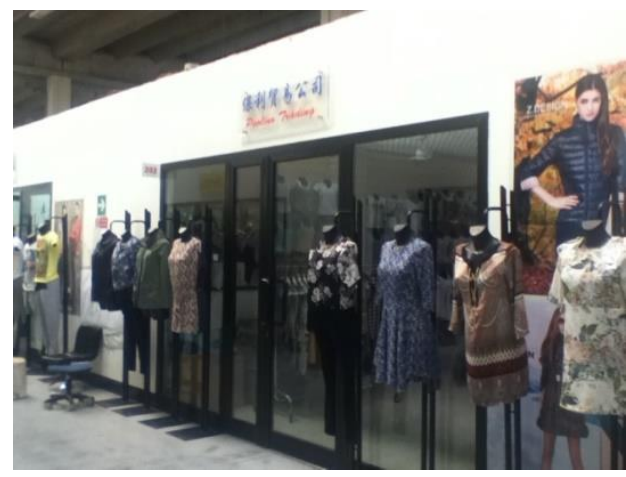
traditional authority of the family, tend to experience moments of breakdown that weakens its potential role.

Zhenzhen ${ }^{5}$, Shu's younger brother is also a very successful business man, a typical bossChristian, very visionary for his job, purpose-driven. He works very hard and in the same time he is also involved in position of leadership as a deacon in the church. This first element goes then

\footnotetext{
${ }^{5}$ Outside view of Zhenzhen store. Zhenzhen and Shu have their stores one in face of the other.
} 
together with the provision of a network of which the sphere of influence tends to be much larger than the one of lineage. From ethnographical observations on Zhenzhen I saw his professionalism in action, his trustworthiness with the clients, his intention to work hard and at the same time his busy schedule in his ministry serving the Chinese church. Zhenzhen goes every weekend in a different Chinese church around Italy (Florence, Venice, Genoa...) to preach sermons ${ }^{6}$ and build the other migrant believers across the country. This complex network of evangelical churches, as it has been notified by Zhenzhen (more than 44 churches all over Italy plus other secondary contacts with Pentecostal churches which raise the number over 100), provides for him and many others also the ground for business transactions, through contacts, passing of the word and mutual economic support as well as the itinerary ministry of preaching. Similar to him and looking at him as a model with the desire to become a Tong Gong and later on a Mushi as a full time minister, Delun started to preach in several Chinese churches of Milan

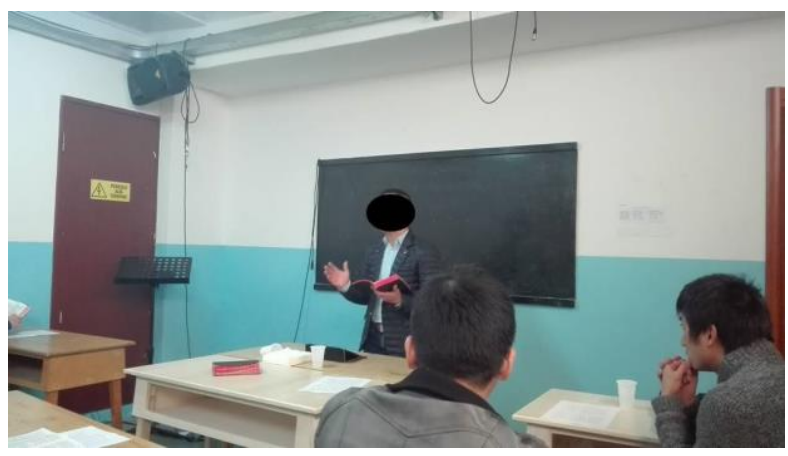
receiving the favor of other church members apart from being a successful entrepreneur. All of this was done in order to show character qualities that are essential in order to be accepted in the church and that are also used in his business (courage, dedication, humility, sacrifice, setting high goals).

Another important example of how this house church network works in the job is what I had the possibility to observe in my ethnographic observation of a group of Christian entrepreneurs (see Appendix) linked together in business among a larger group of Chinese businesses. Zhenzhen and Shu are a leading part of this network and they often organize a group of entrepreneurs to go around the different shops of the pavilion one by one to build the relationships with them, encouraging them, having spiritual conversations with them and inviting them to come to their religious meetings. This is a good example of how those entrepreneurs, already engaged in a network through the house church, expand their influence in the context of business through friendly engagement based on their religious identity. It is important again to see that it is not just a form of network but also an expression of their inner-worldly asceticism, that helps them to give an image and identity in front of the surrounding social context without any contradiction between their religious beliefs and their job.

\footnotetext{
${ }^{6}$ Zhenzhen in one of his abitual session of preaching at the Chinese Church. He represents a model of business of excellence as well as leadership in the church. 


\subsubsection{Work, Purpose and Meaning}

However, the economic success as God's blessing that I've described before and that has been identified in the area of Wenzhou it is subordinated to a major supreme objective that represent another precondition: the Glory of God and love of Christ ${ }^{7}$. Among the different descriptions of the purpose of their work, according to their social representation and reconstruction this particular precondition stands out as a dominant one. When asked about the main purpose for their work those entrepreneurs regularly referred to a metaphysical idea of "bringing glory to God" in everything they did. When compared with the non

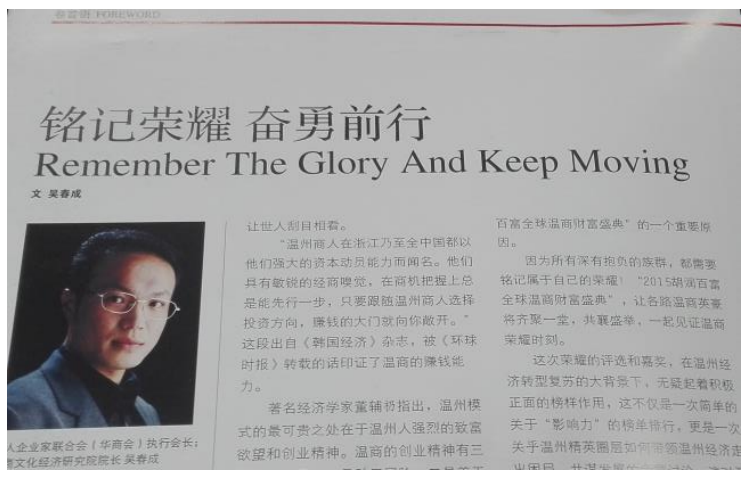
Christian Chinese entrepreneurs that find more material purposes such as support for the family, living a decent life, I then received a quite different response. But what exactly means and why it is interesting for my argument such emphasis on bringing glory to God? From what I was able to observe on the field this specific belief, strictly connected with the other preconditions such as the inner-worldly asceticism sees every single activity, especially work, as having an ultimate higher purpose, no matter how low or humbling it may be. It must be recalled how low level jobs in ancient Asian societies, as well as in the classical era, were considered bad and in opposition to the pure benefit of otium and intellectual investigation. Here instead, behind the religious interpretation, it is possible to see the exaltation of work at any level even the lowest as a way to accomplish their goal both spiritually and professionally, a conviction that results in duty, meaning and purpose for business. Every activity therefore, even the most repetitive or difficult finds its container of greater meaning and higher purpose:

[...] God will prepare the best for us, whatever I will do the most important thing is to bring glory to God. [...] If I wasn't a believer I would be doing business only for myself but now I do this asking myself if I'm bringing glory to God (Minzhe, Ibidem).

Life must be offered to bring glory to God [...] work with all of your strength to give glory not just to myself. Any work you are doing this has to bring glory to God. [...] The main purpose in life is to bring glory to God. (Bo, Ibidem).

To have a sense of mission helps you [...]. Some churches gather the laoban [bosses] and ask them to dedicate themselves for the church, some don't do that, they don't focus in the company, we have instead to grow the company so that it will glorify God (Yi, Ibidem).

The purpose [of work] is maybe to make money but if you want to make money you must follow the rules of the Bible and glorify God, you must gain money but money is controlled by God (Da, Ibidem).

\footnotetext{
${ }^{7}$ Front page of a Chinese journal of Christian entrepreneurship in Wenzhou. The title speaks loudly of the importance of this concept of 'glory of God' in business. Many of those Christian entrepreneurs cited in the journal are in direct contact with the 'East \& West International Cultural Exchange Association' in Milan (Source: 2015 Hurun Report, http://www.hurun.net/en/Magazine.aspx).
} 
I worked to change my life, to give to my family a good life but since I became a Christian it is not just the money my goal, I must manage the money for God, work together with colleagues, bring them to the faith, make God happy, for the glory of God (Nai, Ibidem).

I investigated many stores and decided to rent them and I thought to find something to glorify God, sometimes very important for me, therefore I opened the foundation (Ning, Ibidem).

For me the purpose [of work] was make money and support the family, now if work can express my faith it is good. Working is for God, but sometimes is hard, we have to work hard and make money, if it can grow for God I will be blessed (Xiu, Ibidem).

Accomplish goals is important but put always God at the first place and don't ever forget Him (Hop, Ibidem).

To obey is important, Jesus wants me to obey, the true life of the persons is important, the goal remains the kingdom of God (Jun, Ibidem).

The purpose of my life is to be always with the Lord the other things that the Lord puts ahead of me I live them according to this principle (Minsheng, Ibidem).

I have to discover daily what is the purpose of working, now many live just for the sake of living, but the most important reason is Jesus who gave it to me (Zixin, Ibidem).

The interesting element here is how Zixin, Minzhe, Bo or Hop apart from their religious fervency common to all forms of religiosity, they hold to a strict unusual connection between this belief and the way they do and interpret socially their work. During my visit in Wenzhou I had the chance to see through the interviews to Yi or Xiu how the degree of connection and personal interiorization between these two element was much higher. Also from ethnographic observations and job-shadowing at their workplace, a strong emphasis from the participants emerged on the importance to 'glorify God' even in the worst of situations, and that each individual must do it in many ways as possible. This helps also the entrepreneur to find the strength necessary to face difficult tasks and at the same time to "think big" about any business action. Once again apart from judgement of values on the particular content of the belief, such precondition seems to enhance a sense of self-efficacy. Work and business find therefore a different special source of motivation that brings to have a good relation with the clients, colleagues, suppliers and anybody they come into contact with. Pushed by this belief the entrepreneur feels an obligation to share it. Even an economic transition can be the opportunity for "sharing the Gospel", not just being focused then on the material aspect, giving them the motivation, purpose as well as the trust for the good success of the economic transaction:

As a seller I want to give to customers the love of God [...] the purpose of course is the kingdom of God, to bring salvation to the souls. (Deming, Ibidem).

[...] I have this faith I have to give the news of the Gospel share and let them see God. [...] I have to help the people to find purpose, meaning. [...] if I do something I worship God, is not me. (Fai, Ibidem). [...] the Gospel is an opportunity to glorify God through work, how can you share otherwise, to work is to glorify God the only motivation that I can work hard (Ling, Ibidem).

In this situation Ling, Fai and Deming sense to be the mere executors of an higher plan. Ling found a purpose that led her to work hard. They all search for an unique ingredient that can give motivation and effectiveness to their work. From the micro level of this social phenomenon to the macro level, it can still be possible to see the major role of this belief. Some of those entrepreneurs are particularly encouraged by what is happening today in China, through its Protestant revival. 
This revival is seen by Delun or Xun as something that will lead the whole world to benefit from the turn of China into a Christian nation. These new economic contributions and benefits that China is experiencing today are seen by him as a direct consequence of China's acceptance of the Gospel. In light of such perceived climate of spiritual and economic revival Delun perceives that he has to do his part through his business to make it happen:

\begin{abstract}
[...] Many of us think that in 15 years if we reach $30 \%$ of Chinese population then China will become a Christian country is this that we want to believe in China, when China will become a Christian nation, it will be a contribution and a benefit for the whole planet [...] (Delun, Ibidem).

Relationships were focused on business, me as a pastor I thought we don't have to stay just for money, but exchange culture, thoughts, ideas, the most important thing is faith in all the exchanges is easier. [...] Our roots of faith we want to bring them in society, religion doesn't just refers to the four walls of the church but we are the salt and light of the world, we reveal what we have from the Bible, we have the duty to witness, we show what we do in research, technology and mass media that speak about us. $[\ldots]$ we have to move in the social (arena) and this the government likes it (Fang, Milan, Wenzhou, 25/01/2016).

The Christians in the future will be very important, they will be the center of support in China, without any doubts. We see a nation that want to rise up, the heart of this energy comes from God (Xun, Ibidem).
\end{abstract}

Because of its implications on the macro level and its pervasiveness in every aspect of life this precondition results to have priority over the others. This set of preconditions can now be conceptualized in a progressive way: from choosing the job (Yi Xiang), to the way to work (BossChristian), with what social resources (house churches) for what ultimate goal (glory of God). To these elements some significant premises are added (the presence of a dramatic conversion, a necessity of high standards, a stress on charisma and a clear view of the future). All those aspects seems to have a common denominator in pushing the individual to work hard through a meaningful set of values. It is clear however that in and of itself a propensity to work hard is not the ultimate guarantee for economic success in business. There must be an internal state of being in the individual able to direct such propensity toward a functional economic action. In the field a sense of self-confidence emerged that seems to contradict with the Weberian state of anxiety about salvation.

\title{
6.1.7 The role of Assurance in Business
}

On the other hand, in the same realm of salvation, what I was able to notice through ethnographic observations, job-shadowing and interviews was something slightly different if not totally opposite to the central aspect theorized by Weber. Like for the case of Calvinism those Christian entrepreneurs hold the belief in PAS, that consists in believing without doubt in the perpetual assurance of salvation (Que ju, 确据) as a result, not of works (total depravity of men), but of God's action in Christ's sacrifice at the cross. Having received by grace through faith (xinyang de endian 信仰的恩典) in Jesus the total forgiveness of all their present, past and future 
sins, those individual possess the perpetual assurance of salvation. This means that the individual who hold such belief knows that when he will die he will surely go to heaven not because of his good works, since he perceives to be a sinner, but because of Christ ultimate sacrifice for his sins at the cross. But the question may rise: what such strictly metaphysical element has to do with work and economic success? Now, if what concerns the realm of salvation among those Chinese entrepreneurs is true, as it will be showed through interviews excerpts and job-shadowing, and if in accordance with the historical sources on Calvinism it proves to be a confirmation of the reality of a reversal in the thesis, it will become evident that the Weberian connection between belief and economic success was going in the right direction but with the wrong conclusions. Before passing on to analyze the validity of any alternative explanation let's define first the details of such belief from Delun's own words:

[...] Because of the faith that I received [...] all of us are condemned to death, we are all sinners but with Jesus Christ we are saved in His blood, then we can change the future trusting in this Christian faith. (Delun, Ibidem).

I believe I'm saved, Jesus said when I will come back I will bring you into heaven, the eternal life, when Jesus will come. [...] Life then is very peaceful and when something bad happens I know Jesus will help me (Huizhong, Ibidem).

[...] You can have salvation if you believe, you will receive love and you will have peace in every difficulty, it will give you joy, hope in your life [...] I'm totally changed, now I have eternal life. (Minzhe, Ibidem).

Jesus say I care about you. It was the most peaceful night I ever had, I didn't had fears, I slept like a child [...] I went through many difficulties but I was following Jesus and the Bible that helped me to overcome difficulties (Enlai, Ibidem).

Enlai in this line is reconstructing the details of his dramatic conversion and how in that moment of salvation he felt freedom from anxiety. The same thing is possible to see in Huizhong, a sense of peace and assurance that reflects on future events, leaving him in a perpetual state of assurance about his destiny, in a sort of 'self-fulfilling prophecy'. In trying to understand how then such belief can influence the achievement of economic success it is important to make two introductory considerations: i) this belief generates a feeling of confidence and peace, ii) such feeling is said to be very important in bad circumstances and moments of difficulties. The centrality of such belief becomes evident by answering the question: 'did you have challenges or difficulties at work? How did you react? What helped you?' the answers were almost uniformly related to PAS. Also, a sense of peace and confidence is the direct output of this belief, and I will explain later why it is so important to emphasize it. Not only through interviews but also through ethnographic observations I have witnessed during several social meetings how the entrepreneurs had to answer to several questions and among those addressed these were some of the items: "when you obtain salvation, how do you live? What does salvation brings in you?" or "when you are weak do you think God loves you? In which situation you didn't received what you expected?". Listening to their spontaneous answers I saw a repetitive reference to a sense of peace, a condition of comfort in 
challenges and an ability to overcome difficulties. Referring to difficulties at work one of the participants to the meeting mentioned his testimony of how the business at his shop was not going good and how 'knowing to be saved' helped him to overcome the challenges through calmness.

Not only that, but both from the interviews and the job-shadowing the belief in PAS emerges repetitively as the guiding element of their life, particularly in times of struggle. If someone was to subtract, by using the trick of Wittgenstein, this important belief from their religious experience, the entire structure of their system of values that guides them in business, loose its meaning and relevance. Without this belief, according to them, is better to stay atheist or Buddhist, life loses all of its meaning and purpose, there's simply no ultimate support, all the castle of preconditions falls down. Those entrepreneurs relate directly to this belief in every aspect of their daily life, especially work. The belief in PAS generates in them a state of "confidence" that has everything to share with what I've described before as the main characteristic of self-efficacy, a trait that in the field of psychology of work has already been proven to be related with economic success. This particular and perpetual state described by Minsheng, Bingwen or Hop as "efficiency" "confidence", "peace in the heart", "joy", "God's continuous presence" is able to lead them to overcome difficulties, particularly in trade and work:

\begin{abstract}
Faith in God helps me to stay calm, I work more efficiently with less inconvenience, I used to feel a big hole in me, now God gives me peace and I'm always calm and everything goes well, I overcome problems at work and in life all because of God. [...] It changed me a lot, I'm not like the others, somebody who doesn't believe in this religion, when he puts his trust in him everything changes (Minsheng, Wenzhou, Milan, 20/12/2014).

Sometimes is difficult to have peace in your heart in difficulties, you will have fears, you will be nervous, evil thoughts but $[\ldots]$ to God it matters [...] He will helps you to overcome them, therefore you will have peace and joy in every situation. Salvation is based on faith [...] I know that if I believe I have eternal life, and I know that God cares about me, when I have difficulties, I will pray and God will be with me, it's easier to overcome difficulties, I know that God is with me and I will not be nervous. (Bingwen, Ibidem).

Before I didn't believe in God and today I don't have anxiety anymore, in difficulties that God helps me. Even if I had success without God my heart will be empty, I have a hope for the future [...]. I don't cry in front of difficulties, nothing depends on my efforts but on the hand of God. (Hop, Ibidem).

Whenever I was weak, poor, it happens something terrible, this doesn't scare me, I have a spiritual eternal life, I know that when I will die I will go to heaven (Jun, Ibidem).

Jesus already saved me I feel I'm more calm that with Jesus near me nothing bad will happen to me. At work I pass every day without worrying about how much money I gain, Jesus is enough, the things we obtain are the things He gives us. Even if you want more you don't obtain it, if He gives you that part then is enough you don't have to worry (Shaiming, Ibidem).
\end{abstract}

Once again, behind their religious interpretation what really interests me here is the strict connection with the realm of work, and the psychological and sociological considerations that it is possible to make from that. Economic success as it is known from the literature has various explanations and among those there is the necessity of a strong belief in someone's abilities to reach his goals. In a strictly formal way that's exactly what it is possible to see in Jun and Shaiming beyond the substantial character of their belief. Not only that but even from their own perception of 
how success in business is achieved Delun goes beyond his own skills or competences and talks about a source of strength and confidence derived directly from his belief. For example Delun and Bingwen during the first stages of their shared business of high technology were particularly challenged by the newness of what they were trying to do but also by the lack of any certainity of success. Sometimes one of them was particularly discouraged in the circumstance but having a 'brother' as a business partner was a good influence. When some of them had to face a problem both were able to find a way out together. Bingwen and Delun in this circumstance had confidence and assurance in the fact that the necessary clients would have been provided for them. In direct response to the risk and challenges Delun showed confidence, not in himself but in a supernatural force. When he faces a problem there was a solution. Bingwen was giving an example of this related to his task of printing phone covers at the Hi-Tech store. When they found a spot in the picture, risking to lose a client, they tried in a matter of weeks to resolve the problem. Wisdom and confidence were necessary in those situations where is hard to work every day without any certainty that the problem can be fixed. Faith helped Delun and Bingwen to be calm and to find a solution to resolve the problem.

But the reason for economic success goes also further than the static definition of it. The belief in PAS and the self-efficacy can show their dynamic role only when analyzed in moments of true economic risk. For example Shaiming reveals the significance of this when he shared with me his difficulties at work. Shaiming lamented the fact that 4 years ago the business was going very well for him. Yet this was not any more the case because of the concurrence coming from bigger chains of Chinese stores providing the same type of products. He was referring to

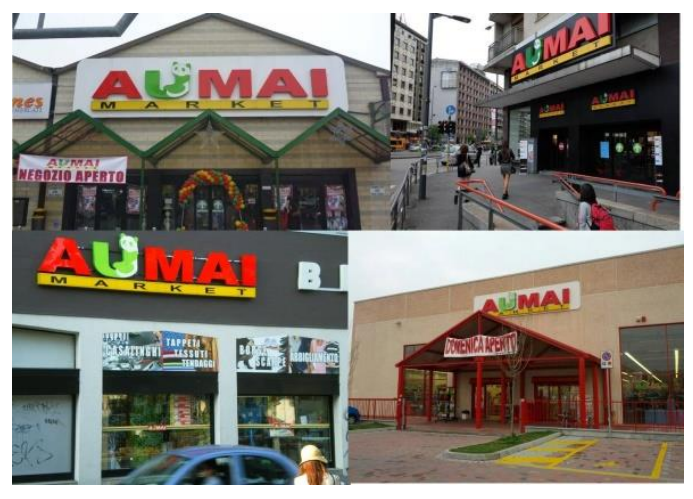
AUMAI, a Chinese chain of franchising born from the idea of three Chinese brothers in 2004 that later on spread all over North Italy. Those stores are 10 times bigger than Shaiming store and only in the area of Milan there are 50 of them ${ }^{8}$. In reconstructing his past experience before and after having believed in PAS, the entrepreneur acknowledges a drastic change in his life, especially in his management of economic risk:

[...] I think that success in business is due to God's blessings [...] in the beginning I thought that was destiny, skills, because I'm smart, but as time went on I understood that wasn't the case [...] in difficulties then there is a reason beyond that, a God that blesses you [...] (Delun, Ibidem).

Faith helps us all at work [...] so, it is that in times of difficulties through our faith we are able to go ahead (Guang, Ibidem).

\footnotetext{
${ }^{8}$ Some of the many stores of AUMAI in the city area of Milan. This Chinese brand took over and replaced many Italian stores that were not able to survive the economic crisis. 
The belief in PAS instead of creating anxiety, gives Hop and Heng the very important resource to manage the anxiety derived from the "competitiveness" of their job at any level:

[...] When I'm doing a competitive job it doesn't matter how hard it will be, I know that God will help me [...] I don't get worried, I'm not mad anymore, God healed me. Emotionally I have an ability to overcome the difficulties and to be at peace. (Hop, Ibidem).

In my experience I had shopkeepers clients that are difficult to communicate, I had pain speaking with them, in prayer Jesus helped me to love also people who are difficult to love. (Heng, Ibidem).

Even if there is no time the entrepreneur must have the peace that comes from faith, he must lead his company with an higher power. During hard moments, whether because of the economic crisis, because of difficulties with clients, while making hard managerial decisions or facing debts... what really motivates the entrepreneur is to find a higher reason that will help him to stay focused and to avoid being "slave of his bad circumstances". This is provided again by the belief in PAS especially beneficial in case of Zixin or Fai that interpret their challenges as opportunities. Economic risks, failures and defeats are as much important as economic success for Bo, Enlai and Zhenzhen. They must be faced, accepted and they must bring to a response that will favor a lasting success or that at least will remove confusion. In order for that to happen the emphasis switch to an higher unshakable source of assurance that is able to help in managing inconveniences and to provide the necessary perseverance in going ahead "facing the challenge, going right through it":

There are difficult moments at work, but I'm joyful, I believe that Jesus helps me always and I'm not afraid of things of this life. Sometimes it's hard, when I came here I didn't had anything, I had difficulties and God helped me. It wasn't easy, at that time I thought: why this is happening to me? My life doesn't have to be always straight, some problem must occur so that I will become stronger, succeed in overcoming fear and become a better man (Zixin, Ibidem).

When I have stress at work and pressure, I have this, I believe I can pray read the Bible ask in church to other believers the meaning, if I wasn't a Christian I would had acted in a bad mode drinking alcohol seeking a way to release the stress and difficulties that is not good, now I have a way to release my stress I have peace (Fai, Ibidem).

If something difficult happens at work is good to go on knowing that God is always with me (Deming, Ibidem).

In moments of difficulties you don't know what happen tomorrow but you have a landmark the goal you reach not as a mere earthly success but toward eternity you already have everything. In risk you trust that you will have your bread it gives you confidence in what you do. (Bo, Ibidem).

I was confused and anxious about future, I read the Proverbs and I've found directions on where to go. When I am down and sad I know that God is with me and comforts me whatever may happen. God is creator [...] the fear in difficult and unknown situations the people that I'm not able to deal with it is exceeded by God [...] I have Jesus and God I have the Spirit and I have confidence with any person not because I'm smart but because my treasure is in heaven and He prepared the best for me. (Enlai, Ibidem).

We have to set what's important, the important thing is life after [death] I work in light of the things that after we will have to do as we enter into eternity with the rewards from the things we are doing now (Zhenzhen, Wenzhou, Milan, 30/01/2015).

The fact that the entrepreneur believes in the afterlife is not really exceptional to this religion neither in and of itself brings him to economic success. But given the connection between the belief in an assurance and the preconditions bringing an output of constant, unchangeable confidence and self-efficacy, the entrepreneur is strenghtened in times of economic crisis. Wing especially in his 
beginning stages of business needed strength and patience in order to be able to "never give up" even in the most difficult situation, and that came from his awareness of being saved:

\begin{abstract}
When there's every difficulty what I have in my heart I can't say to my friends but I say to Jesus. At work when I'm mad I pray the name of Jesus to give me patience [...] I prayed and I'm not mad anymore [...]. The first job that I was doing as a dishwasher was very hard, the first day I started to cry in my heart, tears were falling and I thought why is this so hard and then I thought where in the Gospel is written: Jesus suffered for our sins at the cross and then God abandoned Him. So I thought I remembered in the Bible this and that I am saved, I don't think how is difficult or I'm alone Jesus suffered for me I just suffer a little bit (Wing, Ibidem).

I sent 200 flyers and only one student came, I kept pressing on [...] I never worried of numbers, God provides. God takes care of me he provides good scores and success. [...] The reason of my strength is that I go to church, I pray and I read the Bible, if I didn't believe in God I would have given up but I never gave up, I do it, the Bible speaks to me, up until now I have no anxiety [...] People ask me why I don't get worried, but I don't do it, but God will do it (Zhong, Ibidem).
\end{abstract}

Zhong while working at the Kindergarten faced challenging moments, and through those situations of risk she felt the strength to persevere and 'never give up' because of her religious convictions. Another element very connected to PAS and that perhaps needs to be added to the model is the practice of prayer at work. This was a recurrent phenomenon in their business activity. In the eyes of the entrepreneur praying in situations of difficulties at work really helps him to overcome the challenges, to find his peace and the necessary confidence. Once again I'm not advocating that prayer somehow helps the business since it can be found in many other religions and from an outside point of view it doesn't have any factual result. In fact to introduce prayer as a practice in itself inside a model about economic success may be a critical step to take. Nevertheless, it must be taken into account as part of their personal interpretation.

If I consider such religious practice there's no factual difference between a Buddhist meditating, a Catholic praying the rosary or a Protestant praying at work. The difference with other religions, although not sufficient for my argument, is that prayer here, as well as other beliefs, is more connected with their material needs, their business life and their daily difficulties at work. Also, the confidence and strength in their abilities generated by PAS is the unique container of such practice that therefore becomes important for my argument. This practice for Huizhong, Kong or Zhenzhen turns into a mean able to transform a situations of economic risks into a chance to grow the business. A difficulty at work turns into an opportunity to work better. It is not something therefore that must be avoided or escaped but it needs to be faced and embraced. Prayer therefore results to stimulate self-efficacy in light always however of the belief in PAS:

[...] I've passed through many difficulties at work and God helped me through prayer, I've asked Jesus to help me and he helped me. I've many stories that I can share, being here in Italy, when I did an accident for example I prayed Jesus and I pass through it because Jesus helped me, people don't understand when I tell them, you know that is Jesus because when it happens he helps you (Huizhong, Ibidem).

If we have difficulties at work we pray to God to resolve the problem [...] we all believe in God therefore this gives us the strength (Chao, Ibidem).

The situations of difficulty... I had them in my business. First we prayed together as shareholders we have not blamed each other, we find the confidence even if somebody did something wrong, we unite 
together to win the difficulties. When some investment failed, I felt sadness, I prayed to God, prayer gives peace, joy, hope and confidence, the promises from God make me feel even better (Da, Ibidem).

The things you ask God he gives them to you. I've asked to God things for this business, He gave them to me and He strengthened my beliefs in God. [...] When I was working somewhere else I had few customers but I was serene because I knew that there is God with me, maybe he gave me this path to become more honest and stronger, there are tragedies but they are good, I've prayed and surely they are moments that God allowed you to have so that you improve. There's a lot of Chinese Christians that pass through those moments allowed by God to bring fruits in your life (Kong, Ibidem).

In difficulties that I need to face the first important thing is to pray, to trust in the salvation of God (Yi, Ibidem).

First I pray when I am in difficulties, about what to do. But the major things I ask to God, the smallest I do them by myself because I think I can do them by myself (Xiu, Ibidem).

Whatever difficulties comes it is God giving us an assignment to learn those things here, when there is difficulty, this piece I must learn. [...] When you don't understand why there is this problem it is Jesus that explain to you all those problems and gives you a solution (Zhenzhen, Ibidem).

We all have difficulties, I often pray to God, it is very important in order to have the peace and the faith that gives you peace, I bring my burdens to God and I feel relaxed. [...] In difficulties the faith helps me in the company to be righteous, to take guided and focused decisions, it helps me to raise up and face the difficulties to overcome them, it gives me the daily help, if I'm in difficulty I pray, I read, I ask for help (Nai, Wenzhou, Wenzhou, 24/08/2015).

Everything has its purpose and from every circumstance in business there is a lesson to learn. But apart from their explanation in spiritual terms, what really counts is that economic risk and difficulties are the factual elements and the difference in the reaction to those challenges is what interests me the most here. In fact another cause of anxiety and risk on a large scale is the peculiar situation of economic crisis that those entrepreneurs went through. The financial crisis of 2008 has touched many entrepreneurs like Shu and many businesses in the surrounding environment failed as a result of it. More recently during my observations a current topic was the financial fall of the stock market of Shanghai. During my ethnographic observations at Via Sarpi, the China town of Milan, Ah Cy shared with me his feelings on that critical situation he was dealing with. Ah Cy sensed that the level of inflation in China caused an increase in costs and a need of higher salaries so that many companies in China were forced to fail. The only thing that helped $\mathrm{Ah} \mathrm{Cy}$, from his own words, in that moment was the network of Christian entrepreneurs he was part of. This gave him hope for the future even in the midst of difficulties. This consolation came from his religious beliefs and by imitating the example of other Christian entrepreneurs around him. The stress caused by bad behaviors, debts... finds its solution in Delun's use of prayer as a social act, uniting different entrepreneurs facing the same obstacle or in Shu's perception of it as a source of strength:

I had to go trough many moments of difficulties at work, there was the economic crisis and also since 2008 is very hard but always prayer to God helps me. My heart then is peaceful, all that I lose, debts, failed clients that cheat on me and I lose a lot of money but I'm here, I'm not scared they want to cheat me but I'm a believer. Up until now people own me 300.000 euro's but I don't go there with a gun, what should I do? Faith in God helped me, God never fails me, I've listened and I've heard, always he helps me, the things that I lack I don't want to push, not everyone has bad behaviors, but when I meet them I must pray, Jesus has done this (Shu, Ibidem).

[...] when somebody finds difficulties, feels exhausted and desperate, it happens sometimes in the trade, because not always things go right, it happens sometimes, for example with the financial crisis that impacted us heavily, then we started to pray, then prayer helps us [...] (Delun, Ibidem). 
Again prayer must be considered here more as a formal mean, what really must be taken into account is its sociological and psychological implications. In other words in absence of such interpretation the business would have lost part of its revenue or it would have become bankrupt, like for many of the surrounding businesses operating in the same field. A very interesting case came out from the description of Yongnian about how in a circumstance of economic crisis and depression prayer and an interpretation of business as centered on an higher purpose intervened to actually bring him out of that same economic crisis:

God always give us courage to work, when we do things we always pray, we thank God for everything. When I've started the business I prayed to God and He sent me many clients and many people. But then I forgot about God, and I finished all the merchandise, I've stolen from God blessings, I thought it was because of my abilities to sell, then the second season I've bought a lot of merchandise that was blocked in the store, it was hard to get the bill going, then I went to God, I've prayed confessing my sin and little by little I've finished selling all that was blocked in the store (Yongnian, Ibidem).

Yongnian cannot explain in purely mathematical terms why his business was able to survive to a concrete threat of failure, which shouldn't be a surprise for those that pursue a more sociological explanatory strategy. Coming out of an economic crisis for him and many other entrepreneurs signified the putting in practice of those beliefs and acts which was the necessary source of strength and meaning. Another great example of this came from the interview with Xun that while reconstructing his experience of conversion he pointed out how his experience of salvation helped him to overcome his difficulties:

For three years I had debts and I didn't know it was because of God, I didn't want to listen to the warnings, God was correcting me. I tried with any system, I gave away money, I asked to the police, people around me but it didn't work. My mother called me, she asked me what I was doing, I said that I'd found the money I needed but my mother was praying for me. At that moment I gave up and I've accepted that she pray for me, half hour late the shareholder of the company that did not acted honestly gave me back the money. It was a miracle (Xun, Ibidem).

Xun here is telling the story of his conversion, from being in a moment of crisis, both for his business and for his personal life, he decided to 'give up...and accept', to give his life to God embracing the Christian faith. This experience led Xun to embrace Christianity and led him to a drastic change in his life. He started to share his beliefs, to follow honest principles of business in an environment of corruption and economic crisis:

In the beginning and for several years the deficit of the company was high but I insisted, I insisted and God was taking care, I followed the biblical Christian values, it wasn't easy but I overcame it. God gives faith and confidence, I had a courageous heart to resolve the things in a managerial way. [...] When we lose riches we feel anyway peace and grace and we can face the problems (Xun, Ibidem).

Up to this point I was able to show the presence in the field of the theoretical model, with some contextual adjustments for the case of prayer and some assistants to the preconditions. It shouldn't be surprising to find the presence of this set of Calvinist beliefs among today's Protestant Chinese entrepreneurs, in the same way any social structure reproduces itself in a different 
historical context out of the same cultural origin. This anyhow doesn't happens without a certain degree of syncretism like for the case that I mentioned of the organizational form of the church. So far considering these results the belief seems to have its effect on how an entrepreneur works. If someone wants to consider unbiasly the business practices of those Chinese entrepreneurs he must therefore consider the role of this unreplaceable set of beliefs. Evaluating whether or not such explanation is the only one valid will be the object of the following section.

\subsubsection{Behind the Scene}

In fact, before I turn into the analysis of the results concerning the second group of entrepreneurs with no link at all, or very few links, with Protestantism I must report some statements of Protestant entrepreneurs that may lead the reader to consider the possibility of the intervening influence of a Wenzhou's profit-oriented mentality. I've considered this category as an all-encompassing factor that for a number of reasons (cultural, economic, social...) may lead to the same conclusion about economic success without the need of any religious belief, invalidating the final analysis. Since my first interview with Delun the possibility for such explanation came right into the scene:

[...] we had this success also because we are Chinese and we have a very strong entrepreneurial willpower. [...] to be an hard-worker... the Chinese culture, mainly the Chinese culture that encourage us to take the risk in trade [...] (Delun, Ibidem).

The business is strong in Wenzhou, they pay low taxes, there is more money therefore they accumulate more. [...] In Wenzhou the business is strong because they work hard [...] the people of Wenzhou travel a lot, we are like the Jews of China, in all Europe we are known for this. Since ancient times we are of a stronger thought, also the other cities consider us this way (Chao, Geu $\mathrm{Xi}$, Wenzhou, 26/08/2015).

The Chinese people are known to be hard workers everywhere. It also depends by which part of China they come from, the people from the south work harder, you give them opportunities, they make money then they work harder because they see the profit very clearly (Ling, Baoding, Milan, 29/05/2015).

In the mind of Wenzhounese the money is very important, it come first, they think that if you have a lot of money you can speak louder, you can have a strong voice, it doesn't matter if you are a good person (Xiu, Ibidem).

In the beginning Wenzhou was poor, you had to work very hard, many [now] do business and are successful, if you live here you want to learn from those that have success, is the environment (Tai, Ibidem).

The case for a Wenzhou's profit-oriented mentality, rather than a generic Chinese profitoriented mentality, can be made both on the basis of results from this sample and on historical and contemporary findings about Wenzhou's contribution to business compared to other areas of China and also in European countries of their migration such as Italy (Vendassi P., 2014; Cao N. 2013). Ling introduces here what soon will be identified as a cultural propensity toward business present in the area of Wenzhou. In several cases I saw the entrepreneurs identifying their entrepreneurial uniqueness primarily on the basis of their Wenzhou's identity, compared to other cities and regions 
in China (as it is evident from the words of Zixin). Among the Christian entrepreneurs, there is another important element that came out from their own description and that may interfere with the interpretation of the model. Such element concerns an absence of awareness on human rights that came out from their own words which results in what I've defined before as Stakhanovism, a behavior characterized by hard work not as a consequence of a set of values but as a result of mere constriction (what will be described as Constriction explanation for the second group). When Kong is asked about 'why work is so important for him' he doesn't give any interpretation based on belief or values but he confesses to be 'forced that way'. Shaiming even criticizes his countrymen, especially the first generation of immigrants arrived in Italy during the 1980's from the surrounding country side of Wenzhou.

This generation, as it will be clear from more examples from the second group of entrepreneurs, came out from poverty and saw work as a necessity, and was led to work hard just to escape from poverty. It is because of this first generation of migrants that such economic boom has happened. During my visit in Wenzhou for example I had the chance to hear the story of how the parents of Bingwen were able to grow in few decades from being a poor family of farmers in the village to become the owners of a textile company in the city, exporting all over China and abroad:

\footnotetext{
If somebody tries to work less he loses a lot, the other person is forced to proceed and take his place, some tried to work less but you can't accomplish anything, in some sense we are forced that way (Kong, Ibidem).

[...] the world is very beautiful but many of us Chinese we don't look at it we only know how to work. Chinese people have will, a will that for me comes from poverty, when the people is poor. It also comes from following the others, if you have a job, I see that you work and the same will to do the same work comes on me. You are rich and the other person spontaneously wants to become rich, they copy each others after all (Shaiming, Ibidem).

I work hard because those that come from China here to look for a job and improve their economic condition (Guang, Ibidem).

Many people come from mainland China and the economy wasn't good, things weren't easy, when policy and freedom came then it changed their lives, because they were not able to do that in China, to make money was hard in mainland China (Ling, Ibidem).
}

Guang and Ling, although being Protestants, tend here to give a quite more materialistic interpretation of hard work based on the mere desire to make money. Ah Cy during my ethnographic observations at Via Sarpi, the China town of Milan confessed with me, behind the 'romantic' view of work, how this tension toward profit was only due to the love of money among Chinese people, regardless of their religious beliefs. Ah Cy lamented how Chinese businessmen in Via Sarpi thought always about money. Ah Cy gave me a clear social interpretation of the role of money among those workers. 'If you don't make money', he said, 'you are not respected, you may be a person full of qualities and good values but if you don't have money, you are nobody for them', both for Christian and not Christian entrepreneurs. This points out another important element involved in this constriction explanation, what I can call 'the law of imitation'. It is very common 
among Chinese people, and particularly among the entrepreneurs to do what others are doing. If the other people around you become rich, as it is happening in today's China, then you want to have the same things. Many times if somebody among friends or relatives decided to open a clothing store, the other people around him decided to open the same type of business. During my visit in China I interviewed Mei, an entrepreneur that regardless of the fact that she was not Christian, stated the influence of such process of imitation in Chinese business:

Another reason is that people are competitive and jealous, if your neighbor has more you want more, if you are poor they don't respect you, if rich they respect you. It doesn't concerns things but the culture, it comes from the culture, they search respect so they want to come out of poverty (Mei, Ibidem).

The same goes for Christian entrepreneurs. For example during the interview with Nai it came out that the business environment of Wenzhou pushed him to decide to be involved in business. And this process of imitation leads them to use their surrounding also as a personal network. During my visit in China I've witnessed how among the family members of Bingwen in Tonglu his parents started first a business producing scarves, then one aunt decided to do the same business with the same system of fabrication but with more modern machines. Then another uncle was appointed to pack the material and send it to the city of Yiwu close to Tonglu, a trading center for the majority of products that many foreign companies buy and send in Europe and all over the world. Likewise, at Via Sarpi, the China town of Milan if a store opened during the holiday then all the other stores remained opened. In fact the Chinese entrepreneur brings the same exact pattern of business, the same type of products in Milan from his motherland in Wenzhou. Ah Cy sees also a difference between the first and second generation of Chinese immigrants. Young people are more integrated with the Italian culture, they result to have a weaker propensity toward money whereas the old generation is more oriented to make money and become rich at all costs. Even among Christians there were cases of ruthless actions, taking advantage of others for the cause of money. This view of Ah Cy may then lead the analysis to consider how critical it is to establish a unilateral view of the role of beliefs in business.

In order to understand the real role of the religious belief, it was also very important to adopt an ethnographic strategy based on taking the perspective of the 'outsider'.

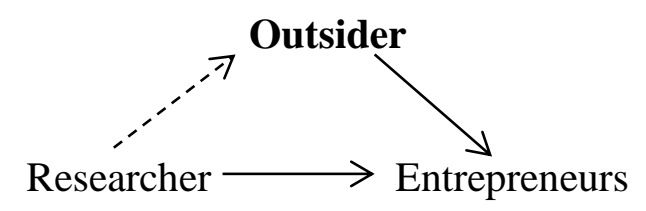

The outsider in the case of the interest group was an Italian entrepreneur. I will call him here Mario, Luca or Giulio. During my ethnographic observations I had the chance to interview several outsiders. Mario with his business is always in strict relation with the network of Christian entrepreneurs that were part of my investigation. I've asked him particularly if he noticed any 
difference between the Chinese Christian entrepreneurs and the rest of Chinese entrepreneurs that he encountered on a daily basis. His answer gives me some interesting insight on how difficult it is for an outsider to do business with Chinese entrepreneurs and how then the Christian Chinese entrepreneurs helped him get started, especially in the case of Heng:

When I first came here it was hard because there was suspicion, to whom could I talk to? The only one who gave me trust was Heng [...] he helped me because there was a wall with everybody else [...] I thought the problem was that I was Italian but then I understood they were afraid if what I proposed was legal, why this suspicion with business? [...] now the benefits came when there was mutual trust in the job concerning merchandise, payments [...] they don't let me enter the circle because they thought I wasn't trustworthy (Mario, Milan, Milan, 30/01/2015).

Mario, started working with Chinese entrepreneurs after his own Italian business of furniture failed. He initially experienced a cultural shock. Nobody was willing to cooperate with him among the Chinese businessmen until Heng, a Chinese Christian entrepreneur, decided to give him a chance. Later on Mario, because of his knowledge of the Italian language became the administrator of the whole storehouse of Chinese stores for the administrative things. The Christian Chinese entrepreneur that acts inside a context of Chinese entrepreneurship worked in this case as a bridge, and offered what was missing in the surrounding Chinese entrepreneurship context: trust. Added to this Mario expresses his external view of the Christian entrepreneurs in a context of other Chinese businesses. When I interviewed Mario he didn't necessarily knew that those Chinese entrepreneurs were Christians but what appear to be just a uniform environment had some fundamental differences in the business approach. Even if Mario didn't know that they were Christians he noticed from the beginning something different in their behavior that all those entrepreneurs had in common and that was crucial to build trust, guarantee the flow of economic transactions and better interactions:

I didn't noticed this immediately among Christians, now I see it better in Heng, Bo or Zhenzhen [...] recently I understood, is not just friendship but something more that they have in common, I appreciate it although I don't belong to it, there is a better dialogue, I give value to their behavior in business (Mario, Ibidem).

There is therefore a substantial difference in the way those entrepreneurs do business depending even on their religious identification. More interestingly during my job-shadowing with Chun I had the chance to witness the presence of another Italian outsider that was working in partnership him, Luca. During our interview Chun described how after working for a long time with Luca they decided to open a new business together. It must be noticed that it is very unusual for a Chinese entrepreneur to get into a business partnership of a shared business. Chun underlined how this partnership helped him to start his own business (Network explanation):

Then with an Italian associate we decided to start, for one year and a half, two years, he is my friend.

We work together and there is a good relationship between us (Chun, Milan, Wenzhou, 06/10/2015). 
This inter-ethnical unusual business partnership gave a huge potential on the level of the range of economic actions that Chun was able to activate. The Italian law in fact prohibit strangers to own a tobacco shop unless they obtain the Italian citizenship. Working with an Italian helped Chun to open a bar and also a Tobacco shop, increasing his business potential in an environment of mutual trust and friendship. Luca on the other hand found it easier to work together with a Chinese colleague because of the notorious Chinese flexibility on the job. What came out from Luca, the outsider in the case of the second group, may lead to the acknowledgement of the possibility of trust and multi-ethnic network creation regardless of the religious factor. During my interview with Luca it was interesting to see his perspective on the Chinese people he was working with (Chun and his cousin), their mentality, and the differences in the way they do business compared to the Christian Chinese entrepreneurs:

\begin{abstract}
Chinese people have a way of thinking, an ideology, they are too much framed. We often argue because we have different ideas of working [...] Chun is framed in his theories, I don't understand much his way of doing. Compared to what I see in China I see that Chun is immersed in work but is more Westernized. [...] Between Italian and Chinese is difficult to work together, the way to express themselves, the ideologies, it is the most critical part. The positive part is that they are more malleable, willing, which can be a positive thing but also negative since people take advantage of it. [...] I don't see all this hard work in Chun, his cousin also does not reason properly. In China they are rigid, I wish they were rigid here too. I don't see it here anymore today (Luca, Milan, 14/10/2015).
\end{abstract}

Luca points out here the challenges of working together with a Chinese entrepreneur running the same business as a co-boss. Particularly, according to Luca's perspective, there is an emphasis on work among entrepreneurs of Wenzhou, but after coming to Europe they somehow lose such emphasis. Also apparently in the eyes of Luca, Chun is not particularly different from other workers in his hard work although he, like many Chinese workers, is more flexible and willing to work long hours (Stakhanovism). However coming in Italy, according to Luca, many Chinese entrepreneurs lose their hard work propensity. Apart from that, and contrary to what I mentioned about Mario for the interest group, there's no real significant difference then in terms of the external perception of their business. Another clear evidence of this came when I've interviewed Guiying. Guiying had to decide who to hire for his new restaurant and he gave me an interesting reason for choosing Chinese workers instead of Italians:

Chinese guys work faster, work is work, we must do it. Even with strangers [non Chinese] but is slower, they come late. It is not easy for a Chinese to find a job, the level is high in Italy and still low in China, we must grow. The restaurant is always full of Chinese people. Working hard is normal in China, before us [in this company] there was an Italian group with twenty products but we were forced to do more, even Friday I finished but the Italians want that we do Photoshop. We are forced. They don't work as us, they are lazy (Guiying, Beijing, Milan, 22/01/2016).

Furthermore, after submitting the questionnaire on the measurement of the General Selfefficacy Scale to both the first and second group of entrepreneurs there were interesting results. They seem to confirm, with the necessary caution, the presence of self-efficacy for both groups. 
Self-efficacy seems also to be strongly present in the case of the Protestants. Exception must be made however for items two and three since they contradict their ethical values. If I go to the second group of questions based on the Self-efficacy Scale through PAS, the level of agreement with the items tends to be more than double. From those elements it can be seen a presence of selfefficacy, that, although not uniform in the sample, it is not accidental and is somehow in line with my original theoretical argument.

TABLE 17: $\quad$ Results from the questionnaire on the presence of self-efficacy for both first and second group. It is possible to see a higher presence of self-efficacy among the first group particularly from the area of Wenzhou. It becomes more than double considering the belief in PAS. Regardless of the belief however self-efficacy tends to be prominent among young male small business owners.

$\mathrm{n}=(48 \mathrm{C}+31 \mathrm{NC})=79$

self-efficacy $>3$

$\mathrm{m}$ AGE $=30$
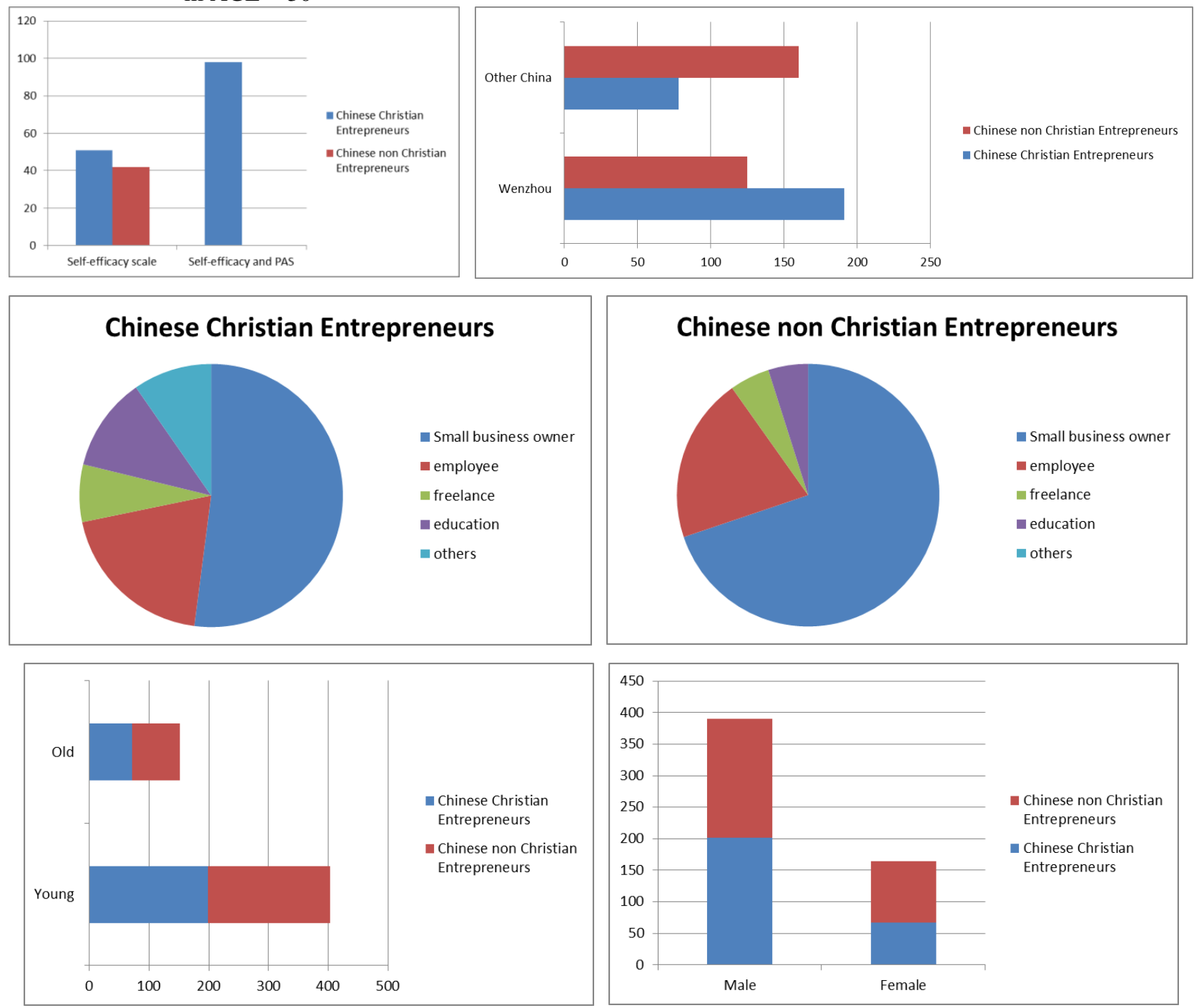

The results so far, with some exceptions, show therefore the presence of the preconditions and the presence of self-efficacy. It was also possible to isolate the crucial effect of the belief in PAS on self-efficacy. In this way it was possible to see indirectly the impact of PAS on the 
economic success, especially considering their exposition to situations of economic risk and crisis through job-shadowing and reconstructions done in the interviews. The next step now will be to see if this argument can still be valid if someone decides to consider the findings for the second group of Chinese entrepreneurs with no or very sporadic relation with Protestantism. Another critical aspect that may affect my final analysis so far is the difficulty in verifying the borders between the different categories of the model for the system of belief. In other words even if the Protestant belief should be playing a determinant role, it remains still a challenge to define the degree of such role.

\subsection{Further Confirmations from a Visit to Wenzhou}

\subsubsection{Similar Propensity on a Larger Scale}

As I've examined the economic interactions of those entrepreneurs involved often a strict relation with the Chinese motherland. The migration process in fact was not an hindrance for the networks of relations of those Chinese entrepreneurs living overseas. In order to investigate more and to have a clearer idea of the phenomenon under my analysis I decided to go straight to the origin of this profit-oriented mentality and I went to visit Wenzhou. My access to the area was possible both because of personal contacts through the entrepreneurs living in Milan and also through support from the Academia. Through my personal connection with some professors at the Bejing University I was able to enter into contact with an informant in the city of Wenzhou that as a researcher in the same field already interviewed many people in the area and was willing to pass me his contacts. In Wenzhou I had the chance to interview a consistent amount of entrepreneurs and to visit their workplaces. The visit also helped me to extend the framework and understand better all the background of the reality of Chinese entrepreneurship, its Wenzhou model and the impact of Protestant Christianity. Many of the elements that I've observed and found in my fieldwork in Milan were confirmed overseas and sometimes on a much larger scale than what I was able to observe in Milan. One example that almost immediately captured my attention was the large-scale presence of the Boss-Christian phenomenon as already pointed out by the literature:

I share topics of faith during work [...] doing these activities can help to share the Gospel, I put my faith in my job and I can work for God as I share through the job the Gospel. My job is to build a platform to share thoughts not just among Christians, they come to the table to share 15 people only 5 are Christians. In the beginning the brothers could not understand, it is not common, if you serve you serve in the church but this is a bridge, some came to help in the beginning we were few, by the time it attracts more clients (Bai, Wenzhou, Wenzhou, 20/08/2015).

Bai is a good example of what a Boss-Christian really is. During my visit in Wenzhou I had the chance to interview him and to witness his strong work ethic mixed with a huge involvement in 
church life. Bai first worked in the logistics, then from 2005 he started his own business for hardware accessories. In 2012 he opened a photographic store for weddings and in 2014 he started a bar and center for social activities (Amazing Dreambar). Apart from his strong entrepreneurial spirit, Bai uses his funds to support students to study theology in seminaries. He supports Chinese missionaries to south-East Asia and he directs a fellowship of Laoban (Christian Bosses) in Wenzhou. During my visit I had the chance to attend such fellowship of Laoban and after it I had the privilege to interview Xun, a visionary businessman and president of that association. As I interviewed him he told me how important it was for him to find and promote a religious-based identity and interpretation for his business:

One year later the 'commerce fellowship' changed into a traditional church, I thought however that was important to maintain that emphasis on business, so that I created my new fellowship of commerce. [...] In the new fellowship I changed the target and became World Chinese Association not in the form of a church but as a voluntary association based on biblical values that can contribute the nation and give thoughts rooted in the Bible and in the thought of Christ with the purpose of having an economic growth (Xun, Ibidem).

Xun is a great example of successful Boss-Christian in Wenzhou. He is also director of the fellowship of Laoban (Christian bosses). His association has a leading role in promoting the expression of religious values through the accomplishment of business success. Even when he had the chance to go back to a more traditional type of religious involvement he could not imagine a situation of disconnection between his managerial activity and his business. This led him to the decision of creating a new business fellowship which has a strong impact in the community of Wenzhou, especially among young boss-Christians ${ }^{9}$. Cases like Yi or Qiang are very significant examples of Bosses (Laoban) also permeated by a vision for their business that goes beyond the mere working activity.

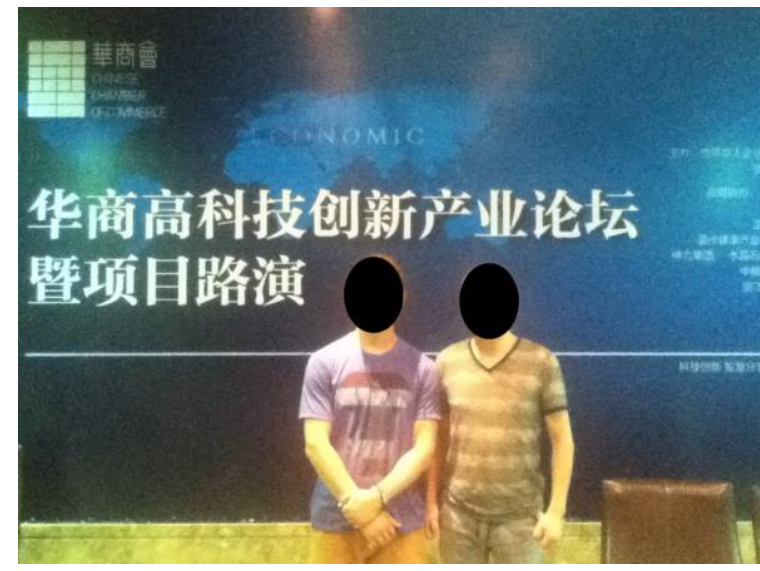

During my visit in Wenzhou I also had the opportunity to attend a meeting of more than 30 Christian Bosses called 'commerce fellowship'. The meeting consisted of a lecture from professors both from Hong Kong and Wenzhou on how to be able to succeed in the financial crisis. The meeting started with a time of worship then several professors participating to the meeting spoke about business on trying to understand how to glorify God in this situation of economic crisis, how to become strategic with new forms of management, utilizing the web and other sources of information, adopting a new 'community economy'. This type of meetings promoted by an

\footnotetext{
${ }^{9}$ Xun and Bai (from the right) at the center of their 'fellowship of commerce'. Xun is training the young Bai to become a successful businessman but they both are very active in expressing their faith through their business. 
association (World Chinese Merchants Union Association) encourages the boss Christians to enter into a social network for business in order to achieve greater results with the change brought by the advent of e-commerce in China. Every business strategy however in this case finds its origin in the principles of the Bible.

The case of Xun or Bai was not an isolated one but it was common. Those strongly involved in church leadership were also Christian bosses of multiple businesses. Yi during my interview gave his interpretation on the source of motivation for his business:

I opened the first store and I was teacher on Sunday school. After graduating in 1993 I worked for ten years at the store but I was also part-time preacher [...] In the past there were a lot of part-time preachers, then I thought innovatively that the church is structured to enlarge itself, for this reason I changed the store into a multiple business, this is my reason [...] some companies don't know the management, I suggest to learn it [...] the other companies don't know how to plan, they only think about money and perhaps they even obtain them illegally. (Yi, Ibidem).

Yi found the motivation to increase his business in the application of a religious principle of multiplication. The success that came out of this strategy was evident, Yi now manages directly 9 pharmaceutic stores all over the Zhejiang province, his company is objective-oriented and he was able last year to open 100 new stores in Wenzhou.

Another element confirmed by my visit in Wenzhou is the one of gender. Men and women alike were strongly involved in business creation and success. At the same time the religious interpretation seemed to last in their personal interpretation of being a Boss-Christian woman:

[...] we don't cheat people we give the ordered products, with reasonable prices, we don't invent false growth of sells, my sell is true we don't cheat. We give trust even if others cheat us. We don't share our faith with everybody but we [mostly] talk of production (Min, Wenzhou, Wenzhou, 23/08/2015).

In Wenzhou after interviewing Min I also visited the factory owned by her and Ju, two sisters that perhaps best represents the important role of women in business creation and economic success ${ }^{10}$. Min and $\mathrm{Ju}$ are mostly designers that together created and are currently running a factory for export of furnishing in Wenzhou. They also have an online store with Taubau and they are very involved in export overseas, specially Europe. Min frequently travels to Europe to do business. Her company produces high quality furniture and cabinets for big chains of shopping centers and stores. Contrary to almost every factory in China

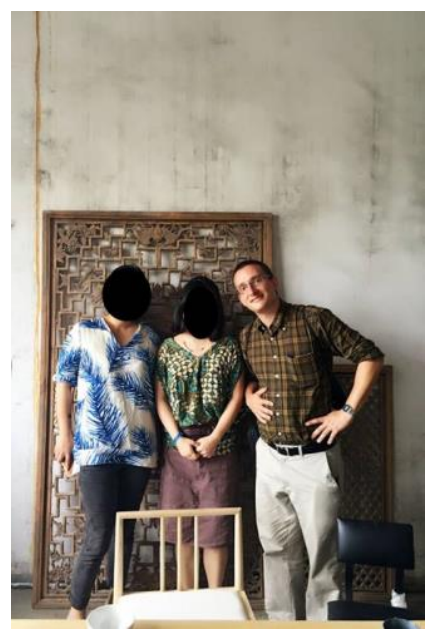
Min and $\mathrm{Ju}$ decided to change recently their production strategy and transform into a customer made production. They had the visionary strategy to change the image of made in China from low cost and low quality products to good quality and reasonable prices. Min expresses her faith as a Boss-Christian woman in the way she manages her company and the workers. They have in the

\footnotetext{
${ }^{10} \mathrm{Ju}$ and Min (from the left) at the factory of furnishing that they manage.
} 
factory an area of rest for workers, a smoking area. She tries to treat well the workers with respect differently than most of the businesses around her in the area of Wenzhou.

During my visit in Wenzhou I had the chance to interview also Du, a Boss-Christian woman that does business with chemical products for printing and packing, plus a clothing store and moreover she's also a pastor in a huge house church at the last floor of a skyscraper in the financial area of Wenzhou. Chao is also another interesting case for what concerns the migratory process. She is a woman entrepreneur that I had the chance to interview in Wenzhou and that lived in Trieste, Italy for thirteen years. Like her many Chinese entrepreneurs are divided between their children living in China and relatives working with them in Italy. Chao was also able to integrate herself in the foreign context of Italy through a big Chinese church in Trieste with more than 200 members. What is important to take into consideration behind the words of those women entrepreneurs like Min is also that trust is a very rare element in today's Chinese society and is rarely displayed outside the circle of family as I will explain later for the second group of entrepreneurs.

Another element confirming the findings that I've done in Milan Italy, concerns the role of the house church. Xiu, which I had the opportunity to interview during my visit in Wenzhou is a Christian entrepreneur that owns a factory of LED lamps and exports them in Italy through the contact he has with some believers of the Chinese church in Milan. Mainly Bo, Deming and Shing, three Christian business partners, were selling those same type of LED lamps in Italy, produced by Xiu in his factory in China. Even in Wenzhou Xiu has many clients from the house $\operatorname{church}^{11}$ :

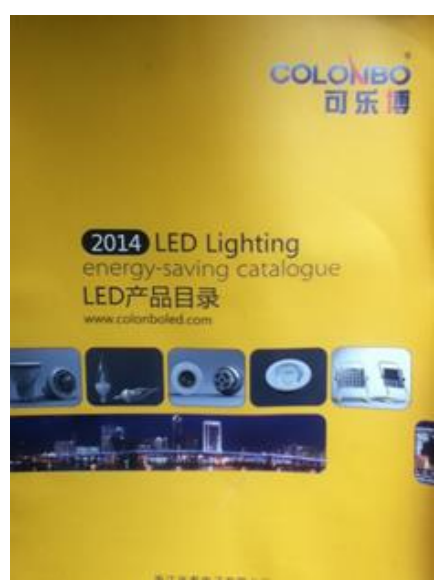

I provide LED at church when it was built I provided the lamps with a cheap price, if you buy them in the regular market is expensive. Another church knows that I make LED lamps, some people introduce me and they let me build the lamps. [...] We have many Christians, many people ask but ask because the prices are high (Xiu, Pan Qsiao, Wenzhou, 28/08/2015).

Another element confirmed and deepened by the visit in Wenzhou was the assistant to the preconditions of my model on the role of Sacred Scriptures in business. During my visit in Wenzhou when I attended the meeting of Boss Christians called 'commerce fellowship', a group of visits to several Christian companies was publicized, in order to teach the participants how to use the Bible in order to do business, how to manage an enterprise, how to advance the values of a company, how to do good advertising:

\footnotetext{
${ }^{11}$ Brand and logo of Xiu's business of LED. Xiu exports LED in western Europe from Wenzhou and is also an active member of his house church. 
I also follow lessons in Shanghai about Bible and management, then in Taiwan I follow the 'Joshua management' to follow and rule the business. The brothers helps me if I have difficulty, we talk and they help me with advices. This year for example I had great difficulties and the brothers gave me advice about what to do, which decision to take, it was very good (Nai, Ibidem).

During my visit in Wenzhou I also had the opportunity to interview Nai, a Boss-Christian also very involved in his house church, connected with a network of Christian fellowships for Bosses (Laoban). Nai is a manager of two factories of materials for hospitals in United States. Through the connections with other Boss-Christians and the principles of management from the Bible Nai wondered how to manage his company at best, deciding recently to enlarge his factory, expanding the portfolio of clients, having a better communication according to international standards. Such emphasis on the Sacred Scriptures (Literal reading of the Bible) involved teaching and training focused on the application of biblical principles to their business strategies such as 'being an agent of change', 'believing in the impossible', 'living with a purpose', 'having high expectations', 'living according to high moral standards', 'striving for excellence', etc.,....

But the greater and exhaustive example of the network role of house church during my visit in Wenzhou came when, after participating to a 'Laoban fellowship', I had the privilege to interview Xun, an excellent case of Boss-Christian, president of the World Chinese Merchants Union Association and member of honor of the Chinese Chamber of Commerce. Xun worked in the clothing sector with his own brand and as a successful entrepreneur was involved in training younger Bosses like Bai. When Xun was telling me the story of his dramatic conversion to Christianity he recounted how the real turning point of his life was when he met a 'commerce fellowship' of Boss-Christians, a place where Christians of all sorts, some were Bosses, some party members, some University professors, met together to talk about business, something that let his faith to a drastic growth:

\begin{abstract}
In the commerce fellowship they were talking about business, it was a new world for me, my eyes were wide open. In this job life and business can go together, it was an important place for me a new earth. [...] Belonging to this association [Laoban fellowship] helps people to build relationships, it is like a part of the whole, a line inside a bigger composition that combines many contacts and every part is important, and the influence is big, from Wenzhou to Guangzhou or Shanghai. Our association has its points between the lines and its circles, some of them are interesting, all based on business. The impact is also on the development of personal talent, this is what we seek, the services of the Association help the industrial élite or other sectors. If we introduce the Gospel inside those points and lines and circles of relationship they will impact more areas of China, more businesses of what we by ourselves can do, it is very important. We have 200 areas combined, exhibitions, people that convert [to Christianity], constant communications, we are all together somehow connected and we express the values that have their impact on business (Xun, Wenzhou, Wenzhou, 22/08/2015).
\end{abstract}

The spiritual conversion of Xun occurred when he finally found the possibility to connect his business with his personal faith. As it is clear from his personal biographic reconstruction such choice to belong to the house church has its instrumental reasons but it is not limited to it. Xun therefore feels like he is an 'helper', a support, a business consultant and a network promoter at 
work. He uses his resources specially to help the young members of the Association. He shares his business wisdom with them and does a pioneering activity asking experts to train young members of the Association to establish partnerships and share resources $^{12}$.

The visit in Wenzhou also helped me to see beyond the romantic representation of the

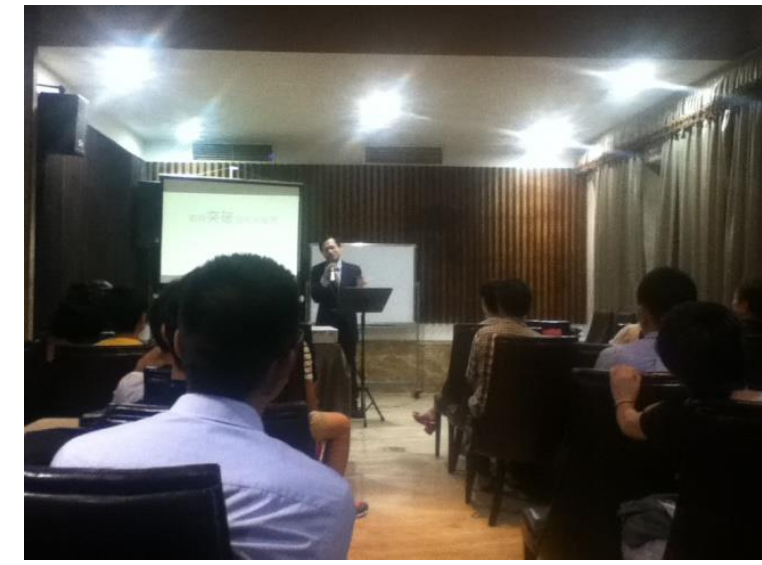
phenomenon and to realize also the downfall of the theoretical background. For example during a focus group in Wenzhou Ya pointed out that, although Wenzhou still remains the capital of private economy in China, the city was facing a financial crisis at that moment. Many traditional businesses were failing, the government had an huge public debt and many companies were not able to face the crisis. Ya works in a bank and gives a lot of loans to Christian entrepreneurs that although were facing sometimes situations of economic debt, which can cause discouragement and depression, they were confident and had hope that in the future the economy may grow back again. Economic risk, challenges and difficulties usually tend to cause stress, frustration and hypertension in any entrepreneurial activity and if not addressed they can lead to failure or substantial losses.

Concerning the role of economic risk the visit to Wenzhou also helped me to see the consistency of the impact of the belief in PAS in the life of those entrepreneurs. When I was in Wenzhou and I participated to the meetings of Laoban with more than 30 Boss-Christians, a speaker talked for example about the importance to 'relax' and 'rest in God's salvation' as a legacy in front of the financial crisis that is taking place in China today. Same reaction was present in the entrepreneurs that I've interviewed even though it was not possible to apply more prolonged techniques of observation such as the job-shadowing due to limits of time.

Another interesting dimension that seems to confirm what I've observed in Italy was observed in Mainland China among entrepreneurs with no relationship at all with the Protestant faith. It has to do with the possible presence of a minority-effect among those Chinese entrepreneurs. Can the fact of being a Chinese migrant in a condition of minority in and of itself guarantee economic success? During my visit in Tonglu, not far from Hangzhou, I had the chance to interview Cheng a Taiwanese migrant living and doing her business in China:

In the beginning I had difficulties to get settled in China, the language was a problem, even if for me not so much since I'm from Taiwan, I'm strong and I was able to face the difficulty (Cheng, Ibidem).

\footnotetext{
${ }^{12}$ A guest-speaker from Hong Kong speaks at a fellowship of Laoban (Boss-Christians) organized by the World Chinese Merchants Union Association in Wenzhou about business according to the principles of the Bible. 
Cheng was an important exception to the study whereas in general were the Chinese people who were constantly migrating overseas. The economic market in Taiwan during the recent years was not going good so Cheng decided to establish her own factory in China where labor costs were cheaper and there was possibility to reach higher profits in Wenzhou. However with the rise of labor costs even in China she had to face challenges and economic risk. Whereas in the other cases under my analysis the migrants were coming out of China in Italy, she was a migrant from Taiwan to China and she expressed the same type of challenges, the same lack of a network of support added to the lack of cooperation from workers copying her design and re-selling it to other companies. Yet she was able to overcome those difficulties without any significant consequence on her work ethic. Therefore somehow the Chinese minority, or minorities coming from the extremeEast, usually are more oriented to pursue business. The reason why such minority-effect is not equally valid for other ethnic minorities will be analyzed in the following pages. 


\section{Chapter VII}

"If you work hard enough at it, you can grind even an iron rod down to a needle"

Chinese Proverb

\subsection{The Other Side of the Chinese non-Christian Entrepreneurship}

\subsubsection{Inheritance of Materialism}

I come now to present the results of my investigation on the second group composed by Chinese entrepreneurs in Milan with no contact, or small and irrelevant connection, with the Christian church. The information collected from interviewing and job-shadowing the Christian entrepreneurs is then here compared with the second group of Chinese entrepreneurs with no link with the Protestant faith in order to check the presence of other sociological explanations:

TABLE 18: List of the non-Christian entrepreneurs under investigation. The ones with the grey line were part of the job-shadowing activity and Luca is the Italian outsider.

\begin{tabular}{|c|c|c|c|c|}
\hline Nickname & Work Sector & $\begin{array}{c}\text { City/Region of } \\
\text { Origin }\end{array}$ & Age / gender & $\begin{array}{l}\text { Date of the } \\
\text { Interview }\end{array}$ \\
\hline Shilin & Tailoring & Wenzhou & $40 \mathrm{M}$ & $30 / 03 / 2015$ \\
\hline Ruomei & $\begin{array}{l}\text { Manager of } \\
\text { Restaurant }\end{array}$ & Wenzhou & $32 \mathrm{~F}$ & $30 / 03 / 2015$ \\
\hline Quan & Marketing & Zhejiang & $26 \mathrm{M}$ & $23 / 04 / 2015$ \\
\hline Quianfan & $\begin{array}{c}\text { Store Manager in } \\
\text { a café }\end{array}$ & Wenzhou & $32 \mathrm{M}$ & $30 / 03 / 2015$ \\
\hline Boqin & $\begin{array}{c}\text { Boss of a } \\
\text { corporation of } \\
\text { entreprises }\end{array}$ & Zhejiang & $45 \mathrm{M}$ & $26 / 03 / 2015$ \\
\hline Ho & $\begin{array}{c}\text { Shopkeeper in } \\
\text { watches }\end{array}$ & Nanjing & $26 \mathrm{M}$ & $30 / 03 / 2015$ \\
\hline $\begin{array}{c}\text { Chu Hua } \\
\text { Fuhua }\end{array}$ & $\begin{array}{l}\text { Psycologist } \\
\text { Customer } \\
\text { Assistant in } \\
\text { fashion }\end{array}$ & $\begin{array}{l}\text { Heilongjiang } \\
\text { Laoning }\end{array}$ & $\begin{array}{l}19 \mathrm{~F} \\
28 \mathrm{~F}\end{array}$ & $\begin{array}{l}28 / 03 / 2015 \\
20 / 06 / 2015\end{array}$ \\
\hline Chun & $\begin{array}{c}\text { Bar and Tobacco } \\
\text { shop Manager }\end{array}$ & Wenzhou & $25 \mathrm{M}$ & $06 / 10 / 2015$ \\
\hline Bao & $\begin{array}{c}\text { Store manager in } \\
\text { a restaurant }\end{array}$ & Wenzhou & $24 \mathrm{~F}$ & $30 / 03 / 2015$ \\
\hline$M u$ & $\begin{array}{c}\text { Store manager in } \\
\text { a restaurant }\end{array}$ & Wenzhou & $44 \mathrm{M}$ & $14 / 07 / 2015$ \\
\hline Peng & Business advisor & Zhejiang & $26 \mathrm{M}$ & $06 / 07 / 2015$ \\
\hline Sheng & $\begin{array}{l}\text { Store manager in } \\
\text { a restaurant and }\end{array}$ & Wenzhou & $23 \mathrm{M}$ & $08 / 07 / 2015$ \\
\hline
\end{tabular}




\begin{tabular}{|c|c|c|c|c|}
\hline & business advisor & & & \\
\hline Ting & Food Consultant & Wenzhou & $46 \mathrm{~F}$ & $13 / 07 / 2015$ \\
\hline Zan & $\begin{array}{l}\text { Store Manager in } \\
\text { clothing }\end{array}$ & Wenzhou & $47 \mathrm{M}$ & 06/07/2015 \\
\hline Jiao-long & $\begin{array}{l}\text { Store Manager in } \\
\text { a restaurant }\end{array}$ & Wenzhou & $51 \mathrm{M}$ & $30 / 01 / 2015$ \\
\hline Cheng & $\begin{array}{l}\text { Manager of a } \\
\text { clothing factory }\end{array}$ & Tonglu & $45 \mathrm{~F}$ & $20 / 08 / 2015$ \\
\hline$J u$ & $\begin{array}{l}\text { Boss manager of } \\
\text { a factory for } \\
\text { furnishing }\end{array}$ & Wenzhou & $29 \mathrm{~F}$ & $24 / 08 / 2015$ \\
\hline$M e i$ & $\begin{array}{l}\text { Boss of a clothing } \\
\text { store for children }\end{array}$ & Tonglu & $43 \mathrm{~F}$ & $20 / 08 / 2015$ \\
\hline$Q i$ & $\begin{array}{l}\text { Boss of a clothing } \\
\text { factory }\end{array}$ & Tonglu & $44 \mathrm{~F}$ & $20 / 08 / 2015$ \\
\hline Ping & $\begin{array}{l}\text { Boss of a clothing } \\
\text { factory }\end{array}$ & Tonglu & $47 \mathrm{M}$ & $20 / 08 / 2015$ \\
\hline Biming & Banker & Taizhou & $26 \mathrm{~F}$ & $22 / 09 / 2015$ \\
\hline Luca & $\begin{array}{l}\text { Bar and Tobaccco } \\
\text { shop Manager }\end{array}$ & Milan & $36 \mathrm{M}$ & $14 / 10 / 2015$ \\
\hline Jing & Art Dealer & Chong Ching & $34 \mathrm{M}$ & $22 / 01 / 2016$ \\
\hline$L e i$ & $\begin{array}{l}\text { Founder of Sales } \\
\text { website }\end{array}$ & Wenzhou & $25 \mathrm{M}$ & $21 / 01 / 2016$ \\
\hline Jie & $\begin{array}{l}\text { Restaurant and } \\
\text { Bed \& Breakfast } \\
\text { Owner }\end{array}$ & Hebei & $28 \mathrm{M}$ & 28/01/2016 \\
\hline Guiying & $\begin{array}{l}\text { Photographer and } \\
\text { Restaurant Owner }\end{array}$ & Beijing & $27 \mathrm{M}$ & $21 / 01 / 2016$ \\
\hline Ning & $\begin{array}{c}\text { Waiter and Web } \\
\text { Manager }\end{array}$ & Jilin & $20 \mathrm{M}$ & $20 / 01 / 2016$ \\
\hline Tao & Bar Owner & Wenzhou & $31 \mathrm{M}$ & $30 / 01 / 2016$ \\
\hline Chang & Restaurant Owner & Beijing & $29 \mathrm{M}$ & $02 / 02 / 2016$ \\
\hline Jian & $\begin{array}{c}\text { Project Manager } \\
\text { of a Travel } \\
\text { Agency }\end{array}$ & Henan & $28 \mathrm{M}$ & $15 / 02 / 2016$ \\
\hline Jiahao & $\begin{array}{c}\text { Multiple } \\
\text { Restaurants } \\
\text { Owner }\end{array}$ & Wenzhou & $38 \mathrm{~F}$ & $09 / 05 / 2016$ \\
\hline Guozhi & $\begin{array}{c}\text { Tobacco shop and } \\
\text { bar Owner }\end{array}$ & Zheijian & $34 \mathrm{M}$ & $31 / 05 / 2016$ \\
\hline
\end{tabular}

This second sample of interviews may point out the potential influence of several factors that may play some role in enhancing hard work and in contributing to economic success. This section may be an interesting test to understand the dynamic of business from a more neutral perspective and to see if the theory on the belief can still hold its value. As I recall, the purpose of adding the second group was to check the presence of a Wenzhou profit-oriented mentality. As I've said few lines before concerning the case of Christian entrepreneurs, apart from their religious 
identity, the possibility of such factor emerged. More importantly even for the case of the second group the same idea was mentioned by Fuhua:

[hard work] depends on the area, in the Zhejiang province they work a lot, we from Beijing we want to work but we also want to enjoy life, so we understand better when is time to work, if there is free time I want to do what I like, for example knowing the culture, music, passing time with friends (Fuhua, Ibidem).

Wenzhouren are rich, traders, more ahead of us [rest of China], they have the basis to do business. A lot in quantity. At first they were doing export-import now they do food, and family is very important for them. [...] for me Wenzhouren are more narrow-minded, it is easier to enter if you are part of their group, they think we come from another planet [rest of China] the dialect, they are very closed with [Chinese] students (Jing, Chong Ching, Milan, 22/01/2016).

In Wenzhou the people are different, for them is not important to study, more important for them is money and work, since their grand-parents they don't focus on studies but on business [...] the culture of Wenzhou is different from north China [...] also there is more religion and superstition in Wenzhou $[\ldots]$ in that region they have a greater propensity toward the outside world (Chu Hua, Ibidem).

Chu Hua goes even behind the pure description of it and tries to give a cultural reason for such propensity for money and work in the area of Wenzhou. Before I go on explaining such possibility I will orderly examine all the possible explanations (not all the existing one's of course) that may potentially invalidate the model. First I can easily reject the validity of a self-evident explanation that lean on the impact of the communist ideology (Communist explanation) ${ }^{13}$. Once again Chu Hua, although she grew up learning about the ideology as many of her colleagues, belongs to a second generation of immigrants. Like many other Chinese people she directly

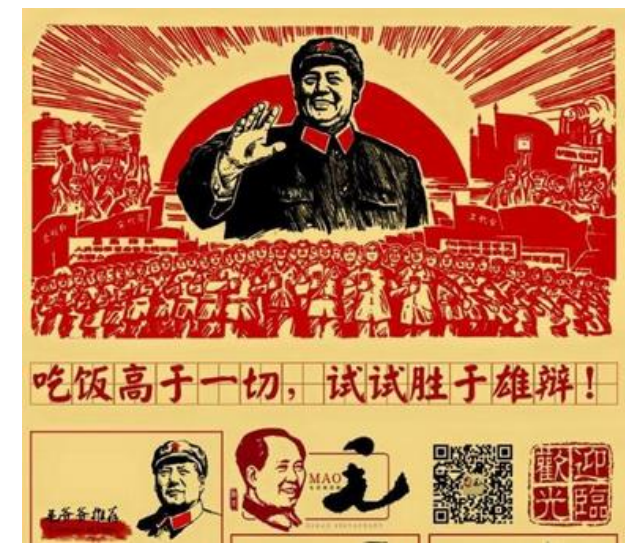
denies the reality of such ideology as a guide or source of identification. Nobody except the governmental elite believes in Communism today in China and after the economic reforms of 1979 Ting senses a radical change in the Chinese society. The economic reforms re-directed the purpose of the people from a socialist project that in its nature was against entrepreneurship into a pure effort to transform China into a capitalistic country:

I've heard of Marx in class growing up [...] thirty years ago they believed in communism but when I was a child they didn't tell me anything, my parents work for the government but there is no identity in it, like government here in Italy, is not communism, nobody thing that anymore (Chu Hua, Ibidem).

[...] also the culture before the reform we always worked but now no more for Communism but for money. Chinese people think to be Communist but they are not! (Ting, Ibidem).

In the case of Chinese people living outside of China we perceive communism in ideological and symbolic terms but inside China you don't feel this way, compared to the past now there is future, before there was the Chinese empire, then the civil war, finally freedom, we passed through the bad times of cultural revolution that damaged our culture, but after the political opening we are close to the western society, we study the market system economy, the market economy, the project economy. We also had many influences from the Soviet Union, we learned from them, they failed because they didn't used a capitalistic system like the one of United States. Thirty years ago China had already abandoned

\footnotetext{
${ }^{13}$ Menu of a Chinese restaurant in Milan often attended by participants to the study. Named after Mao even if no more object of praise of the Chinese migrants of today it still evokes a simbolic identification with their homeland. 228
} 
the ideology of communism, today the Chinese don't talk anymore of communism or defend the ideology (Quan, Wenzhou, Milan, 23/04/2015).

Quan holds what I consider a more polite view of the Communist ideology. She acknowledges the benefits that Communism may had play for her country and she is reluctant to neglect the critical stands of many people against the control of the government. In any case Quan acknowledges that nobody believes anymore in Communism and in its ideology. The only indirect role that Communism have played in the economic scenario was the ability to uniform the country and to bring it to a necessary level of cohesion, very important in the future economic development of China. The fact that the Communist ideology has lost its priority in the lives of the people in China today doesn't mean that it does not exert any role anymore. In fact many are the examples still possible to notice today in China of a strong control over the mind and the social views of people. For example the system of education in China is still today controlled by Communists, permeated by the Marxist ideology that indirectly exalt the value of work on a macro-social level. The Communist explanation can nevertheless be dismissed in having any guiding economic role.

Also, in the biographical records of the older generation there was a sense of exploitation by the government, present during the cultural revolution that was hindering any form of economic development for decades. From 1979 with the end of the 'real communism' on the other hand the Chinese workers were finally left free to commerce, and quickly China was transformed by the hard work of the people. I can see in several cases the signals for the presence of what was previously defined, even for the case of Protestant entrepreneurs, as a form of Stakhanovism, a willingness to work under constraint due to the lack of human rights. For example Minzhe was recalling the fact that many Chinese people come in the country with false documents and therefore work in a factory spending their whole time trying to pay off their debts:

In Prato I've met a woman in the factory that didn't speak, her son died in the factory, she stayed and doesn't want to go back to China, her heart broke. The bosses do pressure but also workers want to work they are the same, the majority in clothing sector (Minzhe, Ibidem).

Those findings may lead me to consider the consistency of the Constriction explanation. From the descriptions of Boqin, Fuhua or $\mathrm{Mu}$ it is possible to identify the struggles of the first generation of migrants, coming from the surrounding countryside of the province of Wenzhou, starting their business with just a background as farmers with no education. The peculiarities of those people was simply a strong desire to escape poverty as it was the case for example of Italian immigrants to America during the twentieth century:

[...] among farmers [first generation immigrants] where everybody knows that to survive in China the population has always been numerous then everybody knows that in order to survive they need to work, the land (Sheng, Ibidem).

First of all in their generation the condition of life in China thirty years ago was that everybody was poor, they suffered, they are afraid of poverty, then they transmit also to the next generation those bad memories, and [desire to escape] bad life (Boqin, Ibidem). 
In the Zhejiang province they work harder because they are very poor, they come from the countryside [...] they didn't come as regular immigrants, how they managed to arrive in Italy? Many died. Therefore surely when they arrived they tried to work and gain money (Fuhua, Ibidem).

From the beginning my parents worked very hard, the money wasn't there, the food was missing, I saw my parents working hard and I wanted to have the same thing (Mu, Ibidem).

We Chinese guys work faster, work is work, we must do it. Even with foreigners but is slower, they come in late [...]. To work hard is normal in China, before us an Italian group had twenty products but we are forced to do more. Friday I finished working but the Italians want that we work on the Photoshop. We are forced. Work not as much as us, they are lazy. (Guiying, Milan, Beijing, 21/01/2016).

Among all my friends I arrived that we didn't have anything, we sweated and worked hard, giving up a lot, there was no holiday and no Sunday. My first holiday was when my son was 4 years old, for decades I didn't have any holiday. And to us not to do any holiday or Sunday rest, for us is normal, if there is work to do you work, if you have this lifestyle you don't have that need, you don't even think about it (Jiahao, Milan, Wenzhou, 09/05/2016).

We work hard in order to work and have more money, I work so much until three in the morning to live a better life, to make more money (Qi, Ibidem).

During my visit in China I had the chance to visit the factory owned by Qi. The machines for the production of scarves were working twenty-four hours a day with turns in the day and at night through the handwork of some sixty years old women. Such type of factory so common in China is a witness of the reality of Stakhanovism due to the lack of human rights and a big desire to escape from poverty. The direct consequence of this evasion from poverty is therefore a willingness to work hard at the point of having no personal will of their own, no desire to change their condition of exploitation as it is the case of Shilin or as it is described indirectly by Sheng:

I come from Wenzhou and in China I've worked as a tailor and working here it has been painful, it was a painful experience, all that I do is the tailor as it was in China so here (Shilin, Wenzhou, Milan, 30/03/2015).

[...] The economic crisis led me to open the restaurant in the middle of the crisis and I must say we opened the restaurant during the crisis and we didn't feel it, you feel it if you have a comparison with the previous years (Sheng, Ibidem).

Yes I work hard because there is competitiveness, if you want to have a career but you don't work for it others will substitute you. We Chinese are more willing to sacrifice, is culture, since the state was never free or democratic, we are not like you [Italians] that pretend (Biming, Ibidem).

The Chinese people work hard, before they were poor, having the possibilities now we do a lot of efforts. The lifestyle is different, we are interested in the next generation. For me work is to have money good life and wealth for the kids (Ping, Tonglu, Tonglu, 20/08/2015).

During my visit in China I had the chance to see the factory of Ping that produces scarves to export outside of China through the help of a trading company. Ping pointed out during the interview how the realm of rights at work in China is recently changing. The workers require an higher salary since the costs of life and the inflation in China are rising. Many of those wholesale factories have dislocated in south-east Asia where the labor cost is cheaper. Ping points out then an important consideration concerning the limit of this potential impact represented by the constriction explanation. This makes the case for a drastic important change that took place in the 1990's with the advent of the second cycle of migration mainly from the urban part of Wenzhou in Italy. Consequently then there was also the rise in the role of the second generation of immigrants in the Italian economy. Such transformation that Jiao-long, Ting and Quan describe, reveals the centrality 
of recent most interesting developments. The constriction and lack of human rights today is decreasing. This will soon change the way somebody should consider the characteristics of work in China, behind the common public opinion:

\begin{abstract}
When we arrived here we wanted a better future from the 1990's we arrived in many, the food safety was hard in China. I worked first as a dishwasher, then at the restaurant, then as a cook assistant lifting the level (Jiao-long, Ibidem).

At first the Chinese worked in a factory but since the 90's it starts the import-export, the power of investment, the possibility to invest [...] the Chinese gain few [money]? He saves money, he works four-teen hours, twenty hours... he works and always like to work the Chinese, also the culture before the reform always worked (Ting, Ibidem).

After the 90's life, everything has changed, in the 30's everybody was trying to survive, find a job, help their family [...] those who are born in the 90's didn't have any difficulties, China has changed, people didn't work with difficulties anymore, but the past generation passed this tradition [of working hard], the new generation search freedom, to travel, to have a good life (Quan, Ibidem).

The question is it is a class of different people, first all those Chinese from the country came, especially from Zhejiang, they don't understand what is the great power that is developing China and they remained at the mentality of those years. The last generation is growing as soon as they enter diverse sectors and places (Peng, Ibidem).
\end{abstract}

The turning point represented by the 90's and the advent of a new social and economic class, in the words of Peng, shows how a constriction explanation is no longer valid today and it will not be valid for the upcoming future of work in China. Furthermore, although such explanation frequently emerged from the data in both groups and especially in the case of first generation immigrants, it is still unclear how such constraint can lead eventually to accomplish any form of economic success. If someone was to compare this social group with many other historical cases of social groups under extended job-constriction (exploitation of children-work by multi-nationals in Africa, similar low-cost work force in South-East Asia or Brazil, work in East Europe under Communism), it doesn't necessary brings them to reach the same output and to have the same tension to work hard. On the contrary in those cases constriction may act as a limitation for economic success in the long term, blocking the real power of action of the individual and his potential. In any case constriction is still a reality among Chinese migrants as results showed from job-shadowing and interviews but it doesn't act as a catalyst for economic success.

In light of such challenges and alienation caused by work it was clear how the Christian entrepreneurs tried to find an elaborate system of belief in order to give meaning and purpose to their economic activity even by pushing them to the achievement of economic success. Now the question rises on how do the Chinese entrepreneurs with no relationship with Protestantism react to this challenge and what pushes them toward the accomplishment of economic success. The frustration and lack of meaning behind the job is often clear among those entrepreneurs and there's no substitute to that system of belief. On the contrary there is almost no type of long-term purpose for their working activity. In the case of Fuhua or Shilin the ideal purpose leaves room to a more 
materialistic enjoyment of goods and commodities, a pure love of money that, as Weber noticed, is common to all humanity and all history:

[...] I want to gain money, I want to find meaning in life, that I'm important, I wanted to be important, to serve others, I want to learn to know other people at work, trying to improve myself (Fuhua, Ibidem).

In China work is very important, I want a house, gold, I want to live, to have a car and live in a better world and I work more for this reason. I don't have dreams I just wish my life can be more comfortable [...] I just would like to live better in the future (Shilin, Ibidem).

My dream is to have an happy life despite work, I do a job to gain and have a better life, to travel, to have money therefore working hard (Jie, Hebei, 28/01/2016).

Like everybody want to have success, Chinese people are ambitious, they always want to go higher, I've worked here, if there is no channel to go up then maybe I need to change and work in another place, the best enterprise realize my dream (Quan, Ibidem).

It is true that also for the first group of entrepreneurs, the love of money can sometimes be linked to the desire of receiving social acceptance. In this case money becomes an instrumental motivation for the achievement of other goals that differ from person to person. But in this circumstance money and prosperity is just a dream or desire that has no link with practical steps to achieve it nor it is connected with any sort of higher purpose able to enhance the diligence and motivation of the individual. Quan nevertheless shows a strive for success, but the source of such emphasis it is not of the same kind. Many entrepreneurs like him embrace the desire to grow their business simply because they enjoy money and they want to get rich. There's nothing new again here, or specific to a capitalistic spirit in the desire to be rich. Values, or the absence of them, doesn't seems to make any substantial difference, whether it is atheism or agnosticism and even in the case they embrace some forms of religiosity such as Buddhism. Many of those entrepreneurs in fact identify themselves as Buddhists, in few cases as Confucianists or Daoists. Daoists or Buddhists possess a radically different set of beliefs compared with Protestantism and their degree of identification with those systems of beliefs is very fluctuant (I will treat Confucianism in a separate section on the Cultural explanation). The religious practice here is perceived by Ruomei as something totally separated from his business, a completely different dimension of life with no influence whatsoever on work:

I'm Buddhist, I don't know if Buddha helped me in difficulties because I can't see paradise, I cannot touch it (Ruomei, Ibidem).

There seems to be so far then no clear and strong source of purpose and meaning for the job of an entrepreneur, whether in trying to give an oriented view of work, a vision for someone's business or in stimulating the emotional background necessary to face difficulties. Work therefore, by many of those entrepreneurs, is often perceived just as a necessity, an obligation that becomes heavy being migrants (Minority explanation). Ruomei, Boqin, Quianfan and Quan express openly their personal struggle to integrate themselves in the Italian context. Among many different migratory groups the Chinese, although strongly involved in work, in reality live in heavy isolation 
from society. They are a very close group, difficult to access from the external society but also hardly welcomed by the hosting country because of the fear of competition. A consequence of this unhappy realm is in the eyes of those entrepreneurs a necessity to work hard, even above the legal levels allowed (even above 48 working hours for week) and without even having a legal contract:

For the Chinese work is important because family needs to eat not as the other Italians, we have children, we need to bring them to school (Ruomei, Wenzhou, Milan, 30/03/2015).

We work hard because life is hard, we are in a foreign land, if I don't work is difficult [...] we have worked so hard as Chinese here then we go back to China at sixty years old, but we need to work hard in order to accumulate cash (Boqin, Ibidem).

We work to live, for example you Italians go to school without paying, when you are sick you go to the hospital without paying, in China school and hospital you need to pay, so we work harder for the future, in order to have more money. For us Chinese when we will be old there will be no money to live, so the Chinese works double the time, we work 16-17 hours for kids, for expenses, all has a cost (Quianfan, Wenzhou, Milan, 30/03/2015).

Our process is a hard process of socialization, in the same way Italians in the past were immigrants in other countries so for us in China we are passing through this phase now [...] the previous generation of Chinese and us, we are divided in two, one part is studying [in italian schools] so is easier to enter in the Italian society, the other part is undecided and out of the Italian society, they live among themselves (Quan, Ibidem).

Those migrants from Wenzhou identify their social condition of minority as a cause of their working hard attitude. The question however must be formulated this way: is it because of their position as a ethnic migrant minority that those entrepreneurs work hard and achieve an economic success? If someone was to compare different immigrant communities living in Italy (sub-Saharan, south-American, etc., ...) with the case under my investigation it is undoubtedly evident that even if they belong to a similar condition of minority, they don't reach the same outcome in the realm of work. In fact although they live in a even more minoritarian condition than the Chinese migrants, they perform sometimes opposite results, showing no intention at all toward hard work. Being in a state of minority, although it may sometimes push toward a positive innovative way of doing business, acting as a bridge between two cultures, it doesn't cause an individual to work hard nor it leads him to achieve economic success. 


\subsubsection{The Power of the Chinese Network}

Coming to the major aspect that seems to play an important role and that may be a potential explana5..1tory factor to the model especially among Wenzhou Chinese entrepreneurs regardless of their religious identity is the lineage, the strong ties of family. In both of my samples I've observed how often building and using new links with Chinese people in a foreign context becomes suddenly a crucial part for the start, progress and accomplishment of

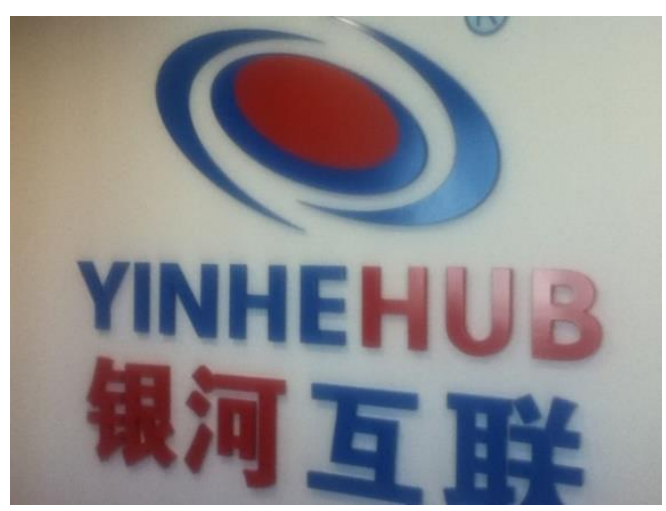
business transactions. All of the sudden when a Chinese immigrant crosses the borders of his country and comes to Europe he becomes part of the 'big family' of all the Chinese immigrants, regardless of all the cultural differences between localities no longer important in the new context (Network explanation). This does not mean that those differences disappear or that the local or family networks cease to produce their effect. It reveals that in situations of major challenges, such as the migration in another country, those differences are suddenly replaced instrumentally by a more general Chinese 'national pride'.

As I've already introduced for the case of Christian entrepreneurs, the case can be made in both parts of my sample for the presence of a network, organized in different levels and in a complex interrelation (family, associations, mafia, circle of friends...). It is therefore crucial to define more clearly how this network operates in the realm of business. The first major role of the network can be found in the weak ties provided by the adherence to a Chinese association. This refers to cases of associations for Chinese business like Boqin, Mu, Ting and Zan or to more mixed social groups like the case of Peng ${ }^{14}$ and Sheng. Sometimes the network provided by the associations helped the individual to find a job, like in the case of Ting. Jian during my interview explained how

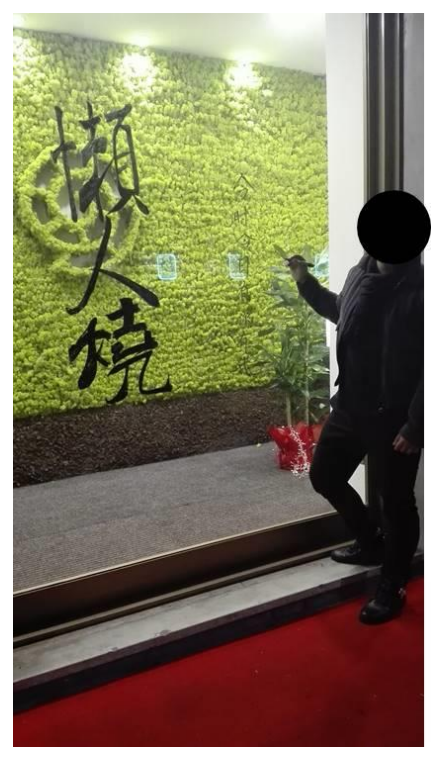
Peng helped him in the realm of his business:

I've met Peng the owner of the agency, he placed me as a project manager. [...] Peng thinks I am good as a project manager, now I calculate the prices and I look for co-workers among businesses. [...] Peng is the director of both Chinese agencies. Peng and many other entrepreneurs are among those that start a business then they bring it to completion and open a new one (Jian, Milan, Henan, 15/02/2016).

\footnotetext{
${ }^{14}$ Peng in front of his new Chinese restaurant writes down the name of his other friend restaurant in Chinese making publicity at the Chinese visitors invited to the gathering of Chinese entrepreneurs that night in Milan. 
Jian points out here what I mentioned in previous chapters on the role of network in business creation and multiplication. Basically Jian worked as the one taking charge of the business started by Peng as Peng moved along with a new opening. In other cases it is the circle of friends that plays this role like in the case of Biming, introduced to her job because of her friend who already worked there. Tao on the other hand, because of the key location of his business in China town and the wide range of influence in the Chinese context, experienced success in his business from a variety of influences: from his circle of friends to the associations, from his family to the mass media:

\begin{abstract}
I started this business with my parents they put finances and mental support. Friends then loaned money, them too young, cleaning, counseling, working together, we've known each other since we grew up together. I subscribed to UNIIC of the second generation of entrepreneurs, the other associations are less used for culture. We grew up here and we help each other culturally for language and bureaucracy, passing information. Each of us does his own business (Tao, Milan, Wenzhou, 30/01/2016).
\end{abstract}

More commonly however, the associations connect already existing Chinese businesses together with the purpose of sharing competences, ideas and even financial help ${ }^{15}$. Such support is crucial in a foreign context already critical without the knowledge of the local language. Therefore this kind of network is very crucial in the primordial stages of a business in order to make connections with entrepreneurs that otherwise, in the words of $\mathrm{Mu}$, 'will not be able to survive situations of economic crisis'. The network here, like for the case of the house church, provides financial and social support through the flow of information and financial credit. In many cases this network instead of creating business is important for the further development of business with the circling of information that Peng talks about. But as well as the house church the network of associations provides here also the necessary gain of trust from the client as Sheng points out and it constitute a sign of identity for many of those entrepreneurs like $\mathrm{Mu}$.

In their business card I saw how many of those businessmen tend to emphasize their presidency or general involvement into Chinese associations as an element of identity and distinction among the other Chinese migrants. All this may confirm the idea that associations can play a similar role to the house church without the religious connotation. It must be remembered however that network was only one of the functions displayed by the house church precondition. The main aspect that Weber pointed out about the house church was the output on the individual propensity to business through a control of the conduct among its members that here is missing. Surely through the associations there is a flow of money, work force and mutual financial help based on the relations of friendship. Operating like weak ties therefore the Associations result to play a crucial role in the embryonal phase of business making:

\footnotetext{
${ }^{15}$ Logo of Yinge Hub, a network of Chinese businesses of Milan. Boqin is the president of it.
} 
We have many partners more than ten, many members, a big entrepreneurial network that has competences and personal nodes, mainly somebody may have technical or economic skills in order to help others without them, sharing their channel of knowledge (Boqin, Ibidem).

The associations that I'm part of are non profit, the money is based on donations, the purpose is to help the Chinese companies here, if somebody wants to open a business we give some opinions and help, the members open a new job, we give the communications that circulate about offers, another aspect of China is that if there are groups they give economical aid or direction. To be enrolled and boss of an association is also an element of identity, we serve the people, we are connected with the Italian government for events, we organize dinners where we invite the major, then the second generation of Chinese in Italy is also involved. The financial crisis of 2008 has touched but hard work and mutual collaboration can resolve the problems (Mu, Wenzhou, Milan, 14/07/2015).

I do business consultancy [...] for many Chinese and Italian enterprises [...] contacts, the passing of word that we do, we occupy several sectors, design, eco-marketing, accountancy, business consultancy. Often a passing of word of the Chinese associations through many events and parties between communities, receiving friends, we engage a lot in community but bringing the members of the associations to do the most useful things for our business [...] in the difficult times that are common when you enter into the work realm I am lucky to have my Chinese friends that helped me both economically and psychologically. The office of consultancy in the beginning was hard, nobody wants to help you. The help we received from friends and we started to do the job (Peng, Zejiang, Milan, 06/07/2015).

Concerning the associations [...] we are active for the entrepreneurs of the first generation, UNIIC we are the first of the second generation then ASSOCINA [...] our purpose is to integrate better and enhance synergy with the Italian associations and institutions. Since we are identified as Chinese entrepreneurs they give us a connotation then we make this thing fruitful [...] among the restaurants we are the most affirmed, the associations they know us, in the beginning there was suspicion, they weren't used to a Chinese opening an Italian store, if Chinese we demonstrated that it is not so, it was sufficient to demonstrate first that we are also Italians because we grew up here and the entrepreneur is independent from the ethnicity and is enough to be and use adequate professionals (Sheng, Ibidem).

I'm the vice-president of the Association of entrepreneurs from Wenzhou [...] the associations of entrepreneurs [...] and the Association of the Chinese women of whom I'm part of we had a project to help the hospital [...] then this helped me to find a job, among Chinese we help each other for business, we loan money, we create corporations, huge activities (Ting, Ibidem).

I am president of the Association of Chinese Enterprises in Italy, Chinese enterprises overseas [...]. In my activity in the beginning I received help from friends and family members [...] the association that I manage first of all there are clear information between the organization and the members, they, among the information if there are difficulties of the entrepreneur give help then among each other they have a budget on prices and value so that the economy will not ruin. Perhaps somebody in the economy of crisis undersell and they do things that were out of their own individual possibilities (Zan, Ibidem).

Sometimes those weak ties provided by the associations go even beyond the national borders and connect together in a macro level several migrant communities. The large and broad expansion of the network results to be very important again in moments of need and widespread economic crisis. Since the cooperation involves several countries and a wide spectrum of businesses, it is almost impossible for people like Jiao-long to be cut off from the market. Leaning on the reciprocal support, the friendship that Ruomei and other entrepreneurs build up during the years always results to pay back its benefits:

I am friend with the owner of the restaurant here at Sarpi avenue. With him we are in common with the Chinese association in Milan of which I am the president [...]. Opening the restaurant I had a debt in four countries, from Spain, from China, from Spain, from Holland... and they helped me, we help together, if a friend is in difficulty I help him therefore is mutual. We were already friends before, we were part of the same association, we helped one another. I had a family member here then in the 1990's and I came here, then my kids and little by little all Chinese people are like that we start with someone selling and then followed by the family. In the economic crisis I have been influenced a lot, the restaurant diminished especially this year. The expenses diminish but we will see how to do it. For the most part I trust my friends if I have problems, work diminished but there is always somebody that 
is not touched, we keep on resisting, if we have problems friends will help us (Jiao-long, Wenzhou, Milan, 17/07/2015).

Sometimes we needed a lot of money to let the business go on, then we asked money to our [Chinese] friends that live here (Ruomei, Ibidem).

Concerning the main thesis then, the social network between Chinese entrepreneurs seems to play its role especially in situations of economic risk and crisis regardless of the presence of a belief in PAS. In order to remove any doubt that in this study the religious interpretation was considered as the only plausible one, some clarification must be made. If the network is considered as the main final explanation for economic success, then every typology of network in business should bring economic success.

Before jumping to a way too optimistic conclusion about the role of those networks in business it must be therefore taken into consideration that many of those network are managed by the Chinese mafia. When I've interviewed Ting, she mentioned the role of the Chinese mafia which in many of those circles of businesses is very important and that exploit such network structure as a whole. Ting was surprised that I didn't asked her about the role of mafia. Although she found herself to be reluctant in giving me more details about this aspect, she made it clear that the Chinese mafia was very pervasive inside those business networks. Even if not as a prevalent form of business, Chinese criminality in Milan as in other parts of Europe plays some role. From the first arrival of the migrant in Italy often the Chinese worker, in debt because of his investments, is forced to stay under the constraint of a boss that is compromised with illegal traffics and criminal networks. Sometimes those activities involve prostitution, drugs, traffic of toxic waste, technology counterfeit, money laundering, gambling, provision of false documentation, etc., ... All those illegal services are often underlining the business that goes on façade. Those activities are often sided by many forms of violence and despotism. Sometimes those hidden activities touch also associations and social groups recognized on a public level (Ceccagno A., Rastrelli R., 2008). In this case the network becomes then a negative social structure, based on corrupt relations and it ends damaging the very nature of business.

Someone may more rightly say then that network sometimes is an instrument for business even if it is not always used in an efficient way among Chinese entrepreneurs. If that's the case then the network, regardless of its specific nature and content is a guarantee for a financial support in case of lineage and associations. Secondly and more importantly, the social network provided here by the Chinese associations or circles of friends, when it was giving a positive contribution, it was intended to give an help in situations of economic risk, in order to guarantee the survival of a certain business not its economic success. The case of the belief in PAS on the other hand directly pushed toward the economic success. Furtheremore I witnessed many cases where instead 
belonging to an association was making no difference at all for business especially because of internal divisions and antagonism. Network in both samples resulted to provide important resources in several stages of the business trajectory.

Furthermore a case for a network explanation on the pursuing and achievement of economic success can be made only for the precondition on the house churches ${ }^{16}$ and not for the main model presented here. There is a substantial difference on the way an house church network operates compared with all the other general social networks. The Chinese groups of migrants in Italy in general can be considered as groups of families in kinship relation, groups or particular associations that generally are not very supportive of one another. It involves individuals with distinct interests and only occasionally united with boundaries of reciprocal unity. Even while belonging to a specific network they still see each other more as competitors and their relationship is always subordinated to their individual short-viewed interests connected with their individual business (Ceccagno A., Rastelli R., 2008). The house church on the other hand works as an all-encompassing form of social network that unites under a committed identification an otherwise fragmented complex group of business resources.

Some of the points made by Quianfan, Jiao-long, Zan and the statements of many other entrepreneurs introduce here what can be considered as a sub-section of the network explanation on the role of lineage and family. The lineage is culturally very strong in China and especially in this area of Wenzhou. Business in fact for the majority of the cases under my investigation was almost never just based on an individual. The extended family was investing as a whole into a specific business. The extended family (sometimes even far relatives) becomes therefore the first place where the economic network starts and develops. The lineage and the extended family helps Quianfan or $\mathrm{Mu}$ and many other cases witnessed in both samples to find a job otherwise difficult to start. The family helped Quianfan also to initiate the business through their financial support necessary for a new activity. I had the chance to witness this many times during the research. The financial support from the family, which is possible because of the trust in the family, helps Ting and many others to avoid the request of loans from the bank. Similar role is the one of Qi's family in giving advice, provide clients and offer maintenance of machines, so crucial at the starting point of a factory. The role of family in Qi's business reveals the importance of the lineage network through its necessary resources in order to do successful business, to have customers, advice and

\footnotetext{
${ }^{16}$ Apart from providing a network of connections the house churches have the supplemental role of motivating their members to the achievement of economic success. When it comes to economic success the house church surpass any other form of network explanation. But even among the house churches this is just partially valid, only in what concerns the emphasis on performance and control of the conduct, not the network in its generic nature. 
competences otherwise impossible to receive. In the case of Ting the family helps reducing the transaction costs too:

I've found this job when I was still in China, the boss is a relative of my wife then we bought this business [...] my father is a little bit rich and I want a little bit of strength to work for my children. Also, my parents helped me to buy and start the business (Quianfan, Ibidem).

The Chinese families help their sons, the brothers, or the parents. Among Chinese is easier to loan money, it is a common custom, not like in Italy, Chinese people do everything by giving their word (Ting, Ibidem).

First my uncle wanted to rent a restaurant but then they closed and then the mother of Bingwen advice me to start a business like that. [...] The family helped, how to repair a machine then I improve in the purchases, I started the business, if there's no business the mother of Bingwen will give me some orders that she had (Qi, Tonglu, Tonglu, 20/08/2015).

I worked for seven years and then I became the boss of the restaurant. My sister was the boss of the restaurant, she needed a cook so they let me work thanks to the family (Mu, Ibidem).

When the parents need help searching to open their own restaurant we help one another [...] When I came here I arrived with my parents in the restaurant of my parents (Peng, Ibidem).

My parents wanted that I will do business to make more money [...] my parents wanted that I marry a businessman and that I may be rich with him (Zhong, Pan Qsiao, Wenzhou, 28/08/2015).

This last point made by Zhong shows how the lineage and the family in the cultural context of Wenzhou enhance the propensity to do business. Zhong felt a lot of social pressure from parents to start a business and be successful in it. In the surrounding environment of Wenzhou every family had at least somebody in the family involved in entrepreneurial activity. The role of family and lineage therefore, specifically in the area of Wenzhou, goes beyond a mere financial provision and has its cultural implications being able to shape the propensity to work hard and to start new business activities. Ho talks about a circular relationship between parents and sons, a sacred view of family relationships, in part rooted in the cult of the ancestors. According to this view one generation invests in the next and the next generation must pay back what was received. The financial help received must therefore be paid back and all this cultural emphasis on family ends by pushing the individual toward business early in his stage of life. In fact compared with other ethnicities the entrance in the work life among those Wenzhou entrepreneurs starts very early:

The parent teach his son to work, is in the culture. Is the family, in part also school, that promote this (Boqin, Ibidem).

At first I worked to survive then for the kids of the second generation. Because of the Chinese thinking we must earn something to pass it to the next generation. We Chinese if you gain 1.000 then you spend 200 whereas you Italians if you gain 1.000 you spend 1.000 (Mei, Tonglu, Tonglu, 20/08/2015).

There is a dream and an objective in me, then the family for which I have to provide specially for children, that they may have a good education (Cheng, Taiwan, Tonglu, 20/08/2015).

I work hard, and the reason is to help the family. Parents helped to work and to invest to start this restaurant, investing. [...] the family wanted me to come here, the family wants that I'm here [...] my family is the one that have built this business (Bao, Wenzhou, Milan, 30/05/2015).

The purpose of work is to gain money, first of all, when you have four parents and three children you must pay a lot then you need to gain money [...] then family is important because is a passage from a father to a son the family enterprise. We Chinese work for the children when the daughter is well it is easier (Chao, Ibidem).

We work to have a better life compared to others then for the family and for the next generation. [...] The people from Wenzhou is seen by us as work hard and an heart for business (Qi, Ibidem).

I believe for every Chinese work is done for the children, it is like a circle between parents and children, you expect an economic return from your children upon whom you have invested [...] the purpose is always to have a good life, our culture you see is different. We don't have holidays, we want that our 
children live in a good situation we want to have a good life and more money give you a better life, working hard, you are more busy but then you gain more money, the people that come here wants to make money (Ho, Nanjing, Milan, 30/03/2015).

I helped my parents in their business of manufacture [...] save money, and then this to maintain the parents, the Chinese families tended to be very numerous, many kids were maintaining better the parents. [...] The family helps because there is the Italian family enterprise that has difficulties but it has always been the stronghold. It is important with more eyes the owner gets the horses to be fat. We do a communion. Then the family favors you with loans there is also an use of patronage and revenue (Sheng, Wenzhou, Milan, 08/07/2015).

Lineage and family however, compared with the more wide and all-encompassing influence of the Associations and circle of friends, results to have a more limited economic influence in space and time. In other words if asked about the benefits of all the economic contribution received through this heterogeneous forms of network, lineage and family result to play a more marginal role. Without other sources of help it would have not be possible to continue their business.

\subsubsection{Cultural Basis for the Exaltation of Work}

I said earlier that among the second group entrepreneurs I witnessed the absence of any correspondent factor to the role played by the system of beliefs among Protestant entrepreneurs in giving a purpose and meaning beyond the mere acquisition of money. This can be seen for example in the answer of Ruomei to the question in the interview on 'what is the main purpose in your work'. All the elements such as a target on the job, an higher purpose or the sense of a calling seem to be absent:

I don't have a target, I have no purpose, I just want to live here and live a decent life (Ruomei, Ibidem).

I never thought about the purpose of work, not like my sister, for me is just part of life ( $\mathrm{Ju}$, Wenzhou, Wenzhou, 24/08/2015).

$\mathrm{Ju}$ is an interesting case because she is the sister of Min and together with her she founded a factory for furnishing at an international scale. Differently from her sister however $\mathrm{Ju}$ is not a Christian and therefore doesn't sees any specific purpose behind her work. In reality Ju was still able to display a strong hard work mentality. Since she was not able to find a company, she decided together with her sister to establish one. So, in $\mathrm{Ju}$ there may be a partial presence of profitorientation. Since this potential explanation has no all-encompassing religious system of beliefs, like for the case of Protestant entrepreneurs, the main focus must be re-directed toward a more cultural explanation:

Wenzhou does not have raw material, therefore we do business. It is a tradition in Wenzhou, we pay attention to the financial business, from parents, compared with other cities we have a financial education since childhood (Ju, Ibidem).

The Chinese mentality in the last 30 years is changed, now the important thing is money. The economic reform changed the desires of the people [...]. For the Chinese somebody that works has success, it doesn't matter if the cat is black or white, says a Chinese proverb, what matters is if he catches the mouse. Life is based on money (Ting, Wenzhou, Milan, 13/07/2015). 
Even if Ting tends to find the justification for the presence of hard work among the Chinese people because of the institutional change after the economic reforms and "open door" policies of 1979 in China, she still indirectly displays a profit-oriented mentality that seems to be originated by her cultural background. It is in this case that according to Fuhua the area of Wenzhou finds its geographical, historical and cultural uniqueness compared to other areas of China in enhancing an entrepreneurial spirit. In the same way geographically and historically the Italian city of Genoa was in past centuries one of the most important harbor of the Mediterranean sea, playing a central role in trade, reflecting in today's cultural traits and a money-oriented mentality. Wenzhou, like a littleGenoa, has an entrepreneurial spirit that is passed on through its culture. In fact Mu, Zan or Ho describe the details of such Wenzhou's entrepreneurial culture when they point out the common desire of every true citizen of Wenzhou to open a new enterprise, to become the owner of a smallmedium business:

Like us we want to become important but they [the people from Wenzhou] want to have a bar, a restaurant, something that they can decide despise the fact that they don't have a lot of skills, but they work a lot [...]. Like the Italian people come from the south to the north, is different it depends from the culture, the social environment. Like in Genoa people are more stingy in the same way Wenzhou's province, many years ago I saw their boss of the restaurant is thirty or forty years old, they are the first generation that came in Italy [...] I saw a lot of people becoming very rich (Fuhua, Ibidem).

People from Wenzhou are very smart, they know how to gain money. We people from the north have the head, we think and we do, they are more practical, they find many ways to live and gain money, they came early [in Italy]. We from the north don't have a lot of will, 100 euros are enough, a travel... they [from Wenzhou] spend a lot of hours for living and working (Chang, Beijing, 02/02/2016).

[...] Wenzhou I don't know why they are like that, they want to be on their own, to make money, in my opinion is a cultural thing, is like the Jews, they want to do things for themselves (Biming, Milan, Taizhou, 22/09/2015).

Wenzhou, we that come from there we work a lot from generation to generation we passed on this thing, we have the culture of working hard. We have the common desire to reach our own propriety, to open and manage our own personal business, the desire to not depend from others [...] I don't want to make money but however I want to be the boss of this activity (Mu, Ibidem).

This is a Chinese trait that the more you work, the more you get reward then the majority of China are all that want to work they need to have a business then by the time the business went well and there is improvement. There is a little bit of difference, the area of Wenzhou the majority of people has interest on work. As the president of China says we from Wenzhou are there, are able to be the boss but also to be dependent and sleep in the pavement, they have a different heart, they are able to endure different situations. Is a provenance from the ancestors, fathers, grand-fathers, so then this culture is inherited (Zan, Wenzhou, Milan, 06/07/2015).

[...] it's a way to contribute to society, to have your own company, personal, if you do it you feel honored, you've succeed in working hard, you help the family, the society, people esteem you, they respect you and they clap at you because you are ambitious (Ho, Ibidem).

From the Chinese culture we work a lot, when we were kids the parents were teaching us to be workers and educated with the people, to be educated you go to work, you keep the things to do and wealth comes for your family [...] if you are employee is easy because you take a salary and you continue life, my job [entrepreneur] has the value of discover the rest of the world, and interesting things to see, to have more dignity $[\ldots]$ I believe we have a future to make I don't know which but I seek to do the right thing to do (Peng, Ibidem).

Our Chinese tradition push us to work in this way, we Chinese have in mind money: he who has more money is respected, we try to be better (Jiao-long, Ibidem).

Peng and Jiao-long point out how important it is to promote the social model of a successful independent entrepreneur able to achieve it with his own hands. Enlai during my ethnographic 
observations pointed out how people from Wenzhou, because of this cultural trait, would feel more satisfied in owning their own little business instead of being the CEO employee of a rich multinational company. Among the non Christian entrepreneurs it is interesting what Chun says concerning this matter:

I think that our mentality of Wenzhou, people like to do things on their own [concerning business] first starting with others then with others then finding their own [business], it is in our blood, different from north China, without any help from government we built our own entrepreneurship in a free market (Chun, Ibidem).

It is this desire to work as a freelance and independently that becomes the basis of the Wenzhou's entrepreneurial spirit. But what can be the cultural trait able to account for such entrepreneurial spirit that goes hand in hand or even works as a substitute for the Protestant ethic? When a certain sociological factor (mainly the Yi Xiang) results to play a definite role on the formation of an ethos useful for the realm of business in a precise context, if an alternative factor it is said to intervene, or even to replace its effect in the same context, it must be of similar form. The origin of such cultural explanation becomes therefore clearer when understood in religious terms involving a specific set of beliefs. I've already shown how Daoism and Buddhism, two main systems of belief proper of China, are substantially incompatible, if not even opposite, with the reflections based on the theoretical model. From the interviews a notable emphasis instead was made by the entrepreneurs about the teachings and principles derived from Confucius. This element points out the necessity to consider the cultural inheritance of Confucianism Its values and principles are applied even unconsciously by Sheng or Boqin to the realm of business. According to those results the influence of Confucianism may therefore represent the heart of this alternative interpretation (Cultural explanation):

\begin{abstract}
Hard work in China comes from the mentality, from the Confucian mentality [...]. There is this mentality to work hard and save money for years of famine of bad harvest. It has been shaped for centuries also due to natural disasters, rooted in centuries, the Confucian mentality to make order. Wenzhou is a little bit like the Brianza, each family has an entrepreneur (Sheng, Ibidem).

For us Chinese and the Chinese culture there is a thought of prevision of the risk, if there is some inconvenient I must go on [...] there is a way of saying in Chinese that say 'richness don't stand after two generations' so, you must work always, if not where will you be? [...] like Confucius and the moral theories that we derived from Confucius. 'Even if you don't reach your goal don't do any arm to others'. This is the old culture that has in the heart how to treat others (Boqin, Zhejian, Milan, 23/03/2015).
\end{abstract}

Work hard, a saving mentality, the importance of order, predicting risk, have goals in mind... all those elements are said by Sheng and Boqin to be derived from Confucianism and many of them supposely overlap with some of the beliefs of Protestantism. Some may wonder therefore how this is possible. In fact this finding goes in harmony with some recent studies on work ethic in Asia (Leong F. T. L., Huang J. L., Mak S., 2013) that found out how the Protestant work ethic together with Eastern Confucian values can influence the attitude and behavior of the workers. Both 
of those systems of values are said to influence today's economic development in Asia. More importantly some of the values of those two different systems of belief were found to be overlapping. The scholars mention in particular two principles proper of the Confucian philosophy that are said to influence the entrepreneurial activity: diligence, where personal achievement can be reached through hard work, skills acquisition, education and perseverance, and harmony, the necessity of submission of individuality to maintain harmonious relationships in all social organizations (Leong F. T. L., Huang J. L., Mak S., 2013, p. 4). Other scholars (Redding G. S., 1990) pointed out how the Confucian ethic and family attitudes significantly relate with the entrepreneurial behavior among overseas Chinese entrepreneurs. 


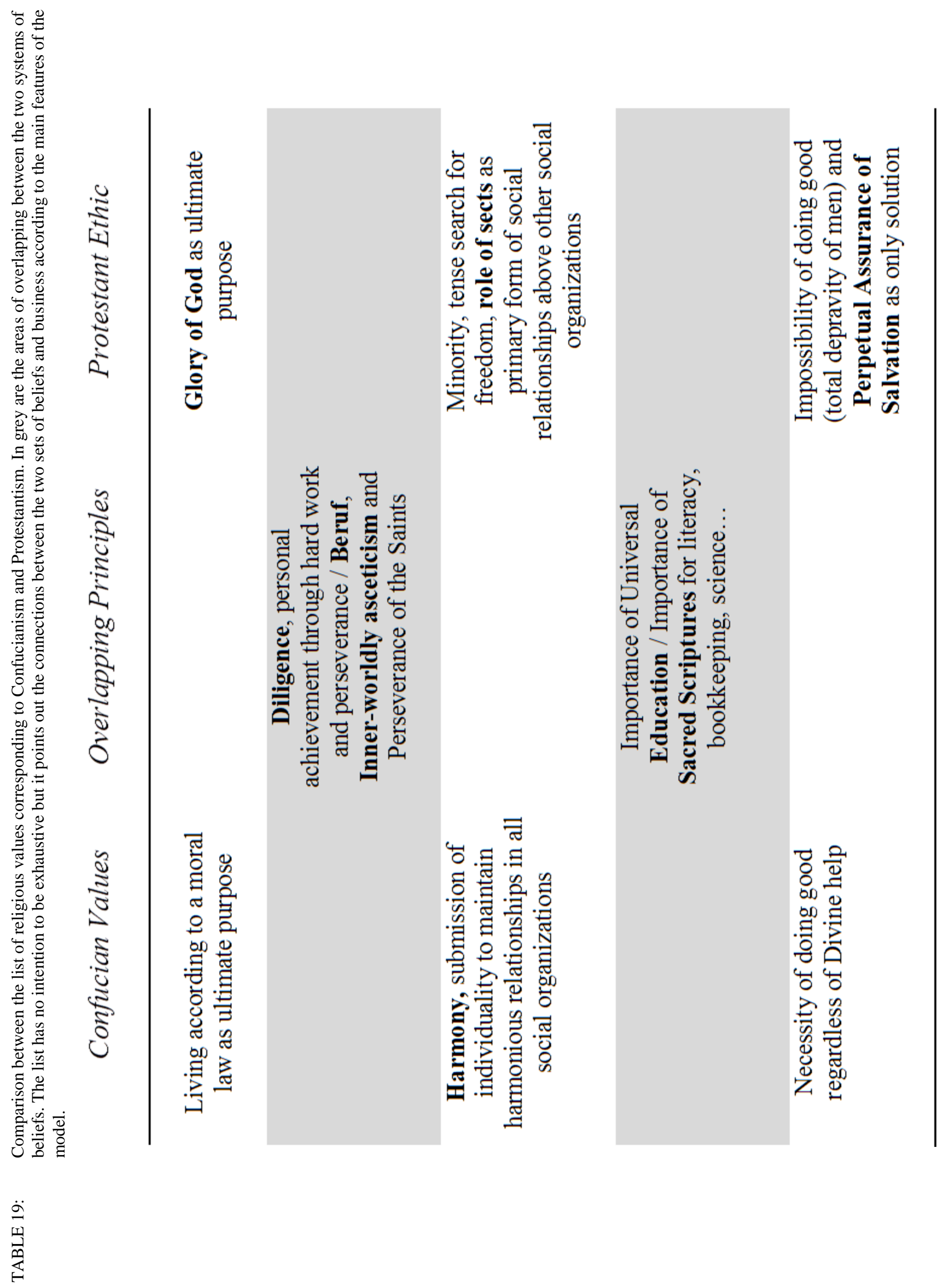


From those empirical findings, mainly about the principle of diligence and education, therefore Confucianism results to possess overlapping principles to the Protestant ethic potentially able to influence economic attitudes and behaviors, acting therefore as a cultural alternative explanation. Those overlapping values seems to act as a substitute to the Protestant ethic and could be responsible for the emphasis placed on hard work in Chinese culture regardless of the presence/absence of some preconditions proper of Protestantism. However the presence of some degree of commonality between those two sets of beliefs should not underestimate the role of the group of preconditions that are absent in Confucianism. Confucianism first of all does not have a substitute for the role of sects. Although as I've shown through the network explanation the role of sect can find other ways through associations, circle of friends, family and lineage acting as a network and as 'business card' in the second group it still lacks the control of the conduct, the emphasis on Charisma that was a priority in Weber's explanation. The universal and inclusive philosophical stand of Confucianism is contrasting and incompatible with the Protestant exclusive and minoritarian view of the world. The set of beliefs that are not present in Confucianism (glory of God, role of sect, sovereignty of God, anti-superstition, etc., ...) are therefore are equally important. A right understanding on the potential effect of Confucianism must be reached before it will be possible to conclude a possible effect of the cultural explanation on the initial thesis. In other words it is legitimate to say that Confucianism brings a contribution to part of the economic ethos, but it doesn't provides a clear and widespread alternative source able to bring economic success.

Those similarities on hard work propensity between Protestantism and part of Confucianism have no substitutional explanation. In fact assurance and salvation is absent in Confucianism, a system of thought that as the majority of existing religions (as Catholicism was to Protestantism for Weber) provides no consistent escatological solution for the salvation of the soul apart from good works and pursuing education. Confucianism actually doesn't even considers the afterlife as a reality and, although it possesses some ethical guidelines that may impact the work ethic, it is unable to push for the achievement of economic success. An interesting cultural alternative to PAS came out during my interview and job-shadowing with Chun that has to do with the 'I Ching', also known as the 'Classic of Changes' or 'Book of Changes', an ancient divination text and one of the oldest Chinese classic texts. When asked about difficulties at work and how to overcome them Chun replied spontaneously in reference to the principles contained in the I Ching:

When I have difficulties at work I like to read the book of I Ching. All our culture is based on this book that the first emperor wrote. He found a turtle says the story, and from this story come the principles for living. This helps me because all the projects when you develop them there is always a moment of growth but also of decline, and when there is the moment of crisis it is not forever, you must therefore be prepared for all things (Chun, Ibidem). 
Chun's personal interpretation is the closest case to what I can call 'alternative explanation' to the belief in Perpetual Assurance of Salvation. In front of situations of economic risk the non Christian entrepreneur may find his strength to overcome and achieve economic success through the application of philosophical principles from the I Ching $^{17}$. I Ching was a text revered since the times of Confucius and so foundational to the Chinese culture. The book of I Ching in fact many times invites the reader to walk the earth with confidence in the One Power and Cause in order to win and triumph along all

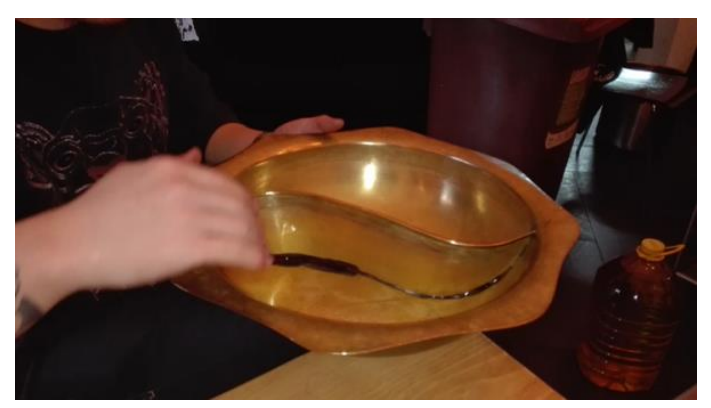
lines (Murphy J., 1999). Behind the simple cultural application of a tradition, I Ching becomes a crucial explanation among Chinese entrepreneurs in situations of challenge and economic crisis. In situations of danger it is said in the I Ching book that the person can receive symbolic messages able to guide him morally, psychologically and physically. What results from this is a state of harmony and confidence. Also asking direction to the I Ching is particularly crucial when making business investments of money, and the fruition of the book is for any type of work or professions.

What is even more interesting for my comparison is that the I Ching has been analyzed by famous psychiatrists such as Carl Jung because of the psychological implications of this sets of guidelines of values and beliefs (Murphy J., 1999). Very much like the people's beliefs about their efficacy, somehow the I Ching represents a similar source of influence. The only critical point in this is the fact that the case of Chun was a rather unique one that cannot be considered as a widespread phenomenon like for the more systematic religion of Protestantism. Furtheremore the I Ching book is also much more mystic and abstract, approached mainly to cast lots and foresee certain things. Void of any rationalized systematic answer to many areas of life and much closer to superstitious practices, the I Ching cannot actually replace what has been noticed on the other side of the Protestant system of beliefs. Yet the determination and perseverance that this concept contains may exhert some cultural influence on the common people apart from the conscious identification with those philosophies. In the way risk and challenges are managed at work they don't necessarily allow the individual to overcome them:

I was working in the restaurant, to order another plate is not easy... wrath...relationships problems, when they are too many... I apologize and I try to move on. [...] When I have to write new things for new selling's, I write and I realize I did a mistake, it is not perfect, I write and delete, I loose strength and confidence but I try again (Ning, Ibidem).

\footnotetext{
${ }^{17}$ Guiying showing the Chinese hot-pot of his traditional Chinese restaurant. The hot-pot has the unique shape of a T'ai Chi, part of the I Ching philosophy. Chinese entrepreneurs try to express their cultural values in business sometimes even in light of their wish for economic success. 
Apart from relying on probability, the Book of Changes provides little guidance on how to do business in moments of crisis, on how to react and behave in order to maintain patience and confidence in moments of risk. Offering random oracles to apply in any circumstance is not enough to guarantee for the individual a support strong enough against failure and daily challenges (AA. VV., 1997). Even if determination as a cultural value can be considered as a common value for the Chinese entrepreneurs as a whole, the confidence and strength that were present with the PAS are here absent. Ning therefore fails to resist the pressures of challenges and risks. Concerning the last element of my main thesis (Economic explanation) only few cases pointed out the possibility for an explanation that, excluding any sociological or psychological interpretations, sees economic success just as a result of external factors due to the economy. Even considering the theoretical reflection on the matter (AA. VV., 1997) it is questionable to see an impact of the I Ching philosophy on such a large scale. Protestantism is systematically having an influence in Wenzhou and even for the whole contemporary China.

Not only those entrepreneurs don't make the case for any metaphysical explanation, but they even neglect any cultural, social or even personal trait as the reason for their economic success. When found in situations of difficulties and economic risk Fuhua doesn't appeal to any personal or social dimension, but speaks of an effectiveness in business that can be due only to economic and tangible reasons:

We work hard because we own our own bars, restaurants, if you want to save more or gain more money you must work harder, there's no other way (Fuhua, Laoning, Milan, 30/05/2015).

It does not depend on how you manage it for the business we need to pay money, now the problem is only capitalistic we cannot say that there is other reasons (Chu Hua, Ibidem).

According to Chu Hua then the only explanation for economic success it is still an economic one. 'Save the money someone gains' is surely the heart of capitalism but why, however, somebody may be led to embrace such strategy as a lifestyle is not part of this deterministic interpretation. Apart from the economic transaction and the application of business principles which can be done in any part of the planet, there must be a reason of different nature that is leading China today toward an embracement of Capitalism. Possibly this happened because of the advent of a capitalistic spirit that was absent in the past and that is changing the Chinese society. Therefore, because of the little mention of it in the data and because of its inconsistency with the huge amount of behaviors that I was able to witness among those entrepreneurs, such deterministic explanation of economic success uniquely as a mere result of economic factors can be easily dismissed.

But Chu Hua, is also interesting because she points the analysis back to the role of Protestantism in the economy of contemporary China. Chu Hua had many contacts with Chinese Protestant entrepreneurs when she was in China and through her role as an outsider she gives here 
an interesting external perception of the lifestyle of those entrepreneurs in today's Chinese economy. Such perception is quite different if compared with the common Chinese entrepreneurs with no religious identification. Her thoughts, from an external perspective, may confirm the presence of an inner-worldly asceticism, a saving mentality and a control of the conduct that, although partially present in Confucianism, is still able to generate a capitalistic spirit in a degree that is much higher than any other social group:

I know some Christians in China, they are different, they always work, they don't work just to have fun as all of us, they don't work to buy a new car, they don't work to buy rich clothes, in this Christians in China are different than us (Chu Hua, Ibidem).

This last point on the social perception of Protestants in China and their peculiar view of work may reveal that the Protestant ethos in business is much higher than any other ethos even with the addition of the Confucian values. However the question remains open on how Confucianism may be able to count for such economic success.

\subsection{The Chinese Common Denominator}

\subsubsection{Direct Causality vs. Justification Logic}

Whether someone may tend toward the acknowledgement of the role of Protestant beliefs in business or frame them into a more broad set of values it is important to point out a turning point in my theoretical understanding. I started my approach to the field with a theoretical background that was more similar to the one of causality even though I referred to correlation and not to direct causality. Yet the approach was the one of finding the psychological consequences of a belief (mainly PAS on producing self-efficacy and therefore favoring economic success).

Yet, the reality of this dynamic observed in my qualitative field suggests that the reality is more complex than what some deterministic approaches may advocate. During my prolonged period of job-shadowing of Delun I observed for example the use of a certain Christian vocabulary in order to receive recognition from the community. Also after a period of observations I realized how Delun was portraying the role of the honest Christian entrepreneur. This was a figure that somehow was recognized among his Protestant circle of friends and that needed to be in place in order to be accepted and recognized. The same dynamic was observed with Minzhe that started her job for personal interest then began to fill her role as a buyer with the Christian vocabulary in order to give meaning to her activity.

Heng on the other hand grew up in a Christian family and inherited his religious interpretation of work from his parents, trying to represent the profile of the honest Christian 
entrepreneur required by his community. Therefore the Christian vocabulary instead of generating that psychological propensity, was more effective in the still valuable outcome as a channel of rhetoric. Interestingly enough a similar justificatory function of the belief was reported sometimes among several other Christian entrepreneurs. For some of them like Hop a motivation to work hard was already present in the family environment under a Communist ideology that wasn't able to justify the capitalistic accumulation. In the same way Bo, Yi, or Xun were led to find justification for their economic involvement in the Protestant beliefs. Christianity then turned out for many of them to be a way of escape from this dilemma:

\begin{abstract}
I was from a Communist family, my father works for the government. My father works for the government. A family that believes in Communism, I grew up believing that there's no God and that we must work hard for the benefit of the nation, life is just a striving. [...] I didn't know what was religion, in church I met many people and decided to follow this way of the Lord (Hop, Ibidem).

Success at work comes from the fact that your work is acknowledged for his quality. Then faith, for whatever work you are doing (Bo, Ibidem).

I studied theology, business administration and I don't ask myself which is over or under, I want to meditate the two, some companies don't know the management, I suggest to learn it, I preached this morning about knowing the social, newspapers, web, to understand things (Yi, Ibidem).

I left a church that I was part because they didn't teach how to manage money [...] I decided to go in another church where I met entrepreneurs and my faith grew [...] one year later the commerce fellowship changed into a traditional church but I thought it was important to maintain this emphasis with business so I created my new commerce fellowship (Xun, Ibidem).

If you're a Christian and you don't work, people then think that we [Christians] are lazy, we work but we don't take advantage, also to differentiate ourselves from other unbelievers, work is important because we live in this world. You work better imitating but we don't try to imitate, we try to be more honest (Nuo, Ibidem).

It also comes from following the crowd, if you have a job I notice it and immediately I want to do the same job. If you are rich the other person that looks at you wants to become rich, they copy each other at last (Shaiming, Ibidem).

In the mind of the Wenzhounese money is very important, they come first, they think that if you have a lot of money you can speak louder, it doesn't matter if you are a good person. Is sad that also in church some people think that way (Xiu, Ibidem).

In Wenzhou society started to change. They are no more Communists but liberals. Wenzhou is like that also for its trade position. In flat land. There is minimal difference in trade between the Christian and non Christian, we go to church (Na, Milan, Wenzhou, 14/12/2015).
\end{abstract}

Nuo, $\mathrm{Na}$ and Shaiming on the other hand pointed out the influence of the imitation process among Chinese people that led many to embrace the sets of values simply in order to conform to the standard of other entrepreneurs. A more evident demonstration of this process came when I interviewed Fang, a Chinese pastor that previously was a successful entrepreneur and that gave me an interesting insight on the relationship between the economic and spiritual need:

Everyone has his own business, we created from China an association. We came in Italy to make money, then slowly we became believers. [...] I was among the first famous entrepreneurs in China, there is a lot of materialism but a need inside. People believe in Jesus for health, work, money, me on the other hand not for this but for the emptiness and sadness, the internal fulfillment and the external are linked (Fang, Ibidem).

Fang, as a spiritual leader reveals however how in many cases the religious faith was only a subsequent step in the migratory process while the entrepreneur, after starting his business was then 
turning into the church to find a justification and strengthening channel for his work ethic. In the case of the second group of entrepreneurs under job-shadowing, even if there was a minor necessity to give such type of interpretations from the individual, the same justificatory role came into the scene among them. Ho for example during the job-shadowing was usually giving a more direct and materialistic interpretation of the reason for his strong hard work involvement. Yet the role of family values and work seen as a contribution to the Chinese society was at the center of his interiorization of the entrepreneurial propensity taken from his father:

My father worked very hard for two kids he worked hard, an high quality of work, contributing to society, he had his personal company, if he does it he fells honored, he succeed to work hard, helping the family, helping society, people admire you, they applaud you because you are ambitious (Ho, Ibidem).

A more elaborated interpretation in cultural terms was given by Chun in reference to his work attitude and the principles of I Ching:

When I have difficulties at work I like to read the book of the I Ching. All our culture is based on this book that the emperor wrote. [...] from it comes the principles for living. This helps me because all projects when you develop them they always have a moment of growth but also of fall, and when there is a moment of crisis is not forever, you must be therefore ready for all things. It is a philosophy on which our culture is based upon (Chun, Ibidem).

Chun as a non Protestant, when asked about how he reacts to situations of difficulties at work, pointed out the role of I Ching not as a cause of his behavior but as an instrument to move on. By doing so he was justifying its economic behavior in light of a philosophical principle. In fact from further ethnographic observations it was clear that such view was intended to justify rather than really enhance his economic activity already in place. Among other entrepreneurs of no affiliation with the Protestant faith, for many different reasons, it is possible to find the same justificatory effort. Quan and Ting for example show how behind the declared communist ideology people now are instrumentally open to capitalism, justifying therefore this apparent contradiction in the system. Sheng on the other hand goes beyond that and tries to give a cultural interpretation of such economic propensity in the Confucian mentality:

They failed [communist Russia] because they didn't used the capitalistic system of United States. So China abandoned [Communism] because of Confucianism where your culture and identity can be different from mine. We can live and work together. Now this generation of Western countries work with China. Now we compete but the common interest is greater than the conflict (Quan, Ibidem).

The Chinese gain less money? He saves money, works 14 hours, 20 hours, works and likes always to work the Chinese, also the culture before the reform we work always, but now no more because of communism but for money. The Chinese think to be communist but they are not! (Ting, Ibidem).

Hard work in China comes from the mentality, the Confucian mentality of farmers where everybody know that to survive in China they must work, save money and maintain the family. [...] Since we are identified as Chinese entrepreneurs they give us the connotation then we make it count something (Sheng, Ibidem).

People are competitive and jealous, if your neighbor has more you want more, if you are poor they don't respect you, if you are rich they respect you. It doesn't has to do with things but with culture, it comes from culture, they look for respect therefore they want to go out of poverty (Mei, Ibidem). 
Our Chinese tradition pushes us to work like that, we have thoughts for money: the one who has more money is respected, we try to be better (Jiao-Long, Ibidem).

I don't know why in Wenzhou they are like that, they want to do it by themselves, to make money, for me it is a cultural thing, it is like the Jews, they want to do things by themselves (Biming, Ibidem).

We from Wenzhou are able to be bosses but also to be independent or sleep in the pavement, it is a different heart, we succeed in bearing different situations. It comes from our ancestors, parents, grand-parents, so this culture is inherited (Zan, Ibidem).

This same imitation process observed in both groups of entrepreneurs is said by Jiao-Long, Biming and Zan to have his roots in a cultural economic propensity in their area of origin (Wenzhou). The reality of the matter however is that behind such cultural interpretation there is still an effort in trying to justify the economic propensity.

All those elements coming from the field, independently from their specific features, they all respond to a need that in social theory has been defined as process of identification and recognition. Beyond the methodologic individualism of the Weberian interpretation of the belief with which I started this research, it is important now to consider the intentions of the actions and to look at the 'reception', identification, recognition of the social action by those that take part in it as well as those that observe it (Pizzorno A., 2007; Sciolla L. 2008). This polemic with the classical methodological setting was further developed by the production of culture perspective and by the theory of markets in economics (Azarian G. R., 2005). Rejecting the sociological dogmatism of the past but still defending the idea of an empirical social scientist, these scholars seek to see the social logics behind the action.

According to this perspective there are specific expectations from the side of the actor that involve his need of identification. This does not just include an individualistic intrinsic intention as in the neoclassical model or just the generic structuralistic instance as in the analytical sociology. Especially when there is a community of reference, like in much of the cases under my analysis, the circles of recognition are very elaborated and important to consider. For example a specific group, like the one of those Chinese entrepreneurs, may view something as appropriate and in the economic action the judgement of the individual on the action is as important as, or even more than, the intention behind it. This is a constitutive aspect of the social action, not just an instrumental one (Azarian G. R., 2005).

In light of what some have postulated on a mere political and instrumental level (Hirschman A. O., 2013), regardless of the specific features, all economies have a moral component, what Stark names as 'worth', in its double connotation of economic and moral good (Stark D., 2011). Beliefs as part of the moral good are designed to give meaning to the social actions, that sometimes differ from what the individual actually does, but in any case serve for the recognition and creation of identity (Barbera F., Negri N., 2015). In order to observe this in action therefore recognition is a key 
element even in the day to day economic transactions of those Chinese entrepreneurs that need to face uncertainty. This specific element has been called by some scholars as the 'economy of conventions', where such set of recognitions are central for the understanding of the economic action (Chicchi F., 2006).

This change of focus is also due to the changes and reorganization that capitalism has undergo from the times of Weber. Those same transformations in capitalism therefore had a consequent impact in ideological changes associated with the economic activity (Boltanski L., Chiapello E., 2005). The spirit of Capitalism from which I started my reflection here underwent therefore inevitably some changes, identified by those scholars. They therefore need to be taken into account here for our final interpretation of the matter. They basically imply an historical shift from the first bourgeois spirit of capitalism to a more 'globalized' spirit of capitalism. The ideology that justifies the involvement in Capitalism today is according to them somehow different from the one present at the times of Weber or before. The spirit of capitalism is then less based on an ethical motivation and more related with a generic call to look for the common good of society. Therefore in light of this common good, individuals and organizations on a micro and macro level give birth to a process of 'justification' and legitimation of their capitalistic enterprises in terms of the 'common good' (Boltanski L., Chiapello E., 2005).

More neutral concepts as the one of goodwill become the potential substitute to the Protestant foundations of what today was being transformed into a spirit of global capitalism. Goodwill can be defined in this context as the sentiments of friendship and the sense of diffuse personal obligation which occur between individuals engaged in continuous contractual economic exchange. Some literature has already observed the power of this principle in action in the Asian context close to China, namely in Japan (Dore R., Sacco M., 1983). Similarly to the context of China this element of goodwill basically invites entrepreneurs to share both good and bad times in business, ethics are institutionalized, being part of a national culture. This therefore provides a sure guidance for everyone. All of those elements reduce risk through relational contracting and allow greater investments among firms (Dore R., Sacco M., 1983). Yet is hard to say how such an allencompassing concept in a context like Japan based on benevolence as a duty can in and of itself guarantee efficiency, economic success, as well as the presence of many other indispensable elements for the growth and promotion of market capitalism that I described in previous chapters (Dore R., Sacco M., 1983).

And this is exactly what can be observed behind the words of those Chinese entrepreneurs about their capitalistic involvement in terms of legitimizing the 'right actions' to perform in order to make profit in terms of the common good of the Chinese people, of themselves and their family 
lineage or Protestant circles. Such baggage of rhetoric is composed by a vocabulary of motives that is framed in the community, whether Protestant or other types of communities among Chinese entrepreneurs. In their routines observed during my job-shadowing the entrepreneurs tended to legitimize their behaviors through those rhetorics and the effect was a motivation to success.

In this sense ideas initially alien, or even hostile, to capitalism, such as communism, religion, lineage, culture, are now incorporated into it by the Chinese entrepreneurs to defend and justify themselves in face of a challenge to their entrepreneurial identity. The cultural and religious aspects are therefore embodied in the form of procedures (Lizardo O., Strand M., 2015). If for example the Protestant entrepreneur uses certain practices of recognition, he knows that he will be accepted by the others, therefore such stress on the religious aspect of work is given by him. The imperative for profit accumulation in this case, even if permeating every ideological aspect, it also demonstrates that work still possesses a meaning, it still testifies to the presence of a spirit of capitalism even if its features are changed (Boltanski L., Chiapello E., 2005).

\subsubsection{Brief Excursus on a Non-Chinese Entrepreneur}

As a brief suggestional footnote and in light of a question that sometimes arose during the development of my research I here turn to reflect briefly about the surrounding environment of those Chiense Wenzhouren entrepreneurs I studied mainly in Milan, Italy. What is the perception and practice of entrepreneurship in the Italian surrounding environment beyond the Chinese context under my analysis. When analyzing the economic success of a specific group of people such as the entrepreneurs from Wenzhou it is in fact important to consider the surrounding environment that somehow may favor or penalize the economic success of those small businesses. I briefly already mentioned the environment of China town and entrepreneurship in general in Milan but here is more important to reflect on what relationship there is between the Chinese business and the Italian surrounding entrepreneurship.

In order to understand better the weight of the Chinese-Wenzhouren propensity toward hard work, regardless of the specific set of values, I briefly choose to take into consideration the logical opposite situation where there is an absence of Chinese workers. I decided for this reason, in addition with the interviews to the outsiders that I've mentioned on previous chapters, to do some occasional job-shadowing in places and stores close by to the China town of Milan, owned and managed by non-Chinese Italian entrepreneurs. For example I've passed my time in several occasions at a bar around the corner to China town (see Appendix). In light of the whole research this must be considered more as a suggestion, not as a complete explaination. It is not my intention 
to be exhaustive on the Italian counterpart of those small businesses but only to give a brief reflection on what would happen to this analysis if in the same context around China town someone was to compare what was said with the Italian counterpart of an Italian bar owned by a traditional Italian small business owner.

Briefity of time at my disposal limited the possibility to give a complete description of this Italian counterpart of small business entrepreneurship. The typology of business chosen for this type of comparison was almost identical to the type of businesses the Chinese entrepreneurs were leading right across the street from one another. Yet even if extremely close to the field the prices of the merchandises were doubled and the place was almost empty. There were some regulars but in this case they were extremely annoying, drinking, smoking or screaming, almost scaring away new clients. The owner was an old 'Milanese', dressed in a very informal dressing, reading the newspaper almost all the time and very slow in every single action. Yet the place was much larger than any other bars that I've investigated and the variety of products that were sold was larger.

Also the interior design was more refined if compared, with some exception, with the Chinese stores. The clients were usually Italians and only rarely they were foreigners or Chinese despite that the area was full of them. The relationship with the client in this case was warmer and overall more conversational than the Chinese counterpart. The owner had the privilege to associate with the culture of the people of all ages, being able to capture their interest to come more frequently to the bar. Also, the store had often visits from sellers in contact with the owner to organize parties or ceremonies for big groups of people. This gave them an easier way to make business not just with the bar but also for the furniture of food services of all kinds. This was easier giving the fact of not being a foreigner.

By reporting this I am not equating what randomly observed in a bar nearby Chinatown to any other Italian small businesses in the city or in the province where the study was done. Clearly I am not denying the possibility of an Italian counterpart of succesfull and innovatory small businesses even on an international scale. Yet what I want to point out here is the fact that in two almost identical contexts of business the business strategies and daily operations were radically different. The case of a Chinese way to approach business, totally different from the one surrounding it, can be sufficiently and confidently made. Generally speaking, as I already mentioned in previous chapters the economic context of Italy and of Milan during the times of my observations was not at its best. Many Italian businesses were forced to fire their workers and small businesses in particular were forced to close or sell. In this some cases like the one of Guozhi and many other Chinese business owners came into the picture, taking over businesses in a situation of 
bankruptcy and they were able through an immense quantity of hard work to let them flourish under circumstances of economic crisis.

On the other hand the Italian context somehow offers a good environment for Chinese business because of some peculiar unintended cultural similarities. In the same way as the Chinese context of Wenzhou the Italian context of small businesses too is characterized by a strong familial orientation. Basically in the same way as in Wenzhou business is started and run through familial networks of reciprocity. Furtheremore small business entrepreneurship was historically always very important for the Italian economy so the Wenzhouren model, trans-planted in the Italian context resulted to be very fruitful. At first Chinese small business were opened for a Chinese clientele but more lately they basically took over many of those Italian small businesses and their range of clientele opened beyond the ethnic borders of Chinese immigrants. If at first there was a general suspicion toward immigrants of all sort as I've already witnessed in previous chapters where the China town of Milan witnessed clashes and disagreements between the local Italian community and the Chinese small businesses on working hours, later on the Chinese community started to have a more respectable identity in the eyes of the Italian society. This is specially true during the context of economic crisis that was ongoing while my research was done. Chinese entrepreneurs were seen as hard-workers by the Italian counterpart, and potential business partners instead of competitors.

Apart from the difference in forms, this confined hint on an Italian comparison in addition to what discovered in previous chapters, supports the idea of a presence-absence of an hard work mentality depending on the fact of being Chinese or not. Some may argue that there is a chinese common denominator characterized by an hard work propensity, especially for the case of Wenzhou. Many other factors are responsible for this presence, in particular the geography and historical origin of the area of Wenzhou must be taken into account. Also the economic reforms that I've mentioned on previous chapters, together with the contribution of the internationalization of the Chinese market. This contribution is valid also regardless to the fact of being Protestant or not but it generally encompasses all the Chinese entrepreneurs. Italian workers in the same type of position, with some few exceptions are not able to display the same hard work mentality and diligence toward their tasks. In other words a set of values, beliefs or ideas, clustered here in the encompassing concept of ethos (not just in its Protestant connotation), originated from different reference systems in the individual, are able to give their contribution in a process of favourable succesful entrepreneurship already set in motion. And in understanding this a brief parenthesis on the Italian context and entrepreneurial counterpart was worth being mentioned. The concluding thoughts ahead will determinate up to which point it is possible to isolate and clearly identify the nature and intensiveness of such Chinese ethos. 



\section{Conclusions:}

I come now to the interpretation of the data from the field that I've presented and I propose here a final analysis of the thesis. So far, although some mention was made on the practical influence of the set of values on business, I was able to identify mainly the subjective interiorization of the set of beliefs included in my model (self-perception of the process). Although this step in qualitative analysis represents already in itself a valid attainment, through further research it may be possible to explore systematically the same phenomenon in motherland China. This could allow to compare both the actions and perceptions among the two groups and to see the effectual difference.

When I started this text in the beginning I stated what at the time I thought to be the expected series of possible results of the study. In particular going through the fieldwork can show clearly how a direct correspondence of the primal thesis $(a)$ is impossible. In the same way as I will sum up here briefly the presence of intervening elements $(c)$ is true only in part. So in light of the empirical findings here presented and in accordance with similar observations from other scholarly works done in the past, the more legitimate conclusion that the reader can draw from this work is that Weber was going in the right direction but with the wrong conclusions $(b)$. Mainly then the study points clearly to the necessity of an adjustment of Weber's original claims in light of this fieldwork and other contemporary findings that go in the same direction.

At the beginning of this investigation I was pointing out how the risk-propensity was a key element in literature when considering entrepreneurship. Empirical cases such as Enlai and many more, specially from Wenzhou, show how autonomy and independence are viewed as key values in the culture of that area, reflected in many of the entrepreneurs I came into contact. In the same way Delun and other cases under job-shadowing showed the readiness to embrace challenges typical of the entrepreneurial type. The field also points out the crucial role of the belief in PAS for what the literature defines as 'over-confidence' and 'endemic optimism'. In particular 'over-precision', the excessive certainity over the accuracy of one's belief was dominant. All these aspects mentioned by the literature can be clearly be applied to the case under analysis in light of those empirical findings. Furtheremore when it comes to evaluate the role of risk-taking, risk-management and riskpropensity in entrepreneurship the job-shadowing clearly showed that Protestant believers in general tend to have a stronger source of emotional and personal support which was poor or absent among the people of the second group case-control of entrepreneurs. When faced with financial risk or for example dealing with tuff situations or bad clients the entrepreneurs of the first group were more able to maintain an emotional balance and personal strength. The case-control second group 
of entrepreneurs on the other hand resulted to be more stressed or propense toward a general inability to manage cumulated forms of economic risk.

When it comes to evaluate innovation, the second important point that characterizes entrepreneurship, I pointed out how the cases under analysis offer a clear affirmative answer to the theoretical premise. Five out of the six individuals under the job-shadowing (exception made for Ho) responded positively to the profile of the entrepreneur expressed in the literature. Delun as a leading figure possess many of the elements proper of this definition of innovation. It was possible to see in the field how he often tended toward the break of the static equilibrium, combining factors in a new way and creating different forms of production and business. From a bar Delun was able to open 3 different creative innovative businesses during the period of job-shadowing. The innovative approach of Delun was also notorious in trying to solve the Italian problem of unemployement through a more integrational approach if compared with his countrymen. Like Delun many other cases were theater of imprudent financial choices that nevertheless characterized the entrepreneurial profile. I did not observe any significant difference between the two groups on the search for efficiency, the importance of teamwork or the ability to build relationships.

The progressive and continuous exploration of new unknown sectors from cases like Delun, Enlai or Heng was also connected to their identity as a second generation migrants, outdistancing them from the counterpart of the first generation migrants. This was visible comparing the outlooking and appeareance of those new stores of Heng or Delun with the 'traditional' way of doing small businesses among the first generation migrants. Another important source of innovation was the role of e-commerce among Chinese entrepreneurs both in the motherland Wenzhou and in Milan, like the cases of Minzhe, Lei, Chun's wife and many others. In some cases like Heng's the proportions of this involvement were significant on an international scale. Particularly interesting was in both samples of entrepreneurs the creative relationship with the Italian counterpart of business, like in the case of Guozhi, Delun or Chun.

Concerning the main thesis the application of the original theoretical model into the field represented in some way a challenge. In a first analysis it is possible to see the presence of almost all of its element and therefore allow for the legitimate application of it to the case of Wenzhou in contemporary China starting from evidences in countries of migration such as Italy and the big metropolis of Milan. I showed how several of the assistants to the preconditions of the model where present in the field of the Chinese entrepreneurs of Milan. Some of those details were not covered in detail but for example the role of Sacred Scriptures in the rationalization of practices and ethical standards was clearly evident among others in Zhenzhen activity of continuous preaching connected to its business or in Guang and his daily reading of the Scriptures in the work-place. 
Furtheremore I hopefully was able to point out with clarity how the Boss-Christian phenomenon among Chinese entrepreneurs both in Wenzhou and abroad somehow strongly points back to the forms of inner-worldly asceticism that Weber referred to. This was clear throughout the job-shadowing of Delun, how his stress on personal integrity in all things was derived among other things from the Calvinist teachings of Dr. Stephen Tong or from the application of the ethical rules of his Christian association to his personal business. In the same way in the words of the interviews of Ling, Guang, Wing, it was possible to see the range of action of such a principle. Many times both during the job-shadowing and during the interviews it was clear how Protestant members regularly involved in church activities and with a strong faith were also those that were doing exceedingly well on business and did not see any contradiction between business and their beliefs. On the other hand members supposedly 'on the edge', distant from the church life somehow saw a strong contradiction between faith and their work and were not doing as well economically.

The idea of 'calling' and 'vision from God' (Yi Xiang) reported by the literature for the case of Wenzhou was clearly present also in the business led abroad in Italy. I quoted cases like Hop or Jun that express such awaraness or biographical experiences like those of Deming in finding his 'job-calling', Enlai and his being in 'God's schedule'. Even more persuasive was the journey of the business calling of cases like Bai or Xun where the strong connection between faith and this sense of calling for business reaches the entire interpretation of their personal achievements and success. Then, as is also clear from the chart, other elements were found in the field matching what I previously expected to find approaching the field. In particular recurrent was the stress on the Calvinistic desire to glorify God in everything they were doing. This belief had a strong impact in legitimizing and giving a sense of profound purposes for every sort of jobs and employements.

In the same way and connected to it the house churches model somehow was present in its structure even overseas in Milan. I pointed out the role of house churches in business mentioning the circles of favours and finances connected with the house church for example with Xiu and his leadership role in a commerce fellowship as well as other examples even with the Job-shadowing of Delun or Minzhe. Also I mentioned how the multiplication strategy of the house churches was often applied to business and countless cases of business partnership among church members represent the turning-point of many migrants recently arrived in the new context of Milan. But the field showed once again how house church, in the same way as the role of sects in Weber, goes far beyond its role as a network. The emphasis on the control of the conduct was witnessed among many examples such as Delun or cases like Hop. In this it was very beneficial to consider the connection between church leadership and tendencies toward economic success as in the cases of Zhenzhen and his brother Shu or even Shing. 
And when it comes to establishing the role of the main element of my thesis (belief in $P A S$ ) it was possible to see plainly how such belief is present. Not only that but the force of influence of such belief enhancing confidence and a state of peace was clearly displayed by many of the cases under investigation. Furtheremore the results from the questionnaire on the Self-efficacy scale showed a strong connection with the belief in PAS, mainly among young Protestant small business owners from the city of Wenzhou. The role of this belief was witnessed to be very crucial in many situations of risk and challenge at work. In the personal reconstructions from the side of the entrepreneurs another unexpected element that frequently was mentioned was the role of prayer, but some may wonder how such element could be taken in consideration in the model. So in one sense those specific findings show that a 'spirit of capitalism' emerges not always nesessarily as a consequence of Protestantism but wherever it emerges someone would expect it to emerge for the exact same reasons. And some of those reasons were clearly present in the field as empirical findings show.

Yet, as it will be clear from the following chart such interpretation is somehow one-sided and needs to be taken in light of other possible intervening factors that are worth being mentioned here in detail. For this reason the counterpart of the non Christian entrepreneurs from the casecontrol group under my investigation might complicate the simple picture described above. Going behind the scenes of certain façade statements and in light of the dark sides of stories quoted above in the investigation, even among Christians, it is important to consider the possibility of a Wenzhou Profit-oriented mentality. At first the field, concerning the second group of non Christian entrepreneurs, almost immediately detected the possibility of some sort of intervening role of communism (Communism explanation) apart from just giving the framework for the exaltation of work. This specially because communism is no longer held as a belief by the majority of the common population involved in business among my sample. In the same way the idea of a constriction explanation somehow related to the cliché of a constriction explanation, that could relate this hard work propensity to some form of Stakhanovism is to be questioned. Specially in light of the context of the second generation of migrants and the changes in Chinese entrepreneurship, a constriction or even a minority explanation looses its validity. Furtheremore even when present, the fact of being an ethnic migrant minority or experiencing some sort of extortion to work hard in and of itself does not guarantee in any way the achievement of economic success which is the main point of this thesis. 
TABLE 20: $\quad$ Synthetic table representing the dynamics of the model for the case of Wenzhou in light of the results from ethnographic observations and the interviews.
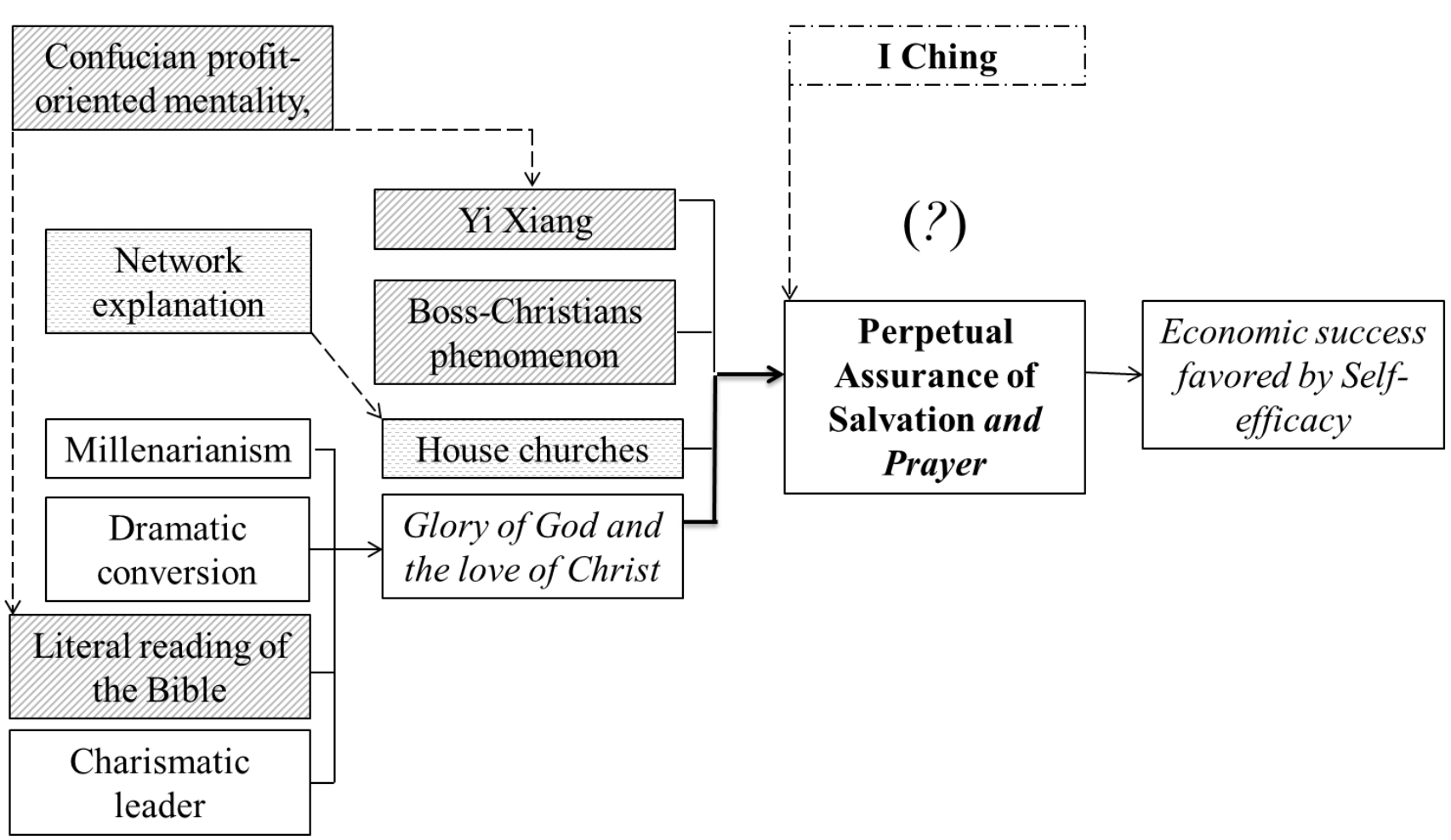

In any case the results for the second group of entrepreneurs can be summed up in two major intervening influences that may lead to an adjustment of my initial theoretical model for the case of Wenzhou. The first major influence that came out of the data for both samples was the influence of network (Network explanation) that in the case of Protestants goes with the name of house churches and for the case of non Protestant entrepreneurs simply changes its name with 'associations', 'circles of friends', lineage and family. In other words it is clear that regardless of the specific religious label network results to play its crucial role in business among both categories of Chinese entrepreneurs. This was clearly witnessed in the role of network of different natures for business among the same individuals: house church, family and lineage, etc., ... Cases of business partnerships like Delun and Bingwen or Minzhe, Fai and Enlai, based on their commonality of faith go toward that direction. However from the same Delun and Heng we see the overlapping somehow of church and lineage network of businesses. The house church as a network was also witnessed for example at the 'Girasole' storehouse with a deep ramification of business connections with one another. A counter-part of that was seen with the case of the widespreading of a chain of businesses named AUMAI across Milan. Particularly interesting was to see how network plays its decisive role as an emergency channel especially in situations of economic risk and crisis, regardless of the presence or absence of a religious connotation giving an essential help in the initial stages, providing information, partnership and resources crucial for business. It must be noted though that 
such type of influence vary on the base of the type of network (Associations, church membership, migrant community, informal entourages, family, circles of friends, personal connections, etc., ...).

The field showed that not all those examples of networks result to play a role in business and their function was not always effective. For example some associations that supposedly were intended to promote business among Chinese entrepreneurs actually were considered to be more a burden than an help. Any network has costs and constraints. In the Chinese context, it functions in an exclusive manner, bringing traditions that especially for the first generation of migrants results to hinder innovation. In fact when it comes to business multiplication and evaluating the financial weight of networks for business success, it was possible to see that regardless of the type of network, wether associations, circles of friends, religious networks, etc., ... what was crucial was the presence of a specific Chinese principle of relationships: Guanxi. The principle of obliged reciprocity of guanxi was present in cases such as Ning, Jahao, Peng, Delun, Yan, Yi, Na's parents and many others.

So it is not enough to be part of any type of network that somehow could give access to finances for those small business owners in order to achieve economic success. It is a particular configuration of network therefore that results to play an active role in business, the one that involves what in literature is defined as 'circle of recognition' (Barbera F., Negri N., 2015). In this case the interactions between actors in the network have structurally equivalent nodes and their connections become representations of state of being and belonging, acquiring the value of rituals. This was observed in the field especially for the case of church membership or certain types of associations. The house church network in particular is able to generate and reproduce its own organizational schemes that in literature are called 'disciplines': stable modes of action displayed in order to support a collective identity and to allocate social roles accordingly (Barbera F., Negri N., 2015). Furthermore however I pointed out that there is still a substantial difference in the way that network operates in the two samples. For the second group the network operates with the function of guaranteeing the survival of a specific business whereas in the case of the house churches I pointed out that the main function beside the provision of a network remains the control of the conduct, a stress on Charisma and a strive for affirmation that pushes the individual toward the economic success.

Secondly another major influence that came out of the data as a potential expression of a Wenzhou's profit-oriented mentality was the role of Confucianism (Cultural explanation). Particularly it has been noticed how some values proper of Confucianism (stress on diligence and education) may play a similar function than that one of the Beruf, the inner-worldly asceticism and the role of Sacred Scriptures for the case of Wenzhou's Protestant entrepreneurs. Such emphasis on 
ambition was noticed in cases of new generation entrepreneurs like Ho or Hop and the pressures of their families for the achievement of a profession. This doesn't mean however that those reported similarities in Confucianism are a precise and rigorous reproduction of the several preconditions present in Protestantism. Nor it means that they are able to bring a similar outcome in business in light of the observed influence that preconditions and assistant to the preconditions had only in Protestantism.

The absence of a systemic set of values and of a large scale religious identification as the one that I was able to find in Protestantism limits necessarily the extent of such comparison. Furthermore, not only the degree of identification with Confucianism in Wenzhou is generally low, sometimes just as a slogan and without the strong identity proper of Protestantism in Wenzhou, but also, such Confucian values already existed long before the advent of today's capitalistic spirit and were not by themselves able to bring the necessary economic change. On the contrary some of those Confucian values were actually considered in the historical analysis of Weber as the cause for the absence of rational capitalism (segregation and aristocracy). An effort to try to find in Confucianism an all-encompassing cultural category for such Chinese entrepreneurial spirit must be therefore considered as misleading since it doesn't clearly identify what is at stake here. Some principles of Confucianism may nevertheless survive, sometimes unconsciously, like in Sheng's strife to accumulate money, in the devotion to luck through symbols of economic success (dragons, writings for blessings...) but they must be considered more as cooperative rather than substitutive to the sociological model, in light also of their matching with the rather new nascent Protestant ethos in Wenzhou.

Even counting those two main intervening influences however the belief in PAS that I've analyzed before finds no effective substitute for the case of the second group of entrepreneurs. An exception may be made for the 'I Ching' somehow connected to the previous point of Confuciansim (Cultural explanation) which remains however a question mark since it remains a principle circumscribed to few cases. One of them clearly reported was the one of Chun in his business. To say it in different words the Protestant ethic displayed by a series of beliefs, especially the belief in PAS, can lead to an economic success favored by the self-efficacy connected to it, taking into account the role that networks and some Confucian values already exert in the area of Wenzhou. Giving the difference in self-efficacy observed on the questionnaires results, the distinctiveness observed through job-shadowing and the significant information collected from the interviews, a case for the centrality of a Protestant ethic and particularly for what concerns the belief in PAS can be made for the case of Wenzhou. Those findings on the micro level however in order to be linked with the macro dimension of the rise of capitalism in contemporary China will need to find support 
in further qualitative studies in other geographical areas and with a more systematic quantitative analysis today still missing in this field. Another critical point of this research consists of the long distance between the historical study of Weber and the particular case under my analysis. This gap may therefore affect the extension of the results that someone may try to seek.

Lastly, even if through this study I was able to identify clearly each factor under analysis in the field, questions remain on the intensiveness of their impact. As I showed the belief in PAS among the Chinese entrepreneurs tends to play a crucial role in displaying self-efficacy especially in situations of risk and difficulty. With which intensity this metaphysical concept permeates the work-life of the entrepreneur remains still a question mark that may limit the conclusions that I can reach. This has to do mainly with how this belief, together with the preconditions observed, can actively lead to economic success. Further studies and investigations may lead to re-define the element expressed in the model. What emerged from the data in any case is an undeniable commitment toward an internalized belief that is more than a formal declaration if considered inside the proper relationship with other statements and inside the general structure of the model. When compared with the results for the second group I was able to see a consistent difference in the way work is internalized by the entrepreneur, the absence of a purpose-driven activity, but also the potential impact of some intervening factors in my thesis (mainly Network explanation and Cultural explanation).

Nevertheless, as I've already mentioned, the possibility of the presence of a Wenzhou profitoriented mentality that would be able to invalidate the role of the Protestant ethic for the case of Wenzhou cannot rely simply on those two factors that by themselves may be able to push toward hard work but they are not able to provide an alternative consistent explanatory interpretation for the achievement of economic success. The fact in any case is that a Wenzhou profit oriented mentality exists today. In both cases under analysis however, regardless of the role of Protestantism, unlike much of the critics to the Weberian thesis I pointed out how such orientation is originated anyway by cultural and social factors and not by mere economic factors. This in itself is already an achievement. But in the last thirty years during the transformation of Wenzhou from being a fishing poor city into a business capital for all China and the world, although not working as a universal condition, Protestantism may be conceived still as a necessary one. I mean that it might not be totally absurd to think of the Protestant ethic, expressed through the huge religious revival of Wenzhou, as a sort of small little fuse that together with many other external factors slowly set in motion the genesis of a 'Wenzhouren spirit of capitalism'. Later on such spirit by a law of imitation scattered and is now present in Wenzhou and its common citizens with no link at all with the Protestant faith. 
The field however also pointed out the possible presence of a justification logic that instead of identifying the belief as a cause for certain behaviours was functioning more as a justificatory instrument of their business. Some interviews and job-shadowings in fact pointed to this possibility also taking into account more recent theoretical contributions on the topic. The justification logic can reveal the subjective interiorization of why success matters to the eyes of the entrepreneur beside the actual reason of it. Having said that, the Chinese ethos doesn't simply disappear nor it loses its significance, it simply changes in its influence of the dynamic. Instead of influencing the behavior through some sort of psychological connotation it serves as a rethoric tool in order to legitimize and motivate the economic activity toward success.

Therefore some may legitimately say that successful entrepreneurship involves specific social, cultural and even religious aspects that move beyond mere business strategies. As someone said in order to be intentionally successful rarely the homo oeconomicus is able to control uncertainty without resorting to the symbolic worth contained in his actions, becoming therefore even unintentionally homo sociologicus (Barbera F., Negri N., 2015). Furthermore according to my results values-driven entrepreneurs, as opposed with need-driven entrepreneurs, possess the necessary confidence to overcome economic risk and therefore they are more able to enhance economic success. Success in a condition of economic crisis like the one I witnessed in Italy becomes possible only through specific values as for the case of Chinese small businesses. This case teach that success in a crisis is for the one creatively exploiting it not for the one desperately fleeing it. This is the degree of hypothetical conclusion that some may reach without resulting in any neglect of the benefit of the doubt. I trust that the reader by now has properly understood that the goal of this final analysis is not to support a deterministic application of the theoretical argument for the case of China. But, taking into consideration several potential intervening critical dimensions, this study interestingly enough points out some unexpected degree of confirmation in the validity of the theoretical model.

Ethos is therefore at stake, certain ethics seem to make a real difference in business even for the accomplishment of economic success. Motivations of an individual when derived from radical forms of morality can have an impact on actions of individuals. Such is the case of salvation viewed by the Protestant Reformation as entirely the gift of God's grace, or with the Lutheran idea of calling in secular pursuits, and most of all through the Calvinistic idea of Soverenty of God impacting upon creaturely existence at every point, in a community on which the 'glory of God' will be realized (Wogaman J. P., 1993). These ethical premises as many others (see the Calvinist idea of stewardship as religious basis for every active economic life deferring consumption and amassing capital for further economic investments) have an immense influence in shaping the subsequent secular as well as religious history. 
But what could be the place of ethics in a secular society? Prescriptive behavior, duty, obligation, distinction between right and wrong, justice and injustice, responsibility and irresponsibility are seriously regarded by secular authorities, and society doesn't cease to be somehow concerned with ethics. Yet a fundamental peculiarity of the Religious ethics is the relationship with an objective and personal source of the conduct: God. I started this analysis by pointing out the neglect of the "God factor" in sociology. Sociology as a discipline in fact started as a rejection of the metaphysical stage in favor of the positive stage of science. By doing so however conventional analyses of the discipline of sociology of religion so far failed in recognizing their own biases. Labeling any theological explanation as irrelevant or fruit of rhetoric is as limiting as the opposite case of an uncritical defense of a religious position only on the ground of theological claims. Hopefully through this analysis the reader has been offered with a third way that can make justice to the influence of Theos in society while guarding against an uncritical reception of it. Like under the wall of Berlin, academia today is forcing an unnecessary compartimentalism between sacred and profane, God and scientific investigation, methaphysics and empiricism. I have only tried to open a small breach on this giant wall by testifying that ethos is at stake even in business, even today. The Judeo-Christian ethics particularly address the whole being and it has as its ends practice and responsive behavior (Hughes $\mathrm{P}$. E., 1983). Moral guides not only respond in situations of crisis but also train the individual to transform the crisis into a success (Reuschling W. C., 2008). A case of profound social and economic transformation such as the one of contemporary China may show therefore how, against all odds, the business ethics and the principles coming from a long path of sociology of religion, for so long neglected and underestimated, can become the real ambitious and significant added value for both contemporary society and future sociological theories. In conclusion this study testifies for the reasons why ethics still matter in today's secularized society. 



\section{Appendix ${ }^{1}$ :}
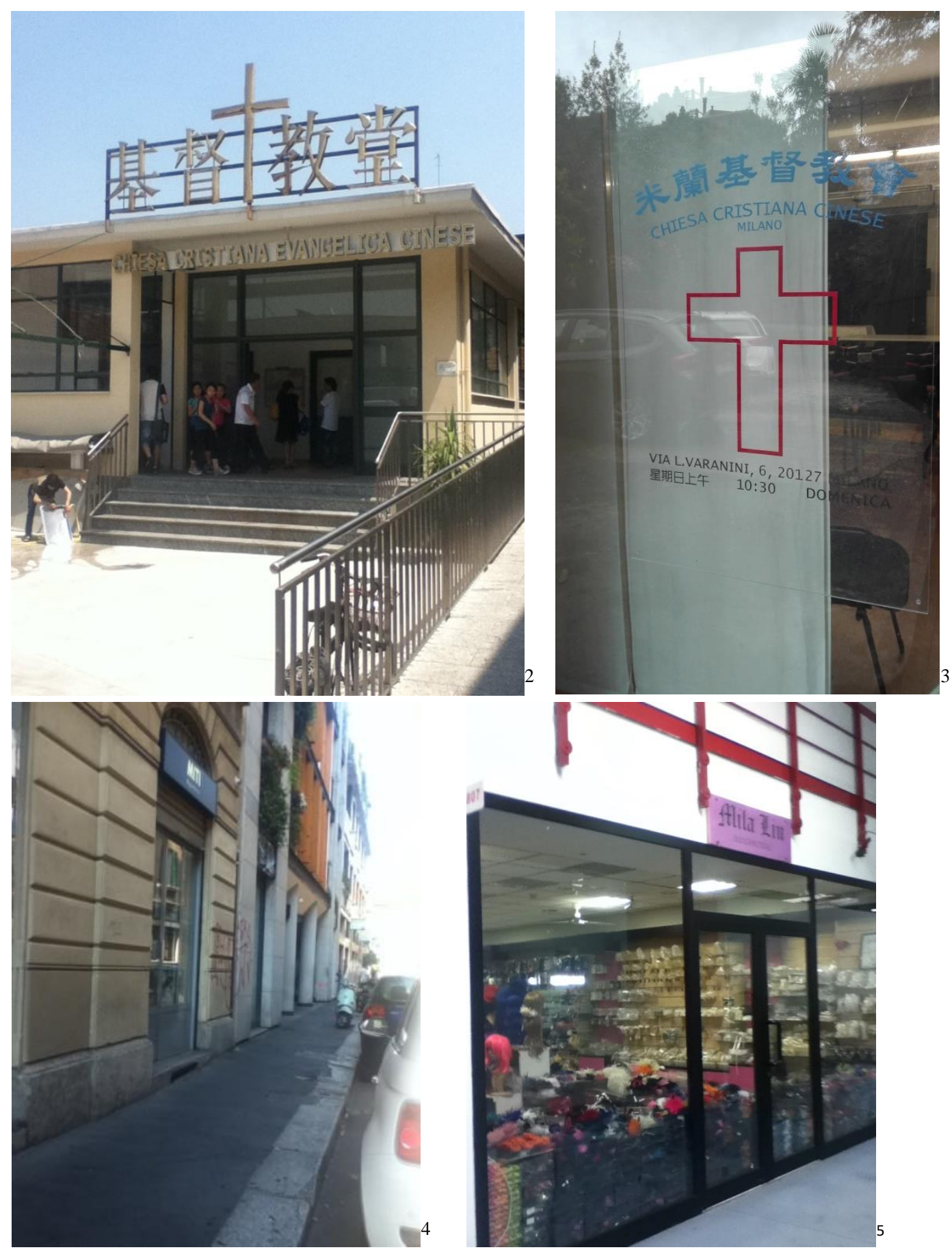

\footnotetext{
${ }^{1}$ This appendix contain pictures, maps and charts part of the study. If someone may be interested to explore more the whole empirical documentation it is possible to examine the CASE REPORT at the end of the text. The majority of the material in the CASE REPORT is in Italian or Chinese. When included in quotation in the official text of the thesis the material has been always translated into English.

${ }^{2}$ Facade of the evangelical Chinese church in Milan where many ethnographic observations where done.

${ }^{3}$ Outside sign of the evangelical Chinese church in Milan where Niu is pastor. The owner is a Laboan (Christian boss) from Taiwan that gave the lower floors of his house as a place for building the church.

${ }^{4}$ Outside view of one of Heng's stores, his jewelry in the China town of Milan, where many hours of shadowing were done.

${ }^{5}$ Heng first clothing store at the wholesale mall of Girasole. He started with this business then moved to China town to open his second store.
} 

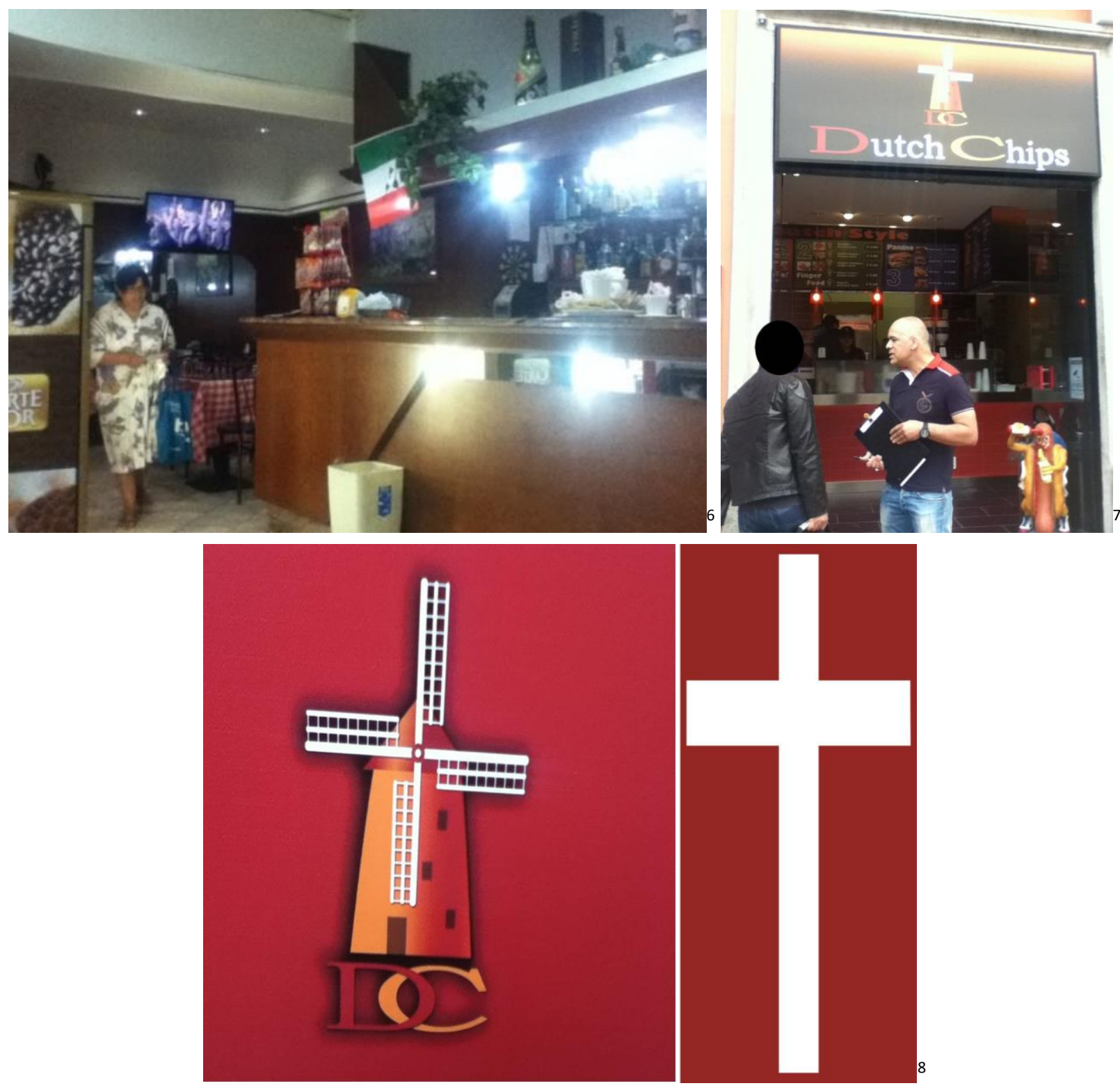

\footnotetext{
${ }^{6}$ Internal view of Delun's coffe bar where many hours of shadowing were done.

${ }^{7}$ Delun talking about business in front of his new franchising company. Delun try to express his faith at work often with underlying messages.

${ }^{8}$ Delun's logo on the right for his franchising company. The logo represent a mill and has the shape of a cross as it is clear when I compare it with the image on the right. 

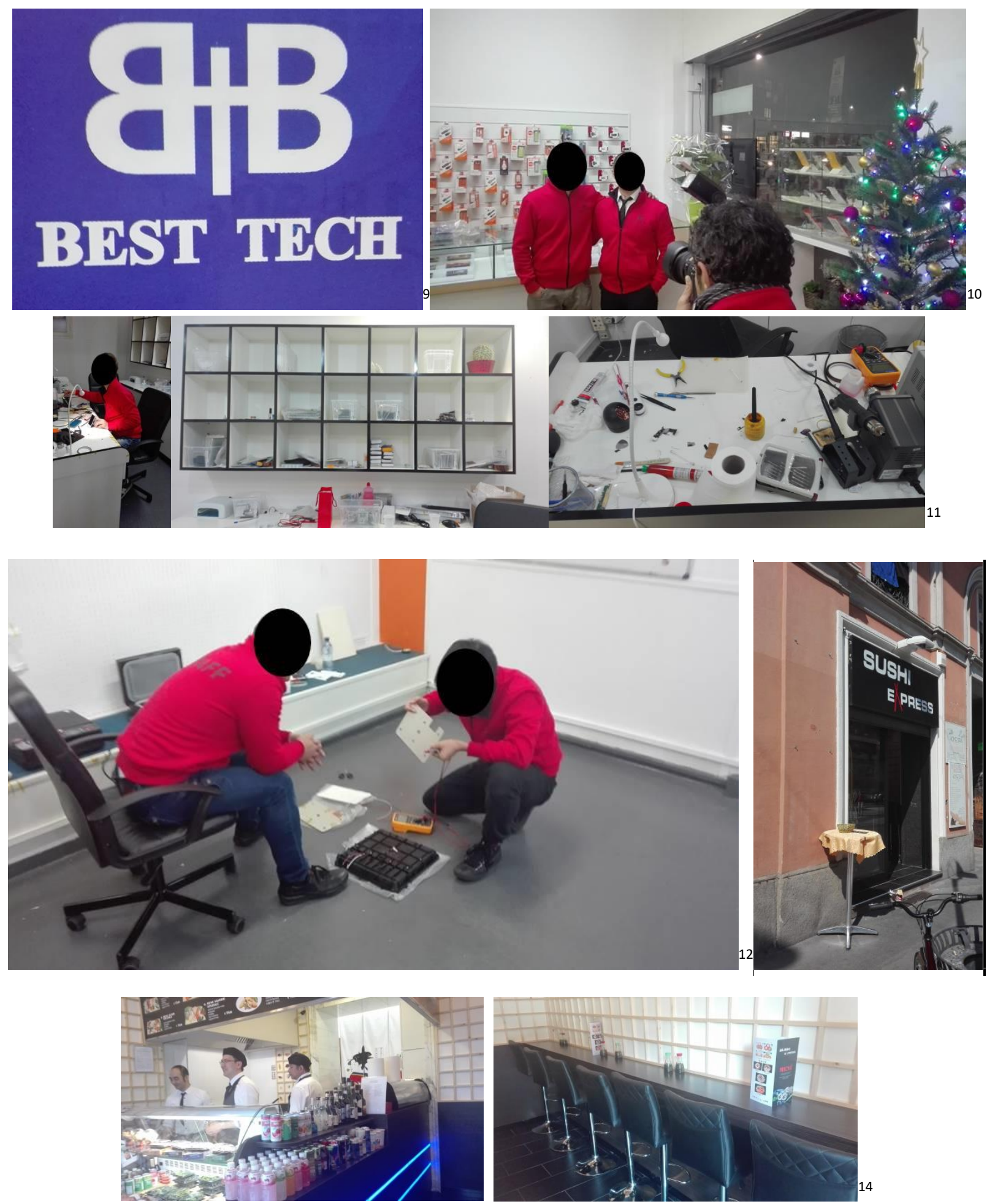

\footnotetext{
${ }^{9}$ Delun's logo for his new business of phones and technology. In the middle again the shape of a cross.

${ }^{10}$ Bingwen and Delun the day of the inauguration of their new business.

${ }^{11}$ Chinese worker at the store of Delun and Bingwen fixing cell phones. Some of the utensils and facilities necessary for the job.

${ }^{12}$ Delun (on the left) and Bingwen fixing a printer at their new business just few months after opening the business. The ability and interest to explore something totally new in a short time is commendable in them.

${ }^{13}$ Delun's new project after the Dutch Chips, in the same place he converted the business in a Sushi restaurant take away. Delun' strategy of innovation is quite impressive even for his co-national entrepreneurs.

${ }^{14}$ Internal view of Delun's new business Sushi express. From the left him and his workers.
} 

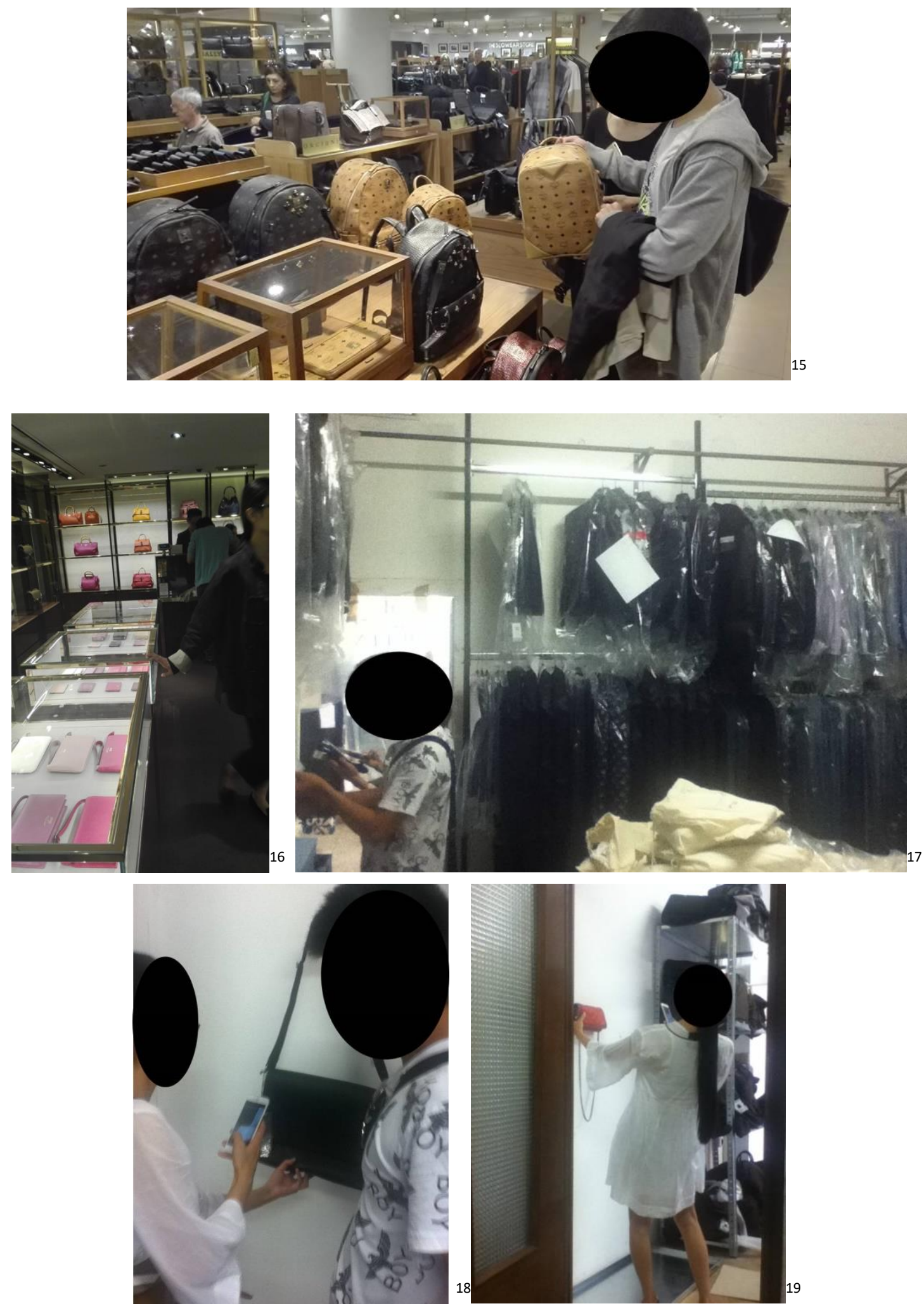

\footnotetext{
${ }^{15}$ Minzhe and Bingwen at Rinascente in Milan checking high quality bags.

${ }^{16}$ Minzhe after having checked the new bags arrived at the Gucci store of Rinascente in Milan.

${ }^{17}$ Minzhe selecting jackets and shirts in the warehouse of one of her choosen boutiques in Milan during my jobshadowing.

${ }^{18}$ Bingwen, Minzhe boyfriend, helps her in the process of choosing the right product. Although Bingwen is an engeneer he also started a business in fashion in Milan during my time of job-shadowing in a boutique.

${ }^{19}$ Minzhe taking one of her many pictures with the bag she thinks can be selled to her clients. 

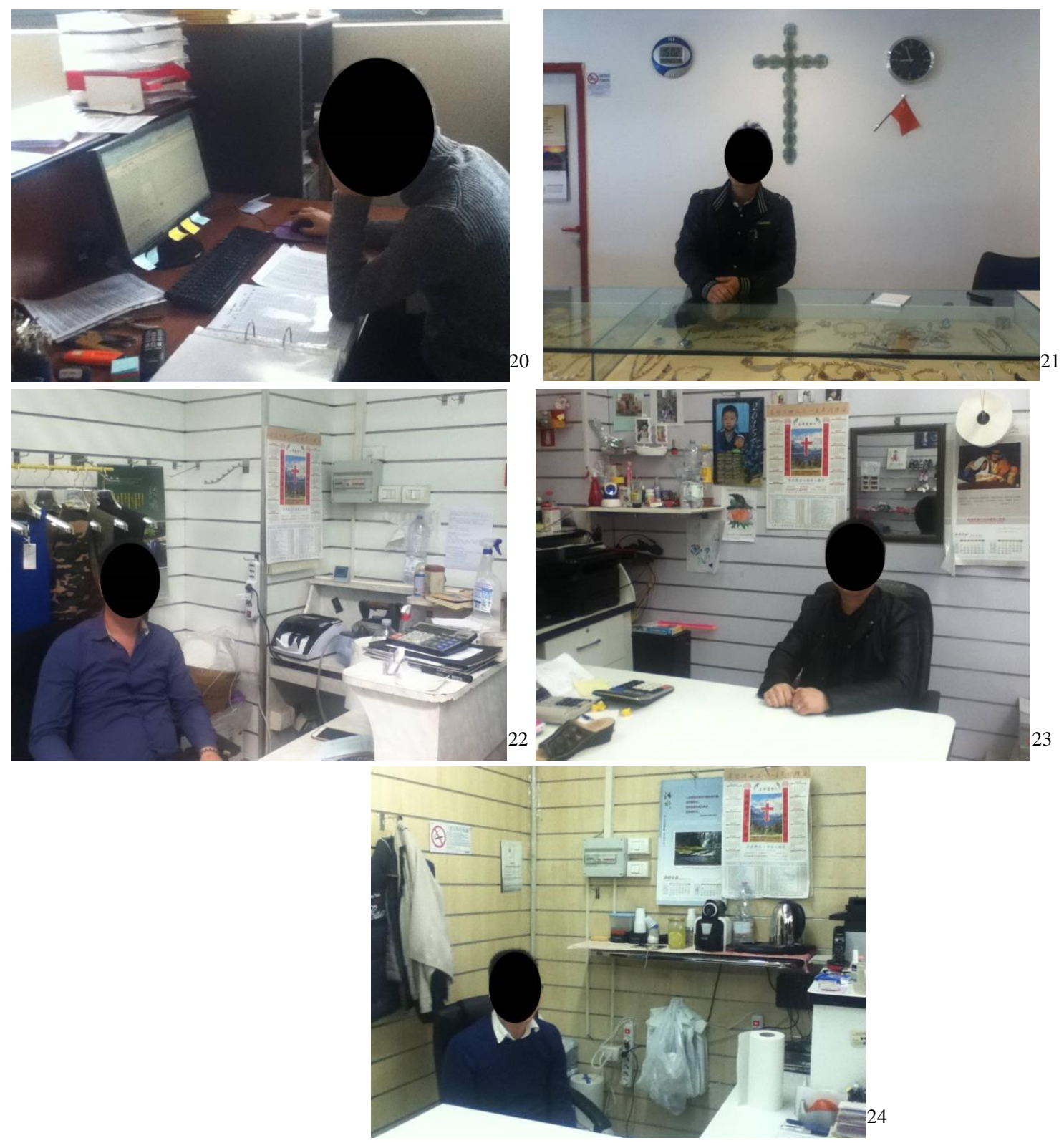

\footnotetext{
${ }^{20}$ Wing in his office. Wing does a more administrative work. He found job in the network of 'Ingrosso Uno' thanks to his connection with some Christian entrepreneurs that opened the door for his position.

${ }^{21}$ Zixin in his jewelry. His boss is a Christian part of the Chinese church and his boss-wife is his aunt. Thanks to his family and religious connection he got the job. On the back a huge cross made of silver.

${ }^{22}$ Huozhong in his office. Huizhong has trouble attending church in Sunday and due to his lower involvement with church activities he sees contradiction between his faith and his job.

${ }^{23}$ Yongnian in his office. As it is particularly evident from the background in this picture full of Christian calendars and religious items he is not ashamed of showing his faith at work.

${ }^{24}$ Kong in his desk at work. Kong is first generation Christian, he was led to the faith by a friend at work just two years ago, he saw many changes in his work after he came to salvation.
} 

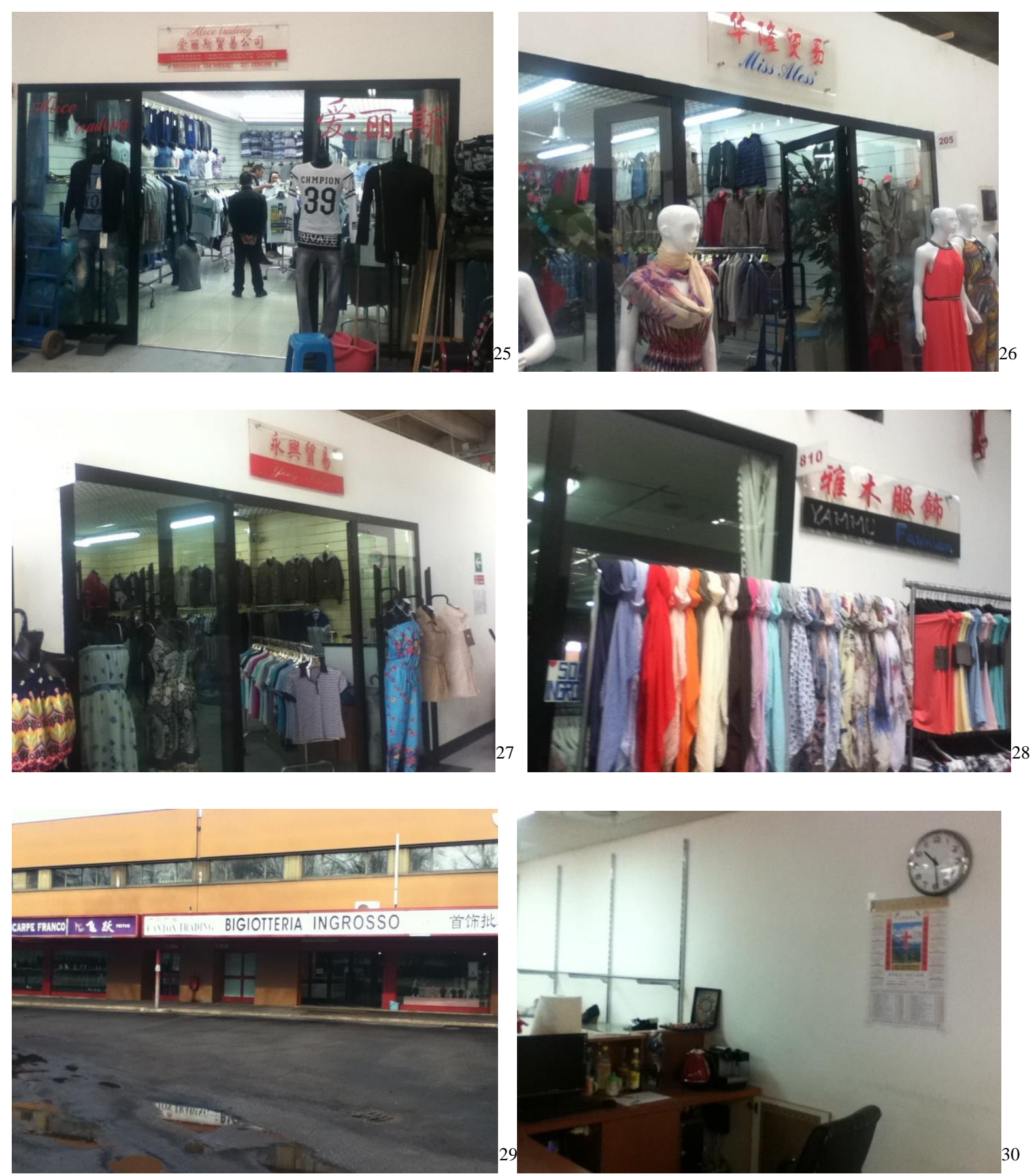

\footnotetext{
${ }^{25}$ Huizhong's outside facade of the store. Huizhong as many others is only 26 years old and he already owns his own business.

${ }^{26}$ The outside of Shu's store. Funny names like "miss mess" tend to drive clients in search of a warm welcome.

${ }^{27}$ Outside of another Christian Chinese entrepreneur store.

${ }^{28}$ Ibidem.

${ }^{29}$ Outside of the store of Bo. Deming too uses this office as a base to find more customers in all other Chinese pavilions. Shing is Bo's boss and sometimes attends the store as well.

${ }^{30}$ Desk of Bo's workplace. The Chinese Christian calendar on the wall is an expression of his identity as a Christian expressed at work with colleagues and customers. 


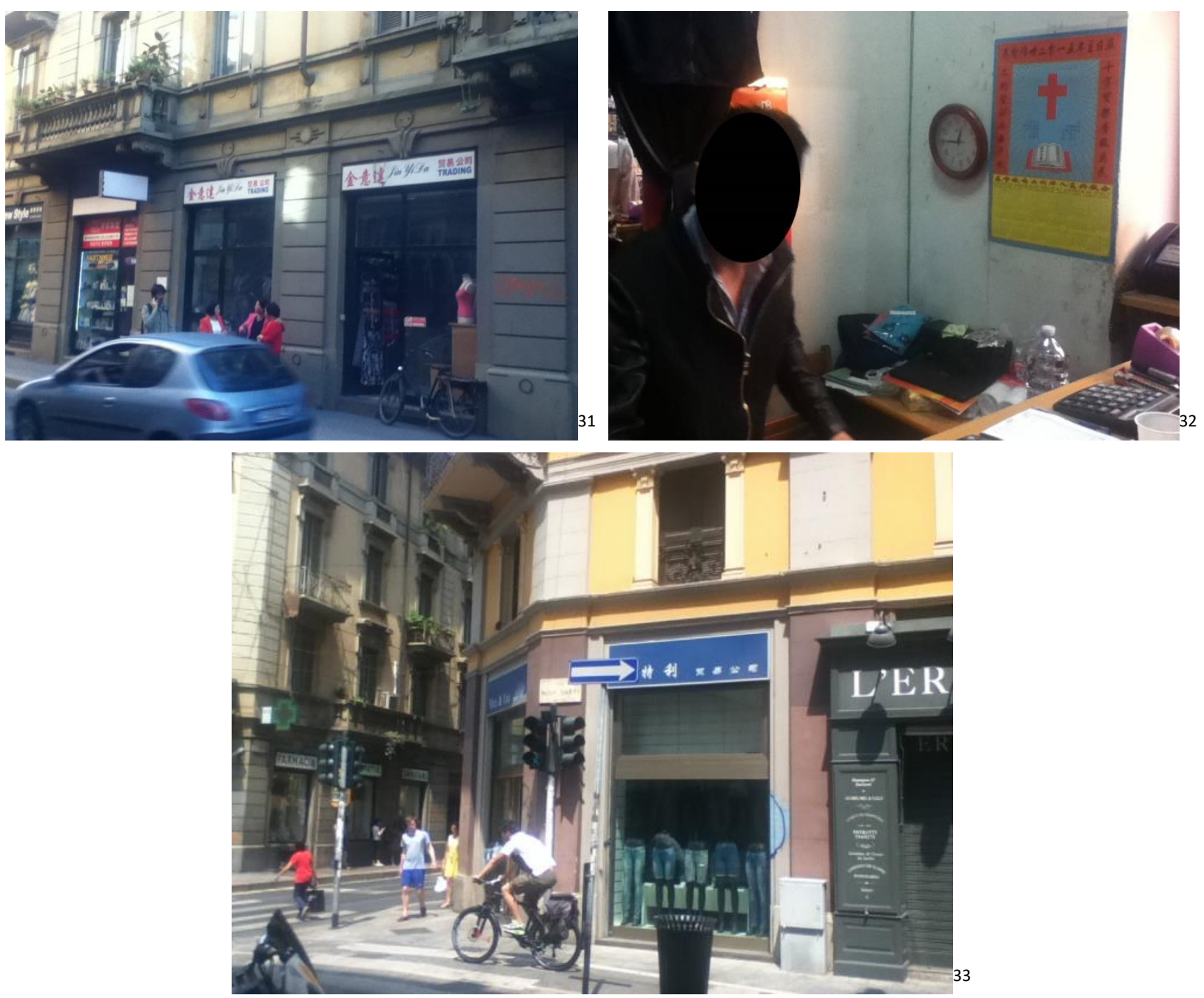

${ }^{31}$ Outside of the store of Ah Cy at Sarpi Avenue, the China town of Milan.

${ }^{32} \mathrm{Ah} \mathrm{Cy}$ in his office at Sarpi Avenue, the same Christian calendar is on the wall.

${ }^{33}$ Outside view of Guang and Na store. The business is owned by Guan's uncle and Na's father. Many of the workers of their store are Christians. 

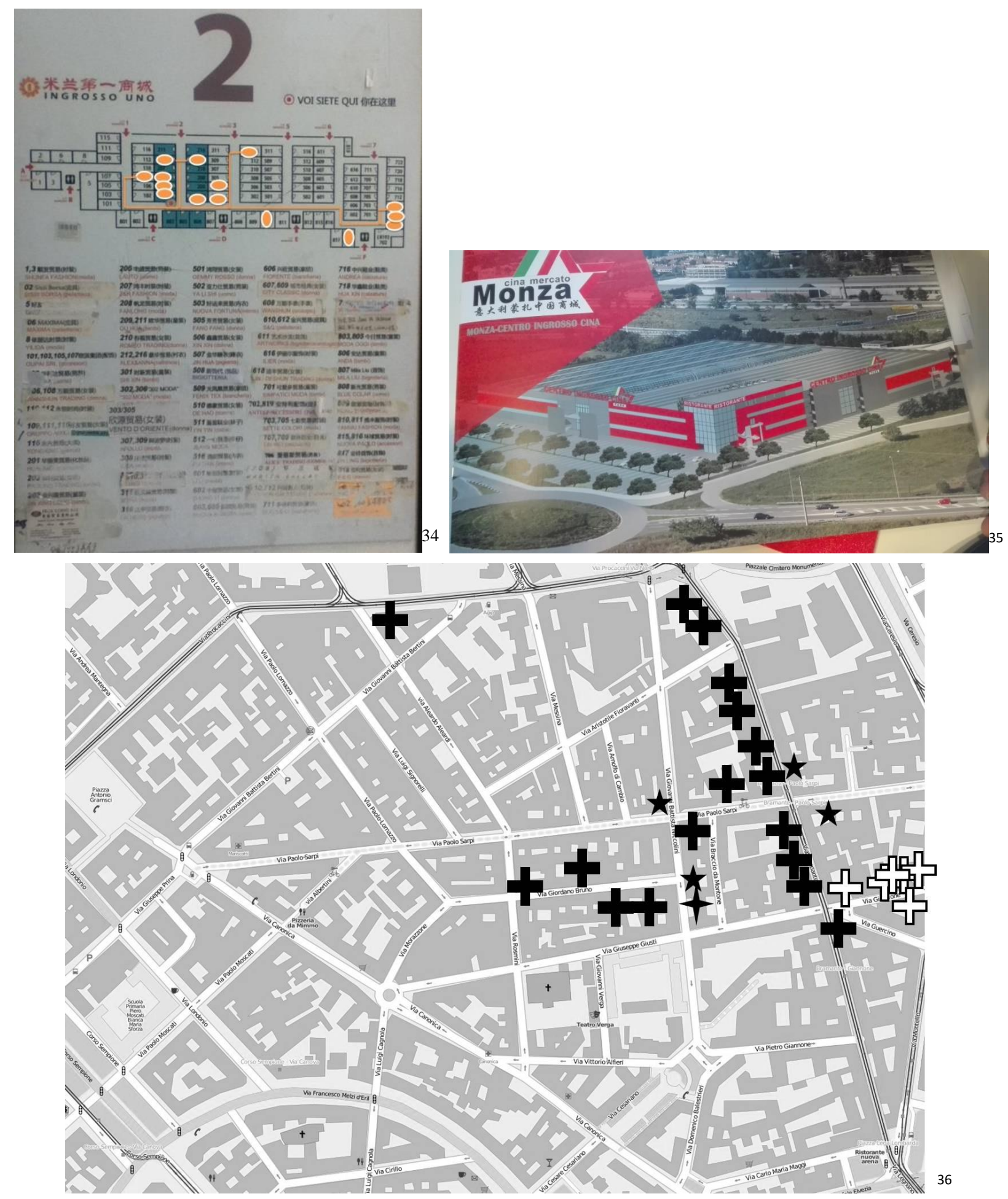

\footnotetext{
${ }^{34}$ Map of the Pavillon 'Ingrosso Uno' where many ethnographic observations where done. The yellow points represent stores owned by Christian entrepreneurs often united in a business network based on their sharing of a common faith.

${ }^{35}$ Wharehouse of AUMAI where Ho worked as a Marketing Developer in the suburbs of Milan.

${ }^{36}$ Map of the China-town of Milan, crosses in black are the business owned by Protestant entrepreneurs, crosses in white business owned by Protestant entrepreneurs from a Pentecostal branch. The stars are some of the more influential businesses owned by non Protestant entrepreneurs that I interviewed. The star with only four tips is one of the rare examples of business owned by a Chinese Catholic. The picture reveals the influence of the religious network on business.
} 

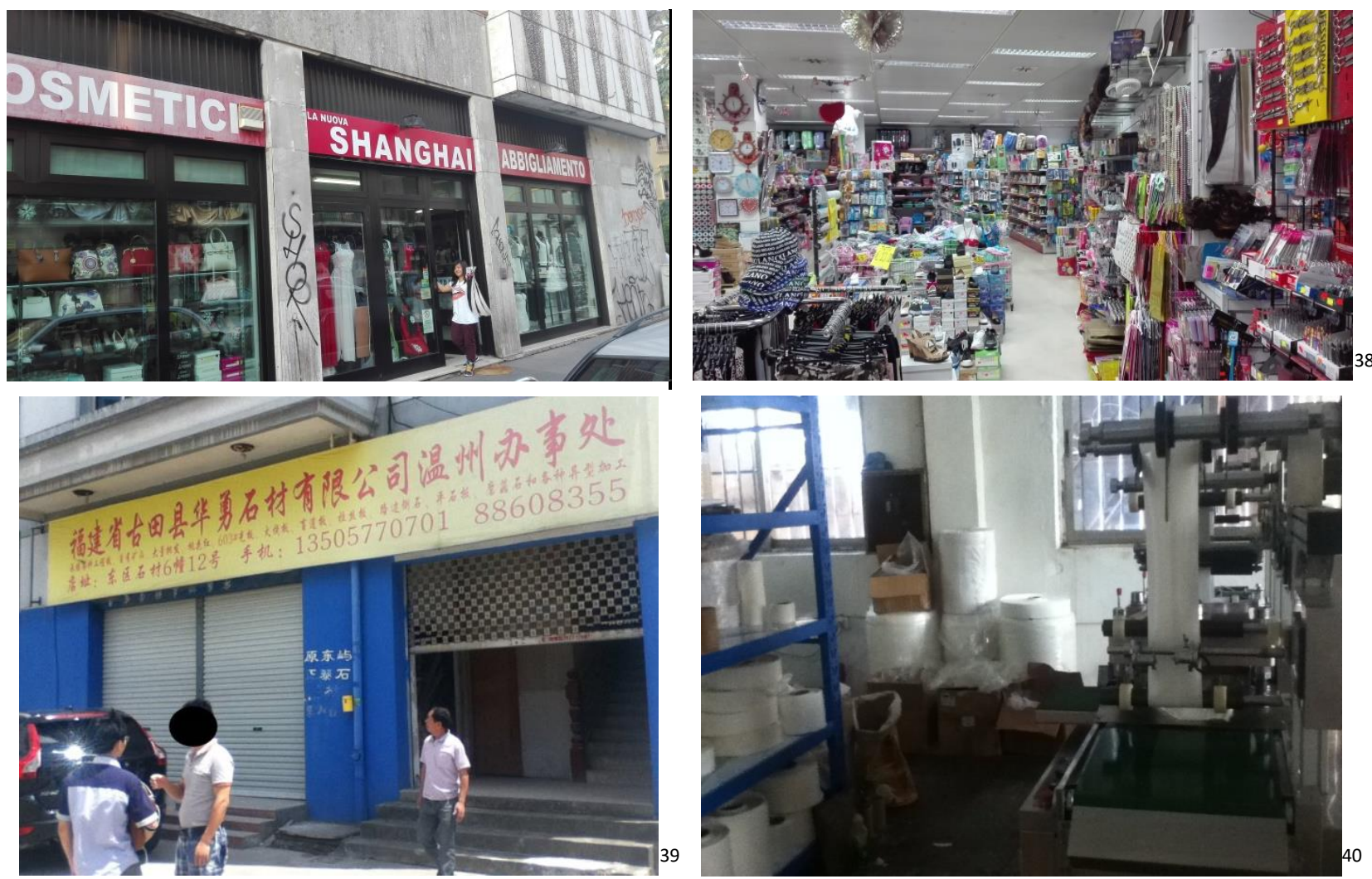

\footnotetext{
${ }^{37}$ Outside view of the store of Shaiming. He manage the store together with his parents, that are both Christians.

${ }^{38}$ Inside view of the store of Shaiming. This type of store that sells a little bit of everything is common among Chinese entrepreneurs in Italy.

${ }^{39}$ External view of the new four floors factory that Nai just bought to enlarge his business.

${ }^{40}$ Inside view of the factory for material for hospitals that Nai exports in United States.
} 

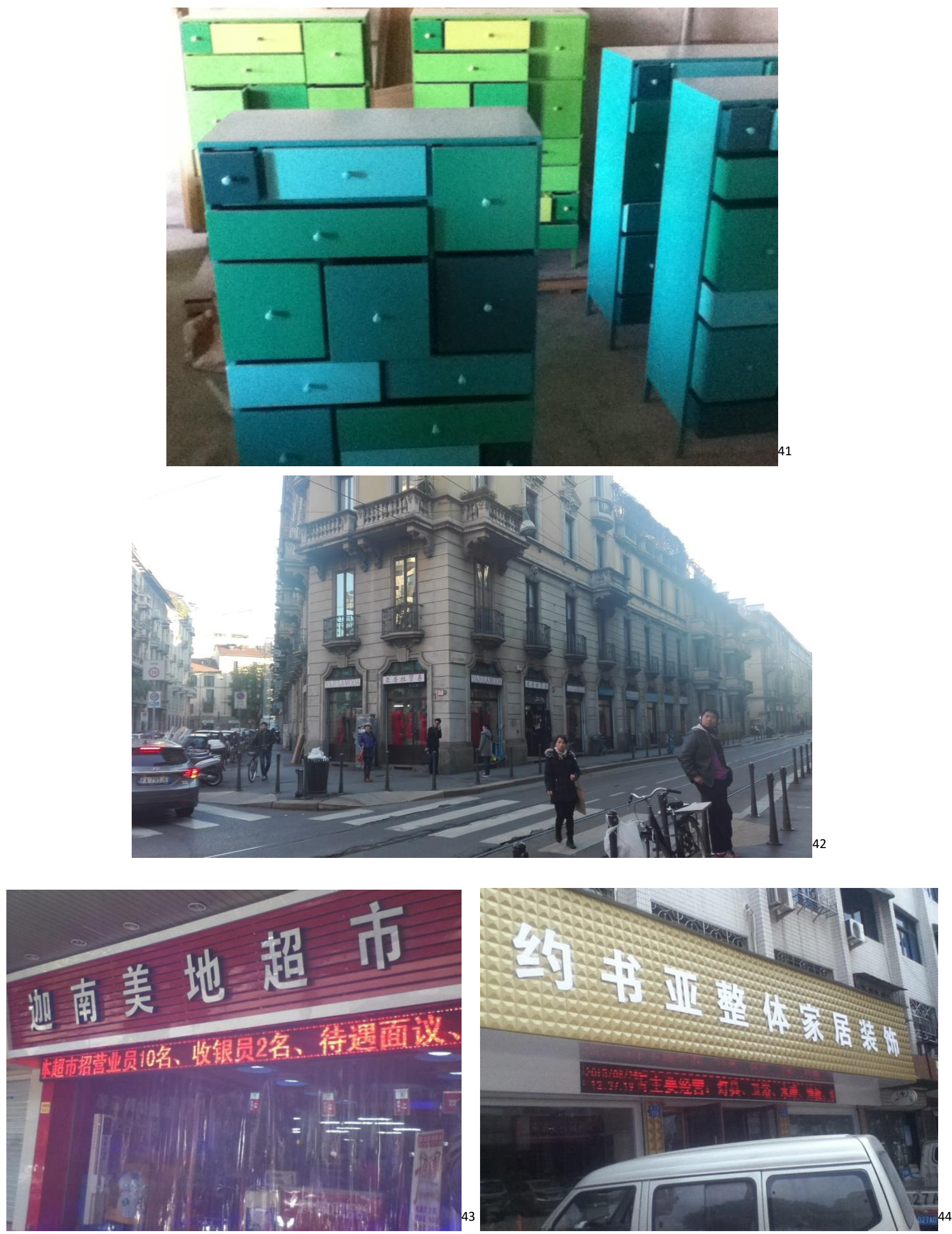

\footnotetext{
${ }^{41}$ Some sample of furnishing that are sold primarily through e-commerce and exported in Europe by Ju and Min. ${ }^{42}$ Business in the China town of Milan with a biblical name (Aquila\&Priscilla) given as a sign of Christian identity. ${ }^{43}$ A Christian supermarket in Wenzhou named after the biblical name of 'Canaan'. Many Boss-Christians express their faith at work through the use of biblical names.

${ }^{44}$ Another store named after the biblical name 'Joshua' in the surrounding area of Wenzhou.
} 


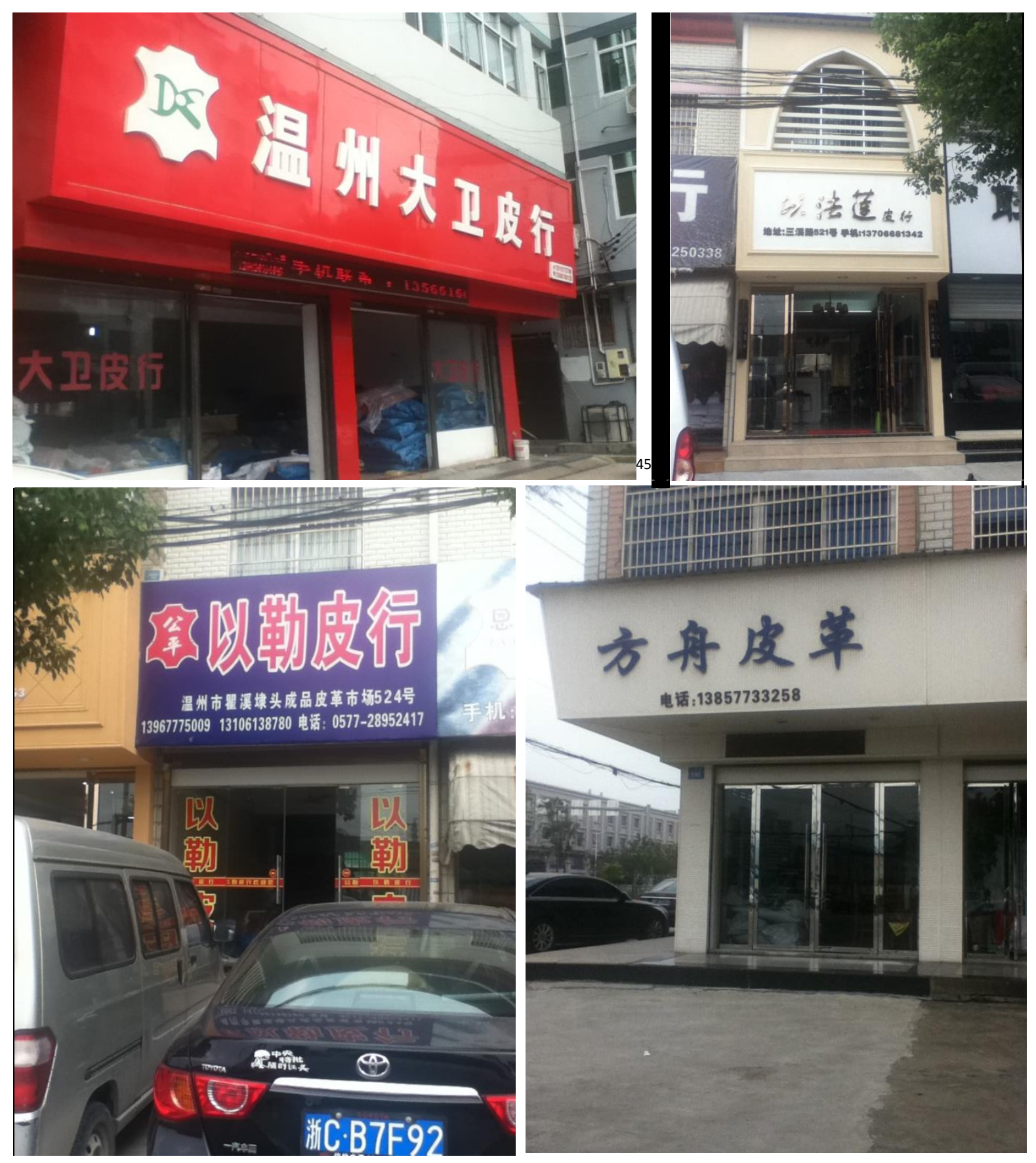

\footnotetext{
${ }^{45}$ Another store named after the biblical name 'David' in the surrounding area of Wenzhou.

${ }^{46}$ Another store named after the biblical name 'Ephraim' in the surrounding area of Wenzhou.

47 Another store named after the biblical name 'Jahveh-Jireh' in the surrounding area of Wenzhou.

${ }^{48}$ Another store named after the biblical name 'Noah' in the surrounding area of Wenzhou.
} 

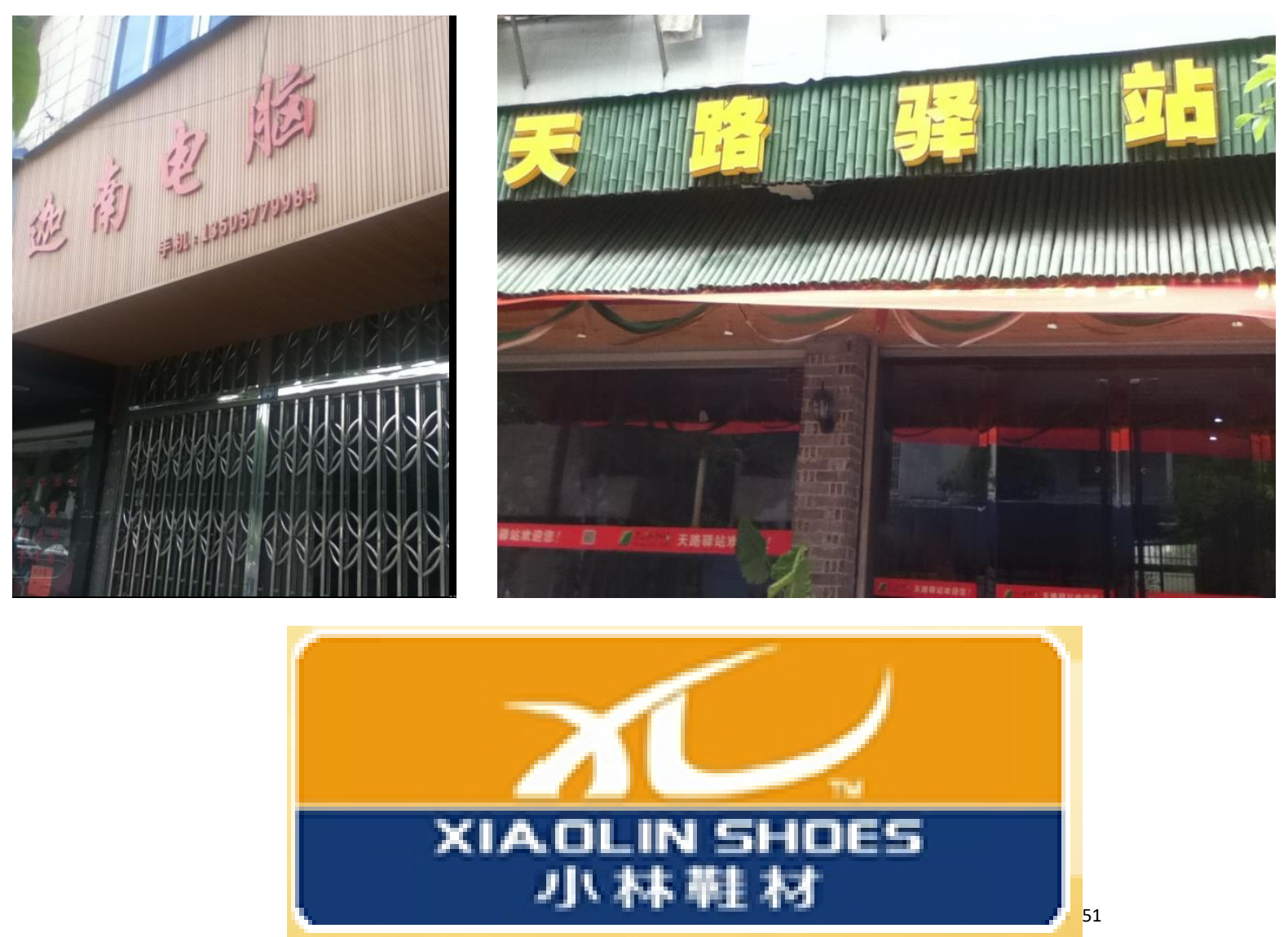

\footnotetext{
${ }^{49}$ A computer store named again after the biblical name 'Canaan' in Wenzhou.

${ }^{50}$ The bar-library owned by Qiang, named as a 'rest place during the pilgrimage to heaven'.

${ }^{51}$ Logo of Xiaolin, a famous brand of shoes in Wenzhou which owner is a Christian. This brand is very famous even in the export outside of China and has many benefits. Xiaolin follows the ethic to always pay taxes to government and avoid forms of lying and cheating in business, practices very uncommon in the surrounding entrepreneurial environment. 

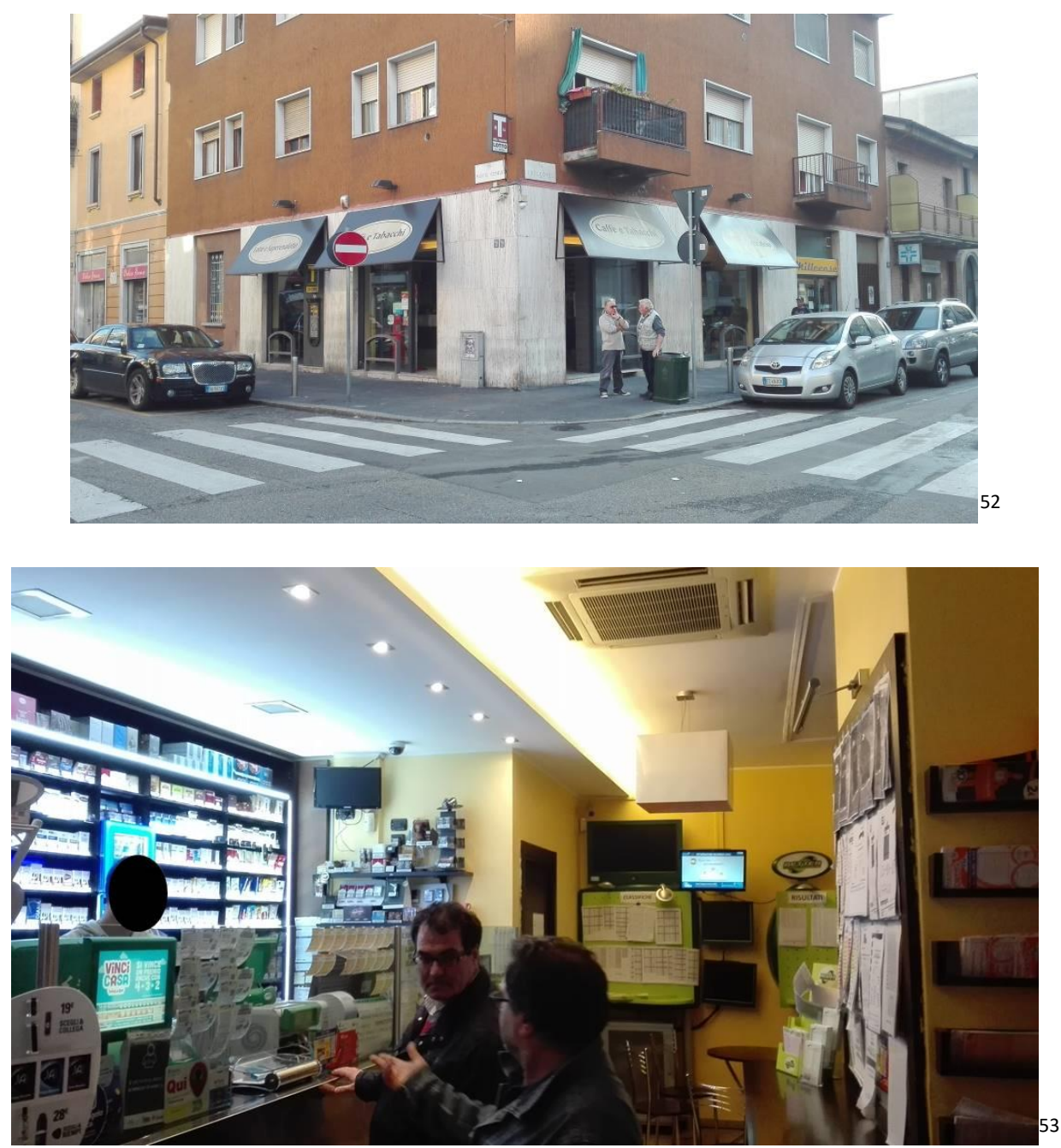

\footnotetext{
52 Outside view of the bar/Tobacco shop of Chun. Chun's view of business is to have the largest variety of services to offer to the customers in order to make money.

${ }^{53}$ Chun's cousin at the counter of the Tobacco shop and betting shop. During the job-shadowing they both worked in team, anytime there was people at the betting shop Chun was leaving the counter to go serve the clients and viceversa.
} 

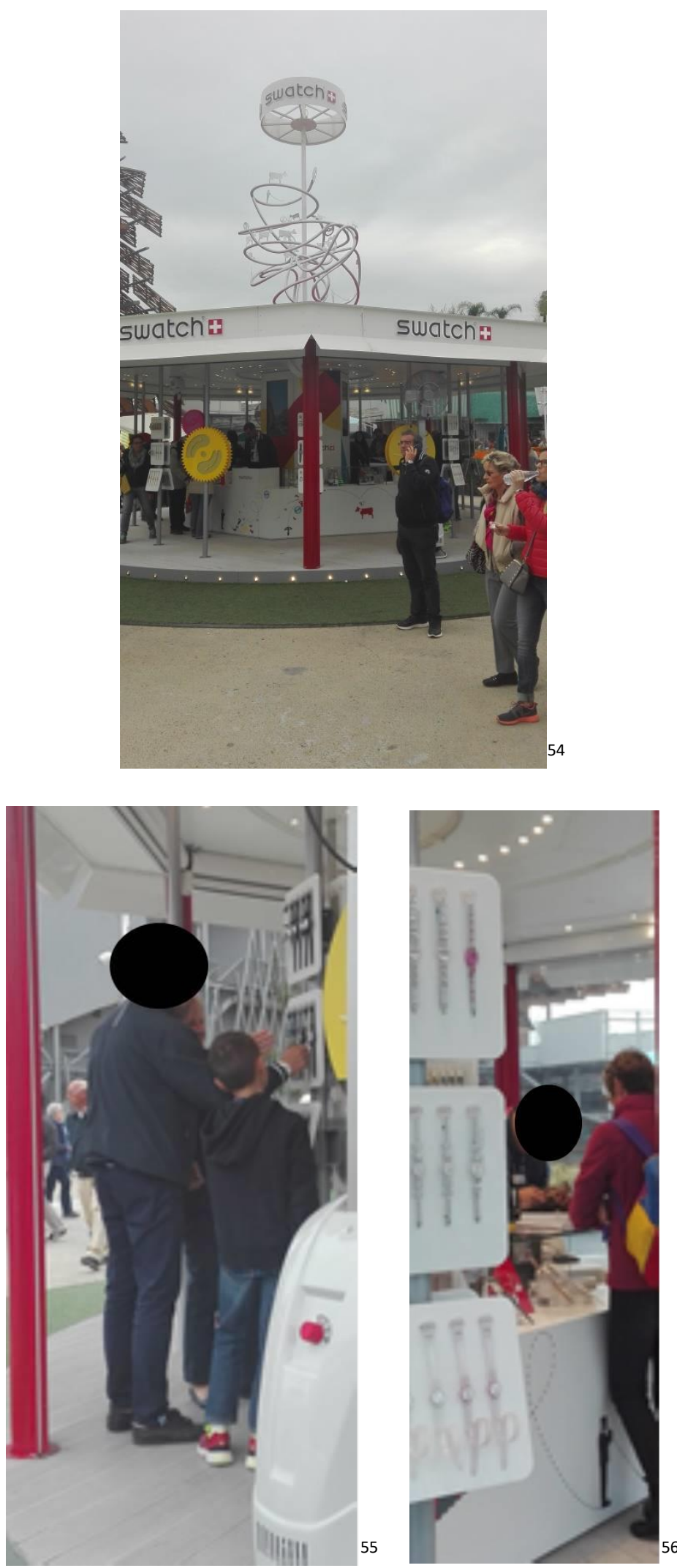

\footnotetext{
${ }^{54}$ Outside view of the store where Ho works and were many hours of job-shadowing were spent. The store is right in front of the Chinese Pavilion of EXPO 2015 in Milan.

${ }^{55}$ Ho presenting the product to a potential client.

${ }^{56}$ Many times Ho had to fix and repair damaged watches or change their batteries. Among his team Ho was the expert on it. 

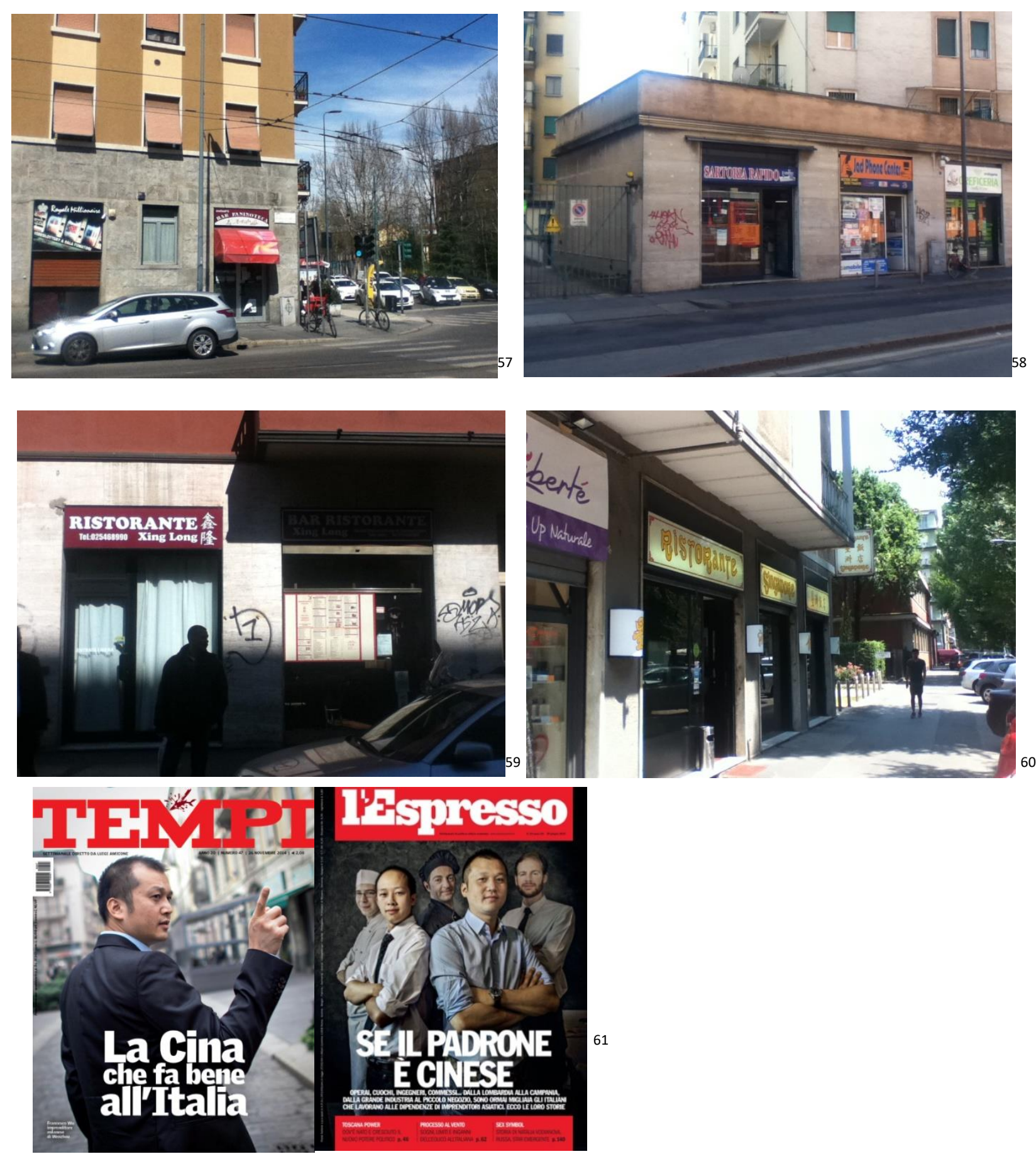

\footnotetext{
${ }^{57}$ The outside view of the bar of Quianfan. Quianfan first worked in a kitchen of a restaurant now he has opened his own personal business.

${ }^{58}$ The outside of Shilin's store. Working as a tailor has become very often among Chinese immigrants in Italy.

${ }^{59}$ Outside view of Ruomei's restaurant. Ruomei is the manager and owner of the restaurant.

${ }^{60}$ Outside view of Singapore's Restaurant. The owner is also president of the Chinese Association of Wenzhou in Milan.

${ }^{61}$ Sheng, a Chinese entrepreneur of success in the area of Milan that had a strong mediatic impact with his vision for business and strong Confucian ethic. Sheng started his business in the middle of the economical crisis of 2008 in Milan. Source: http://www.associna.com/it/2013/06/14/francesco-wu-sulla-copertina-dellespresso/.
} 

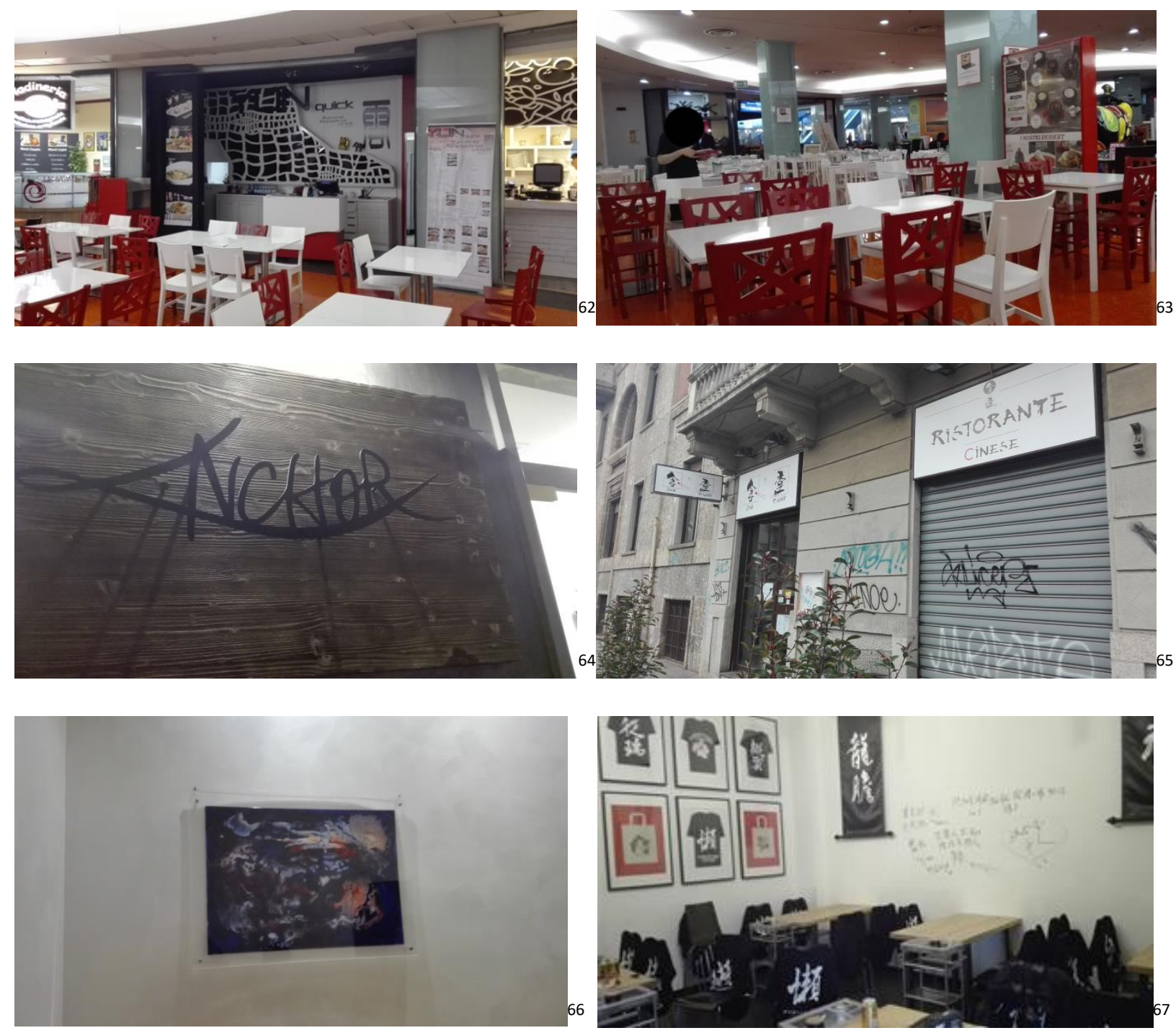

\footnotetext{
${ }^{62}$ View of the Chinese restaurant where Ning works. The store is linked with other 11 restaurants in the area of Milan owned by Jiahao, a Chinese woman entrepreneur.

${ }^{63}$ Chinese colleague of Ning setting the table at the restaurant.

${ }^{64}$ Logo of Peng's new Chinese restaurant. Despite his young age, after being already involved in 3 different intermediary businesses, he decided to open his fourth branch with a modern-looking new type of Chinese restaurant. ${ }^{65}$ Outside view of Jie's restaurant. Jie just recently opened this business at the time and already had a bed and breakfast running in Milan.

${ }^{66}$ One of the paintings at Peng's restaurant, many Chinese students like Guiying (artists, photographers or sculptors) find their own patrons in the Chinese entrepreneurs of their social network and receive the mandate to adobe their stores. Jing for example as a sculptor had 4-5 Chinese patrons for adobing their restaurants in different parts of the city of Milan (Via Padova, Porta Venezia, Porta Romana, etc., ...).

${ }^{67}$ Inside view of Guiying restaurant. Guiying as a businessman but also as a Fashion photographer and artist was responsible of all the design and gadget related to the logo he invented for the store. 

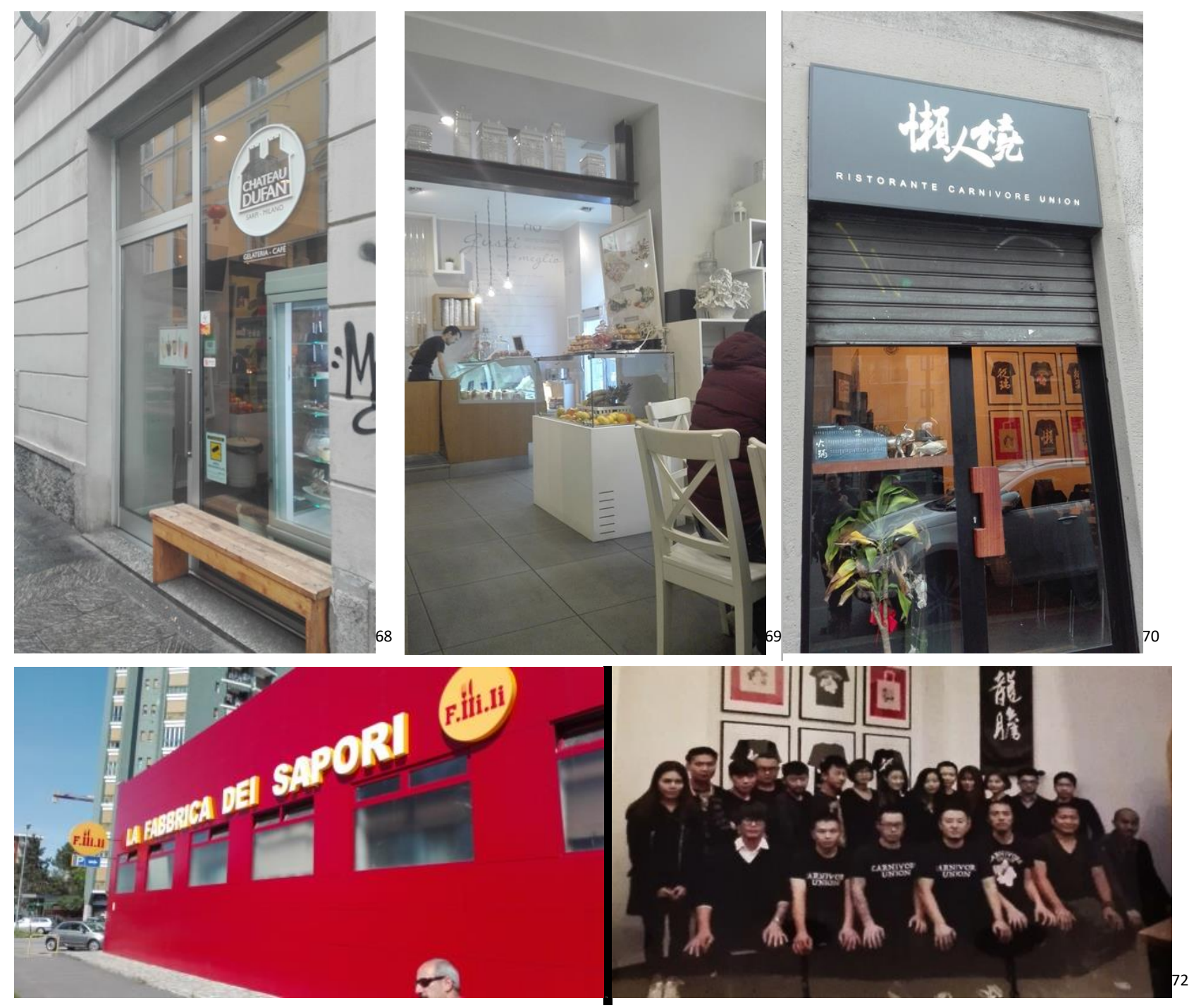

\footnotetext{
${ }^{68}$ Tao's bar at the beginning of Sarpi avenue. The bar (Chateau Dufant) is in a strategic location of China town.

${ }^{69}$ Inside view of Tao's bar unique artistic furnishing. Tao, similar in this to Delun, as a second generation migrant tries to find new and more modern ways to do traditional Chinese businesses.

${ }^{70}$ Outside view of the restaurant of Guiying. He designed the logo of the restaurant. This small store is well known among Chinese living in Milan for the typical and unique dishes.

${ }^{71}$ Outside view of a new mega-restaurant all you can eat in the hinterland of Milan that has its success due also to Chinese investments and foresight. The restaurant was built on an abandoned factory.

${ }^{72}$ Guying (third from the right on the first row) during the inauguration of his restaurant with all his Chinese business partners.
} 


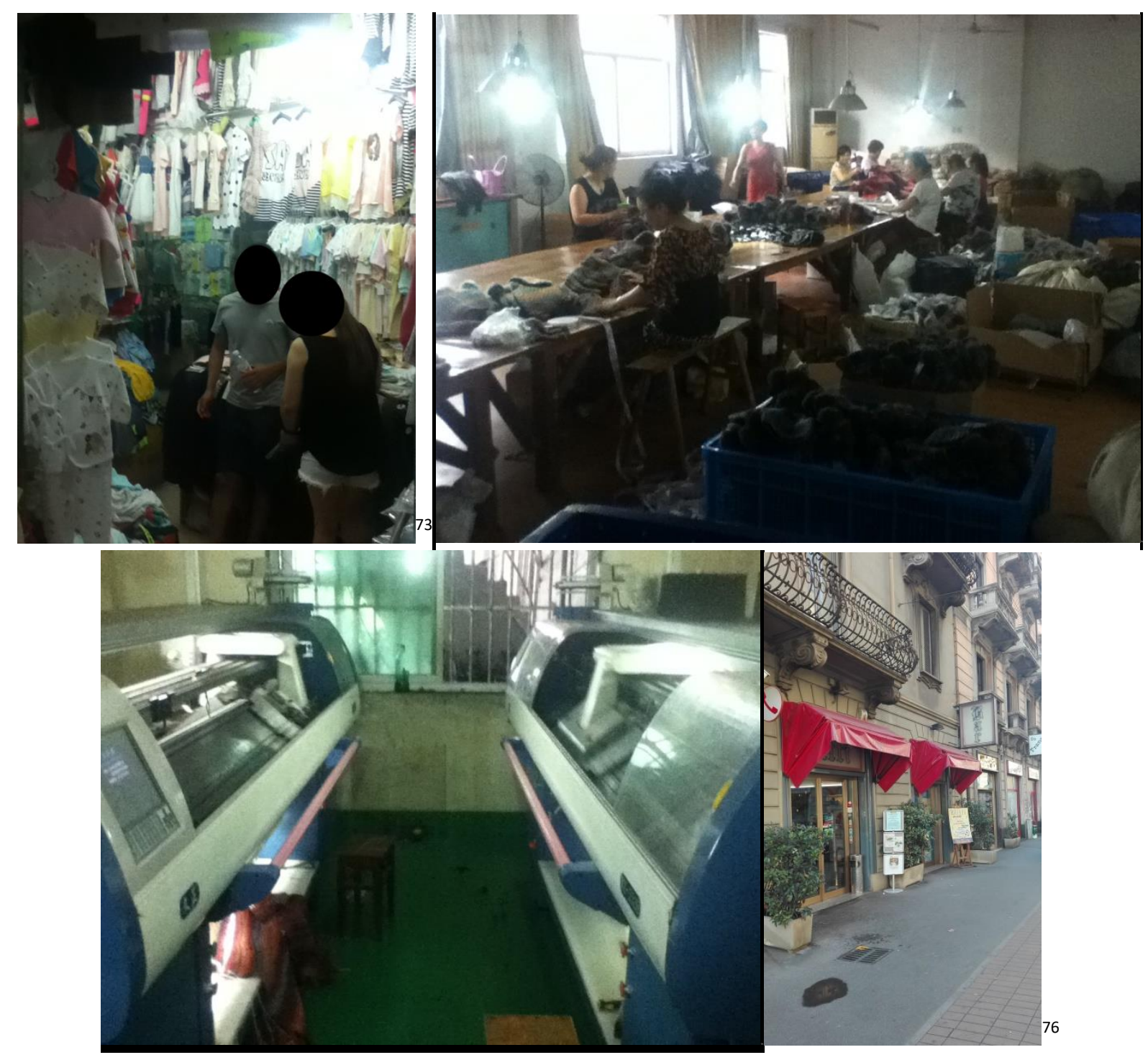

\footnotetext{
${ }^{73}$ Mei in her clothing store for children with her nephew Bingwen in Tonglu.

${ }^{74}$ The inside view of the clothing factory owned by Ping in Tonglu. His wife directs the workers that pack the scarves and hats for the expedition to Europe.

${ }^{75}$ Some of the machines of the clothing factory owned by Qi in Tonglu. Those machines stay opened every 24 hours, non stop, producing the scarves that then are sent to the big cities like Yiwu and then collected to go in Europe or North America.

${ }^{76}$ Outside view of the italian bar under occasional job-shadowing close to the China town of Milan. 


\begin{tabular}{|c|c|}
\hline & Biographical Record - Delun \\
\hline 1900 & Great-grandparent become Christian \\
\hline 1987 & Delun was born in Wenzhou's province \\
\hline 1992 & $\begin{array}{l}\text { The father of Delun comes to Italy, in the beginning washing dishes then becoming cook } \\
\text { assistant for a Chinese restaurant then working for an Italian company. }\end{array}$ \\
\hline 1996 & $\begin{array}{l}\text { Delun's mother arrives to Italy together with her six sisters and } 5 \text { brothers and sisters } \\
\text { from Delun's father side of the family. She starts to work with her husband in a chicken } \\
\text { factory, butchering chickens and packing the meat in the city of Piacenza. They have no } \\
\text { other Chinese people around them, working hard and very solitary. }\end{array}$ \\
\hline $1990-2000$ & $\begin{array}{l}\text { Delun studies at school, not very diligent yet able to pass the exams. He build } \\
\text { relationship with people outside school, being like a gangster, watching his friends fight } \\
\text { and killing feeling protected. }\end{array}$ \\
\hline 2002 & $\begin{array}{l}\text { Delun arrives in Italy february the 22nd. His parents move from Piacenza to the suburbs } \\
\text { of Milan San Giuliano Milanese. Delun starts to learn Italian, doesn't has hany friends } \\
\text { and must start his life all over again. He fells hatred toward his parents, his country and } \\
\text { communism. Delun was forced to migrate to find a better life. Delun's father open his } \\
\text { first bar having saved all his money to open his own business in November of the same } \\
\text { year. Rythms of working hours were difficult, from } 4 \text { AM to } 2 \text { AM everyday being first- } \\
\text { generation migrants. }\end{array}$ \\
\hline 2004 & $\begin{array}{l}\text { Delun goes to school and in the freetime he works at the bar, he was rebuked by his } \\
\text { parents that wanted him to become like them and work hard. }\end{array}$ \\
\hline 2006 & $\begin{array}{l}\text { Delun meet his future wife through his aunt that in her own bar of San Giuliano Milanese } \\
\text { invites Delun to know this Chinese girl. }\end{array}$ \\
\hline 2008 & $\begin{array}{l}\text { Giving the lack of options Delun marries her. In the same year in march Delun opens his } \\
\text { own first bar in Milan, at the metro stop Udine at the age of } 21 \text { years old, following the } \\
\text { same path of his parents with rythms of working hours that were oppressive. For a year } \\
\text { and a half Dleun wakes up to go to work before sunrise and goes to bed late at night. In } \\
\text { the same year he move with his wife into a new house closer to his business. }\end{array}$ \\
\hline 2010 & $\begin{array}{l}\text { Delun with his first bar decides not to continue wwith those rythms, and decides to work } \\
\text { less and stay closed on Sunday. }\end{array}$ \\
\hline 2011 & $\begin{array}{l}\text { Delun buys another bar at the metro stop Piola. After one year he decides to sell it } \\
\text { because of family duties and difficulties in managing it. }\end{array}$ \\
\hline 2012 & The first child of Delun was born. \\
\hline 2013 & $\begin{array}{l}\text { Delun convets to Christianity and gets baptized in an Evangelical church. Despite the fact } \\
\text { of being grown up in a Christian family and going to church every sunday he experience a } \\
\text { true conversion, observing the religious zeal of other Christians and experience a big } \\
\text { change. This is a turning point in Delun's life, he becomes humble, less arrogant, } \\
\text { changing direction of his life, from being selfish to trying to help other people. }\end{array}$ \\
\hline 2015 & $\begin{array}{l}\text { Delun starts a new business called 'Dutch Chips', desiring to expand his business. In } \\
\text { december of the same year he opens a new activity of phones and technology called } \\
\text { Best-Tech. }\end{array}$ \\
\hline $2016-\ldots$ & $\begin{array}{l}\text { Delun transforms the 'Dutch Chips' into a SUSHI EXPRESS bar. He does a covenant with God and } \\
\text { together with his wife that if he would be able to realize his business goal before reaching the age } \\
\text { of } 30 \text { years old he will dedicate his whole life for the work of God. In the Future Delun hopes to } \\
\text { reach the age of } 40 \text { 's in peace and with his family looking his kids grow. }\end{array}$ \\
\hline
\end{tabular}





\section{Bibliography:}

AA. VV., The American Heritage Dictionary, Turtleback School \& Library Binding Edition, St. Louis.

AA. VV., 1990, Economy and society: overviews in Economic Sociology, Sage Publications, London.

AA. VV., 1991, The Shorter Catechism: a Baptist version, Simpson Publishing Company, New Jersey, n. 93.

AA. VV., 1997, I Ching. Il libro della versatilità, UTET, Torino.

AA. VV., 1997, Cina a Milano. Famiglie, ambienti e lavori della popolazione cinese a Milano, Abitare Segesta Cataloghi, Milano.

AA. VV., 2000, The Practical Works of Richard Baxter, Vol. I-IV, Soli Deo Gloria Publications, Morgan.

AA. VV., 2002, L'Imprenditoria degli Immigrati Cinesi. Conoscere per Capire: l'Immigrazione e l'Imprenditoria Cinese a Vicenza e in Italia, Confartigianato \& Camera di Commercio, Vicenza.

AA. VV., 'Imprenditori Cinesi a Milano: Quasi tremila, 560 Milioni di Fatturato, il 40\% è donna', (Febbraio 2008), Camera di Commercio, Milano.

AA. VV., 2010, A Summary of Recent Literature on China's Development, SSDPP, Beijing Normal University, China. AA. VV., 'A Reforming People. Puritanism and the Transformation of Public Life in New England', in Kirkus Reviews. (Feb. 2011), Vol. 79 Issue 4, pp. 286-287.

AA. VV., 'Justification Logic', in The Stanford Encyclopedia of Philosophy, (Winter 2015), Zalta E. H. (eds.).

AA. VV., 'Milano, ogni giorno nascono due imprese cinesi', su Il Giorno, (Dicembre 2012), Camera di Commercio, Milano

AA. VV., Biographical dictionary of Chinese Christianity, Contrast \& Motion, London.

Abbas A., 1988, 'Scaling an Islamic Work Ethic', in Journal of Social Psychology, n. 128, pp. 575-83.

Abbruzzese S., 1992, Sociologia delle Religioni, Jaca Book, Milano.

Acquaviva S., 1992, La sociologia delle religioni. Problemi e prospettive, La Nuova Italia Scientifica, Firenze.

Adair-Toteff C., 2015, Fundamental Concepts in Max Weber's Sociology of Religion, Palgrave Macmillan, London.

Adamo P. (et alii), 1994, Modernità, politica e protestantesimo, Claudiana, Torino.

Adams J. E., 1986, The Biblical View of Self-Esteem, Self-Love, Self-Image, Harvest House Publishers, Oregon.

Aikman D., 2003, Jesus in Beijing. How Christianity is transforming China and changing the global balance of power, Regnery Publishing Inc., Washington DC.

ANS (Amity News Service), 1997, How many Christians are there in China, Available at http://is7.pacific.net.hk/ amityhk/96_4_spe.htm

Aron R., 1996, Le tappe del pensiero sociologico, Milano, Mondadori.

Asmus, B., 2013, The Poverty of Nations: a Sustainable solution, Crossway, Wheaton.

Åstebro T., Herz H., Nanda R., Weber R., 'Seeking the Roots of Entrepreneurship: Insights from Behavioral Economics', in The Journal of Economic Perspectives, Vol. 28, No. 3 (Summer 2014), pp. 49-69.

Azarian G. R., 2005, The General Sociology of Harrison C. White. Chaos and Order in Networks, London, MacMillan.

Austin A., 2007, China's Millions: The China Inland Mission and Late Qing Society, 1832-1905, Grand Rapids, Michigan, Eerdman's.

Babbie, E., 2015, The Basics of Social Research, Thomson Wadsworth, New York.

Baechler J., 1975, The Origins of Capitalism, Oxford, Blackwell.

Bainton H. R., 1958, La riforma protestante, Einaudi, Milano.

Ball D. W., 1965, 'Catholics, Calvinists, and rational control: Further explorations in the Weberian thesis', in Sociological Analysis, 26 (Winter), pp. 181-188.

Bandura A., 'Social Cognitive theory: an agentic perspective', in Annual Review of Psychology (2001), n. 52, pp. 1-26.

Barbalet J.M., 2008, Weber, passion and profits: the Protestant ethic and the spirit of capitalism in context, Lavoisier, Paris.

Barbera F., Negri N., 2015, 'Rituals as Mechanisms', in Paradoxes, Mechanisms, Consequences: Essay in Honor of Mohamed Cherkaoui, edited by G.L. Manzo, Oxford, Bardwell Press.

'Crypto-Rational Choice or Complex Mechanisms?', in Sociologica, (n. 2, 2014), il Mulino, Bologna.

Barbieri G., 1961, Origini del Capitalismo Lombardo, Credito Lombardo, Milano.

Barclay H. B., 1969, 'The Protestant Ethic versus the Spirit of Capitalism', in Review of Religious Research, n. 10 (Spring), pp. 151-158.

Barker J. E., 2005, The Christian roots of Capitalism, San Francisco Chronicle.

\& Carman J. C., 'The Spirit of Capitalism? Religious doctrine, values and Economic Attitude Constructs', in Political Behavior, Vol. 22, No. 1, (2000), pp. 1-27.

Barlow A. J., 'Puritanism and modernist novels: from moral character to the ethical self', in Current Reviews for Academic Libraries, (Sept. 2015), Vol. 53 Issue 1, p. 68.

Barnes D. F., 'Charisma and Religious Leadership: an Historical Analysis', in Journal for the Scientific Study of Religion, (1978), n. 17, pp. 1-18.

Barro J. R., McCleary R. M., 'Religion and economic growth across countries', from American Sociological Review, Vol. 68, No. 5, (Oct. 2003), pp. 760-781. 
'Religion and Economy', from The Journal of Economic Perspectives, Vol. 20, No. 2 (Spring. 2006), pp. 4972.

Barth K., 1983, La dottrina dell'elezione divina, Torino, UTET.

Baugus B. P., 2014, China's Reforming Churches. Mission, Polity and ministry in the next Christendom, Reformation Heritage Books, Grand Rapids.

Bavinck H., 2003, Reformed Dogmatics, Vol. I-IV, Baker Academic, Grand Rapids.

Baxter R., 1678, A Christian Directory, London, Robert White.

Bays D. H., 'Chinese Protestant Christianity Today', from The China Quarterly, No. 174, (Jun. 2003), pp. $488-504$.

Becker S. O., Woessmann L., 'Was Weber Wrong? A Human Capital Theory of Protestant Economic History', in Quarterly Journal of Economics, (2009),124(2), pp. 531-596.

Beder S., 'Selling the Work Ethic: From Puritan Pulpit to Corporate PR', in Zed, New York, (2000), pp. 410-411.

Beeke J. R., 2011, 'The Assurance Debate', in Drawn Into Controversie: Reformed Theological Diversity and Debates Within Seventeenth-Century British Puritanism, Göttingen, Vandenhoeck \& Ruprecht, p. 273.

2009, Living for God's Glory. An Introduction to Calvinism, Reformation Trust Publishing, Lane Mary. 2007, Meet the Puritans: With a Guide to Modern Reprints, Reformation Heritage Books, Grand Rapids.

Belardinelli S., 2005, Contro la paura. L'Occidente, le radici cristiane e la sfida del relativismo, Liberal, Roma. 1999, La comunità liberale. La libertà, il bene comune e la religione nelle società complesse, Studium, Roma.

Bell D., 1976, The Cultural Contradictions of Capitalism, Heinemann, London.

Bellah R. N., 1968, 'Reflections on the Protestant Ethic Analogy in Asia', in The Protestant Ethic and Modernization:A ComparativeView, Basic Books, pp. 243-251.

Bendix R., 'The Protestant ethic - Revisited', in Comparative Studies in Society and History, Vol. 9, No. 3 (Apr., 1967), pp. 266-273.

Benedict P., 2002, Christ's Churches Purely Reformed. A social History of Calvinism, Yale University Press, London.

Bennet A., 1975, The Valley of Vision. A collection of Puritan Prayers and Devotions, The Banner of Truth, Edinburgh.

Bennion L. L., 'The Business Ethic of the World Religions and the Spirit of Capitalism', in International Journal of Politics, Culture and Society, Vol. 6, no. 1, (Autumn 1992), pp. 39-73.

Benton G., Pieke F. N., 1998, The Chinese in Europe, MacMillan Press, London.

Berger P. L., 1969, The Sacred Canopy: Elements of a Sociological Theory of Religion, Garden City, New York, Anchor.

Berger S. D., 'The Sects and the Breakthrough into the Modern World: On the Centrality of the Sects in Weber's Protestant Ethic Thesis', from The Sociological Quarterly, Vol. 12, No. 4 (Autumn, 1971), pp. 486-499.

Bernbaum J. A., Steer S. M., 1986, Why Work? Careers and Employment in Biblical Perspective, Baker Book House, Grand Rapids.

Berzano L. (et alii), 2010, Nessun idolo. Cultura contemporanea e spiritualità cristiana, Glossa, Milano. 2008, I lifestyles nella partecipazione religiosa, Il Segnalibro, Torino.

1997, Forme del pluralismo religioso, Il Segnalibro, Torino.

1996, Religiosità del nuovo areopago. Credenze e forme religiose nell'epoca postsecolare, Franco Angeli, Milano.

Besnard P., 1970, Protestantisme et capitalisme: La controverse post-Weberienne, Paris, Presses Universitaire.

Bland G., 1972, Success! How to set goals and make plans that really work, Living Books, Wheaton.

Blum U., Dudley L., 'Religion and Economic Growth: Was Weber Right?' in Journal of Evolutionary Economics, (2001), n. 11, pp. 207-230.

Boltanski L., Chiapello E., 2005, The New Spirit of Capitalism, London-New York, Verso.

Bottum J., 2014, An Anxious Age: The Post-Protestant Ethic and the Spirit of America, Image, Victoria.

Bouma G. D., 'A Critical Review of Recent Protestant Ethic Research', in Journal for the Scientific Study of Religion, Vol. 12, No. 2 (Jun., 1973), pp. 141-155.

Bratt J. D. (Eds.), 1998, Abraham Kuyper. A Centennial Reader, Eerdmans, Grand Rapids.

Brentano L., 1916, Die Anfdnge des modernen Kapitalismus, Munich.

Bressan N., 2013, L'Imprenditoria Cinese in Italia. Due Casi Studio: la Ristorazione Cinese a Milano e il Distretto del Porfido a Trento, Università degli Studi di Trento.

Breton Y., 'La théorie schumpétérienne de l'entrepreneur ou le problème de la connaissance économique', in Revue économique, Vol. 35, No. 2 (Mar., 1984), pp. 247-266.

Brown G. T., 1986, Christianity in the People's Republic of China, Atlanta, John Knox Press.

Bruce F. F., 2004, The Spreading Flame: The Rise and Progress of Christianity from Its First Beginnings to the Conversion of the English, Wipf \& Stock, Manchester.

Buchan A., 'Is the Chinese Church Chinese enough?' in ChinaSource, Vol. 3, No.1 (2001), pp. 1-10.

Bunyan J., 2013, Grace Abounding to the Chief of Sinners, Chapel Library [ed. orig. 1666] 2003, Pilgrim's Progress, Bridge Logos, Alachua [ed. orig. 1668].

Burawoy M. (Eds.), 1991, Ethnography Unbound. Power and Resistance in the Modern Metropolis, University of California Press, Berkeley.

Burg B. R., 'Godly republicanism: Puritans, pilgrims, and a city on a hill', in Current Reviews for Academic Libraries, (Oct. 2012), Vol. 50 Issue 2, p. 350. 
Burgos J. M., 1996, Weber e lo spirito del capitalismo. Storia di un problema e nuove prospettive, ACTA PHILOSOPHICA, vol. 5, fasc. 2 -PAGG. 197-220.

Burkett L., 1990, Business by the Book. The complete guide of Biblical Principles for business men and women, Thomas Nelson, Nashville.

1989, The complete financial guide for young couples. A lifetime approach to spending, saving and investing, Victor Books, Wheaton. 1975, How to manage your money. An in-depth Bible study on personal finances, Moody Press, Chicago.

Bush R. C. Jr., 1970, Religion in Communist China, Nashville, Abingdon Press.

Buss A., 1999, 'The Concept of Adequate Causation and Max Weber's Comparative Sociology of Religion', in The British Journal of Sociology, Vol. 50, No. 2, pp. 317-329.

Calvin J., 2010, A treatise on Relics, Edinburgh, Johnstone, Hunter \& Co [ed. orig. 1543, Traité des reliques, Genève]. 2009, , Institutes of the Christian Religion, B. Eerdmans Publishing Co., Grand Rapids [ed. orig. 1559, Institutio Christianae religionis]. 1991, La Divina Predestinazione, Claudiana, Torino. 1845, On the Christian Life, B. Eerdmans Publishing Co., Grand Rapids.

Cantoni D., 'The Economic Effects of the Protestant Reformation: Testing the Weber Hypothesis in the German Lands', in Journal of the European Economic Association, (May 2014).

'Adopting a New Religion: The Case of Protestantism in 16th Century Germany', in Economic Journal, Vol. 122, n. 560, (May 2012), pp. 502-531.

Cao N., 'Renegotiating Locality and Morality in a Chinese Religious Diaspora: Wenzhou Christian Merchants in Paris, France', in Asia Pacific Journal of Anthropology, Vol. 14, (February 2013), pp. 85-101.

'Boss Christians: the business of religion in the "Wenzhou Model" of Christian Revival', from The China Journal, No. 59, (Jan. 2008), pp. 63-87.

'Christian Entrepreneurs and the Post-Mao state: an Ethnographic account of church-state relations in China's Economic Transition', from Sociology of Religion, Vol. 68, No. 1, (Spring. 2007), pp. 45-66.

'The church as a surrogate family for working class immigrant chinese youth: An ethnography of segmented assimilation', in Sociology of Religion: a Quarterly review, Vol. 66, (June 2005), pp. 183-200.

Cardano M., 2011, La ricerca qualitativa, Bologna, Il Mulino.

Cavalli L., 1968, Max Weber: religione e società, Il Mulino, Bologna.

Ceccagno A., 'The Mobile Emplacement: Chinese Migrants in Italian Industrial Districts', in Journal of Ethnic and Migration Studies, (Oct. 2014), pp. 1-21.

Rastrelli R., 2008, Ombre Cinesi? Dinamiche Migratorie della Diaspora Cinese in Italia, Carocci, Roma. 2003, Migranti a Prato. Il distretto tessile multietnico, Milano, Franco Angeli.

Chalcraft D. J., Harrington A., 2001, The Protestant ethic debate, Liverpool University Press.

Chao J., 1997, A history of Christianity in socialist China, 1949-1997, Taipei, China Ministries International Publishing Co.

1981, 'Cong huaren liaohui fazhan shi kan jiaohui zengzhang' (Church growth in the history of Chinese churches), in Jindai Zhongguo yи Jidujiao lunwen ji (Essays on modern China and Christianity), Taipei, Yuzhouguang Press, pp. 345-362.

Chau A. Y., 2006, Miraculous Response. Doing Popular Religion in Contemporary China, Stanford University Press, California.

Chakrabarty, D., 2000, Provincializing Europe: Postcolonial Thought and Historical Difference, Princeton University Press, Princeton.

Chang L. T., 2009, Factory Girls: From Village to City in a Changing China, Tantor Audio, Old Saybrook.

Chee-Beng T., Storey C., Zimmerman J., (Eds.), 2007, Chinese Overseas. Migration, Research and Documentation, Chinese University Press, Hong Kong.

Chen N. N., 2003, 'Healing Sects and Anti-Cult Campaigns', in Religion in China Today, pp.199-214.

Chiang A. C., 'Religion, Proverbs and economic mentality', from American Journal of Economics and Sociology, Vol. 20, No. 3, (Apr. 1961), pp. 253-264.

Chiapello E., Boltanski L., 2014, Il Nuovo Spirito del Capitalismo, Mimesis, Milano.

Chicchi F., 2006, Per un'analisi critica dell'Economia delle convenzioni: alcune brevi riflessioni sul suo statuto teorico e sul suo rapporto con la sociologia del lavoro, in Franco Angeli, Milano.

Chodorov F., 2011, The Radical Rich, Ludwig von Mises Institute, Auburn.

Chunguang W., Béja J. P., 'Wenzhou ren zai Bali: yizhong dute de shehui rongru moshi' (The Wenzhounese in Paris: A Unique Model of Social Integration), in Chinese Journal of Social Science, Vol. 6 (1999), pp. 106-19.

Cipriani R., 2009, Nuovo manuale di sociologia della religione, Borla, Roma.

Clark G., 2009, A Farewell to Alms: a Brief Economic History of the World, Princeton University Press.

Cohen B. I. (Eds.), 1990, Puritanism and The Rise of Modern Science. The Merton Thesis, Rutgers University Press, London.

Cohen J., 2002, Protestantism and capitalism: The mechanisms of influence, CJS, California.

1980, 'Rational capitalism in Renaissance Italy', in American Journal of Sociology, n. 85, pp. 1340-1355. 
Collino A., Biggeri M., Murgia L., 2014, Processi Industriali e Parti Sociali. Una Riflessione sulle Imprese Italiane in Cina (Jangsu) e sulle imprese Cinesi in Italia (Prato), Firenze University Press, Firenze.

Collins R., 'Weber's last theory of capitalism: A systematization', in American Sociological Review, (1980), n. 45, pp. 925-942.

Cologna D., 2008, Deconstructing Milan's Chinatown Problem, CIDOB Foundation, Barcelona.

2006, L'immigrazione Cinese in Italia, una realtà in Rapida Evoluzione, Aesse-Azione Sociale, n. 8, Codici s. c.. 2005, 'Differential Impact of Transnational Ties of Chinese Migrants from Zhejiang Province in Italy on the Socio-Economic Development of their Districts of Origin', in Asian Pacific Migration Journal, Vol. 14, n. 1-2, pp. 121-147.

2004, (a cura di), Asia a Milano. Famiglie ambienti e lavori delle popolazioni asiatiche a Milano, Abitare Segesta, Milano.

'La Comunità Cinese a Milano', su Mondo Cinese, (Maggio-Agosto 2004), Milano, n. 117.

2000, Chinese immigrant Enterpreneurs in Italy. Strenghts and weaknesses of a ethnic enclave economy, Routledge, London, pp. 262-284.

Constable N., 1994, Christian Souls and Chinese Spirits: A Hakka Community in Hong Kong, Berkeley, University of California Press.

Cook W. H., 1974, Success, Motivation and the Scriptures, Broadman Press, Nashville.

Corbett M., Corbett J. M., 1999, Politics and Religion in the United States, New York, Garland.

Corona M., Del Bello D., 2009, I Puritani d'America, Aracne, Roma.

Covell R. R., 1995, The Liberating Gospel in China: The Christian Faith among China's Minority Peoples, Grand Rapids, Baker Books.

Covey S. R., 1990, The seven habits of highly effective people, Simon \& Schuster, New York.

Crowley J. W., Ballweg J. A., 1971, 'Religious preference and worldly success', in Sociological Analysis, n. 32 (Summer), pp. 71-80.

Cunfu C., Tianhai H., 'The Emergence of a New Type of Christians in China Today', in Review of Religious Research, Vol. 46, No. 2 (2004), pp. 183-200.

Dana L., (Eds.), 2010, Entrepreneurship and religion, Edward Elgar Publishing Inc., Cheltenham.

Duneier M., 1999, Sidewalk, New York, Farrar, Strauss and Giroux.

De Feo M., 1970, Introduzione a Weber, Laterza, Bari.

De Laveleye E., 1889, Elements of Political Economy, New York, G. P. Putnam's Sons, p. 44.

De Marco P., (et alii), 1995, Identità europea e diversità religiosa nel mutamento contemporaneo, Edap, Firenze.1

Kenneth D., 2003, 'Local Communal Religion in Contemporary South-east China', in Religion in China Today, pp. 32 52.

Delacroix J., Nielsen F., 2001, 'The beloved myth: Protestantism and the rise of industrial capitalism in nineteenthcentury Europe', in Social Forces, Oxford.

Derman J., 'Max Weber and Charisma: A Transatlantic Affair', in New German Critique, No. 113, (Summer 2011), pp. 51-88.

Devine J. D., 1977, Find God's will for you, Regal Books, Glendale.

Diamond N., 1996. 'Christianity and the Hua Miao: Writing and Power', in Christianity in China: From the Eighteenth Century to the Present, Stanford University Press, pp. 138-58.

Dizikes P., 'Faith and reason. Was Christianity the engine of Western progress?' in The Boston Globe, (December 25), 2005.

Doepke M., Zilibotti F., 'Social Class and the Spirit of Capitalism', in Journal of the European Economic Association, (2005), n. 3(2-3), pp. 516-524.

Dore R., Sacco M., 'Goodwill and the Spirit of Market Capitalism', in British Journal of Sociology, (1983), n. 34, pp. 459482.

Dorn J. A., 'The death of Communism in China', in The Journal of Commerce, (March 5, 1999), CATO Institute.

Dow T. E. Jnr., 'An Analysis of Weber's work on Charisma', in British Journal of Sociology, Vol. 29, n. 1, (March 1978).

Drummond A. B. Jr., ‘The Episcopalians: an American Elite with Roots going back to Jamestown', New York Times (August 2012).

Duilmen R.,1989, 'Protestantism and Capitalism: Weber's Thesis in Light of Recent Social History', in Telos, n. 78, pp. 71-80.

Duncan A., 'Reimagining the Self-Made Man: Myth, Risk, and the Pokerization of America', in Western Journal of Communication, 2014, Vol.78, p.39-57.

Dunch R., 2001, Fuzhou Protestants and the Making of a Modern China 1857-1927, New Haven, Yale University Press.

Durkheim E., 2005, Le forme elementari della vita religiosa, Meltemi, Roma [Ed. orig 1912].

Durston C., Eales J., 1996, The Culture of English Puritanism, 1560-1700, Palgrave MacMillian, New York.

Edin P. A., Fredriksson P., Åslund O., 'Ethnic Enclaves and the Economic Success of Immigrants: Evidence from a Natural Experiment', in The Quarterly Journal of Economics, Vol. 118, No. 1 (Feb., 2003), pp. 329-357.

Edwards J., 2006 [ed. orig. 1754], Freedom of the will, Ed. Paul Ramsey, Vol. 1-2, Yale. 
2003, [ed. orig. 1734] The Preciousness Of Time And The Importance Of Redeeming It, A Puritan Mind, Yale. Egbert H., 'Business Success through Social Networks? A Comment on Social Networks and Business Success', in The American Journal of Economics and Sociology, Vol. 68, No. 3 (Jul., 2009), pp. 665-678.

Egli J., Hoerr B., 1984, The I factor. How to influence your world, North Star Strategies, Urbana.

Eisenstadt S. N., 'Max Weber: On Charisma and Institution Building', in The British Journal of Sociology, (1970), pp. 458-460. 1968, The Protestant Ethic and Modernization, New York, Basic Books.

Elvin M., 'Why China failed to create an endogenous industrial capitalism: a critique of Max Weber's explanation', in Theory and society, Vol. 13, No. 3, (May 1984), pp. 379-391.

Emerson R.M., 2001, Contemporary Field Research. Perspectives and Formulations, Long Grove, Illinois, Waveland Press.

Fanfani A., 1940, Cattolicesimo e protestantesimo nella formazione storica del capitalismo, Einaudi, Milano. 1933, Le origini dello spirito capitalistico in Italia, Milan, chap. 6.

Fayou M., 1998, A History of Wenzhou Christianity, Hong Kong, Alliance Bible Seminary Press.

Feldmann H., 'Protestantism, labor force participation, and employment across countries', from American Journal of Economics and Sociology, Vol. 66, No. 4, (Oct. 2007), pp. 795-816.

Ferguson N., 'Why America Outpaces Europe. The God Factor', New York Times, (June 2003).

Ferrarotti F., 1965, Max Weber e il destino della ragione, Laterza, Bari.

Finke R., Stark R., 1992, The churching of America, 1776-1990: Winners and losers in our religious economy, New Brunswick, Rutgers University Press.

Finnane A., 'China on the Catwalk: Between Economic Success and Nationalist Anxiety', in The China Quarterly, No. 183, Culture in the Contemporary PRC (Sep., 2005), pp. 587-608.

Fisschoff E. (Eds.), 1944, 'The Protestant Ethic and the Spirit of Capitalism: The History of a Controversy', in Social Research, 1-XI, pp. 53-77.

Fishman A., 1989, 'The Religious Kibbutz: A Note on the Theories of Marx, Sombart and Weber on Weber and Economic Success', in Sociological Analysis, n. 5, pp. 281-290.

Forcese D. P., 'Calvinism, Capitalism and Confusion: the Weberian thesis Revisited', in Sociological Analysis, Vol. 29, No. 4, (Winter 1968), pp. 193-201.

Foster S., 'Their Solitary Way: The Puritan Social Ethic in the First Century of Settlement in New England', in Yale Historical Publications Miscellany, N. 94, (Jan. 1972), pp. 200-214.

Fox R., 1987, 'The Liberal Ethic and the Spirit of Capitalism', in Center Magazine, (Sept./Oct.), pp. 4-11.

Franklin B., 1903, Poor Richard's Almanack, B.E. Smith, Century [ed. orig. 1733].

Fried H. M., ' Reflections on Christianity in China', from American Ethnologist, Vol. 14, No. 1, (Feb. 1987), pp. 94106.

Froese P., 2004, 'After atheism: An analysis of religious monopolies in the post-communist world', in Sociology of Religion, n. 65, pp. 57-75.

Fukuyama, F., 1995, Trust: The social virtues and the creation of prosperity, New York, Free Press.

Gaer J., Siegel B., 1964, The Puritan Heritage. America's Roots in the Bible, New American Library, New York.

Gautier M. L., 1997, 'Church Attendance and Religious Belief in Post-communist Societies', in Journal for the Scientific Study of Religion, n. 36 (2), pp. 289-297.

George C. H., George K., 1961, The Protestant Mind and the English Reformation, 1570-1640, Princeton University Press.

Gerhardt U., 'Much More than a Mere Translation: Talcott Parsons's Translation into English of Max Weber's "Die protestantische Ethik und der Geist des Kapitalismus": An Essay in Intellectual History', in The Canadian Journal of Sociology / Cahiers canadiens de sociologie, Vol. 32, No. 1(Winter, 2007), pp. 41-62

Gernet J., 1985, China and the Christian Impact: A Conflict of Cultures, Cambridge, Cambridge University Press.

Gerstner J. H., 1960, The Theology of the Major Sects, Twin Books Series, Ann Arbor.

Getz, G. A., 1987, When the job seems too big, Regal Books, Ventura.

Giddens A., 1973, Capitalism and modern Social Theory: an Analysis of the writings of Marx, Durkheim and Max Weber, Cambridge University Press.

Giordan G. (a cura di), 2006, Tra religione e spiritualità. Il rapporto con il sacro nell'epoca del pluralismo, Franco Angeli, Milano.

Giorgi L., Marsh C., 1990, 'The Protestant work ethic as a cultural phenomenon', from European Journal of Social Psychology, London.

Glock C. Y., Hammond P. E., 1973, Beyond the Classics: Essays in the Scientific Study of Religion, Prairie Book Cellar, Iowa City.

Goldsmith M. M., 'Mandeville and the Spirit of Capitalism', in Journal of British Studies, no. 1, (Autumn 1977), pp. 63-81.

Goldstein S., 1969, 'Socio-economic differentials among religious groups in the United States', in American Journal of Sociology, n. 74 (May), pp. 612-631.

Goody, J., 2010, The Eurasian Miracle, Polity Press, Cambridge. 
1996, The East in the West, Cambridge University Press, Cambridge.

Graf F. W., 2013, Fachmenschenfreundschaft: Studien Zu Weber Und Troeltsch, Walter De Gruyter Inc, Berlin.

Gramling R., Forsyth C. J., Mooney L., 1987, 'The Protestant Ethic and the Spirit of Cajunism', in Journal of Ethnic Studies, n. 15, pp. 33-46.

Granovetter M. S., 1973. 'The Strength of Weak Ties', American Journal of Sociology 78, pp. 1361-1381.

Greeley A. M., 1964, 'The Protestant Ethic: A time for a moratorium', in Sociological Analysis, n. 25, (Spring), pp. 2030.

Green R. W. (ed.), 1959, Protestantism and Capitalism: The Weber Thesis and Its Critics, Boston, Heath.

Groethuysen B., 1964, Le origini dello spirito borghese in Francia, il Saggiatore, Milano [ed. orig. 1927, Die Entstehung der bürgerlichen Welt- und Lebensanschauung in Frankreich].

Grossman H., 'The Beginnings of Capitalism and the New Mass Morality', in Journal of Classical Sociology, (July 2006), Vol. 6, n. 2.

Guiso L., Sapienza P., Zingales L., 'People’s opium? Religion and economic attitudes', in Journal of Monetary Economics, (2003), n. 50, pp. 225-282.

Guthrie D., 'The Quiet Revolution: The Emergence of Capitalism. China', in Harvard International Review, Vol. 25, No. 2, (Summer 2003).

1999, Dragon in a Three-Piece Suit: The Emergence of Capitalism in China, Princeton University Press.

Hagen, E. E., 1962, On the Theory of Social Change, Dorsey Press.

Halsey A. H., 'Who Gets Ahead? Determinants of Economic Success in America', in American Journal of Sociology, Vol. 87, No. 4 (Jan., 1982), pp. 965-967.

Hamilton G., 2006, Commerce and Capitalism in Chinese Societies, London, Routledge.

Hannerz U., 1980, Exploring the City. Inquiries Toward an Urban Anthropology, New York, Columbia University Press.

Harrison L. E ., 2012, Jews, Confucians, and Protestants: Cultural Capital and the End of Multiculturalism, Rowman \& Littlefield Publishers, Lanham.

1992, Who Prospers? How Cultural Values Shape Economic and Political Success, Basic Books.

Hefner R. W., 'Religious Resurgence in contemporary Asia: South-east Asian perspectives on Capitalism, the state and the New Piety', from The Journal of Asian Studies, Vol. 69, No. 4, (Nov. 2010), pp. 1031-1047.

Henry C. F. H., 1964, Aspects of Christian Social Ethics, Baker, Michigan.

Hewett R. S., 'Thrift and thriving in America: capitalism and moral order from the Puritans to the present', in Current Reviews for Academic Libraries, (Mar. 2012), Vol. 49 Issue 7, p. 1319.

Hill A., 1997, Just Business. Christian Ethics for the Marketplace, InterVarsity Press, Madison.

Hill C.,. 'Protestantism and the Rise of Capitalism', in Essays in the Economic and Social History of Tudor and Stuart England, (1961), pp. 15-39.

Hirschman A. O., 2013, The Passions and the Interests: Political Arguments for Capitalism before Its Triumph, Princeton University Press.

Holton R.J., 1983, 'MaxWeber, Rational Capitalism and Renaissance Italy: A Critique of Cohen', in American Journal of Sociology, n. 89, pp.166-180.

Hou J. W., 'Economic Reform of China: Cause and effects', in The Social Science Journal 48 (June 2011), pp. 419-434.

Howland D., 2011, 'The Dialectics of Chauvinism: Minority Nationalities and Territorial Sovereignty in Mao Zedong's New Democracy', in Modern China, Vol. 37, No. 2, pp. 170- 201.

Hsu P., 2014, China's Quest for Liberty: A Personal History of Freedom, St. Augustines Press, South Bend.

'Why Beijing's Largest House Church Refuses to Stop Meeting Outdoors', in Christianity Today, (April 2011), Carol Stream.

Huang K., Wang K. Y., 'How Guanxi Relates to Social Capital? A Psychological Perspective', in Journal of Social Sciences, n. 7-2, (2011), pp. 120-126.

Huang L. J., 'The role of religion in Communist Chinese Society', from Asian Survey, Vol. 11, No. 7, (Jul. 1971), pp. 693-708.

Hudson W. S., 1961, 'The Weber Thesis Re-examined', in Church History, n. 30, pp. 88-99.

1949, 'Puritanism and The Spirit of Capitalism', in Church History, n. 1, pp. 3-17.

Huenemann R. W., 'Economic Reforms, 1978-Present', in Oxford Bibliographies, (18 May 2015).

Hughes P. E., 1983, Christian Ethics in Secular Society, Baker Book House, Michigan.

Hulse E., 2000, Who are the Puritans? And what do they teach?, Evangelical Press, Darlington.

Human Rights Watch/Asia, 'Continuing Religious Repression in China', (June 1993), 'China: Persecution of a Protestant Sect' (June 1994), and 'China: State Control of Religion' (October 1997).

Hunter A., \& Don Rimmington, 'Religion and social change in contemporary China', in All Under Heaven, pp. 11-37. \& Kim-Kwong C., 1993, Protestantism in Contemporary China, Cambridge University Press.

Huntington S. P., Harrison L. E., 2001, Culture Matters, how Values Shape Human Progress, Basic Books, New York. IDOS, 2014, Rapporto Immigrazione e Imprenditoria, Edizioni IDOS, Roma.

Introvigne M., 2009, Storia della riforma, n. 23, Trento.

'Max Weber aveva torto. Una recensione di «The Victory of Reason» di Rodney Stark', in Cristianità, gennaiofebbraio 2006, n. 333, p. 5-10. 
Italian Chamber of Commerce, 'In Arrivo l'Anno del Toro', in Camera di Commercio di Milano, (Jan. 2009), Milan, pp. 12.

Iyigun M. F., Owen A. L., 'Risk, Entrepreneurship, and Human-Capital Accumulation', in The American Economic Review, Vol. 88, No. 2, Papers and Proceedings of the Hundred and Tenth Annual Meeting of the American Economic Association (May, 1998), pp. 454-457.

Jepperson, R. Meyer, J., 2011, 'Multiple Levels of Analysis and the Limitations of Methodological Individualisms', in Sociological Theory, n. 29 (1), pp. 54-73.

Jianhua M., 'The development of rural Christianity in China and its challenges', in Chinese Theological Review, No. 13 (1999), pp. 65-71.

Joas H., 1996, The creativity of action, Chicago, University of Chicago Press.

Johnson B., 1971, 'Max Weber and American Protestantism', in Sociological Quarterly, n. 12, (Autumn), pp. 473-485.

Jonassen C. T., 'The Protestant Ethic and the Spirit of Capitalism in Norway', in American Sociological Review, Vol. 12, No. 6 (Dec. 1947), pp. 676-686.

Kahn J., 1995. 'China's Christians Mix Business and God: Wenzhou Church Thrives on New Capitalists Wealth', on The Wall Street Journal, June 16.

Kalberg S., 'On the Neglect of Weber's Protestant Ethic as a Theoretical Treatise: Demarcating the Parameters of Postwar American Sociological Theory’, in Sociological Theory, Vol. 14, No. 1 (Mar., 1996), pp. 49-70.

Kahneman D., 'A Psychological Perspective on Economics', in The American Economic Review, Vol. 93, No. 2 (May 2003).

Kangsheng D., 2001, 'Xin Zhongguo Zongjiao Yanjiu 50 Nian' (50 Years of Religious Research in New China), in Annual of Religious Research, (1999-2000), pp. 38-57.

Kennedy S., 2011, Beyond the Middle Kingdom: Comparative Perspectives on China's Capitalist Transformation, Stanford University Press.

Kim H. C., 'The Relationship of Protestant Ethic Beliefs and Values to Achievement', in Journal for the Scientific Study of Religion, Vol. 16, No. 3 (Sep., 1977), pp. 255-262.

Kippenberg H. G., 1997, Die Entdeckung der Religionsgeschichte. Religionswissenschaft und Moderne, C. H. Beck, München.

Kirven R., Destination: Excellence, GCI, Worthington.

Klein S., 'First founders: American Puritans and Puritanism in an Atlantic world', in Current Reviews for Academic Libraries, (Jan. 2013), Vol. 50 Issue 5, p. 942.

Knight J., Song L., 2005, Towards a Labour Market in China, Oxford University Press.

Kosmin B. A., Lachman S. P, 1993, One Nation Under God. Religion in Contemporary American Society, Harmony Books, New York.

Krech V., 2011, Wo bleibt die Religion?: Zur Ambivalenz des Religiösen, in Der Modernen Gesellschaft (Sozialtheorie), Auflage.

Kristiansen S., 'Social Networks and Business Success: The Role of Subcultures in an African Context', in The American Journal of Economics and Sociology, Vol. 63, No. 5 (Nov., 2004), pp. 1149-1171.

Kristof N. D., 'Christianity is Booming in China Despite Rifts', in New York Times (7 February 1993), p. A16.

Krug B., 2004, China's Rational Entrepreneurs: The Development of the New Private Business Sector, Routledge, London.

Kuyper A., 1931, Lectures on Calvinism, Eerdmans, Grand Rapids.

Lachmann R., 1989, 'Origin of Capitalism and the State in Western Europe', in Annual Review of Sociology, n. 15, pp. 47-72.

Laguna M., 'Self-efficacy, self-esteem, and entrepreneurship among the unemployed', in Journal of Applied Social Psychology, (2013), n. 43, pp. 253-262.

Laitin, David D., 1986. Hegemony and Culture: Politics and Religious Change among the Yoruba. Chicago, University of Chicago Press.

Lambert F., 2003, The Founding Fathers and the Place of Religion in America, Princeton University Press, New Jersey.

Lambert T., 1999, China's Christian Millions, London, Monarch Books. 1994, The Resurrection of the Chinese Church, Wheaton, IL: OMF/Shaw Publishers.

Landes D. S., 1998, The Wealth and Poverty of Nations: Why Some Are So Rich and Some So Poor, New York, Norton.

Lang G., 1998, 'Religions and Regimes in China', in Religion in a Changing World, Westport, Praeger, pp. 149-158.

Latourette K. S., 1975, A History of Christianity. Reformation to the Present, Harper Collins Publishers, New York, Vol II.

Laurence B., The practice of the presence of God, Spire, Grand Rapids.

Le Beau, B. F., 'The Puritan origins of American patriotism', in Current Reviews for Academic Libraries, (May 2008), Vol. 45 Issue 9, pp. 1602-1603.

Lehmann H., Roth G., 1995, Weber's Protestant ethic: origin, evidence, contexts, German Historical Institute, Washington DC.

LeMond J. G., 1997, 'A Brief History of the Church in China', in Word and World, n. 17, pp. 144-153.

Lenski G. E., 1961, The Religious Factor, Garden City, New York, Doubleday. 
Leong F. T. L., Huang J. L., Mak S., 'Protestant Work Ethic, Confucian Values, and Work-Related Attitudes in Singapore', in Journal of Career Assesment, Vol. 00 (0), (2013), pp.1-13.

Leung, K. L., 1999, The rural churches of Mainland China since 1978, Hong Kong, Alliance Bible Seminary Press.

Li Z., 'China denies church demolition is persecution of Christians', from CNN International, (April, 2014), Atlanta.

Light, Ivan, and Edna Bonacich, 1991, Immigrant Entrepreneurs. Koreans in Los Angeles. 1965-1982, University of California Press, Los Angeles.

Lin-Liu J., 2005, 'At Chinese universities, whispers of Jesus', in Chronicle of Higher Education, (June 10), p. 40.

Lipset S. M., Bendix R., 1959, Social Mobility in Industrial Society, Berkeley, University of California Press.

Lisci A., 2011, Wenzhou, la Patria dei Cinesi d'Italia, Gruppo Editoriale L'Espresso, Roma.

Little D., 'Max Weber Revisited. The Protestant Ethic and the Puritan Experience of Order', in Harvard Theological Review, n. 59, (1966), pp. 415-428.

Lizardo O., Strand M., 'Beyond World Images: Belief as Embodied Action in the World', in Sociological Theory, (March 2015), n. 33, pp. 44-70.

Locke J., 2000, Scritti Etico-Religiosi, UTET, Torino. 1982 [ed. orig. 1690], Due Trattati sul Governo e altri scritti Politici, UTET, Torino.

Lortz J., Iserloh E., 1990, Storia della riforma, Bologna, Il Mulino.

Love J. F., 1987, McDonald's. Behind the arches, Bantam Press, Guernsey.

Lowy M., 1989, Marxism and Christianity in Latin America, Scribd.

Lu Y., (et alii), 'Deregulation and the Religious market in Taiwan: a research note', from The Sociological Quarterly, Vol. 49, No. 1, (Winter, 2008), pp. 139-153.

Luther M., 2002, The Small Catechism, Project Wittenberg, Fort Wayne. 1967, Scritti religiosi, Torino, UTET.

Luthy H., 1970, From Calvin to Rousseau: Tradition and Modernity in Socio-Political Thought from the Reformation to the French Revolution, Basic Books.

MacDonald W., Think of your future, Walterick Publishers, Kansas City.

MacKinnon M., 'Calvinism and the Infallible Assurance of Grace: The Weber Thesis Reconsidered', in The British Journal of Sociology, Vol. 39, No. 2 (Jun., 1988), pp. 143-177.

Maclnnis D. E., Xi'an Z., (eds.), 1991, Religion under Socialism in China, Armonk, NY, Sharpe.

Madsen R., 1995, China and the American Dream: a Moral Inquiry, Berkeley, University of California Press.

Manser M. (Eds.), 1999, Concise Chinese-English, English-Chinese Dictionary, Oxford University Press.

Marshall G., 1982, In search of the Spirit of Capitalism, New York, Columbia.

'The Dark Side of the Weber Thesis: The Case of Scotland', in The British Journal of Sociology, Vol. 31, No. 3, Special Issue, Aspects of Weberian Scholarship, (Sep., 1980), pp. 419-440.

Marshall T. H., 'Capitalism and the Decline of the English Gilds', in Cambridge Historical Journal, vol. iii., no. i., 1929.

Martello L., (eds.), Sulla genesi del capitalismo, Armando, Rome, 1992.

Masland J. W., 'Communism and Christianity in China', from The Journal of Religion, Vol. 32, No. 3, (Jul. 1952), pp. 198-206.

Mather C., 1825, Essays to Do Good, Chalmers and Collins, Glasgow.

Maurer J. T., 'A comparison of Likert scale and traditional measures of self-efficacy', in Journal of Applied Psychology, (March 1998); Vol. 83, n. 2, pp. 324-329.

Maxwell J. C., 2003, There's no Such Thing as Business Ethics, Warner Business Books, USA.

Mayer, A. J., Sharp H., 1962, 'Religious preference and worldly success', in American Sociological Re-view, n. 27 (April), pp. 218-227.

McAllister I., 'Occupational Mobility among Immigrants: The Impact of Migration on Economic Success in Australia', in The International Migration Review, Vol. 29, No. 2 (Summer, 1995), pp. 441-468.

McClelland D. C., 1961, The Achievement Society, Boston University Press.

McClosky Z., 1984, 'The American Ethos', in Cambridge Journals, Harvard University Press.

Mccloud S., Mirola W. A., 2009, Religion and class in America: culture, history, and politics, Brill, Leiden.

McCotter J., 1984, The Secret of Success, Great Commission International, Silver Spring. 1983, God's revealed plan for Your Finances, Great Commission, Silver Spring.

McKinnon A. M., 'Elective Affinities of the Protestant Ethic: Weber and the Chemistry of Capitalism', in Sociological Theory, Vol. 28, No. 1 (March 2010), pp. 108-126.

McLain D. L., Hackman K., 'Trust, Risk and Decision-making in Organizational Change', in Public Administration Quarterly, Vol. 23, No. 2, (Summer 1999).

McNeill J. T., 1957, The History and Character of Calvinism, Oxford University Press, New York.

Means R. L., 1966, 'Protestantism and American sociology: Problems of analysis', in Sociological Analysis, n. 27, (Fall), pp. 128-137.

'Protestantism and Economic Institutions: Auxiliary Theories to Weber's Protestant Ethic', in Social Forces, Vol. 44, No. 3 (Mar., 1966), pp. 372-381.

Meinhold P., 1994, Manuale delle Religioni, Queriniana, Brescia. 
Melton G. J., 1993, Encyclopedia of American Religions, Gale Research Inc., Washington DC.

Merton R. K., 'The Thomas Theorem and The Matthew Effect', in Social Forces, (Dec. 1995), Vol. 74, No. 2, pp. $379-424$. 1962, Puritanism, Pietism and Science, The Free Press, Glencoe Illinois, pp. 33-66.

1957, Social Theory and Social Structure, (Revised ed.), New York, Free Press.

Miegge M., 2010, Vocazione e lavoro, Claudiana, Torino.

Miller D., 1997, Reinventing American Protestantism, Berkeley, University of California Press.

Milton J. Y., 1961, Sociologia della religione, Torino, Paolo Boringhieri.

Miranda R., 'La presenza Cinese in Italia. Numeri, sfide e prospettive', su Formiche, (Giugno 2014).

Mirels H. L., Garrett J.B., 1971, 'The Protestant ethic as a personality variable', from Journal of consulting and clinical Psycology, London.

Mocombe P., 2012, Liberal bourgeois Protestantism the metaphysics of globalization, Ebrary Inc., Leiden.

Molloy S., 'Max Weber and the religions of China: any way out of the Maze?', in The British Journal of Sociology, Vol. 31, No. 3, (Sep. 1980), pp. 377-400.

Montinola G., Qian Y., Weingast B. R., 'Federalism, Chinese Style: The Political Basis for Economic Success in China', in World Politics, Vol. 48, No. 1 (Oct., 1995), pp. 50-81.

Mooneyham W. S., 2014, China, a New Day, Logos International, New Jersey.

Moore R. L., 2005, L'intreccio di Sacro e Profano nella Storia Americana, Claudiana, Torino.

Mulder J. M., 'Pursuing the Puritan Ethic', in Theology Today, Vol. XXXII, No. 4, (Jan. 1976), pp. 341-344.

Muller R. A., 2008, Christ and the Decree: Christology and Predestination in Reformed Theology from Calvin to Perkins, Baker Academic, Ada.

Muratorio B., 1980, Protestantism and capitalism revisited, in the rural highlands of Ecuador, The Journal of Peasant Studies, Taylor \& Francis.

Murphy J., 1999, Secrets of the I Ching: Get What You Want in Every Situation Using the Classic Book of Changes, Prentice Hall Press, New York.

Naso P., 2014, Fratelli e Sorelle di Jerry Masslo. L'immigrazione Evangelica in Italia, Claudiana, Torino.

Nelson B., 1973, 'Weber's Protestant Ethic: Its Origins, Wanderings and Foreseeable Futures', in Beyond the Classics?, New York, Harper and Row, pp. 71-130.

1969, 'Conscience and the Making of Early Modern Cultures: The Protestant Ethic

Beyond Max Weber', in Social Research, n. 36, pp. 4-21.

North G., 1988, Puritan Economic Experiments: Puritans and Government Controls, Institute for Christian Economics. 1986, Sinai Strategy: Economics And The Ten Commandments, Institute for Christian Economics. 1986, Honest Money: Biblical Principles of Money and Banking, 1986 Dominion Press. 1973, An Introduction To Christian Economics, Craig Press.

Novak M., 1993, The Catholic Ethic and the Spirit of Capitalism, Free Press, New York.

Nuccio O., 2003, Addio all'«Etica protestante». Umanesimo civile ed individualismo economico nella letteratura italiana: da Albertano ad Alberti, Casa Editrice Universitaria degli Studi La Sapienza, Roma.

Oberg B. B., (Eds.), 1996, The Papers of Benjamin Franklin, New Haven, Yale University Press.

Ocejo E. R., (Eds.), 2013, Ethnography and the City. Readings on Doing Urban Fieldwork, New York, Routledge.

Offenbacher M., 1900, Konfession und soziale Schichtung: Eine Studie uber die wirtschaftliche Lage der Katholiken und Protestanten in Baden, Paul Siebeck, Tubingen.

Otsuka H., 1976, Max Weber on the Spirit of Capitalism, Tokyo, Institute of Developing Economies.

Overmyer D. L., (ed.) 2003, 'Religion in China today', in The China Quarterly special issues, Cambridge, Cambridge University Press.

Pace E., 2007, Introduzione alla sociologia delle religioni, Carocci, Roma.

Parsons T., 1967 Societies: Comparative and Evolutionary Perspectives, Englewood Cliffs: Prentice-Hall.

1963 'Introduction', in Max Weber, The Sociology of Religion, Boston, Beacon Press.

1947 'Introduction', in Max Weber, The Theory of Social and Economic Organization, New York, Oxford

University Press.

1937, The Structure of Social Action, Glencoe, Free Press.

'Capitalism in recent German Literature: Sombart and Weber', in Journal of Political Economy, Vol. 37, No.

1 (Feb., 1929), pp. 31-51.

Pas J. E., 1989, The Turning of the Tide: Religion in China Today, Oxford, Oxford University Press.

Peabody L., 1974, Secular Work is Full-Time Service, CLC, Fort Washington.

Pellicani L., 2006, La genesi del capitalismo e le origini della modernità, Marco Ed.

Perkins W., 1603, Treatise of the Vocations or Callings, Princeton, New Jersey.

Persico R., 'Il Logos ti fa ricco', in Tempi, (Dec. 2006), n. 49/50, p. 46-47.

Peters T. J., Waterman R. H. Jr., 1984, In search of Excellence. Lessons from America's Best-run companies, Warner, New York.

Petullà M., 2004, Vero uomo. L'urto antropologico di Gesù, DePa Communication, Gioia Tauro.

Phillips M., 2001, Puritan View of Work, Grace Baptist, Fremont.

Piper J., (eds.), 1974, Resolutions. Works of Jonathan Edwards, Banner of Truth, Vol. 1, Eidinburgh. 
Pizzorno A., 2007, Il Velo della Diversità. Studi su Razionalità e Riconoscimento, Feltrinelli, Milano.

Poggi G.,1984, Calvinismo e spirito del capitalismo, Il Mulino, Bologna.

Pointer R. W., 'Philadelphia Presbyterians, Capitalism, and the Morality of Economic Success 1825-1855', in The Pennsylvania Magazine of History and Biography, Vol. 112, No. 3 (Jul., 1988), pp. 349-374.

Pomfret, J., 2002, 'Evangelicals on the Rise in Land of Mao Despite Crackdowns, Protestant Religious Groups Flourishing in China', in Washington Post, (December 24), p. AO1.

Potter P. B., 2003, 'Belief in Control: Regulation of Religion in China', in The China Quarterly n. 174 (2), pp. $317-337$.

Poupard P. (Eds.), 1990, Grande Dizionario delle Religioni, Cittadella-Piemme, Paris.

Quinney R., 1981, 'Religion and the Spirit of Capitalism', in Morality and Capitalism, (Sept.), pp. 55-58.

Qingpeng L., 1999, Zhongguo de Youtairen: Shenmi de Wenzhou Ren (Jews of China: The Mysterious Wenzhouness), Beijing, Jingji Ribao Chubanshe.

Rauch A., Frese M., 'Let's put the person back into entrepreneurship research: A meta-analysis on the relationship between business owners' personality traits, business creation, and success', in European Journal of Work and Organizational Psychology, (Nov. 2007).

Rauscher M., 'Protestant Ethic, Status Seeking and Economic Growth', in Universität Rostock, (1997), Working Paper No. 9.

Razzel P., 'The Protestant Ethic and the Spirit of Capitalism: A Natural Scientific Critique', in The British Journal of Sociology, Vol. 28, No. 1 (Mar., 1977), pp. 17-37.

Redding G. S., 'The Spirit of Chinese Capitalism', in Journal of International Business Studies, Berlin, (Third Quarter, 1992), pp. 572-ss.

Reuschling W. C., 2008, Reviving Evangelical Ethics. The Promises and Pitfalls of Classic Models of Morality, Brazos Press, Michigan.

Ricca P., Tourn G., 2010, Le 95 tesi di Lutero, Claudiana, Torino.

Ricolfi L., 1997, La Ricerca Qualitativa, Carocci, Roma.

Riesebrodt M., 'The Promise of Salvation: A Theory of Religion', in American Journal of Sociology, Vol. 116, No. 4 (January 2011), pp. 1384-1386.

Rimlinger G. V., 'Max Weber on the Spirit of Capitalism', in The Journal of Economic History, Vol. 36, No. 4 (Dec., 1976), p. 990.

Rives J. B. (eds.), 1999, Tacitus : Germania, Oxford University Press.

Robertson H. M., 1933, Aspects of the Rise of Economic Individualism: A Criticism of Max Weber and His School, Cambridge University Press.

Robertson L., 'Could China's underground churches soon meet openly ?', in CBN-Christian Broadcasting Network, (Jannuary 2009), Virginia Beach.

Roosevelt Malloch T., 2008, Spiritual Enterprise. Doing virtuous Business, Encounter Books, New York.

Roulleau-Berger, L., 2012, (eds.) Sociologies et cosmopolitisme méthodologique, Toulouse, Presses universitaires du Mirail.

Samuelsson K., 1961, Religion and Economic Action: A Critique of Max Weber, New York, Harper and Row.

Schaefer R., 'Infallibility and Intentionality: Franz Brentano's Diagnosis of German Catholicism', from Journal of the History of Ideas, University of Pennsylvania Press Vol. 68, No. 3 (Jul., 2007), pp. 477-499.

Schlozman, K. L., Brady H., Nie N., 1993, 'Race, Ethnicity, and Political Resources: Participation in the United States', in British Journal of Political Science, n. 23, pp. 453-97.

Schluchter, W., 1996, Paradoxes of Modernity. Culture and Conduct in the Theory of Max Weber, Stanford University Press, Stanford.

1989, Rationalism, Religion, and Domination. A Weberian Perspective, University of California Press, Berkeley. 1985, The Rise of Western Rationalism: Max Weber's Developmental History, University of California Press, Berkeley. 1979, Max Weber's Vision of History. Ethics and Methods, University of California Press, Berkeley.

Schnitger, M., 1995, Max Weber. Una biografia, Il Mulino, Bologna.

Schorn-Schütte L., 2001, La riforma protestante, Il Mulino, Bologna.

Schreiner T. R., Caneday A. B., 2001, The Race Set Before Us. A Biblical Theology of Perseverance \& Assurance, Inter Varsity Press, Downers Grove.

Shriver, G. H., 'The Protestant ethic and the spirit of sport: how Calvinism and capitalism shaped America's games', in Current Reviews for Academic Libraries, (August 2011), Vol.48, p. 2354.

Shulevitz J., 2001, The Puritan Ethic, Times, New York.

Schumpeter J. A., 2010, Capitalism, Socialism and Democracy, Kessinger LCL [ed. orig. 1947].

Schwarzer R., Jerusalem M., Hahn A., 'Negative affect in East German migrants: Longitudinal effects of unemployment and social support', in Anxiety, Stress and Coping An International Journal, 1993, Vol 6, no. 1, pp. 57-69.

Sciolla L., 'La forza dei valori', in Rassegna Italiana di Sociologia, n.1., Studi sui valori, (Jan-March 2008), pp.89-115.

Scofield C. I., 1999, The Study Bible, Oxford University Press.

Shaeffer F., 2009, How Should we Then Live? The Rise and Decline of Western Thought, Paperback, New York. 
Sharot S., 2002. 'Beyond Christianity: A Critique of the Rational Choice Theory of Religion from a Weberian and Comparative Religions Perspective', in Sociology of Religion, n. 63 (4), pp. 427-454.

Sherman D., Hendricks W., 1987, Your Work Matters to God, NavPress, Colorado.

Simmel G., 2007, 'A Contribution to the Sociology of Religion', in American Journal of Sociology, pp. 359-376. 1994, La religione, Bulzoni Editore, Roma [ed. orig. 1906, Die Religion, Frankfurt am Main: Rütten \& Loening].

Simpson A., 1955, Puritanism in Old and New England, University of Chicago Press.

Singer M., 1966, 'Religion and Social Change in India: The Max Weber Thesis, Phase Three', in Economic Development and Cultural Change, n. 14, pp. 497-505.

Smith H. W., 1994, The 10 Natural laws of successful time and life Management. Proven Strategies for increased productivity and inner peace, Time Warner, New York.

Soanes C., Stevenson A., 2010, Oxford Dictionary of English. Oxford University Press.

Sombart W., 1962, The Jews and Modern Capitalism, New York [ed. orig. 1911, Die Juden und das Wirtschaftsleben, Leipzig].

1932, L'apogee du capitalisme, Paris, Introduction.

1928, Der moderne Kapitalismus. Historisch-systematische Darstellung des gesamteuropäischen

Wirtschaftslebens von seinen Anfängen bis zur Gegenwart, Paperback ed., 3 vol., Munich.

Soothhill W. E., 1907, A Mission in China, Edinburgh, Oliphant, Anderson and Ferrier.

Spradley J. P., 1979, The Ethnographic Interview, Orlando, Holt, Rinehart and Winston Inc.

Sprenkel van der O. B., 'MaxWeber on China', in History and Theory, 1963, vol. III, p.348.

Stanley Mooneyham W., 1979, China. A new Day, Logos International, New Jersey.

Stark D., 2011, The Sense of Dissonance: Accounts of Worth in Economic Life, Princeton University Press.

Stark R., 2014, How the West Won: The Neglected Story of the Triumph of Modernity, Intercollegiate Studies Institute, Delaware.

2005, The Victory of Reason. How Christianity Led to Freedom, Capitalism, and Western Success, Random House, New York.

2004, For the Glory of God: How Monotheism Led to Reformations, Science, Witch-Hunts, and the End of Slavery Princeton University Press, New Jersey.

Finke R., 1992, The Churching of America 1776-1992: Winners and Losers in Our Religious Economy, Rutgers University Press, New Jersey. 1968, American Piety, University of California Press.

Steele R., 1684,The Tradesman's Calling, London.

Stevens J. W., 2010, God-fearing and free: a spiritual history of America's Cold War, Harvard College.

Stokes R. G., 1975, 'Afrikaner Calvinism and Economic Action: The Weberian Thesis in South Africa', in American Journal of Sociology, n. 8, pp. 62-81.

Strickmann M., 2005, Chinese Poetry and Prophecy. The written Oracle in East Asia, Asian Religions \& Cultures, Stanford University Press.

Swanson G. E., 1967, Religion and Regime A Sociological account of the Reformation, University of Michigan Press.

Swatos W. H. Jr., Kivisto P., 'Max Weber as Christian Sociologist', Journal for the scientific study of religion, Vol. 30, No. 4, (Dec. 1991), pp. 347-362.

Sweezy P. M., 1942, The Theory of Capitalist Development, New York, Oxford University Press.

Tagliabò C., 2001, Max Weber e lo spirito del capitalismo, n. 128, Milano.

Tam S., 1969, God Owns my Business, Wordbooks, London.

Tamney J. B., Burton R., Johnson S. D., 1989, 'Fundamentalism and economic restructuring', in Religion and Political Behavior in the United States, New York, Praeger, pp. 67-82.

Tawney, R. H., 1967 [ed. orig. 1922], La religione e l'origine del capitalismo, Feltrinelli, Milano. 'Bibliography: Studies in Bibliography. II. Modern Capitalism', in The Economic History Review, Vol. 4, No. 3 (Oct., 1933), pp. 336-356

Thornton P. H., 'The Sociology of Entrepreneurship', in Annual Review of Sociology, Vol. 25 (1999), pp. 19-46

Tipson Jr. L. B., 'Heavenly merchandize: how religion shaped commerce in Puritan America', in Current Reviews for Academic Libraries, (Dec. 2010), Vol. 48 Issue 4, p. 704.

Tong K. J., 2013, Overseas Chinese Christian Entrepreneurs in Modern China: A Case Study of the Influence of Christian Ethics on Business Life, Anthem Press, London.

Tourn G., 2008, La predestinazione nella Bibbia e nella storia, Claudiana, Torino.

Treiber H., (eds.), 1993, Per leggere Max Weber, CEDAM, Padova.

Trevor-Roper H. R., 1968, The Crisis of the Seventeenth Century, Harper \& Row.

Troeltsch E., 1987 [Ed. orig. 1906], Protestantism and Progress: The Significance of Protestantism for the Rise of the Modern World, Fortress Pr., Toronto. 1958, Protestantism and Progress, Beacon Press. 
1931, The Social Teaching of the Christian Churches, 2 vols., London [ed. orig. 1912, Die Soziallehren der Christlichen Kirchen und Gruppen, Tiubingen].

Turner B. S., 'Islam, Capitalism and the Weber theses', in The British Journal of Sociology, (Jun. 1974), Vol. 25, No. 2 , pp. 230-243.

Tversky A., 'Ambiguity Aversion and Comparative Ignorance', in Quarterly Journal of Economics, Vol. 110, No. 3, (1995), pp. 585-603.

Tyler L. L., 'The Protestant ethic among the black Muslims', in Phylon, (1966), Vol 27, No. 1.

Uhalley S. Jr., Wu X. (eds.), 2001, China and Christianity: Burdened Past, Hopeful Future, Armonk, NY, Sharpe, pp. 195-216.

Vala C. T., 2009, 'Pathways to the Pulpit: Leadership Training in 'Patriotic' and Unregistered Chinese Protestant Churches', in Making Religion, Stanford University Press, pp. 126-50.

Van Der Veer P., 2012, 'Religion, Secularism and National Development in India and China', in Third World Quarterly, Vol. 33, No. 4,

2012 Governing difference: inequality, inequity and identity in India and China, pp. 721-734.

Veblen T. B., 1899, The Theory of the Leisure Class, New York, Macmillan.

Vendassi P., 'Religious Change as Migration Chinese Converts to Christianity in Shanghai and in France', at Palacky University, Paper presentation, (Nov. 2014).

Verba, S., King G., Keohane R. O., 1994, Designing Social Inquiry. Scientific inference in Qualitative Research, Princeton University Press, New Jersey.

Veroff J., Feld S., Gurin G., 1962, ‘Achievement motivation and religious background', in American Sociological Review, n. 27, (April), pp. 205-217.

Wagner H., 'The Protestant Ethic: A Mid-Twentieth Century View', in Sociological Analysis, 1 April 1964, Vol.25, pp.34-40.

Walker G. P. C., 'Capitalism and the Reformation', in The Economic History Review, Vol. 8, No. 1 (Nov., 1937), pp. 1-19.

Waller G. M., (Eds.), Puritanism in Early America, D. C. Heat and Company, Lexington.

Wang J., 1997, 'The House Church Movement: A Participant's Assessment', in Word and World, n. 1 (7), pp. 175-182.

Wang Q., Lin X., 'Does religious beliefs affect economic growth? Evidence from provincial-level panel data in China', in Chinese Economic Review, (December 2014), pp. 277-287.

Warner, R. S., 1970, 'The Role of Religious Ideas and the Use of Models in Max Weber's Comparative Studies of NonCapitalist Societies', Journal of Economic History, n. 3, pp. 74-99.

Warren R., 2002, The Purpose Driven Life. What on earth am I here for? Zondervan, Grand Rapids.

Washer P., 2008, Ten Indictments against the Modern Church, Pensacola, Chapel Library.

Wayne S. F., 1989, 'An Instrument to Measure Adherence to the Protestant Ethic and Contemporary Work Values', Journal of Business Ethics, n. 8, pp. 793-806.

Weber M., 2003, General Economic History, Dover, New York [ed. orig. 1923, Wirtschaftsgeschichte]. 1993, The Sociology of Religion, Vol. I-IV, Beacon Press, Boston [ed. orig. 1920, Gesammelte Aufsätze zur Religionssoziologie].

1991, The Protestant Sects and the Spirit of Capitalism, Routledge, London [ed. orig. 1906, Die protestantischen Sekten und der Geist des Kapitalismus].

1978, Economy and Society: An Outline of Interpretive Sociology, California University Press.

1952 [ed. orig. 1917-1919], Ancient Judaism, Translated by Hans H. Gerth and Don Martindale, Glencoe, Ill., Free Press.

1951 [ed. orig. 1916], The Religion of China, Translated by Hans H. Gerth. Glencoe, Ill., Free Press.

1949, The Methodology of the Social Sciences, Free Press.

1930, The Protestant Ethic and the Spirit of Capitalism, Unwin Hyman, London [ed. orig. 1905, Die protestantische Ethik und der Geist des Kapitalismus].

Wenger J. E., 'Official vs. underground Protestant churches in China. Challenges for reconciliation and social influence', from Review of Religious Research, Vol. 46, No. 2, (Dec. 2004), pp. 169-182.

Whyte B., 1988, Unfinished Encounter: China and Christianity, London, Fount.

Whyte M. K., 2009, 'Paradoxes of China's Economic Boom', in Annual Review of Sociology, Vol. 35, pp. $371-392$.

Willems E., 1968, 'Culture Change and the Rise of Protestantism in Brazil and Chile',

in The Protestant Ethic and Modernization: A Comparative View, Basic Books, pp. 184-200.

Williams A., 1983, A simple Plan for Financial Independence, Parklake Publishers Inc., Atlanta.

Winckelmann J., (eds.), 1968, Die protestantische Ethik II: Kritiken und Antikritiken, Siebenstern, München.

Wisman J. D., Davis M. E., 'Degraded work, declining community, rising inequality, and the transformation of the Protestant ethic in America: 1870-1930', in The American Journal of Economics and Sociology, (Nov. 2013), Vol.72, p.1075.

Witherington III B., 2011, Work, A Kingdom Perspective on Labor, William B. Eerdmans Publishing, Grand Rapids. Wittgenstein L., 1953, Philosophical Investigations, Basil Blackwell, Oxford, pp. 175-178.

Wogaman P. J., 1993, Christian Ethics. A Historical Introduction, Westminster John Knox Press, Louisville. 
Wong M.. 'Guanxi and its role in business', in Chinese Management Studies, Print, n. 1-4 (2007), pp. 257 - 276.

Wright Mills C., Gerth H. H., 1946, From Max Weber, New York, Oxford University Press.

Xiaoxin W. (Eds.), 2009, Christianity in China. A Scholars' guide to resources in the libraries and archives of the United States, M. E. Sharpe, New York.

Yang C. K., 1960, Religion in Chinese Society, Berkeley, University of California Press.

Yang F., 2012, Religion in China. Survival \& revival under Communist rule, Oxford University Press, New York. Lang G., 2011, Social Scientific Studies of Religion in China. Methodology, Theories and Findings, Brill, Leiden. 'The Red, Black, and Gray Markets of Religion in China', from The Sociological Quarterly, Vol. 47, No. 1 (Winter, 2006), pp. 93-122.

'Lost in the market, saved at McDonald's: conversion to Christianity in urban China', from Journal for the Scientific study of Religion, Vol. 44, No. 4, (Dec. 2005), pp. 423-441.

2004, 'Between secularist ideology and desecularizing reality: The birth and growth of religious research in communist China', in Sociology of Religion, A Quarterly Review, n. 65(2), pp. 101-119.

2004, 'An economics of religious shortage: Communist China in transition', in Society for the Scientific Study of Religion Annual Meeting, Kansas City, (October 22-24).

1998. 'Chinese conversion to evangelical Christianity: The importance of social and cultural contexts', in Sociology of Religion: A Quarterly Review, n. 59 (3), pp. 237-57.

Yiwu L., 2011, God is Red. The secret story of how Christianity survived and flourished in Communist China, Harper Collins, New York.

Zamagni S., 2008, L'etica cattolica e lo spirito del capitalismo, Working paper n. 49, Bologna.

Zanotto P., 2008, Cattolicesimo, protestantesimo e capitalismo, IBL, Milano.

Zaret D., 1992, 'Calvin Covenant Theology and the Weber Thesis', in British Journal of Sociology, n. 43 , pp. $369-391$. 1980, 'From Weber to Parsons and Schutz: The Eclipse of History in Modem Social Theory', in American Journal of Sociology, n. 85, pp. 1180-1201.

Zhang Y., Zhang M., 'Can overseas migrants develop sustained entrepreneurship? Multiple case studies of Wenzhou migrants in Italy', in The Journal of Chinese Sociology, (2016), n. 3, p. 4.

Zhao H., Seibert S. E., 'The Big Five Personality Dimensions and Entrepreneurial Status: A Meta-Analytical Review', in Journal of Applied Psychology, (2006), Vol. 91, No. 2, 259-271.

Zhao L., Aram J. D., 'Networking and Growth of Young Technology-Intensive Ventures in China', in Journal of Business Venturing, n. 10 (5), (1995) pp. 349-370.

Zhiming Y., (et alii), 1997, Soul Searching: Chinese Intellectuals on Faith and Society, Wheaton, China Horizon.

Ziegert Van S., Global Spaces of Chinese Culture. Diasporic Chinese Communities in the United States and Germany, Routledge, New York.

Zuo J., 1991, 'Political Religion: The Case of the Cultural Revolution in China', in Sociological Analysis, n. 52 (1), pp. 99-110. 


\section{Web Sources:}

\section{Data on China}

<http://www.thearda.com/Archive/Files/Downloads/SPRTCHNA_DL2.asp>

$\langle$ http://www.worldvaluessurvey.org/wvs.jsp >

$<$ http://chinadataonline.org/religionexplorer/religion39/\#>

$<$ https://dbk.gesis.org/dbksearch/sdesc2.asp?no=3190>

$<$ http://www.stats.gov.cn/english/Statisticaldata/AnnualData/>

$<$ http://chinadatacenter.org/ProjectDemo/ProjectDemo.aspx $>$

$<$ Http://chinaarchive.tamu.edu/portal/site/chinaarchive/>

$<$ http://www.library.illinois.edu/ias/Databases/Chinese.html $>$

$\langle$ http://www.arts.kuleuven.be/info/eng/OE_sinologie/CCT>

$<$ https://pwt.sas.upenn.edu/php_site/pwt71/pwt71_form.php>

<http://web.worldbank.org/WBSITE/EXTERNAL/EXTDEC/EXTRESEARCH/EXTWDRS/0,,cont entMDK:22295291 pagePK:478093 piPK:477627 theSitePK:477624,00.html>

$<$ http://library.hkbu.edu.hk/electronic/libdbs/cccc-e.html>

$<$ http://www.religioninchina.org/default.aspx >

\section{Other Sources on Economy, Religion and Chinese Society}

〈http://www.danwei.org/business/churches_and_the_market_econom.php〉

$<$ http://www.economist.com/news/briefing/21629218-rapid-spread-christianity-forcing-official-

rethink-religion-cracks? frsc $=\mathrm{dg}|\mathrm{a}\rangle$

$<$ http://www.bdcconline.net/en/>

$<$ http://www.bbc.com/news/blogs-china-blog-27279762>

$<\mathrm{http}: / / \mathrm{www}$. globaltimes.cn/content/855208.shtml>

$<$ http://www.economist.com/news/briefing/21629218-rapid-spread-christianity-forcing-official-

rethink-religion-cracks>

$<$ http://pechino.corriere.it/>

$<$ http://www.charismamag.com/blogs/fire-in-my-bones/23294-you-can-t-ignore-the-miracle-ofchristianity-in-china $>$

<http://www.worldmag.com/2015/04/hassles_and_joys>

$<$ http://www.breitbart.com/national-security/2015/01/06/christianity-plays-decisive-role-in-chinaseconomic-boom-study-finds/>

<http://www.worldmag.com/2014/08/risks_and_rewards>

$<$ https://petitions.whitehouse.gov/petition/chinese-goverment-forcing-christians-churches-weredemolished-force-zhejiang-province/1j6cNRZW>

$<$ http://www.romanoprodi.it/articoli/italia/il-futuro-degli-scambi-italia-cina-passa-da-

wenzhou_2745.html>

<http://www.worldmag.com/2012/09/chinese_multiplication>

$<$ http://reader.ilmiolibro.kataweb.it/v/612166/Wenzhou_la_patria_dei_cinesi_d_Italia\#!\%22>

<http://www.repubblica.it/2006/05/gallerie/esteri/wenzhou/1.html>

$<$ http://www.lastampa.it/2012/05/17/blogs/estremo-oriente/wenzhou-italia-allo-nella-citta-di-

provenienza-dei-cinesi-italiani-vMSPURSja5ZPd7Uk4KqXYI/pagina.html>

<http://www.christianitytoday.com/ct/2011/aprilweb-only/beijinghousechurch.html?paging=off > 
$<$ http://www.yourarticlelibrary.com/economics/factors-that-influence-the-economic-developmentof-a-country/5942/> 


\section{CASE REPORT}

«DETAILED REPORT OF THE ENTIRE EMPIRIC DOCUMENTATION

FEATURING INTERVIEWS, FIELDNOTES AND CHARTS USED DURING THE STUDY »

\footnotetext{
${ }^{1}$ This section includes transcriptions of interviews, questionnaires, charts, timelines, etc., ... as well as fieldnotes of the job-shadowing. The majority of the assertions made during the study were drawn from this original material. The majority of the material is in Italian and when quoted in the official text of the thesis it has been translated into English. When it was possible many of the interviews were recorded, recordings are available in audio format if requested with the folder of the entire Archive of Qualitative Research (write at ottavio.palombaro@unimi.it).
} 
Preconditions

Boss Christian

Yi Xiang

House church

Glory of God and the love of Christ

Perpetual assurance of salvation

Self-efficacy

Communist explanation

Stakhanovism

Minority, migration

Network lineage, mafia

Family values, culture

Economic reasons

Self-efficacy

\footnotetext{
${ }^{2}$ Colours used in the analysis of the empiric documentation in regard to the original theoretical question. The first group of colors refers to the case of interest of interviews of Protestant Chinese entrepreneurs while the second refers to the case-control of non Protestant Chinese entrepreneurs. Some additional colors might have been added in the text due to a specific interesting point related to the analysis.
} 


\section{Intervista a Leo Delun 24 anni 08/06/2014:}

O: allora.. ti dispiacerebbe parlarci un po' di te? Da quanto tempo sei in Italia e che lavoro fai.

L: allora io mi chiamo Leo Qui e cioè Leo perché è un nome italiano che ho scelto io ormai è da quasi 13 anni che sono qua in Italia. Quando ho finito di studiare

barista, cioè gestisco un bar.

O: e.. cioè hai anche famiglia?

L: si, venivo in Italia perché i miei genitori erano già in Italia. Allora come una normale famiglia di immigrati cinesi ok.

O: quanti anni avevi quando sei venuto in Italia?

L: avevo 15 anni

O: e i tuoi genitori sono venuti per lavoro qua?

L: si esatto con è cercando una vita migliore.

$\mathrm{O}$ : e loro erano cristiani?

L: All'epoca mio papà era cristiano ma mia mamma non era ancora

O: e quando sono venuti qua in Italia sono entrati subito in contatto con la chiesa evangelica?

L: all'inizio no.

O: perché non trovavano oppure perché..

L: perché all'epoca, sai cos'è per tanti cinesi o per tanti stranieri siamo sempre impegnati a lavorare. Sette giorni su sette quasi quindici ore al giorno, allora quando uno è troppo impegnato a lavorare cioè trascura spesso la fede.

O: e dopo quanto tempo sono entrati in contatto con i cristiani evangelici?

L: mio papà è entrato in contatto con la chiesa cristiana evangelica di Milano negli ultimi cinque sei anni dopo vent'anni che è stato qua in Italia

O: e i suoi genitori erano cristiani? I genitori di tuo padre?

L: i miei nonni sono tutti cristiani. E il villaggio dove c'è mio nonno siamo tutti cristiani

O: quindi non vengono da wenzhou ma da un villaggio

L: esatto da un villaggio vicino a Wenzhou, chintien

O: e prima dei tuoi nonni i tuoi bisnonni erano cristiani anche loro?

L: sinceramente non saprei dire perché è già troppo lontano secondo me si, mi hanno detto una volta mia nonna che

O: incredibile! Invece venendo al tuo lavoro tu hai, che tipo di lavoro fai?

L:

O: raccontaci il percorso, hai sempre gestito un bar che tipo di lavori hai fatto prima?

L: quando ho finito il corso scolastico mi sono subito buttato giù nel commercio. All'epoca, sono sei anni fa, perché siccome prima di gestire da solo un bar lavoravo già a fianco di mio papà perché avevano già un bar.

O: tuo padre aveva un bar?

L: aveva un bar esatto, per questo sapevo già questo mestiere e ho cominciato a fare questo.

O: e tu poi hai preso un altro bar oppure lo stesso di tuo Padre?

$\mathrm{L}:$

O: e poi hai anche ampliato mi ricordo che ci avevi il tuo bar

L: Poi dopo un paio di anni ho voluto comprare un altro bar, ok, era molto stressante.

O: tanto lavoro insomma. A cosa attribuisci questo successo nel tuo lavoro, cioè nel senso il fatto che sei riuscito a, sei partito con subito nel commercio, ti sei affiancato a tuo padre poi hai iniziato un bar tuo, poi ne hai fatto un altro, perché hai avuto questo successo?

L: abbiamo avuto questo successo perché grande parte di noi diamo questo contributo perché siamo cinesi che abbiamo la volontà imprenditoriale molto forte.

$\mathrm{O}$ : ok, e la prima ragione del successo qual è secondo te?

L: eh.. essere laborioso, la cultura cinese, soprattutto la cultura cinese che ci incoraggia di correre sempre il rischio nel commercio. 
O: dicci invece un po' della tua fede. Che se sei cristiano?

L: sono diventato cristiano negli ultimi anni, io il primo contatto con la chiesa cristiana li ho avuti quand'ero piccolo mi ha portato mio nonno alla chiesa, però all'epoca a dire la verità non ero credente. Non sapevo niente, poi da quando sono venuto qua in Italia ho sempre studiato alla scuola italiana perciò non ho mai avuto contatti con la chiesa italiana, chiese evangeliche cinesi.. fino a quando ho avuto contatto con Frank che è un missionario dall'America e allora da quel momento in poi erano cinque anni fa ho cominciato a frequentare la chiesa evangelica e pian piano mi hanno convinto.

O: che rapporto vedi tra il tuo lavoro e la tua fede? Come sei arrivato a scegliere il lavoro che svolgi nel commercio e che rapporto c'è tra la fede che tu hai e il lavoro oggi.

L: Allora il rapporto all'inizio perché uno non pensa tanto sulla fede, perché uno fa questo lavoro perché ti permette di guadagnare, ti permette di vivere in una situazione più benestante, agiata, ok però pian piano conoscendo la fede ci aiuta di più a conoscere tipologia di lavoro che dovrei fare, tipologia di commercio dove dovrei fare.

$\mathrm{Ci}$ sono tante volte tante contraddizioni tra lavoro e fede soprattutto uno è imprenditore l'altro la fede cristiana. Perché la fede cristiana ci dice di essere coerente ci dice sempre di essere corretto e di non fregare ma nel commercio, nel commercio italiano essere imprenditore è difficile in tanti aspetti perché se tutti lo fanno perché non lo fai? Perché è una cosa molto comune nel settore imprenditoriale.

O: e qual è il risultato di questo? Cioè se tu non freghi gli altri qual è il risultato poi nel tuo lavoro?

L: all'inizio magari ci perdo un po', ci perdo perché non fregando la gente ci perdo lavoro, ci perdo i soldi, però ci guadagno la fede, perché è vero che al momento non vedo il risultato di aver guadagnato tanto per essere fedele ed essere giusto, però dopo un po' di tempo mi sento più felice interno. Perché mi sento di aver fatto qualcosa giusto.

O: ma secondo te il fatto che poi hai Dio,

\section{di Did?}

L: penso di si.

O: in che modo?

L: nel modo che quando uno che trova difficoltà o uno si sente proprio esasperato, se uno disperato, succede alcune volte nel commercio perché non tutto il tempo che ti vada sempre giusto, succede sempre qualche volta, come quest'ultima volta la crisi finanziaria ci ha colpito pesantemente. Allora abbiamo cominciato a pregare, allora con la preghiera ci aiuta.

O: in che modo la tua comunità di fede è stata in grado di aiutarti nel tuo lavoro. I credenti, gli altri credenti, in che modo questo ha aiutato per esempio nel tuo lavoro nel raggiungere i tuoi obiettivi? L: ok alla fine mi sono reso conto che mi ha aiutato tantissimo per essere una persona giusta, essere una persona corretta le altre persone ti capiscono che guarda tu sei una persona affidabile.

Possiamo lavorare con te, all'inizio non vuoi fregare ma

persone, è un approccio diverso in più, con le altre persone che si fidano, sei cristiano, mi

Tanti pensano che siamo predestinati, io non penso questo. Tutti siamo peccatori e con Gesù siamo salvati con il suo sangue, possiamo cambiare il futuro con la fede cristiana. Il successo pensavo che era destino o bravura, perché sono in gamba. Non è così facile. Ho visto persone che sono bravissime ma non fanno lo stesso, il motivo è un Dio che ti benedice. La chiesa cristiana in Cina ha avuto uno sviluppo forte negli ultimi 25 anni. Ora siamo più di cento volte in più. Ma è un successo incredibile. Siccome la Cina è comunista e dittatura e non permette minacce al suo potere, cristianesimo è minaccia dunque discriminazioni e persecuzioni vengono. Anche se il governo cinese non vuole che cresciamo in maniera incredibile. La associazione nazionale cristiana deve stare con il governo, la chiesa familiare house church invece è un'organizzazione privata. In Italia godiamo libertà e democrazia. Abbiamo chiese costruite da noi senza aiuto, per offerte. La chiesa cinese in Italia deve fare di più. Molti cinesi lavorano e trascurano la fede, sono cristiani ma trovano 
conflitti tra lavoro e fede. Non trovano il tempo di adorare Dio. Per il momento resto in Italia, se un domani Dio mi commuove di andare lì andrei volentieri. Io sento che c'è ottimismo, in 25 anni milioni di cristiani, non è un caso, senza l'aiuto di Dio non può succedere. Entro 15 anni se arriviamo al $30 \%$ della popolazione cinese diventiamo paese cristiano. Sarà un beneficio per la popolazione mondiale. Conosco amici imprenditori cristiani, faccio parte di associazione imprenditori seconda generazione in Italia, aiutiamo la comunità cinese in problemi comuni. Gran parte di loro sono cristiani la maggior parte da wenzhou, 95\% dei cinesi in Italia viene da Wenzhou. Loro organizzano tavola rotonda con il governo, favoriscono il commercio. La comunità cinese è chiusa mentre noi vogliamo aprire, essere portavoce per collegare le due parti, aiutare cinesi in difficoltà.

\section{Focus Group Wenzhou (Wenzhou) 23/08/2015}

- Jessie (F Entrepreneur 27 anni) Min

- Anthony (M Banker 43 anni) Ya

- Zhu Philip (M Pastor 44 anni) Zhi

- Moses (M Teacher 28 anni) Kun

- Xiao (M Interpreter, sociologist 26 anni) Dong

JESSIE inizia il focus group, racconta la sua esperienza di laurea, poi come commercial designer usando il software TD-MAX. Disegnavo la cabinet, modelli 3D, dopo 4 anni sono andata a Pechino, poi di nuovo a Wenzhou, prima aprii un negozio mio, ho anche un negozio, anche un negozio online con Taubau, a volte ci sono buoni affari oltremare. La mia fabbrica è solo per centri commerciali e negozi. Molte persone fanno shopping online ora, il mio business di clienti dunque diminuisce, la mia fabbrica dunque deve cambiare più verso customer made production. In Cina c'è la produzione di massa ma non vogliamo, è basso costo ma cerco di fare invece alta qualità e buon prezzo, un'altra strada contro la produzione di massa. Noi soffriamo perché i salari crescono, le persone non vogliono pagarci e siamo in debito. E' stancante, molti vogliono investire nelle finanze. Io ho un negozio virtuale, le persone vedono le foto, noi non freghiamo le persone, diamo i prodotti ordinati, con dei prezzi ragionevoli, non inventiamo false crescite di vendita, la mia vendita è vera non freghiamo. Noi diamo fiducia anche se gli altri ci fregano. Non condividiamo sempre con tutti la fede, ma parliamo di produzione.

Attorno a Wenzhou ci sono monti e mari, non abbiamo risorse naturali, non siamo una grande città come Shanghai, dobbiamo fare business se vogliamo sopravvivere. Mio padre e mia madre non mi controllano, però mi incoraggiano, mi sento libera nel lavoro. Quando vado all'estero vedo che le persone non amano il made in China, voglio cambiare l'idea di made in China. Voglio fare qualcosa di unico non ordinario, il prezzo dunque si alzerà di necessità. Nella house church siamo diversi nel modo di conoscere Dio, se non vado in chiesa non conosco Dio, abbiamo fellowship in inglese, loro ci incoraggiano a parlarlo. Io faccio import-export, l'inglese è fondamentale, se ho il background di conoscenze che serve al designer per aprire la mente e andare attorno al mondo.

ANTHONY è manager della banca per i prestiti a imprenditori per fristiani che non cristian, e non vede alcuna differenza, non c'è differenza di etica. In questa crisi
governo ha un grande debito. 50 billioni di income ha il governo finanziario, è pieno di debito. Il
governo ha aziende non buone che non profittano, è solo un investimento pubblico, su prezzi e cose.
Perderemo economicamente per 10 anni, ora è finito il tempo per l'emerging market e ci sarà un
turning point. Wenzhou certo resta la capitale dell'economia privata in Cina. Gli imprenditori
cristiani sono in debito, vengono da me scoraggiati, depressi, non vedono buoni segni nel business
futuro. 
ZHU PHILIP ho visto cose negative spesso tra imprenditori, non noto quasi nessuna differenza tra credenti e non, lasciano i creditori, nascondono il loro profitto prima di andare in bancarotta o lo trasferiscono prima ad altri conti. Molti hanno business illegali, l'usura, non sono sensibili alla natura del business. Siccome l'economia va giù ne approfittano.

speranza che l'economia rifiorirà. Ci sono buone storie e cattive,

hanno fede nel governo e nella

ma in generale non c'è grande differenza tra persone che fanno business come non cristiani. Questi imprenditori non sono molto discepolati in chiesa.

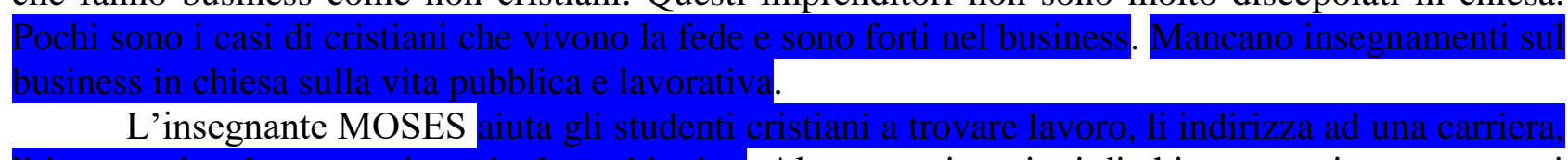

del genere.

Altre organizzazioni di chiesa organizzano progetti

\section{Intervista Alessandro Huizhong 26 anni Wenzhou 14/05/2015}

Sono venuto in Italia con genitori genitori e nonni già cristiani. Sono venuti qua per lavoro venire a vedere come è la situazione. Prima lavoravo nel confezionamento poi abbigliamento, in Italia da 13 anni. Il negozio lo ho aperto io prima con i genitori. Per

. Importante noi di Wenzhou tanti fanno il commercio così. Quando ero piccolo andavamo sempre alla scuola domenicale, aula nostra maestra cristiana che ci insegnava di Gesù e Bibbia. Solo questi tre anni non vado in chiesa anche domenica aperto. Vedo contraddizione, tanti lavori non riesci più ad andare in chiesa perché tanta gente vengono.

Cristiani mi hanno aiutato, vengono a salutare o pregato per me, tanto quando c'è qualche domanda mi rispondono aiutano non so fare queste cose mi aiutano a farle. Lavoro per vivere ovviamente devi lavorare se non lavori come fai?

Ho attraversato difficoltà al lavoro mi ha aiutato con la preghiera, ho chiesto a Gesù di aiutarmi e mi ha aiutato. Tanto da parlare molto lungo qua in Italia diciamo che quando ho fatto un incidente ero ancora vivo Gesù mi ha aiutato, le persone non sanno cosa succede, Gesù sapeva quando ti aiuta si vede quando è successo, quando stai in pericolo. Al lavoro sto sempre tranquillo grazie a Gesù, non c'è granché difficoltà. Pochi si comportano male solo personale quando è successo qualche incidente al lavoro Gesù mi ha aiutato.

Non c'è tanta gente che parla, quando lavoro devo essere veloce, la gente viene e va via, non c'è tempo e stai seduto a parlare, come stanno come erano.

Credo di essere salvato, Gesù ha detto quando vengo Gesù ti porta in paradiso, vita eterna, quando Gesù viene a Gerusalemme. Tanti quando ci credi sin da quando ero piccolo, anche le canzoni. La vita siamo sempre tranquilli non che succede qualcosa di grave così Gesù mi ha aiutato.

\section{$\begin{array}{llll}\text { Alex Guang Wenzhou } 23 \text { anni } & \text { 18/07/2015 }\end{array}$}

Mio zio è il proprietario del negozio Max Liu in Viale Sapri, con lui ho aperto un negozio al Lago Maggiore. Lavoravo duro, quelli che escono dalla Cina vengono per cercare lavoro e migliorare la loro situazione economica.

La fede ci aiuta tutti nel lavoro anche se non tutti la trovano la fede, dunque funziona sempre che in difficoltà tramite alla nostra fede riusciamo ad andare avanti. Al lavoro per me la fede è una 
parte, la fede, il

Siamo tutti credenti noi in famiglia e le mie esperienze con mio zio mi hanno

insegnato molto.

Mio zio fa il lavoro e io imparo da lui. Per me lo scopo del lavoro è fare il dovuto per mantenere la vita. Al momento non ho dovuto affrontare grandi difficoltà è andato tutto bene, sono stato graziato da Dio per questo.

\section{Intervista Ali Xiu M 34 anni Pan Qsiao (Wenzhou) 28/08/2015}

Ci sono business diversi che feci prima di fare le lampade led, prima facevo occhiali, poi compravo il pesce, vendevo scarpe sul web, dopo il matrimonio scelsi i led. Li fabbrico qui poi li vendo in Cina, vado attorno per trovare opportunità. Spero l'anno prossimo di fare export anche in Italia, che è la maggiore nazione export tramite persone sul web. Provvedo led in chiesa anche quando fu costruita io provvedetti le luci con un prezzo economico, se lo compri al mercato è più caro. Un'altra chiesa sa che io faccio luci LED, alcune persone introducono a me e mi fanno costruire le luci. Per me è difficile con la chiesa perché vogliamo dare buona qualità e i costi sono bassi. Abbiamo molti cristiani, molte persone hanno bisogno ma chiedono perché i costi sono alti. Nella mente dei Wenzhounesi i soldi sono molto importanti, vengono prima, loro pensano che se hai molti soldi puoi parlare forte, avere la voce grossa, non importa invece se sei una persona buona. E' triste, anche in chiesa alcuni pensano così.

. Per me lo scopo è far soldi e supportare la famiglia, se il lavoro può esprimere la mia fede sarà bene. Lavorare è per Dio ma a volte è difficile, dobbiamo lavorare duro e fare soldi, se può crescere per Dio sarò benedetto. Prima prego quando sono in difficoltà, sul cosa farsi. Ma le cose più grandi chiedo a Dio, le più piccole le faccio da solo perché penso di poterlo fare da solo.

\section{Intervista Brother Lu Yi 45 anni M Wenzhou (Wenzhou) 23/08/2015}

Brother Lu possiede 9 negozi farmaceutici è un Laoban di successo. Ha studiato medicine cinesi tradizionali,

1993 per . Dopo la laurea nel di essere chiamato al ministero full-time. Nel 2003 pensai di spendere tutto il tempo in chiesa perché c'era bisogno di operai per la messe che cercassero nuovi credenti, dunque decisi di trasformare la mia azienda in compagnia multipla (Ijèn), con l'aiuto di alcuni fratelli della chiesa. Nei giorni passati c'erano molti predicatori part-time,

. La seconda ragione è che nel passato i negozi singoli su base familiare erano classici in Wenzhou, ma io ho voluto innovare, i predicatori part-time non hanno esperienze sociali, io invece avevo molte esperienze, dunque

. Dal 2003 ero imprenditore, alcuni però pensavano che i passi della Bibbia contraddicono chiesa e imprenditoria, allora

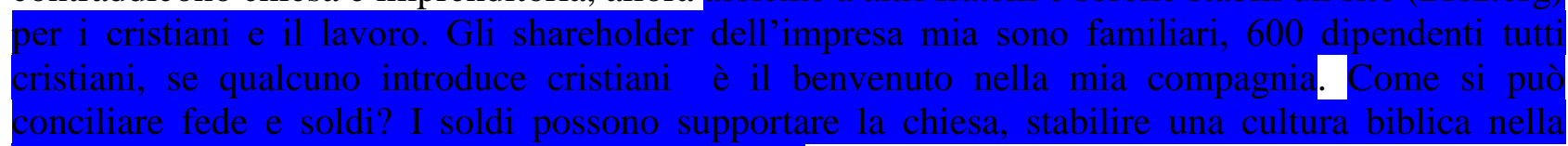

. La mia compagnia è orientata a obiettivi, per esempio aprire 100 negozi a Wenzhou e ne abbiamo raggiunti, il mio orientamento è biblico, le altre compagnie non sanno pianificare, pensano solo ai soldi e magari raggiunti anche in modo illegale. Le imprese cristiane stabiliscono invece imprese sociali, sono sensibili al profitto ma anche agli aiuti filantropici. Ci sono fondazioni a cui la compagnia si affida. Nelle difficoltà affrontate la prima 
cosa importante è pregare, affidarsi alla salvezza di Dio e poi avere un senso di missione che aiuta anche a superare le difficoltà. Non ci sono grandi compagnie cristiane, noi siamo un piccolo business e sparsi ma

Alcune chiese radunano i Laoban e chiedono che si dedichino alla chiesa, alcuni non lo fanno, non si concentrano nella compagnia, dobbiamo invece crescere la compagnia affinché possa glorificare Dio ed è

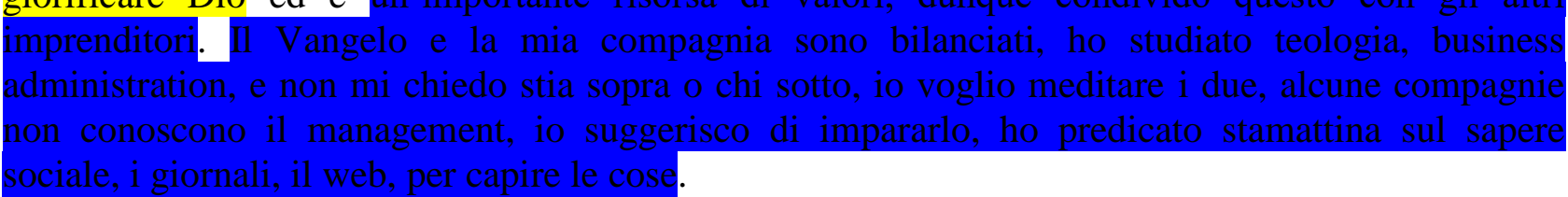

\section{Intervista a Chen 28 F Minzhe Shuzhou}

Chen, fidanzata di Pan Chen, viene dalla Cina ora vivo a Milano. Vengo da Shuzhou vicino a Shanghai. Il mio lavoro è

di moda in Cina per clienti. Successo è avere molti clienti mandare avanti il business, avere molto
successo. Quando prendo piccole o grandi decisioni nel business prego, se devo avere partner in business prego se è nel piano di Dio, se no mi fermo. Ho iniziato il lavoro per interesse, mi piaceva quel lavoro e ho iniziato. Le house churches ne conosco tante perché mia nonna ha una, ma la maggior parte sono vecchie persone, si riuniscono e cantano ma nessuno insegna sulla Bibbia, condividono sentimenti e testimonianze, ma non c'è insegnamento, i giovani vogliono conoscere più sulla Bibbia. E' un problema nella mia città. Lo scopo della vita non c'è l'ho ma ancora cerco, Dio preparerà il meglio per noi, qualunque cosa farò la cosa importante è portare gloria a Dio. Salvezza si ha se tu credi riceverai amore ed avrai pace in ogni situazione e difficoltà, ti da gioia speranza nella tua vita. PAS: sono totalmente cambiata dalla vecchia vita. Miei parenti sono saggi ma ora ho vita eterna, anche mia madre non può controllare tutto. Quando avevo 16 anni mi lasciò, non riuscivo a dormire, credevo che le persone potessero amarsi per sempre. Se non fossi credente farei il business solo per me, ma ora faccio questo credendomi se sto portando gloria a Dio.

\section{Daniele 30 anni M Jun Wenzhou 08/11/14}

Daniele ha due fratelli nella chiesa, è sorridente e disponibile a farsi intervistare, non vuole il registratore. Il suo italiano è medio-buono. Daniele dice di essere

cristiana, il papà pure. Non ricorda in particolare il momento in cui ha ricevuto Cristo. Quando è
cresciuto ha vissuto Gesù. Lavora impiegato di agenzia di viaggio. Il lavoro per lui è solo una parte
della vita, se guadagna si sente bene. La sua è un'agenzia cinese che ha contattato inviando il
curriculum online. Come cristiano lavora in modo onesto, è simpatico, noi cristiani non possiamo
fare o dire qualcosa, faticando a raggiungere il risultato. Non sente che Dio abbia aperto il lavoro
direttamente, ma qualcosa è successo e Dio ha preparato le cose per lui che vuole che lui fa.

A volte ero in difficoltà, quando pensavo non c'è soluzione però improvvisamente Gesù ha risolto. Per sociale, non è molto buono, nel lavoro non dico di essere religioso. Obbedire è importante, la vita vera delle persone è importante, l'obbiettivo resta il regno di Dio. La credenza nella certezza della salvezza mi ha aiutato perché qualunque situazione dove ero debole, povero, succede qualcosa di insopportabile, questo però non mi spaventa, ho una vita spirituale eterna so che quando morirò vado in paradiso. 
Sono in Italia da 16. Genitori non cristiani io non ero cristiano. Sono entrato in contatto con la chiesa mi ha portato un amico. 2 anni fa sono diventato cristiano, all'inizio ci ho creduto, ho letto la Bibbia in cinese, quello che tu preghi Dio te lo da, ho pregato e Dio me lo ha dato ed ha legato fortemente la mia credenza a Dio.

Ho sempre lavorato sempre nel commercio, prima facevo lo studente poi abbigliamento. Ho lavorato a Genova e Milano diversi luoghi.

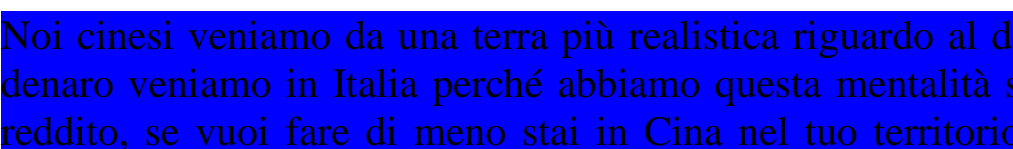

, in Italia trovi spesso il razzismo noi

siamo qui e purtroppo il mestiere che facciamo

l'altro è costretto a proseguire il procedimento, alcuni hanno provato a lavorare di meno ma non riesci a fare niente, un po' siamo costretti.

Ho visto dei cambiamenti nel lavoro da quando sono diventato cristiano, sono le cose che meno vedi ma più te la senti nel lavoro anche nella vita, senti che qualcuno ti protegge che il denaro non è così tanto importante, non come prima che il denaro era tutto, vivo in un ambiente non così ci sono quelli che vivono per il denaro, siamo contenti perché abbiamo Dio, abbiamo la salvezza.

Preghiera mi ha aiutato ho pregato diverse volte non solo al lavoro anche nella vita, nelle relazioni e mi ha sempre aiutato e protetto portato nella strada giusta e sono molto contento.

Sono fortunato perché ho i genitori mi hanno aiutato tantissimo, mi sento fortunato, hanno iniziato il negozio. Nei momenti quando ero altri lavori

ma dopo che sono cristiano purtroppo questo pensiero trascorre nelle vene, ti viene voglia di reagire in modo brutale erano pochissimi momenti ma alla fine non è successo niente

male che hai fatto, noi sulla terra facciamo del male agli altri. In quel modo subisco solo moralmente e fisicamente sul denaro ma la mia vita va avanti non devo piangere su questa cosa, penso di essere stato cortese se siamo sempre in cambiamenti eravamo cattive non lo sappiamo cerchiamo di perdonare il più possibile. Sono venuto in Italia per famiglia e i genitori sono venuto per lavoro.

Altri cristiani aiuto diretto no ma nella vita quotidiana si anche un saluto mi tira su, mi fa capire che stiamo moltiplicando come credenti. Il lavoro è obbligatorio per mantenerci per andare avanti per dare una vita più bella a te e agli altri ma non bisogna essere eccessivi perché fa venire il male. Non tutti i cinesi sono così per loro il denaro vale più della vita sono stati controllati da Satana e fanno avere sempre di più se arriva malattia o morte sai che non hai più niente davanti hai fatto tutto il resto per niente.

Quando ero altre parti pochi clienti ero sereno perché so che c'è Dio magari mi ha dato questo percorso per diventare più onesto e più forte, sono tragedie ma buone, ho pregato e sicuramente sono momenti che Dio ti ha concesso di avere, in questo modo migliori. Ci sono tanti cinesi cristiani che passano in momenti concessi da Dio per fare frutto su di te.

Lavoro nell'abbigliamento perché in questo momento va. 
Bisnonno cristiano, famiglia credente, andavo in chiesa come bambino, poi non andavo più, poi arrivato in Italia sono entrato in chiesa. Ad un campo a Padova ho conosciuto che Dio mi ama e volevo conoscerlo di più.

Lavoro e fede. Mi aiuta ad essere tranquillo, lavoro meno male sempre senza imprevisti, cose che sento un grande buco. Rischio: Dio mi da pace e sono sempre tranquillo e tutto va bene, non ho avuto problemi non solo nel lavoro ma nella vita, la base è tutto grazie a Dio. Scopo della vita essere sempre con il Signore, le altre cose che mi porta avanti il futuro non lo so.

PAS: mi da fede, mi ha cambiato tanto, non sono come gli altri, qualcuno non crede in questa religione, quando si è affidato cambia subito, quando ero bambino conoscevo questa religione, ma poco a poco mi ha cambiato dentro.

Ho trovato questo lavoro attraverso mio cognato anche lui cristiano.

Federico

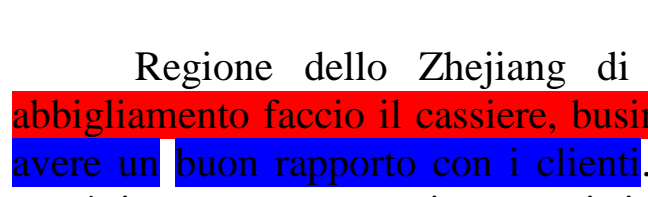

23 anni

29/11/2014 pregò io ero neonato e piangevo, i riti buddhisti non funzionavano ma la preghiera a Gesù si, e da allora lei credette. Poi mia mamma mi portava sempre in chiesa. A Wenzhou. Io lasciai la chiesa e poi ritornai in chiesa. Lavoro in un negozio di abbigliamento dei miei genitori.

Nel lavoro non mi preoccupo se c'è o non c'è lavoro perché so che il lavoro me lo da Dio. Il lavoro qualche giorno va male qualche giorno no. Al lavoro ci sono stati momenti di difficoltà $\mathrm{i}$ miei gestivano io non mi preoccupavo, facevo la mia parte come cassiere. Fino ad adesso le difficoltà non ce ne sono state. I miei genitori mi hanno aiutato a trovare lavoro. I miei lavoravano per altri, poi iniziarono una loro attività.

La chiesa nel lavoro mi ha aiutato a rimanere calmo senza agitazione perché la agitazione non risolve tutti i problemi. Ho sempre pregato per avere Gesù accanto. Vorrei battezzarmi ma penso di non aver imparato ancora abbastanza. Quando uno va battezzato deve capire tutte le regole ogni giorno faccio qualche errore.

Ho sempre avuto in mente questa idea: lo scopo della vita è che Dio ci ha creati per visitare il suo mondo la terra, ha creato la terra e ci ha creati per visitare la bellezza. Per questo una persona non deve solo lavorare ma anche viaggiare, il mondo è bello ma tanti noi cinesi lo trascuriamo sappiamo lavorare e basta. I cinesi hanno la voglia, secondo me viene dalla povertà, quando la gente è povera. Viene un po' anche dal seguire la massa, se hai un lavoro vedo che tu lavori e mi viene spontaneamente la voglia di fare lo stesso lavoro. Se sei ricco l'altra persona che ti guarda vorrebbe diventare ricca, si copiano alla fine.

PAS: secondo me mi ha già salvato, mi sento più tranquillo che con Gesù accanto non mi succederà niente di brutto. Nel lavoro passo tutti i giorni senza preoccuparmi di quanto si guadagna, mi basta che Gesù quello che otteniamo è quello che ci da. Anche se vuoi di più non lo ottieni, se ti da quella parte basta non devi pensare al di più, sicuramente non morirò di fame. 


\section{Intervista a Franco Shing 45 anni M Wenzhou 30/01/2015}

boss di Jin e degli altri, sono credente della prima generazione. Sono venuto in Italia con moglie da Wenzhou. Siccome c'era più lavoro anche se adesso c'è poco lavoro.

\section{Intervista Giovanni $\quad$ Shu 45 anni $\quad 30 / 01 / 2015$}

92 arrivato a Firenze dal 18 Luglio arrivato a Firenze e poi a Milano.

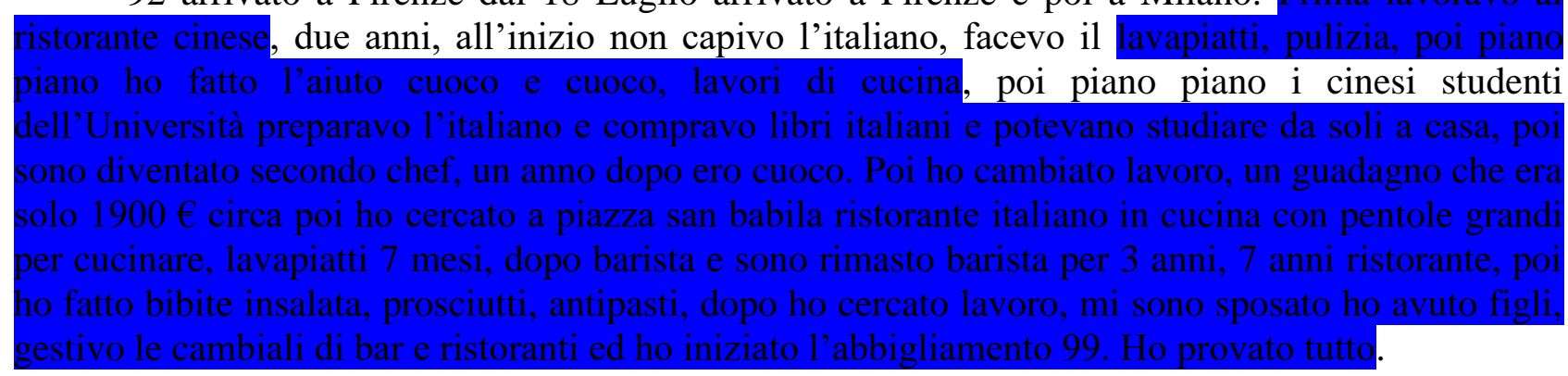

Il lavoro è importante per famiglia e business e vivere bene.

Noi la religione da mio nonno e nonna e quando ero in cina a 18 anni ho fatto il battesimo, so qual è la storia, credo in Dio e Gesù Cristo, mai dimentico quando la domenica, ci incontriamo per la preghiera. Quando c'è tempo cerco di frequentare ma quando ero al ristorante non avevo tempo, era più difficile. Dall'inizio appena arrivato è più tempo, non c'era macchina né tempo, dunque sono andato in chiesa sin da subito. A Milano già dal 96 c'era la chiesa. Quando sono arrivato ho visto tanta crescita. Non c'era cibo per mangiare anche se andare in chiesa era più facile (pomeriggio andavo in chiesa, mi incontravo con i fratelli).

Dovevo venire in Italia già con i miei genitori, prima in Cina non c'era lavoro, difficile cercare ma la nostra zona veniva da Francia, tutta Europa voleva guadagnare per la famiglia, io sono il primo della mia famiglia, dopo mio fratello, zia, zio sono venuti qui a Milano, Parigi, Spagna.

Con la mia famiglia i miei genitori erano 6 o 7 fratelli, dai miei genitori tutti siamo diventati cristiani e abbiamo scelto la buona religione, prima erano buddisti, non c'era Dio e non si sa cosa vivere.

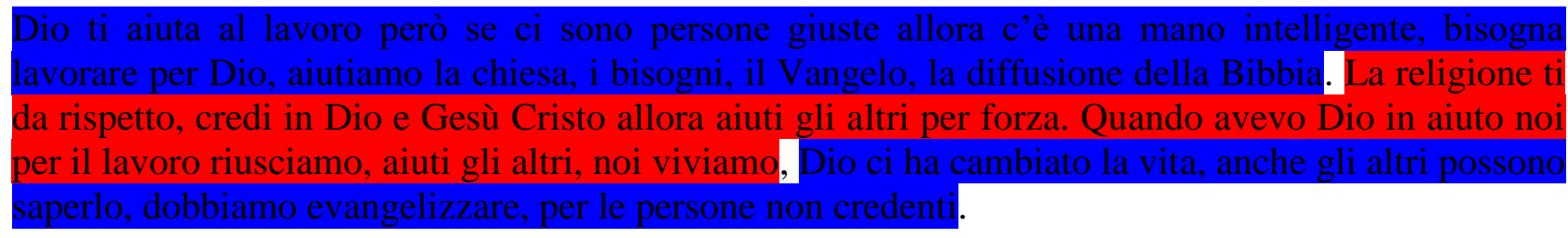

Io ho attraversato momenti di difficoltà per il lavoro, c'era la crisi e anche dal 2008 è molto difficile ma sempre la preghiera aiuta Dio. Il mio cuore però è tranquillo, quello che perdo, i debiti, i clienti falliti che mi fregano e perdo tanti soldi, ma io ci sono, non mi preoccupo, loro volevano fregare ma io sono credente. Fino adesso persone mi devono trecentomila euro ma non vado con la pistola, se non c'è cosa faccio. La fede in Dio mi ha aiutato, Dio non mi manca mai, ho ascoltato e sentito, sempre mi aiuta, quello che manca lo lascio perché non voglio spingere, non sono tutti maleducati, ma quando li incontro devo pregare, Gesù ha fatto così, quello che povero io lo aiuto. 


\section{Intervista Grace Zhong F 28 anni Pan Qsiao (Wenzhou) 28/08/2015}

Grace è direttrice di una summer school di inglese per bambini. Iniziai da un anno a fare questa scuola. Prima facevo business con export stranieri, parlando con loro anche nel cuore della notte, per 5 anni, dopo l'università. C'erano più soldi ma non abbastanza tempo per fare le cose mie, il mio sogno è essere insegnante, amo i bambini. I miei genitori volevano che io facessi business per fare più soldi. Poi mi sono sposata. I miei genitori volevano che sposassi un businessmen e fossi ricca con lui ma io volevo una famiglia. Se hai successo non hai tempo per andare in chiesa e leggere la Bibbia, quindi ho deciso di seguire questa strada. La pressione dai parenti per fare business. Per avere famiglia è importante non solo fare soldi ma famiglia viene prima, ho scelto questo lavoro perché mi permette di seguire una famiglia. Iniziai mandando volantini sulla summer school, a nessuno importava, ma anche se solo un bambino è sufficiente. Inviai 200 volantini e venne un solo studente, continuai perseverando, dopo un po' 3 poi 5 , etc... io credo che Dio provvederà studenti nella mia classe.

Oltre a questo vado alla scuola ed insegno inglese lì, questo è come Dio ha provveduto per me. Poi ebbi un figlio ma la mia scuola è continuata. Ringrazio Dio per avere i numeri necessari per insegnare. Non so quanti vengono ma faccio del mio meglio, se sono bravo nel piccolo i genitori ci sceglierann, non mi sono mai preoccupata dei numeri, Dio provvede. Dio si prende cura di me, provvede buoni voti e successo. Ho scelto il nome della scuola 'Samuel' perché Dio ascolta i miei bisogni,

dire le storie della Bibbia ad altre persone. Alcune famiglie cristiane scelgono la nostra scuola. Tutti gli studenti sanno che sono cristiana, faccio anche la Sunday school, sanno che la domenica vado in chiesa. Alcuni studenti sono cristiani. Mi piacciono i bambini molto, il mio sogno è essere insegnante, è la mia idea di esserlo, posso insegnare gli studenti cristiani. La ragione della mia forza è che vado in chiesa, prego e leggo la Bibbia, se non credevo in Dio mi sarei arresa ma non mi sono mai arresa, lo faccio, la Bibbia mi dice fino ad ora non ho ansia per questo, mostro le foto ed $\mathrm{i}$ documenti e mostro tramite wechat.

Molte scuole fanno corsi e messaggi diversi per aumentare gli studenti, ma tutti sanno che insegno, se ci scelgono bene ma non li spingo, io aspetto. Le persone mi chiedono perché io non mi preoccupi ma io non lo faccio, ma Dio lo farà.

\section{Intervista Huan Tai F 47 anni Tangxia (Wenzhou) 26/08/2015}

Sono cristiana e gestisco un asilo nido come boss di 5 piani e 150 bambini, lo anni fa con diversi partner cristiani. L'asilo iniziò nel 1994 per costruire educazione e connetterla

insegniamo a seguire la Bibbia e

questo è importante. Ho fatto questo asilo perché i bambini abbiano pace, gioia ed è molto importante per i bambini, che ognuno abbia un buon cuore. Nelle difficoltà prego Dio prima poi agisco. Ho molti partner magari hanno idee diverse, tutti pregano per Dio insieme per ascoltare le vie di Dio. Tre cristiani in particolare mi hanno aiutato a costruire tre asili, da 16 anni lavoriamo insieme. All'inizio c'erano difficoltà ma lavoriamo bene perché siamo cresciuti, siamo molto uniti. La cosa più importante è che siamo cristiani e questo ci connette. All'inizio Wenzhou era povera doveva lavorare molto duro, molti fanno business e successo, se vivi qui vuoi imparare da quelli di successo, è l'ambiente. Il successo, all'inizio avevo solo 1 asilo ora 3, molte famiglie scelgono questo asilo, lavoro anche in chiesa facendo Sunday school. La ragione di questo business è che Dio benedice, come Dio ha benedetto gli ebrei. Non posso essere mostrare la Bibbia ad ognuno ma nell'asilo posso mostrare la cultura di Cristo. Perché faccio Sunday school porto qui i principi all'asilo.

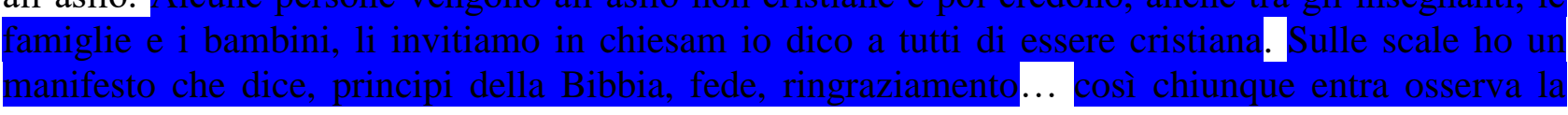


Il primo anno avevo solo 70 persone,

La ragione è che siccome ho la fede io lavoro molto duro, Dio fa avere alle persone molti lavori, alcuni fanno business ma Dio mi ha fatto studiare lavorando nell'educazione e lavoro molto duro per Dio non per me stessa. Ho lavorato in chiesa come Sunday school e asilo nido nello stesso periodo, penso che sia la direzione di Dio. Tutto questo senza alcun supporto dal governo ma da sola siamo auto-finanziati.

\section{Intervista \\ Ile \\ Wing \\ Wenzhou \\ $06 / 12 / 2014$}

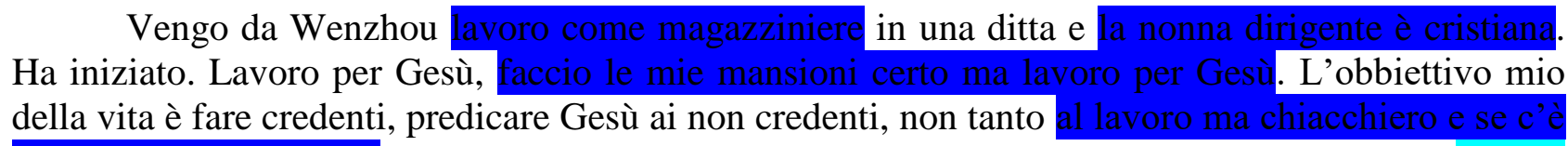

'opportunità condivida. Ho trovato lavoro, prima facevo il cameriere barista come servizio tornato in Italia non volevo più farlo, allora ho pregato Gesù che mi desse un altro tipo di lavoro e ho trovato, e la proprietaria. Ho trovato un contatto appena entrato nel posto non sapevo che la padrona era credente.

PAS: Gesù è un amico e quando c'è ogni difficoltà ed io ho in cuore io non posso dirlo agli amici ma lo dico a Gesù. Sul lavoro quando sono arrabbiato prego al nome di Gesù di darmi una pazienza, col cliente. A volte ho pregato e ho pace e non sono più arrabbiato. Al lavoro c'è anche un filippino credente.

Quando mangio prego e c'è un'occhiata strana dagli altri, prego allora Dio che mi dia una fiducia e una forza per non avere condizionamento né vergogna ma pregare davanti a loro. Prima mi prendevano sempre in giro ora sono abituati che prego. Nel lavoro sono sempre andato bene, nella vita non c'è difficoltà che non passa ma quando soffro di solitudine penso che c'è ancora Gesù.

Il primo lavoro che facevo come lavapiatti era davvero pesante, nel primo giorno iniziavo già a piangere nel cuore, scendevano le lacrime e ho pensato perché è così difficile e poi ho pensato che nel Vangelo è scritto: Gesù soffre i nostri peccati sulla croce e poi Dio lo ha abbandonato. Così pensando ho ricordato nella Bibbia questo e che sono stato salvato, non penso quanto è difficile o sono solo, Gesù soffriva per me io non soffro che un pochino.

\section{Intervista Jessie Min F 27 anni Wenzhou (Wenzhou) 23/08/2015}

JESSIE inizia il focus group, racconta la sua esperienza di laurea, poi come commercial designer usando il software TD-MAX. Disegnavo la cabinet, modelli 3D, dopo 4 anni sono andata a Pechino, poi di nuovo a Wenzhou, prima aprii un negozio mio, ho anche un negozio, anche un negozio online con Taubau, a volte ci sono buoni affari oltremare. La mia fabbrica è solo per centri commerciali e negozi. Molte persone fanno shopping online ora, il mio business di clienti dunque diminuisce, la mia fabbrica dunque deve cambiare più verso customer made production. In Cina c'è la produzione di massa ma non vogliamo, è basso costo ma cerco di fare invece alta qualità e buon prezzo, un'altra strada contro la produzione di massa. Noi soffriamo perché i salari crescono, le persone non vogliono pagarci e siamo in debito. E' stancante, molti vogliono investire nelle finanze. Io ho un negozio virtuale, le persone vedono le foto,

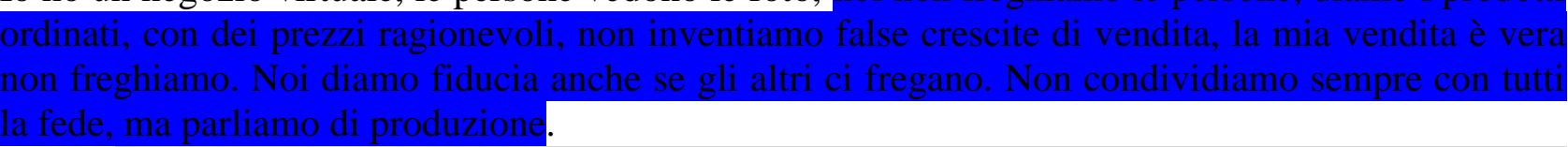

Attorno a Wenzhou ci sono monti e mari, non abbiamo risorse naturali, non siamo una grande città come Shanghai, dobbiamo fare business se vogliamo sopravvivere. Mio padre e mia madre non mi controllano, però mi incoraggiano, mi sento libera nel lavoro. Quando vado all'estero 
vedo che le persone non amano il made in China, voglio cambiare l'idea di made in China. Voglio fare qualcosa di unico non ordinario, il prezzo dunque si alzerà di necessità. Nella house church siamo diversi nel modo di conoscere Dio, se non vado in chiesa non conosco Dio, abbiamo fellowship in inglese, loro ci incoraggiano a parlarlo. Io faccio import-export, l'inglese è fondamentale, se ho il background di conoscenze che serve al designer per aprire la mente e andare attorno al mondo.

\title{
Intervista Jian Shawei $D a 36$ anni F Wenzhou (Wenzhou) 25/08/2015
}

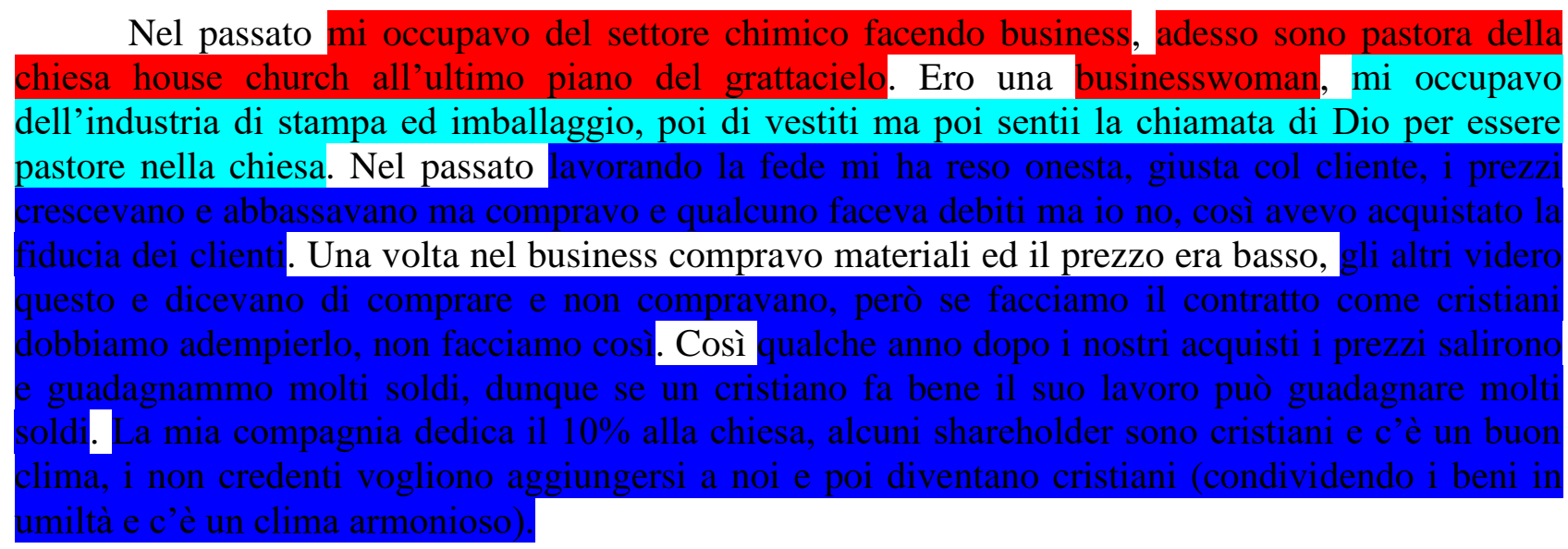

\begin{abstract}
C'è
(per esempio Xiaolin fa scarpe molto famoso, ha molti benefit, paga le tasse al governo e non ha mai mentito) mentre imprenditori cristiani, abbiamo laoban fellowship, e la nostra chiesa (God's power) faceva fellowship di Laoban, connessi l'uno con l'altro. Lo scopo forse è soldi ma se vuoi fare soldi devi seguire le regole della Bibbia e glorificare Dio, devi guadagnare ma i soldi sono controllati da Dio. Le situazioni di difficoltà ci sono state nel mio business. Primo abbiamo pregato insieme come shareholder, non ci siamo colpevolizzati, troviamo la confidence, anche se qualcuno ha sbagliato, ci uniamo insieme per vincere le difficoltà. Quando qualche investimento è fallito ho sentito tristezza, ho pregato a Dio, la preghiera da pace, gioia, speranza, e confidence, promessa da Dio che mi fanno sentire meglio ancora.
\end{abstract}

\section{$\begin{array}{llll}\text { Intervista Jin } & \text { Bo } & 27 \text { anni } & \text { 22/11/2014 }\end{array}$}

Sono cresciuto in il vero momento in cui ho conosciuto Gesù è stato nell'estate del 2003. Ero sin da bambino molto pessimista e taciturno, il fatto che mia mamma mi avesse fatto nascere era uno sbaglio ma dopo c'è stato un cambiamento la vita va nata per dare gloria a Dio. Sono di Wenzhou a 8 anni sono venuto in Italia.

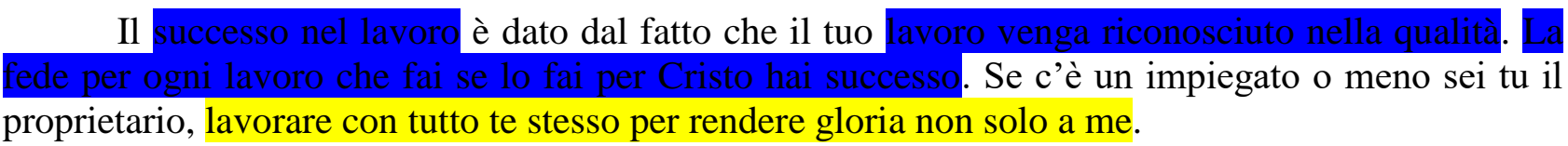

Qualunque lavoro tu faccia questo deve portare gloria a Dio. A volte magari sono pigro,

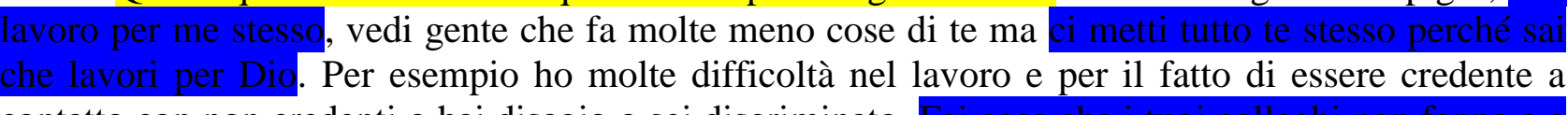

contatto con non credenti o hai disagio o sei discriminato. 
Il lavoro che faccio adesso è per un fratello di chiesa, ho il lavoro perché ci siamo uniti e messi d'accordo con un fratello per lavorare insieme per questa persona. Con un fratello di chiesa stai lavorando con loro e ti rende più fiducioso, oltre che colleghi fratelli e amici.

Lo scopo più importante nella vita è dare gloria a Dio.

PAS: viene dalla Parola di Dio e lo Spirito Santo da quando sono stato salvato sento un fuoco che a volte si affievolisce mi da pace. Nei momenti di difficoltà non sai quello che accade domani ma hai un punto di riferimento la meta la raggiungi, non come successo terreno ma verso l'eternità e hai già tutto. Nel rischio hai la fiducia che il pane quotidiano non ti mancherà, ti da più fiducia in quello che fai.

\section{Leu Ming Lang F Nuo 37 anni $\quad 30 / 01 / 2015$}

Iniziato questo lavoro sei anni fa, sempre qua, attività iniziata dai genitori quando sono arrivati in Italia. Il lavoro ha importanza nella mia vita, lavoro tutti i giorni, non per volontà.

Sono arrivati i miei genitori in Italia nel 97 e dopo quattro anni ci hanno portato qua,

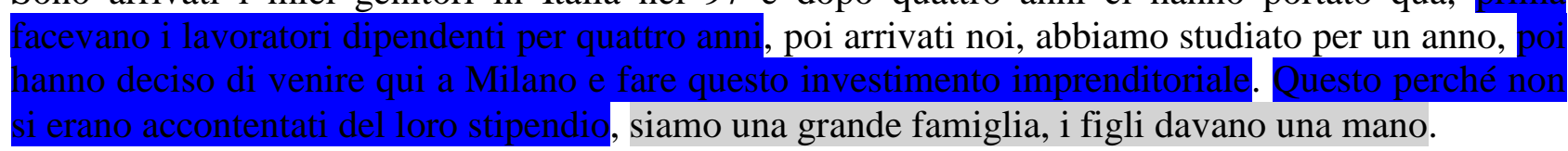

La fede ha aiutato al lavoro, se eri da solo è difficile resistere, invece con il gruppo ti può portare più avanti, inizialmente resisto ma poi perdo la voglia, meglio avere una compagnia.

Tutti cercano opportunità di business qui e ci siamo parlati tra di noi.

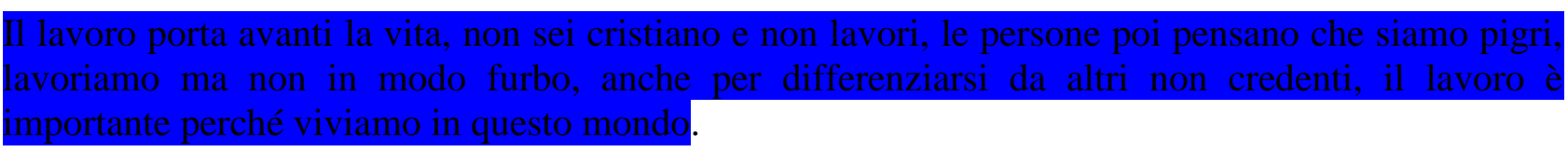

Ostacoli: ogni anno c'è sempre qualche sfida da affrontare. I controlli sono una sfida e si lavora meglio facendo imitazione ma non vogliamo imitare cerchiamo di essere un po' più onesti.

Comunque noi crediamo che che basta che noi facciamo l'azienda, Dio non ci fa rimanere con la pancia volta, certe cose crediamo che si lavora tanto ma certi giorni non lavoriamo mai, tutto è già fatto così. Mia mamma dice Dio ti da questa ciotola di riso. Fino a due tre anni fa ero molto più nervosa lavorando tutti i giorni, litigavo con mia mamma, poi ho pensato che essendo una cristiana anche avendo brutto umore le cose devo farle, dunque ho accettato. I genitori è importante vedendo il cambiamento in fede anche mio padre va in chiesa, accetta pian piano.

\section{Marco (27 anni) M Deming Wenzhou 08/11/14}

A 17 anni ho conosciuto Gesù, mia madre mi portava in chiesa. Andavo in chiesa per vedere i miei amici. Poi sono venuto in Italia ed ho iniziato a lavorare in fabbrica con la famiglia. Lavoro in una Industria di confezionamento di capi di abbigliamento. Un amico cristiano mi ha aiutato a trovare lavoro. Avevo una ragazza non credente, pregai a Dio e Dio mi aiutò (qui Marco diventa nervoso, non vuole parlare dei dettagli della storia).

C'è per quanto riguarda la relazione tra business e fede un gruppo di 40-50 persone, ed un maestro dalla Cina che 40 anni fa arrivò, era 
Abbiamo un ufficio a Milano, per amare e servire i fratelli stranieri in Italia. Così io come venditore voglio dare ai clienti l'amore di Dio. Prima di avere il lavoro pregavo sempre Dio per scegliere se scegliere questo lavoro. Ora lavoro con un fratello della chiesa. Se qualcosa di difficile succede sul lavoro è giusto andare avanti sapendo che Dio sta sempre con me. Lo scopo certo è il regno di Dio, portare la salvezza alle anime.

\section{Mark M Bai 28 anni Wenzhou (Wenzhou) 20/08/2015}

Sono Cristiano da 4 generazioni, prima lavoravo nella logistica, poi dal 2005 ho iniziato un mio business per accessori hardware. Nel 2012 aprii un'azienda di fotografia per matrimoni. Dal 2014 ho aperto Amazing Dreambar dove le persone vengono per leggere insieme, ascoltare la musica, c'è l'english corner, abbiamo uno sharing time e facciamo lezioni di chitarra. Vivo la Bibbia, condividiamo argomenti di fede durante il lavoro, ogni settimana il tema cambia (a volte parliamo del Jazz, della musica...). Abbiamo una time-table al tavolo, il lunedì english corner, martedì musica, poi lezioni di chitarra. Penso che

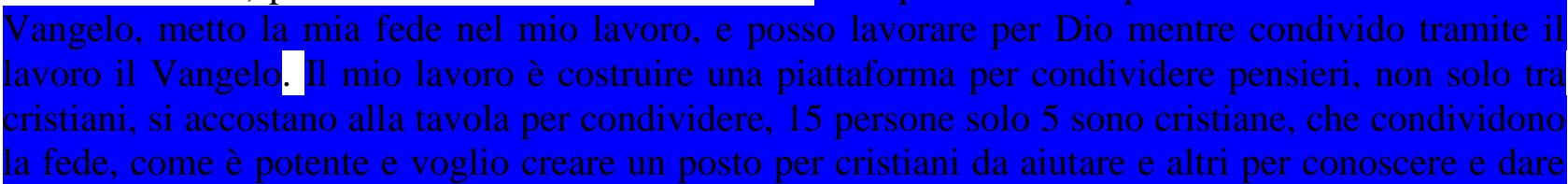

i. Per trovare un lavoro la prova è che servivo nella chiesa sempre fino ad oggi. All'inizio servivo insegnando agli studenti o altri servizi, poi sentivo di voler essere pastore, ho preso una chiamata, se apro il bar beneficierà più persone se Dio apre questo bar è un'opportunità per fare Vangelo, Dio ha guidato i miei passi.

i. Lo scopo del lavoro è trovare i talenti, nelle persone (continuiamo a parlare dello scopo del lavoro) ciò che faccio non è permanente, alcuni anni e chissà, ma

Se tante gocce tornano cambiano

l'intero oceano.

’è una società di boss cristiani dietro a questo scopo.

Non ho affrontato problemi finanziari, mio fratello e l'azienda hardware e quella dei matrimoni ancora vanno quindi Dio gli da il sufficiente. Se ho problemi al lavoro Dio mi aiuta, mi tiene nel sufficiente, ho abbastanza, mi viene a dare aiuto.

\section{Martin 34 anni Yongnian Wenzhou $14 / 05 / 2015$}

Ho fatto anche negozi a dettaglio dal 1997. Lavorato prima sulle scarpe poi abbigliamento. Sono cresciuto sento da quando iniziato. Quando facciamo una cosa sempre preghiamo prima da Dio, se tutto tranquillo facciamo lavorare, se viene qualche sogno che da fastidio non faccio. Facevamo negozio dettaglio pregavamo poi decidevamo di fare quel lavoro. All'inizio non hai tanti soldi dunque ci vuole coraggio per prendere e aprire un negozio, la fede ci ha dato coraggio.

Ci sono stati momenti particolari, il nostro lavoro è concorrenza però c'è tanta gente intelligente, però sempre stati falliti, io non tanto intelligente però prego a Dio che mi aiuta, mi fa guadagnare qualcosa però il nostro lavoro è molto difficile, ho sentito che Dio che mi aiuta.

$\mathrm{Ci}$ sono troppi pesi noi pensiamo dobbiamo guadagnare soldi lavoriamo in debito, soldi prestati da banca e parenti, per noi la fiducia è importante, possiamo perdere soldi non fiducia dei parenti.

Non lavoro importante importante noi tanto per fiducia. 
Questi buddhisti cinese io non so niente il mio cuore sento tanto che Dio mi ha aiutato tanto, loro sono intelligenti fanno qualcosa, io non tanto capace ma Dio mi aiuta tanto, loro tanti parenti che li aiutano e capaci di fare lavoro.

Tanti clienti sono cristiani e quando sono cristiani vengono da me ci parliamo tanto abbiamo stesso linguaggio. Con i non cristiani non parliamo i cristiani sono più bravi.

Per cliente diciamo che i cristiani qualche persona mi aiutato, preferisce comprare da cristiani.

Io sono venuto qua per i miei genitori, già cristiani. La mia famiglia solo da mia nonna, inizio andavo qualche volta in chiesa, poi ho conosciuto e creduto, mia mamma era già cristiana, io bambino piccolo mia nonna mi portava in chiesa, non credevo tanto, poi sono arrivato qua, da giovane pensavo sono più potente di tutto qua piano piano ho conosciuto Dio che sono piccolo così. Questo ha cambiato la mia vita è stato un momento ho preso una malattia, un diavolo sognato al buio che segue dietro di me non riesco a svegliarmi. Poi mi sono ricordato Dio e subito svegliato, piano piano da solo non ce la facevo poi arrivato in quel momento non riesco più a dormire, tante persone che parlano ridono piangono e fanno molto rumore, parlavo con mia mamma e le persone della chiesa. Poi arrivati i fratelli a casa mia hanno pregato insieme a Dio da quel giorno tutto tranquillo.

Scopo del lavoro: quando ci sono problemi scelta di articolo o cose è Dio che manda clienti da me, Dio mi fa scegliere l'articolo giusto.

Dio mi ha fatto sempre fatto pagare, sin dall'inizio abbiamo pregato, Dio ci da coraggio di lavorare, quando facciamo le cose sempre preghiamo, ringrazio Dio di tutto. Io quando inizio le persone ho iniziato il lavoro pregato Dio, mi manda tanti clienti e tante persone, mi sono dimenticato di Dio, finito tutta la merce, ho rubato da Dio benedizioni, pensavo che era le mie capacità di vendita, allora seconda stagione ho comprato tanto tanta merce bloccata in magazzino difficile girare il pagamento poi capito andato da Dio fatto preghiere confessai il peccato e piano piano finito tutto quello che bloccato in magazzino, Dio mi ama tanto quando dimentico Dio sempre problemi quando ricordo mai problemi.

\section{Intervista a Ming Jing Meixiu 23 anni F Wenzhou 30/01/2015}

Sempre lavorato con Mila, da un anno. Lavoro per i miei genitori. Ho studiato all'università nel 2014.

Prima lavoravo come interprete per un'azienda che prende abbigliamento da un'azienda italiana.

Ho trovato questo lavoro perché mia sorella lavorava qua. La mia famiglia è cristiana viene da Wenzhou, siamo arrivati nel 2001 da 14 anni, i miei sono arrivati prima, loro

avoro in fabbrica poi in una fabbrica di batteria, poi hanno aperto questo negozio qua. I miei nonni erano già cristiani da quando erano piccoli, quindi noi come tradizione andavamo già in chiesa, poi nell'ultimo mese i miei genitori vanno a un gruppo della loro età per studiare la Bibbia.

Lo scopo del lavoro, è troppo difficile, passo il giorno. Non c'è scopo nella fede, perché non c'è tempo di andare in chiesa.

Difficoltà al lavoro finora no perché c'è già mia sorella e miei genitori se incontro problemi chiedo a loro, mi danno risposta più adatta. 
Al lavoro non c'è possibilità di testimoniare la fede.

\section{Intervista Pam Chao F 32 anni Geu Xi (Wenzhou) 26/08/2015}

Ho vissuto in Italia 13 anni come commessa, 10 anni fa l'euro era più grande, lavoravo in ufficio, sono partita da sola poi ho trovato mio marito e ho avuto 3 figli. Sono cristiana da 3 generazioni. Il business è forte a Wenzhou, pagano poco le tasse, c'è più soldi e dunque accumulano di più. I cristiani sono uguali, solo

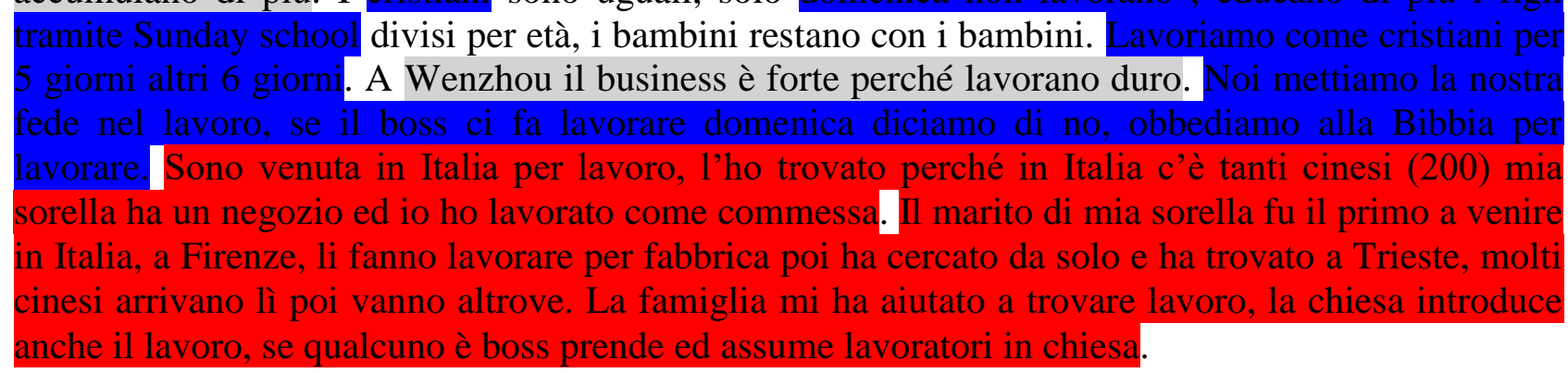

Lo scopo del lavoro è guadagnare soldi innanzitutto, quando hai 4 genitori e tre bambini, devi pagare tanto dunque devi guadagnare, là in Italia i soldi sono più forti. Se abbiamo difficoltà e lavoro preghiamo a Dio per risolvere il problema. Ora sono in Cina per visitare la famiglia poi tornerò in Italia. Lavorare in Italia anche la domenica, allora volevo lavorare in Cina, adesso il lavoro è duro. Tutti crediamo in Dio e dunque ci da la forza, poi la famiglia è importante perché è un passaggio da un padre a un figlio, l'azienda familiare. Noi cinesi lavoriamo per i figli quando la figlia sta meglio ed è più facile. Le persone di Wenzhou viaggiano molto, siamo come gli ebrei della Cina, in tutta Europa siamo conosciuti per questo. Sin dall'antichità siamo dal pensiero più forte, anche le altre città ci considerano così.

\section{$\begin{array}{lllllr}\text { Pan Chen } & 28 & M & \text { Bingwen } & \text { Tonglu } & \text { 12/09/2014 }\end{array}$}

Pan Chen viene dalla Cina Hanzhou, in zijan, vicino a Shanghai. Viene da un piccolo villaggio. Studente ingegneria. La ragione del successo al lavoro è lavorare duro. Devi essere diligente e hon pigro per fare profitto, avere un salario per vivere. Posso fare un esempio di relazione tra fede e lavoro. Dovevo portare una lavatrice pesante e metterla nella macchina. Mi sentivo senza forze. Allora ho pregato Dio che mi dia la forza per portare a casa la lavatrice, non ero solo, non sono mai solo, Dio mi aiuta sempre. Anche se esausto Dio è con me ogni momento. Per scegliere un lavoro: "tutte le cose sono permesse ma non tutte lecite". Se vai in posti difficili c'è Dio ma ci sono conseguenze, meglio fare un lavoro buono per te e Dio. Per me ingegneria, businessmen commerciando è lecito nella legge e puoi obbedire Dio. In Cina avevo un amico cristiano in università e mi parlava di Gesù. Sette anni dopo lo ho riincontrato e la sua chiesa house church di 50 credenti, hanno un pastore che usa tutti i suoi soldi per 3 anni al fine di andare a Singapore per studiare teologia portando sua moglie e figli. La sua famiglia passò due anni in seminario con i loro soldi, poi andò ad Hanzhou per servire la chiesa, altruista, sacrificando tutto, sua moglie lavora perché il marito deve servire nella chiesa. Lo scopo della vita è pace gioia amore, a volte è difficile avere pace nel cuore in difficoltà, avrai paura, sarai nervoso, cattivi sentimenti, ma se hai un fondamento: a Dio importa, tutto ciò che accade perché Dio ha deciso che accadano, ma ti aiuterà a superarle, perciò avrai pace e gioia in ogni situazione. La salvezza è basata sulla fede, se credi nel tuo cuore e confessi con la bocca in Gesù sarai salvato (Romani 9, 10). La PAS so che se credo ho la vita eterna e so che Dio importa di me, quando ho difficoltà pregherò e Dio sarà con me, è più facile superare difficoltà, so che Dio è con me e non sarò nervoso. 
Intervista Paolino

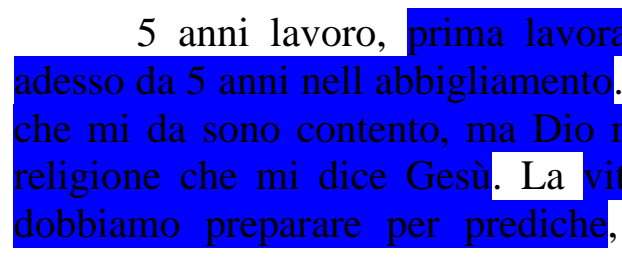

settimana Veneto, poi Bologna.

Il lavoro è importante fino a un certo punto, famiglia da mantenere, questo è un buono inizio, quello che aiuta anche in chiesa e a casa aiuta pure. Dobbiamo dire quali sono importanti, l'importante è la vita dopo, lavoro per quello che dopo dobbiamo entrare nella vita che stiamo facendo.

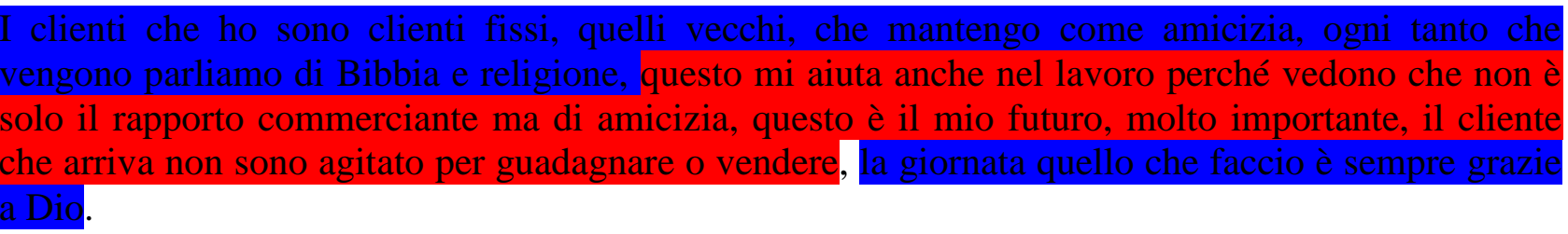

Sono venuto in Italia da solo per lavoro, con la famiglia costruito qua, figlia nato qua, la mia vita è iniziata qua, avevo 23 anni quando arrivai qua.

- iniziata qua, avevo 23 anni quando arrivai qua.

Per la questione del network e se mi hanno aiutato altri credenti questo non tanto devi tu gestire il negozio, lavoro questa attività perché è un negozio come gli altri. Gli altri credenti dipende fino ad adesso no, la nostra vita dipende da Dio e da quello che mi manda.

Il lavoro serve per mantenere la vita, la famiglia, i bambini e crescere nella loro vita. Non ho idea di quello che deve esserci, sento persone, non puoi fare troppe cose, nostre vite sono diverse, io voglio fare questo, ma da oggi non so come fai a sapere. Io ho capito che Dio ci fa esistere, perché noi gestiamo, compreso anche sul lavoro, lui vuole che noi gestiamo, magari in altra vita fanno soprattutto ministero, al momento invece faccio lavoro e in più quella cosa lì.

Qualsiasi difficoltà Dio consegna un assegno per imparare queste cose qua, quando c'è la difficoltà questo pezzo qua bisogno di imparare, o sono influenzato con il tuo lavoro o stacco con la religione. Prima parto dalla religione e vedi cosa succede. Quando uno non capisce perché c'è un problema, è Gesù che ti spiega tutto i tuoi problemi. Dalla Bibbia la parola di Gesù mi ha aiutato soprattutto la vita, prima dobbiamo esserci con la Parola di Dio, ti da significato, perché non c'è lavoro devi riposare ma ancora più rilassarti.

\section{Intervista $26 \mathrm{M}$ Pastore Huang Yizi Hung Pingshan 26/08/2015}

Vedi fliednotes. ${ }^{3}$

\section{Intervista Lin Xiaoping 46 anni M Niu Qing Tian 13/09/2015}

Vedi fieldnotes.

\footnotetext{
${ }^{3}$ Some interviews of pastors were not included in this case report because they contain sensitive data giving the critical situation that pastors have to face with the Chinese Communist Government. In this particular case the pastor was arrested and put in prison few weeks after the interview. 


\section{Intervista Zhi Bing Shui 45 anni M Yong Rui An (Wenzhou) 27/08/2015}

Vedi Fieldnotes

\section{Intervista Qian Wang Ling 30 anni Baoding Hebei Province 29/05/2015}

Sentì il Vangelo prima di essere membro del partito comunista ero pronta per diventare Cristiano, e proprio allora sono diventata Cristiana. La mia famiglia è molto debita al partito comunista, è molto importante perché se sei del partito è facile essere promossa, dunque mia madre mi spingeva ad aderire al partito. 2007 dopo due anni ho incontrato le persone cristiane e sono diventato cristiano della chiesa house church. La mia house church non ero diretto ma più all’Università.

Nessuna esperienza lavorativa, studiavo. Non ho avuto necessariamente persecuzioni, la mia famiglia era arrabbiata, pensava che avevo alta educazione e dicevano che ero superstiziosa. Adesso i miei parenti stanno comprendendo il Vangelo, mio padre ancora no.

Le persone cinese sono conosciute per essere lavoratori duri ovunque, dipende anche da che parte della Cina vengono, persone del sud lavorano di più, gli dai opportunità fanno soldi allora lavorano duro perché vedono il profitto molto chiaramente, non osservano il Sabbath è ok se lavori domenica. Molte persone vengono dal Mainland Cina,

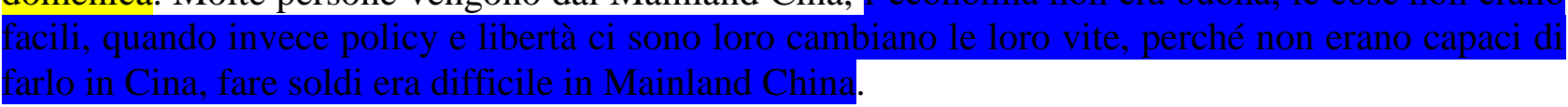

Ho visto

falliva le lezioni perché non era preparato, anche io ero una pessima studentessa. Dopo essere venuta in America il Vangelo è un'opportunità per glorificare Dio attraverso il lavoro, come fai sennò a condividere, lavorare è glorificare Dio l'unica motivazione che posso lavorare duro.

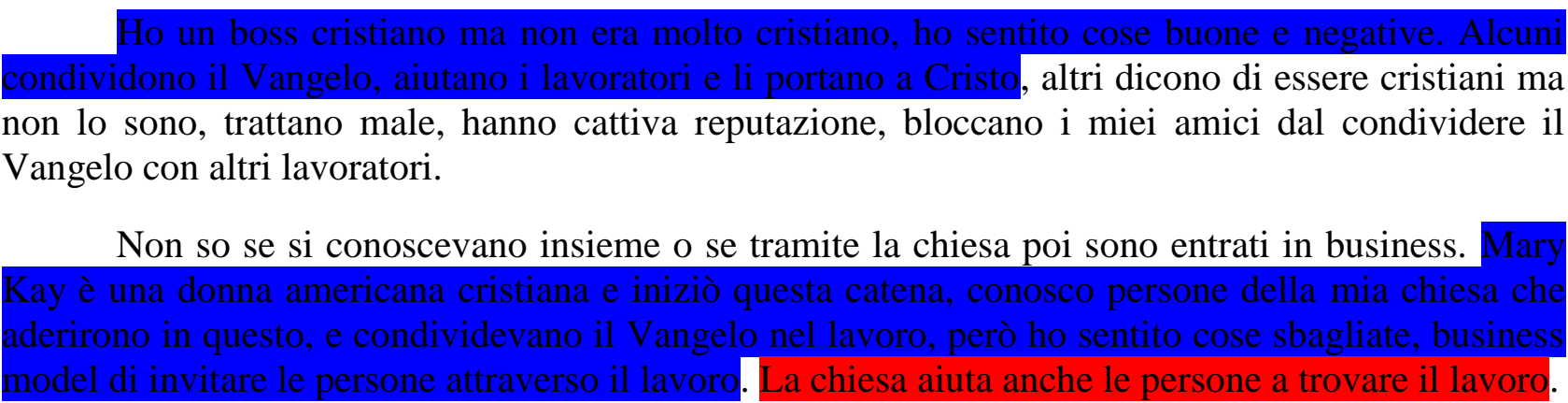

Prima quando facevo la specialistica ero contrasto tra condividere il Vangelo, servire il Signore e poi lavorare in università, cercavo di essere una buona studentessa, il mio boss pensava di essere cristiano ma non lo era. La ragione che sono restata in quella città è perché il mio mentore si era laureato, lasciò la città, mi chiese se volevo restare per alcuni anni, aiutando i fratelli a costruire un'altra chiesa. Mia madre era arrabbiata perché la città non era buona, odiavo quella città, mi dicevo non resterò per un minuto di più. Potevo applicare per la laurea, e mia madre non capiva, non potevo dirle la vera ragione, restavo per Dio. Spiegai perché e restai per alcuni anni e tornai a tutte le sfide, restare e servire o lavorare. Dio mi convinse sulla mia etica del lavoro, dovevo lavorare, non ce la facevo. Quando applicai per la graduate school volevo essere una buona studentessa.

Io ero molto sfidata volevo andare in America vedere cosa Dio stava facendo lì, trovare qualcosa che mi trattenesse lì. Mi applicai per il seminario, poi però applicai per biologia. Poi ho pensato, 


\begin{abstract}
. Ho applicato per questo. Mi sono chiesto se applicare e tutte le volte non ho nemmeno iniziato e ho detto lo faccio con loro ho passato l'esame e non lavorai molto per quella application, non sapevo che dovrei avere avuto tutti i documenti. L'Università mi rigettò, il professore però gli chiesi se c'era qualcuno per risolvere il problema e scrisse una lettera di raccomandazione, per questo mi diedero un'opportunità per l'intervista. Un'altra persona nel laboratorio mi aiutò, e mi sfidò a leggere tutta l'applicazione. Tutto questo è da Dio, non ero una buona studentessa, ho zero confidenza nel mio background, è davvero Dio, che mi diede conferma.
\end{abstract}

\title{
Intervista a Qu Beijing Hop 28 anni $M \quad$ 15/11/2014
}

Qu lavora in architettura una compagnia che ha un'università, un istituto di ricerca (tsinghua university). E' la università numero uno in Cina. Sta costruendo un design di una abitazione in luoghi con disastri naturali, e un museo della memoria per il disastro avvenuto, e anche siti archeologici, e un parco della memoria. C'è anche un italiano.

Ero di una famiglia comunista. Mio padre lavora per il governo. Una famiglia che crede nel comunismo, ero stato cresciuto credendo che non c'è Dio e che dobbiamo lavorare duro per il benefit della nazione, la vita è solo sforzo. Non tradizioni umane, il rispetto familiare era la cosa più importante. Quando crescevo dovevo fare la mia parte per dare ai miei genitori un benefit per aiutarli. Conobbe Gesù quando ero in Italia, non sapevo cosa fosse la religione, venivo da una famiglia comunista, Chen e Pan Chen erano cristiani, le loro vite erano speciali. Ebbero un incidente e vidi Dio in azione nelle loro vite. In chiesa ho conosciuto molte vite e ho deciso di seguire questa via dal Signore.

Dio quando mi aiuta al lavoro, ascolto musica cristiana, disegno e mi da gioia. Prego anche il Signore di darmi la forza nel lavoro.

. Le cose stanno andando bene. In maggio volevo fare un tirocinio, il boss mi ha aiutato, è stato bello, ringrazio Dio perché ha trovato il lavoro per me. Credo che Dio mi abbia aiutato molto, quando inizio qualsiasi cosa prego, e rifletto su queste cose. Prima non credevo in Dio e oggi non ho più ansia, nelle difficoltà che ho Dio mi aiuta. Anche se avessi successo senza Dio il mio cuore sarebbe vuoto, ho una speranza per il futuro.

Mentre cercavo lavoro Dio mi aiutò, pregavo, cercavo e non trovavo lavoro, ricordo che bussavo alle porte credendo che Dio avrebbe aperto una porta, non importa, Dio guarda e gli importa di me, avrebbe aperto una porta, non mi avrebbe abbandonato, continuai a bussare, cercare intership, alla fine non trovavo in Italia e sono andato in Cina e ho trovato sufficiente. Volevo lavorare in qualcosa di ricerca, dove lavoro adesso è esattamente ciò che cercavo, una compagnia internazionale, una porta aperta da Dio. Pregai al Signore anche per ciò che mi aspetta nel futuro.

PAS: ho deciso di seguire Gesù e ho realizzato che l'orgoglio è stato spezzato. Dio mi ha provveduto non sono i miei sforzi. Non piango di fronte alle difficoltà, tutto non dipende dai miei sforzi ma dalla mano di Dio. Quando faccio lavoro competitivo, non importa quanto sia difficile so che Dio mi aiuterà. Il bene, mi aiuta a continuare a superare le difficoltà, anche se non ho risolto a volte so che forse non è il tempo giusto, la prossima volta lo risolverò. Prima ero orgoglioso, oggi non mi preoccupo, non sono più arrabbiato. Dio mi ha guarito. Emozionalmente ho una capacità di superare le difficoltà ed essere in pace.

Lo scopo della vita secondo me è credere nel Signore e nella sua parola e sempre crescere nella fede. Questo è il fondamento della vita e aiuta a superare le difficoltà. Compiere gli obbiettivi è importante ma mettere sempre Dio al primo posto e non dimenticarlo mai.

Routine: mi sveglio alle 8 vado a lavorare, lavoro e dopo lavoro torno a casa ceno, guardo i film, prima di dormire leggo la Bibbia o la sera o la mattina. Ho comprato anche alcuni 

una religione per regolare le persone e le loro vite.

A volte vado in una family church, house church, una chiesa con persone amichevoli. Si amano, adorano Dio essendo resi al signore. E' bellissimo. Vivono insieme in un appartamento. Sono toccato da quello che fanno.

\section{Ren Heng (26 anni)}

\section{8/11/14}

Incontrai Gesù da piccolo, famiglia cristiana (fratello di Daniele). Incontrai Gesù a 15 anni.
Sono Impiegato di azienda ad un centro commerciale. Trovai il lavoro tramite i contatti di mid
padre con suoi amici comunque non credenti. Tra noi cinesi sempre pensiamo che i cristiani sono più buoni, rispetto alle altre persone. Tanti momenti di difficoltà dove la preghiera mi aiuta, alla sera sei tranquillo ma quando le cose vanno avanti di giorno Dio ti dice più cose. Sono impiegato faccio le cose che dicono i capi,

Nel mio lavoro ho contatti con negozianti (70 negozi) $1 / 3$

Con le persone che frequenti tutti i giorni è un po' imbarazzante se vieni rifiutato, è un problema nelle comunicazioni successive (relazione è importante).

guardano il volantino. Tutti i soci della tua società non credenti. Due capi hanno parlato della frequenza in chiesa ma non dimostrano un interesse profondo. Scopo della vita: evangelizzare, aiutare gli altri a conoscere Dio, far vivere meglio te stesso spiritualmente, perché vivere in tristezza dipende dal tuo pensiero interno. Non dipende dalle situazioni che hai, ricchezza, ma da quello che pensi nel cuore.

PAS: nel lavoro centra meno nella vita c'entra tutto. Penso che questa vita è solo una breve sosta, non è la vita vera. Viviamo in una sosta. Avendo questo in mente, tutte le cose che fai e che incontri penserai che sono meno importanti, sia in termini di difficoltà che di ricchezza. Nella mia esperienza ho avuto negozianti, clienti, che sono difficili da comunicare, ho subito dolori parlando con loro, nelle preghiere Gesù mi ha aiutato ad amare anche le persone che difficilmente puoi amare. Il rapporto tra me e il capo, mi fa fare tantissime cose, non è mai contento di quello che faccio, la mia idea è che fai le cose nel tutto tuo possibile poi gli altri se ti criticano non dipende da te.

Giornata tipo: mi sveglio la mattina, non prego quasi mai, mi preparo, vado al lavoro, poi finisco la sera, in macchina mentre guido ascolto musica cristiana, poi la sera a casa mangio leggiamo la Bibbia di gruppo su wechat, anche se non tutti i giorni, poi leggo la Bibbia personalmente un giorno sì e un giorno no, preghiera da sposato a volte preghiamo insieme io e mia moglie. Io la domenica non lavoro, e va bene per altri non possono venire la domenica i negozianti non possono.

\section{Santiago 28 anni $\quad$ Zixin Wenzhou}

Bigiotteria, prima lavoravo nel commercio, magazziniere, sono dipendente qui e il padrone è cristiano. Il boss è marito e moglie sono cristiani. Dipende chi lavora il paese se sono tradizionale, ma noi di Wenzhou è diverso dalle altre città, questo è semplice non è particolare lavoro, qui a Milano più moda altre città diversa e non c'entra. La situazione di altre città dei genitori cosa fanno questo è naturale.

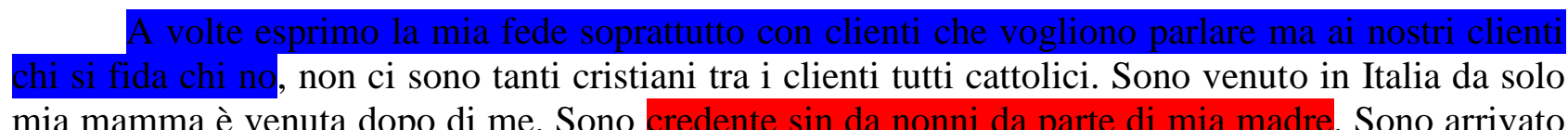
mia mamma è venuta dopo di me. Sono credente sin da nonni da parte di mia madre. Sono arrivato 
qui nel 2009 da cinque anni e mi sono battezzato qui a Milano, ora conosco bene, prima credevo un po' ma mai come adesso, capisco e credo fino in fondo.

vedevamo.

cristiani mi hanno aiutato nel lavoro nella vita, nelle difficoltà di vita, ci sentivamo ci

Devo scoprire qual è lo scopo del lavoro, adesso molti vivono per vivere ma il motivo che è più importante me l'ha dato Gesù aspetto che mi da un motivo e qualche verità.

$\mathrm{Ci}$ sono momenti difficili al lavoro, io sono una persona allegra, qualcosa è passato è passato, credo che Gesù mi aiuta sempre non c'è paura di niente su questa vita qua. A momenti è difficile, quando arrivai qua non c'era patente, ho avuto un incidente e in quel momento Dio mi ha aiutato. Non è semplice quando era successo ho pensato perché mi deve succedere questo? La mia vita non deve essere sempre diretta deve succedere qualche problema perché io sia più forte, riesca a vincere la paura e diventare più forte.

Io avevo la padrona come parente, arrivato qua mi è piaciuto il lavoro e sono rimasto qua.

\section{Intervista Shewuu Zhen M Nai 41 anni Wenzhou (Wenzhou) 24/08/2015}

Sono manager di due fabbriche di materiali per ospedali esportati negli ospedali USA. Ho 10 dipendenti, la nuova fabbrica ha 4 piani di stanze. Sono cristiano di prima generazione, i miei nonni erano pescatori su di un'isola vicino a Wenzhou. [Ora sta concludendo una transizione con un fornitore per il confezionamento. E' molto amichevole e pieno di onestà, sta cercando di allargare la sua fabbrica e stabilire un commercio internazionale].

Non ho lavorato sempre in questo, prima lavoravo in uno studio per avvocati. L'ambiente a Wenzhou è di business e ci influenza, molto business e dunque decisi anch'io di essere nel business (law of imitation). A Shanghai lavorai per due anni poi mi sono sposato e ho deciso di darmi al business (è mia moglie che mi ha portato alla fede).

Tutti abbiamo difficoltà, io spesso prego Dio, è molto importante per avere la pace e la fede ti da pace, porto i miei pesi a Dio e mi sento rilassato. La Bibbia dice che Dio è dalla nostra parte e dunque non dobbiamo temere.

lezioni a Shanghai sulla Bibbia ed il management, poi da Taiwan seguo il 'Joshua management' per
seguire e regolare il business. I fratelli mi aiutano se ho difficoltà, parliamo e mi aiutano con i
consigli. Questo anno per esempio avevo grande difficoltà e i fratelli mi hanno dato consigli su cosa fare, quale decisione da prendere, è stato molto buono. Io lavoro per cambiare la mia vita, per dare alla mia famiglia una buona vita ma da quando sono diventato cristiano non è solo i soldi il mio obiettivo, devo gestire i soldi per Dio, lavorare insieme ai colleghi, portarli alla fede, rendere felice Dio, per la gloria di Dio. Nelle difficoltà la fede mi ha aiutato nella azienda, nell'essere giusto, prendere decisioni guidate e focalizzate, mi aiuta ad alzarmi ed affrontare le difficoltà per superarle, mi da l'aiuto quotidiano, se sono in difficoltà prego, leggo, chiedo aiuto. Lo scopo per la compagnia è una ricerca lunga, mi chiedevo come gestirla, se allargata beneficia per poter comunicare con gli altri, se sei piccolo non vogliono fare business con te, non certo essere un gigante ma almeno seguire gli standard internazionali.

\section{Intervista Shi Qiao Qiang M 46 anni Wenzhou (Wenzhou) 26/08/2015}

Ho aperto una libreria che vende libri di carattere spirituale,

e così i non credenti che vengono sono incoraggiati a venire qui. Me ed un altro pastore abbiamo avuto l'idea di costruire questa libreria. Quando 
chiesa non condivideva dunque lasciammo la chiesa. Abbiamo costruito e decorato facendolo da soli. Molte chiese sono venute a visitare questo posto, il suo nuovo stile appena creato. Noi mettiamo i soldi anche se la chiesa non ci supporta.

anni.

Alcuni Buddhisti si sono uniti a noi. Lavoriamo insieme per 8 ancora molto visibile il risultato del nostro lavoro ma

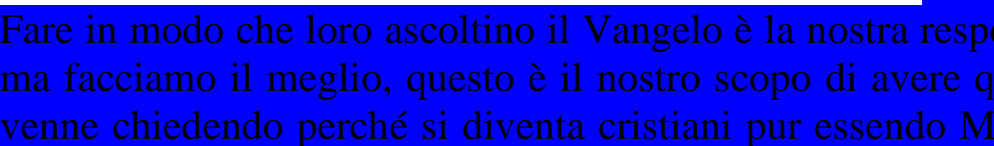

ma lui disse è gratis, allora stupiti comprarono una Bibbia. (55 miles, bike riding, aiuti ai bambini poveri...)

. Il customer care è molto buono.

\section{Intervista a Tony Enlai 28 anni M Chong Qing}

$15 / 11 / 2014$

Nato a Chong Qing, ottobre 2007 accetta Gesù, è in Italia e studia da solo, non parla italiano, la vita era dura, non c'erano amici. Ho visto un gruppo di ragazzi davanti all'Università, qualcuno mi ha dato un volantino, poi ho partecipato all'English club nel posto con la scritta "il Rifugio". Per me era una cosa totalmente nuova, persone che sono gentili e amichevoli, mai provato nella mia vita. Uno dei membri del gruppo era cinese, crebbe negli Stati Uniti, parlava in cinese, condivise il Vangelo. All'inizio ero chiuso, pensavo fosse superstizione, anche per il background di educazione, la nostra filosofia di educazione era il Marxismo. Ho avuto molte discussioni con loro per provare che i cristiani credono in cose stupide e superstiziose. L'ultimo giorno ci fu una cena molto lunga e al momento degli addii un gruppo di persone pregò per me ero commosso. Lessi la parabola della pecora smarrita. Quando crescevo avevo un professore che diceva se ho uno studente in meno non mi interessa invece Gesù dice: mi importa di te. Fu la notte più pacifica che ebbi, non avevo paure, dormii come un bambino, avevo mio Padre con me non ero solo non ero solo non più. La fede crebbe veloce, andai attraverso molte difficoltà, ma stavo seguendo Gesù e la Bibbia che mi aiutavano a superare le difficoltà. Poi nel 2009 aiutai Frank e Pam a fondare la chiesa a Milano. Fu il momento più bello ma anche più duro della mia vita. La chiesa era difficile perché eravamo solo noi tre, iniziando da nulla, andando a Bicocca a incontrare studenti. Il tempo con Frank e Pam era come una famiglia benché non avevo soldi o amici. Cercavo lavoro e non trovavo uno, non era

facile, un uomo non può servire due dei. Trovai solo un part time job, non era facile e nel 2011 13, 14 interviste all'ultima trovai lavoro con Gucci. Ebbi un altro lavoro per Prada. Lavorai due anni a Milano. Non è facile lavorare e servire la chiesa allo stesso tempo. Ebbi un tempo davvero difficile durante il primo anno,

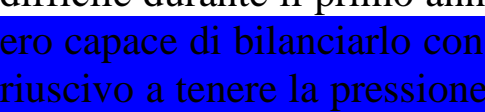

. Negli ultimi mesi volevo andare via dalla chiesa perché

, la mia fede non stava ferma, ero attaccato da tentazioni, il mondo del lavoro è molto materialista, incontri tanta gente e diventi curioso sul mondo (soldi, prosperità...). La tua testa diventa grande. Volevo andare via dalla chiesa perché c'erano così tante regole, e mi sentivo in una gabbia, nutty boy che cerca di andare via dal controllo per fare le sue cose. Nel 2012 il lavoro mi ha aiutato e sono andato a scuola ancora una volta allo IELT, finendo la specialistica, pur richiedendo molto tempo, sono uscito da casa di Frank,

personale. Finita la scuola incontrai Chaiying. Iniziai la relazione con lei, volevo andare a Barcellona stando con la sua famiglia. Ero in un certo senso il padre per due mesi. Cercai di sposarmi con lei per avere una famiglia. 
Le interviste dicevano di no, alle prime tre volevo abbandonare, non è ciò che cerco. A quel momento la preghiera e la fede mi aiutarono molto. Volevo avere la fede e perseveranza, provando ancora ancora, e le interviste andavano meglio, alla tredicesima intervista, dopo due mesi dalla prima sono andato, ero molto calmo e pacifico perché ebbi molte interviste. Vendere e boutique era il mio target che avevo scelto. E così trovai lavoro. Dio mi tenne come una formazione, ringrazio Dio per avermi fatto attraversare la difficoltà, preghiera e perseveranza. Durante il lavoro la fede mi aiutò, ero straniero, non parlavo bene in italiano, comunicare con i clienti, l'atmosfera, competizione, corruzione sotto il tavolo.

Le persone vedevano, a

volte ho avuto l'opportunità di condividere il Vangelo con colleghi. Nel mondo del fashion c'è molta omosessualità, stili di vita confusi, era duro perché tutte le persone vogliono, e provai molto duro di essere chi Dio voleva che fossi.

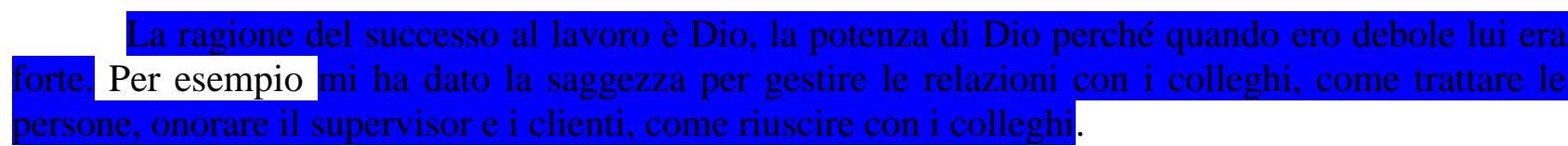

La PAS: ero confuso e ansioso sul futuro, leggevo i proverbi e trovavo le direzioni dove andare. Quando mi sento giù e triste so che Dio è con me e mi conforta, qualunque cosa succeda Dio è creatore e lui ha il controllo. Non ho paura. La paura nelle difficili situazioni o sconosciute situazioni, le persone che non so gestire viene superata da Dio. La confidence è la cosa più importante, le persone del mondo si comparano spesso con gli altri, guardano all'income, famiglia e macchine, perché ho Gesù e Dio ho lo Spirito e ho confidence con qualsiasi persona, non per quanto sono bravo ma perché il mio tesoro è in cielo e ha preparato il meglio per me.

Lo scopo della vita è condividere il Vangelo, seguire i passi di Gesù e fare discepoli. In questo momento questo scopo non è cambiato ma ho aggiunto qualcosa di specifico e non so come distinguere o categorizzare le cose. L'obbiettivo spirituale c'è ma ci sono obbiettivi materiali per cercare cose materiali: quanti soldi, che tipo di famiglia, dove voglio vivere, che tipo di stile di vita voglio avere.

\section{Intervista Wan $\quad$ Fai 26 anni $22 / 11 / 2014$}

Yun nan nato nel Sud ovest 32 ore da Shanghai (vicino al Vietnam). Prima lavoro a Quandong (vicino a Hong Kong) in una tramite e-mail per spedire beni, ora manifatturare e produrre i beni, assemblarli. Scuola media, ho trovato amici dalla città, c'erano dei predicatori, i miei parenti credettero e mi chiesero di credere e leggere la Bibbia, non c'era chiesa nella nostra regione, ed eravamo perseguitati dal governo, la polizia venne nella nostra famiglia e qualcosa brutto accadde. Alcuni credenti studiavano a casa, non c'era modo di avere un culto. Seguivo i miei parenti, nel liceo andai vicino a Shanghai, incontrai tanti amici. C'erano tanti studenti da Wenzhou e mi chiedevano di leggere la Bibbia con loro, e fui cambiato da loro. Fu molto speciale, studiai la Bibbia molto, e capivo più la Bibbia. Venivo da un piccolo villaggio, $\mathrm{i}$ miei parenti non potevano provvedere per me gli studi, sono stato benedetto da Dio, studiai in Italia in un momento bellissimo, fui trasformato, sono diverso da chi ero prima. Tornai in Cina con passione grazie a voi. La situazione in Cina è diversa, è difficile per i credenti in Cina, tanti credenti hanno bisogno di sentire il Vangelo, pregate per me. Il punto è che ho trovato lo scopo nella mia vita, ho ancora questa passione nel mio cuore. Nella scuola media nei villaggi 150 famiglie, 20 o 30 credevano in Dio, pregavamo e studiavamo la Bibbia, credevamo che c'era un Dio, le persone dal governo non ci volevano, pensavamo che non eravamo cristiani e escludevamo loro. Studiavamo privatamente, non potevamo aprire la Bibbia in pubblico, a volte a casa, le persone alle $11 \mathrm{o} 12 \mathrm{di}$ 
notte venivano anche da altri villaggi, avevamo una nuova chiesa. Un giorno la polizia bussò alla porta e eravamo spaventati, chiesero a noi di lasciare il villaggio. Un pastore fu messo in prigione, il polizziotto lo picchio, l'uomo tornò a casa. Questo successe diverse volte. Al liceo studiavamo la Bibbia domenica con 40 studenti e il pastore. All'improvviso la polizia arrivò e chiese di lasciare al pastore era insicuro. Ora i cristiani del villaggio sono sfidati dai non credenti, non studiano molto.

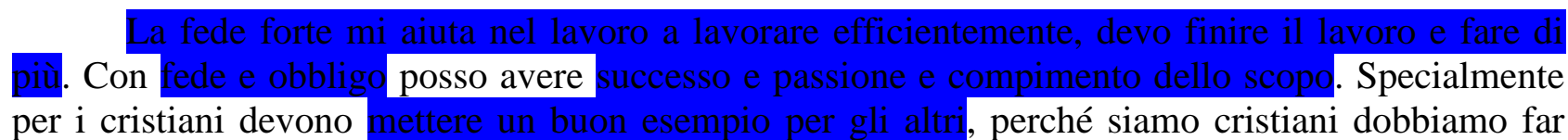
sapere agli altri, seguire la Bibbia, anche se facciamo sbagli, Dio vuole che crediamo e abbiamo la responsabilità di dire ad altri e fare in modo che gli altri credano a Dio tramite il nostro comportamento. L'ambiente è importante. Se incontri qualcuno con fede e passione puoi essere motivato da quella fede e passione. Lavoro di gruppo è anche importante, per lavorare per lo stesso scopo.

Nella Bibbia c'è scritto, sii pronto a condividere le ragioni della speranza che sono in te, spiegando ad altri, è molto speciale per me.

attorno a me in un modo molto naturale.

Fede e lavoro. Penso che la mia fede è la mia forza nel lavoro. Il mio lavoro mi aiuta a rafforzare la mia fede. La fede aiuta anche a lavorare bene, indica la fede. Per esempio adesso vorrei essere un businessmen, aprire una fabbrica devo chiedere alle persone di lavorare nella mia fabbrica, per produrre e

Se volessi fare qualcosa di male mi fermo e dico sono cristiano, la Bibbia dice di no, e lasci le cose brutte,

ed essere di esempio.

Prima di trovare questo lavoro sono tornato a Cina mi ci è voluto un mese, ci sono così tanti studenti, non era così facile. lo avevo già fatto ed ha funzionato, cercavo lavoro, un mese passò e continuavo a cercare. La mia esperienza mi influenzò. La mia fede in Dio c'era sempre e volevo andare avanti. Sono molto felice che sono nella strada giusta verso la mia schedule, rispondendo a ciò che Dio mi ha chiesto di fare. Non era facile il primo mese, con colloqui, fallimenti, e alla fine ho trovato. I credenti pregavano per me e altri credenti pregavano per me, i miei parenti ed io. Pensavo a queste preghiere ed ero incoraggiato dalla fede e non mi abbattei, continuai a cercare e alla fine lo trovai. A volte ho avuto difficoltà dubitai, l'ambiente non era facile ma la mia fede mi portava a fare qualcosa di diverso migliorare, con Dio e Gesù questa è la via migliore e felice.

Adesso sto cercando una chiesa in questa nuova provincia solo da una settimana, mi sto contattando con altri credenti, forse domani. In Shanghai ero parte di una chiesa. Ogni giorni andavo all'Università e conoscevo qualcuno che leggeva la Bibbia o studenti che studiavano la Bibbia. Uno era parte della chiesa, c'erano uomini e ci vedevamo dalle 8 del mattino fino alle 12 per pregare e leggere. In Shanghai la stessa chiesa ci sono 12 ramificazioni, era una house church, family church, 50-70 persone non state church, in una casa privata. E forse un mese o sei mesi i credenti di tutte le chiese si riunivano (500-1000 persone, un momento bellissimo). Una volta nella chiesa pubblica sono solo persone vecchie, 1000 persone a volte piangevo, Dio è buono, la Cina è una grande nazione abbiamo bisogno di Dio. Quando vai ai negozi nelle strade vedrai qualcosa diverso: Buddisti, Kindle... Ovunque in Cina. Nella chiesa condividevo le mie esperienze di lavoro, pregavamo insieme e chiedevamo a Dio. Studiavamo insieme e se lasciavo la chiesa non leggevo insieme ma quando andavo in chiesa mi motivavano, condividevano le esperienze, ero incoraggiato, e tornavo a casa volevo crescere. 
Lo scopo della vita per me prima era diverso: non ero cristiano o all'inizio, pensavo che dovevo fare i soldi aiutare i miei parenti a diventare ricchi, poi fui trasformato da Dio, ero peccatore ma Dio mi ha cambiato ed ho questa fede, devo dare la notizia del Vangelo, condividere e fare in modo che vedano Dio. Devo ancora crescere e studiare la Bibbia. Devo aiutare le persone a trovare lo scopo, significato.

PAS: devo cercare Dio fortemente, se faccio qualcosa lodo Dio, non sono io. Fui salvato da Dio e dovevo fare qualcosa che Dio mi ha chiesto, non dovevo vantarmi: se ti vanti vantati nel Signore. Ora sto bene e vedo fortemente come sono cambiato e se vuoi posso condividere con te e fare in modo che anche tu sia cambiato. Dio mi conosce, il Dio perfetto e devo introdurlo ad altre persone. Credo che Gesù mi ha salvato ma a volte sono debole dubito se posso meritare il suo dono e credo sempre che Gesù mi ha salvato. Sono un peccatore e senza Gesù sarei morto nell'inferno, ora invece posso vivere bene perché ho uno scopo, andrò in cielo, ho trovato il mio scopo, con l'amore di Gesù nei prossimi 60 anni crescerò nella fede e Gesù mi guida in questa strada. Quando ho stress sul lavoro e pressione, ho questo credo posso pregare leggere la Bibbia chiedere in Chiesa ad altri credenti qual è il significato, se non fossi cristiano mi comporterei in un modo brutto, andrei a bere alcol, a cercare un modo di lasciare lo stress e le difficoltà brutto, ora ho un modo di lasciare il mio stress ho la pace, sono usato da Dio per finire il lavoro, per provare la sua testimonianza. C'è tanta pressione in Cina, tante tentazioni.

\section{$\begin{array}{lllll}\text { Wei } & A h C y & \text { Wenzhou } & 26 \text { anni } M & \text { 22/11/2014 }\end{array}$}

Quando ero piccolo andavo in chiesa, a 19 anni sono tornato in chiesa. La mia famiglia è complessa, mia mamma è cristiana, mio padre no. Mia mamma al matrimonio andava in chiesa poco però adesso anni nel 2001 sono in Italia. . Vengo da Wenzhou, periferia. A 13 abbigliamenti, gestisco le rimanenze quando rimangono ancora e preparo la roba e la spedisco.

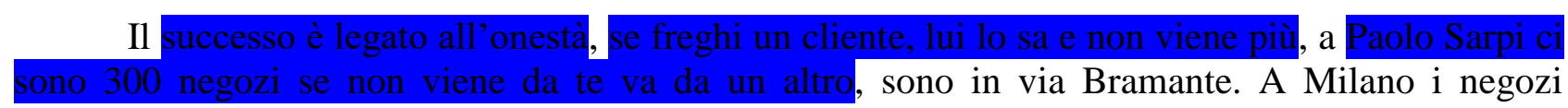
prendono a Roma noi direttamente dalla Cina, quindi il prezzo è scontato.

La mia fede mi ha impedito nel lavoro perché ogni tanto devo dire menzogne, sulla qualità della merce però dopo non mi sento in pace. E' una fregatura però il mio lavoro non glorifica Dio. So che Dio mi guida sempre, la mia famiglia non è cristiana vera quindi sul lavoro e la fede non c'è tanta connessione.

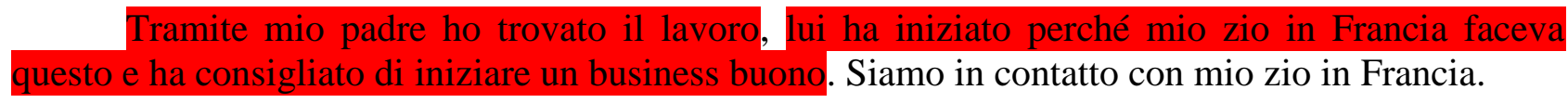

La chiesa mi ha aiutato nella vita privata non sul lavoro. Nelle difficoltà mi ha aiutato. Se io lavoro male è abbastanza normale, perché se succede qualche problema io dico a Dio io ti lascio guidarmi, quello che succede succede. Non gli chiedo esplicitamente perché sento che è sbagliato.

Lo scopo della vita è come scritto nel Vangelo, dobbiamo evangelizzare e portare la notizia di Gesù in tutto il mondo. pacco di roba non lo prendo lo lascio e poi il cliente me lo chiede.

PAS: ancora non sono sicuro. Non mi sento in pace, perché ho fatto tante cose sbagliate però a volte mi sento ancora in colpa, alcuni errori li sto facendo ancora adesso, cerco di migliorare. Ho la certezza ma ho momenti di dubbio. Qualche anno fa un periodo sognavo incubi, qualcuno che mi soffoca, succedeva abbastanza spesso in quel periodo. Nel momento che mi stava soffocando chiamavo Gesù facevo la preghiera, e da quel momento non c'è più. 
Ho l'abitudine di rimandare, ho tanta pressione al lavoro e non so dove ho letto in un sito evangelico, le cose di oggi le faccio oggi, le cose di domani le lascio al domani. Quella frase mi ha aiutato tanto nel lavoro perché ho tantissime cose da fare.

\section{Intervista Wu Chen Chen Xun Wenzhou (Wenzhou) 46 anni M 22/08/2015}

Brother Wu è il presidente della World Chinese Merchants Union Association, nonché membro onorario della camera di commercio Cinese. Brother Wu è il Laoban di successo, prima lavorava nel settore dell'abbigliamento (RYNO come rinoceronte). Brother Wu discepola anche Mark per diventare un buon imprenditore di successo. Studiai come dottorando a Cambridge. Quando avevo 18 anni ero cristiano, andavo in chiesa, la mia fede era forte ma la mia vita era povera, i miei parenti erano poveri ma mia madre era malata e spesi molti soldi per la malattia di lei. Dovevo trovare i soldi dunque per fare business, la chiesa aveva diversi malati, dunque

, in quei giorni mi allontanai dai fratelli per essere sempre di più immerso nel business. Se a volte avevo successo nel business avevo però bassi e alti, i giorni erano lunghi. Dio chiamò me molte volte ma io non volevo rispondere, dubitai di Dio. Alcune compagnie di Shanghai erano in debiti, così per tre anni ebbi debiti e non sapevo che era per Dio, non volevo ascoltare gli avvertimenti, Dio mi stava correggendo. Provai ogni sistema, davo via soldi, mi rivolgevo alla polizia, ai miei coetanei ma non funzionò, mia madre mi chiamò, chiese cosa stavo facendo, io dissi che avevo trovato i soldi necessari, ma mia madre pregava per me. A quel punto mi arresi e accettai che lei pregasse, mezz'ora dopo gli shareholder dell'azienda che non si erano comportati bene ridiedero indietro i soldi a me. Era un miracolo ma non tornai comunque a Dio fino al 2007, il miracolo avvenne nel 2005. Allora ebbi un sogno ero in ginocchio e sentivo un coro, sul risorto, date gloria a Dio, allora capii di essere peccatore e piansi allora mi svegliai dal sonno e mi ricordavo ogni parola, ogni melodia. Tornai in chiesa dove si cantava la stessa canzone del sogno, però in chiesa mi addormentavo, c'erano anziani. I mesi passavano, decisi di andare in un'altra chiesa (la 'commerce fellowship' di Ton Aly) dove incontrai imprenditori, alcuni erano anche membri del partito, altri professori universitari... la mia fede crebbe. Nel commerce fellowship parlavano di business, era un nuovo mondo per me, i miei occhi erano spalancati. In questo lavoro la vita e il business possono andare insieme, era un posto importante per me, una nuova terra. Un anno dopo la commerce fellowship cambiò in chiesa tradizionale, io però

Alcuni fratelli lasciarono la commerce fellowship d'origine, erano come pecore perse, perché la fellowship è fondamentale.

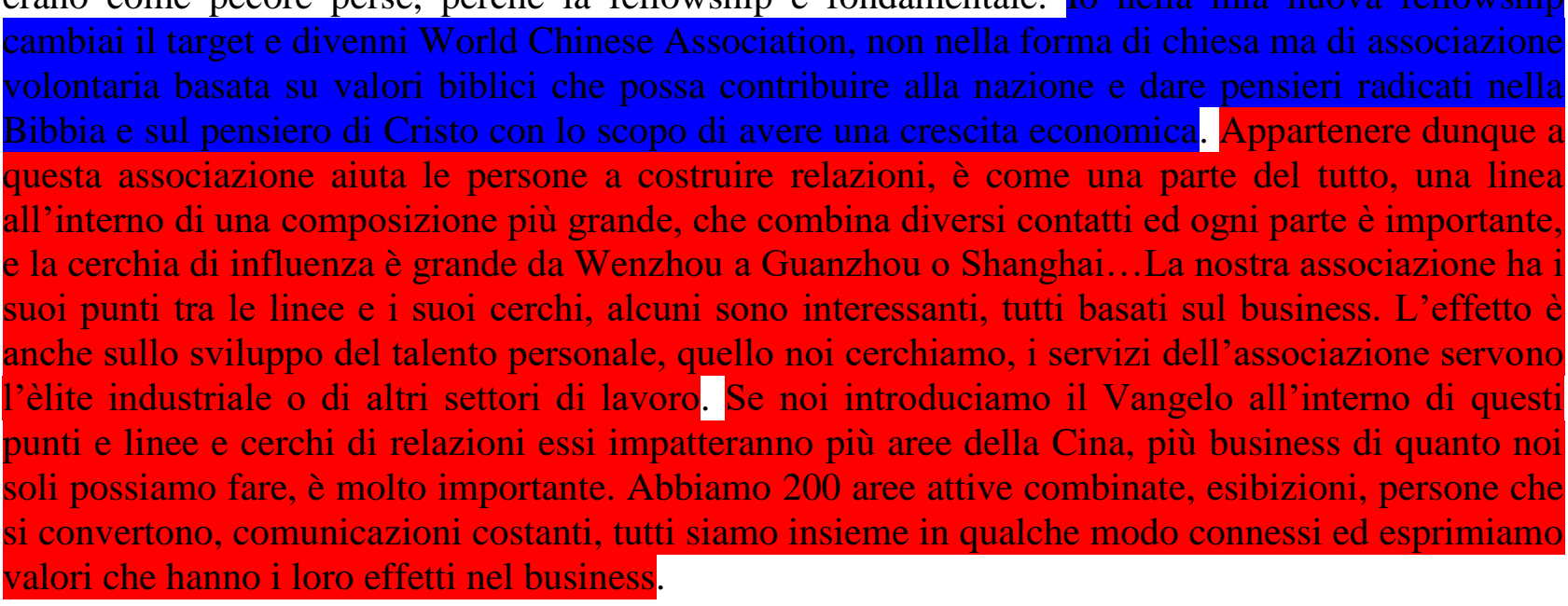

Il cuore e la mente sono tutto in momenti di crisi, essere cristiano è difficile qui, c'è corruzione, quando usi i valori biblici manageriali ti bloccano, non ti permettono, è difficile in 
questi momenti. All'inizio e per diversi anni il deficit della compagnia era alto ma insistevo, insistevo e Dio cura, i valori biblici e cristiani, non era facile ma ce l'ho fatta. Dio da fede e confidenza, ebbi un cuore coraggioso per risolvere le cose in modo manageriale. La Bibbia dice dobbiamo essere luce e sale, ma non lo abbiamo fatto. Le imprese e i manager non sono stati quella luce, se compari i non credenti il nostro grado di velocità di contratti e fede e valori non è migliore, non riusciamo a passare al test. Ma siccome apparteniamo a Dio siamo peccatori, abbiamo sbagliato e dobbiamo tornare a Dio. Quando perdiamo le ricchezze sentiamo comunque pace e grazia e possiamo affrontare i problemi. Io mi sento come un aiutante, sono un supporto e promoter nel lavoro, come Gesù. Posso usare le mie risorse ed aiutare i giovani membri dell'associazione, io ho avuto alti e bassi memorie di fallimenti e saggezze da condividere per curare i problemi degli altri. Io ho fatto un lavoro pioneristico, chiedevo ad esperti di aiutare giovani e membri dell'associazione ad avere accordi tra di loro, condividere le risorse tra loro. Nell'associazione c'è l'imprenditore di successo che può aiutare i giovani e altri membri.

Ci sono stati giorni bui ma si tornerà al passato e ritorneremo a fiorire. I prodotti, le tasse saranno più economici in altre nazioni ma il loro pensiero è vecchio. Confidiamo che Dio regola la nostra nazione e le opposizioni non sono un problema, nessuno può fermare lo scopo di Dio. I cristiani hanno molto da fare.

\section{Wu Kexi \\ Wenzhou \\ Ting-Ting 31 anni}

Donna 1997 arriva in Italia, famiglia cristiana dai nonni, mio nonno problema di salute non guariva dalla malattia non sta sempre bene, un dottore cinese cristiano, hanno dato preghiera e piano piano è stato guarito. Sono venuta con la mia famiglia in Italia poi sono sposata qui.

\section{Xuepeng Ah Lam 37 anni 29/11/2014}

Da dieci anni sono credente, lavoro come commerciante cominciato da me. I miei genitori non leggono la Bibbia. Mio papà va in chiesa, lei all'ultimo momento ha creduto. Nato a Wenzhou, da venti anni sono qui in Italia.

Per il lavoro non so che dire ma lei ha seguito la mia strada e siamo entrambi credenti. Dio mi aiuta in alcune situazioni per crescere:
con i problemi della casa, ancora è difficile, sento che Dio ogni momento è insieme a noi.

Il lavoro col tempo posso leggere ciò che dice le prediche e la Bibbia. Nel tempo libero posso leggere e ascoltare qualcosa. Al lavoro la fede non mi ha aiutato. Non mi interessa questo lavoro, mi intessa più servire il Signore a tempo pieno. Nella vita privata la fede aiuta ma non nel lavoro.

Nel lavoro non mi sento in difficoltà perché so che Dio mi aiuta. Seguo questa strada più avanti vorrei fare qualcosa per Dio, impegnarmi più in chiesa, anche la credenza non è solo per noi, Dio vuole tutto noi stessi nel modo che Dio indica.

c'è poco lavoro, posso studiare quello che il pastore dice per avanzare nella fede, dobbiamo crescere e sentire Dio come dirige per cosa fare.

Per me dobbiamo vivere ogni situazione per aiutare gli altri a credere in Dio. Mio fratello e sorella diventano credenti e poi da li altri si convertiranno.

PAS: credere che vado in cielo mi aiuta ad andare avanti. Questa credenza mi aiuta ogni giorno, mi aiuta a passare le difficoltà, gli ostacoli. 


\section{Intervista Zhou Zhong De Ning 47 anni M Wenzhou (Wenzhou) 24/08/2015}

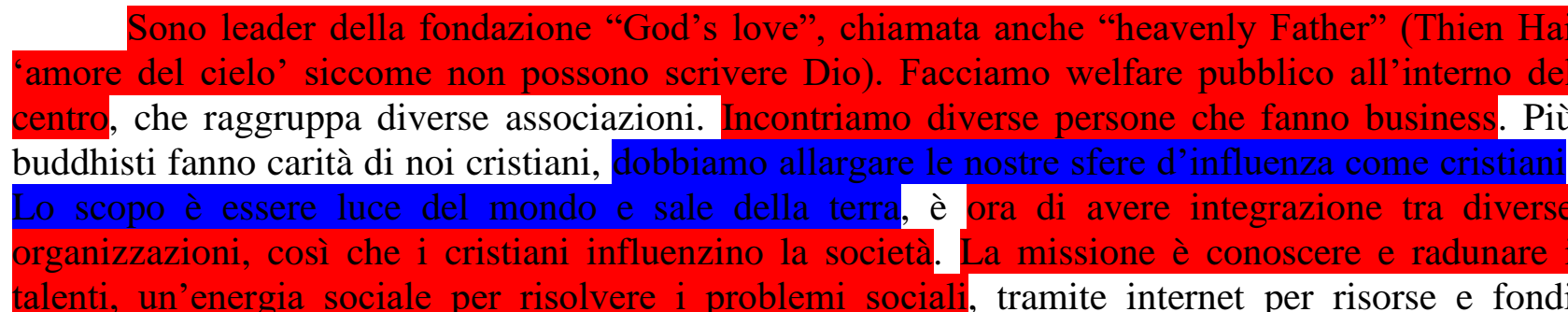

insieme. La nostra fondazione è nata solo da un anno così abbiamo aiutato i terremotati. Siamo andati dove c'era bisogno e parliamo del Vangelo e fede anche se non possiamo condividere siccome il governo ci ferma. Dio provvede i fondi per le nostre attività, se ti fidi di Dio puoi vedere un maiale volare.

associazioni di Wenzhou siamo molto attivi, espriamo la cultura cristiana al pubblico e al governo,

Raccogliamo soldi tramite imprenditori cristiani sul web, tramite pubblicità. Nel passato gli imprenditori ci aiutavano ma ora non è facile con l'economia, specialmente i giovani imprenditori cristiani (sono stati imprenditori cristiani a fondare l'associazione).

Anch'io ero imprenditore in passato,

connetterci socialmente. Io mi occupavo di laser e led per grandi produzioni, avevo una grande fabbrica di vestiti in cooperazione con l'Italia. Poi investigai diversi negozi per decidere di affittare negozi ad altri e pensai di trovare qualcosa per glorificare Dio, qualcosa molto importante per me così aprii la fondazione. Senza cultura cristiana è inutile.

\section{Fratello Jin Fang Wenzhou $50 \mathrm{M}$ Pastore 25/01/2016}

C'è il pastore, lei gli sta spiegando le domande, parlano in dialetto cinese. Siamo dei credenti in Gesù, da trent'anni in Italia, da 15 anni a Milano. Ognuno ha un business, abbiamo creato dalla Cina l'associazione. In Italia siamo venuti per fare soldi, poi pian piano diventati credenti. Dobbiamo pensare quello che dice la Bibbia mettendo in pratica la Bibbia. All'est abbiamo tante cose belle e brutte, c'è conflitto, non c'è scena per discutere, per risolvere i problemi, scambiamo, per prendere cose buone e negative via. Lo scopo è capire come integrarsi nella società ed economia italiana. (mentre porge il suo business ticket si china sempre) Tutti quelli che sono venuti cercavano una vita migliore, i rapporti erano incentrati sul business, io come pastore ho pensato non dobbiamo stare solo per soldi, ma scambiamo la cultura, i pensieri, le idee, la cosa più importante è la fede, con tutti gli scambi è più facile. In Italia solo da 4 anni sono qui. I cinesi arrivarono alla altezza culturale, economica ma non quanto l'Italia. Per questo nasce l'associazione per scambiare con la cultura Europea. La mia creazione, abbiamo parlato con tanti Italiani, per evitare tanti problemi e malintesi culturali. Il mondo è diventato come un piccolo villaggio, possiamo sapere che scopo ha questo mondo, è la nostra famiglia, parlando siamo felici. I cinesi non sono solo per vivere ma per parlare con la società italiana (cambia capovolgendo tutto). Il nostro gruppo in Cina organizza beneficienza in due case di cura. Facciamo volontariato, crisi terremotati, orfani, handicap, anziani, 100 persone ciascuno coinvolto nell'agricoltura scientifica. Le nostre radici di fede le vogliamo portare nella società, la religione non riguarda solo le quattro mura della chiesa ma siamo sale e luce nel mondo, riveliamo quello che abbiamo dalla Bibbia, abbiamo il compito di testimoniare. Facciamo vedere quello che facciamo nella ricerca, nella tecnologia e mass media che parlano di noi. Abbiamo costruito una fattoria, e il governo non ci blocca, addirittura stimano noi come credenti perché solo noi riusciamo. Se parli solo è difficile, ti credono se fai tanti credono in Gesù. Dobbiamo andare nel sociale e questo piace al governo (totalmente capovolto alla rivoluzione culturale). Senza questa impostazione il governo non è 
contento, la croce nel cuore deve essere fatta vedere fuori, testimoniando nella vita concreta (così saremo accetti alla società). In Cina tanti soldi sono stati fatti, chiese grandi ma hanno dimenticato di praticare la Parola. Gesù ci ha detto di andare a fare discepoli. Il governo ci aiuta e piaciamo, ne ragioniamo così, nessuno può dirci niente contro, ci creiamo una immagine rispettosa nella società. Dobbiamo cambiare il modo di pensare. $\mathrm{Ci}$ apprezzano e danno 20 pagine a articolo, di una storia così, mai successo in Cina! E noi diverso da noi non abbiamo nulla di nascosto, nessuna fregatura nascosta. Arriva dunque l'accettazione (addirittura politici convertiti tramite questo). L'insegnamento del gruppo è che la Parola della Bibbia mettiamola in pratica testimoniamo al mondo, i comunisti, loro vedono la differenza. Dobbiamo dare un Gesù che metta in pratica un Gesù vivente. Siamo in questo legati alle nazioni unite con scuole di insegnamento, con diverse imprese. Cerchiamo di incoraggiarli, chiediamo perché sono in Italia, come cambiare modo di pensare, per i giovani, per i problemi anche italiani, contribuendo alla società, con volontà di aiutare. In Cina ci sono tanti dèi, la mentalità di Dio come strumento, ho bisogno (materiali e spirituali eterni). In Cina chiesa o no, io ero prima generazione aperto il business, a quel tempo (30 anni fa) ero il primo famoso imprenditore in Cina, tanto materialismo ma un bisogno interno dentro. La gente crede in Gesù per salute, lavoro, soldi, io invece non per questo ma per il vuoto e la tristezza, la pienezza interna esterna è collegata. Prima erano separati, sbilanciati, una parte bruciata e una cruda, deve esserci amore di vita e mondo del Padre da bilanciare. Per questi bisogni siamo arrivati in Europa (Gesù mi benedice spiritualmente e fa lavorare bene), noi dobbiamo bilanciare queste due. Sia in Cina che in Europa così le imprese sono contente, ci ascoltano, e impatta il loro business, fino ad adesso sbilanciati e noi bilanciamo facendolo diventare testimonianza di vita.

\section{Vittoria Wenzhou 45 F Yan Presidente Associazione Est-Ovest 25/01/2016}

Al bar accanto c'è stata una riunione di donne cinesi il bar è cinese, due commesse cinesi in
stretto rapporto con le donne in riunione. Lei è presidentessa dell'associazione culturale est-ovest'
(Dong Xi Fang Wen Hua Jiao Liu Xie Hui), associazione cristiana che riunisce imprenditori.

Chiese cinesi a Milano:

1) Chiesa evangelica di Via Fortunato Stella 700 membri;

2) Chiesa casa di 30 membri, gestita da un uomo del Taiwan;

3) Chiesa di Piazza Bosa, pentecostale con 400-700 membri.

Alibabà ha capovolto il business in Cina, i pensieri e le strategie sono diverse, in Europa tante cose economiche sono belle, per esempio la rivoluzione agraria, mescolando la saggezza orientale occidentale allora viene un buon risultato. I miei figli sono la terza generazione già italianizzati, se tornano in Cina è un dramma. Loro non stanno bene fra due fuochi, però l'opportunità c'è del doppio fra occidente e oriente. In Europa ci sono tanti rapporti buoni e così c'è più opportunità mescolando le due nell'associazione. Europa da più tempo hanno iniziato con la sicurezza, l'ambiente, la qualità del lavoro, in Cina solo da poco, c'è difficoltà con l'inquinamento, la sovrappopolazione... L'obbiettivo è integrare gli imprenditori nella cultura Europea soprattutto in termini di sicurezza, ambiente e altre lacune che gli imprenditori cinesi non hanno. Sono in contatto anche con Legambiente, parlando di verde, sicurezza, ambiente, è un compito difficile per i cinesi, in contatto con tante realtà della società civile (ASL).

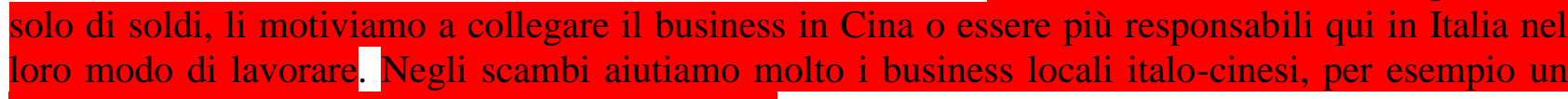

membro fa gemellaggi con città cinesi e italiane. La Cina sceglie l'Italia per la storia e cultura, noi abbiamo scelto Milano perché la religione era forte in Italia si cerca di far rinascere questa spiritualità sepolta, controllava il mondo. La Cina vuole fare buoni rapporti di business con l'Italia, noi usiamo questa situazione di scambio. La beneficienza e il business vengono uniti. Abbiamo un avvocato Paolo (avvocato italiano) business sociale è meglio ma è difficile ci interessa il cuore. Qui 
in Italia estremamente fanno beneficienza ma il cuore manca molto. Parliamo con vari esponenti della società, noi abbiamo bar, negozi, stock, abbiamo bisogno di personale, vogliamo personale cinese ma non c'è più manodopera, e tanti disoccupati in Italia, manca fiducia.

una scuola per disoccupati stranieri, come assumere nei locali cinesi, facciamo questo modo di cinesi che i non disoccupati. Con i soldi poi facciamo beneficienza. Abbiamo buoni rapporti con i laoban, su 500 business, tanti sono cristiani. Abbiamo posti di incontro con loro per dialogare, e A volte aiutano in casi di bisogno di necessità (per esempio i rifugiati). Più di 100 chiese in tutta Italia possono aiutare. Anche i grossisti con gli avanzi vogliono aiutare.

cinesi. Abbiamo bisogno di personale e l'Italia ha disoccupati. All'inizio c'è paura, ora al negozio lo mando. Così c'è costretto tra tutti i bar e locali cinesi a tutti i disoccupati evangelici in bisogno. Molti rubano ai cinesi che hanno business. Come confrontiamo il governo? Fin quando aiutiamo il sociale ci sostengono, ma senza la Bibbia è difficile, dobbiamo mettere in pratica nella vita e $\mathrm{i}$ comunisti chiedono perché lo facciamo e condividiamo con loro il Vangelo.

imprese 1/3 sono credenti. Vogliamo creare una nuova Wenzhou, contattando imprese cristiane, condividendo idee, buoni rapporti con loro, li raccogliamo anche per fundraising. L'associazione cerca di risvegliare la comunità cinese in Italia per aiutare la società italiana. I Cinesi non vengono più dalla Cina, ma si cerca manodopera. Ora stanno bene in Cina, mi pagano poco in Italia, preferiscono rimanere là. I figli cresciuti qui non lavorano più come noi, vogliono benessere, vogliono essere liberi, noi invece della vecchia generazione oppure migranti lavoravamo duro, ora (2-3 negozi, macchine, figli non vogliono, invece di vendere ora si da in gestione ad altri migranti). Avevo un debito, dover pagare i parenti e dunque lavoravo, i figli si sono occidentalizzati invece.
Noi invece continuiamo a crescere un nuovo business, l'italiano fallisce ma noi lavoriamo 16-17 ore
e riusciamo. Raggiunta l'autonomia si delega, si cambia la mentalità ora.

\section{Intervista Matteo 20 anni M Na Wenzhou 14/12/2015}

Negozio Max \& Liu di Viale Sarpi, mio padre è proprietario. I miei genitori hanno iniziato 10 anni qui, quest'anno a Cernusco hanno aperto un nuovo negozio. Sono nato in Italia, i miei sono arrivati nel 1989 dopo Tianmen. In teoria sono cristiano di terza generazione. Wenzhou, la società ha iniziato a cambiare. Non sono più comunisti ma liberali. Wenzhou è così anche per la sua posizione commerciale, su pianure. Differenza minima nel commercio tra cristiani e non, noi andiamo in chiesa. La chiesa aiuta nei primi anni appena arrivati mi hanno aiutato. Il lavoro può piacerti, darti soldi, poi devi sfamare la famiglia. La situazione ora va avanti prima del 2005 aprivamo delle fabbriche, difficoltà non sono stati nel salario.. la chiesa ha provveduto aiuto.

\section{Intervista Italiano}

Alfredo Mario

30/01/2015

Crisi settore immobiliare, mutui e soldi per far comprare la gente. Ho parlato con persone e una persona mi ha parlato della vendita di abbigliamento, con alle spalle che avevano licenze. Bisognava avere acquirenti, ho iniziato a venire a girasole per proporre, difficile perché c'era diffidenza: quale interlocutore? L'unico che mi ha dato retta è Sandro Modaoggi, a fianco a Ren, tratta abbigliamento bambini, all'inizio muro, le tue robe autentiche, lotta impari, tutti bruciati e cerchiamo di prevenire. Parlando e spiegando chi ero il prodotto e le garanzie, il tipo di società che è... qui propongono di tutto e di più la maggior parte tarocca, pensavo l'opposizione era non italiano ma quello che proponevo fosse o meno lecito, perché c'è questa timidezza a confrontarsi con le altre persone? Maleducazione nel non considerare il diverso.. Pur sapendo da dove arrivi e cosa fai, non capivo qual'era l'approccio migliore. Sandro mi scrutava, gli feci fare un assaggio, lui mi ha fatto un piccolo ordine come importo. Ma in realtà era una prova, lui era preparato e maturo, e iniziai, vide la merce, un assaggio che ci ha aiutato a conoscerci dal punto di vista umano. Da lì ho 
proposto altri prodotti, ero il fornitore esterno lui acquirente, ha visto che seguivo le consegne, e riuscivo ad interpretare le diverse mentalità, non mi sono creato problemi. Ci deve essere empatia, essere psicologo. Loro non li conoscevo come mentalità. Dal dialogo ho meno difficoltà a interpretare ciò che vogliono dirmi linguisticamente. Estrapolavo i messaggi nascosti, ragionamenti lavorativi difficili, non parlare di una serata ma di rapporti lavorativi, io fornitore lui cliente, come una partita a scacchi, con problemi di linguaggio. I vantaggi ci sarebbero stati se il rapporto lavorativo avesse preso fiducia reciproca (merce, pagamenti...). Dovevamo essere elastici. Noi italiani conosciamo la Cina in modo distaccato, qualcosa di astratto, un paese chiuso con i rapporti degli altri, visione limitata, popolo che lavora, tante formiche senza interessi, li compativamo. Pian piano ho capito che più che minaccia, erano diversi, hanno dei diritti. Anche fra di loro, se parlo con qualcuno, il gruppo all'esterno sembra coeso ma poi ci sono contrasti anche tra di loro, mi fanno capire che hanno contrasti. Non mi fanno entrare nel giro perché magari non sono affidabile, persone che se ne approfittano per fare mordi e fuggi, mi rapportavo con lui ma con nessun altro, erano freddi e distaccati. Con Sandro abbiamo iniziato a scambiarci le idee, il declino della nostra cultura, ci scambiavamo le idee sulla politica, ho iniziato a portare i bambini, mi presentava agli altri, capivo che avevo raggiunto un traguardo importante. Loro pensano subito che li voglio fregare, parlavo delle possibilità di lavoro, ci sono carenze nella conoscenza della burocrazia, le leggi, gli usi che noi abbiamo fatto nostri, noi siamo esasperati nella burocrazia mentre loro affrontano tutto molto più pratica ma hanno difficoltà sulle questioni burocratiche. Allora ho creato un centro servizi, loro hanno orari continuati, non hanno possibilità di rivolgersi agli uffici, svolgono lavoro sempre, bisogna qualcuno che si rapportasse agli uffici esterni, senza sanzioni, multe, siccome sono il capro espiatorio dei mali dell'Italia, loro invece sono una delle poche comunità che vogliono rimanere stanziali, non ritornare a casa, soprattutto le nuove generazioni.

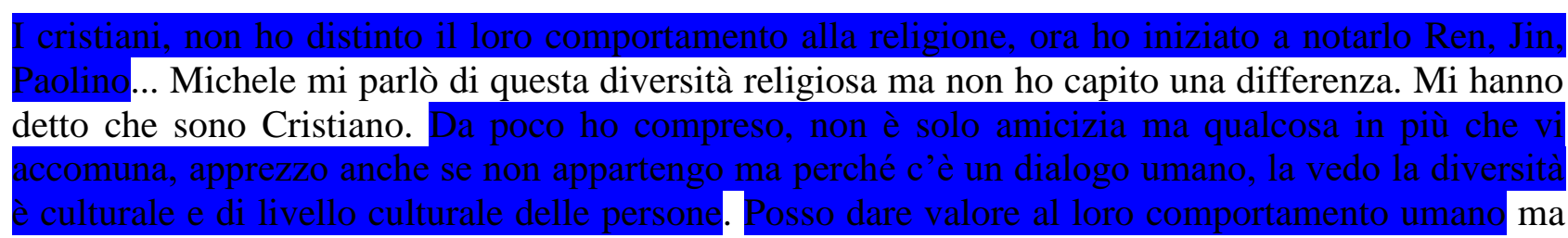

ho preclusione quando impongono dei dogmi e delle regole che non sono accettabili, metti i Testimoni di Geova. Vorrei andare a sentirlo perché mi hanno invitato. Io guardo le chiese da un punto di vista storico.

\section{Ken Giulio M 27 anni Italiano Milano 16/01/2016}

Ho trovato lavoro guardando dalla vetrina del bar, ho lavorato cinque mesi al Dutch Chips. La produzione è di cibo fritto, verdura, tempure, polli, panini. Io ero cuoco, facevamo turni, tre al mattino, tre alla sera (17:30 -18:00), uno fisso alla cassa, all'inizio fino all'una, poi fino alle 11. Sabato c'è più gente, lunedì niente, inizio si poi stallo col caldo, preferivano il gelato, adesso meno movimento. Se devi, devi trovare punti strategici, troppe spese, fornitori, affitto e stipendi. Patatine, verdura, da fornitori, guadagno tanto sulle patatine. Inizio bene, di mezzo così così, adesso mandano Amsterdam Chips c'era. Prima ho lavorato sempre per cinesi, bar tavola calda a Loreto, titolare cinese, chef italiano. Duro lavorare con Cinesi, loro visione del lavoro, vita basata solo sul lavoro, tante ore, il resto non esiste. Da un lato è dura per i ritmi ma ti insegnano bene il mestiere, sono quadrati. Ti stanno parecchio addosso, occhio puntato, sanno fare tutto loro, quello che fai tu è sbagliato, la situazione sotto mano ce l'hanno loro. Leo rispetto al ex capo è più alla mano, più anni. E' pesante quando il capo e la madre non andava per niente bene (lavoro precedente). La potenza loro è che sono tanti e collaborano tra familiari, si danno una mano, non falliranno mai, è dura che un cinese è in perdita, sanno gestire gli investimenti. Leo pensa sempre le cose in grande, non si ferma. Mi ha visto subito, bella faccia, ha fiducia, ha voglia di fare, non è un favore. Serve uno che parli Italiano. Preferisco questo, ho fatto informatica. Inizio attività era difficile, non eravamo 
preparati. E' lavoro esagerato, 14-12 ore, è la loro forza, la cultura è diversa, sono abituati sin da piccoli, la loro forza è basata sul lavoro. Sua zia (di Leo) insegnava, ha il bar vicino al negozio, ti martella subito, esageravano a starti addosso. Leo si occupa di amministrazione, il titolare è lui e sua zia, il bar sotto la metro (30 bar familiari hanno) tra parenti, zii, etc. La zia lavorava a contatto col cibo, per molto. Un filippino italo-brasiliano, italiano, per loro novità, abituarsi alla mentalità cinese. 2-3 sono cambiate, 2 rimpiazzate. I clienti lavoratori dei dittoni, via Maghera, aristocratici, clientela totalmente diversa da Via Padova.

\section{Dyagram of Gantt of the Entire Research:}

\begin{tabular}{|r|r|}
\hline Data collection & gen-14 dic-16 \\
Ethnographic observations Christian \\
Participation to seminaries \\
Data analysis of the empirical documentation \\
Ethnographic observations non-Christian \\
Visiting student at Purdue (USA) \\
Ampliation of the study \\
Visit and observation in Wenzhou, China \\
Adjustment of the theoretical argumentation \\
Preparation final dissertation
\end{tabular}
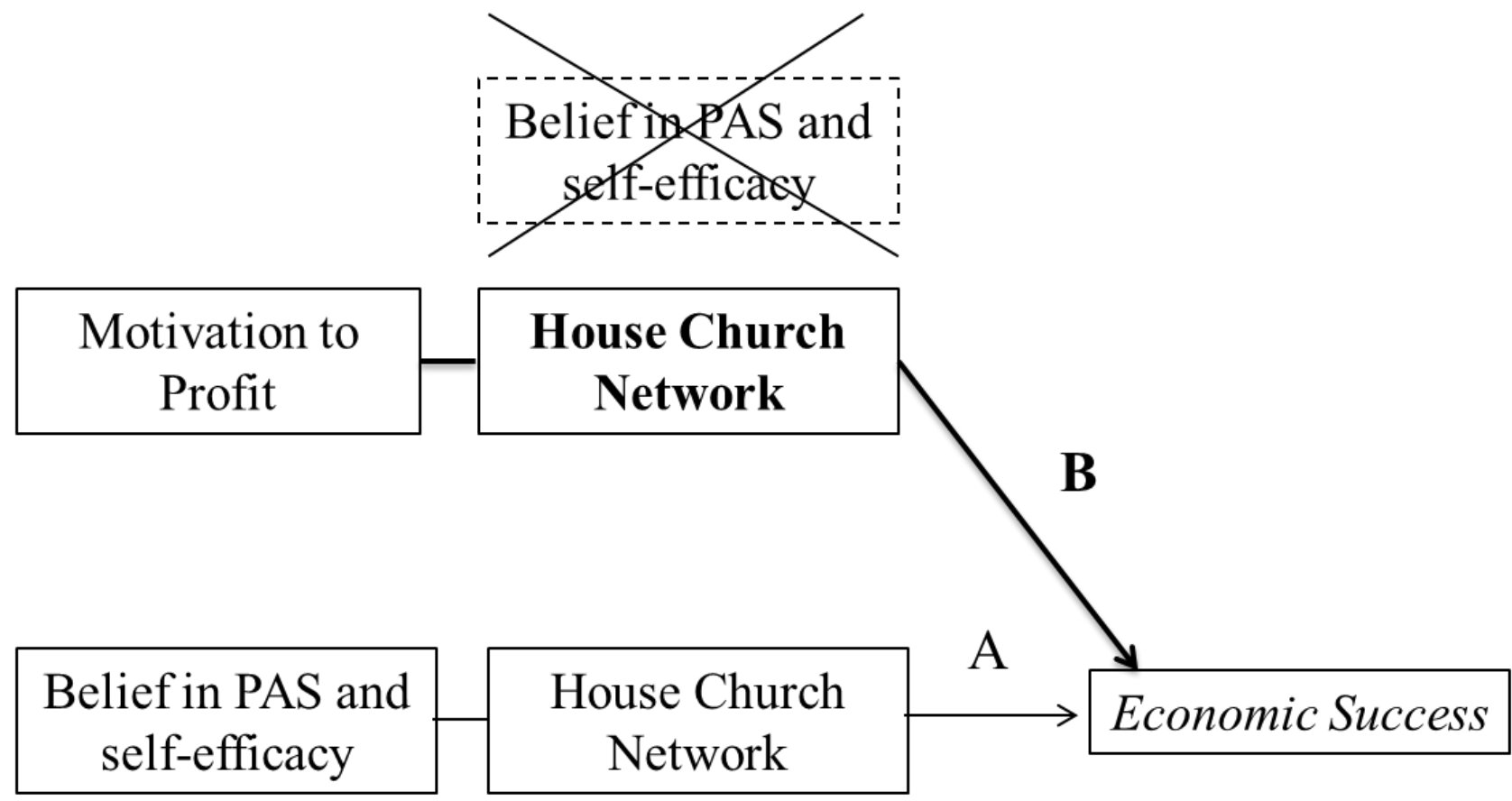
Arrivato in Italia da Cinque anni, lavorato in sartoria, sono arrivato da solo poi adesso la famiglia. Vengo da Wenzhou, in Cina

Cina lavorare è molto importante, voglio casa, oro, vivere e vivere con macchina mondo più bello e lavoro più per questo. Non ha sogni ma la mia vita possa essere confortevole.

No tutto da solo, non ho ricevuto aiuto da altri cinesi.

La ragione più importante vogliono essere in tempo, il cliente sia soddisfatto, avere più clienti al negozio e più clienti.

Lui ha avuto difficoltà come clienti non contenti e comprende che non faceva un buon lavoro sui tessuti ed ha cercato di risolvere il problema da se stesso.

Lui non crede molto in Buddha ma crede in sé stesso.

Lui vorrebbe vivere meglio nel futuro con la famiglia, la società italiana beneficia delle persone cinesi qui.

\section{Chi Xiaoyun $M u \quad$ Wenzhou 44 anni $\quad 14 / 07 / 2015$}

Sono il presidente dell'associazione della comunità Cinese di Wenzhou, proprietario del ristorante Singapore. Sono arrivato nel 1993 in Italia con mia moglie, quando sono arrivato ero cuoco e ho iniziato con le esperienze che avevo in Cina,

istorante come boss. Mia sorella era il boss del ristorante, aveva bisogno di un cuoco e mi fecero
generare grazie alla famiglia. Wenzhou noi che veniamo da lìmo passati questa cosa, abbiamo la cultura di lavorare duro. Abbiamo il desiderio
comune di raggiungere una propria proprietà, aprire e gestire un proprio personale business, il
desiderio di non dipendere da altri. Dall'inizio i miei parenti lavoravano duro, i soldi non c'erano, il
cibo mancava, vidi i miei parenti lavorare duro e volli avere la stessa cosa. Così disegnai di fare
questo lavoro, non per soldi ma per aiutare gli altri nel lavoro. Le associazioni di cui faccio parte
sono no profit, i soldi sono basati su donazioni, lo scopo è aiutare le compagnie cinesi qui, se uno
vuole aprire un business diamo delle opinioni ed aiuto, i membri aprono un lavoro, diamo delle
comunicazioni che circolano sulle offerte, un altro aspetto per la Cina è che se hanno gruppi danno
aiuto economico o una direzione. Essere iscritto e capo di un'associazione è anche un elemento di
identità, serviamo le persone, siamo connessi con il governo italiano per eventi, organizziamo cene
dove invitiamo il sindaco, poi la seconda generazione di cinesi in Italia è coinvolta anche.

La crisi del 2008 ci ha colpiti ma lavoro duro e la collaborazione reciproca risolvono problemi. I miei parenti sono buddhisti. Ci sono diversi tipi di Wenzhounesi: chi vive in città, $\mathrm{i}$ ricchi, e quelli della periferia, di Wenzheng Tinchieng, i poveri delle aree rurali, che desiderano venire in Italia. Il governo li ha resi legali pagando anche soldi per loro. Ancora oggi sono legali, io sono invece cittadino di Wenzhou, non voglio fare i soldi ma comunque voglio essere boss di quest'attività.

\section{Chin So Hue Cheng F 45 anni Tonglu 20/08/2015}

Sono imprenditrice, gestisco una fabbrica di vestiti fatti a mano, d'alta moda disegnati e venduti in Giappone, vengo da Taiwan. Prima vendevo prodotti di vestiario o altri vestiti, poi ho iniziato il mio business vendendo vestiti. Nel 2002 venni in Cina per fare la fabbrica. C'è un sogno 
e un obbiettivo in me, poi la famiglia a cui io devo provvedere, specialmente per i bambini, che possano avere una buona educazione. La risorsa è la responsabilità, da sposato con bambini hai delle responsabilità. Venni in Cina per il 2002 con il boom economico cinese, le risorse umane costavano poco, in Giappone i costi erano troppo alti e non ci sarebbero stati profitti. Ora il costo del salario è salito anche i ricavi dunque scendono. Ora la situazione è così non puoi controllarla, spero sia solo una fase e in futuro i costi scenderanno. Ora un vestito costa 4000 yuan, i lavoratori devi pagarli per un mese, poi devi vendere in Giappone ma il costo totale è alto e pochi sono dunque i profitti. All'inizio ebbi difficoltà ad ambientarmi in Cina, il linguaggio era un problema, anche se per me non tanto siccome sono Taiwanese, sono forte e sono riuscita ad affrontare le difficoltà. Il modo in cui facciamo business, seller, gestisco il mercato, mentre mio marito è il responsabile di produzione, arriva un ordine e si inizia a comprare i materiali e io sto in Giappone a vendere, mio marito non conosce bene, fa quello che sente, non era facile, non avevamo alcun network di sostegno. Gli ultimi 13 anni non c'erano grandi difficoltà ma da quando i lavoratori cercarono di rubare il mio design e portarlo ad altre aziende era difficile, dovetti quasi chiudere e reiniziare. , voglio ri-iniziare e non tirarmi indietro. Prima lo facevo per i bambini ora loro sono cresciuti, ora lo scopo è ri-iniziare ed essere di successo, dove ti fermi e fallisci re-iniziare è fondamentale.

\section{Intervista $\quad$ Elisa $R$ Romei 32 anni $\quad 30 / 03 / 2015$}

Dirigente del Ristorante Xing Long, buddhista, da 5 anni in Italia. Ha lavorato sempre qui a questo ristorante.

Per i cinesi il lavoro è importante perché la famiglia ha bisogno di mangiare non come gli altri italiani, noi abbiamo figli dobbiamo portare i figli a scuola. Mio marito è venuto qui in Italia per lavoro poi il marito ha ricevuto un permesso per lavorare e poi tutta la famiglia è venuta.

Suo marito lavorava in una fabbrica, lei stava a casa annoiata e ha deciso di fare qualche lavoro ed ha aperto questo ristorante, per aiutare i bambini. E' stato mio marito che mi ha aiutato.

Non ha un target, no scopo vogliono vivere qui e vivere una vita decente.

La lingua era molto importante non sapeva nulla dell'italiano non capiva di cosa gli italiani parlavano, a volta avevano bisogno di tanti soldi per mandare avanti il business e così dovevano chiedere soldi ad amici che vivono qui. Non sa se buddha l'ha aiutata nelle difficoltà perché non può vedere il paradiso, non può toccare.

\section{Zhejiang Peng Fabio 26 anni $\quad 06 / 07 / 2015$}

All'inizio ho iniziato

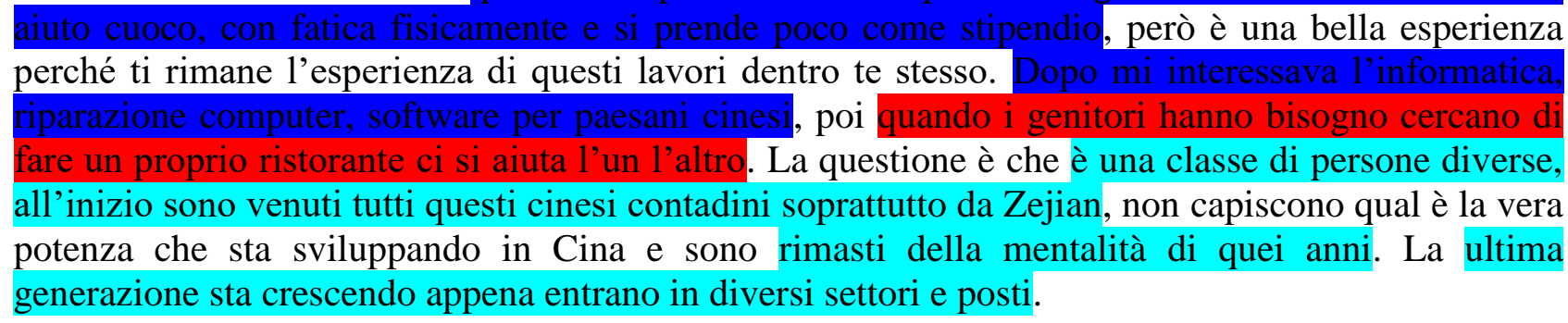

Dalla cultura cinese lavoriamo molto, quando eravamo piccoli i genitori ci insegnano di essere lavorativi ed educati con le persone, per essere educato vai a lavorare, tieni le cose da fare viene benessere per la tua famiglia. Poi visto che abbiamo attraversato tutto questo oceano per venire a vivere in Italia dobbiamo lavorare altro che non far niente. Maggior parte dei cinesi 
pensano quando saranno di una certa età vanno in Cina. Tutti i cinesi sono tornati in Cina. Ha una cultura fortissima che siamo cinesi e torneremo da dove siamo venuti da generazione a generazione. I Cinesi guadagnano ma restano a lavorare nell'attività la seconda generazione in Italia, la piattaforma si manda avanti.
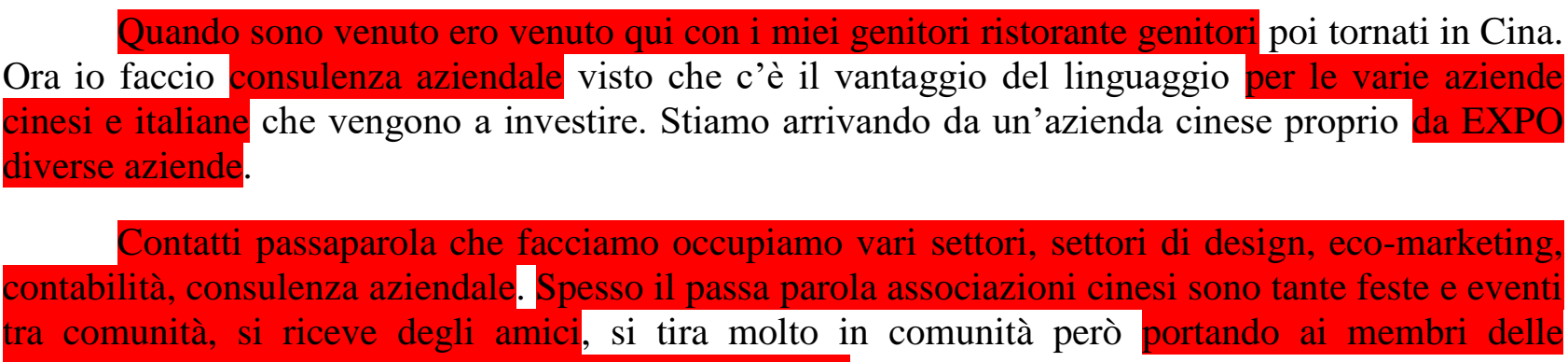
associazioni a fare le cose più utili al nostro business poche associazioni stanno facendo perché ci vole tempo, per fare questo lavoro di miglioramento tra generazione e generazione c'è una differenza, e credo nei prossimi 10 anni avrà un'altra classe migliorando la classe di appartenenza.

Il valore del lavoro per me è intanto ti da da vivere un'idea di quanto guadagni e devi rispettarla, ha un senso insegnarti come stare convivere condividere con altre persone se fai parte della società come puoi vivere? Il lavoro esce da come vuoi vivere allora devi lavorare in un modo diverso, da dipendente è facile prendi stipendio e la continui la vita, il mio lavoro ha il valore di scoprire il resto del mondo e cose interessanti da vedere, avere più dignità.

Nei momenti difficili c'è quando entri nel momento del lavoro sono fortunato che ho i miei
amici i cinesi che mi hanno aiutato sia economicamente che psicologicamente. In famiglia al
ristorante si è svenduto a basso costo, gli altri anni che avevamo un buona clientela avendolo
svenduto è rimasto in condizione diversa. Lo studio di consulenza era all'inizio difficile nessuno
vuole aiutarti. Aiuto da amici abbiamo iniziato a fare i lavoro. Come faccio a resistere? Credo che
abbiamo un futuro da fare, non so quale ma cerco di fare la cosa più giusta da fare, sacrifici senza

\section{Francesco Wu Sheng Wenzhou 08/07/2015}

Ristorante italiano cucina italiana, e consulente per aziende italiane che vanno in Cina, sfrutto le mie esperienze per contatto con campo della ristorazione. Esperienze di lavoro ho fatto l'ingegnere laureato lavorato per due aziende italiane in rapporto con la Cina, prima in cina a lavorare, responsabile produzione e poi crisi 2009 ho deciso di cambiare e darmi all'imprenditoria. Ho dato una mano ai miei nell'azienda di manifattura.

Genitori cinesi io sono seconda generazione arrivarono nell'86. Secondo me il lavoro duro in Cina viene dalla mentalità, della mentalità confuciana contadina dove tutti sanno che per sopravvivere in Cina la popolazione è sempre stata numerosa quindi tutti sanno che per poter sopravvivere devono lavorare, la terra, sodo risparmiare e perché poi questo per mantenere i genitori, le famiglie cinesi tendevano ad essere molto numerose, più figli mantenevano facilmente i genitori. C'è questa mentalità di lavorare sodo e risparmiare per anni di carestia di raccolta magra. S'è forgiata nei secoli anche dovuto a disastri naturali, radicati nei secoli, la mentalità confuciana del fare ordine. Wenzhou è un po' come la brianza tutte le famiglie hanno un imprenditore. Poi ho visto questa cosa che come in Italia il nord è più progredito lontano dalla capitale e impero austriaco sempre periferia del regno quindi questa cosa qua costringe le persone a essere più virtuosi, stessa cosa in Cina dove Pechino è a nord e sud cina è più progredito, chi sta vicino al potere centrale vive del potere semplicemente statali e burocrazia. Wenzhou era sempre a vocazione della Cina, la zona più ricca è lo Zeijan a sotto Shanghai e poi zona del Canton. 


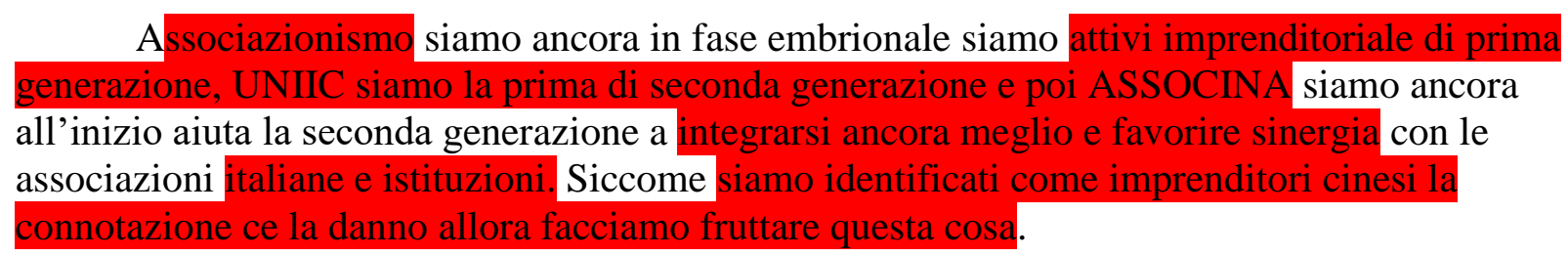

\begin{abstract}
La crisi economica mi ha fatto aprire il ristorante in piena crisi e noi diciamo che abbiamo aperto durante la crisi non la abbiamo sentita, la senti se hai paragone con anni precedenti, per noi era la normalità, a Legnano siamo tra i ristoranti più affermati, le associazioni di categoria c conoscono, all'inizio era diffidenza, non erano abituati a vedere un cinese aprire un locale italiano, se cinese invece dimostrato che non è così bastava provare uno che eravamo anche italiani perché siamo cresciuti qua e l'imprenditore è indipendente dalla etnia e basta essere avvalersi di professionisti adeguati.
\end{abstract}

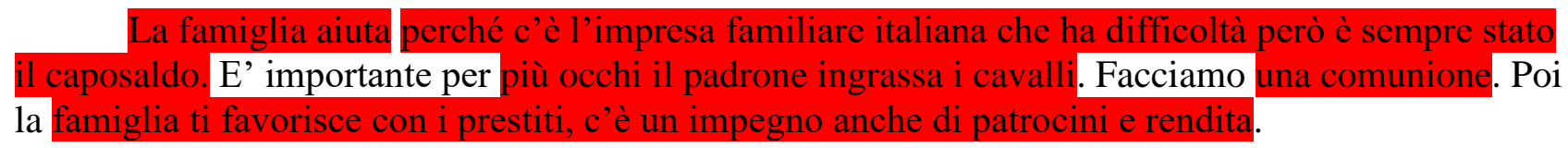

\title{
Intervista 26 M George Zheijian Quan 23/04/2015
}

Collega azienda cinese associazione cinesi dello Zejian. Portale internet, contatti imprenditori sia in Cina che in Italia, soprattutto made in Italy, moda e cibo italiano, anche design. Sono venuto in Italia quattro anni fa, ero studente cinese venuto in Italia, studio qui in Italia. Lavoro nel marketing per questa società, prima lavoravo in agenzia viaggio, agenzia di consulenza, commercio, vari tipi di lavoro. Questa azienda non è molto gerarchica ognuno può sviluppare le sue capacità e il suo futuro se sei bravo sviluppi un certo obbiettivo.

Questa generazione in Cina non so se lavora tanto, soprattutto dopo anni 90 la vita tutto cambiato, anni 30 pensavano di sopravvivere, trovare un lavoro, soddisfare la famiglia, mamma papà curavano, sotto c'era figlio e sopra mamma e papà, quindi c'era una responsabilità. I figli dovevano lavorare forte sia per genitori che figli, chi è nato negli anni 90 non difficoltà la Cina cambiata, la gente non lavora più con difficoltà, ma generazione prima ha passato questa tradizione, generazione nuova cerca libertà, viaggiare, bella vita. E' un processo di socializzazione, anche gli italiani erano emigrati fuori, anche in Cina c'è stata questa fase.

Per i cinesi il punto di vista fuori della Cina guardano in modo simbolico ed ideologico comunista ma interno Cina non si sente così, rispetto prima c'è futuro, prima impero cinese, poi guerra civile finalmente liberati, periodo brutto rivoluzione culturale che ha danneggiato la cultura, ma dopo l'apertura politica abbiamo più vicino occidentali, studiamo il sistema economico di mercato, economia di mercato, economia di progetto, tantissime influenze dall'Unione Sovietica, abbiamo imparato da loro, hanno fallito perché non usato sistema capitalistico Stati Uniti. Trent'anni fa la Cina aveva già abbandonato ideologia del comunismo, oggi il cinese non parla più di comunismo, difendere l'ideologia. Però la Cina ha abbandonato perché confucianismo anche tua cultura e identità diversa dalla mia. Possiamo vivere e collaborare insieme. Adesso la generazione paesi occidentali che lavorano con Cina. Ora competiamo ma interesse comune maggiore del conflitto.

Prima studiavo marketing ho visto annuncio del lavoro poi mi è piaciuto sistema di questa società molto libera e ho deciso di lavorare. Questi ragazzi venuti qua per annuncio. Per me è così i cinesi precedenti, suddiviso due parti, una parte studiano dunque è più facile entrare nella società italiana, l'altra parte è indecisa e fuori della società italiana vivono tra loro. Io sono quello che vivo insieme con italiani, che studiano all'università e per me non è difficile vivere in comunità con italiani. 
Come tutti gente voglio avere successo, i cinesi sono ambiziosi, sempre vuole andare su, ho lavorato qua se non c'è canale per salire forse devo cambiare e lavorare in altro posto, lazienda migliore realizza il mio sogno.

Difficoltà al lavoro si, per me ancora le cose sono molto favorito anche se a volte. Il datore di lavoro molto amichevole molto bravo anche i colleghi mi ha aiutato tutto hanno visto che sono straniero quindi sempre aiutato, anche prima vuole che io rimanga a quella'azienda.

\section{Intervista Gino 32 anni Quianfan 30/03/2015}

Arrivato in Italia da 7 anni, sono buddhista, da solo, prima mia moglie e dopo un anno sono arrivato io.

Quando arrivato a Torino lavorato 3 anni a torino poi 4 anni fa questo bar, prima facevo il cuoco ed il pizzaiolo adesso gestisco un bar. Lavoriamo per la vita, per esempio voi italiani scuola senza pagare, quando malato andare ospedale senza pagare, in Cina scuola e ospedale tutto pagamento, lavorare più duro per il futuro per avere più soldi. Come per noi cinesi quando vecchi non c'è soldi vivere è importante, cinese doppio tempo lavorare noi 16 ore 17 ore per figli per acquisto, tutto pagamento.

Solo per guadagnare un po' e per la vita. Non so il futuro dove andare, io lavorare solo per la vita solo così facile non come pensiamo che il futuro è che cosa, dove fare viaggio a me fino adesso mai pensare così.

Sono venuto in Italia per lavorare, mia moglie è in Cina. Ho trovato lavoro di là il capo è parente di mia moglie poi solo così, questo comprato.

Per cambiare come io ancora piccolino come mio paese, mio padre un po' ricco, voglio di più forza per lavorare per i miei bambini. Anche i miei genitori aiutato a comprare bar.

Mai successo difficoltà, ogni tanto iniziato non parlavo italiano solo questo poi piano piano imparare adesso passato tutto, prima sono cuoco, e dentro cucina tutto ragazzi cinesi non parlano Italiano cosi non imparato bene cominciato questo bar imparare italiano molto difficile e adesso passato. Cominciato tutto soldi prestato da cina e inizio poco lavoro adesso si può passare tempo guadagno per pagare. Già sono grato per tutto. A volte c'erano clienti difficili, ubriachi, che ho dovuto allontanare ma ce l'ho fatta.

Conosco dei cristiani, credono soldi adesso Cina senza soldi e crede nella vita

Come italiani domenica fare chiesa e fare cose ma io mai andato io sentito e visto però non come chiesa così grande come duomo.

\section{Intervista Gu Jin Bjang Zhejian Boqin 45 anni 26/03/2015}

Presidente Associazione Cinesi del Zhejiang a Milano. Sono buddhista, venuto in Italia per parentela, quando è venuto la condizione economica non era come adesso. Per legame di parentela ha lasciato la Cina in situazione di difficoltà economica. Prima lavorava nella fabbrica, faceva le borse, cuciva i vestiti, lavorava nei ristoranti come cameriere, magazziniere, adesso invece faccio parte dell'associazione per aiutare le persone, integrare le risorse e le competenze degli imprenditori cinesi. Abbiamo fondato questa nuova società per aiutare imprenditori italiani e cinesi.

Per noi cinesi e la cultura cinese, c'è un pensiero di previsione del rischio, penso al futuro, se c'è qualche sfortuna devo lavorare in avanti. Siamo lavoro duro perché la vita è difficile siamo in un 
altro paese se non lavoro è difficile, ogni cinese cerca la migliore qualità della vita, realizzare il suo sogno.

L'unico modo per raggiungere l'obbiettivo è il lavoro, se non fai niente non c'è nulla. Modo cinese, anche due pare la ricchezza non passa dopo due generazioni dunque devi lavorare sempre per forza se no da dove vieni? Non cadono le cose dal cielo. Genitore insegna al bambino a lavorare è nella cultura. E' la famiglia, parte anche scuola tantissimo nella nostra scuola cinese promuove questo, c'è una lezione sulla morale dove insegnano il comportamento come essere studente, padre, madre nella società. Rispettare i nonni, gli anziani, chi è in difficoltà aiuta, non rubare, è una cultura morale, come Confucio, morale teoriche derivato da Confucio. Anche se non raggiungi l'obbiettivo non fare male agli altri. La vecchia cultura tutto a cuore avere una linea per la gente. Anche Giappone corea siamo confuciani.

Prima la maggior parte dei cinesi vecchia generazione problema della lingua e anche per la cultura, anche ci sono italiani maggior parte impresa medio piccoli difficile business in Cina perché non hanno questa competenza, imprenditori cinesi vengono Italia per aiutare questa competenza, ancora adesso ci sono difficoltà della comunità cinese per questo abbiamo questa idea di creare questa impresa.

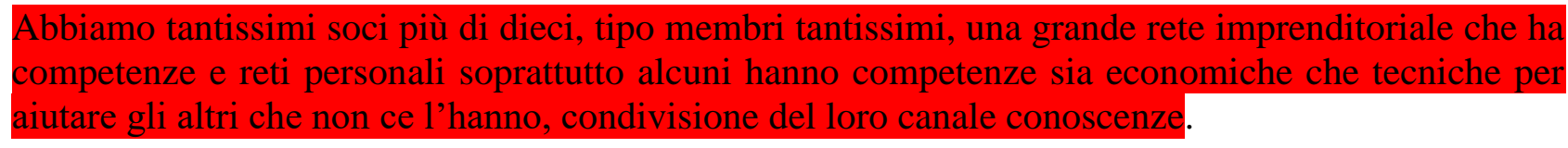

Prima cosa nella loro generazione la condizione della vita in Cina trent'anni fa tutti poveri quindi hanno sofferto, hanno paura della povertà quindi anche pensano la generazione successiva la stessa brutta memoria e brutta vita per la generazione successiva. Adesso tante persone cambiato idea tornare di la perché più lavoro. Adesso quasi non viene più nessuno lavorare, pensione pochi lavoro che frega pensione. Abbiamo fatto un sacco di lavoro poi tornano in Cina a 60 anni perché prima lavorare molto forte per accumulare liquidità. Non possiamo dipendere dal governo ci aiutiamo noi no altri, non crediamo che governo, pensione ci pensa noi stesso questo è diverso non ci abbiamo sistema come italia. Governo intervenire pensione.

Loro sicuramente arrivati in Italia un sacco di difficoltà non sanno lingua, cibo, non abituato però loro continua studia, studia, lavora, attraverso lavoro come fare lavoro, continua a cambiare il lavoro per imparare le cose, la situazione migliora, paga meno provo altro che paga più anche la mia competenza migliora come scala, fidarsi c'è però loro mettere cose in piedi passo dopo passo un giorno puoi arrivare alla destinazione.

Successo come gli italiani è una cosa che dipende non è... puoi arrivare lì per forza cammina come la vita è uguale solo un po' il pensiero più importante è il lavoro. Non tanti soldi non è quello.

\section{Huang Ting Wenzhou 46 anni 13/07/2015}

Italia,

Sono vice-presidente dell'associazione di imprenditori di Wenzhou. Da 22 anni sono in almentare. Ho cambiato moltissimo nel lavoro, anche i Cinesi a livello economico stanno meglio, la Cina è cambiata più opportunità ci sono. Prima il cinese lavorava in fabbrica invece dagli anni 90 nasce l'import-export, il potere d'investimento, la possibilità di investire, ora non si manda più soldi in Cina ora in Cina si sta meglio che qua. La mentalità cinese degli ultimi 30 anni è cambiata ora cosa importante è il denaro. La riforma economica ha cambiato i desideri delle persone. Tutta la mia famiglia vive qui, prima ero venuta da sola poi qui ho costruito la famiglia. Ora non voglio tornare in Cina, il costo della vita si è alzato, c'è inquinamento, non c'è pensione, i figli poi sono italiani. I figli sono scresciuti qua non possono tornare. Poi la seconda generazione è metà italiani metà cinesi 
se tornano in Cina è impossibile. Le associazioni di imprenditori invece ci aiutano poco oggi, l'associazione delle donne cinesi di cui anche faccio parte avevamo un progetto per aiutare
l'ospedale Buzzi (poi questo mi ha aiutato a trovare lavoro), tra cinesi ci aiutiamo per il business, si
prestano soldi, si fanno società, attività molto grandi. La famiglia nel lavoro aiuta moltissimo, la Cina ha più possibilità di investimento. La crescita economica ha portato cambiamenti, comprare una casa in Cina costa di più, quindi le persone vendono e investono in Italia, le famiglie cinesi aiutano i figli, i fratelli o i parenti. Fra i cinesi è più semplice prestare soldi, è un'usanza comune, non come in Italia, i cinesi fanno tutto sulla parola.

Per il cinese uno che guadagna ha successo, il gatto non importa che sia bianco o nero dice il proverbio cinese, importa che sia in grado di catturare il topo. La vita è basata sul denaro, in Cina non è difficile, qui c'è crisi qualcuno spende soldi per anni, l'azienda è in perdita.

guadagna poco? Risparmia, lavora 14 ore, 20 ore. Lavora e piace sempre lavorare al cinese, anche
denaro. I cinesi pensano di essere comunisti ma non lo sono!

\section{Intervista Jhang Chong Ju F 29 anni Wenzhou (Wenzhou)24/08/2015}

Sono la sorella di Jessie e fondatrice della nostra azienda di famiglia. Non sono credente allo stesso modo di Jessie, che invece è, ora sono graphic designer, ebbi una compagnia, non riuscii a trovare una compagnia così ne creai una da sola, me da sola con le mie forze. Quella attuale è piccola rispetto a prima che eravamo più grandi. Ora cerchiamo di fare un business particolare. Lo feci insieme a mio marito che è addetto ai sales e marketing. Molte fabbriche fanno cose ordinarie e di massa, noi vogliamo fare qualcosa di diverso. Wenzhou non ha materie prime, dunque facciamo business. E' una tradizione a Wenzhou, facciamo attenzione al business finanziario, dai parenti, comparati ad altre città abbiamo un'educazione finanziaria sin da piccoli.

Questo momento per me è il più difficile perché c'è una trasformazione dello stile e dell'economia dell'intera Cina, la qualità dei clienti non è buona. La speranza è importante, sento la qualità di questo business, che andrà meglio di prima. Non ho mai pensato allo scopo del lavoro (diversamente da Jessie) per me è parte della vita, connesso fortemente alla vita. La mia famiglia è cristiana, io sono in conflitto rispetto a ciò.

L'economia di Wenzhou diventerà razionale, la ricchezza andrà a persone con educazione tecnica, lentamente, prima invece si diventava ricchi facilmente.

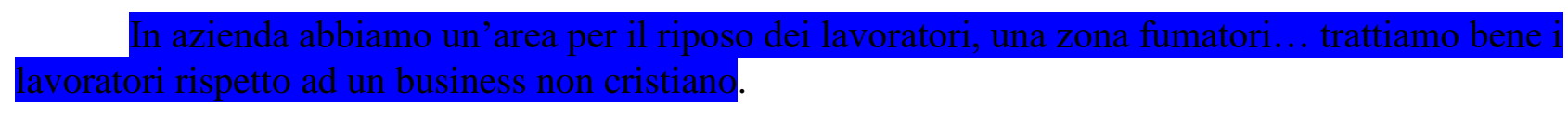

\section{Intervista Jin Ma Naijin $\quad$ Ho $\quad 30 / 03 / 2015$}

Sono figlio di un imprenditore di successo in Cina, non credo in Dio, nemmeno mio padre, mia madre è buddhista, ho un fratello ingegnere. Io credo che il lavoro per ogni cinese lo si faccia per i figli, è come un cerchio tra genitori e figli, ci si attende un ritorno economico dai propri figli sui quali si ha investito, la prima generazione non aveva alcun piano, nessun lavorare per guardare in avanti, volevano fare più soldi dunque sono venuti in Italia, e hanno esportato in Cina, l'obbiettivo è sempre quello di avere una buona vita, la nostra cultura è diversa vedi. Noi non abbiamo vacanze, vogliamo che i figli vivano in una buona situazione, vogliamo avere una bella vita e più soldi ti daranno una vita migliore, lavorando duro, più cose da fare ma poi guadagni molto, le persone che vengono qui vogliono fare soldi. 
Mio padre lavora duro ha due figli per i bambini lavorava, un'alta qualità di lavoro, contribuiva alla società, avere una sua compagnia personale, se lo fa si sente onorato, è riuscito a lavorare duro, aiuta la famiglia, aiuta la società, le persone ti stimano, ti rispettano e ti applaudono perché sei ambizioso, io sono orgoglioso di lui, ci ha dato una figura molto buona.

\section{Kaijun Jiang da Heilongjiang Chu Hua 19 anni 28/03/2015}

Arrivata in Italia per lo studio, psicologia. Figlia unica.

Wenzhou le persone sono diverse, loro non è importante come studiare, più importante soldi e lavoro, loro nonni e famiglia mai studiare sempre lavoro, non sanno neanche scrivere. Capisco ma non è giusto. Poi dipende c'ho molti amici qui Wenzhou italo-cinesi, loro diverso non come genitori, nati qui, cultura metà cinese metà italiani, piace più fare amicizia con noi perché pensano italiani ancora straniero, ma cinese faccia uguale diverso. La cultura di Wenzhou diversa da nord cina anche come cibo, mai mangiato spaghetti tipici di wenzhou, mai mangiato come loro.

A livello di religione secondo me sono diversi, conosco Wenzhou come persone come qui, hanno loro come italiani o come buddha. Dopo Mao tutti non hanno una religione, inizia anche un'altra pagina del nostro pensiero, non bella che tutti hanno altra religione, città non tanta religione, nei villaggi diverse religioni io non so. Qualcosa religione non è molto giusto, per esempio come un foglio giallo poi metti acqua poi bere significa lasciare qualcosa brutto, più a Wenzhou, prima non città famoso solo che da quella parte persone piace più uscire, c'è qualcosa della geografia. Anche in cina c'è problema persone escono per cercare lavoro, wenzhou più come francia, Italia a francia.

Cristiani in Cina diversi, pensiero come vedere il mondo è diverso ma non è strano anche per cattolico cristiano non è uguale. Ma in Cina è meglio se non hai una religione speciale perché in cina la cultura è atea perché più di buddha, anche cattolico è da fuori, taoismo nato qui quindi dentro la cultura più tradizionale. E' qualcosa che a qualcuno piace ma più persone più cattoliche. Noi religione non parliamo mai è personale, non come quanti anni hai.

Un po' diverso per lavoro meglio se una persona non ha molta convinzione per una religione, anche come lo so anche in Italia normale cantare. Non c'è così, non è come per noi è simile italia mezzanotte cantare non è normale.

Cristiani non hanno molto soldi sono molti simpatici, ma non hanno molti soldi anche solo per la religione, lavorano per questa cosa, ma non lo so perché in Cina non hanno religione cristiani, molte buddha, nel nord parte pechino anche per Pechino sempre non hanno religione. Non dipende da governo prima non è qualcosa comune, negozi dobbiamo pagare i soldi, non più comunismo. Adesso cina problema non capitalistico ma non possiamo dire di non esserlo, non parliamo, solo in nome ma dentro no.

Marx si ho sentito, anche come avete classe ma per noi solo per esami. Trent'anni fa si credeva al comunismo ma da piccola non ho sentito niente, i miei genitori lavorano per governo ma non c'entra niente, come governo italia, non è comunismo, nessuna persona pensa questa cosa. 


\section{Intervista Ken M Chun 25 anni Wenzhou 06/10/2015}

Sono arrivato in Italia nel 1998 prima lavavo i piatti in Cina poi arrivato in Italia ero cuoco in una pasticceria e aiuto-cuoco. Trovai il mio lavoro tramite un'agenzia. Non parlavo Italiano all'epoca. Poi con un socio italiano abbiamo deciso di iniziare, un anno e mezzo, due anni, lui è mio amico. Lavoravamo insieme e c'era un buon rapporto tra noi.

Penso che la nostra mentalità di Wenzhou alla gente piace fare una cosa da sé, prima con altri poi trovare una propria, è il nostro sangue, diverso dal nord della Cina, senza alcun aiuto dal governo abbiamo costruito una nostra imprenditoria in libero mercato.

Quando ho difficoltà al lavoro mi piace leggere il libro Yi Jing. Tutta la nostra cultura si basa su questo libro che il primo imperatore ha scritto. Lui ha trovato una tartaruga dice la storia, da lì vengono i principi per vivere. Questo mi aiuta perché tutti i progetti quando si sviluppano c'è sempre un momento di crescita ma anche di discesa, e quando c'è il momento di crisi non è per sempre, devi dunque essere preparato per tutte le cose (è una filosofia su cui la nostra cultura è costruita). Quando c'è qualche problema altri imprenditori (tra cui Delun) mi aiutano,

Questo bar è al civico 14, e sento che sia destino che ho preso questo bar, perché sono nato il 14 (superstizione).

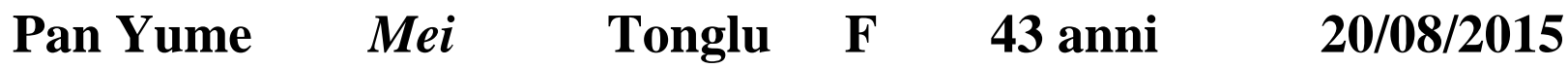

Iniziai a fare business per vestiti per bambini perché vidi che le persone sono focalizzate più sui figli e c'è mercato dunque iniziai questo business. Prima lavoravo per sopravvivere poi per $\mathrm{i}$ bambini della seconda generazione. Per via del pensiero cinese dobbiamo guadagnare qualcosa per passarlo alla prossima generazione. Noi Cinesi se guadagni 1.000 poi spendi 200 mentre voi italiani se guadagni 1.000 spendi 1.000 .

Un'altra ragione è che le persone sono competitive e gelose, se il vicino ha più vuoi di più, se sei povero non ti rispettano, se ricco ti rispettano. Non riguarda cose ma la cultura viene dalla cultura, il rispetto si cerca e allora vuole uscire dalla povertà. Lavoro soprattutto per avere dignità e vivere bene, avere benessere. La perseveranza se qualcuno ti frega è importante, allora li tratti bene, e dunque gli altri crederanno in te, l'attitudine è molto importante. L'onestà è importante.

\section{Panu Haoaian $Q i \quad F \quad$ Tonglu 44 anni $\quad 20 / 08 / 2015$}

Da tanto tempo lavoro per la fabbrica di sciarpe poi iniziai il business da me stessa.

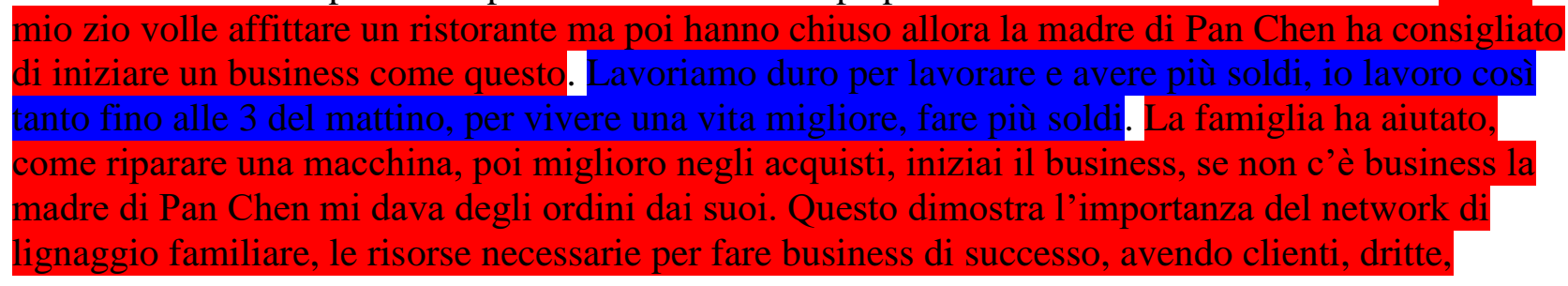


competenze che altrimenti sarebbe impossibile avere. Si lavora per avere una vita migliore (rispetto agli altri) poi la famiglia e la prossima generazione. Terzo devo avere

Pazienza e perseveranza mi hanno aiutato a passare i tempi difficili. Yiwu trading center per il business dove il $90 \%$ di ciò che viene in Italia per il business, dentro quel centro c'è tanta gente da Wenzhou. La gente di Wenzhou è vista da noi come duro lavoro e un cuore per il business.

Si lavora qui 24 ore su 24 con le macchine accese, su due turni notturno e di
andare le macchine per 24 ore. Le donne che lavorano qui hanno 50-60 anni.

\section{Intervista}

Sara

Fuhua

28 anni

Laoning

Vengo da Laoning da 5 anni in Italia, prima vivevo a Genova, venuta per studio, assistente alla clientela per Armani. Prima lavoravo come store manager per un'agenzia in Cina, per eventi e cerimonia e festival del film, facevo eventi, stage manager.

Noi lavoriamo molto perché abbiamo bar, ristoranti nostri, se vuoi risparmiare o guadagnare di più devi lavorare molto, non si scappa, dipende dalla zona, Zeijan lavorano molto, noi di Pechino vogliamo lavorare ma anche godere la vita, quindi capiamo bene quanto lavorare, se c'è tempo libero voglio fare quello che mi piace, come conoscere la cultura, musica, passare il tempo con gli amici. Zeijan lavorano più perché molto poveri, vengono dalla campagna, come noi vogliamo diventare importanti, però loro vogliono avere un bar ristorante una cosa che decidono loro anche se non hanno tanta conoscenza, però loro guadagnano tanto, però quella vita non è quella che voglio io. Come le persone italiane vengono da sud a nord è diverso dipende cultura, ambiente sociale. Come Genova sono più tirchi anche provincia Wenzhou tanti tanti anni fa loro visto che capo di ristorante ci ha tren'tanni o 40 prima generazione che venuta in Italia, loro non venuti regolari, come fare un anno per arrivare in Italia, tante persone morte. Quindi sicuramente quando arrivati cercare di lavorare e guadagnare, ho visto tante persone diventati molto ricchi però secondo me non è felice.

Non è tutti colleghi italiani uguali, dipende da persone, quelle simili diventano amici ma ci sono qualche colleghi italiani manca rispetto, e non so se questo ambiente come assistente a clientela è tutto uguale, quindi pensavo se riesco a trovare un lavoro per vivere meglio però qualunque posto sicuramente ci sono persone diverse. Poi i miei colleghi se c'è tanti clienti cinesi, loro non sono molto gentili, soprattutto cinesi, se non c'è cliente cinese non guadagnano soldi. Alcuni fanno finta gentile ma non è vero.

Sono venuta in Italia per studio, ho trovato il lavoro tramite curriculum, poi l'agenzia mi ha chiamato, anche qualche amici mi hanno consigliato lavori. Come il lavoro che sto facendo qualcuno mi tratta male qualche colleghi devo essere più forte, io non volevo spiegare anche se qualcuno ha detto cosa non vera. Ho studiato ed avuto educazione rispetto ad altri, loro non hanno molta conoscenza, molto maleducazione. Italiani proteggono se stessi molto forti. In Cina colleghi se qualcuno ti parla male puoi parlare direttamente. Ho avuto amici buoni che mi hanno aiutato, quando loro serve aiuto vado a aiutarli ma passato quello che gli serve fanno finta di non conoscermi.

Scopo del lavoro sono tanti, prima voglio guadagnare soldi, voglio trovare significato nella vita, che io sono importante, volevo essere importante che serve agli altri, voglio imparare nel lavoro a conoscere altre persone, cerco di migliorare me stessa. Quando studiavo all'Università non uscivo, volevo studiare, adesso voglio uscire, avere tanti amici italiani.

Difficoltà al lavoro, io sono debole, non voglio parlare subito col responsabile quando successo cosa brutta ma loro si, e loro inventato altra storia, sono triste, ma sono fortunata di aver cambiato reparto a armani jeans, mi trovo meglio, ci sono tanti ex colleghi chiedono colleghi nuovi 
come va Sara, loro detto è molto brava e loro sono molto cattivi, lei tranquilla non importa la vendita e divertenti, per quello ci incontriamo come persone simili. Se una persona vuole fare competizione gli altri sono così, se azienda è difficile io sopporto persone cattive vicino a persone che pensi più buone, imparare per diventare persone più forti.

\section{Intervista Shu Jiang Biming 26 F Taizhou (Zhejiang) 22/09/2015}

Lavoravo prima a Ferraganno, in alta moda come sales woman part time, mi sono laureata in economia bancaria ed ho trovato subito lavoro nella banca extra-banca. Sono immigrata di seconda generazione, i miei genitori lavorano nel commercio. Wenzhou non so perché sono così, hanno voglia di fare da sé, di fare i soldi, secondo me è una cosa culturale, è come gli Ebrei, hanno voglia di fare le cose per sé. Un mio amico lavorava là come stagista, e mi ha presentato questo lavoro, e sono entrata. Io sono molto indipendente, i miei erano contenti che lavoravo in banca, idea era mia. Non mi piace continuare nel commercio, sono una ragazza, tanti ragazzi di seconda generazione intraprendono la strada d'imprenditore, le ragazze no. Non mi rendo conto, nelle situazioni di difficoltà se gli altri ce la fanno, perché io no? Poi magari ho sbagliato lo ammetto.

Il mio obbiettivo è lavorare in banca. Adesso vorrei iniziare la laurea magistrale. Nella mia banca la maggior parte sono italiani i colleghi. La Cina economicamente va bene, spero sia solida.

\section{Sofia Wenzhou Bao 24 anni}

In Italia da 5 anni. Sempre lavorato al ristorante qui. Venuta in Italia mentre i genitori sono rimasti in Cina. Lavoro duro, Il motivo è aiutare la famiglia. I parenti hanno aiutato a lavorare e a investire per fare questo ristorante, investendo.

Prima avevo uno scopo adesso un po' meno, prima ero insegnante di letteratura in Cina. Venendo qui non sono riuscita a trovare, la famiglia voleva che venissi qui, i parenti vogliono che venga qui.

Non posso immaginare il futuro. Ancora è troppo lontana. Sono i parenti che hanno costruito questo business. Ho avuto difficoltà con la lingua ma adesso ho risolto questo problema. Sono rimasta qua da quando sono tornata in Cina.

Budduista.

\section{Wuzhao Qing Ping M Tonglu 47 anni 20/08/2015}

Sono boss del business delle sciarpe, quattro piani d'impresa. Prima lavoravo come sales person, dagli anni 90 dovevo andare in altre città e vendevo vestiti, a quel tempo era solo per vendere sul posto, adesso invece faccio export, c'è una compagnia di trading che mi contatta per la vendita e noi invece ci occupiamo di produrre i materiali richiesti.

Lo stile di vita è diverso, ci interessa della generazione futura. La produzione all'inizio era solo per la Cina, quando il mercato si aprì allora più clienti e connessioni si sono aperte. Prima tre anni fa non c'erano difficoltà ora gli ultimi due anni i costi per la manodopera si sono alzati, i clienti conoscono come si lavora qui e i profitti sono bassi. Questo tipo di produzioni sono stati mossi nel sud-Est asiatico. Il mainstram sarà continuiamo così oppure cadiamo ma posso usare la manodopera per prodotti di alta qualità, perché 
il mercato non è più lo stesso. Per me il lavoro è per avere soldi, buona vita e bella vita per i figli. Il proprietario dell'industria ha meno diritti, se ci sono problemi si prende la colpa ( + responsabilità ma - profitto) ma la trading company si prende i profitti. Alibaba vende online, forse vuole usarlo per prendere più profitto (la trading company può comunicare col cliente, il linguaggio, le regole $\mathrm{e}$ le leggi sulle tasse e trasporti le conoscono loro).

\section{Xu Jianping Zan 47 anni Wenzhou 06/07/2015}

Sono presidente associazione Imprese Cinesi in Italia, Imprese Cinesi d'Oltremare. Ho sempre lavorato in questo mestiere, vendita di vestiti, all'inizio era sinceramente piano, poi sempre si è ingrandito.

Questo è un carattere cinese che più lavori più ricompensi poi la maggior parte dalla Cina sono tutti quelli che hanno voglia di lavorare hanno bisogno di avere un'attività poi nei tempi l'attività è andata buona e c'è un incremento. C'è un po' di differenza, la zona Wenzhou la maggior parte ha interesse sul lavoro. Come dice il presidente della Cina che noi della Wenzhou ci sono riescono a essere il capo ma anche a essere dipendenti e dormono sul pavimento hanno un cuore diverso riescono a sopportare diverse situazioni. E' una provenienza dagli antenati, padri, nonno allora così questa cultura è ereditata.

Sono uscito prima io poi i miei familiari, nell'attività all'inizio ho avuto aiuto da amici sia amici che parenti. Adesso col calo del cambio dell'euro il lavoro è molto calato. Almeno sulla nostra attività esportazione e importazione molti imprenditori sono andati in Cina siccome l'economia cade.

Questo lavoro è già da dieci anni che lo faccio, si che adesso c'è l'economia bassa ma non c'è un'altra via d'uscita, no altro lavoro che può uscire dalla crisi, poi i figli studiano qui in Italia sono abituati sull'ambiente italiano.

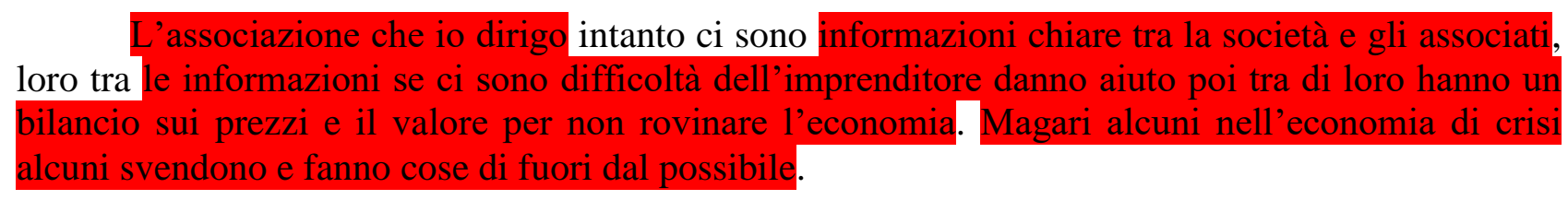

C'è un po' di tutto che aiuta nel lavoro.

\section{Zhou Jien Huan Jiao-long Wenzhou 51 anni 17/07/2015}

Da 25 anni sono in Italia, sono venuto in Italia insieme alla mia famiglia. Sono proprietario di Jubin il ristorante qui a Viale Sarpi. Con lui in comune siamo con l'associazione
cinese in Milano, di cui sono il presidente. Quando siamo venuti qui volevamo un futuro migliore, . Io ho lavorato

tradizione nostra cinese ci spinge a lavorare così, noi cinesi, abbiamo pensiero per i soldi: chi ha più soldi è rispettato, cerchiamo di essere migliori. Aprendo il ristorante ho fatto debito in 4 paesi dalla Spagna, dalla Cina dall'Olanda... e mi hanno aiutato, ci aiutiamo insieme, se un mio amico è in difficoltà io lo aiuto, dunque è reciproco. Eravamo già amici prima, facevamo parte della stessa associazione, ci aiutavamo tra di noi (è un network). Avevo un parente qui poi negli anni 90 sono
venuto, poi i figli e piano piano tutti i cinesi sono così iniziamo venendo qualcuno poi seguito dalla famiglia. Nella crisi economica io sono stato influenzato molto, il ristorante è diminuito soprattutto quest'anno. Diminuiscono le spese ma vediamo come fare. La maggior parte mi fido dei miei amici se ho problemi, è diminuito il lavoro ma c'è sempre qualcuno che non è toccato, continuiamo a esistere, se abbiamo problemi gli amici aiutano. 


\section{Intervista Lu Feng Chong Ching 34 anni M Jing 22/01/2016}

Prima ero studente dell'Accademia di Brera, vengo da Chong Ching. I wenzhounesi sono ricchi, commerciali, più avanti di noi, hanno base per fare business. Tanti nella quantità. Prima facevano export-import ora fanno cibo, la famiglia è importante. 5 anni nello Zejian studiavo all'accademia di Cina, poi 5 anni alla pinacoteca di Brera. In Cina c'era un esame di pittura e scultura che mi piace, è tecnico, si può fare ogni cosa possibile. Secondo me

più chiusi, è più facile entrare nel loro gruppo, pensavo che veniamo da un altro mondo, il dialetto,

Dal 2007 era facile ora è più difficile, gli esami, la lingua, ho amici italiani che mi aiutano, devi capire i nomi del prodotto per segnare tutti, non è facile. Ho 3-4 clienti in Italia, ma è già pieno qui, è difficile entrare. Più facile in Cina fare opere, per esempio fanno in Cina qualche ristorante (Milano, via Padova, Porta Venezia, Porta Romana). Sono amici, posti dove mangio, più giovani, Wenzhounesi. Lavoro duro dalla cultura, da piccolo, dietro noi genitori con la pistola dietro. I miei genitori hanno una casa editrice. La famiglia spinge molto a lavorare, ci sono tante persone, per trovare lavoro ci vuole qualcosa di speciale. La Cina cresce nell'economia ma non nella cultura. Lavoro per tutti non solo pensando qualche materie, devi trovare la strada per me.

\section{Intervista Lu Wei (Wenzhou) 25 anni M Lei 21/01/2016}

Il lavoro è un elemento fondamentale per i Cinesi. Mi piace fare siti web dalle scuole medie, piccoli siti per divertirsi, studiai a Torino, ma la compagnia era cinese lì lavoravo per creare e mantenere siti, arrivai a Milano per espandere il business e creai GROUPON versione cinese (GUUA). Sono nello staff, ciò che vorrei fare è connettere i negozi e ristoranti e metterli online. Ho sete d'imparare. O20 (online 2 online) in Cina è già sviluppato, per trovare un taxi prendi la app al guidatore, il cucinare assumi uno chef online, dove, come. Questo in Italia non è normale, O20. Cambia il business, e-commerce in Cina è positivo e continua a crescere ed anche di più. Ho creato il sito, porto i contatti insieme e prendo una percentuale. Perché cresce?

Come 'vendere ai cinesi' apro il mercato, commettono liberamente al business senza commission, vogliamo gli user che usino il sito, è un punto di partenza. Ora non c'è profitto. Per me il motivo per cui lavoro, come Leo, trovo interesse nel lavoro, cerco di trovare senso in esso. Mi piace e voglio spendere tempo e energie perché mi piace, non è facile farlo devi avere tempo e lavorare duro (facebook). Iniziarono molto presto, questo è ciò che mi piace. Lo scopo è la passione, sono capo con tre persone come fondatori, più i tecnici in Cina, abbiamo molte visioni. Difficoltà è lo stress, molte ore ed energie, dalle 10 del mattino alle 4 del mattino, per poter comunicare con le persone in Cina, creare le app, una settimana per finirla 20 ore di lavoro ed è doloroso. Il motivo è la passione che ho, la cosa importante il fondatore mi aiuta, con soldi per risolvere il problema, mi piace vedere notizie di persone famose (specie per fondatore del enwasmask). Mi motivano queste persone nel carattere e le storie, sono positivi.

\section{Intervista Mario Jie $28 \mathrm{M}$ da Hebei 28/01/2016}

Sono in Italia da sei anni, studiato architettura al Politecnico. Ho fatto la specialistica alla Pinacoteca di Brera. L'anno scorso con un amico ho aperto il bed and breakfast. I soldi li ho ricevuti dai genitori mio padre è direttore di una farmacia. Il ristorante che ho qui è stato aperto da un mese, l'idea mi è venuta. I ristoranti cinesi non cucinano piatti veramente cinesi, anche in Europa invece tipici quindi ho introdotto il cibo tipico rischiando per il gusto. La difficoltà è trovare i piatti tipici, mancano i fornitori, cerchiamo qual è il problema, il cuoco, i materiali. Vengono 
studenti cinesi, testiamo i piatti e parliamo col cuoco. Lavoro duro è importante, gli studenti è già duro studiare, sono stimolati, sennò cosa fai? Non puoi diverti, cambia la mentalità

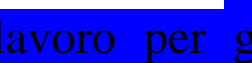

Ho studiato e ho pensato non divento come Renzo Piano, ho visto questa opportunità, ciò che mangia è il cibo tipico. Crisi, l'attività è in competizione con altri, fai anche piccole cose ma meglio dagli altri, devi far bene, c'è crisi ma gli alloggi e piatti servono sempre! Non abbiamo un network noi siamo studenti veniamo dopo i Wenzhounesi hanno il dialetto la mentalità loro è diversa, come funzionano le cose la cultura sono particolari. Un operaio per dipingere Wenzhounese, fraintendimenti, non risponde, non capisce la domanda. Con le altre persone è più facile.

\section{Intervista Nino Beijing 27 anni M Guiying 21/01/2016}

Da Pechino vengo, ho 27 anni e sono venuto in Italia come studente di architettura, al Politecnico, il mio hobby comunque è fare il fotografo, faccio sempre foto. Qualcuno aveva bisogno, poi per qualche brand, ho sentito un'agenzia di e-commerce (casa day, geox..) facevamo foto per modelli di prodotti per 50 capi in un giorno con fotoritocco. Io e il mio amico, noi sette persone cinesi. Ragazzi cinesi lavorano più veloci, il lavoro è il lavoro, dobbiamo farlo. Anche con stranieri ma è più lento, arrivano in ritardo. C'è il fashion week, la settimana di moda per i media cinesi o italiani, brand, dobbiamo fare foto per superstar, pubblicità per il brand, fare la newsletter. Il prossimo mese per Lenovo poster abbiamo una collezione per scarpe. Io e il mio amico facciamo sempre foto di maglioni, conoscendo qualcuno, abbiamo un'amica cinese nell'azienda di ecommerce, trovano una ricerca del gruppo fotografico e allora chiamano noi. Non è facile come cinese trovare lavoro, il livello del fashion in Italia è alto, basso ancora in Cina, dobbiamo crescere. $\mathrm{Al}$ ristorante sono proprietario del ristorante, io ed il mio amico. Forse il prossimo anno farò altre cose, sogno di girare un film. Il cibo cinese che cuciniamo nel nostro ristorante è cinese, la fonduta, abbiamo 5 tavoli, 4 camerieri. Io gestisco sulla cucina, il cliente, come pensare, ma ora sono più al centro fotografico. Il ristorante è sempre pieno di cinesi. Per i soldi è importante andare avanti, ho 27 anni non voglio usare i soldi dei genitori. Io ho tanti interessi, per questo provo, faccio un sito per amici artisti, per fare una piattaforma online, vendono i prodotti.

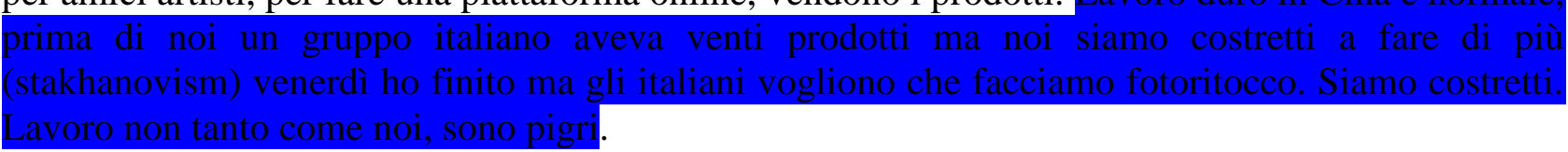

\section{Intervista Shaoyan Jian 28 M Henan 15/02/2016}

Faccio parte di Regard, un'azienda di consulenza e anche gestisco Milan Business Travel. Dopo il liceo ho trovato un'opportunità universitaria, non mi è piaciuto, sono andato all'estero. Avevo una zia in Italia, mi interessava una gioielleria, il primo anno ho studiato come orafo, nella gemmologia. Poi ho fatto lo IED per il design dei gioielli, ho lavorato in una gioielleria italiana, come assistente disegnatore poi venditore. Poi finito lì ho lavorato come giornalista per due case editrici a Pechino (China fashion weekly).

ha messo come project manager. A scuola facevo il traduttore, avevo qualche esperienza di gruppo (SETTWAVS) facevo guida e traduzione, come coordinatore. L'anno scorso ho partecipato alla sfilata per il Fashion week, per l'anniversario all'EXPO. Fabio mi considera bravo, come project manager, ora calcolo i prezzi, cerco dei collaboratori tra le aziende (ISISTAR), abbiamo collaborato. Fabio ha iniziato a lavorare da giovane, tanto lavoro e piano piano ha trovato il modo. 
vivere, abbiamo di meno questa abitudine. I Wenzhounesi all'inizio debole nell'economia, dovevano andare all'estero, difficoltà in Italia. Nuove generazioni universitarie sono famiglie ricche, ci vuole potenzialità e costi (famiglie normali non pagano), a noi non mancano i soldi, abbiamo tempo libero loro invece lavorano $100 \%$, loro cercano una vita. Il problema primario che ho attraversato è la lingua, no come inglese, la nostra lingua (80\%-90\%). Coi Wenzhounesi parlano dialetto, logico diverso. Nel futuro ora faccio esperienze ma alla fine tornerò in Cina (dai genitori), la famiglia anche dopo morto devono tornare a casa, le foglie devono morire sotto l'albero. In Cina l'economia inizia a declinare (palazzi immobiliari troppo). I comunisti hanno stretto questo mercato, l'economia continua a declinare. I soldi vanno all'estero per fare gioielli. Le aziende e le agenzie in Cina contattano noi per viaggi ed eventi in Italia. Nel mio lavoro parlo con diverse persone, ho opportunità di conoscere persone importanti, vale tanto, si può studiare (presidente di un gruppo). Anche aziende di consulenza. Qui sono due uffici gestiti da Fabio, Fabio è il direttore di entrambe le aziende cinesi. Fabio è tanti imprenditori sono quelli che iniziano un'impresa poi la concludono e ne creano un'altra di nuovo.

\section{Intervista Shie (da Jilin) M 20 anni Ning 20/01/2016}

\section{CAMERIERA: Xie Wen Hao}

\section{BOSS: Zhang Yun Yun}

Lavoro a Yun, il mio boss è proprietario di 11 altri ristoranti, il personale è tutto cinese, la cameriera, il cuoco e io. Siamo tutto un network di imprenditori, la maggior parte di Wenzhou.

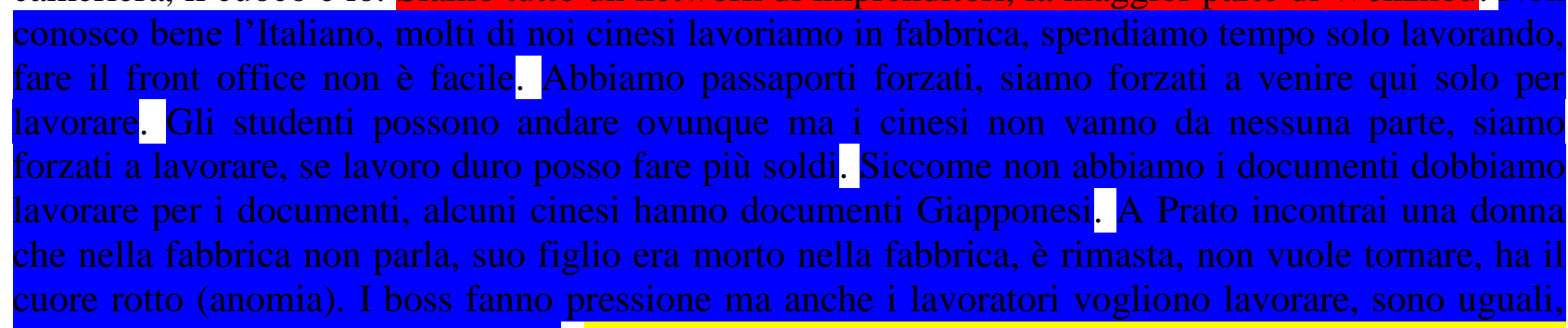

Ho lavorato facendo soldi, lavorare duro, per non chiedere ai parenti, per vivere per sé, per crescere è importante. A 18 anni lavoravo a Pechino al bar, caffè, ricevevo ordini, questo per sei mesi poi in Italia ho lavorato in un'agenzia per aiutare gli studenti cinesi che vogliono venire a studiare, poi io ed un mio amico abbiamo lavorato per GROUPON versione cinese GUUA, per dare sconti ad ogni posto, lavorando molto duro per farlo molto bene, con i nostri amici lavorano lì, risolvono problemi tecnici, creano delle APP. Poi lavoro qui al ristorante. Chen conosce un amico a Torino del team. Io voglio fare soldi da me, essere indipendente. Io sono una persona positiva, voglio essere uomo migliore, anche se non riesco provo duro. Primo a parte la famiglia, che dice di studiare duro, ma penso a quello che voglio fare avere forza e realizzare i suoi sogni. Ho trovato qui lavoro tramite Bicocca wechat group.

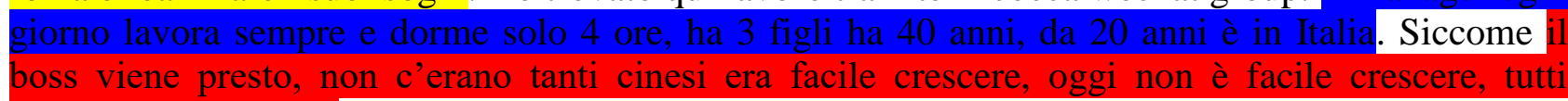

vendono e replicano. Io faccio il cameriere qui, venni per lavorare. Nel gruppo wechat non si conoscono, lavoravo nel ristorante, ordinare un altro piatto non è facile, rabbia, problemi di relazione, ci sono troppi ordini, io chiedo scusa e cerco di andare avanti. Altra cosa è culturalmente accettabile lavorare giovani, qui in Italia no. Come lavorare deve scrivere cose per introdurre nuove vendite, scrive e sa che non è buono scrivere così, non è perfetto, scrive e cancella, perde forza e confidenza ma ci prova. 


\section{Intervista Tommy Guozhi 34 M Zheijang 31/05/2016}

Vengo dallo Zhejian non Wenzhou, un po' distanti, mio padre mezzo wenzhounese. Mio padre dipendente di un bar. Poi abbiamo creato questo bar. Mio padre da 25 anni, abbiamo avuto negozio abbigliamento quasi 20 anni. Dipendenti italiani, secondo me per lavorare bene ci vuole persone giuste, non solo risparmiare, lavorare bene devi investire, stranieri o no per fare qualità serve personale di qualità. Ex proprietario ha selezionato, li abbiamo tenuti, abbiamo aggiunto poi. Prima lavoravo in una tabaccheria della ex fidanzata, per miei genitori, interprete alle fiere, aperto ristorante a shanghai ristorante italiano ma poi ho rinunciato e son tornato qua, ho venduto. Anche abbigliamento genitori a Viale sarpi, lavoro diverso, orari più liberi, più tranquillo però altri tempi, con la crisi adesso tutto cambiato. Wenzhounesi i primi imprenditori, già negli anni della liberalizzazione 1979 chaoping, i commercianti primi erano di Wenzhou, tra città e paesini, tutti amici e parenti, uno lavora bene porta dentro i parenti e parenti portano amici, e tutta la città è portata nel giro, grazie a questo sistema crea città di commercianti. Per commercializzare devi uscire dal paese, prima altre città poi altri paesi, ttutto il mondo. Lavoro inizio la giornata alle 66.30 mezzogiorno dormo, riposo quattro ore, ritorno e faccio chiusura 8.30, domenica mezza giornata.

Famiglia 4 zii, 2 zie, un po' Milano, roma bologna... abbigliamento, bar, tabaccheria, contatto solo online, vedersi spesso difficile. Famiglia ci diamo una mano a vicenda, prestito difficoltà sposa, parenti danno gruzzolo. Sposi è finanziamento.

3 mesi, prestito banca, ora solo pagare, è duro, sfida, è un locale grande e impegnativo, conosci personale, come collaborare, clienti in zona, proporre servizi giusti, migliorare le cose, se clienti vedono cambiamento allora vogliono qualcosa di meglio, sennò sei peggiorato. Quando fanno la metropolitana non c'è più parcheggio e scavi mancano clienti. Stasera riunione zona assessore riunione dei commercianti della zona, risarcimento del comune per danno, a noi non danno perché siete nuovi, abbiamo contratto compravendita abbiamo speso macchine e attrezzi, se hai investito più di 10.000 ti ridanno.

Poche associazione, per tre anni ero a shanghai, qua più tranquillo, shanghai devi lottare dentro vasca di squali. Ci sono tanti truffatori. Commercio più spietato. Devi conoscere il giro. Nella tabaccheria di como della mia ex era noioso, solo gente del paese, poche persone, quasi tutti anziani.

Futuro, cerchiamo di fare andare bene locale. Locale questo lavorava già così, i dipendenti li mantengo tutti, spero con sforzi lavoriamo meglio di prima, spero nel comune di darmi una mano. Almeno risarcimento, ma a me no, io mantengo tante famiglie, se costretto a mandare a casa colpa loro.

Proprietario di prima italiano. Il passaggio non è facile, è impegnativo, da 25 anni in Italia arrivato qui a 10-11 anni.

Momenti critici, aiuto dai ragazzi del locale, un po' di tutto.

SPA puoi riuscire nel business a Shanghai, se privato i soldi non bastano, in Cina per investire servono molti soldi, c'è un mercato diverso, non c'è via di mezzo o prendi tutto il mercato moltiplicando bene o sennò non sopravvivi. Tra successo e non successo servono anni risorse, tempo per crearlo. Anche ristorante crei brand, puoi non guadagnare o perdere però devi resistere, poi dopo 5 anni da lì svolgi e ti evolvi, dalla prima alla $5^{\circ}$.

Guazhi spera di riuscire a aiutare la società italiana, dando una mano alla società, non penso di essere il migliore ne il peggiore che non da proprio niente. Lavoro da mattina a sera senza 
riposare anche domenica, non godo vita ma con nostro sforzo tutti i ragazzi del bar hanno posto fisso, è una soddisfazione. Prima vendevamo all'ingrosso.

\section{Intervista Yaoaoay Chang Beijing 29 M 02/02/2016}

Lavori in corso, appena aperto, montatura cucina ancora in corso, c'è un piccolo bagno, Yao è molto indaffarato. Il locale è pieno delle magliette del suo logo che ha distribuito ovunque, stanno trapanando tutto, c'è anche un mini-bar. Era una festa tra due ristoranti, che Fabio ha voluto proseguire, ci siamo conosciuti quando è venuto qui come cliente, questo ristorante è un po' famoso perché facciamo la fonduta cinese originale, la loro non è buona. Sono laureato in ottica, era solo un'idea, non era possibile trovare lavoro, quindi con amici abbiamo fatto il ristorante, è un po' famoso. Finanziato con i risparmi, un'altra parte prestano i genitori, faccio presente a loro l'originalità, cerco di presentarlo, non avendo alcuna sicurezza (da tre mesi). Insieme a Mirko e Nino insieme. Nono ha messo i soldi, Mirko l'idea, io la burocrazia andando dal comune e dal notaio. Il design del Mirco è su tutte le foto e magliette. I prima generazione volevano solo guadagnare, ma la nuova ha idee però ancora gli schemi tradizionali, ma con idee originali. Tanti ristoranti cinesi cambiano i gusti (questo è di nicchia). Per tradurre la cultura e il carattere cinese sia presente, cercano di mettere la cultura. Cerchiamo di passare agli italiani queste idee originali, sperando che gli italiani accettino, la paura è che non piaccia il gusto, possono accettarlo ma non hanno mai visto questo tipo di cibo. Ora gli italiani erano interessati, forse non troppo piccante, allora troviamo un modo, cerchiamo di raggiungere nella cultura. 'coraggio di drago' dice il nostro motto, 'pelle di drago', secondo noi drago è un segno cinese, drago porta fortuna vai sul cielo, il drago è cultura, è importante non come Europa, cattivo, in Cina ti protegge, porta fortuna, questo segno è speciale (sfrega le dita in segno di soldi). Il network aiuta poco, non possiamo aiutare Fabio ha tre aziende, noi piccolo piccolo ma quando viene offro io non per guadagnare, chiami i giovani, cinesi a Milano, se faccio qualcosa tra cinesi vivo bene in Italia ma non è giusto, dobbiamo uscire parlare con Europei, prima facciamo cibo per cinesi perché più facile guadagnare poi qualcosa con gli Italiani, io posso imparare e faccio altre cose. Io sono di Pechino, quelli di Wenzhou sono molto intelligenti, sanno come guadagnare, noi da nord la testa (penso - dico), loro sono pratici, sanno tanti metodi per vivere e guadagnare, sono venuti presto. Noi del nord non abbiamo tanta voglia, 100 euro bastano, un viaggio... loro grandi ore per vivere e lavorare. Il nord dopo gli anni $50 \mathrm{col}$ governo vicino più ricco di loro quindi loro devono cercare qualcosa per guadagnare, e vanno all'estero. Io non ho tempo per fare altro, mattina mercato, poi vengono qui a cucinare, però

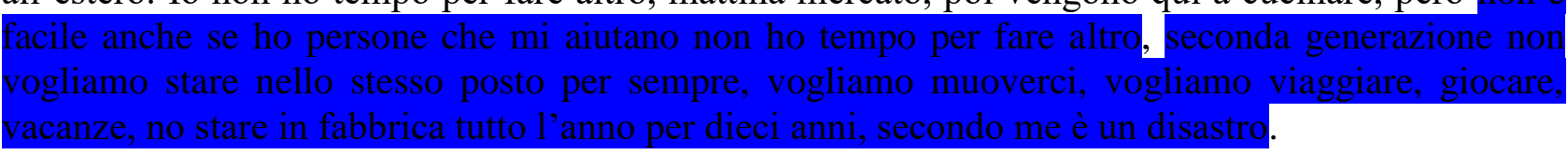

\section{Intervista Yun Yun Zhang Wenzhou Jiahao 38 F 09/05/2016} Lombardia.

Xie Wen Hao e Shie mi hanno parlato di lei. Lei dirige altri 11 ristoranti in tutta la

- Come ha iniziato questo percorso? Arrivata dal 1990, in Italia, da 26 anni ho iniziato, studiato, fatto le medie, genitori hanno piccolo laboratorio pelletteria, dopo tre anni, nel tessile, abbigliamento. Da lì fino a 20 anni nel campo tessile c'era una concorrenza pazzesca, aziende non pagavano. Allora ho detto di no. Ho cercato un lavoro che la gente mi pagasse, fatto ristorazione, dopo matrimonio punto vendita.

- Cosa ha portato lei ad avere un simile successo? La differenza, essere differente dagli altri mi ha aiutato a riuscire a avere successo, nonostante piccola subivo diversità tra i compagni, 
un po' di razzismo l'ho vissuto su di me, ho sempre voluto che la gente mi guardasse e trattasse alla pari.

- Questa catena coinvolge la sua famiglia? Chi altro ha avuto un impatto decisivo per il successo del suo business? Parenti e amici ci aiutiamo molto, dal matrimonio molti regali tra amici e parenti molti inviti, grossi regali da parenti e amici. Nelle buste di matrimonio altissimi, cifra 500-1000 poi con tutti gli invitati grande capitale, se non investivo dovevo rendere indietro ai prossimi matrimoni. Abbiamo primo ristorante avventura da giovane, mai lavoro ristorante e bar, neanche frigo e lavandino. Prima birra era calda.. Io non sapevo ingenuamente. Nel frattempo imparo e faccio, modifico e miglioro, attività molto bene, clienti piano piano si sono fatti, da lì la terza e la quarta catena. Marito lavorato insieme per molto tempo, ho un nuovo compagno italiano, sto trascinando a lavorare insieme, mi da una mano. Personale trovato tramite sito internet, poi maggioranza passaparola, nel mercato sappiamo come siamo come famiglia, tra amici e parenti si presenta, personale stesso mi aiuta a cercare quando c'è bisogno, personale forte è la potenza, stabilità sul personale. Prima sono arrivati i miei genitori da Parigi in Italia nell'1988 poi siamo arrivati dopo. Io arrivata insieme ai genitori.

- La sua esperienza per me è molto ricca, cosa ne direbbe se per un periodo la venissi a trovare per osservarla sul lavoro?

Iniziamo, Moltiplicazione di business per motivo personale, voglia di fare, opportunità c'erano, la gente ci conosceva. Le società mi chiamano, mi chiedono se voglio entrare nella loro realtà nuova, se sono buone opportunità non ho rifiutato. Nella zona nostra di Wenzhou la gente non si accontenta, questo ti influenza

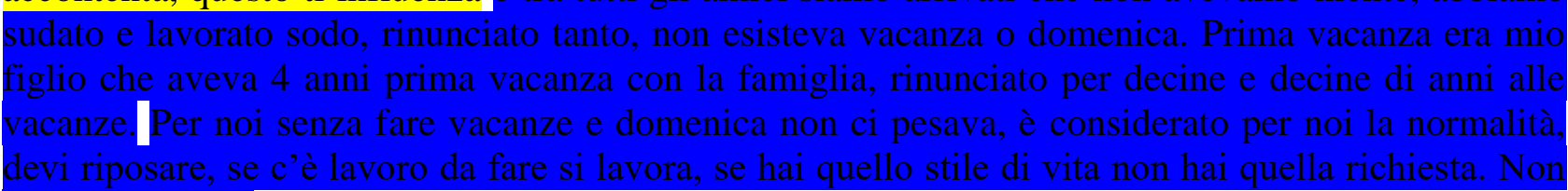

Ora la mentalità sta cambiando.

ROUTINE: la cosa più importante adesso è la famiglia, da un po' di anni vedo che i figli crescono, da 5 anni ho preso il controllo dei miei figli, prima viene la mia famiglia e poi il lavoro. Dalle 9 uscivo e tornavo la sera, lavoravo nel ristorante, facevo molto più prima fino a sette anni del mio bambino. Poi ho tolto tata e donna di casa e ho preso piena responsabilità sulla famiglia. Ogni ristorante ho persone di fiducia, non devo portarlo avanti da solo, vado a seconda del bisogno, non tutti solo i nuovi, poi gli altri vanno avanti da soli. Al tempo di oggi a parte delle telefonate, gestione delle questioni amministrative, incontri con finanziatori e firme per questioni burocratiche la mia vita è più a casa e libera. Non devo più contattare i fornitori, ogni ristorante ha la sua persona di fiducia e lei ci pensa al posto mio, io devo solo gestire nel background, raramente vado a visitare i miei ristoranti a meno che siano agli stadi iniziali, ma una volta che si reggono in piedi sono a posto. Ormai i business si reggono da soli, io devo fare da amministratrice di essi. Nei ristoranti cinesi non è che ci sia un capo, se mi chiedono comando io ma a parte quello non ci sono capi, ognuno ha la sua funzione e basta, rispondono ai compiti ma non gli piace essere comandati.

\section{Intervista Zhang Fang Tao $31 \mathrm{M}$ Wenzhou 30/01/2016}

Proprietario di Chateau Dufan, lui ne è il boss, c'è un gruppo di ragazzi di diverse nazionalità che praticano l'inglese, qui siamo nel cuore di Viale Sarpi. Ho iniziato l'attività con i miei genitori, messo finanze e supporto mentale, fortuna di aver trovato. Gli amici hanno prestato i soldi, anche loro giovani, pulire, insegnare lavoro, ci siamo conosciuti crescendo insieme. Sempre lavorato nel bar, anziché tradizionale, ma ho fatto uno moderno.

Prima lavoravo con i miei genitori, poi part-time al ristorante di altri. Mi ero sposato giovane per provvedere alla famiglia, non avevo una cultura italiana (o laboratorio in fabbrica o ristorazione, passo successivo avere una tua proprietà, voglio essere capo). Altri cinesi 
hanno dialetti diversi, ormai vivo a Milano dal '97, esigenze sono diverse, lavoravo per piacere. Lavorare duro, c'è una

, in Cina hai il terreno qui non hai niente, non puoi chiedere aiuto ad amici e genitori sempre, non ha più dignità. Anche gli Egiziani, i Marocchini... lavorano, fornitori nostri sono africani, anche loro lavorano duro da tutte le parti.

generazioni, le altre associazioni sono meno sfruttate nella cultura, noi cresciuti qua ci aiutiamo
culturalmente per la lingua e le pratiche, con passaggio di informazioni, ognuno si fa il suo business (90\% italiani $10 \%$ cinesi qui i clienti). Il business si fa da solo, è territoriale, non come il ristorante dove ci sono contatti più tra i cinesi. Sogno di poter finire i debiti e finanziamenti, sogno era avere un locale mio da quando ero bambino, io dormivo nel laboratorio, non c'è posto per camminare, si lavorava sempre per altri.

so

Ci sono state rotture di barriere culturali: è maleducazione chiedere ad altri imprenditori per un'intervista. Ricorda di fare foto ai carretti di Viale Sarpi.

\section{Intervista Alessio Luca 36 anni M Milano 14/10/2015}

Iniziai a lavorare a luglio 2011 in questo locale di cui sono collega con Ken. Io ero barista prima lui invece addetto alla cucina. Volevamo metterci in proprio, per poi continuare un nostro business, c'era fiducia, e io lo ho accolto come un fratello. I cinesi hanno un modo di pensare, un'ideologia, e sono molto inquadrati. Ci scontriamo, perché abbiamo idee diverse di lavoro, ci sono alcune cose che non è possibile fare qui, ma poi una volta chiarito si continua. Lui (Ken) è una persona particolare, è

c'è nessun problema di fiducia, solo io parto malfidente, so con chi ho a che fare ma solo in parte. Col business ho intestato a me la tabaccheria, ma una parte molto buona l'ha messa Ken. Io ho ipotecato la casa, rimango dunque vincolato. Ken fa ancora fatica a capire la burocrazia. Tra italiani e cinesi è difficile lavorare insieme, i modi di esprimersi, le ideologie (i pareri su cosa mettere qui o li), è la parte più critica. Invece di positivo c'è che sono molto malleabili, tranquilli, il che può essere buono ma anche no, perché alcuni se ne approfittano, rispetto a loro davanti a certe cose io non sono lascivo. Nel futuro vogliamo andare avanti qua, poi chi lo sa, finché si sta bene,

Non è stato facile subentrare in questo locale, tante erano le insidie burocratiche, ora siamo subentrati, prima erano dall'altra parte della strada i proprietari.

Ken lavora duro, alcune cose dovrebbe essere tranquillo, non più come in passato però. Io lavoro le ore passano, diventa tanto, le cose della banca, la stanchezza... Apriamo alle 6 durante la giornata sei stanco, la gente non capisce, rischi di perdere il cliente, questo deve migliorare, a volte do risposte sconnesse. Io la prendo di petto, non vedo tutto questo accanimento da Ken, suo cugino poi ragiona male invece. Io non riesco a stare fermo. Essendo tutto il giorno nel lavoro vedo questo, quando c'è da lavorare c'è da lavorare anche se non ne hai voglia. Purtroppo sono costretto ad accettare le cose come sono. La realtà è diversa in Cina, lì sono rigidi, ce l'avessero qua questa rigidità. Io oggi non la vedo più qui, vedo molti più italiani che fanno sacrifici tanto per fare quattro soldi. Anche se ripeto le cose non è che cambia molto, se dobbiamo lavorare dobbiamo farlo a 1000 non a 500, i rischi qui son tanti, l'incasso scende e non arrivi a fine mese. Devi fare scelte difficili, bisogna darsi da fare, se devo spostare qualcosa ai tavoli vado, non lo lascio fare agli altri. Se anche nessuno lo vede sono comunque problemi miei e di tutti. Altre aziende conosco che hanno società con cinesi, alcuni si trovano bene altri no. A me che piace viaggiare sono anche andato a Wenzhou in Cina. Per il futuro alzo le mani, passo dopo passo vediamo. Il problema dell'etichetta è molto forte, se i clienti arrivano e il cassiere non dice buon giorno, non ti da neanche il benvenuto, non sono propositivi, allora non va. E' una questione di carattere, un problema nell'instaurare 
conversazioni. Se vedi alcuni bar cinesi sono tutti silenziosi quelli che lavorano lì, altri parlano almeno un po', altri ancora arrivano a dominarti, ed è troppo. La gente comunque si arrabbia se non saluti mai, perdi un cliente, se invece il cliente è contento lui torna. All'uscita dici grazie; ma perché? Per aver scelto questo bar. Devi spiegare i dettagli dei prodotti, tra di loro (cinesi) invece si arriva troppo subito al punto, bisogna invece saper comunicare col cliente, a volte sorridi e non va bene per un determinato cliente, a volte sei serio e comunque non va bene per un altro cliente. Ho 20 anni di esperienze e ho immagazzinato cose buone. I cinesi hanno un modo di lavorare diverso, noi dobbiamo trattare il cliente conversando con lui. Sono un po' impulsivo io quando i clienti mi fanno domande, la mia pazienza ha dunque un limite.

\section{Job Shadowing Wei $A h$ Cy 26 M Wenzhou Viale Sarpi 14- 16/07/2015}

L'osservazione di Chen e Tony è andata in fumo. Sono andati a Magenta la mattina per incontrare un cliente. Nel pomeriggio faranno un incontro per pianificare il business futuro poi una cena a porta Romana. Chiedo a Chen il contatto dell'amica di Leo, ho visto un ragazzo della chiesa cinese fare una bancarella alla fermata metro Agostino oggi. Oggi dovevo intervistare Zhou a Viale Sarpi però è andata in fumo l'intervista. Però ho passato bel tempo con Wei, mi ha mostrato i due negozi di Zheng Song Bo, due grandi negozi dal nome Pan Bosco, uno ha delle bandiere. Wei dice che Zheng è proprio un boss importante a Viale Sarpi. Arriviamo al Mc Donald e parliamo della crisi economica in Cina, finanziaria dovuta all'inflazione, si alzano i costi si alzano gli stipendi, molte compagnie in Cina sono costrette a fallire. 9 euro un kilo di fragole mi dice sconcertato Wei. Poi arriva il fratello di Ren di passaggio, lui ha un lavoro da un commercialista cinese e vestito con la camicia. Mi chiede come vanno le cose io ho offerto caramelle a Wei, sto cercando di costruire un ponte di fiducia con loro. Con Wei torniamo davanti a Juping ma l'imprenditore non viene. Sono scoraggiato, ci sediamo. Wei mi spiega l'estremo materialismo che regna in Cina, che forse questo imprenditore non ha voluto calcolarmi, anche i cristiani a volte mi mettono in società il boss gestisce ma poi manda via tutti e si prende i ricavati, è successo anche nella nostra chiesa. La fissazione per il denaro è troppo alta tra i cinesi, non si pensa ad altro, se fai soldi sei rispettato, se non fai soldi puoi essere la persona piena di tutte le qualità del mondo ma non sei nessuno, anche tra i credenti. Wei pensa bene di Paolino, un po' più perplesso di Giovanni. Lui dice che i giovani della chiesa sono diversi, cresciuti insieme, i gruppi adulti sono divisi tra ricchi e più poveri, sono molto più improntati a fare soldi e arricchirsi. La spietatezza c'è anche tra i cristiani, l'evasione o l'approfittarsi non mancano.

RIFLESSIONE: Ammettiamo pure che il network sia la spiegazione del successo economico affinché non si creda che scegliamo l'interpretazione religiosa perché l'altra ci è contraria. Se è così ogni tipologia di network del business dovrebbe portare al successo economico (cosa che non si riscontra ad esempio nei circoli mafiosi cinesi). Piuttosto potremmo dire che il network è uno strumento non sempre usato e non sempre efficiente tra i cinesi che velocizza i tempi, garantisce un appoggio finanziario come nel caso del lignaggio, ma non può in sé stimolare il successo economico o la propensione al duro lavoro come pratica interiorizzata.

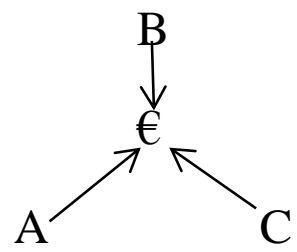

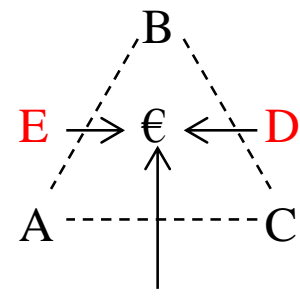

$\mathrm{F}$

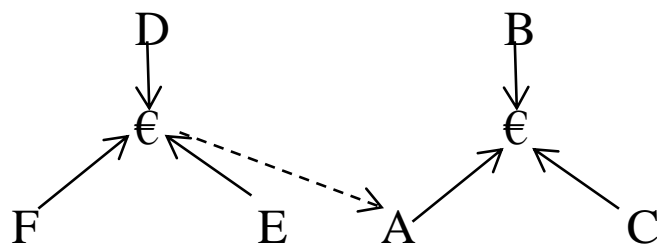

$\mathrm{E} \mathrm{A}^{\prime} \mathrm{C}$ 
Il business tra i cinesi di viale Sarpi è caratterizzato spesso da un sistema proprietario fluttuante, ossia la proprietà nominale di un business passa in secondo piano spesso rispetto all'effettivo sviluppo del business stesso. Spesso le persone vicine, o tramite il network di fede o tramite un network cinese legato a lignaggio, associazionismo, amicizia o mafia, si mettono insieme portando ciascuno le proprie risorse finanziarie spesso tramite prestiti familiari dalla Cina evitando mutui bancari. Iniziano e fondano l'attività che poi cedono ad altri membri del loro network (esempio Ren ha lasciato ad Ile il negozio al Girasole). Il gruppo fondatore nel frattempo inizia un altro business. Se il business originario funziona tornano indietro e rivendicano il loro controllo del business originario quali fondatori (i collaboratori allora spesso della seconda generazione sono però tagliati fuori).

\section{Note Job-shadowing Bingwen 14/01/2016}

Leo viene ogni giorno, da indispensabilità. 9.30 apertura negozio, sistemare telefoni nelle vetrine, aspettare i clienti, pulizia, lavori indietro dal giorno prima, cellulari da riparare, per i lavoratori, se il cliente compra o vende, e diamo tutti una mano. 2 cinesi riparano, io e Leo prendiamo l'idea, se è un problema semplice lo faccio sennò imparo. C'è necessità per me di controllarli sennò non lavorano. Loro hanno fatto tirocinio apprendistato in altri negozi. L'inizio non è male, all'inizio è molto buono benefit ma Dio provvede molti clienti, abbiamo imparato molto, buon inizio. All'area ci sono tanti negozi, ma le persone vengono da noi, loro sono più professionali nel riparare ma i clienti vengono a noi, hanno esperienza tecnica nel suppliers ma noi guardiamo tutto, come prendere la supplier, come scegliere i prezzi come fare lavorare il cliente. 2 inconvenienti, il telefono è rotto e dobbiamo compensare, succederà, dobbiamo sapere come affrontare. Leo sta qui almeno 5 ore al giorno a volte se non vengo sta 9-10 ore. E' sempre occupato ma ha più interesse a questo posto, vuole altri che gestiscono Dutch Chips e bar, se è stanco, gli piace nuove cose, no tradizionale cose, tutti hanno bisogno di un cellulare sennò perdi contatto col mondo. Ora picco sabato 20-30 persone, alcuni giorni meno di 5 altri più. Chiudiamo alle 8 e ci sono cambi turno, apriamo la porta qualcuno prima qualcuno dopo. Il ragazzo italiano, parla la lingua, è front-face, fa che il cliente si senta vicino, cresce fiducia e relazione, paperwork, pubblicare corregge la lingua, conosce il software del telefono, e aiuta con la cassa. Non è l'italiano tipo, arriva puntuale, è tranquillo, aperto, Leo lo conosce da 2 anni, prima lavorò per un anno al Dutch Chips. Leo ha investimenti in una farmacia in Cina, per trattamenti, gruppo nello Zejian, introducono da lì il trattamento in tutta la Cina negli ospedali, da 2 anni. Il lavoro è interessante, un lavoro diverso, prima buyer ora riparo, è delicato lavoro, tecnologicamente. Difficoltà: telefoni che non riponiamo pagarli per quel prezzo ma perdiamo soldi (1000 ma poi scopriamo di aver pagato con tasse $1.200 €$, perdiamo $200 €$ ), suppliers per nuovi telefoni e parti cellulari, macchine, computer. Suppliers devono mandare shipment delle parti, sono lenti, il cliente deve aspettare, viene il cliente ma ancora non sono arrivate le parti (da Roma, da Lecco), a volte danno le parti sbagliate, cambi ancora e il cliente non può aspettare. Nonostante questo la situazione va meglio, abbiamo superato. Leo in risposta diretta ha confidence non in sé ma in Dio, che quando c'è un problema ci da una soluzione, stampe ci sono macchie nella foto, cerchiamo in una settimana di risolvere e Dio da confidence e saggezza per risolvere il problema. E' difficile lavorare ogni giorno, la fede ti calma, c'è una soluzione per risolvere. Per la transazione, alcune persone portano cose rubate, dunque devi mantenere controllo, non aiutare il taccheggio. Lo hanno rubato, chiedono un prezzo basso, lo accetti o no? E' un tranello, se lo accetti fai profitto ma ti senti male. Accende il cell se non appartiene alla persona allora non lo prendiamo, facciamo questo business per onorare Dio. Non solo italiani, Spagna, Francia, inglesi, coreani cinesi, è bello, quest'area è piena di stranieri. A volte condividiamo la fede con i colleghi. Leo arriva e chiede notizie sul lavoro e parla con Pan Chen e colleghi, sono le 11.00, il clima è di scherzo e allegria. Sopra è meglio per lui, buone relazioni e comunicazioni, competenze per riparare i telefoni, cambia schermo, lotteria e camera. Preferisce stare giù e riparare, più centro, uno sopra appartiene a lui. Il fatto che lui è credente ti 
incoraggia e influenza, legge la Bibbia dalle 23 alle 3 le scorse settimane guidando da casa a qui ascolta la Bibbia. Leo fa qualche chiamata. Non c'è timetable, dipende dai clienti, alcuni cell si riparano in 10 minuti, altri non riusciamo a risolvere. Alcune volte è ovvio altri chips, main-board. Prima trovi il problema poi trovi la soluzione. Richiede esperienza, conoscenza, devi avere competenze per metterla. Scheda madre. Alcune volte spendi l'intero giorno e non trovi nulla, è frustrante ma lo fanno comunque. Leo scende. Se non riesci cerchi youtube, chiami il trainer e spieghi il problema. Pan Chen e Leo visti come direttori gli altri no. All'inizio non avevo competenze, Leo sapeva che cercavo lavoro, aveva bisogno di partner, è troppo occupato. Prima no interest e confidence ora invece si. Ero disponibile, poi abbiamo la fede, può fidarsi di me. Col cliente cerco di parlare italiano, ci vuole ancora tanto, devo migliorare. A volte mi sentivogiù nella situazione ma con un fratello è buona influenza su di te. Quando affronti il prossimo problema non ti intrappola, c'è una via d'uscita. Gli altri non credenti c'è differenza, cose mondane come dopo il tel morto, prima questione quanto diamo al cliente, non si interessano molto del profit, income, ma Dio provvede per te. Se non riparano, noi (Leo e io) paghiamo la prossima volta si rifiutano di farlo, fallimento devono condividere responsabilità, non pagando l'intera cifra. Se c'è un problema c'è paura, fai il meglio e fallisci, compensazione e riprovi. Se condividi responsabilità sarai più attento e provi E' lavoro non puoi rifiutare. ...

\section{Note Job-shadowing Chun 03/02/2016}

Ken da dei consigli alle persone attorno con cui parla, favori a persone che vengono qui come client, si parlava di qualcosa che Ken aveva per un cliente, c'è molto savoir faire. La signora al bar è cambiata forse hanno licenziato la vecchia persona che lavorava qui. Ken guardando i tavoli comanda come un boss che l'inserviente levi dal tavolo le tazzine usate. C'è anche un ragazzo che lavora alle tazzine. A quanto pare c'è un cambio di manodpera continuo ci sono sempre molti clienti quaggiù. Anche il cugino di Ken se ne va, hanno fatto il turno mattutino delle 6:00, più disponibili a sforzi, meno dichiarazioni su questo. Ora che a lavorare è l'italiano le cose sembrano andare molto più lente. Arriva un pacco con delle merci (sigarette e una scatola) il cugino di Ken prende la roba a + la porta dentro. Seconda, terza, quarta scatola (almeno 10 scatole) che porta dentro dal camion dei fornitori. Mezzogiorno, devi ricordare i nomi di clienti e salutarli quando esci . Arriva un altro fornitore che porta arance col carretto. Un mussulmano risponde male e parte quasi una discussione col barista che ha risposto male. Ci sono conflitti ma bisogna mantenere i nervi saldi se si vuol continuare a lavorare questo tipo di business.

\section{Note Job-shadowing Chun 08/10/2015}

Appena arrivato Ken girava con un pacco o due di sigarette ed un foglio con una lista. Insieme a lui suo nipote cinese sempre alla cassa, sull'altro angolo il tabaccaio. Signori anziani indugiano parlando, il fatto che sia un business misto tra italiani e cinesi aumenta il fattore di fiducia. Ci sono tanti signori e signore pensionate di quartiere, l'ambiente è pulito. Mentre lavora indugia molto a conversare col cliente, ogni tanto chi vuole vincere, la lotteria, altre volte chi vuole un caffè. Il nipote praticamente non si smuove dalla cassa, ha un cliente al minuto c'è un gran vociare, sebbene cinese ha una relazione personale col cliente, sembra l'ambiente di un circolo sociale, da dibattito d'assemblea. Si scherza e si ride, vengono anche famiglie con bambini. Ken ora è al banco. 98-06 a casa del cugino, ora lavorato insieme, prima lui cameriere. II generazione molto più facile genitori già fatto da tanti anni. Lavoro dalle 7.30 poi commissioni banche 1 da 4 a 9.30 , commissioni per prodotti commercialista, compere. Per gestire bene i tuoi fornitori, tanti vengono al bar a proporre offerta, alcuni cose fanno. Faccio cassa, poi dipendenti pranzo, a volte bar, siamo io mio cugino e socio italiano e 3 dipendenti. Prima io 4 poi crisi ho dovuto licenziare, guadagni $>$ su dipendenti, gran parte a contributi, stipendio e tasse. Se in Cina sono gestore ristorante non dovrei 
nemmeno lavorare qui + dei dipendenti. Clienti sono i vicini, c'è una rotonda con quartiere chiuso, tanti e soliti, difficile nuovi clienti. Mia moglie abbigliamenti con fratello, adesso cambiato, tutto conta internet quindi i negozianti non ci stanno, non come in Italia, di là compri tutto a casa. I valori di negozio tutti caduti, export non più, studenti stanno qua e fanno tax free, i negozianti non hanno più guadagno in Cina. Da Cina a Italia non è così facile troppa gente fa, costa poco, tanta quantità, troppa gente adesso non più buono. Con economia di adesso gente troppo da pagare 2 sett. Bene due no, tasse, sono 2 dipendenti, crisi. Sigarette da 10 italiani pochi stranieri, lotteria + stranieri, italiani pochi, per problema economico. Gelati aggiunti, problema orario macchinette, non è, c'è troppa roba su internet, 24 ore vanno di là a giocare (1/3 di prima). Tante cose tu puoi vendere, allora comprano + venti meglio è ma bisogna bilanciare con i costi della manodopera del lavoratore. C'è un momento con tanti clienti, in questo momento sia giovani che anziani. Ora Ren torna a lavorare e parla al cliente con una voce forte. Ken si è posizionato alla cassa, serve veloce prende cose da sotto banco e da resto e scontrino. Ken usa il tablet per la lotteria e la cassa, serve dice ciao, fa espressioni facciali di benvenuto. La dipendente va in giro a pulire le superfici sporche al bancone. Ora Ken prende una scatola di accendini e la posiziona al posto suo. Ci sono clienti sia italiani che stranieri, sono in fila. Qualcuno prende un gelato. Ken continua a dare resto e servire i clienti. 'Quale vuoi? Questo rosso?' E' molto gentile e tranquillo. La gente lo conosce e non scambia semplici parole ma interi dialoghi, rispetto a Leo qui sono tutti clienti abituali non solo alcuni, è uno scambio di idee per questo somiglia più a un centro sociale. 'Cosa ti serve?'. Ken si muove tra la ricevitoria e la cassa. Ora la gente attende in fila, Ken si è dimenticato dei clienti. Ken è anche al telefono ora, non smette mai di parlare, il suo italiano è buono ma non è come Leo. C'è un continuo vociare e viavai. Ken prende gli accendini, controlla le buste. Ken si china sempre per prendere qualcosa. C'è un continuo via vai. A volte i clienti sono indecisi o semplicemente passano il tempo. 'ciao grazie'. L'ambiente rimbomba, il tono della voce è sempre più alto rispetto al bar di Leo. Ken non lascia la cassa, descrive conti, da resto, riceve soldi. Ci sono tanti clienti, c'è sempre una fila. 'grazie' 'ciao' Ken parla sempre con un alto tono della voce e scherzoso. I clienti si siedono col gratta e vinci. Ken sembra lavorare in una borsa a Wall Street, una mano alla ricevitoria, una alla cassa. Ken conosce i nomi dei clienti, parla con loro, si pone al loro livello. Il vociare aumenta, i clienti parlano tra loro e con Ken scherzano 'voglio vedere' risate 'giocare il lotto', Ken ha un ruolo di cassiere, lì da il massimo, quando lui non c'è c’è suo cugino. Le signore anziane che non parlano di solito con stranieri parlano invece molto con Ken. Ken da di nuovo i prezzi 'gioco al lotto' 'ancora?' Da una parte Ken ha il tablet del lotto, dall'altra la cassa e al centro un display con i comandi per il bar 'arrivo è' Ora Ken discute alla ricevitoria siccome non c'è nessuno alla cassa, dice da alta voce i numeti che sono recentemente usciti, poi però già c'è la fila di nuovo e deve tornare alla cassa. La dipendente fa il lavoro sporco di pulire le tazzine mentre Ken si occupa della cassa. Mentre parla col cliente ostenta sicurezza, imita il milanese. Ora i clienti sono diminuiti un po'. Sopra il banco tengono uno scaffale con bicchieri e sigarette. Arriva un gruppo di clienti. Ken è ora assente quando 5-6 clienti sono in fila, la folla ora è 10-15 persone!! Ora Ken stressato cerca di soddisfarli. Chi chiede lecca lecca, chi sigarette, chi altro. Ken parla delle ore di lavoro che deve fare con un cliente, c'è una conversazione profonda. I clienti tra diverse etnie parlano frequentemente insieme. Ken sorride e ha un rapporto stretto, un cliente abituale è qui da molto tempo e continua a parlare con Ken. Questo bar è frequentato incredibilmente, soprattutto la sera. Ken parla di sconti al supermercato, sembra che fa comizi alla gente. Saran passate almeno 50 persone. Clienti di tutti i tipi. Quando non ci sono clienti Ken si sposta alla ricevitoria. Ken torna alla cassa, segna i prezzi sulla cassa, da ciò che chiedono. Di nuovo fila, Ken deve andare dritto al punto con le richieste del cliente per non spazientire gli altri in coda. Ken è molto veloce a comporre nella tastiera. La dipendente lava le vetrine. Vengono anziani, donne e bambini, uomini con cani, è un bar molto affollato. La dipendente viene anche a servire al tavolo, fanno di tutto, aperitivo, tabaccaio, bar, gelateria, lotteria, slot.... Ora Ken si da il cambio col cugino, troppi clienti alla ricevitoria. Questo luogo è davvero affollato, persino fuori dalla porta. Il cugino ricorda un ebreo sobrio che si massacra di lavoro tra serietà e auto-compiacimento nel lavorare con dignità. 
Ken torna alla cassa. Dopo un po' secondo cambio dei due. Ci sono sia giovani che vecchi ma un forte chiacchiericcio. Ora si crea un momento morto. Pochi sono i momenti di pausa, per Ken, quasi sempre c'è la fila alla cassa.

\section{Note Job-shadowing Chun 10/02/2016}

Oggi c'è la barista dell'altra volta, si sono semplicemente dati il cambio. L'italiano dentro di sé pensa: è più facile lavorare con stranieri perché sono flessibili. Ken è intento a fare scontrini al lotto. Ken è alla cassa ora che il cugino si muove, lavorano sempre in coppia anche se è Ken quello che parla sempre. Sistema le sigarette negli appositi contenitori. Ken e il fratello non hanno amici cinesi e la loro vita sembra ruotare attorno al locale. Ora Ken riceve un gruppo di vecchietti. Ken saluta sempre le persone e ha un'aria da public relations, qui è gente di quartiere, tutti più o meno si conoscono tra loro. La barista saluta dei clienti, c'è un rapporto molto cordiale ed amichevole. Nel frattempo Ken velocemente serve biglietti della lotteria alla velocità della luce. Arriva una gran folla di anziani, riempono la cassa e la lotteria, Ken nel frattempo è al telefono mentre suo cugino, spalla destra, gli da il cambio. In questi momenti Ken ha una quantità di clienti enorme. Adesso molti stranieri meno italiani, la gente compra sigarette, lotto più estrazione, c'è più gente. Fornitori dipende da chi offre più basso. Noi lavoriamo diverso, più seminiamo per attirare più clienti, alcune volte c'è meno gente (vacanze). Difficile passaggi maggiori parte della zona. Lavoro dipende 10-11 ore al giorno, se emergenze a volte 14 ore. Tutti giorno sono qui per il lavoro. Ho scelto questo lavoro, vado avanti. Se gente ha soldi spende sennò no. Imparare a trattare il cliente, devi immedesimarti, tanti stranieri non parlano italiano, non è facile, io sento di più questa difficoltà. Non c'è più qualcuno che insegna e devi imparare, ecco la differenza (italiani pensano questa difficoltà e questioni di educazione). Noi apriamo anche la domenica, gli altri bar chiudono e noi siamo aperti. 4 anni e mezzo fa. Italiano apre poi 7.30 arrivo e mio cugino mi dà il cambio, compro merce, chiudo i conti con fornitori, affari con monopoli. Dalle 4 ritorno fino alle 9.30 . C'è troppo da fare, lotto molto complicato, devi conservare i pagatidividere i prenotati, poi inviarli il monopolio e se sbagli multa 200-300 €. All'inizio sbagliavo era facile ora riesco più. Devi seguire la roba, devi avere tutto, tutti i tipi di sigarette, caffè dettagliati, 3 alla caffetteria, io lo faccio solo in emergenza. Se uno malato tu devi stare al banco. Io carico ATM mensile, annuale, all'inizio tanta gente, dunque corri, fai di fretta, se chiami o sbaglia carichi una cosa sbagliata, stampando il biglietto (dipendente italiano). Dopo 7-8 volte seguire i nuovi lavoratori se non ce la fai a campare non si capisce. Mio cugino ha un modo diverso di servire la gente. Io ancora devo pagare debiti ai parenti che hanno prestato, così amici. Ancora devo comprare casa, non ho ancora figli (38), ho tanti impegni qui. Devi essere servile, veloce, regolando tu, è esperienza. Prima era molto stressante, la gente spendeva tanti soldi adesso non ha le stesse risorse. Ken torna a lavorare alla cassa, è una vita per il lavoro e il collega italiano non vuole Ken si accorga che è workoholic. Il posto del lotto ha tre monitor. Ken parla, ride e scherza con tutti quelli che vengono, il clima è di conversazioni forzate, quasi colloquialità continua. La crisi economica in Italia è incredibile e i cinesi stanno approfittando della situazione a loro beneficio. Il co-socio italiano sta andando via, sono le 17:30-40. Adesso diminuisce il numero di clienti, per quest'ora si è svuotato il locale.

\section{Note Job-shadowing Chun 14/10/2015}

Ken è al banco e tra una fila lunga quasi ogni giorno. I clienti sono diversi, vogliono parlare. Ken oggi è molto estroverso ma non era così quando iniziò. Usa un tono della voce volutamente alto. Per adesso Alessio e lui pagano l'affitto ma pagare il mutuo sui muri sembra troppo costoso, impossibile da sostenere, già solo l'affitto paga tanto. Prende dalla cassa e da resto ma nei punti morti colloquia con loro. Ken conta i biglietti della lotteria giocati e da i soldi necessari. Molti clienti sono anche ubriachi e difficili, questo rende ancora più tosto riuscire a gestirli. Le slot funzionano nell'altra sala. Ken ora ha un momento morto. Il giovedì è il giorno più pieno perché è il 
giorno dell'estrazione dunque è pieno di gente. Alcuni clienti sono particolarmente difficili, Ken si volta dall'altra parte, la sua pazienza ha un limite. Ken si è occidentalizzato secondo Alessio, ormai non lavora poi così tanto, non ha l'etica che aveva quando era in Wenzhou. Ora nel momento morto Ken comunque cammina impaziente. Ci sono alcuni bar cinesi che alle 5.30 già aprono e alle 9-10 ancora aperti e dentro vedi la stessa persona lavorare, che magari non si prende neanche un'ora di pausa. Adesso Ken ha un cliente difficile, cerca di parlare con lui ma è ansioso. Il cugino di Ken non dice una parola invece, è asociale, questo non contribuisce a creare quel ponte necessario con i clienti. Quando non ci sono clienti Ken tira fuori il cellulare e controlla. Quando arriva un cliente abituale lo si saluta come un amico, specialmente se è un cliente facile. Quando da i prezzi o spiega i prodotti Ken è sempre con un tono alto di voce. La cameriera scherza col cliente al tavolo 'l'ho spaventato'. Una signora si siede per fare il gratta e vinci. Saltella Ken in segno di impazienza, per servire il prossimo cliente. Il mio caffè finito mi è stato levato quasi subito. Ora il cugino prende il posto di Ken perché Ken è alla lotteria, è una sorta di ruota di scorta. Ken legge il giornale. Ora da una busta con un pacco di pasticcini che un cliente ha comprato. CRISI un cliente si lamenta, dice di non essere stato rispettato, discussione e alla fine il cliente va via. Ken non prende parte a questa discussione e sembra teso al riguardo, ha paura di prendere una responsabilità per l'accaduto.

\section{Shadowing Ken Chun Milano 20/11/2015}

Il business gli va bene per ora, diciamo che dopo gli attentati di Parigi era un po' dura per lui. Il capo italiano mentre lui parlava con me ha indicato la cassa invitandolo a tornare a lavorare alla cassa. Diciamo che ha le occhiaie Ken e lavora come non mai. Rispetto a Leo Ken è molto sedentario, nel senso che ha questo business ma non espande la sua giornata è molto più monotona, spesa dietro al banco tra la cassa e il negozio della lotteria. La signora prende un caffè e racconta storie con molta allegria. Leo da delle chiavi del bagno a qualcuno, poi fa gli scontrini della lotteria e intanto ha 3 persone in fila alla cassa. C'è sempre tanta folla qui. Ora c'è tanta gente, lo spazio è molto grande, un'altra cosa che noto è che Leo sceglie spazi piccoli e multipli invece Ken spazio largo e costoso, siccome si lamenta per i costi dei muri. I due seguono due strategie di business diverse, Leo vende uno specifico prodotto intensivamente, Ken vende di tutto in un unico negozio. Incredibile come questo bar si trasformi in luogo di associazionismo. Pieno di clienti e di ogni tipo. Alcuni sono ubriachi, alcuni fumano, altri bevono, altri sono famiglie che vogliono un gelato. C'è talmente tanta folla che alcuni sono sul bordo del banco per quanta folla c'è. Ken da ordini a quella che sta al bar mentre stampa i biglietti della lotteria. Ken inoltre non ha tutta la rete sociale articolata che ha Leo, conosce un cinese a Padova e uno a Reggio Emilia, questo è quanto, poi c'è la famiglia ma non ha il supporto di chiesa o di estroversione che Leo ha, anche essendo seconda generazione immigrato. Il cugino ne è l'esempio, perfetto ameba, non parla, non dice niente alla cassa, non ha alcuna dote personale di estroversione. La cassa è senza nessuno adesso, questa è negligenza. Ora Ken torna, lui invece ha una voce determinata, saluta, da dirette istruzioni. Ci sono anche famiglie con figli ma sembrano un po' alienate, è vita di periferia, difficile qui. Nuove persone arrivano, c'è una relazione di amicizia e profonda amicizia. Quello che succede al bar è un susseguirsi di relazioni sociali, alcune deleterie direi ma comunque un luogo di socialità. Ken deve intavolare delle opinioni, deve riuscire a sviluppare un'opinione generica su alcuni temi ed argomenti del momento per avere di che dire ai suoi clienti, ha sviluppato un adattamento alla cultura italiana. Ogni tanto Ken parla e scherza con gli altri lavoratori per scherzare su. Tiene su il morale pensare a qualcosa che è successo. Ken prende e passa con mano veloce ed esperta i biglietti della lotteria. E' la seconda persona mezza ubriaca che entra, in queste situazioni Ken diventa imbarazzato, non sa come reagire, entra in ansia. Quando ci sono dei momenti morti Ken si mette le mani dietro e pensa e aspetta. In ogni caso il suo sguardo è stanco, dimostra quanto lui lavori duro, sempre più e più ogni giorno. Il cugino di Ken va in giro con un foglio verso la lotteria, forse qualcosa che deve attaccare al muro. Contrasta la sua freddezza con il calore della barista dell'est Europa. Certo che l'italiano è incredibile come abbia creato un business italo cinese con una barista 
dell'est, è multietnico. Molti giovani di mezza età tra i trenta e quaranta danno l'idea di essere drogati, che pensano a divertirsi e del tutto adolescenti nel loro comportamento. Ken rassegnato guarda per terra nel vuoto, in realtà osserva di sbieco la gente quando è alla cassa e nessun cliente è presente. Il bar è in questo caso spazioso luogo di interazione sociale. E' un ora di punta questa, piena di gente di tutti i tipi. Ken è di nuovo alla lotteria mentre la barista fa cappuccini. Ken è facilmente distraibile, perde la concentrazione. I 40 enni che sembrano 15 enni sono qui all'opera davanti a me e parlano e scherzano. Dietro Ken parla e scherza con un cliente, quando vengono da lui non vogliono solo comprare ma parlare, hanno bisogno di qualcuno con cui parlare e scherzare e sentire la confidenza. C'è come un clima di pub quasi più che semplice bar. Soprattutto venerdì a quest'ora, un clima più agitato, più da divertimento, più pieno di far macello. Ken prosegue alla cassa a fare i clienti. Ora c'è un cliente di colore poi uno basso italiano, tutti sorridenti e contenti di avere Ken come proprietario.

\section{Note Job-shadowing $\quad 06 / 10 / 2015$}

Questa volta c'è la moglie di Leo, è professionale, veloce, gentile, ma parla meno italiano di Leo. Recentemente convertita, la televisione mostra un film in cinese. 'prego ciao' sempre gentile, sta a lavorare i piatti. Fa le stesse cose di Leo, parla con la collega cinese. Prepara i caffè mentre parla in cinese con la dipendente. C'era una cliente mussulmana, la moglie di Leo era gentile. L'approccio è molto buono solo più introverso di Leo. La moglie passa tanto tempo parlando con la dipendente. Sono in un buon rapporto, ripeto il clima è molto familiare, la dipendente non è cristiana ma si vede la sorpresa nei suoi occhi c'è qualcosa di diverso in Leo e sua moglie (fede) che attrare. C'è un clima scherzoso, ma allo stesso tempo la moglie di Leo va molto di fretta. Fuori dal negozio ci sono venditori di ombrelli. La dipendente è col telefono mentre lavora. Stessa cosa la moglie di Leo. Quando io parlo con Leo o la moglie se è entrato un cliente mi mettono da parte perché il cliente ha sempre la precedenza. Il servizio è molto veloce. C'è una terza dipendente che pulisce i vetri, ha una voce molto forte.

\section{Note Job-shadowing Delun 09/09/2015}

Un cliente dice di conoscere la zia e il fratello di Leo ne parla come se fossero due altri bar. Riferito a Leo e alla sua famiglia dice 'siete due bravissime persone'. Ha avuto un inconveniente col frigo rotto. Mattina chiamate fornitori, poi vado in macchina, a prendere le ordinazioni, Leo ha volantini 'sorridi Gesù ti ama' nella macchina, li distribuisce. Ascolta musica cristiana Amy Sand, legge la Bibbia in macchina. Alle 4.30 la collega cinese abbandona il bar così Leo viene per dare il cambio, almeno una persona deve essere presente in più. Il discorso in macchina era su Stephen Tong, pastore cinese calvinista che Leo apprezza moltissimo, segno della sua etica calvinista in cui Leo si riconosce. Ora Leo è intento ad accendere le macchine da slot, parla in cinese con la dipendente, il rapporto è molto cordiale. Leo è molto emozionato sulla via della salvezza di sua moglie avvenuta giorni fa in chiesa. La rivoluzione culturale ha creato un vuoto totale che ha portato all'avvento del cristianesimo, dunque davo la colpa a loro per la mia migrazione, hanno rovinato il mio paese. La fede ha cambiato la mia mentalità, invece di odiare porto gloria a Dio. 1/3 dei Wenzhounesi sono all'estero, sono gli ebrei cinesi, bravi nel business. Storia dell'Amsterdam Chips, nuova attività, che ho voluto aprire, dopo essere andato in Cina l'anno scorso, a Shanghai avevo investito in un business. In una cena col socio in Cina, lui sapeva che sono cristiano, la crisi in Italia era forte, i giovani non possono lavorare, mi viene pena, sono bravi ma non hanno possibilità. Lui sapeva che ero cristiano e mi consigliò di usare i miei valori, voi cinesi potete assumere italiani. E' più facile gestire $\mathrm{i}$ cinesi, non hanno diritti, vogliono fare extra e sacrifici. Allora ho notato che la maggior parte sono connazionali che abbiamo. L'imprenditore deve pensare all'interesse, tanti imprenditori cristiani fanno quello che faccio io, siamo però parziali, non aiutiamo chi non è della stessa razza. Pensavo a missionari che hanno sacrificato la vita per la Cina 
e tutti questi dubbi erano nella mia testa, volevo fare qualcosa per il popolo italiano. Non posso parlarne apertamente è ancora nascosto, prima facciamo poi ne parliamo per vedere i risultati. Dopo questo viaggio ebbi 4 opportunità di business (uno Dutch Chips, gli altri tre non potevo offrire posto di lavoro agli altri - settore finanziario - broker, rivenditore di cose di lusso, rappresentante delle merci per settore cosmetico). I tre erano limitati a me l'altro invece, dopo lungo tempo di preghiere, non sapevo che cosa fare, non avevo indizi, ho seguito le regole di Stephen Tong per quando non sai che fare:

1) Quello che stai per fare glorifica il Signore?

2) Può aiutare gli altri?

3) Non è sotto il potere del peccato?

Non tutti lo fanno per glorificare Dio (danneggiano, concorrenza sleale, non fare pagamenti, frodi finanziarie). I soldi che ti sei arricchito viene dal diavolo. Non è facile scegliere quando non c'è risposta chiara dal Signore. Ho parlato con altri, e la quarta opzione è più vicina ai principi biblici. Tutto quello che faccio è per glorificare Dio, come il luogo, dentro il cuore glorifica Dio, ho assunto 7 ragazzi, aiuto gli altri, la concorrenza è leale, non ho corrotto nessuno, è guadagno onesto dunque non sto lavorando sotto peccato. Questo è il motivo che ho aperto il fast food. Da fuori sembra un negozio normale ma dentro è cristiano, se non era cristiano non sarebbe esistito. Merce la prendiamo all'ingrosso, alcuni prodotti ce li portano in azienda, altri sono questioni burocratiche. Ho rispettato pienamente i diritti dei dipendenti, se lo fai troppo la gente se ne approfitta, perdi autorevolezza, ma io garantisco i diritti dei lavoratori secondo la legge italiana, mai abusato di loro di fare cose disumane, li tratto come me stesso, perché Dio ci ha creato a sua immagine. Ognuno di noi è prezioso, questo è il principio di come tratto le persone anche se sottomesse sotto di te. La fede e la vita quotidiana possono essere collegate insieme, può testimoniare la gloria del Signore. Mio padre iniziò il business 13 anni fa, a Milano, dopo 10 anni ho accumulato i risparmi e ho deciso di fare la mia attività. Mia zia è socia del negozio Amsterdam Chips. Mio fratello uguale e anche lui ha un business suo di bar. La chiesa in Cina non si ha intenzione di partecipare ma incoscientemente sono coinvolti nel business, sta diventando comune, tanti fanno business in chiesa. Tanti però fanno ricchezza facendo del male, chi fa business in base alla legge è più lontano. Leo ascoltava in un periodo 10 ore i sermoni di Stephen Tong, che ammira molto, è come l'epicentro dell'epicentro, la chiesa riformata lo è. Presidente associazione culturale UNIIC sono membro ora per associazione non profit (est-west) partecipo a conferenze, l'obbiettivo è promuovere la cultura Cinese in Italia (stessa associazione Marco). L'obbiettivo nascosto è evangelizzare, 90\% sono cristiani, hai contatti con altri, persone di alto livello, quando c'è conferenza dibattito ci sono dirigenti, ministri... parliamo di cose ufficiali poi al tavolo condividiamo il Vangelo. Non puoi avere contatti normali dunque con l'ass. lo facciamo. In più dopo il terremoto abbiamo creato una casa di accoglienza per orfani o disabili, no profit, soldi stanziati da cristiani. Marco è stato lì. L'associazione riunisce imprenditori. Leo vorrebbe creare un'associazione per aiutare le persone e condividere il Vangelo (disagi cinesi nel capire la lingua). Ora Leo va a lavorare al bancone, apre la cassa e serve il cliente, apre le macchine slot alle 5 come di regola, poi cambia le monete per chi usa le slot, ci sono sempre via vai di clienti che però sanno il suo nome. L'altra cinese serve un panino, sono arrivati altri clienti cinesi, Leo parla con loro forse si conoscono da tempo. Ora Leo è al banco e controlla un assegno per pagare la dipendente che se ne va col sorriso siccome è trattata molto bene. Ora controlla i tavoli e un'altra cliente compra acqua, ci sono anche famiglie intere. Poi Leo va sul retro dove controlla le telecamere dell'altro negozio. Leo controlla una borsa. Arriva un cliente abituale, dice 'weilà dottore, amico come va?' e prepara il caffè. Ora è col telefono controlla alcune cose. 'Ciao grazie buona serata' sempre caloroso è Leo. Ora prepara un caffè, poi lava le lavastoviglie. Ora Leo è al telefono, una cliente prende dell'acqua. Leo controlla la cassa, le entrate giornaliere. Leo è sempre indaffarato a fare qualcosa, molto concentrato in ciò che fa. Un cliente prende $\mathrm{i}$ centralini della lotteria. Leo porta i gettoni da dare ad una cliente (79 gettoni) da cui poi riceve un ricavo. I due cinesi continuano a parlare tra loro, forse si trovano a loro agio in un posto cinese. 
Altri clienti sono entrati, un cinese prende gettoni per le slot. Leo affranca dei fogli. Leo da altri biglietti della lotteria, tra slot e lotteria fa molti soldi Leo. Ora lui scrive qualcosa al banco. Arrivano 3 clienti chiedono caffè, nella frazione di un secondo Leo prepara il caffè. Una cliente chiede 'mi dai $20 €$ ?' probabilmente il risultato del gioco nella macchinetta. Leo pulisce i tavoli poi torna alla cassa 'mi dica signora' subito servita, anche per le indicazioni Leo è molto gentile e subito al punto. 'Ciao caro' nuovo cliente chiede una birra specifica che Leo ha. Leo controlla il bancomat, con codici e scontrini che poi sigilla. Qualcuno è arrivato a cui Leo da una lettera poi ritorna all'uso del telefono, frequentemente legge la Bibbia. Clienti abituali entrano ed escono. Un cliente chiede una birra. Ora Leo prende una torta dal freezer, è sempre molto tranquillo e gentile coi clienti. Dietro Leo ha un frigorifero e un retro del bar. Poi Leo è intento a controllare il forno a microonde, un'altra cliente chiede caffè al ginseng, scherzando l'uno con l'altro 'vecchia strega' c'è atmosfera calorosa. Il telegiornale è acceso, sempre. Così i clienti alle slot sono sempre gli stessi e restano quasi tutto il giorno. Ora Leo ha un momento morto, i clienti sono di meno dell'altra volta. Arrivano clienti sia italiani che stranieri. Leo prende tazzine o cose lasciate da clienti, molto professionale e veloce. Ora Leo sembra stanco ed è al banco e arriva un altro cliente. Molti dei clienti (maggior parte sono alle slot). Leo è sempre alla cassa o al lavandino, distrugge e butta le bottiglie di plastica. I clienti sono rapidi nel ricevere ciò di cui hanno bisogno, 'sissignore', 'ecco qua' rapidità e cortesia insieme. Qualcuno lascia qualcosa allora vuol dire che è occupata la slot, Leo spiega questo in modo chiaro e deciso. Leo prepara un altro caffè alla macchina. 'Bonsoir' Leo scerza usando anche il francese, cerca di essere ottimista anche di fronte a difficoltà perché dice ha posto la sua fede in Dio. 'Va bene così', scherza con i clienti, ha una sicurezza nei gesti, quando strappa lo continua o chiude la cassa, vuole dare una buona impressione al cliente. Qualcuno chiede dove sta la farmacia. Leo conta i soldi.

\section{Note Job-shadowing Delun 10/12/2015}

Leo è stanco morto, provato dai tanti pensieri che ha in testa, è pieno di cose da fare e la situazione è di forte rischio economico. Aprire il business causa molti problemi burocratici è una scommessa economica, ora è al telefono, nonostante lo stress e l'alta dose di tensione Leo mantiene la calma. Pan Chen mi ha detto che Leo è davvero un modello per lui, riesce a lavorare tutto il giorno poi alle 3 di notte fa una lettura completa della Bibbia, legge spesso. Ora scherza col cliente, parla inglese con i clienti inglesi, si adatta ad ogni tipo di cliente. Leo è determinato, lavora con la occhiaie soprattutto quest'ultimo mese. Chiedono un brandy, Leo è esperto e sa i dettagli. Alcuni clienti sono molto tosti e difficili da trattare. Leo sistema il pulici-scarpe poi introduce diversi clienti. Ancora scherzi, si parla del menu, della birra, parla sempre con un velo d'ironia, cerca di creare rispetto ma allo stesso tempo empatia. E' un tipo di reazione amichevole che cerca di creare ponte. Leo saluta la gente 'dottore pino' a volte non ricambiano ma lui è tranquillo. Il tizio parla del programma dei cinesi in Italia, è una continuazione. Leo parla della morte ed è tranquillo ma infervorisce i clienti. Leo parla con Chen al telefono. La conversazione è molto animata, mentre è al telefono Leo prepara il caffè. I clienti inglesi se ne vanno. Il tizio non ha abbastanza, ma Leo gentile dice 'la prossima volta me li paghi'. E' sempre molto disponibile. Uno entra alle 18.30 chiede 'faccio ancora in tempo per un caffè?' ha convinzione che il posto stia per chiudere quando in realtà non è così. Leo sistema le sedie al loro posto. Chen è arrivata dalla Cina, mi dice Leo che gli hanno quasi fatto la multa per dazi doganali su macchinari per il nuovo negozio. E' arrivato Pan Chen, stanco, di fretta ma anche formale con Leo, subito parlano in cinese. Questioni burocratiche sul nuovo lavoro. Oltre a Pan Chen c'è anche un altro fratello della chiesa che è arrivato, anche lui imprenditore. Si discute su logistica per il nuovo posto di lavoro. Il fratello della chiesa ripara e fissa le telecamere nei negozi di Leo. Lui è della chiesa e aiuta Leo a ripere le telecamere (è un network). Ora sul retro Leo e questo fratello parlano ed osservano le telecamere. Il network di credenti garantisce amicizia, comunanza di scopo, fratellanza nelle quali il lavoro diventa 100 volte più facile per via della fiducia. C'è un clima di amicizia profonda tra i fratelli. Direttamente dal telefono Leo osserva le persone al lavoro. I problemi non sono mai troppo grandi quando uno 
spirito così è presente tra loro. Pan Chen e Leo crescono nella loro amicizia, Leo passa dalle chiavi all'altro fratello, è anche un clima di forte amicizia. Tutti contribuiscono alla discussione. Leo conosce i suoi clienti da loro sempre tutto ciò che cercano. Leo offre 'questa sera per te'. Sono tutti in un clima fraterno scherzoso. Si discute di business ma anche ad un livello scherzoso. Pan Chen è dietro Leo come cane al guinzaglio, lo onora molto.

\section{Fieldnotes Job-shadowing Delun 11/09/2015}

Leo ascolta con la cuffia i sermoni di Stephen Tong mentre lavora, esprimendo così la sua fede ed il suo perseverare. 'Offriamo qualcosina in più, Leo è generoso con le persone, le aiuta', 'Leo sono qua a fumare', tutti lo conoscono e lo avvisano se fanno qualcosa. Leo è appassionato di esegesi. Parla con un bambino in modo gentile. Arriva un altro cliente, 'ha questo?' 'si tutto, ci siamo attrezzati'. Risponde nei dettagli 'tazza piccola o grande?' velocità nel servire 'grazie' 'signora' velocità e gentilezza, 'cosa bevi Rosy? Ti do spumantino?' Leo è gentile, una persona chiede in prestito una penna, Leo offre volentieri. 'Ciao Leo' tutti, almeno uno su due lo saluta col suo nome. Alcuni non pagano, hanno forse conto aperto. 'Vado Leo' si scherza su tante cose, lui conosce la vita privata di loro, fanno gli spiritosi, scherzano, sulle loro cose, questioni di soldi, tutti scherzano. Una volta andati Leo tra sé e sé prega in Cinese o legge la Bibbia. Le slot sono sempre piene di gente. Clienti abituali o sono quelli che in piedi prendono caffè o un alcolico, o quelli delle slot o chi prende tabaccheria (gratta e vinci) o seduti ai tavoli prendendo cibo e bevande. Ascoltate sermoni al lavoro da Leo lo forza. Leo cerca di essere gentile con tutti. Leo ha messo un annuncio, sono stati vinti qui $1.000 €$ il 21/07/2015. Arrivano altri clienti intanto discutiamo di evoluzionismo. Arrivano altri clienti, alcuni giovani, altri no, sono italiani ma anche stranieri. Molti chiedono di cambiare soldi in gettoni per la slot. Parliamo delle Sacre Scritture, Tong 3/5 sono cristiani grazie a lui in Asia oggi. Parliamo anche di John Sung, antenato di Tong. Cliente carissimo, 'tornato in Cina' 'mi scusi per l'altra volta ero al telefono è maleducato', 'grazie dottore'. Parliamo anche di John Sung, antenato di Stephen Tong. Ora Leo usa la calcolatrice e fa i conti per la chiusura della cassa. Ora Leo prende i soldi dalla cassa e li ha contati tirandoli fuori dalla cassa, dopo aver fatto la calcolatrice. 'Ciao bello' 'stanco?' 'caffè pronto mister' 'adesso arrivo'. Multi-tasking (4-5 clienti) 'cosa sbuffi?'. Questo clima fa tornare le persone al bar di Leo. 'Domenica no?' 'no, domenica giorno santo' 'per te si' Leo spiega che lui la domenica non lavora e si riposa, segno identitario cristiano. Il cliente lascia il bar riflettendo. I clienti della slot si convertono, uno lascia dice non ce la faccio più. Leo ama la pesca, sciare... Lui è caloroso e gentile, con alcuni clienti però si imbarazzano per la sua eccessiva calorosità. Ora sono le 8.30 il bar è ancora aperto, meno gente, Leo sistema le stoviglie delle tazzine. '10 minuti chiudo, oggi chiudo prima' avviso ai giocatori di slot. Apre la chiave della macchina di gettoni e li mette via. Si prepara la chiusura 8.45 , di solito chiude alle 9.00. La cassa dei gettoni è chiusa non si può più prenderne. Ancora ci sono clienti comunque nonostante l'ora. ' 5 minuti e stacco la spina', discute Leo su un particolare piatto con un cliente, del tempo con un altro. 8.50 Leo sta chiudendo. Riscossione degli slot di quanto hanno guadagnato. Leo chiude la macchina del freezer, le slot. Le ultime operazioni di cassa, chiude il tutto. Cliente dell'ultimo minuto, si scherza, mai arrabbiato Leo. Amsterdam Chips non va, lui pensa aprirlo in Cina a Shanghai perché comunque ha il brevetto ma si tratterebbe di lasciare la famiglia qui. In Cina va molto questo tipo di attività. Leo chiude le luci. Prima faceva 5.30 mattina fino alle 10 di sera, 16 ore per un anno e mezzo, tutti i giorni. Era troppo disumano. Ormai più di 8 anni. Bar genitori a San Giuliano Milanese, 6 anni ha lavorato li. Siamo andati a prendere i figli e la moglie. 


\section{Fieldnotes Job-shadowing Delun 16/11/2015}

Arrivo e c'è la collega cinese di Leo. Oggi il posto è deserto, nessun cliente, sarà perché è lunedì. Una mamma è entrata e ha preso qualcosa. La tizia che lavora qui non ha un orario preciso, se Leo arriva tardi lei aspetta comunque, si adatta e non si lamenta. Questo elemento è unico tra i cinesi. Ora qualcuno parla con la tizia ma è molto più fredda di Leo (o social skills), il tizio un po' brontolone va alla slot. L'arrivare di Leo è pieno di allegria. 'Da quanto lavori?' 8 anni, 'ormai sei diventato Milanese'. Serve i clienti. Sullo sottofondo c'è musica cinese probabilmente cristiana ogni giorno. Leo parla al telefono e da numeri. Un uomo alla slot parla di $200 €$ spesi. Leo descrive il problema al telefono, non c'è volontà di risolvere il problema, vuole recedere dal contratto. C'è un senso di mancanza di professionalità, il suo business non può andare avanti. Un cliente slot si lamenta ma Leo parla amichevole. Leo è stra impegnato, gli hanno affidato 18 business in zona metropolitana, pieno lavoro reazione è dura, difficile riuscire a gestire lo stress per alcuni, Leo nonostante tutto è tranquillo. Adesso Leo parteciperà ad una gara di appalto per questi business. E' arrivato un cliente che parla molto con Leo. Leo descrive al cliente i suoi pensieri sul lavoro, le tasse che lui deve pagare, ma in modo giovanile e sempre comunque ottimista. Leo parla del muratore che ha rimesso a posto il suo nuovo posto, più che cliente credo si tratti di un business partner. Il tizio si fida di Leo è incredibilmente amichevole con lui e soddisfatto della loro relazione. 'lascio lì come preconto?' Leo non segue bene le ore dei pasti, lavora moltissimo. Leo ha molto commitment. Leo aprirà il posto a via Padova a dicembre, a Dutch Chips ha dovuto licenziare 3 dipendenti, è sempre in perdita per via della burocrazia e delle tasse che deve pagare per assumere $\mathrm{i}$ dipendenti. E' amareggiato dalla situazione, il sistema protettivo non va, lascia che le persone abbiano troppe tutele e privilegi. Ammira tutti gli imprenditori perché non è facile. Quello che era venuto prima era un dipendente di Dutch Chips che è a lui molto vicino in rapporto di amicizia, e sono anche visite che fa per riferire come sta andando al locale. Nel nuovo locale Leo deve assumere 2 front office 2 tecnici (preferibilmente cinesi, 30 minuti ciò che un italiano fa in un giorno) e lui e Pan Chen alla direzione. Per Leo è importante essere diretto, difficilmente assume persone che conosce, perché lui deve essere diretto nel dare consigli e critiche, con un amico è rischioso o c'è paura perché si conoscono o c'è perdita di amicizia.

\section{Note Job-shadowing Delun 19/01/2016}

Tutti sono intenti a rispondere al cellulare. Conversazioni in Cinese, Leo è appena uscito, non ci sono clienti è un tempo di attesa, non c'è molta gente, si stà fermi in attesa, l'italiano non sembra annoiato ma lavora. Un cliente entra e l'italiano si chiede avanti per rispondere alle domande perché è lui il responsabile clienti, la signora infatti era preoccupata a vedere tanti cinesi. Suona musica cinese. In media 1 telefono al giorno viene riparato. All'ingresso dei clienti si fa un 'buonasera' e si risponde alle loro domande, le interazioni sono veloci, si chiede quanto costa riparare un telefono e poi vanno via. Alcune persone vengono solo a comprare i prezzi per poi scegliere. Modelli usuali (inlone o altro riesci subito a dire quanto costi ripararli). Entrano due clienti mussulmani. I clienti chiedono il tipo di telefono ( $3 \mathrm{G} 4 \mathrm{G} \ldots$ ) e si chiedono quanto costa, le custodie, i tipi di modello. E' sempre l'italiano che sta in prima linea relazionandosi col cliente ('lo so ma non decido io' forse si tratta di punti sui quali l'italiano non è d'accordo). Pan Chen scherza in Italiano, cerca di parlare la lingua e integrarsi, è ancora l'emozione del nuovo lavoro, che rende emozionante lavorare. Il posto ha un sistema di telecamere ma l'addobbo ancora un po' spoglio. I due clienti arabi sono ancora lì che discutono fra loro sui prezzi. Il luogo è un fulcino di arrivo di amici di amici di amici, tutti cinesi. Ora gli arabi vanno via. Ora l'italiano va sul retro e Pan Chen è rimasto solo. Le conversazioni sono sempre in cinese e parlano fra loro. Non si capisce bene quello che dicono ma è un parlare cordiale, questo negozio è cinese d'identità. 


\section{Job shadowing Leo Delun M Wenzhou SUSHI 20/05/2016}

Questo locale ha aperto solo da qualche settimana, ci sono tre lavoratori cinesi e uno giapponese-taiwanese che fa il sushi. Non ci sono molti clienti, lo spazio è stato riorganizzato in modo totalmente diverso, ora c'è un tavolo laterale per sedersi, e il banco sulla destra. Leo è riuscito a ricavare spazio dal nulla, da uno spazio molto piccolo. Il ragazzo viene dalla Cina probabilmente Wenzhou, è simpatico sorride. Ha chiamato Leo e ha detto di non farmi pagare, mi trattano bene perché sanno che sono amico di Leo. E' un cambio radicale di business, chissà se riuscirà a volare, Leo è stato impaziente a cambiare subito, la gente del luogo deve abituarsi a nuovi locali. Non è facile perché tutto è moderno e la gente anche se parla sull'uscio o cammina curiosa non entra. L'idea è di un sushi take away ma i prezzi sono prezzi di ristorante. Il locale è molto meglio addobbato dell'altra volta. Ora i due lavoratori cinesi dialogano fra loro. Parlano Italiano comunque. E' una situazione molto tranquilla, nessuno si ferma e non la prendono molto a cuore, il leader comunque è più reattivo, vuole essere simpatico. Gli altri passano la maggior parte del tempo al cellulare. L'arredamento da l'idea di un ristorante raffinato e moderno, il problema è che non ci sono clienti, i prezzi forse sono troppo alti. Un altro più anziano viene da dietro e in cinese da dei comandi. Lui forse è il cuoco, l'altro mentre il comando è stato dato e se ne è andato a fare una commissione sono tutti sospettosi, mi guardano, gli spazi qui sono molto piccoli, non stanno avendo clienti, neanche uno da quando sono entrato. E' sempre così quando uno inizia una nuova attività bisogna sempre osare e all'inizio non si vedono tanti frutti, c'è scoraggiamento. I lavoratori sono quasi annoiati dalla mancanza di clienti. Ora sono le 18 Leo passerà di qui fra un po' ma non si sa esattamente quando. Leo è indaffaratissimo con le tante cose da fare. La musica è musica pop non Giapponese. C'è un po' d'inflazione con questo tipo di business ma alla fine è creativo provare questo tipo di sushi take away, innaugurato da un locale dietro al duomo da cui Leo probabilmente ha preso l'idea. Qualcuno sul retro lavora in cucina mentre il dipendente indaffarato osserva il telefono. Leo sappiamo li osserva tramite la telecamera. E' appena arrivato Leo, incravattato, parla in cinese con il ragazzo e chiede come vanno le cose. Va sul retro e controlla come vanno le cose dietro. Osserva che tutto sia a posto, tra le mani alcuni documenti burocratici. Il cambio qui è radicale adesso solo dipendenti cinesi, nessun italiano, tutti pagati ma comunque flessibili, dopo la cattiva esperienza passata con Dutch chips. Leo si trova a suo agio coi cinesi, parlano amichevolmente sulle questioni burocratiche con il ragazzo di fiducia sorridente, deve chiamare il capo del settore, mancata assistenza.. condivide con il ragazzo affidabile queste questioni burocratiche. Lui ci conta di diventare un giorno store manager affidabile per Leo. Ci sono tante questioni amministrative all'inizio, Leo condivide e anche gli altri dipendenti ascoltano. Si ride al riguardo anche se non è facile con tutte queste questioni amministrative che in Italia frustrano Delun come imprenditore. Delun porta sorriso, da istruzioni a tutti sul da farsi. Leo viene a chiedermi cosa voglio mangiare, ora mette i lavoratori all'opera. I prezzi sono $10 €$ ciascuno, $\mathrm{i}$ lavoratori sono curiosi che genere di persona io sono, non sanno dire ma sono curiosi. Ora tutti sul retro a lavorare. Il locale ha un mini tavolino invitante all'esterno con volantini e business card. Ora sono le 18.30 forse arriverà gente per cena. Chiedono i lavoratori istruzioni a Leo sul da farsi. Leo è stanco passando dal bar, al best tech al sushi, è difficile da gestire la giornata. Ci sono ampie gamme di birre giapponesi, anche moderni succhi dalle marche ricercate, oltre che quelle classiche bevande. Ora i lavoratori sono all'opera, il lavoratore di fiducia è alle pentole per accendere il fritto, l'altro giovane spezza il pesce ed il riso da mettere nel sushi. Anche a livello di colori Leo ama il nero come espressione della modernità comunque gli addobbi sono sempre ricercati. Nel frattempo sul retro parla con i dipendenti. E' un momento molto cordiale e colloquiale fra loro specialmente con il responsabile di fiducia, lui da aiuto e consiglio, ascolta Leo ed i suoi problemi e difficoltà che deve affrontare. Luci moderne al neon escono dal fondo. La gente fuori grida, 'sushi express anche d'asporto', sono giovani e curiosi sui prodotti ma non entrano, certo desta l'attenzione l'insegna. Ora il cuoco parla in cinese con Delun, lui è prima generazione, Wenzhounese ben più diretto. C'è comunicazione, Leo prende del tempo per tutti i dipendenti, spende tempo con tutti loro. Altri 
potenziali clienti arrivano. Ma non entrano, sono imbarazzati. Ora il lavoratore mi porta il sushi, sembra molto gustoso. Il cibo è preparato di qualità Leo utilizza materie e pesce dalla Cina. Questo tipo di business è più rapido da preparare e meno costoso, adatto ad ogni stagione, primavera e inverno, per questo anche all'avvento dell'estate Leo ha scelto questo tipo di business. Il lavoratore mi guarda con sorriso vuole assicurarsi che mi piaccia il cibo. Mi porta la seconda portata, cibo fritto. Leo è ancora sul retro che parla con il collega. Si chiedono se io sia un personaggio del business, analizzatore. Arriva il primo cliente, 'buonasera', vogliono prendere un menu, c'è una famiglia, selezionano ciò che vogliono. Leo è alla cassa, ora si è vestito in uniforme. La signora con la figlia non prende niente da bere, amano take away, sono piccoli cibi prelibati e più costosi del solito ma di qualità, Leo punta su questo. Leo è velocissimo alla cassa, mette tutto il sushi nella busta, e la cosa buona è che il cibo si può prendere a temperatura ambiente. Madre e figlia hanno preso tutto e vanno. Leo aspetta a venire qui. Leo parla e scherza sul retro con alcuni dipendenti, finalmente la cucina si scalda e iniziano a lavorare. L'importante per questo tipo di business è trovare un buon cuoco. Leo vuole dare l'impressione di grande professionalità qui, è in cravatta e uniforme, ci tiene a dare l'idea di un locale professionale. Intanto incartano i prossimi ordini, qualcuno sull'uscio si avvicina edavanti al tavolino parla, altri osservano dentro per vedere com'è. Si parla rigorosamente cinese, qui sono autorizzati. Altri due clienti arrivano, chiedono dal menu cosa prendere. Leo presenta i prodotti, quelli già pronti, si può consumare qua, altri chiedono ordinazioni da asporto su richiesta. Da bere non prendono niente, già il secondo cliente, prendono sushi d'asporto senza fretta tanto non si fredda, danno il numero del menu e chiedono cosa prendere. Ci sono anche bevande Giapponesi, Leo da un'idea di professionalità mentre serve, molto di più che al bar. Leo chiede se vogliono pagare adesso, per un prezzo alto Leo da sconto e cerca di invitarli a venire la prossima volta. Leo porta loro il cibo, entra adesso un altro cliente. Va alla cassa, già con idee precise sul menu, chiede se hanno menù vegetariano, terzo cliente non prende da bere, prendono solo il sushi. La signora è stupita dalla musica rock che suona nel sottofondo. Leo ha servito subito il cliente, porta via il tutto il prossimo cliente. Di solito una persona spende 13-15-20 euro ciascuno, dipende dall'occasione e da quanto prendono. Altra cliente sta osservando la merce in esposizione. Un cliente dice che non vuole bacchette, augura buon appetito. Ora sono tutti al lavoro, prima dei pasti, hanno molte più ordinazioni dalle 6.30 ora 19 e già tre quattro clienti ogni 10 minuti. La situazione si sta scaldando. Leo fa riferimento a sua zia e che lei aiuta sulle questioni culinarie in caso di bisogno da parte degli ingredienti. Alcune ricette sono nuove c'è discussione tra i lavoratori su cosa fare, puzza di bruciato, momenti difficili. Essendo nuova apertura sono tanti i momenti di sfida, ma Leo resiste vista l'abitudine con così tanti diversi locali. Leo porta la merce e cerca di avere un savoir faire. La strategia di Leo è cambiata, merce di qualità a prezzo alto, non punta più sulla quantità ma sul servire clienti con un prezzo più alto. Il terzo piatto viene portato da Leo. E' un cameriere ed improvvisa se stesso in goni tipo di lavoro. Intanto sul retro alcuni discutono. Leo chiede se il vegetariano è pronto. Quando ci sono tante ordinazioni la situazione diventa tesa per i lavoratori. Tante ordinazioni, tante esigenze, tante richieste. Ora Delun non ha molto tempo per parlare perché è indaffaratissimo, apre frigo, svuota materiale per pesce e riso... molte cose da fare. Il sushi sa di cibo aristocratico e su questo Leo fa leva per fare business in questa area benestante di Milano, cercando di offrire maggiore qualità e professionalità rispetto al Dutch Chips, la clientela qui è totalmente diversa, è disposta a spendere un po' di più per cibo di qualità, e Leo ha adesso un team le cui tasse di manodopera saranno più basse, essendo tutti cinesi. Alle 20 di solito Leo stacca, ora sta impacchettando la merce, e la cliente vegetariana aspetta. La musica è contemporanea non Giapponese. Il momento è quello dell'ora di punta, diverse persone pigre che non vogliono cucinare prendono d'asporto sushi che non devono cucinare e che è mangiabile in modo pratico, pur costando tanto per la manodopera. Questo spera di rilanciare il business. Il cliente è stato soddisfatto adesso dopo un po' di attesa. Il cibo ordinato viene preparato dai cuochi. Ora un lavoratore ciclista porta il sushi direttamente in consegna a casa delle persone, ha un casco ed è pronto per andare. Leo gli spiega la strada. Lui è pronto ad andare con l'ordinazione d'asporto, Leo lo invita ad andare piano. Fra le consegne al telefono, siccome hanno già un numero 
e un sito web su google riescono a fare un po di clienti in ogni modo. Leo spiega al ciclista la differenza e lo sconto, cerca di aggraziarsi nuovi clienti. Ora il ciclista esce velocemente. Entra di nuovo forse non ha capito bene cosa consegnare. Le difficoltà si incontrano nell'imballaggio. Leo sta parlando fuori con una ragazza cinese sul suo nuovo locale, anche il suo lavoratore di fiducia si affaccia. Leo invita i ragazzi a mettere mi piace sulla pagina facebook, li ha attirati dalla strada e li invita a mangiare qualcosa. Una persona spiega a Leo un tipo di idea simile che aveva visto a Londra, e spiega alcune idee a Leo. Spiega anche di un sushi asporto di qualità che aveva visto in Cina, e spiega alle persone dando il nome e sperando di fargli assaggiare qualcosa. I due parlano liberamente e Leo ascolta. Un cliente riesce a pagare in ticket. Un altro cliente si chiede se il cuoco è bravo, Leo dice che è un cuoco Giapponese, dice che prende tanta roba e che mangia tanto, sta testando se è buon cibo, ricorda che qui c'era il Dutch Chips, è un cliente locale che si ricorda. Il tizio dice che la zona è buona. Leo riceve un'ordinazione al telefono, chiede se si tratta di un luogo di zona vicino per fare consegna a domicilio, prende indirizzo e civico chiedendo che tipo di menu vogliono, è difficile all'inizio orientarsi, Leo si confonde ma va bene. Leo richiede di nuovo l'indirizzo della via. Subito attacca il telefono e c'è un'altra chiamata, chiede quando sta arrivando il ragazzo, non ha messo le bacchette dentro.. Leo chiede scusa. Altra cliente chiede alcune cose già preconfezionate da portare via. Alcuni clienti sono molto sbrigativi. Leo chiede se vuole guardare al menu. Leo saluta col classico 'grazie dottore'. C'è anche la zia di Leo adesso, il ragazzo senza bacchette è tornato comunque Leo non è troppo severo. $\mathrm{Ci}$ sono diversi clienti nuovi, anche stranieri, che parlano inglese con Leo. E' molto cordiale e ride Leo. I clienti sono curiosi probabilmente un'idea nuova per loro stranieri. Mentre Leo serve i turisti invita duramente i cuochi a preparare e non fare attendere il cliente. Il cliente accanto a me italiano è seccato si sente scomodo lì al tavolino, lo spazio è piccolo. Ora arriva il suo cibo, il vantaggio di Leo è che parla inglese. I ragazzi inglesi hanno preso tanta roba dopo averli serviti Leo è contento perché hanno preso tanta roba, un'altra persona consulta e testa un campione poi ripasserà. Leo ha aperto da 16 giorni, risponde dunque alla domanda di una cliente. Dopo il test seduta e servita al volo chiede altri due, le è piaciuto il servito. Leo avverte che servono 8 minuti di attesa al cliente, da direzioni precise. Una potenziale cliente viene e vuole testare, 'dice di essere molto severa col sushi', Leo gentilissimo parla loro con calore, e gentilezza. Ora c'è un momento morto dopo le otto, nessun cliente a parte gli inglesi che sono seduti e si azzuffano. Una cliente chiede quanto c'è da aspettare, se già pronto non devono aspettare, oppure su richiesta 10 minuti. Lei chiede se quelli in vetrina li hanno fatti loro. La folla e il traffico è intenso ogni tanto entrano altri clienti, Leo li saluta con gentilezza. Chiede subito se vogliono mangiare qua o portare via. E' incredibile come Leo si riesce ad abituare ad ogni tipo di lavoro in modo del tutto plastico, e lo fa da leader. Da 2 minuti e è pronto, cerca di essere velocissimo. 'tanto a fine serata ci aggiorniamo!' dice ad una cliente scherzando. 5 lavoratori, la zia di Leo forma e fa training al giovane cinese, Leo istruisce sugli spazi, il cuoco di fiducia suda molto per preparare il tutto. La zia di Leo è tampinante col fiato sul collo sul lavoratore cinese controllando che non sgarri di una virgola. Totale da pagare 38 euro, ma fa uno sconto 34, molto frequente soprattutto perché nuova apertura. 6 lavoratori adesso, forse si danno il cambio. Leo porta il cibo da portar via fuori la porta direttamente alle signorine che avevano ordinato. Qualcuno da fuori grida 'avete cambiato?' si ricorda probabilmente Dutch Chips. Gli inglesi se ne vanno 20 euro a testa circa, Leo si fa un bel gruzzoletto. Ora c'è più calma. Diciamo che con tutti Leo è molto caloroso e tranquillo. I camerieri sistemano e cambiano la roba del tavolo dove stavano gli inglesi. Ora Leo parla con sua zia, si consultano su qualcosa di importante. Arrivano due altri clienti giovani da asporto, veloci e rapidi, chiedono prendono e vanno. Leo da istruzioni al lavoratore adesso e parla con sua zia. Leo chiede sempre se vogliono alcune bevande Giapponesi, da sempre i minuti 5-6 cercando di dare idea che sono svelti. Un cliente su due questa sera ha ricevuto lo sconto. Mentre arrivano tanti clienti, spesso famiglie, Leo deve rispondere alle ordinazioni telefoniche. È entrata una vegetariana ultra-intransigente che vuole senza formaggio, Leo calorosamente si scusa. 


\section{Note Job-shadowing Delun ２1/03/2015}

Leo ha predicato un sermone ieri nella chiesa cinese, messaggio sulla croce. Ora vuole aprire un nuovo locale, trasforma il Dutch Chips in Sushi express, sarà pronto alla fine di Aprile. Leo vuole essere Tong Gong, quindi ha successo nel business e poi fa sermoni, prima predicano i pastori, poi qualcuno predica se ha chiamata e il pastore aggiunge qualcosa alla fine. Dutch Chips non va, le persone non vogliono, lui ha visto la stagnazione e decise di cambiare. Leo ama il sushi e ha voluto provare. Pan Chen è stanco, lavora 6 giorni per 10 ore ciascuno. Arrivo dei prodotti in questo momento, BARTOLI, pagamento, poi aprono il pacco, sono pezzi di ricambio per cellulari. Subito dopo un altro arrivo (che maggior parte lunedì). Pan Chen si occupa dei pagamenti, non possono aprire i pacchi se non davanti al tizio delle consegne (SDA). Sono nuovi telefoni, più economici di quanto si paga online o in negozio. Ora Leo ha iniziato a fare un locale di cibo cinese sushi. E' sotto ristrutturazione, ha appena trovato un sushi man, è quasi pronto, aprirà a fine mese. E' stata un'idea del Signore. Ora ha appena fatto firmare il foglio presenze a Pan Chen. C'è troppo stress per Leo in questo periodo. Arriva un cliente che chiede se il cell è un falso o un originale. Leo dice che è originale, ma è stato rifatto l'esterno. Non si sa cosa vuole, chiede 'se vuoi vendi a noi', chiede quanto costa fare un i-cloud, $20 €$. Il quartiere è pieno di stranieri quindi non si può dire se onesti. Sul video sempre i ragazzi fratelli della chiesa, tutti insieme. Tante persone sulle foto sono state probabilmente in prova per i primi mesi. Chen invece continua in autonomo perché non è facile instaurare una partnership, continua risucchiata dal suo lavoro. La persona che era venuta per controllare se il cell era falso, se era stato fregato. Ora Leo mostra a Pan Chen documenti per la burocrazia del nuovo locale sushi. E' di aiuto discutere loro insieme. Ecco una lista di cose da fare:

- ISEE

- CISL

- TAIWAN PER VISTO INGRESSO

- ASSUNZIONI DIPENDENTI

- UFFICI ASSICURAZIONI

- AVVOCATO

La metà non riesce, non ha più tenacia di una volta. Governo italiano chiede tanti dettagli burocratici. Leo è molto stanco, non è facile gestire tutto insieme. Parla con Pan Chen esprimendo il suo stress per la situazione attuale. Lo stress è molto, i due vanno e controllano qualcosa sul computer, lo stress è tanto, tanti pensieri per la testa. Questioni amministrative sono ora discusse dai due insieme, Leo chiede opinione a Pan Chen, su fatture e quant'altro. Altri italiani clienti entrano, chiedono preventivo per cambiare il vetro $(40 €)$ un'ora e mezzo per farlo, no garanzia sul display, ma è uguale come prima. Il tizio va a comprare con un altro locale. Si scherza anche ma si parla sempre in cinese fra loro. Anche Pan Chen è stanco morto. Rispetto al passato ci stiamo stabilizzando. Quando un'attività va male: chiudi, vendi a prezzo basso o trasformi più strategico. SUSHI è accettato dagli italiani, + più facile gestire essendo cinese, già sappiamo farlo. Il problema era lo stile orientato male in quel posto (portabilità medio-bassa, sushi medio-alta), poteva funzionare più in zine turistiche. Già prima del Dutch Chips volevo fare un sushi bar, nel frattempo c'era la moda patatine. Occupava non c'era altri, ora socio è il marito di mia cugina, è settore facile, ATM mi ha assegnato 8-9 posti per riparazione cellulari ma manca personale capace, e sono tanti. Il settore funziona ma c'è tanta concorrenza, manca personale qualificato (19 negozi), noi diamo fiducia, professionalità ed efficienza, immagine. Molto impegnativo, è cose nuove da imparare, impari nuovo allora migliori. Se non lo so fare quando hai l'idea stai migliorando, 'non so' stai facendo un ambito che non sapevi, è un migliorare te stesso ogni giorno, non rivivere una vita d'ignoranza. Ritmo, dimentichi il pranzo, mi sveglio alle 9.00 apro youtube, ascolto Stephen Tong (40 minuti). E' il momento più bello della giornata, una puntata, poi mi alzo, mi vesto, prego 1-10 minuti, esco alle 10, 10:30 ho lista di cose da fare nel giorno, inserisco piena totalmente che per un 
uomo normale non completi, non completo mai una volta mi ricordo che sono un uomo, non devo sprecare il tempo libero, faccio 3-4 telefonate da casa al bar fissando appuntamento, parlo con mia moglie, leggo il giornale, momento tranquillo. Dopo lascio il bar a mia moglie, vado al negozio di cell, guardo le cose da fare, completare io o il socio, a volte mi fermo io, gestisco l'aiuto, mi faccio insegnare le tecniche dai dipendenti. A volte 1 ora a volte un giorno. Di solito 12 o 14 tutte le commissioni, al negozio controllo che i lavori avanzano, contatto con altre cose se i tempi sono rispettati. Vado a vedere un po' nuove idee, per rispondere Giapponese ricette, bollette, attrezzature, articolazione ho fatto tutto io, difficile è trovare personale Giapponese, tre attività ma io esamino e scelgo, dipendenti sono anima viva della ditta. Poi torno al negozio cell. A volte arrivo che già le 8 e è chiuso. Poi vado al bar dipendente chiude alle 8.15 poi resto fino alle $9.30-10$ chiacchiero con $\mathrm{i}$ clienti che mi mancavano. Torno a casa alle 22 la tata ha già preparato tutto una cena, ci metto 50 minuti, guardo preaching di Stephen Tong, sto con i bambini 11, poi punteggio e costo generale 15, preparo cose da fare per il domani 12:00, doccia, poi ricomincio avventura, tutta la famiglia dorme, inizio a leggere Bibbia 12-1.00 da un anno che lo faccio. Raramente se non mi sento male non faccio ma con la volontà ed il piacere. A volte se devo predicare scrivo le cose da predicare e finisco alle 2-2.30 del mattino, poi guardo notizie generali fino alle 3. Se non devo predicare guardo un film e vado a dormire (routine da lunedì al sabato). A volte ricevo 100 chiamate al giorno in più per lo studio biblico dirigo gruppo, siamo 5-6 persone (alle-luia-amen) 5 o 6 a rotazione domande sui versi che leggiamo e ci metto una mezza giornata a dedicare a questo, non voglio trascurare, qualsiasi cosa per Dio va fatto eccellente. Se qualcuno se ne va via (licenziamento, discussione..) al congedo condivido sempre la Bibbia, a volte sono 18enni, signore di 35 anni ma condivido la mia testimonianza. Maggior parte atei o indifferenti, nell'evangelizzazione sorpresi, chiedo a loro: ti prometto mai sprecare questo libro, appena puoi leggi questo libro, mi faccio promettere da loro. Non è facile, a volte lo buttano ma se fanno una promessa è una promessa. Non puoi tenere controllo $100 \%$. Per l'aspetto personale non ho mai ritardato stipendio di un giorno anche se l'attività va male, è un loro diritto. Non sono favorevole con la scusa di crisi ritardando ricattano. I miei dipendenti sono andati via insoddisfatti, non ho mai sfruttato dipendenti, sempre trattati con dignità (immagine di Dio, se tratto male sto trattando male Dio). Distinguo dovere da vizio, devo sgridare sugli sbagli, ma mai calpesto la dignità. Prima di iniziare ho immaginato, è critico quando devi trasformare. Credevano che questa attività andasse bene ma Dio deve difendere, cerchiamo di fare bene. Prossima tappa è a 30 anni, promessa a Dio: se mi fa diventare raggiungendo quel target farò tutto come servo del Signore a tempo pieno. Farò tutto quello che mi chiede di fare Dio, pastore con immagine giovane, vivace e attraente, va rispettato e imitato. Le persone possono farlo, tra uomo e Dio. Adesso per me è la prima tappa se Dio mi realizza non solo sempre seri pastori, emarginati, religiosi, contro la scienza. Voglio essere amato ed imitato da altri (essendo pastore sei imitato). Le persone devono apprezzare, non hanno coraggio, impegno, umiltà, paura di sacrificare tante cose (scelta egoistica). Capire la volontà di Dio è indirizzare te stesso verso la Sua volontà. Il mio target è veramente impossibile da raggiungere. Sono molto determinato, sul futuro, so già cosa voglio fare. 80 chiamate oggi, 60 per ricerca di lavoro. Nel leggere la Bibbia ho un sogno: il Signore mi ha piazzato qua a portare il Vangelo in Italia, un domani andiamo a predicare il Vangelo. Mi attrezzo per la Bibbia in Italiano.

\section{Note Job-shadowing Delun 22/09/2015}

Leo è cordiale, un cliente dice 'fammi... come sai fare tu' poi parlano del suo lavoro da animatore, tutti sono gentili. E' un benvenuto caldo 'weee' anche quando i clienti reagiscono male Leo è sempre gentile, soprattutto quelli della slot machines. Ci sono clienti abituali qui alla slot, parlano fra loro, sono in richiesta delle lasagne. C'era la baby sitter di Leo oggi, Leo è al telefono, poi anche il cordless suona. Arriva una cliente che chiede un prodotto particolare. La cliente scherza con Leo, è una cliente abituale, alle slot. Si scherza su telefoni, venduto? Come mai? Quanto 
venduto? 'su a tavola bambina'. Leo deve avere pazienza spesso con clienti che se ne approfittano. Un cliente è stupito che Leo lavora fino alle 9 la sera. Dice ad un cliente 'tenga dottore'.

\section{Job shadowing Delun Leo M 26 Wenzhou 23/07/2015}

Sono venuto qui al bar di Leo e parlargli della possibilità di fare job-shadowing, ieri ero da Ren al suo nuovo negozio di Viale Sarpi, esattamente Via Giordano Bruno 12. Leo non risponde al telefono, tra mezz'ora arriva Leo, dice che ha avuto commissioni da fare. Sembra essere più positivo sulla possibilità che io svolga shadowing, mi dice di osservare le ragazze lavorare. Una delle due cinese è intenta a lavare i piatti l'altra è al banco in attesa di clienti. Ogni tanto qualcuno entra, prende qualcosa e va via, forse sono amici di Leo. Entrambe le commesse sono cinesi. Qui al bar dentro la metro c'è sempre un gran via vai. Alcune foto sul bordo del bancone c'è Leo con il figlio. La commessa prepara le bottiglie d'acqua da mettere nel frigo. Leo si sposta giornalmente tra Amsterdam Chips di nuova apertura ed il suo bar qui. La commessa continua a mettere le acque in frigo, fa molto caldo. C'è anche un'altra cinese che guarda la TV. Quando Leo arriva di solito controlla la cassa e da direzione alle dipendenti. Leo è molto gentile. Arriva una cliente cinese. Sono osservato dalla signora che è seduta, ora fa per andarsene. C'è un'altra cliente che chiede un caffè. È arrivata un'altra cliente italiana. Nel frattempo c'è una discussione animata tra le ragazze cinesi. La signora dopo aver preso il caffè va alla slot machine. Mi chiedo come Leo permetta le slot nel suo bar. L'ultima volta che ero passato c'era molta gente, persino una madre con bambino che giocavano alle slot forse per questo le tiene perché ci fa tanti soldi. Le discussioni proseguono tra le due dipendenti cinesi. Altra cosa c'è il gratta e vinci qui da Leo, molti ci giocano. Un altro cliente cinese sorridente è entrato, forse è cristiano o cliente abituale che conosce Leo. Le due dipendenti parlano molto tra loro, forse hanno preso questa parlantina dal capo. Leo che è molto estroverso. L'ambiente sembra sereno, sembrava contente di lavorare per Leo, non c'è pressione o terrore. E' arrivata un'altra persona cinese, forse lavora per Leo o dirige con Leo. I video della televisione sono un po' espliciti, mi sorprende che Leo li lasci proiettare. Ora la discussione vede tre cinesi che parlano tra loro animatamente. E' arrivata una cliente italiana e africana, c'è un bel via vai in questo bar, almeno 5 clienti ora in fila. Chi fa la cassa, chi prepara i caffè, chi prende e prepara le bibite, Leo ha un team di lavoratori. C'è una discussione tra le lavoratrici, il tutto in cinese, una sta svuotando la spazzatura e urla all'altra perché c'è qualcosa che non va. La cinese che discute porta fuori la spazzatura sembra scontenta. Ora hanno chiuso la musica e la televisione. Sembra un momento di tensione. La cliente cinese sorridente se ne va, la lavoratrice sta portando via l'immondezza. La persona cinese che sorrideva viale ed esce. Ora c'è un ragazzo cinese in televisione che canta, forse un DVD di musica cinese. La tizia della spazzatura è tornata. Fanno suonare musica cinese forse per una questione identitaria. Ora la tizia della spazzatura sta spazzando qui attorno. La tizia africana se ne va. La ragazza cinese mi chiede se ho sentito Leo e le dico che Leo arriva fra mezz'ora circa. Un ragazzo cinese alto entra e parla in cinese con il cassiere, gli chiede informazioni sulla zona. La tizia delle pulizie entra con degli scatoloni. Il locale è ben arredato ci sono bottiglie bandiere italiane, c'è poi un manifesto sul muro in cinese, quando torna Leo gli chiedo. La cassiera riceve ordini su cosa comprare alla lotteria, è gentile e scherza. L'italiano è molto limitato 'tutte le tle' dice ma continua la discussione tra le cinesi al banco. La signora di colore non se ne sta andando ma è lì che compra molti biglietti alla lotteria e scherza con la signora cinese che lo serve facendo battute sulla vincita o meno alla lotteria. Questo signore che gioca alla lotteria sembra dipendente dal gioco, prende un altro di lotteria, lei scherza con lui sul gioco. La tizia delle pulizie esce dal bar momentaneamente. Ora il tizio della lotteria legge la gazzetta. Il luogo sembra essere scarno e privo di ogni simbolo di fede proprio a significare la separazione tra chiesa e lavoro. Leo ci tiene moltissimo che non ci sia interferenza tra i due. Il bar sebbene ci provi non può essere tabaccaio perché è necessario avere cittadinanza italiana per questo. C'è di nuovo una discussione tra le due donne cinesi, questa volta la discussione è più tranquilla, una sciacqua i piatti, l'altra sistema le bottiglie. L'altra volta che ero venuto Leo mi aveva offerto 
acqua e cappuccino e aveva fatto sconti a diversi clienti. Ora aspettiamo quando arriva, è un po' in ritardo, forse ha avuto un contrattempo. Le donne cinesi intanto proseguono a lavorare, ma fa i caffè l'altra lava i bicchieri, ogni tanto parlano. Si prepara un caffè. C'è molta diligenza nell'operare. A questo punto mi verrebbe da pensare: la differenza da notare dovrebbe essere tra un cinese e un italiano invece che tra un cristiano e non cristiano. Si proseguono le discussioni in cinese mentre si lavora preparando la macchina del caffè. Una delle due guarda l'altra scherzando. Forse Leo vuole arrivare intenzionalmente in ritardo così da farmi osservare le sue dipendenti mentre lavorano. Dopo si rimettono a posto tazzine e posate, il tutto in fretta e continuando a parlare in cinese. Il tizio che ha preso i biglietti chiede alla cinese se se ne va, prende la metro gialla fino a Maciachini, così la dirigente cinese se ne va adesso, lascia l'altra cinese al bar da sola, sono le 4.30. Forse hanno turni, forse ha un altro bar che deve gestire. L'altra cinese ora è sola con il cellulare, guarda la gente passare e sta al telefono con qualcuno. Il signore chiede se arriva Leo o Cristina (sua moglie) per aprire le macchine da gioco di solito dice vengono alle 5 meno 20. Entra una cliente che è passata già prima, così una sud-Americana che era già passata prima. Il signore della lotteria dunque conosce leo non solo sa chi è ma sembra essere cliente abituale. Anche la signora che è entrata con gli occhiali porta con se una vincita e compra altre lotterie. C'è un gran via-vai in questo posto. La dipendente cinese quella della spazzatura osserva il livello di temperatura del frezer. Anche la signora con gli occhiali rossi sembra essere cliente abituale, l'ho vista entrare tre volte oggi. La dipendente cinese è di nuovo al telefono in cinese. Ora la sud-Americana e quella con gli occhiali parlano tra loro. Il tizio chiede ancora di Leo se viene ad accendere le macchine. Il cliente viene trattato bene qui. E' appena arrivato Leo, l'ordine viene chiesto a Leo, lui dice 'tutto' quello che vuole lo zio o la zia. Forse si riferiva a qualcosa da fare come offrire i soldi o altro. Credo che era aprire le macchine da gioco. Leo rientra e chiede se è arrivata cristiana, lascia le chiavi. Il tizio della lotteria è andato a giocare adesso che hanno acceso le macchine. Leo ha portato merce, mi ha offerto un cornetto. Ora Leo parla di Davide (suo figlio). Leo sistema alcune cose e parla intanto sospirando con la dipendente, forse alcune cose non vanno. L'ambiente è cambiato, c'è il capo, c'è più tensione. Leo da il benvenuto ai clienti dicendo 'dimmi dottore' 'buona sera dottore' apre il telegiornale sullo schermo. C'è una discussione in corso davanti alle macchine da gioco. Leo è alla cassa, saluta sempre ed è cordiale. Alla macchina da gioco l'uomo prende monete. Una ragazza parla di Leo (lo conosce come cliente abituale) prende una brioche dopo di me sperando forse nello stesso atto di gentilezza. Ora Leo è al telefono sempre alla cassa. La dipendente cinese sembra più tesa, guarda quello che dice Leo di fare. Arriva un cliente abituale.

\section{ORA LEO VIENE AL TAVOLO E MI PARLA.}

Leo mi saluta per servire il cliente, da i prodotti, saluta, 'eilà' 'dottore'. Ora Leo da direzione alle dipendenti sul da farsi. La dipendente cinese deve andare, Leo è al banco e serve. La relazione col cliente è molto calorosa, Leo serve veloce ed è gentile. Ora quando non ci sono clienti Leo va nel retro. E' al telefono e parla in cinese. Sta scaldando un panino per un cliente. Forse è stato messo il telegiornale siccome c'ero io. Leo parla al telefono in italiano propone alla persona con cui parla di richiamarlo. Leo porta un panino al tavolo, l'altra persona chiede un toast anche lei così che ce l'ha anche lei. Leo ride e gioca. Arriva un uomo e parla con Leo, chiede un gioco alla lotteria. Leo parla al telefono di qualche guasto che deve riparare. I collegamenti del cliente alla cassa hanno qualche problema che non risultano registrati (forse parla con Amsterdam Chips). Sai che ho potato dice Leo c'è un blocco alla cassa e deve spegnere e riaccendere, gente in coda, perde tempo con i clienti perché la macchina non funziona. Leo sembra risolvere tutto con tranquillità, non è teso. Il cliente chiede a Leo di contarli ('o è Fabio avere scambiato per rossella!' clima scherzoso e caloroso). Leo serve con sorriso e saluta le persone con calore, 'fammi sapere quello che vuoi' 'cappuccio?' sempre molto caloroso. Leo prepara il caffè e risponde alle persone. Le persone sono invitate ed invogliate a tornare. Leo da una bottiglia ben fredda per il cliente così che sia soddisfatto. Leo è venuto e si è scusato per avermi respinto sullo shadowing. Torna al cliente è molto solare e veloce, 
arrivano molti clienti. Tutti chiedono acqua da bere. Leo viene chiesto 'mi devi dare... c'è un gioco di scherzi tra tutti. C'è un bimbo con la madre. Leo ha sempre un tono scherzoso con i clienti abituali. Sempre gentile, forse sta cercando di apparire bravo davanti a me. C'è un via vai continuo. E' arrivata un'altra chiamata sul problema della cassa nell'altro negozio, è un problema del tablet che si incanta. Leo scherz con i suoi dipendenti al telefono sull'orario. Si parla davanti al cliente sull'avere pazienza. Ora c'è un momento morto. Leo ora lavora al computer e vede la videosorveglianza dell'altro negozio per vedere se lavorano e come vanno. C'è un'altra cliente a cui Leo dice 'gratis' riferendosi a una brioche che aveva preso, lei esce dal bar sorpresa e contenta. Questo tipo di gesti parlano davvero alle persone facendole ritornare contente. Una signora va e ritira altri gettoni per giocare alle slot machine. Leo credo sia sfidato dalla mia presenza, sa che sono cristiano impeccabile ha paura di avere cattiva impressione. Domani dice Leo e Rossella devono essere vincite significanti dice. Ora le donne messicane, tre prendono gelato. Scherzano sul gelato con Leo. Leo ha ricevuto una telefonata sulla macchina che è stata venduta. Un altro cliente chiede se vuole un alcolico, scherza sul suo essere viziato, quasi moralizza, ride sempre però. Bevono un Barbera, 'tenga dottore' parlano del vino, Leo è esperto sulla gradazione del vino, si salutano, conoscono Leo di nome. Leo è conosciuto da molti nella zona a quanto pare. C'è un clima caldo e accogliente che prima che arrivasse Leo era del tutto assente, con le tre colleghe cinesi. Leo ci sa fare e sa trattare il cliente come un principe. La donna alle slot chiede Leo mi cambi questi due euro, chiede perché non vanno, parlano di cibo e scherzano. Tutti conoscono Leo per nome, sanno chi è e lo stimano molto apprezzano venire qui a questo bar, se dovessero scegliere anche se ci sono bar vicini verrebbero qui. Il cliente dice 'dottore' riferendosi al signore, chiede come va il lavoro? Si discute. C'è un clima felice e accogliente. Leo prega spesso e sa che il suo lavoro è diretto alla gloria di Dio. Si avvicina uno alla cassa per segnalare quello che ha vinto. Leo mette a posto i piatti e le posate, si avvicinano le 6 è il momento di iniziare a mettere le cose a posto. La signora torna a ritirare le monete, il business delle slot frutta molto bene forse più che il bar in sé. Qualcuno ha vinto molte monete. Arriva un nuovo cliente 'weilà' mister tutto bene? Scherzano, conosce Leo. Sa cosa il cliente prende, scherza 'tienilo al fresco' gli ha dato qualcosa che passerà a ritirare. Il cliente ritorna dice di non avere chiuso, non si sa cosa. Leo è al telefono la questione del difetto non riescono a risolverla. Tutto bene? Dice all'altro cliente, si scherza con l'altra alla slot, 'dai non mi rompere'. E' arrivata un'altra cliente, legge una rivista, aspetta per qualcosa. Cliente inglese, Leo gli risponde in inglese, parla bene e fluentemente. Poi va a dare gettoni alla signora che gioca alla slot (150 gettoni, forse un regalo). Ora due persone sono in attesa, guardano verso di me. Leo prende acqua per una cliente e scherza su questo, poi scherza con quella delle slot. Leo è molto amichevole, soprattutto con i clienti abituali. C'è sempre questa signora con la rivista che legge. Arriva un nuovo cliente, prende caffè, parla di iscrivere, fa battute, chiede 'il solito dottore?' 'ciao mister'. Leo memorizza quelli che sono clienti abituali, sa chi sono e cosa prendono, questo aiuta il cliente a sentirsi importante. C'è sempre questa ragazza in piedi forse vuole il mio posto.

\section{Note Job-shadowing Delun 30/05/2016}

Sono arrivato al BEST-TECH e c'era Pan Chen, il lavoratore italiano e un lavoratore cinese. Pan Chen ha finito il pranzo, ora deve andare a prendere alcuni pacchi per consegne, io attendo l'arrivo di Leo. Nel sottoscala un lavoratore cinese è intento a riparare un cellulare, è silenzioso, non parla ma lavora duro in scrivania. Pan Chen parla italiano molto scarso con 1'altro italiano, scherzano comunque l'uno con l'altro. Il magazzino è stato bagnato per via del diluvio di questa mattina, dunque non c'è molta gente, l'acqua ha invaso il magazzino, il ragazzo cinese deve pulire l'acqua dal pavimento. Leo viene da me e mi racconta la sua storia, e di come ad esempio nel 2006 c'erano problema con le autorità italiane a China town perché avevano limitato gli orari di scarico delle merci a solo due ore al giorno. Inoltre Leo lamenta di nuovo il fatto che non si possono assumere Italiani, sono un peso e col loro essere spocchiosi non capiscono che noi siamo un network di imprenditori cinesi e che rimangono tutti a casa se rifiutano di lavorare. I cinesi certo 
sono a volte un po' egoisti perché aiutano solo cinesi ma è anche vero che aiutare gli italiani è molto costoso nel lavoro, non conviene.

\section{Note Job-shadowing Tommy Guozhi 23/06/2016}

Tommy era al bancone ma adesso si è spostato al lotto, esce dalla porta con dei fogli amministrativi. È come outsourcing l'approccio di Tommy e tanti altri cinesi adesso, comprano il locale ma la manodopera è tutta italiana. Anche il tizio al tabacchi ora è di mezza età. Verso quest' ora (10:30) Tommy si da il cambio con l'italiano dopo aver fatto la mattina presto. I lavoratori sono molti e si danno il cambio in continuazione, al tabaccheria nel giro di pochi minuti ci sono cambi continui. Un italiano nuovo sembra avere l'aria di co-boss di fiducia per Tommy. Adesso Tommy assume sempre nuovi lavoratori, probabilmente li seleziona tra quelli che costano di meno, in ogni caso c'è un largo turnover. Questo momento di tarda mattinata è piuttosto silenzioso e tranquillo, tutti sono al lavoro e solo alcuni vengono. Per ora di pranzo il bar si trasformerà in tavola calda, c'è una multi-funzionalità grande, una cucina grande e spaziosa dove i cuochi stanno già preparando il cibo per il pranzo. I lavoratori italiani sono piuttosto pigri, tranquilli, parlano tra loro, e fanno ciò che devono ma la velocità è diversa quando c'è Tommy. Ora la clientela aumenta leggermente. Arriva una consegna di frutta, almeno sei scatole portate da un italiano, Marco non c'è, ma è arrivato il carico. Marco probabilmente è l'addetto scarico merci. Gli italiani salutano ma c'è comunque una sorta di freddezza. I clienti abituali sono ad esempio gli anziani che passano il tempo a chiacchierare, uomini singoli che leggono il giornale. Lavoratori di quartiere che si fermano per una breve sosta caffè, compratori di sigarette, giocatori del lotto. Il tizio delle consegne ha scaricato ed ora ha un modulo da far firmare al tizio al tabacchi che conferma lo scarico della merce. Nel frattempo è al telefono, probabilmente ha tante consegne da fare in diversi bar e locali della città. Una signora chiede se lui è il barista, il fatto che questo locale sia posseduto da cinesi passa volutamente inosservato e gli incassi salgono per maggiore fiducia verso gli italiani. Un altro sostituto si è avvicinato alla cassa adesso. Arrivano più clienti, è quasi ora di pranzo, ultimi caffè. La gente saluta ed è calorosa, si fidano di italiani e comprano di più, questo Tommy lo sa e non vuole distruggere la baracca che era già in piedi quando ha acquistato il locale gestito da italiani, in questo serve strategia e lungimiranza, non tutti avrebbero perseguito questa opzione rischiosa.

\section{Note Job-shadowing Tommy Guozhi 25/05/2016}

Il nome del bar è AQUARIUS, fa angolo ed è in una posizione strategica. Sofisticato bar italiano, due alla caffetteria, uno alla cassa e tabaccheria, tutti e tre italiani, e il cinese allo spazio della lotteria. Il cinese sembra quasi nascondersi, è dietro le quinte mentre i tre lavoratori sono tutti italiani. Il padre di Tommy si preoccupa della questione della lotteria, il resto ci pensano gli italiani, il locale è molto raffinato, tipico bar italiano, cerca di passare quest'idea. C'è anche una ragazza cinese più giovane del padre di Tommy, forse la sorella, che è in piedi alla tabaccheria e sta sul cellulare. Alcuni clienti cinesi sono arrivati alla cassa. I clienti anziani danno più fiducia ai lavoratori italiani, forse per questo Tommy li ha assunti. Tommy è arrivato e in camicia nera va al banco a parlare con i due cinesi. Ho presentato il mio caso e ha detto che possiamo vederci nel week-end per un'intervista. All'inizio lo ho un po' spaventato, non sa cosa pensare. Lo zio è fuori che fuma una sigaretta, Tommy dietro al banco che controlla qualcosa. E' appena arrivato e deve gestire il fine serata esattamente come fa Leo. Ci sono tre italiani che parlano con Tommy come un amico, li conosce, si parla dei problemi quotidiani, come Leo Tommy ha un italiano quasi impeccabile, riesce a parlare molto fluente e ha un interazione che a parte il suo volto passerebbe per un italiano. Ora Tommy è alla lotteria, come Chun anche qui la lotteria appare come un business molto fruttuoso. Alla cassa sono molti i clienti, il padre di Tommy si muove coi gettoni, dall'altro lato c'è un gruppo di slot machines. Tommy e il cinese anziano parlano, probabilmente degli incassi della lotteria, la ragazza giovane cinese si muove da questo lato. Lei in realtà è solo un'amica, viene 
trattata come cliente. L'anziano cinese passa di qua. I lavoratori italiani sono giovani ma sembrano un po' indisciplinati. Una cliente si rivolge alla giovane cinese, è la moglie di Tommy, e chiede di parlare con Tommy, lei è molto calorosa. Tommy parla con lei, è molto allegro ed aperto. La signora scherza sul fatto che la moglie di Tommy aspetta un bambino, sembrano molto aperti, e volenterosi di avere una relazione di amicizia, chiacchierano al bancone. Tommy è loquace. Si parla del fatto che la moglie di Guozhi non parla italiano, poi discutono scambiando opinioni, la signora italiana è molto loquace nel modo in cui parla. Descrive il fatto che la moglie non parla italiano e la invita a venire ad una scuola d'italiano. Altri dipendenti italiani, rigorosamente giovani sono presenti adesso. Arriva un altro cliente loquace che si introduce nella conversazione scherzosa "è ora che lei faccia un bambino'. Lei è molto contenta e dice che i due sono bellissimi insieme, giovani. 'ti voglio bene, tanto bene' dice la cliente, sono molto stretti nel rapporto di amicizia, e disponibili ad ascoltare una cliente. La signora è un po' svitata, ora va a cercare qualcun altro con cui parlare. La giovane cinese torna al banco adesso. Qualcuno ha vinto monete alla slot, il bar è molto ampio e spazioso.

\section{Note Job-shadowing Guozhi 28/05/2016}

Il locale adesso che è sabato è più tranquillo, c'è sempre clienti ma comunque meno di prima. Adesso è il giorno della finale di Champions quindi tanta gente si sta preparando, ci sono anche clienti cinesi. E' arrivato Tommy, mi saluta, è indaffarato con il Lotto. Ora parla con il tizio della cassa tabaccaio. C'è un cliente anziano alla cassa, Tommy si muove tra il lotto e le sigarette alla cassa. Ora è alla cassa e da il cambio al dipendente italiano. Ora Tommy è di nuovo alla cassa, si da il cambio in continuazione con l'altro. Eppure Tommy sembra un po' sperso con lo sguardo e guarda la gente un po' in tensione. Tommy adesso è sempre alla cassa, clienti vanno e vengono, tutti emozionati per la Champions. Ora Tommy è al bancone e parla e passeggia, un po' nervoso per via della mia presenza. Ora Tommy si è spostato non è più alla cassa dove l'italiano si trova adesso. Il padre di Tommy viene da questo lato e mi guarda curioso e sorridente.

\section{Note Job-shadowing Guozhi 31/05/2016}

Sono arrivato e ci sono 13 dipendenti tutti Italiani, il padre di Tommy e Tommy indaffarato alla cassa. E' pieno di gente stamattina, anche alle slots ma soprattutto al banco. Ora i camerieri si preparano con tovaglie per il pranzo. Il luogo è multi-service. I lavoratori italiani sono un po' caciaroni, scherzano tra loro fanno comunella. Tommy e suo padre sono sobri, stanno al Lotto, o alla cassa e lavorano duro. I clienti alcuni sono clienti abituali altri no.

\section{Note Job-shadowing Heng $\quad \mathbf{0 4 / 0 9 / 2 0 1 5}$}

E' entrato un signore per portare un foglio e Ren gli ha dato delle monete. Il computer di Ren è acceso sul suo sito web, probabilmente vende anche gioielli. Ora Ren è indaffarato a impacchettare i nuovi arrivi. Sua moglie fa diverse telefonate e parlano insieme sul da farsi, rispetto al rapporto coi fornitori. Ha anche un modello con la struttura architettonica di una nuova sede. La moglie di Ren sembra dettare legge. Ren apre cassetti e introduce la merce di gioielleria già impacchettata. Ren è un tipo organizzato e fiscale, cerca di tenere sempre tutto in ordine, l'ammontare di merce che sistema è consistente, la moglie è dispiaciuta dalla mia presenza che rallenta i lavori. Alcune merci appena arrivate vengono tolte dagli scatoloni e introdotte negli scaffali , ad armadietto, altre vengono impacchettate e spedite. Il lavoro viene fatto in coppia dai due. La moglie fa diverse chiamate mentre Ren impacchetta. Nasce una discussione tra i due rispetto alla merce, sul retro c'è molta quantità di merce impacchettata. Ren porta un conto di roba sul retro da quelle che aveva già spacchettato. Ora Ren va avanti e indietro con i pacchetti, usa la calcolatrice per controllare i prezzi. Poi la moglie riceve una telefonata forse da una fornitrice o una 
cliente cinese. Ren sta bucando col taglierino nuova merce sul retro. La discussione telefonica coinvolge anche Ren. Si tratta di scelte da fare. Il negozio, questo come il Girasole è un continuo rumore di buste da incarto che vengono mosse da una parte all'altra. Il negozio ha anche un piano di sopra dove tengono più merce. Ren ha aperto una scatola dove tiene più merce ancora e la apre per controllare la natura, la costituzione, il codice di riferimento. Poi mette lo scotch per la cassa che verrà spedita dopo essere imballata. Scrive sulla scatola un codice di riferimento. La moglie di Ren controlla il catalogo dove tutti i gioielli sono inseriti. Saluta la gente per strada, è ancora al telefono. E' arrivato un cliente, osserva i prodotti, le collane e i bracciali appesi. Il cliente è indiano. La moglie di Ren spiega il prodotto, 'tutto cristallo' i prezzi sono molto contenuti (5 euro 4, $380 \ldots$ ). Di solito vengono comprati diversi esemplari. La moglie di Ren continua a spiegare i prezzi. Il tizio continua a chiedere prezzi e cerca di abbassarli ma lei insiste che il prezzo è fisso. Ren propone una scatola al cliente, continua a chiedere prezzi più bassi. Ren impacchetta il prodotto che il tizio napoletano ha comprato, cerca di imbustare le collane e sembra gli abbia fatto uno sconto. Il cliente è interessato, il prodotto è un metro insiste lei. Ren impacchetta il tutto. Il cliente chiede altri prodotti. Ora è alla cassa e chiede se vuole altri prodotti, paga un totale $(73 €)$. Il prezzo è buono, Ren è efficiente, veloce. Da il resto e ringrazia. Il cliente probabilmente è abituale, ora di nuovo al lavoro, più scatole da aprire, pacchi da controllare quale materiale sia dentro da essere poi catalogati. Ren è tornato sul retro. Oltre a spacchettare Ren fa anche foto con macchine professionali di gioielli da mettere poi sul sito e vendere nell'e-commerce. Molta di questa merce viene venduta nell'e-commerce. La moglie di Ren controlla il prezzario da applicare poi ai prodotti. Ren chiede informazioni a sua moglie rispetto ai codici dei prodotti, lei controlla la cassa e fa uno scontrino, forse è merce che hanno già venduto e lei gli fa sapere il prezzo totale. Ren è sempre sul retro e sta spacchettando la merce. La moglie di Ren prende dei fogli per poi scriverci sopra $\mathrm{i}$ diversi prezzi, le conversazioni tra i due sono ricorrenti. Gli articoli di gioielleria sono piuttosto raffinati. Parlano di un gioiello a forma di quadrifoglio per determinarne il prezzo. Pan viene verso di qua e controlla dentro i mobili altre merci incartate, le leva dall'armadio. Il telefono è centralizzato. Ora di nuovo Ren scarta merce che muove dal retro avanti e da avanti sul retro. Durante il lavoro Ren canta delle canzoni cristiane.

\section{Note Job-shadowing Heng 23/09/2015}

C'è stata la fiera per 4 giorni, montare e smontare molto faticoso, due volte all'anno. Lavoro dalle 9 alle $7 \mathrm{di}$ sera. Ren usa wechat per invitare i cinesi che non frequentano. Oggi al lavoro c'è la sorella della moglie di Ren, la moglie ed un inserviente cinese che controlla la merce mentre lui è al computer. La sorella della moglie di Ren è al telefono. Ren ha appena finito di lavorare dei piattini. La inserviente è sempre lì che tocca buste di gioielli. Ren dice che è faticoso lavorare alla fiera e ci sono poche entrate considerando la concorrenza, i prodotti che si vendono in fiera sono misti. Arrivano messaggi di segreteria, ci sono immagini con articoli a cui probabilmente qualcuno qui in Italia è interessato, parla in milanese spinto. Ren non si considera Laoban anche se lavora duro. Ren usa wechat molto spesso. L'inserviente continua a spacchettare, forse per lasciare tempo a Ren di fare altre cose. La sorella della moglie di Ren fa foto ai prodotti e collane da mettere poi nel sito. C'è anche la moglie diRen che parla con Ren, ora parla Ren con la moglie che è al telefono. Si parla della gestione ritiri dei prodotti, dal sito, 'abbiamo prenotato stamattina per un ritiro ma non c'è da ritirare, siccome c'è stato un erore. Ren è sempre al computer che fa ordinazioni di prodotti. E' entrato uno per la consegna pacchi, non sono cinesi, di solito arabi, anche se alcuni sono cinesi, portano 
diversi pacchi. Si mangia uno spuntino, Ren di nuovo al telefono, da contatti di un certo Vito ad un cinese. C'è stata anche la consegna di un pacchetto posta, Fedex. Le donne ora parlano con Ren del lavoro. C'è un clima comunque familiare essendo un business di famiglia, tutti sono in giro, l'inserviente sta usando la calcolatrice, Ren parla al telefono di un buono sconto di 20 euro, mentre la sorella della moglie di Ren parla con la sorella. Hanno una carta, forse una carta per acquisti 20-100 € si parla dell'euro-spesa. Anche l'assistente è qua, il clima è tranquillo, non stressante, ci sono diritti. Stanno forse prendendo un calendario per bambini, si parla di un giorno di ritiro per la merce. Ren è di nuovo al computer e discute con la moglie, parlano poi di addobbi, uno si chiama 'inglesina'. Ora Ren va sul retro perché la sorella della moglie ha ricevuto una telefonata dura. Si parla ancora del buono spesa $50 €$ invece che $20 €$. L'inserviente torna a lavorare. Ren controlla anche il sito dell'agenzia delle entrate. Controlla diversi siti Ren, siti per il lavoro, siti per vendita, o fornitori. La dipendente intanto scarta e sposta i pacchi di gioielli. Oggi non sembrano esserci molti clienti. La moglie di Ren è al telefono con un'amica, parlano cinese, parlano di un luogo, Ren anche durante il lavoro ha a cuore il gruppo giovani che guida il sabato, controlla il gruppo di wechat. La moglie prende la calcolatrice per fare i conti. Arriva un cliente italiano, saluta, sono in due. Domanda: 'all ingrosso? Vendiamo solo all'ingrosso'. Il cliente va via, 'c'è scritto fuori' dice la moglie di Ren. Molti sono quelli che entrano pensando sia solo vendita al dettaglio, ma è fondamentale fare all'ingrosso per dare buoni numeri di vendite e non solo quello che vende, col rischio di non avere tutti i pezzi per grandi clienti. Ora Ren sta al computer e controlla alcuni prodotti. Ren sta controllando le ricevute su documento PDF. Ren usa Taubau per acquistare merce dalla Cina ma non vende in Cina siccome non conviene più di tanto.

\section{Note Job-shadowing Heng 26/11/2015}

C'è una lavoratrice per Heng e lavora duro a spacchettare. Ren è su scrivania e risponde al telefono. Arriva un cluente che chiede se hanno borchie ma non ce le hanno, invita a cercare vicino. C'è una cinese che arriva e lascia un volantino in cinese, pubblicità. I pacchi arrivati sono tanti. Un altro tipo di lavoro è fissare i prodotti delle aste metalliche che vanno sul muro. Ren è al telefono per lavoro e controlla le cose amministrative. Dopo questa fa un'altra chiamata, nel frattempo l'altra cinese controlla e apre cassetti, fissa i prezzi, scarta la merce. La moglie di Heng non c'è perché è appena partorito e sta ancora all'ospedale. Aperto sul PC c'è un'immagine del punto design. Ora Ren va sul retro a controllare qualcosa. La famiglia è molto importante per i cinesi, matrimoni, fidanzamenti, tutti organizzati in famiglia, non è difficile immaginare perché non sia difficile per loro mischiare business e lignaggio. Heng ha anche penne gadget dal suo negozio online. Ora osserva diversi fogli con liste burocratiche. Il volantino che hanno oirtato è una pubblicità cinese del commercialista cinese. Ren ha già un commercialista, suo fratello minore lavora per lui ed è un fratello della chiesa che si è messo in società con un italiano per fare commercialista che assista $\mathrm{i}$ cinesi imprenditori con la burocrazia qui in Italia. Telefonata, Ren ha la merce, è un cliente, chiede di andare a Via Giusti da portare la merce alla macchina X. Arriviamo subito. Allora Ren chiede alla dipendente di portare la merce alla macchina in fretta e subito. Nel frattempo Heng muove i pacchetti e li ripone nel cassetto. Il negozio ha due telecamere, onde evitare furti, Heng ci sta molto attento. Heng ha telecamere dappertutto, 5 o 6 , la bigiotteria è così in caso di furti. Heng apre $\mathrm{i}$ pacchetti e mette gli anelli. Heng espone la merce nelle scatolette. I clienti vengono da tutta Europa 
(Germiania, prezzi alti), noi la maggior parte da Milano, chi viene all'ingrosso, ogni tanto da Olanda, alcuni clienti online, altrimenti da nord Italia. E' un mercato buono, sono disposti a venire qua perché i prodotti sono di qualità migliore (per non vendere le solite cose). Questo commercio garantisce una buona riuscita nei profitti. Mi trovano tramite online, google maps, sito e a Viale Sarpi guidando.

\section{Note Job shadowing Heng 27/01/2016}

Scambiamo il posto con la sorella di sua moglie a Girasole, perché i genitori di lei sono andati in Cina. Gennaio cambio stagione, colori scuri e chiari. Ha appena avuto una bambina e lavora molto, tutto sulle sue spalle. Si sistema i nuovi arrivi, ogni inizio anno. C'è una persona che cerca fornitori a Yu, alcuni a Guanzhou. Trovano i fornitori loro. Lì a Guanzhou c'è una chiesa Wenzhounese anche di emigrati da Wenzhou, centinaia di persone. Siamo come soci con la famiglia di lei, genitori di lui vedono cosa fare, devono vedere, sono credenti. Dipende se c'è bisogno va a Girasole sennò stò qui a seconda del bisogno. Ricevute le merci dalla Cina devono spedire le merci, fare le fatture. Arriva una telefonata, forse un cliente, c'è clima caloroso, si arriva dritto al punto, chiede nome, qualcuno che è venuto in settimana, chiedono nuovi modelli primavera-estate, tutti i clienti chiedono come sta la mamma e il bambino, clima caloroso. Chiede dettagli su merce argento-oro, zilcone, braccialetto, collanine, anche colorate con zilcone, misura medio-piccole. 919.30 in media all'ingrosso non dipende dal numero ma la qualità ( 20 persone di media). Cliente buono prende i sacchetti, chi prende pacchi vendono a altri negozianti, noi siamo importatori diretti, loro mettono nel loro magazzino. Arriva la moglie di Ren porta buste, hanno probabilmente una baby sitter, hanno preso un vestitino per la figlia. Anche la dipendente parla mentre impacchetta, discussione. Altra telefonata, apre la porta e controlla la strada se arriva una consegna. Si discute sul vestito per la bambina. Il lavoro principale è aprire pacchetti di nuovi arrivi. Ren ora torna agli scaffali, discussioni di famiglia in corso. E' un business a conduzione familiare, si parla spesso in modo colloquiale, la moglie ha portato molti vestiti. C'è un momento continuo della dipendente dal retro verso l'esterno. E' un continuo spacchettare. Non c'è clientela ora. Stanno entrambi al cellulare, parlano in dialetto Wenzhounese. La moglie è al telefono con un'amica. I momenti sono piuttosto morti. Ren si lamenta che giacca sia disordinata sulla sedia. Ren va al retro, accende il computer e forse anche il wi-fi. Si ascolta musica cristiana sulla radio. Il lavoro è togliere dalle buste e mettere sugli scaffali. Si totalizza migliaia di capi. La moglie ha perso qualcosa, quasi zero gente è venuta oggi. Il negozio ha il suo marchio specifico per ogni prodotto, marchio del negozio. Comperato con negozi qua attorno Ren ha un'insegna moderna e un luogo pulito. E' seconda generazione, questo aiuta ad avere uno sguardo innovativo. Ren risponde ad alcune mail. I fornitori sono più o meno gli stessi in entrambi i negozi. Continua lo spacchettamento e posizionamento sugli scaffali da parte della collega. Quando c'è uno scaffale vuoto la commessa mette delle collane scartate. Ren di solito è sempre in posizione al computer, stampa qualcosa. Ren sistema le fatture su internet, numeri di ordinazioni, bollette, contratti (China Power $\rightarrow$ tanti clienti cinesi, lui ha luce e riscaldamento con loro). Il direttore Songhe ha fatto la Bocconi, per due tre anni aveva studiato questo settore, sono più a Milano. Ren controlla liste e apre documenti PDF di burocrazia. Quando deve fare consegne lontano Ren prende la bici o la macchina per lunghe distanze. Ren sta registrando le fatture sul computer.

\section{Note Job-shadowing Ho $\quad 01 / 10 / 2015$}

Appena arrivato c'è Jin che aiuta un cliente a vedere gli orologi. Arriva un'altra responsabile cinese che allontana due seduti sul terreno. Jin ha un martello e cerca di allargare o stringere l'orologio. Ne ha diversi sul tavolo ma Jin sa quello che fa. Deve essere molto esperto nel muovere le parti dell'orologio. Il capo è italiano ed ha un'altra collegha italiana. Ancora Jin è intento a martellare l'orologio, sembra un fabbro. Ora usa anche le forbici. Il manager fa avanti e indietro. La 
tizia intanto controlla la cassa. Probabilmente questa è una catena di franchising. Ci sono almeno 5 clienti in attesa da Jin, molti semplicemente vanno in giro nel negozio. C'è una grande folla e siamo solo in settimana. Il giro di affari è grande. Jin sembra un po' impaziente, guarda fuori con aria stufata mentre prova a far funzionare l'orologio. C'è tanta gente anche seduta che semplicemente mangia. I clienti ora sono due. Il manager fa avanti e indietro, parla con la ragazza italiana poi invita altre persone a consultare i prodotti. Ora il cliente indossa l'orologio, Jin sorride e parla. Ora rimette dentro i pezzi. Mette dentro una busta il tutto e parlano della garanzia. L'altro ragazzo che lavora con Jin è italiano mentre ha un cliente e l'altro ragazzo cinese è presente. Jin ferma le persone che osservano col sorriso, chiedendo se sono interessati. Arriva una nuova sfilza di clienti almeno 50. Parlano e salutano il manager. Un'altra collega è italiana. Jin ora è fuori dal banco e parla alla gente sugli orologi. C'è talmente tanta folla che non vedo bene. C'è uno stanzino al centro della colonna dove tengono gli orologi di scorta. Jin è ancora intento a parlare con la folla. Si muove lentamente. Parla con gruppi di persone, cerca di essere familiare, tranquillo. Chiede 'siete insieme?' Jin rispetto a tanti cinesi parla un buon italiano. Il giro tondo va avanti fin quando Jin non trova un cliente e allora torna al bancone. Come lui anche altri lavoratori fanno lo stesso (almeno 4) più il manager e la donna. Ora Jin parla con una signora potenzialmente interessata ma non riesce a fermarla, è stressato, sta aspettando di riuscire a fermare qualcuno. Come lui anche la ragazza italiana dimostra lo stress da promoter. Jin deve sempre avere il sorriso e salutare colloquialmente la gente. Jin gira da un lato all'altro, ferma ogni persona, ha sempre il suo sorriso ironico, come lui anche la ragazza italiana. Jin gira ancora apposta un giovane, ride, scherza, chiede se gli interessano gli articoli è nervoso. Ora il capo e l'altra ragazza sono in giro. Arrivano dei cinesi e Jin chiede se parlano cinese, è un ponte per lui (proprio perché il negozio è davanti al padiglione della Cina hanno assunto diversi cinesi). Siccome c'è una grande folla di cinesi che viene e va. I due colleghi italiani parlano tra loro, Jin è più diligente. Va attorno, è stressato, vuole concludere un affare. Ora la tizia collega esce e parla con due anziani, è molto calorosa, introduce gli orologi, è molto stressante da telemarketing. Lei parla in inglese ed attira l'attenzione delle persone con sorriso e gentilezza. Ora Jin parla con una signora anziana ma non riesce a attirarla, diciamo che ha un'aria un po' stufata. L'italiano ha attratto una francese dentro. Jin è stressato, vorrebbe riuscire a fermare qualcuno, guarda ad una signora italiana ma non va, alcuni sono diffidenti con i cinesi al marketing. Ora Jin parla con una signora e bambina, fa vedere il suo orologio. Parla con persone di tutti i tipi che vanno e vengono. Continua a parlare in modo amichevole con la signora con bambino. Dice 'giorno' 'interessa?' insegue i clienti ma dopo un certo limite non insiste. Ora c'è un momento vuoto, 3 lavoratori con 1 cliente, si fanno grande concorrenza. Tempo che Jin introduce l'altra è al banco e ruba i clienti. L'altro tizio italiano è molto tranquillo, parla con un amico forse. Ora Jin è al banco fa vedere un modello ad un cliente, molto di fretta ha pagato e comprato senza tante moine. Jin è alla cassa e paga il cliente, da la busta e lo soddisfa in tutta fretta. Jin è sempre veloce, ora è uscito, di nuovo a rincorrere potenziali clienti. E' arrivata una nuova collega, forse si danno il cambio. Jin parla col capo, col sorriso, mentre il capo è alla cassa, Jin è sempre anche insieme alla ragazza cinese, ora la ragazza cinese ascolta il capo che da istruzioni, il capo comunque è tranquillo e non troppo rigido. La ragazza cinese da dei freddi 'ciao' ai clienti. Jin è sempre lì che gira, saluta la gente da un'occhiata. In tutto questo tempo Jin non è venuto da me perché vuole lavorare diligentemente e non essere ripreso. Si gratta la testa in segno di ansietà. Jin continua a seguire un cliente, non molla l'osso. In tutto questo tempo Jin non ha guardato il cell ne si da pausa, cammina nervoso avanti e indietro, con sguardo preoccupato, ogni tanto sbadiglia. Jin insegue col sorriso i clienti, sembra una mosca mentre li osserva, ha capito che c'è interesse dall'altra parte. La cinese se ne va, saluta tutti, super-fredda. Il capo scherza con una sales woman. Jin passeggia solitario, fa avanti e indietro, osserva, si gratta la testa, è insoddisfatto, guarda quelli che entrano e in modo maldestro e di spalle li insegue chiedendo di poter aiutarli. Ora Jin ha trovato una signora interessata e spiega $\mathrm{i}$ tipi di orologi. Risponde alle domande, è così contento perché ho trovato interesse. Mostra la merce, c'è una signora con bambino. La signora ora si muove con lui più vicino, parlano dei tipi di orologi, lei sembra indecisa, lui da i prezzi. Spiegano anche sui colori, sui 
tipi di materiali. La cliente 'questo tipo lo trovo anche a Torino?' Jin allora dice 'si ma qui facciamo sconti particolari'. La signora poi se ne è andata lo stesso. Ora Jin è al banco, controlla un orologio e lo da ad una ragazza, spiega le qualità e caratteristiche del prodotto. Chiede se vuole far vedere altri prodotti. Jin timbra con lo stampino un foglio e lo firma, forse la fattura, poi va alla cassa e da il resto e scontrino. Si tratta di un tipo di lavoro front office. Da la scatola, busta e da via molto veloce poi di nuovo fuori a rincorrere i clienti per catturarli alla loro attenzione. Jin sente un po' freddo. Ora è di nuovo con la signora di prima, che è al telefono, comunque interessata. Al telefono chiede verifica sulle caratteristiche dei modelli, vuole assicurarsi che non ci sia qualcosa di simile a Torino. E' un cliente esigente, Jin fa facce stufate. Jin ride con la signora, cerca di puntare sulla simpatia per spingerla e comprare. La transizione non sembra essere andata a buon fine, ne parla con il collega. Ora col capo sorride e parlano insieme in modo simpatico, forse cerca di incoraggiarlo nonostante le sconfitte. Ora parlano con un signore e scherzano 'ha già visto abbastanza'. Nonostante tutto Jin insiste e parla col cliente. Forse il capo si sta accorgendo di me. Chiede 'volete il caffè?' Jin è entrato nel magazzino, mentre tutti i venditori parlano col capo, ridono in modo ironico. Ora Jin prova ad approcciare un altro cliente. La musica suona sempre. Il capo scherza e ha sempre il sorriso. Jin è a caccia di un altro cliente, una signora anziana. Sembra ispirare fiducia Jin. Jin gira sempre, alcuni dei lavoratori italiani sono invece più tranquilli e pigri. Ora Jin ha presentato il prodotto dal banco ad una signora che però se ne è andata. I lavoratori parlano di tutto e di più fancar...ismo. Jin però non si associa e continua a cercare di fare di più. Ora Jin parla con una ragazza cinese giovane, solo due chiacchiere, non c'è interesse a comprare. Lei ha un fidanzato cinese, ora però vanno via. C'è anche un'esposizione esterna ma loro non ci fanno caso!!! Jin si è perso l'occasione, è lì che ferma gente quando qui ci sono 4 persone interessate. Finalmente il proprietario le nota, Jin ci passa davanti, non le vede, l'altro collega italiana alla fine l'ha presa. Jin è ancora a vuoto. Ora Jin parla in cinese con un tizio e sua moglie, da direzioni su andare da qualche parte. Parla dei prodotti, mostra gli orologi e parla in cinese. Il signore non sembra interessatissimo, ma Jin conosce bene la cultura, può essere un ponte. Il cinese va via. 'Possiamo aiutarvi ragazzi?' Ora Jin è al bancone, guardo sotto il bancone un orologio è una riparazione o cambio batteria, Jin ha il cacciavite e pinze, tira fuori e prende una batteria. In poco più di 1 minuto Jin ha riparato la batteria. E' interessante che facciamo fare queste riparazioni a Jin. Ora è alla cassa che controlla, parla con il capo ridendo, in modo scaciato. 'posso aiutare?' dice Jin. Arriva una fiumana di clienti. Jin è alle spalle di due clienti, li insegna, chiede se sono interessati. Ora con un signore spiega e chiede se è interessato. Mostra e descrive i prodotti esposti. E' un'anziana coppia. L'altra collega italiana ha fatto vedere una serie di 12 orologi. Prendono in giro Jin su come sta andando coi clienti, fanno gruppo, più di tre o quattro. Ora Jin parla con un altro cliente. Vuole provare l'orologio. I signori sono un po' tardi, 'quale gli piace?'. Forse il cliente è riluttante a dare a un cinese. Mostra un orologio elastico, le qualità, water resistent, che cosa fa... Jin ispira simpatia. Il cliente commenta sulla qualità. 'molto facile da usare' dipende cosa ti piace'. Ha fatto vedere il prodotto, fa giocare tanto il fatto che sono all'EXPO e il prodotto è particolare. La Signora che è venuta prima è tornata, Jin va da lei siccome i due sono andati via. Lei aveva parlato con Jin ora è tornata. Jin è uscito dal banco, ora parla con una signora. A volte è possibile concludere l'affare a volte no, non è facile. Ora Jin spiega alla signora le caratteristiche dei prodotti. Chiede domande la signora, Jin deve essere preparato a rispondere. La transizione non si completa. E' arrivata un'altra fiumana di gente, Jin è in giro che cerca di portare clienti. C'è sempre musica di sottofondo. Jin è sempre in cerca di clienti, ora è al banco e parla con due persone, il capo lo guarda e si avvicina, gli sta un po' attorno a controllare. Ora Jin è fuori con un bicchiere in mano. Va a prendere acqua alla fontanella. Il capo balla... livello di serietà basso. Torna indietro con l'acqua in mano. E' il suo breve momento di pausa. Il capo e company sono lì che scherzano e fanno passatempo. Jin scherza col collega. Jin da il benvenuto ad una signora mentre l'italiana è intenta a passare il tempo. Ora Jin spiega ad una signora il prodotto. Ora ferma un signore che osserva. Jin è preoccupato, si guarda a destra e sinistra, deve trovare clienti, però è più intraprendente dell'altro cinese italiano. Torna al cliente di prima, c'è uno scambio continuo di persone, sotto la stessa 
persona, tanti diversi lavoratori. Portano la stessa divisa. Jin gira ancora mentre gli altri hanno clienti. Ora Jin parla con uno di colore e una signora che continua a guardare, Jin ha scavalcato un potenziale cliente di un'altra ragazza. Ora Jin è al bancone che serve una signora, però se ne vanno. Fanno sempre quel timbro di validazione e comprano. Ora è arrivata una nuova fiumana si passa da momenti bui e vuoti a situazioni con fin troppe persone. Jin ha fatto un cliente fa timbro, firma e prepara lo scontrino e bancomat. Ora c'è un momento morto, niente clienti, tutti parlano tra di loro, Jin ogni tanto gira intorno. Saluta dei clienti. Sono le 4.00 un momento decisamente morto, nessun cliente. Questi sono momenti nei quali i colleghi scherzano tra loro. Ora Jin ha come clienti 3 adolescenti. Il collega scherza al riguardo, non li avrebbe approcciati. Ora Jin parla con uno arrivato sugli orologi esposti. Ora Jin è sul muro va in giro ogni tanto dicendo 'serve aiuto?' Jin parla con un signore anziano. E' arrivato un altro flusso, sono inattesi e difficili da gestire, la sala si riempie in un batter d'occhio. In queste situazioni Jin va in giro e chiede alle persone se serve aiuto, non si fa mai vedere pigro o nulla facente. Il momento è un momento morto, non ci sono clienti. Diciamo che in questi momenti alternati non è facile stabilire un equilibrio. Jin ha addocchiato tre persone, interessate agli orologi, non loro dettagli dopo dettagli, le insegue, risponde ai dubbi e domande ma loro vanno via, c'è troppo stress. Ora i lavoratori scherzano tra di loro. Mentre la ragazza timbra dei fogli di carta. Gli orologi sono incartati in dei contenitori di plastica, le persone sono così tanta che pacchetti regalo non ne fanno. Ora è Jin alla causa, ha fatto un cliente, fa scontrino e dà resto, molto veloce, tempo un millesimo è di nuovo fuori a chiedere ad altri nuovi clienti. Jin parla con due persone, il capo guarda e sorride, forse è soddisfatto della insistenza di Jin con i clienti. Subito Jin va al banco e presenta ulteriormente i prodotti. Ora Jin parla con due signori spiegando gli orologi. Il capo ora sta controllando, c'è un guasto alla cassa. Ora parla con un altro cliente, sempre sorriso in faccia anche se un po' sarcastico. Il momento è decisamente un momento morto. Arriva Jin 'bellissimo signora, è carinissimo!' 've lo dovete scrivere voi' si scherza e Jin è cordiale e amichevole con il cliente. Jin presenta il prodotto con convinzione. 'Prendo quello di EXPO' 'quello è molto carino, ti faccio vedere' dice Jin. Sono due clienti insieme. Il tizio italiano non è così incisivo. Le clienti osservano il prodotto sono sicure di prenderlo. Il proprietario e la ragazza invece sono fuori che parlano tra di loro. Jin non fa dipendere il suo duro lavoro dal controllo del capo. Jin è felice perché le clienti sono state interessate. 'Ci penso' dice la signora, ma torna dentro e prende una foto del prodotto. Ora Jin fa provare un altro orgoglio ad un altro orologio ed un'altra signora, la sicurezza di sé. Ora Jin è andato a prendere la scatola, lascia per pochi minuti la signora sola. Ormai il cliente è interessato, Jin sta controllando il manico dell'orologio, per cambiare la misura. Il ragazzo italiano passeggia, la ragazza italiana parla con il capo, Jin è l'unico che lavora sodo. Jin sta martellando l'orologio. La questione dell'orologio sembra richiedere più tempo del previsto. Ora Jin sta controllando un braccialetto sul polso della cliente. E' molto esperto, Jin sa quello che fa. Il cliente sembra difficile. Ora Jin è alla cassa con il pacco e risponde a domande sulla garanzia. Controlla il bancomat, digita sulla cassa, ridà la roba è un po' maldestro in realtà, ringraziano. Ora parla con la collega, Jin è di nuovo alla ricerca di più clienti, i dipendenti italiani invece passano più il tempo. Riparte la caccia al cliente. Jin è sempre in solitario lanciato sui clienti. Ora Jin prova ad approcciare un cliente ma non va come si aspettava, rimane teso al riguardo. Jin è simpatico ma sotto stress molto teso. Jin è alla cassa e discute col collega sul funzionamento del tablet corretta attribuzione delle provvigioni. Jin ha un altro cliente. Ultimi 10 minuti a volte i turni sono 13-18 altre volte in serata. La situazione è morta a quest'ora, Jin e i colleghi parlano tra loro. Nella mia visita precedente Jin lavorava fino alle 23:00 e doveva fare la chiusura della cassa, un momento di tensione, il capo lo osservava, tutti erano tesi. Cercò d vendersi un orologio. Doveva contare i soldi in cassa e gli scontrini totalizzando la vendita del giorno fino alle 23. La capa cinese è arrivata, apre l'armadio, ha un completo SWATCH. Sulla parte della porta gli orari. Il capo dice 'è arrivato Wei!'. Lei è il boss, è cinese. I colleghi si parlano l'un l'altro, ora tutti parlano con la donna manager cinese. Lei organizza la roba. Jin guarda l'orario la fine della giornata si avvicina. Prende un orologio e lo pulisce. Jin porta l'orologio all'uomo capo, forse chiede consiglio su capi guasti o da riparare, li rimette a posto. Jin parla col capo in cinese e con il collega in Italiano. Il capo 
cinese è molto sistematico, mentre gli italiani scialla, il capo guarda a clienti e spiega, clienti cinesi, mentre Jin saluta tutti. Il capo è una donna italiana. 4 cinesi nel negozio. Io con Giovanni migliori venditori dello scorso mese. TOT. Lavoratori 13 Wei studia nel pubbliche. Saluti il cliente 'benvenuti' cosa posso aiutare, ha visitato padiglione Cina, cerca qualcosa di particolare? Devi stare calmo paziente per fare clienti. Solo 5 ore, 20 ore a settimana 4 giorni, orari variabili. Vecchi colleghi hanno più esperienza. Io sono sales assistant. CHIUSURA: contaggio orologi al termine del giorno. Premio danno giorni di riposo. Nonostante sia stato senza provvigioni, trovato lavoro tramite G-GROUP. Dimostro come poter riuscire a usare l'orologio. Le persone di Wenzhou sono molto maleducate. I negozi della swatch sono collegati, spesso mi chiedono di prodotti che li trovano da altre parti (si trovano) tanto sono catene collegate.

\section{Note Job-shadowing Ho 21/03/2016}

Finito il lavoro adesso Jin vuole iniziare un marchio di moda con sua amica in Cina, un marchio di moda, vestiti, import-export. Lei è tornata in Cina e lui è a Milano. Sempre impegnato a imparare un vestito. Anche lui partecipa agli incontri dell'Associna ma si sente un pesce fuori d'acqua in confronto alla prima generazione di Wenzhounesi che sono un'elite dell'associazione. Anche un'altra idea di Jin è lavorare all'AUMAI, sono cinesi e lo assumerebbero, ma Jin non vuole lavorare come sales assistant, il suo sogno appunto è diventare imprenditore come suo padre anche se adesso il business di suo padre che il fratello Hong segue non sta andando molto bene per via della crisi finanziaria in Cina recentemente.

\section{Marketing development AUMAI}

400 negozi in tutto nord Italia, fatto colloquio, preso subito. Colloqui fatto c'erano anche seconde generazioni di Cinesi. Abbiamo uno spazio, dobbiamo trovare clienti, come l'orologio, il prodotto è il negozio, farlo entrare all'ingrosso, i clienti pagano l'affitto per fare l'ingrosso, devi poi gestire bene questi clienti, fai pubblicità evento e programma, per incrementare questo mercato, non puoi lasciarlo così. In futuro anche Cams, Wechat saranno usati. Sono entrato un po' tardi e loro sono organizzati da tempo. Vendono cose diverse, integrati su ciò che altri non hanno. Maggior parte degli acquirenti sono da Paolo Sarpi, fare ingrosso mercato, il nostro costo più bello. Lì al girasole sono nostri concorrenti ma il posto non è così bello. Al lavoro abbiamo fatto conferenza, scaricare merci, 300 sedie, ancora è da costruire non completo, alla fine di agosto completano tutto, Monza Ingrosso Mercato. AUMAI io appena iniziato non conosco bene capo, prima fabbrica, poi negozio dettaglio 14 anni ne ha aperti 36, sua mentalità diversa, innovativa, moderna, il capo è insieme agli amici che hanno creato questo. Da 4 anni questo progetto è iniziato, tre banche italiane hanno investito $3.300 .000 €$. Ci sono anche dipendenti italiani ma maggior parte cinese. Vado a scaricare merci, sedie, tavoli. Ancora il locale non è pronto. C'è un'altra ragazza cinese che ha lavorato un paio di anni con lui, noi responsabili mercato ingrosso, lui e il capo altro programma, energia immondizia. L'AUMAI di Loreto ha cambiato marchio più internazionale.

\section{Note Job-shadowing Italiano 24/11/2015}

Il locale è semi-deserto, a due passi da China Town, eppure i prezzi sono il doppio. Ci sono un po' di mezzi ubriachi sul retro. Il capo va sul retro e fa qualcos'altro, il bar è quasi vuoto, non c'è nessuno. La radio suona musica in italiano. I tizi sul retro fanno chiasso, il capo in pantofole va verso il retro quando è qui, legge la gazzetta. E' un deserto, certo la location è buona, lo spazio è più ampio e c'è una maggiore varietà di prodotti offerti. Il primo cliente è entrato e ha comprato qualcosa, paradossalmente il capo è molto spento non così tanto caloroso, è vecchio. Ora porta un caffè a quelli delle slot machines. E' molto lento, quasi sotto gamba, saluta e serve ma come freddo milanese non parla troppo. Ora è alla macchina del caffè, c'è un cliente ogni tanto, molto sporadicamente. Poi c'è litigio tra quelli alla slot. Il locale fa anche cibo per pranzo, la scelta è più variegata dei locali cinesi. I clienti generalmente sono italiani, sporadicamente qualche straniero. Ora il capo lava i piatti. Ora comincia ad esserci più gente, bar è italiano pieno di italiani, 
l'ambiente è più curato e colloquiale. Ci sono commenti continui tra il proprietario e la gente, il proprietario può associarsi alla cultura della gente. Il capo sa bene i nomi della gente, è vecchio stampo. I tizi anziani di là strillano. Ci sono anziani di là strillano. $\mathrm{Ci}$ sono anche dei venditori che vengono.

\section{Note Job-shadowing Minzhe 11/09/2015}

La prima impressione è che siamo a Sodoma e Gomorra, Calvin Klein, molto esplicito sessualmente. Ci sono molti cinesi che girano, alcuni molto ben vestiti potrebbero essere buyers. Entra Chen e va da GUCCI, deve prendere una sciarpa, ma parla in inglese. La signora è gentile ha parlato con un'altra signora che sta cercando, ora va al bancone. La persona è arrivata, è cinese come Chen, si conoscono bene. Ora parlano in cinese, forse le ha detto di attendere un momento. Chen fa una foto ad una piccola borsa rosa allo specchio, forse le interessa, mentre attende (marca GUCCI). La responsabile buyer è impegnata con un altro cliente, sono tutte cinesi o orientali. Ora Chen guarda altre borse. Guarda un'altra borsa rossa e controlla come le sta. Due persone coppia cinese anche loro buyers fuori da GUCCI discutono, hanno l'età di Chen. Chen fotografa un'altra borsa. Ora Chen fotografa portafogli, osserva i portafogli e li fotografa. Discutono ora Chen e Pan Chen, forse per via dell'attesa lunga alla cassa. Uno su due dei clienti è cinese. I manager parlano con loro in inglese. Chen sta facendo foto a cinture. Il cliente cinese va via dopo aver pagato. Momento morto di attesa. Tutti i negozi hanno almeno un cinese (alcuni seconde generazioni, parlano male cinese, la maggior parte Wenzhounese). Chen fa foto ad un'altra borsa, e un'altra ancora. Le piace il colore rosa. Ora si sposta su borse rosse. Ora Chen guarda un'altra borsa, non perde l'occasione per fare nuove foto davanti allo specchio. La signora dello store porta gli ordini, apre ci sono almeno 10 sciarpe GUCCI, Chen controlla la merce, piega e ripiega mentre parla con Pan Chen. La responsabile parla ancora sempre in Cinese. Le sciarpe ammontano a 20 ora. Pan Chen indica una borsa grigia. Chen fa una foto alla sciarpa senza plastica, la mette addosso e fa foto con la sciarpa addosso. Pan Chen paga. Chen segue diverse foto, con la sciarpa in diverse posizioni. La commessa raduna le sciarpe in diverse posizioni. La commessa raduna le sciarpe. Forse chiede a Chen come trova il prodotto, sciarpe rosa e nere. Un altro lavoratore cinese parla in Italiano e chiede dove sistemare le scatole. Qualche cliente ha bisogno di traduzione in cinese, va allo store manager cinese che sta servendo Chen. E' pieno di cinesi attorno, almeno uno ogni 3 tra i clienti. Ora c'è discussione tra la store manager e Chen. Un'altra lavoratrice cinese è al telefono in inglese, molto elegante l'ambiente. Ora Pan Chen tira fuori il portafoglio. Discussioni in corso forse su spedizione o tasse. Il cinese ora cliente è al telefono, forse parla con la ragazza su alcuni prodotti che ha visto e che è interessato. Prezzi generali (tot. Chen $1.600 €$ ) molto costosi, alta moda con grandi spese. Inglesi hanno un problema di lingua e comunicazione ma appunto $3 / 4$ del negozio è cinese. Discussione IVA 9 pezzi, ogni persona può comprare solo 3, siccome vogliono bloccare la vendita abusiva. Ora siamo a Salvatore Ferroganno, guardiamo sciarpe. Famiglia di clienti cinesi è qui. Chen osserva le cinture. Chen si preoccupa che la roba non venga venduta (stock) a Chen non piace stock. A volte si vende in giorni (maggior parte) settimane o mesi. Ha scelto questo brand perché le persone cinesi amano questo brand (dipende dal bisogno). Chen fa una foto alla cintura. Ormai è la 5 cintura che Chen esamina. Il broker parla cinese di questo negozio, è richiesto, anche se è italiano. Qualche piano di sopra c'è una che parla 5 lingue. Ora Chen fa una foto ad una felpa Kenzo, brand invernale, popolare in Cina, per questo Chen lo sceglie. Un altro Cinese, buyer deposita la felpa Kenzo, un altro cinese ci guarda per vedere cosa prendiamo. Gli appuntamenti di Chen in settimana sono stati Serravalle lunedì, Magenta martedì e oggi (venerdì a la Rinascente, ogni 2 o 3 giorni tornano qui). Torna dalle cinture vuole prenotare un capo per i prossimi arrivi. Chen guarda ai dettagli del prodotto. Due altri Coreani Cinesi girano guardano portafogli. Pan Chen ha visto un altro Amsterdam Chips con la croce, qualcun altro join the membership. Chen scrive la prenotazione della cintura. Chen controlla una borsa marrone, nera (brand tedesco comprato dai Coreani) popolare in Cina, la sales woman spiega il prodotto in inglese. Ora ha visto la borsa nera. 
Altri tre cinesi guardano prodotti che guarda Chen. Alcuni sono solo turisti. Andiamo al piano terra. Pan Chen va a vedere le sciarpe. Io e Chen andiamo al 3 piano a vedere le sciarpe, + borse, poi siccome arriva l'inverno compra sciarpe. Il negozio di sciarpe dove stiamo andando fa esenzione iva dunque molti buyer cinesi vanno lì. Chen osserva scarpe e fa foto, merce "stelle may coutney". Non ha trovato il modello che lei interessa, è stato venduto in fretta. Non lo prenota perché è ancora presto, prima deve esserci l'interesse dei clienti. Wan fa il business online, manager di 5 shop online, prende dal nostro shop e le condivide sui suoi shop online. Tony è molto occupato è in un altro posto. Io prendo foto, Wan collega le foto e Tony prende tutte le info sul prodotto e le ridà a Wan che le pubblica sui siti. Una ragazza cinese ha contattato Pan Chen per comprare le sciarpe e usare il suo nome per prendere molte sciarpe. Molte persone vengono per questo prodotto che è appena arrivato dunque va a ruba. La sale person aveva avvisato Chen al riguardo. La saleswoman è amica di una amica forte di Chen, da quando ha comprato ha dato wechat a Chen e lei manda messaggi e mette da parte la merce. Gennaio e Luglio sono saldi, pre-sales per Chen solo per 10 buyers, comprammo 1000 prodotti da GUCCI, più di 100 è già tanto. Ci danno pre-sales perché sanno che compro molto, dunque ci mandano foto, ogni negozio fa pre-sales. Tanti sono anche russi nel negozio, lavorano anche loro duro. 10.000 foto, ogni giorno 100-200-300 di cui una borsa 5-7 foto, di cui il $30 \%$ venduto, dipende se le persone apprezzano o meno (memoria $128 \mathrm{~GB}$ ). Serravalle vendono le stesse cose ma l'ultima stagione vanno lì una volta alla settimana. Summerize riceve le foto e vende le borse (Tony e Wan prendono il 10\% di revenue, Summerize il 60\% noi il $40 \%$ ). Il business ora non è bene come due anni fa, cinese non hanno i soldi, comunque alcuni continuano a comprare, prima compravano per regali, ora per se stessi pensano prima di comprare, prima compravano senza pensarci. Altre boutiques, 2 anni in Svizzera con FOXTOWN un altro buyer aiuta, l'outlet THE MORE vicino a Firenze, vive a Prato il dipendente che Chen conosce, più altre boutiques a Via Montenapoleone (Chanel, Pisa, Watch...) molti negozi laggiù, una volta alla settimana o meno. Altre boutique in piccola città vicino a Milano o vicino a Firenze. Clienti facevo all'inizio cliente in Malesia su facebook, poi in Cina con un amico cinese in Weibo (come twitter) e tutti possono vedere i suoi post, poi alcuni vedono foto e diventano clienti, poi wechat facciamo il business lì. Poi il pagamento è su Taubau perché è sicuro pagare.

\section{Shadowing note di campo Chen 20/07/2015}

Siamo arrivati al Tony store a Magenta è un negozio di borse italiano all'ingrosso, Chen guarda le borse e sceglie quelle che sembrano migliori, prodotti di marca, terza o quarta volta che vengono qua a guardare, sono vestiti all'ingrosso. Chen controlla con il cellulare i prezzi e la qualità dei prodotti, il posto è molto vicino a Pero. C'è un'altra ragazza cinese che lavora dando un'occhiata ai prodotti. Questa è la catena di marca ed hanno tutte le camicie della loro marca, su una camicia da 400 euro Chen ci aggiunge 50 euro e la vende in Cina. Chen fa in base alla domanda, viene qui, fa le foto dei prodotti che manda in Cina, pubblica sul sito web, poi in base alla domanda compra la roba. Comprare interi stock costa tanto se non se lo possono permettere preferiscono comprare solo quando il cliente in Cina ha pagato. Il valore della merce è 7000 euro circa, i costi di trasporti 150 euro. Loro non inviano la merce in Cina finché abbia raggiunto un totale di valore accumulato di prodotti sufficiente. Ora è la terza o quarta signora/ragazza cinese che vedo passare oggi. Tutte vanno in giro e fanno foto per fare la stessa cosa che fa Chen, 1 su 10 sono buyer che vengono a comprare i prodotti, più in Duomo, dove ci sono tante boutique di moda. Tony è aiuto a Chen per trovare clienti, vede $\mathrm{i}$ siti, le persone interessate, va a trovarli, presenta i prodotti e li vende. E' però solo un pensiero ancora non si sa'. Il problema è che le cose di lusso sono costose, lo stesso prodotto in Cina (1800 euro laggiù, quindi conviene comprare qui). Tony ha fatto diversi appuntamenti per capire gli sconti, parlare con i manager, capire il miglior mezzo di trasporto, le tasse... Prendevano nomi dai siti e vanno a visitare. La gente attorno è molto fashion, noi diamo idea di sobrietà. Madre e figlia cinesi sono venute a fare compere, hanno preso forse perché sono buyer. I tipi di vestiti venduti qui sono di alta qualità. La merce viene pubblicata su siti 
web come e-bay o alibabà (taobao sottogruppo di alibabà, specialmente per persone che vendono prodotti). Persone più giovani di 40 anni conoscono il sito e vogliono comprare da lì, l'e-commerce ora è molto popolare, qui in Italia invece no, si va al negozio o alla boutique anche per paura di perdere la fiducia. Taobao risolve anche il problema della fiducia in caso di truffe pagando alla compagnia, il venditore manda la merce ma la compagnia è nella transizione per garantire fiducia (sistema di pagamento per il cliente da pagare poi al venditore). Lui iniziò da 200.000 euro ora è la persona più ricca della Cina, 14 bilioni di dollari (Maui). Siamo andati a vedere ora i prodotti nel magazzino, tre cinesi sono con noi, stiamo guardando la merce si parla spesso di tax free, mandando merce in Cina, qui in magazzino c'è la nuova merce arrivata, è passata la proprietaria, conosce Chen. Chen e Pan Chen fanno foto ai brand di borse che ritengono buoni, Chen sceglie il modello migliore in base a ciò che va nel settore e poi fotografa. Le borse sono tutte di marca, poi fanno foto in base a quello che sembra più di moda. Il capo sembra dare più attenzione alle altre due cinesi forse perché comprano di più, tutto sta nell'avere i clienti giusti. Le borse sono tutte nuovi arrivi, Pan Chen le prende e le fa foto a Pan Chen o Chen. Due cinesi parlano, non sono amici, pur facendo lo stesso mestiere da buyer. Il capo torna e chiede se vogliamo dell'acqua. I cinesi sembrano assetati di vedere cose, fanno pochi complimenti, non c'è tutta quest'etichetta all'italiana. Il capo sta con dei fogli e osserva, poi Chen gli passa le borse a cui è interessata (1495 euro il prezzo di una borsa). Poi serviva un'altra borsa, lui guarda il prezzo (495 euro). Quelle che interessano vengono prese perché è sicura che valgono. Entra un'altra persona che è italiana e conosce Chen e Pan Chen. Chen è in un angolo le piace tutto il settore specifico. Sceglie borse molto costose. Gli italiani sono d'accordo con l'avere buyers cinesi. Pan Chen sceglie anche lui due o tre borse che lo interessano. Le borse vanno a ruba, hanno già finito di prendere qualche prodotto che non c'è più niente che si può prendere, Chen voleva la borsa rossa che altri volevano ma lei le ha già prese. I prezzi non scendono sotto i mille euro. Pan Chen porta un'altra borsa che è grigia a Chen chiedendo cosa ne pensa, Chen è al telefono in attesa di risposte immediate in merito ai prodotti, magari qualcuno è interessato e vuole comprare. C'è un commento su una borsa, Chen dice al capo e il capo risponde: "l'hai venduta? Brava!" ormai è la trentesima borsa che Chen osserva e fa foto davanti alle borse forse per dimostrare che è lei che personalmente le compra. Pan Chen osserva altre borse, c'è un'altra cinese, sembra girare esattamente dove è Pan Chen e l'osserva. Pan Chen mostra tre borse di diversi colori a Chen chiedendole cosa ne pensa. Il capo chiede se vuole fare foto, ad un'altra cinese non sembra molto decisa, Pan Chen e Chen invece sono in una corsa per cercare di vendere. Chen indossa un'altra borsa sulle spalle, Pan Chen è il fotografo di turno. Ogni prodotto almeno due o tre foto, sia all'interno che all'esterno. Il capo chiede se vuole stare al caldo? Domanda sullo stress di stare in magazzino. Pan Chen guarda e porta il PC vede quanto costano, tutto rigorosamente di marca. Nel magazzino è molto caldo (questo magazzino vende solo borse mi chiedo se altri vendono anche altri prodotti. Ci sono criteri precisi secondo cui Chen valuta la merce, praticità, uso e gusto, anche la valutazione prima di fotografare è un elemento importante. Si fanno foto fuori e dentro, la valutazione richiede occhio e capacità. Il capo chiede ancora se Chen ha venduto ancora. Nella situazione Chen e Pan Chen sono sicuri, sembrano esperti si aiutano, sono come una squadra. E' importante che il prodotto sia di stile ed alta moda. Pan Chen controlla molto quante tasche il prodotto ha. Appena conclusa una borsa Chen ha l'occhio su un'altra, le controllano tutte. L'esterno è d'interesse di Chen, Pan Chen si preoccupa della praticità del prodotto, delle tasche, delle cinte... Pan Chen chiede il prezzo di altre due borse. I cinesi non hanno interesse sulla forma della transizione, ma vanno dritto al sodo (200-2070 euro 1800 euro sono i prezzi delle borse). Chen scrive subito sul sito il prezzo che è stato dichiarato vedendo se qualcuno vuole comprare. I due discutono sulla praticità della borsa. L'altra cinese nell'altra stanza va sui prezzi ben più basi (173 euro). Ci sono stati primi interessi poi si prende feedback dai clienti cinesi e torneranno dopo tre giorni a comprare. Cambiamo settore del magazzino, ora siamo alle camice. Chen guarda le scarpe, le fotografa, mentre Pan Chen guarda le camice. Tutti i prodotti sono di lusso. Si osservano anche le cinture. Seguiamo Chen che fotografa le cinture. Stanno guardando Gucci, le scarpe e i vestiti. C'è un'altra ennesima ragazza cinese che è arrivata, si osservano a vicenda, si seguono per vedere che 
comprano gli altri. Prada e tutte grandi marche. Prendono un portafoglio che hanno venduto di Gucci c'è una discussione tra loro in corso. Ci avviciniamo alla cassa, 30, 400, 1400 sono gli acquisti di oggi in base alle richieste raggiunte. $\mathrm{Ci}$ sono anche vendite di giorni scorsi che Chen è tornata a prendere. Vengono consegnati gli scontrini delle compere, almeno due pagine. Ora devono controllare di aver preso tutto, tutte le loro vendite che gli sono arrivate. Chen passa ogni scontrino per vedere che tutto sia stato comprato, che il prodotto sia esattamente quello che le serve. Chen rinuncia ad una cintura perché manca la misura esatta che le serve. La proprietaria perde la pazienza, come si fa a vendere così, cita il nome di Dio invano, perde la pazienza mentre Chen e Pan Chen sembrano tranquilli. Le altre due buyer continuano a consultare la merce, con la coda dell'occhio guardano noi. Una lucertola cammina sull'ingresso. C'è un inconveniente lei non sa come mettere i prezzi dunque dobbiamo aspettare. E' un momento morto, si aspetta che ci portino $i$ prezzi di tutto così che si possa andare. Siccome è un family shop sono molto amichevoli, l'uomo che ha la barba è responsabile di tutti i buyer, c'è sconto Chen è sorpresa che ci siano altre cinesi è insoddisfatta di questo, che ci sia uno sconto qui dovrebbe essere un segreto. Chen ha parlato sempre con il manager per gli affari, non necessariamente con il proprietario. E' arrivata la signora con i pagamenti e la lista delle persone per assicurarsi che hanno la merce giusta. Controllano il portafoglio di Gucci... e altre cose da ritirare che lei ha ordinato, si assicurano di prendere il modello giusto. Chen aiuta la signora ad identificare la sua merce da ritirare. 8,9 sono i negozi dove Chen e Pan Chen sono buyer regolari. Ritorna la collega e ha problemi ad indentificare i giusti colori della merce. Il responsabile dei buyer è tornato prende Chen e la porta a scegliere il colore. Un mese fa Chen ha incontrato il ragazzo della chiesa (Pietro) insieme a Tony, un amico di Chen, è amico con Pietro da tanto, sapeva che andavano in Toscana e allora sono andati insieme poi tornati a Milano hanno avuto una conversazione insieme per il business. Anche l'amico comune è cristiano. Chen controlla la merce impacchettata prima di comprare. Il responsabile buyer sorride a Chen sul prezzo, gli ha fatto uno sconto, si vede (6.795 euro prezzo del totale acquisto). La cameriera chiede se vogliono spedire ma lui dice di no perché devono venire ancora domani (ulteriori acquisti da fare ancora). Probabilmente è la questione del feedback di cui mi diceva Pan Chen (riceve feedback dai clienti in Cina dal sito e torna qui a comprare). 5805 prezzo scontato almeno di mille euro. Il medio della rendita per ogni prodotto è 2030 euro in più. Il prezzo è basso se lo alziamo il cliente va da un altro, ci sono molti competitors, per questo è importante mantenere il prezzo basso.

\section{Shadowing note di campo Chen $\quad 20 / 07 / 2015$}

Siamo arrivati al Tony store a Magenta è un negozio di borse italiano all'ingrosso, Chen guarda le borse e sceglie quelle che sembrano migliori, prodotti di marca, terza o quarta volta che vengono qua a guardare, sono vestiti all'ingrosso. Chen controlla con il cellulare i prezzi e la qualità dei prodotti, il posto è molto vicino a Pero. C'è un'altra ragazza cinese che lavora dando un'occhiata ai prodotti. Questa è la catena di marca ed hanno tutte le camicie della loro marca, su una camicia da 400 euro Chen ci aggiunge 50 euro e la vende in Cina. Chen fa in base alla domanda, viene qui, fa le foto dei prodotti che manda in Cina, pubblica sul sito web, poi in base alla domanda compra la roba. Comprare interi stock costa tanto se non se lo possono permettere preferiscono comprare solo quando il cliente in Cina ha pagato. Il valore della merce è 7000 euro circa, i costi di trasporti 150 euro. Loro non inviano la merce in Cina finché abbia raggiunto un totale di valore accumulato di prodotti sufficiente. Ora è la terza o quarta signora/ragazza cinese che vedo passare oggi. Tutte vanno in giro e fanno foto per fare la stessa cosa che fa Chen, 1 su 10 sono buyer che vengono a comprare i prodotti, più in Duomo, dove ci sono tante boutique di moda. Tony è aiuto a Chen per trovare clienti, vede $\mathrm{i}$ siti, le persone interessate, va a trovarli, presenta i prodotti e li vende. E' però solo un pensiero ancora non si sa'. Il problema è che le cose di lusso sono costose, lo stesso prodotto in Cina (1800 euro laggiù, quindi conviene comprare qui). Tony ha fatto diversi appuntamenti per capire gli sconti, parlare con i manager, capire il miglior mezzo di 
trasporto, le tasse... Prendevano nomi dai siti e vanno a visitare. La gente attorno è molto fashion, noi diamo idea di sobrietà. Madre e figlia cinesi sono venute a fare compere, hanno preso forse perché sono buyer. I tipi di vestiti venduti qui sono di alta qualità. La merce viene pubblicata su siti web come e-bay o alibabà (taobao sottogruppo di alibabà, specialmente per persone che vendono prodotti). Persone più giovani di 40 anni conoscono il sito e vogliono comprare da lì, l'e-commerce ora è molto popolare, qui in Italia invece no, si va al negozio o alla boutique anche per paura di perdere la fiducia. Taobao risolve anche il problema della fiducia in caso di truffe pagando alla compagnia, il venditore manda la merce ma la compagnia è nella transizione per garantire fiducia (sistema di pagamento per il cliente da pagare poi al venditore). Lui iniziò da 200.000 euro ora è la persona più ricca della Cina, 14 bilioni di dollari (Maui). Siamo andati a vedere ora i prodotti nel magazzino, tre cinesi sono con noi, stiamo guardando la merce si parla spesso di tax free, mandando merce in Cina, qui in magazzino c'è la nuova merce arrivata, è passata la proprietaria, conosce Chen. Chen e Pan Chen fanno foto ai brand di borse che ritengono buoni, Chen sceglie il modello migliore in base a ciò che va nel settore e poi fotografa. Le borse sono tutte di marca, poi fanno foto in base a quello che sembra più di moda. Il capo sembra dare più attenzione alle altre due cinesi forse perché comprano di più, tutto sta nell'avere i clienti giusti. Le borse sono tutte nuovi arrivi, Pan Chen le prende e le fa foto a Pan Chen o Chen. Due cinesi parlano, non sono amici, pur facendo lo stesso mestiere da buyer. Il capo torna e chiede se vogliamo dell'acqua. I cinesi sembrano assetati di vedere cose, fanno pochi complimenti, non c'è tutta quest'etichetta all'italiana. Il capo sta con dei fogli e osserva, poi Chen gli passa le borse a cui è interessata (1495 euro il prezzo di una borsa). Poi serviva un'altra borsa, lui guarda il prezzo (495 euro). Quelle che interessano vengono prese perché è sicura che valgono. Entra un'altra persona che è italiana e conosce Chen e Pan Chen. Chen è in un angolo le piace tutto il settore specifico. Sceglie borse molto costose. Gli italiani sono d'accordo con l'avere buyers cinesi. Pan Chen sceglie anche lui due o tre borse che lo interessano. Le borse vanno a ruba, hanno già finito di prendere qualche prodotto che non c'è più niente che si può prendere, Chen voleva la borsa rossa che altri volevano ma lei le ha già prese. I prezzi non scendono sotto i mille euro. Pan Chen porta un'altra borsa che è grigia a Chen chiedendo cosa ne pensa, Chen è al telefono in attesa di risposte immediate in merito ai prodotti, magari qualcuno è interessato e vuole comprare. C'è un commento su una borsa, Chen dice al capo e il capo risponde: "l'hai venduta? Brava!" ormai è la trentesima borsa che Chen osserva e fa foto davanti alle borse forse per dimostrare che è lei che personalmente le compra. Pan Chen osserva altre borse, c'è un'altra cinese, sembra girare esattamente dove è Pan Chen e l'osserva. Pan Chen mostra tre borse di diversi colori a Chen chiedendole cosa ne pensa. Il capo chiede se vuole fare foto, ad un'altra cinese non sembra molto decisa, Pan Chen e Chen invece sono in una corsa per cercare di vendere. Chen indossa un'altra borsa sulle spalle, Pan Chen è il fotografo di turno. Ogni prodotto almeno due o tre foto, sia all'interno che all'esterno. Il capo chiede se vuole stare al caldo? Domanda sullo stress di stare in magazzino. Pan Chen guarda e porta il PC vede quanto costano, tutto rigorosamente di marca. Nel magazzino è molto caldo (questo magazzino vende solo borse mi chiedo se altri vendono anche altri prodotti. Ci sono criteri precisi secondo cui Chen valuta la merce, praticità, uso e gusto, anche la valutazione prima di fotografare è un elemento importante. Si fanno foto fuori e dentro, la valutazione richiede occhio e capacità. Il capo chiede ancora se Chen ha venduto ancora. Nella situazione Chen e Pan Chen sono sicuri, sembrano esperti si aiutano, sono come una squadra. E' importante che il prodotto sia di stile ed alta moda. Pan Chen controlla molto quante tasche il prodotto ha. Appena conclusa una borsa Chen ha l'occhio su un'altra, le controllano tutte. L'esterno è d'interesse di Chen, Pan Chen si preoccupa della praticità del prodotto, delle tasche, delle cinte... Pan Chen chiede il prezzo di altre due borse. I cinesi non hanno interesse sulla forma della transizione, ma vanno dritto al sodo (200-2070 euro 1800 euro sono i prezzi delle borse). Chen scrive subito sul sito il prezzo che è stato dichiarato vedendo se qualcuno vuole comprare. I due discutono sulla praticità della borsa. L'altra cinese nell'altra stanza va sui prezzi ben più basi (173 euro). Ci sono stati primi interessi poi si prende feedback dai clienti cinesi e torneranno dopo tre giorni a comprare. Cambiamo settore del magazzino, ora siamo alle camice. Chen guarda le scarpe, 
le fotografa, mentre Pan Chen guarda le camice. Tutti i prodotti sono di lusso. Si osservano anche le cinture. Seguiamo Chen che fotografa le cinture. Stanno guardando Gucci, le scarpe e i vestiti. C'è un'altra ennesima ragazza cinese che è arrivata, si osservano a vicenda, si seguono per vedere che comprano gli altri. Prada e tutte grandi marche. Prendono un portafoglio che hanno venduto di Gucci c'è una discussione tra loro in corso. Ci avviciniamo alla cassa, 30, 400, 1400 sono gli acquisti di oggi in base alle richieste raggiunte. Ci sono anche vendite di giorni scorsi che Chen è tornata a prendere. Vengono consegnati gli scontrini delle compere, almeno due pagine. Ora devono controllare di aver preso tutto, tutte le loro vendite che gli sono arrivate. Chen passa ogni scontrino per vedere che tutto sia stato comprato, che il prodotto sia esattamente quello che le serve. Chen rinuncia ad una cintura perché manca la misura esatta che le serve. La proprietaria perde la pazienza, come si fa a vendere così, cita il nome di Dio invano, perde la pazienza mentre Chen e Pan Chen sembrano tranquilli. Le altre due buyer continuano a consultare la merce, con la coda dell'occhio guardano noi. Una lucertola cammina sull'ingresso. C'è un inconveniente lei non sa come mettere i prezzi dunque dobbiamo aspettare. E' un momento morto, si aspetta che ci portino i prezzi di tutto così che si possa andare. Siccome è un family shop sono molto amichevoli, l'uomo che ha la barba è responsabile di tutti i buyer, c'è sconto Chen è sorpresa che ci siano altre cinesi è insoddisfatta di questo, che ci sia uno sconto qui dovrebbe essere un segreto. Chen ha parlato sempre con il manager per gli affari, non necessariamente con il proprietario. E' arrivata la signora con i pagamenti e la lista delle persone per assicurarsi che hanno la merce giusta. Controllano il portafoglio di Gucci... e altre cose da ritirare che lei ha ordinato, si assicurano di prendere il modello giusto. Chen aiuta la signora ad identificare la sua merce da ritirare. 8, 9 sono i negozi dove Chen e Pan Chen sono buyer regolari. Ritorna la collega e ha problemi ad indentificare i giusti colori della merce. Il responsabile dei buyer è tornato prende Chen e la porta a scegliere il colore. Un mese fa Chen ha incontrato il ragazzo della chiesa (Pietro) insieme a Tony, un amico di Chen, è amico con Pietro da tanto, sapeva che andavano in Toscana e allora sono andati insieme poi tornati a Milano hanno avuto una conversazione insieme per il business. Anche l'amico comune è cristiano. Chen controlla la merce impacchettata prima di comprare. Il responsabile buyer sorride a Chen sul prezzo, gli ha fatto uno sconto, si vede (6.795 euro prezzo del totale acquisto). La cameriera chiede se vogliono spedire ma lui dice di no perché devono venire ancora domani (ulteriori acquisti da fare ancora). Probabilmente è la questione del feedback di cui mi diceva Pan Chen (riceve feedback dai clienti in Cina dal sito e torna qui a comprare). 5805 prezzo scontato almeno di mille euro. Il medio della rendita per ogni prodotto è 2030 euro in più. Il prezzo è basso se lo alziamo il cliente va da un altro, ci sono molti competitors, per questo è importante mantenere il prezzo basso.

\section{Note di Campo osservazione Chen e Tony 14/07/15}

Oggi avevo intenzione di andare con Tony e Chen a Magenta per incontrarli mentre fanno la loro transizione con un cliente. Alla fine sono partiti senza di me e Pan Chen si dice impegnato ad andare in centro, dunque la mia osservazione va in fumo. I due sono andati a Magenta la mattina per incontrare un cliente. Nel pomeriggio faranno poi un incontro per pianificare il business futuro poi ci siamo visti alla cena d'addio di Tony a porta Romana. Tony e Chen hanno intenzione di iniziare una collaborazione, Tony tornerà in Cina e troverà clienti per i prodotti che Chen vende dall'Italia, un portafolio clienti da ampliare e migliorare. Chen invece ha i suoi supplier qui in Italia sei o sette negozi dove va abitualmente più nuove botteghe e negozi di alta moda che Tony ha aiutato a trovare tramite ricerche e contatti di amici. Tony e Chen la scorsa settimana hanno avuto una missione a Prato, Lucca e Firenze da diversi fornitori per vedere la merce, l'idea è loro venuta tramite un amico in comune che fa parte della chiesa evangelica cinese e che è amico di un altro della chiesa evangelica cinese che fa mestiere simile. Hanno deciso di andare insieme a Firenze per vedere $\mathrm{i}$ prodotti e valutare. Il ragazzo mi conosce e mi saluta, conosce la ricerca che sto facendo e ha parlato a Chen e Tony di me. I due si dicono più ancora incoraggiati e tranquilli di discuterne con 
me. Tony mi ha chiesto di tradurre in corretto italiano diverse corrispondenze ha avuto con diverse boutique questi giorni. In particolare chiede se può vedere i nuovi arrivi in magazzino, fare un buon prezzo e capire se interessato come funziona per la spedizione della merce per essere tax free passando eventualmente per Hong Kong. Tony ha un modo di fare amichevole e capace di stringere relazioni che ha imparato passando il tempo con gli Americani, e si vede la differenza nella sua fede quando lavora, la sua maggiore calorosità e strategia. Oggi ho pure incontrato un altro ragazzo della chiesa evangelica cinese che vendeva prodotti e sciarpe e vestiario alla bancarella della fermata Metro Agostino. La volta dopo che ci siamo visti alla chiesa l'osservazione che ho avuto mi ha dato l'impressione che lui era inusualmente aperto con me, e anche con ignorii da parte degli altri ragazzi della chiesa, vedo in questo l'immagine e rispetto che ci sono se hai business di successo e invece disprezzo nel caso in cui non hai molti soldi o il tuo business non cresce.

\section{Studio Biblico Giovani 04 aprile 2015}

Domande Filippesi 2, 12-18:

1) Versetti 12-13, come bisogna interpretare che Paolo all'inizio applaude l'obbedienza ma avverte di adoperarsi al compimento della salvezza con timore e tremore? Sebbene ubbidienti devono non accontentarsi (volere e agire da Dio - no fede passiva), v. 13 spiega il perché...

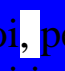

. Siamo stati scelti come figli non perché abbiamo fatto qualcosa, appreziamolo, non diamolo per scontato, tienilo stretto, scordiamo di chiedere quello che Lui vuole da noi. Tremore verso noi stessi pensiamo che facciamo bene per la chiesa ma Dio non vuole solo questo, segui il volere e sentimento di Cristo, rischi di dare la gloria a te stesso, non hai timore per Cristo ma quello che fai per te stesso, v. 12 livello quando con loro in tutti i versetti frutto che Dio ci lascia di avere tutto da Cristo. Paolo è in prigione vorrebbe che andassimo avanti con lo stesso spirito.

2) Vv. 14-16 ci sono dei punti in cui Paolo dice di fare attenzione quali sono? Non avere liti, essere impeccabili, integri, contrario di ipocrita, separati dal mondo, proclamatori della Bibbia, Paolo meriti di aver fatto bene, v. 14 no dispute se ne hai una ed eviti di discutere ti dicono che non sei sincero, fiducia verso i Filippesi non va persa, verso il Signore non avere mormorii, tutta la tua speranza è in Cristo non t'importa di quello che la gente pensa, dobbiamo saper discutere senza litigare, essere integri, essere cristiano nel fare le cose, nella realtà difficile applicare il principio, vantarsi della strada percorsa, della battaglia vinta, non avere rammarico, per quanto perfetti avrai difetti in Cristo potremmo essere perfetti, verso Dio no mormorii.

3) Vv. 17-18 cosa offre Paolo come sacrificio a Dio? perché gioisce davanti alla morte? Cosa avete imparato dalla vita di Paolo? La sua vita, è onorato per morire per la fede condivisa con altri, ha un totale abbandono a Cristo e alla chiesa, offre la cosa migliore, la fede perché ci tiene ai Filippesi. L'Antico Testamento si offrivano le cose migliori, Cristo si è sacrificato se abbiamo fede in Cristo è la cosa più importante.

\section{4/10/2014 Sabato Studio biblico al gruppo giovani (Naturally occurred data)}

L'incontro giovani inizia, siamo circa 14 persone, maggior parte uomini, siamo nella stanza inferiore. Mi accolgono subito con calore, in particolare Jin è molto caloroso e mi fa domande, parla un perfetto italiano, un'altra persona mi ricorda con sarcasmo che Jin è cittadino italiano e che non sono l'unico italiano nella stanza. Iniziamo con due canti di adorazione in cinese. Iniziamo a leggere la Bibbia ad alta voce tutti insieme in cinese, intanto arriva Leo. Ci dividiamo in tre gruppi alle luia amen, io sono nel gruppo luia, c'è anche Jin. Leggiamo Efesini 2, 11-22. Leggiamo di nuovo insieme ad alta voce. Le domande sono: qual è il frutto dei pagani? Cosa pensano del futuro i 
pagani? Iniziano i commenti, essi sono senza elezione, senza speranza, senza Dio. Qualcuno sottolinea la chiara distinzione tra credenti e pagani. C'è un senso di predilezione tra i partecipanti. Si sottolinea l'importanza dell'abbandono della vita prima di Cristo. Lo Spirito deve guidare il credente a fare ciò che deve fare. Do un mio contributo e spiego in italiano la differenza tra Israele dell'Antico Testamento e i credenti Cristiani, nuovo Israele. Noto che la mia presenza attira Jin, vede che sono educato e formato nella fede. Sono arrossiti alcuni perché sono l'unico italiano. Seconda domanda è quando ottieni la salvezza come vivi? Cosa fa la salvezza in te? Il versetto 14 e 17 attira la mia attenzione, la parola pace è ripetuta diverse volte. La pace per me è frutto della salvezza. Alcuni si lamentano della traduzione della Bibbia cinese, preferirebbero averla in italiano. La pace nella traduzione cinese sembra essere ricondotta ad una pace tra uomini invece che con Dio. Iniziano i commenti, la salvezza ci porta a voler stare più vicini al Signore, un cambiamento tra l'uomo e Dio, sia una pace col Signore che con i popoli. La salvezza porta pace tra Dio e gli uomini, una cittadinanza nei cieli, unità tra noi, riconciliazione. Nella sofferenza Dio ci dà la forza, senza Dio sarebbe impossibile. Dopo un momento di silenzio mi viene chiesto di condividere la mia testimonianza, tutti rimangono molto colpiti ed incoraggiati. La terza domanda è qual è il tuo ruolo nel corpo di Cristo. Jin vuole assicurarsi che ho capito, mi dice che è una domanda personale. Qual è il nocciolo della nostra vita, il fondamento. Commento che Gli apostoli erano fondatori della chiesa, questo era il senso del versetto. Alcuni dicono lo scopo è amarci l'un l'altro, siamo come cemento tra i mattoni. Alcuni chiedono come possiamo essere utili nella chiesa.

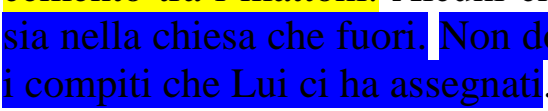

Tutto quel che facciamo è dare gloria a Dio. Importante mi ricorda il ragazzo timido con gli occhiali è passare il messaggio ad altri. La testimonianza ha un grande ruolo dice Jin ricordando ciò che ho detto prima. La pace ce l'ha anche Jin da quando ha ricevuto Cristo. Nel cantare, adorare, pregare, lavorare, tutto è per Dio. Dio non ha in realtà bisogno di noi
ma vuole usarci. Tanti sono i modo in cui possiamo portare gloria a Dio. Come comportarci come
cristiani, la nostra condotta dimostra ai pagani chi siamo, all'inizio siamo timidi ma con Dio

Ritorniamo insieme nella aula comune ognuno condivide tra i tre gruppi che abbiamo imparato. Il responsabile è incoraggiato di vedere nuove persone nelle scorse settimane. Ci sono anche non credenti, nel mio gruppo forse il ragazzo con i capelli rasati. La riunione si chiude con un altro canto. Mi danno un quaderno dove posso mettere i fogli dei canti. Sono gentili, saluto tutti con la mano, sono davvero calorosi, mi invitano a tornare.

Efesini 4, 1-16

1) In quante sezioni possiamo dividere questo capitolo? Quale concetto esprime ogni paragrafo? Vv. 1-6 unità nella fede, vv. 7-10 Cristo da i doni vv. 11-16 doni e scopo dei doni.

2) Come manteniamo l'unità bene nella chiesa? V. 2 sforzandoci, v. 13 sulla base della Parola di Dio, conoscenza profonda come quella di un amico, v. 6 in tutti (credenti).

3) Quali sono i fattori dell'unità? Vv. 4-6 il corpo, le dottrine

4) Come Paolo ha descritto la maniera in cui Cristo da i doni? Gesù è salito al cielo eravamo prigionieri di Satana (vv. 9-10), Cristo è anche sceso, diversi significati (diventare uomo, scendere agli inferi, morire in croce)

5) Le funzioni dei doni? Cosa sono esattamente questi doni? V. 13, unità della fede, maturità, conoscenza, statura di Cristo, verità e amore, distinguersi dalle sette, Cristo ci da i doni (v. 12) per farci uniti nel corpo, ognuno ha diversi doni che usa per costruire e stabilizzare il corpo di Cristo. Il risultato dei doni è il perfezionamento, il saper distinguere le false dottrine.

6) Come costruire nell'amore il corpo? V. 16 l'amore è Cristo, personalmente come costruito nell'amore. Usciamo dal vecchio uomo, diventiamo uomo nuovo. V. 15 cresciamo verso Cristo. Aiutiamoci reciprocamente. Ogni parte fa la sua. 
Prima domanda: cosa pensa Paolo della propria prigionia? Versetti 1 e 13 dolore misto all'amore per glorificare Dio. La prigionia rendeva gloria a Dio, nello Spirito è contento anche se nella carne soffre. La maggior parte degli efesini sono stranieri. Paolo ha gioia e volontà: "per voi" viene ripetuto tre volte. Paolo prigioniero per Cristo lo scopo è servire al Vangelo (v. 7). La gloria è vostra e per gli stranieri non per Paolo, affronta la prigionia con coraggio, non come un male. Il compito di Paolo è infondere bontà innumerabile di Dio agli stranieri, così noi cristiani possiamo superare queste difficoltà.

Seconda domanda: Dio ha scelto specialmente Paolo per fare cosa? Cosa ha dato Dio a Paolo perché lo realizzasse? Evangelizzare, dispensare la grazia di Dio, annunziare agli stranieri le ricchezze di Cristo, il piano di Dio. Dono spirituale di Paolo per evangelizzare. Termine cinese per grazia è "antié".

Terza domanda: qual è il contenuto del mistero? Perché con noi? Qual è lo scopo del mistero? Discussione sui demoni o angeli del versetto 10. Ricordare l'unità insieme all'uguaglianza, stessi diritti degli ebrei, discendenza di Dio, fratelli e sorelle (in tutti i sensi), anche predestinazione, eletti prima della fondazione del mondo, stessi che gli ebrei, speranza, gloria dei santi, adozione, ravvedimento (vivificati in Cristo), redenzione, eredità, salvezza per grazia, stranieri chiamati a Cristo, contrasto tra contenuto e scopo del ministero: dispensazione della grazia, paradiso, conosciuti (angeli decaduti, demoni), e dall'altra parte sapienza di Dio, che tutti "sappiano" di Dio, volere di Dio ed andare a Dio.

Quarta domanda: come progetta questo ministero Dio in Cristo? Attraverso la nascita morte e risurrezione di Cristo, gli apostoli, attraverso la rivelazione, nel suo disegno portato avanti dallo spirito e che ci porta a sperimentare l'amore di Cristo (v. 18). Una volta era un mistero ora non più. Abbiamo la libertà di accostarci a Dio per fede, chi ha Cristo ha tutto (v. 11), c'è un piano di Dio (v. 9), siamo stati scelti prima della fondazione del mondo.

Condividiamo quello che abbiamo imparato, nelle difficoltà c'è un disegno di Dio, non dobbiamo essere pessimisti, siamo ricchi ed uguali a Israele. Bisogna considerare tanti punti di vista (l'umiltà di Paolo, il non scoraggiarsi).

\section{Osservazioni chiesa cinese $13 / 09 / 2015$}

Matteo 12, 33-37 c'è un proverbio cinese che dice la stessa cosa di Matteo 12, 34 come può una persona progredire se è cattiva. L'uomo vede il risultato ma Dio l'origine, il cuore si esprime a parole. Ci sono almeno 20 persone allo studio biblico, alcuni fanno parte dell'altra chiesa. Un laoban ha reso a disposizione la cantina della sua casa per fare la chiesa. Cosa vuol dire buono? Unito con Dio in ogni cosa. Cattivo? Si allontana da Dio. Il pastore in cravatta guida lo studio biblico. E' della stessa regione di Leo vicino a Wenzhou. Alcune persone credono di essere giuste ma fanno per sé stessi, la vera giustizia è essere allineati con Dio. Una persona deve avere una buona relazione con Dio e allora fa buone opere. Chi invece non è allineato col Signore non riesce nonostante gli intenti. C'è tanta gente e non c'è differenza tra loro. L'amore umano è superficiale, quando c'è antipatia non amiamo, Dio ci invita ad amare i nemici. Ci sono questioni di cultura cinese, intraducibili, che crano un ponte per loro. Da che parte stai si chiede il Pastore. V. 37 non solo le parole ma anche i miei pensieri malvagi, Dio legge tutto. Sono tutti giovani all'incontro. C'è un potere nelle parole, influenzi le persone nel male o nel bene. Lettera da pubblicare 20 anni dopo la morte, lo scenziato, dice c'è c'è fonte di energia invisibile quella dell'amore, non si può esaminare ma esiste. 
Prima domanda: Dobbiamo piegarci in ginocchio per pregare? Non necessariamente ma è un rapporto di umiltà e rispetto. Quando possibile sottomettiti a Dio, siccome tutto è di Dio non potremo non inginocchiarci davanti a Dio, non solo in senso fisico ma anche spirituale. Pensiamo alle tentazioni di Gesù nel deserto, Gesù sottolinea che l'uomo vive non di solo pane ma della Parola di Dio (Colossesi 3, 2).

Seconda domanda: quando hai debolezze pensi che Dio ti ama? In che caso non hai ottenuto quello che Dio ti ha dato? Imparare a sopportare non è un segno di debolezza, Leo descrive la gravidanza della moglie, la felicità quando è nato il bambino. La prima domanda ha senza dubbio risposta si. Quando ero appena credente, dice un ragazzo, ero in difficoltà perché mi chiedevo come mai Dio trattava me in modo diverso dagli altri? Ma poi ho scoperto che Dio voleva farmi diventare più forte. Un altro ragazzo, Shen Yue (amato da Dio) pensa che non è Dio infedele ma lui, negli affari al negozio le cose non andavano bene, ho pregato e le cose andavano sempre peggio, adesso nonostante le difficoltà devo affidare al Signore affrontare con calma le difficoltà.

Terza domanda: in che modo Paolo chiede a Dio di farci diventare più forti? Riesce a descrivere la gloria di Dio? O spirito o Cristo in noi? La gloria è come vittoria, doni quelli che camminano sui trampoli, attraverso il creato vedi la gloria di Dio, tutto dipende dalla disposizione del cuore.

Quarta domanda: com'è la gloria descritta nel versetto 21? Qual è la relazione con l'amore di Cristo? Qual è la comprensione attuale della gloria di Dio? Quando mostriamo l'amore di Cristo mostriamo la gloria di Dio. Noi diamo gloria a Dio, la gloria dovrebbe vedersi dai credenti, la gloria arriva dalla chiesa. Con l'amore di Dio Lui ci ha amati. V. 21 è una gloria eterna, noi glorifichiamo Dio. Deve esserci una buona combinazione tra tranquillità e qualità. La strada della chiesa è ancora lunga, la gloria di Dio a volte sembra esterna e apparente ma è spirituale.

In che modo come chiesa riusciamo a mostrare la gloria di Dio? Con l'amore. A volte come chiesa vogliamo tante persone pensando che la gloria sia nella quantità. Lo sbaglio è credere nell'amore diminuendo la giustizia di Dio.

\section{Studio biblico giovani}

\section{0/11/2014}

Viene annunciato che la prossima settimana faremo una hotpot, mangeremo cibo insieme. Lettura di Efesini 5, 1-5. Prima domanda a cosa si riferisce il dunque? Si riferisce a cose del versetto precedente, qual è il nesso? Dio ci ha perdonati e abbiamo possibilità di imparare dal Signore le priorità del perdono di Dio. Perdonati dobbiamo imitare Cristo.

Cristo (v 24), essere persone nuove come Cristo.

Domanda due: in questo capitolo quali sono le cose che potremmo imparare? Dovremo ringraziare anche nelle difficoltà. Amore come sacrificio totale di sé,

(chi controlla la lingua controlla il mondo). Ringraziare di più e diminuire le impurità, riuscire nei problemi piccoli ad essere paziente e avrai fede anche nei problemi grandi. Non ciò che entra ma ciò che esce dal cuore contamina l'uomo.

Domanda tre: dividi in due il testo e riassumi: imitare Dio nell'amore e preservarsi da ogni impurità, non essere avido e avaro ma ringraziare. Entra nella nuova vita, vivi nella vita nuova. Il sacrificio è perdono per una cosa dovuta e va fatto con sangue, l'offerta è di ringraziamento per una cosa volontaria senza spargimento di sangue. Tre tipi di sacrificio. 
Domanda quattro: qual è il legame tra sacrificio e offerta nel passo? Per pulirci dei nostri peccati Cristo si è offerto. Discussione su ideogramma cinese. Comportamento che si addice ai santi. Com'è un santo? Non è come me, oppure in realtà siamo tutti santi ma dobbiamo crescere. L'essere avaro è la causa e l'effetto sono gli idoli, amare qualcosa più di Dio. Il nesso tra essere avaro ed idolatria è che come santi non dovremmo idolatrare, essere idolatri in sé. Quando sei avaro tratti Dio come un idolo, ami qualcosa più di Dio. Quando siamo avari l'oro è Dio, non puoi servire Dio e mammona.

\section{Studio Biblico Giovani 29 marzo 2015}

Abbiamo letto Filippesi 2, 5-11. Domande:

1) Cosa significa non aggrapparsi gelosamente? Cosa significa spogliò se stesso? Non era un gesto protettivo o possessivo verso i suoi privilegi. Divini, non rimase nel trono pur sapendo l'umiliazione che avrebbe affrontato. Levò le spoglie nel cielo incarnandosi e morendo per noi, lascio i privilegi in cielo e il suo ego sottomettendo la sua volontà a quella del Padre. Non prendeva, non stringeva tra le mani la gloria, era uguale a Dio, anche Lucifero voleva ma Gesù non si è aggrappato a questo.

2) Spiega la differenza tra immagine di Dio e di servo. Differenza enorme, servo è al livello più basso di gerarchia, Dio al più alto, può decidere tutto, gode del suo creato. Quello che serve non viene adorato, nuova persona ad immagine di Dio, pura e libera. Dio è il più grande essere, servo è il più piccolo, Dio ordina, governa, comanda mentre il servo serve, non ha poteri decisionali, Dio invece può decidere tutto.

3) Cosa significa nei cieli, sulla terra e sotto terra? Tutta la creazione, i cieli sono gli spiriti che non hanno peccato, angeli, i morti in paradiso, la terra i viventi, gli uomini, sotto terra sono gli spiriti condannati, i demoni, l'inferno, anche se non nel nostro mondo tangibile.

4) Essere umile è una cosa molto difficile, quali sono gli esempi che ci ha dato Gesù? Pur avendo diritto non ha rivendicato, non ha fatto niente da sé, si è abbassato dalla più alta alla più bassa qualifica, è morto in croce insultato e percosso, è stato tra i peccatori, ha servito gli altri.

5) Abbiate lo stesso sentimento di Cristo, cosa ti viene in mente? Devi creare una relazione con Lui, sperimentarlo, non è immediato, amatevi gli uni gli altri come io ho amato voi, per amore nostro lui si è abbassato, in vista della ricompensa, sovranamente innalzato, come nell'antico testamento le persone comunicavano con Dio così noi dobbiamo avere comunicazione con Dio. Cristo sperava che tutti ottenessero la salvezza, Cristo verso sé era sempre umile, rendeva gloria a Dio, Paolo per il Vangelo si è fatto più umile, sentimento, ci ha comandato prima di morire ci ha detto evangelizzate. Abbiamo mancanze ma attraverso Lui ci fa diventare più forti, salvare le persone è ciò che Cristo ha comandato, farsi modellare da Cristo, avere la vita di Dio è ciò che noi dobbiamo avere.

\section{Note di campo \\ Girasole \\ $22 / 04 / 2015$}

Oggi sono andato alla fermata metro e Ren mi è venuto a prendere, arriviamo, mi chiede com'è andato in America, era contento di vedermi. Arrivato vado a cercare Ile al piano di sopra, attendo molto arriva l'italiano mi saluta è piuttosto scortese. Alla fine arriva Ile, seguito da un italiano vestito bene, forse si tratta dei controlli, ed anche un cinese invita Ile a cambiare residenza. Il cinese ha preso una scrivania accanto l'italiano siede sul tavolino. Dopo aver chiesto sulla mappa del luogo Ile mi risponde in modo freddo forse ha paura perché c'è il suo capo. Vado a vedere Paolino, mi offre un caffè,

economica col cliente italiano, molto flessibile e gli chiedo se c'è suo fratello Giovanni, vado da Giovanni e gli spiego il mio problema, di come ho bisogno di fare interviste, lui è gentile, mi fa vedere la lista dei contatti dei cinesi imprenditori che hanno un negozio qui al padiglione. Mi 
consiglia quelli che parlano in italiano. Vado dal primo 810 lui non parla italiano sua moglie parla italiano ma dice che è molto impegnata, si chiama $\mathrm{Ya} \mathrm{Mu}$, mi dice di tornare quando c'è sua sorella. Poi vado da 708 Quai Hun, lei è aperta si fa intervistare poi arriva il marito e si fa intervistare anche lui. Gentile si fa anche fotografare. Il negozio accanto di alice al 706 c'è un cinese ma non parla bene italiano dunque decido di aspettare. Provo poi il 116 dove c'è yong shing. Si fa intervistare è con la moglie, altri due se ne vanno imbarazzati durante l'intervista. Abbiamo un buon dialogo. Torno da Ren per il pranzo, i clienti trattano in modo scortese i cinesi, noto che c'è diffidenza, guardano male me con tutta la mia familiarità con i cinesi. Anche i cinesi però sono diffidenti, dicono di solito che hanno da fare ma la realtà è che sono imbarazzati.

Ren mi dice che la scorsa settimana

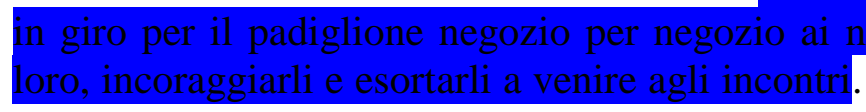

Molti hanno problemi a frequentare la domenica e ci sono gruppi settimanali che essi possono frequentare per poter essere comunque coinvolti, soprattutto la seconda generazione è difficile riuscire a essere coinvolti, si allontanano dalla fede.

Ho parlato con un dipendente di Ren, lui non è credente, lavora qui da un anno, genitori buddhisti,

Bibbia ma è aperto ad ascoltare. I genitori suoi sono in Cina, sua sorella in Olanda. Torna al lavoro, impacchetta tutto, anche Ren, sono tutti indaffarati, pranzo veloce poi di nuovo al lavoro.

Sono tornato a cercare di intervistare706 Alessandro l'ho trovato lì ma mangiava mi ha detto di tornare dopo torno dopo pranzo e lo intervisto in seguito ad un cliente che parlava un linguaggio strano misto tra dialetto napoletano e tedesco. Finito mi concede attenzione nonostante abbia tanto lavoro da svolgere. Lui è due anni che non va in chiesa, giovane credente anche se non vive la vita cristiana. Dopo l'intervista torno a cercare Ren, non lo trovo allora torno da Ile e c'è lui e l'italiano che oggi sembra scocciato. Ile è molto indaffarato riceve sempre dei cinesi qui al padiglione, ogni tanto li segue perché deve fare i controlli contabili sennò tutti uno a uno si presentano da lui in ufficio. Devono probabilmente fare le pratiche amministrative.

La moglie di Ren mi porta da Santiago che si fa intervista. E' impiegato alla bigiotteria, si fa intervistare ed è caloroso. Lui lavora come dipendente i proprietari sono cristiani.

\section{Note di Campo Prima esplorazione al Girasole:}

Alle nove di mattina ci siamo incontrati all'uscita della stazione metro gialla Affori, da lì Jin è arrivato, con lui abbiamo aspettato Marco e siamo andati a prendere Yang. La macchina di Marco suona musica cristiana mentre ci avviciniamo all'autostrada, musica cinese. Parliamo del più e del meno, propongo di aiutarli una volta arrivati lì a fare qualsiasi cosa. Marco mi mostra la tessere d'iscrizione all'associazione cristiana di aiuto business per immigrati, si propone di andare a fare colazione da McDonald, io ho già fatto colazione quindi va bene così per me. Dopo un po' mi ha detto Jin che la conversazione è sul peccato mortale, quale sia. Io ho dato la mia opinione, i ragazzi sembrano soddisfatti dalla mia opinione. Poi arriviamo al centro commerciale girasole, edifici all'ingrosso, qualcuno dice che li ha fatti costruire Berlusconi, arriviamo dove lavora Jin, è un locale spoglio, da una parte abbigliamenti stile cinese, dall'altra le lampade, per cui Jin Marco e Yang lavorano nel padiglione 3, il loro capo è Franco anche lui cristiano. Dietro il negozio un magazzino pieno di scatoloni. Accanto ci sono altri negozi cinesi, ciascuno ha la sua insegna, dall'altra parte della strada mi dice Jin c'è Ren e il suo negozio. Vado con Jin da quella parte e saluto calorosamente Ren al padiglione 1, lui ha un tipico negozio cinese di ciondoli e accessori di bellezza. C'è anche sua moglie e la sorella di sua moglie, poi andiamo al piano di sopra dove c'è Ile e Alfredo, l'unico italiano, Ile è contento di vedermi,

Alfredo. Alfredo è contento dice di aver sentito parlare di me. Jin mi dice che c'è un credente nel 
padiglione 11 che potrei intervistare di nome Betlem, anche detto Angelo, con l'insegna angelo trading, poi al 303 c'è Luca, anche lui cristiano, vado davanti al negozio ma è chiuso, però mi viene dato il numero di telefono da Paolino del 206. Invece intervisto Paolino grazie a Ile che mi presenta a lui. E' il più aperto svolgo un'ottima intervista. Dopo torno da Jin e aspetto il pranzo, discuto con Jin il fatto che in Cina non ci sono pastori a Wenzhou, è una cosa tipica rispetto ad altre zone della cina, ci sono i servi, come Paolino ma loro sono devoti, le decisioni sono tutte in mano ai diaconi. mangiamo riso insieme, c'è anche la signora delle scarpe della porta accanto, lei parla solo cinese si è detta restia ad essere intervistata con l'aiuto di un traduttore. Dopo pranzo chiedo a Yang se posso intervistarlo ma lui scappa da me perché ha cose da fare, così vado da Ren, intervisto sua moglie e la sorella della moglie, entrambe sono disposte ma un po' impegnate. Poi con Ren andiamo al padiglione 11 per vedere se Betlem, Angelo, è disponibile ad essere intervistato, è credente anche se non viene spesso in chiesa. Arrivati mi presento ma lui non vuole essere intervistato, dice che deve lavorare, mi mostra le tabelle che sta riempiendo, così lo saluto, insieme a Ren con la macchina andiamo verso un altro padiglione 13 deve fare vedere un magazzino ad un altro cinese, che ha bisogno di consiglio da Ren. Mostra il magazzino, c'è gente che lavora al magazzino sotto di noi, sembrano davvero quelle formiche senza diritti che spesso immaginiamo, ogni negoziante ha una stanza, tutta roba dalla Cina, il disordine e lo sporco regnano. Si consigliano sul lucchetto e il portone, poi torniamo al padiglione 3, sto con Ren e poi vado a cercare Yang da Jin, mi dice che è al padiglione 1 a montare delle luci. Giro il padiglione 1 e lo trovo dentro un negozio a montare le luci, insieme a lui c'è Marco, sul muro un calendario cristiano, chiedo a Yang se sono cristiani, lui sorride, non crede siano praticanti a volte qualcuno regala loro il calendario, non sono necessariamente cristiani, gli chiedo dell'intervista risponde drastico che io chieda a Marco, mi sento giù, lui sale sulla scala e monta le luci mentre io osservo. Altri portano e scaricano le luci vecchie. Yang si sente in colpa e mi accompagna a prendere un cappuccino. Mi dice che potrei parlare con un certo hui che conosce tutti i cristiani del centro commerciale. Poi incontro Ren e lui mi porta dal fratello di Paolino, Giovanni, lui si fa intervistare, ha due calendari cristiani più una foto di Hudson Taylor, mi mostra le foto della conferenza di chiesa, alla fine è quasi commosso della mia ricerca. Dopo l'intervista torno da Ren ed ho una lunga conversazione con lui, sulla chiesa, su come è bello quello che sto facendo. Esco e trovo Franco, gli chiedo se vuole essere intervistato, lui non parla bene italiano, allora reagisce in modo brusco con Jin, così chiedo scusa e vado da Ile in attesa delle 18.30 per tornare a casa.

\section{Note di Campo visita a Tonglu $19 / 08 / 2015$}

La Cina ha avuto modo di sperimentare uno sviluppo incredibile, nella città di Tonglu, allora solo un villaggio, negli ultimi dieci anni uno sviluppo di business incredibile, grattacieli ovunque, dalla città grande alle piccole città incredibili investimenti. Pan Chen dice che è dovuto soprattutto alla prima generazione, al loro stakhanovismo che li ha spinti a uscire dalla povertà. I genitori di Pan Chen sono un chiaro esempio di questo processo, contadini, aprirono un'azienda tessile al villaggio, poi comprarono un'altra casa in città, e il padre ora ha un'azienda di massaggi, Pan Chen ora in Italia riceve sostegno da loro. Mi chiedeva quale fosse l'origine di tale drastico cambiamento, forse sfruttati durante la rivoluzione culturale del '79 furono lasciati liberi di commerciare e lentamente la Cina si è trasformata. In che modo allora il Confucianesimo ha influenzato il processo? Pochi si identificano col Confucianesimo ormai, è più che altro il principio che sopravvive, inconsciamente Pan Chen afferma il principio dell'accumulare soldi ereditato indirettamente da questa mentalità visibile nelle porte, dove tutti mettono messaggi relativi alla fortuna o il drago all'ingresso con i soldi simbolo di successo economico. In realtà è più complicato di quanto sembra capire l'origine di tale mentalità di lavoro duro. Oggi inoltre ho avuto modo di vedere un altro volto della Cina, i villaggi ponti ancora che parlano della vecchia Cina, quella che ancora vive nelle campagne e si mantiene nell'auto-sufficienza. Qui si vede lo squilibrio economico tra le due aree della Cina. Resta comunque incredibile che anche un'area come Tonglu sia così 
sviluppata. La mentalità del duro lavoro c'è sempre stata in Cina ma con la fine del comunismo reale la gente ora può fare molti soldi. Per Pan Chen la ragione della migrazione prevalentemente Wenzhouniana è dovuta ai network familiari. Oggi dalla finestra ho visto una quindicina di studenti che marciano a scuola simbolo di quanto il comunismo ancora controlla la mente tramite l'educazione.

\section{Note di Campo Viale Sarpi $16 / 07 / 2015$}

Oggi dovevo intervistare qui a Viale Sarpi il sig. Zhou ma l'intervista è andata in fumo. Però comunque ho passato molto tempo con Wei che doveva farmi da interprete, mi ha mostrato i due negozi di Zheng Song Bo, due grandi negozi dal nome DonFan, uno dei due ha delle bandiere sopra l'ingresso, è una traversa di Viale Sarpi. Wei dice che Zheng è proprio un boss importante a viale Sarpi. Io ho provato a mettermi in contatto con lui via telefono ma o la moglie o sorella è stata molto restia ad essere intervistata o a permettermi di intervistare Zheng che non sembra capire molto bene l'italiano. Arriviamo al McDonald e parliamo della crisi economica in Cina, finanziaria dovuta all'inflazione, si alzano i costi si alzano gli stipendi molte compagnie in Cina sono dunque costrette a fallire. Mi dice Wei che un chilo di fragole ora costa 9 euro in Cina, è sconcertante. Arriva il fratello di Ren che è di passaggio, lui ha un lavoro da un commercialista cinese, è vestito con la camicia. Mi chiede come vanno le cose io ho offerto caramelle a Wei, sto cercando di costruire un ponte di fiducia con loro. Con Wei torniamo davanti a Juping ma l'imprenditore Zhang non viene. Sono scoraggiato, ci sediamo. Wei mi spiega l'estremo materialismo che regna in Cina, che forse questo imprenditore non ha voluto calcolarmi, anche i cristiani a volte si mettono in società, il boss gestisce ma poi manda via tutti e si prende i ricavati, è successo anche nella nostra chiesa mi dice. La fissazione per il denaro è troppo alta tra i cinesi, non si pensa ad altro se fai soldi sei rispettato se non fai soldi puoi essere la persona piena di tutte le qualità del mondo ma non sei nessuno, anche tra i credenti. Wei pensa bene di Paolino, un po' più perplesso di Giovanni. Lui dice che i giovani della chiesa i gruppi adulti sono due cose diverse, i giovani sono cresciuti insieme e $\mathrm{i}$ gruppi adulti sono divisi tra i ricchi e i più poveri, sono molto più improntati a fare soldi e arricchirsi. La spietatezza c'è anche tra i cristiani, l'evasione o l'approfittarsi non mancano.

RIFLESSIONE: ammettiamo pure che il network sia la spiegazione del successo economico affinché non si creda che scegliamo l'interpretazione religiosa perché l'altra ci è contraria. Se è così ogni tipologia di network nel business dovrebbe portare al successo economico, cosa che non si riscontra ad esempio nei circoli mafiosi cinesi. Piuttosto potremmo dire che il network è uno strumento non sempre usato e non sempre efficiente tra i cinesi che velocizza $\mathrm{i}$ tempi, soprattutto nelle prime fasi di imprenditorialità, garantisce un appoggio finanziario come nel caso del lignaggio ma non può in sé stimolare il successo economico o la propensione al duro lavoro come pratica interiorizzata.

\section{Wenzhou note di campo 22/08/2015}

Ieri sera sono uscito con Zen Dagao e la fidanzata Zhenzhen amici di Pan Chen. Alla domanda su da dove viene la mentalità orientata al profitto hanno citato la legge dell'imitazione. Lei vende borse allora Pan Chen gli ha parlato del lavoro di Chen. Lei gli ha dato il biglietto da visita per futuri contatti. Lei produce borse da un villaggio, proprietaria del negozio in Wenzhou le vende dal villaggio. Stiamo andadno ad un incontro di Boss Cristiani (Lao Ban) e ci sarà una lezione da un professore su come uscire dalla crisi finanziaria. L'incontro inizia con l'adorazione c'è una ragazza che canta. E' pieno di boss. Xiao dice che molte chiese in Wenzhou sono calviniste. La cerimonia viene introdotta, un professore da Hong Kong viene presentato, si parla dell'attuale crisi finanziaria come lodare come pregare Dio e glorificarlo, l'adorazione è molto importante per ogni fratello e sorella. Ci sarà un nuovo posto che attendono per incontrarsi, il prossimo mese. Due 
messaggi: prof. Hong Kong e prof. Di Wenzhou. La persona signora che parla è manager dell'ospedale. Parla Hong Cheng Ming il Wenzhounese nativo su come usare internet per fare business. L'economia va sotto, è una nuova era, non cresce ma stagna e scende ma il governo crede che Wenzhou crescerà, dobbiamo avere forza, il governo non è al corrente. Marxismo non è usato dobbiamo usare un nuovo management, forse internet è importante, dobbiamo usarlo. Molti non sanno come usarlo ma è il nostro futuro e stile di vita. Un uomo con fede è meglio di uno senza (è cristiano e membro del partito!). Il laoban guarda il giornale ma non credo al giornale, pieno di spazzatura, ma messi insieme diamo un messaggio vero. Oggi i giornali cadono e sale la telecomunicazione. Rimpiazzeranno i telefoni, broadcast sul web crescerà. Le campagne di Wenzhou hanno ostelli, vacanze, cose che crescono l'economia, agriturismi... imprenditori investiranno in questo. Le cose stanno cambiando, dobbiamo scoprire qual è la direzione. Due cose sono successe a Wenzhou, l'andamento economico e cambiamento economico del modello Wenzhounese (privati boss come tante compagnie private tante macchie) quando affronta crisi finanziarie però affronta difficoltà. Wenzhou e le sue persone creano business, non buono per le manifatture, abbiamo buona contrattazione si come business, sono buoni al business perché eravamo poveri negli anni 80 . Facciamo negozi regolari ma nelle internazionali compagnie hanno esperienza e il negozio perde importanza ed è una sfida per Wenzhou. Nuova teoria, nuovi concetti (community economy), promuoveva molto gruppo mentre e-commerce non è buon concetto, può essere rimpiazzato, senza comunità si affrontano molti problemi. Dobbiamo studiare questi nuovi concetti, dobbiamo esplorare negozi che vanno underground, pensare che deve cambiare. Il negozio fa soldi ma l'ecommerce di più, tanti negozi in internet, se non ci vai muori, se ci vai muori, come risolvere? Sporchi i fiumi in Wenzhou, il governo vuole pulire, si incoraggiano gli imprenditori a pulire, loro non vogliono, allora il governo promette di dare monumenti ma non è una buona idea, non è adesso cosa contemporanea! Qual è questa nuova era? Wenzhou ha un buon mercato economico e buone economie ma non abbiamo tecnologia. Alcune religioni non promuovono innovazione. Nel passato business era in asimmetria ora è esplosa l'informazione, ma qualche informazioni sul web e cambiano le nostre abitudini. Il modello Wenzhou ha business molto importante, ma web fa decrescere questo, lo manda all'inferno. Il governo vuole causare i businessmen a tornare in patria ma non è possibile forse possiamo creare un sito web per non dover tornare fisicamente. Negli anni passati Wenzhou ha avuto centralità ora non allora il governo cerca di chiamare e ritornare invece che in altri posti. Il fellowship leader deve accettare la base di leadership del nostro stato, mentre parte del privato. Possiamo usare social network per business, fare gruppi (network) se aiuti altri e hai problemi hai bisogno di comunicazione. In normali transizioni competiamo in internet cooperiamo. The new normal and the new thinking (HaunJanning) arreso alla Bibbia nella sua spiegazione del business. How the faith break the bottom in your growing (Yam). La mia legacy è relax anche se non hai tempo puoi avere pace. Nessun bordo, niente vietato, nessuna restituzione. La Luca 8, 40-56. Il capo della sinagoga rompe un confine o limite con Gesù andando da lui. Dobbiamo promuovere e crescere, molti erano attorno a Gesù ma solo uno aveva vera fede, non temporanea ma fiducia anche se vai in chiesa ma non hai fede non sai qual è la Verità, fiducia in Dio, per Dio niente è impossibile. Lui sa tutto. Non c'è limite o restrizione perché dietro tutto. Iaino va a Gesù sperando benedizione ma non sarà semplice, avrai difficoltà ma se dai la guida a Dio la tua compagnia è in buone mani. La lezione ispira e innova che Dio è il navigatore. Esperti danno avvisi alla tua compagnia, cristiani imprenditori a cui puoi parlare, compagnie guidate da Cristiani oltremare per aiutare i Wenzhounesi. Un professore viene, fanno una conferenza e prendono visite con compagnie (network) di cristiani a Hong Kong, per insegnare come usare la Bibbia per (manager) gestire la tua ditta, come avanzare i valori della compagnia, come promuovere e farne una buona pubblicità (AZIENDA HUNG FOOK TONG). Siamo una famiglia e un gruppo e possiamo cooperare. Esortazione finale a studiare altre compagnie, studiare. Business non si alza di vendita di medicine e ha studiato teologia. 


\section{Studio biblico giovani}

\section{$06 / 12 / 2014$}

Oggi sono seduto accanto al pastore. Dobbiamo approfittare del tempo che abbiamo perché la malvagità ci sovrasta. Efesini 5, 6-21. Nella chiesa di Efeso che vani ragionamenti c'erano? Nella tua vita quali ragionamenti vani hai? Condanna dell'attaccamento al denaro, avarizia (v. 5). I cristiani non dovrebbero dire che non sarà mai più povero. In corinzi si dice bada a su cosa costruisci che poi verrà provato col fuoco. Le cose che diciamo, le parole vane sono gravi, scatenano l'ira di Dio, non solo le cose che diciamo ma i figli ribelli che non obbediscono. Ognuno ha il suo dono, dobbiamo guardarci dai falsi ragionamenti, le parole vuote, le dottrine sbagliate, la morale corrotta. Le persone poi ti chiedono perché fai le cose spirituali. L'idea vana che se sei salvato una volta salvato puoi continuare a peccare credi in Dio e avrai salute, ricchezza. Il motivo è buono ma le parole sono stolte.

Seconda domanda: Come fai a attraverso la Bibbia, quello che Dio ti dice, vv. 10-9, esamina controlla i tuoi frutti, sii figlio di luce, separati da influenze negative, manifesta le cose alla luce.

Terza domanda: che relazione c'è tra recuperare il tempo ed i giorni malvagi? Un pastore una volta ha detto il diavolo controlla il nostro tempo. Un proverbio cinese dice siamo occupati ma il cuore muore. Le cose malvagie sono sempre più evidenti attorno a noi, come quando Noé tutti non apprezzavano il tempo, così nella Bibbia gli uomini pensavano solo a cose malvagie. Spirito Santo, preghiera e Bibbia ti aiutano. Mi ricordo Jonathan Edwards e i suoi sermoni sull'importanta del tempo.

dobbiamo essere occupati troppo nelle cose mondane. Quando accendi facebook la maggior parte delle notizie sono malvagie. Pià la malvagità aumenta più arriva la fine, dunque.

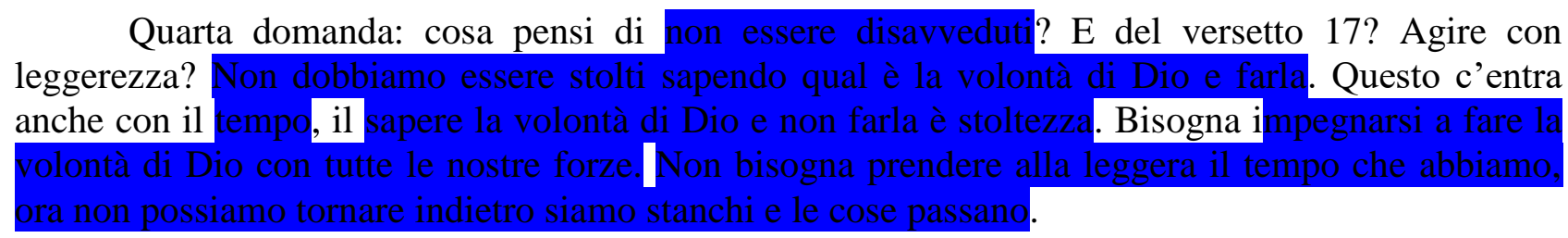

Domanda cinque: Trova negli ultimi tre versetti tre parole fondamentali: cantare o lodare, ringraziare e sottomettersi. Giacobbe scappava dormiva sulla pietra quando non hai niente ti avvicini più a Dio. 


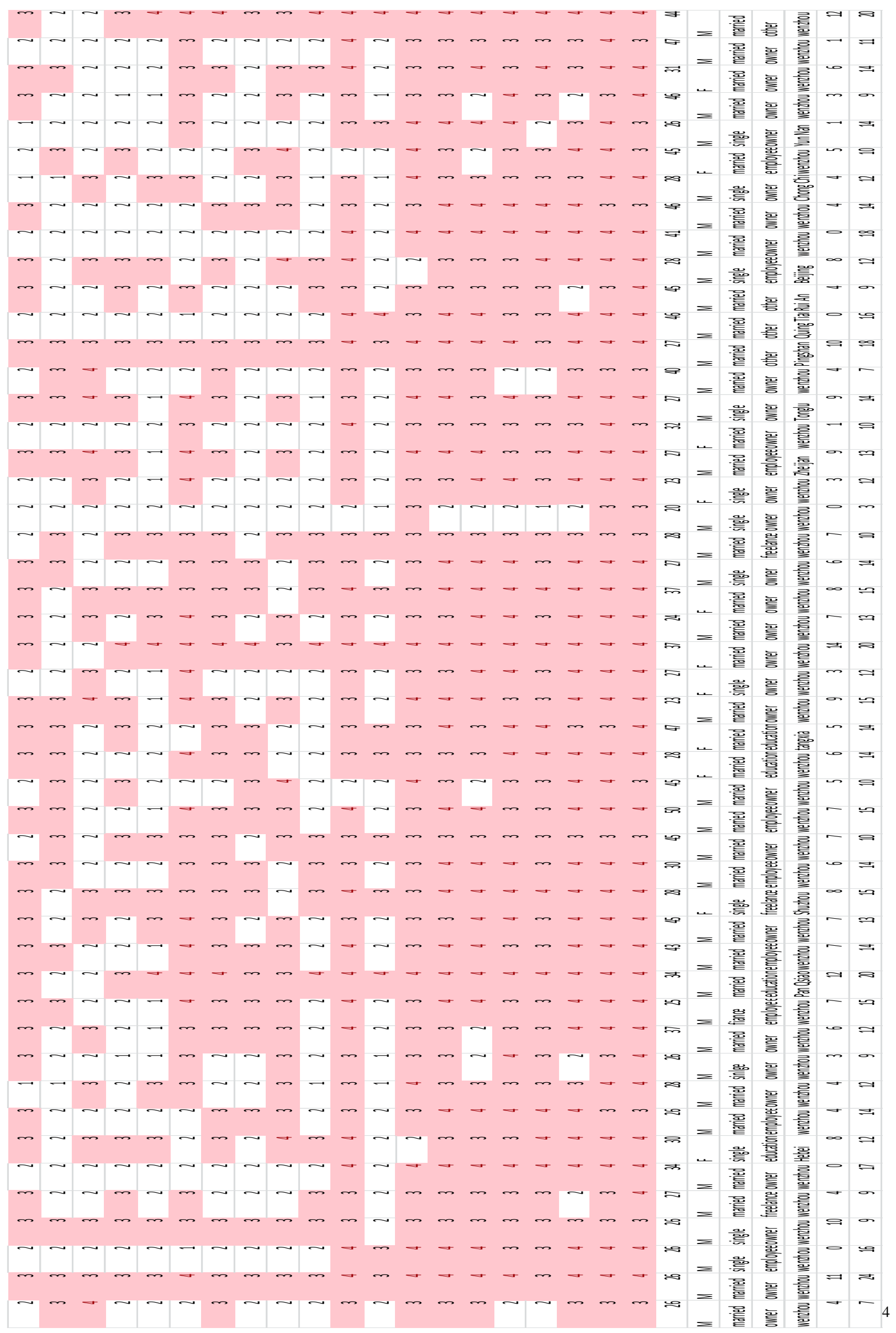

${ }^{4}$ Data from the questionnaire from the first group of Protestant entrepreneurs. N > $2=\mathrm{S}$. E. 


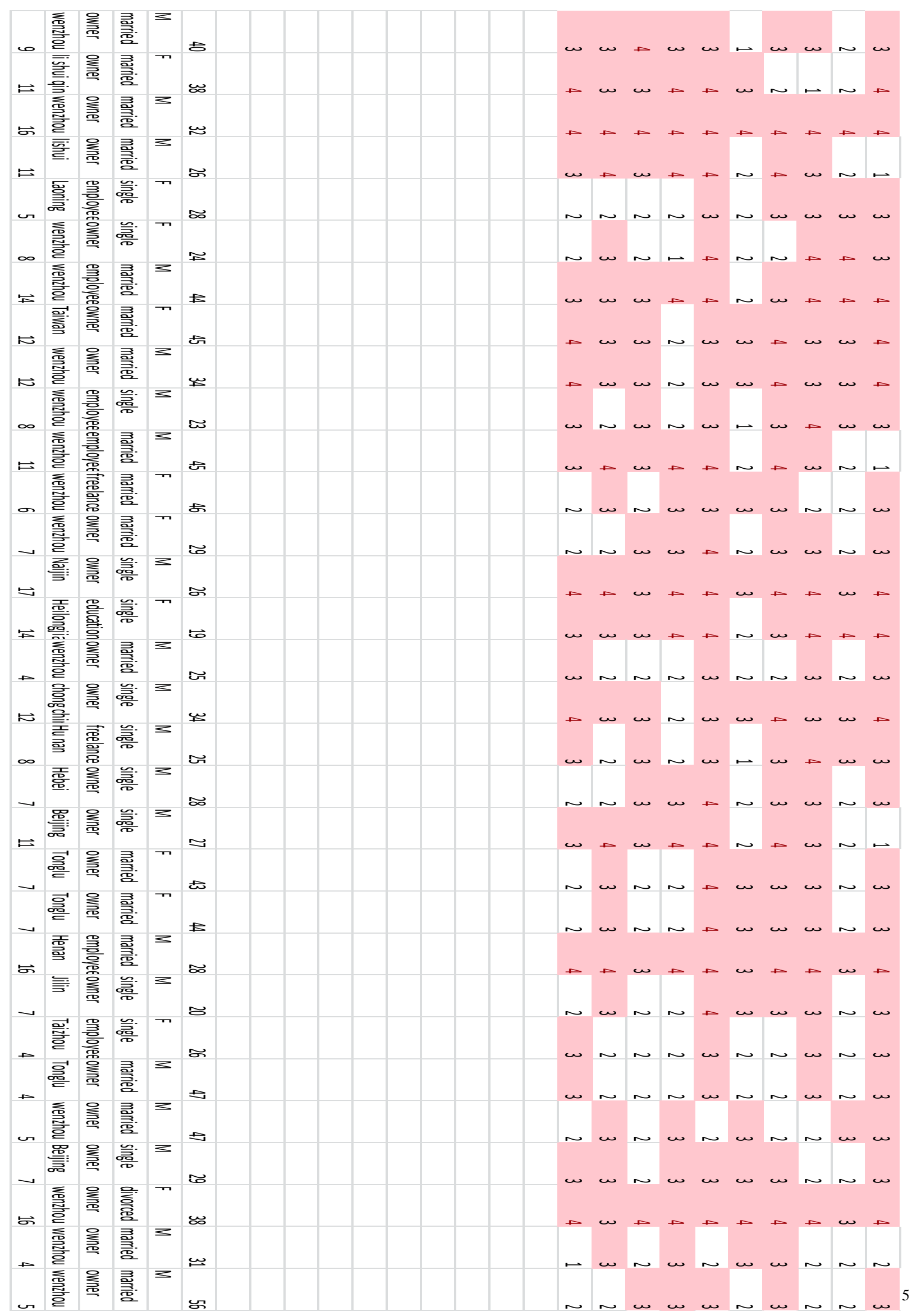

${ }^{5}$ Data from the questionnaire from the second group of non-Protestant entrepreneurs. $\mathrm{N}>2=\mathrm{S}$. E. 


\section{关于信仰和生意之间的研究}

这次学术研究主要是针对于基督徒老板们做生意和信仰之间的紧密关系。你们可以自由 回答这些调查问卷, 没有任何强制性, 而且你们的信息将根据国家个人隐私法进行保 护。

个人信息:

几岁了?_26__

性别: X_— 男 — 女

你的生活状态? (单身, 已婚, 离异, 丧偶) sposato

目前职业? commerciante

出生地方、城市? wenzhou

接下来这些问题, 请选择1-4之间, 然后根据个人的观点把相关答案填在空格上。

\begin{tabular}{|cccc|}
1 & 2 & 3 & 4 \\
\hline 完全不是 & 一点 & 相当 & 完全是
\end{tabular}

1. _ 2 - 如果我认真面对总是能够解决重大困难的

2. - 3 - 如果有人反对我, 我能够找到解决的方法来到达我的目的

3. - 4 _ 对我来说很容易坚持个人意志, 达到自己的目的

4. - 2 — 我很有信心有效的面对一些突发事件

5. - 2 - 我所拥有的资源足够可以面对不可预知的窘境

6. _ _ _ 只要用心就可以解决大部分问题

7. - 3 当遇到问题时, 会保持冷静, 相信自己有能力面对

8. 一 2 — 当我有问题时, 总会找到很多解决方法

9. - 2 _ 当我在宕境时, 总是能想到一些东西来度过

10. _ 2 _ 不管遇到什么, 总是有能力去处理 
接下来这些问题, 请选择1-4之间, 然后根据个人的观点把相关答案填在空格上。

\begin{tabular}{|cccc|}
1 & 2 & 3 & 4 \\
\hline 完全不是 & 一点 & 相当 & 完全是
\end{tabular}

1. 3 _ 当知道自己是 “得救的、有永生” , 会帮助我解决一些困难问题

2. 2 _ 当和一些不信教的人有不同意见时, 我可以到达我的目的

3. 3_ 我的信仰有助于我到达一些人生目标

4. _3_ 在得救、永生的信念之下, 可帮助我面对一些突发事件

5. 3 3 我的信仰可帮助解决一些未知宕境

6. _ _ _ 通过祷告和用心做事可以解决大部分问题

7. _ 2 _ 在得救、永生的信念之下会冷静的解决问题

8. - 3 — 面对问题相信上帝会帮我找到不同的解决方法

9. - 3 — 当我在困境时, 相信上帝会帮我度过的

10._3_ 不管遇到什么, 我都相信有得救、永生和那解决问题的能力

\section{关于信仰和生意之间的研究}

这次学术研究主要是针对于基督徒老板们做生意和信仰之间的紧密关系。你们可以自由 回答这些调查问卷, 没有任何强制性, 而且你们的信息将根据国家个人隐私法进行保 护。

个人信息:

几岁了? 25

性别: $\mathrm{x}$ 男—女

你的生活状态? (单身, 已婚, 离异, 丧偶) fidanzato

目前职业? operaio

出生地方、城市China Wenzhou

接下来这些问题, 请选择1-4之间, 然后根据个人的观点把相关答案填在空格上。

\begin{tabular}{|cccc|}
1 & 2 & 3 & 4 \\
\hline 完全不是 & 一点 & 相当 & 完全是
\end{tabular}

11.3 如果我认真面对总是能够解决重大困难的

12. _ 3 - 如果有人反对我, 我能够找到解决的方法来到达我的目的

13. 2 2 - 对我来说很容易坚持个人意志，达到自己的目的 
14. 2 我很有信心有效的面对一些突发事件

15._1 我所拥有的资源足够可以面对不可预知的窘境

16._ـ 4 只要用心就可以解决大部分问题

17._3 当遇到问题时, 会保持冷静, 相信自己有能力面对

18._ـ 3 当我有问题时, 总会找到很多解决方法

19. 3 当我在窘境时, 总是能想到一些东西来度过

20.__ 2 不管遇到什么, 总是有能力去处理

接下来这些问题，请选择1-4之间，然后根据个人的观点把相关答案填在空格上。

\begin{tabular}{|cccc|}
1 & 2 & 3 & 4 \\
\hline 完全不是 & 一点 & 相当 & 完全是
\end{tabular}

11. 4 4 当知道自己是 “得救的、有永生” ，会帮助我解决一些困难问题

12. 2 2 当和一些不信教的人有不同意见时, 我可以到达我的目的

13. 3 我的信仰有助于我到达一些人生目标

14. _ 4 _ 在得救、永生的信念之下, 可帮助我面对一些突发事件

15. 4 - 我的信仰可帮助解决一些未知若境

16._3_ 通过祷告和用心做事可以解决大部分问题

17. 3 在得救、永生的信念之下会冷静的解决问题

18._4_ 面对问题相信上帝会帮我找到不同的解决方法

19. 4 当我在困境时，相信上帝会帮我度过的

20._4_ 不管遇到什么, 我都相信有得救、永生和那解决问题的能力

\section{Study of the relationship between faith and business:}

This study aims to investigate the connections between faith and business among the evangelical Christians entrepreneurs. Your participation is voluntary and your data will be maintained anonymous and confidential.

First of all we would like to ask some questions about you:

How old are you? 34

Gender:

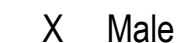
Female

What is your status? (E. g., single, married, divorced, etc.) Married

What kind of job you do? IED business 
Where are you born (city and country)? Pan Qsiao (Wenzhou)

For the next questions please choose a number 1-4 and write a number in every statement to identify how you agree with the statement.

\begin{tabular}{|cccc|}
1 & 2 & 3 & 4 \\
\hline Not at all true & Hardly true & $\begin{array}{c}\text { Moderately } \\
\text { true }\end{array}$ & Exactly true
\end{tabular}

21._3_ I can always manage to solve difficult problems if I try hard enough.

22._2__ If someone opposes me, I can find the means and ways to get what I want.

23._2__ It is easy for me to stick to my aims and accomplish my goals.

24. 3__ I am confident that I could deal efficiently with unexpected events.

25. 4_ _ Thanks to my resourcefulness, I know how to handle unforeseen situations.

26. 4 _ _ I can solve most problems if I invest the necessary effort.

27. 4 ___ I can remain calm when facing difficulties because I can rely on my coping abilities.

28. _ 3_ When I am confronted with a problem, I can usually find several solutions.

29. _ 3 _ If I am in trouble, I can usually think of a solution.

30._____ I can usually handle whatever comes my way.

For the next questions please choose a number 1-4 and write it in every statement to identify how much do you agree with the statement.

\begin{tabular}{|cccc|}
1 & 2 & 3 & 4 \\
\hline Not at all true & Hardly true & $\begin{array}{c}\text { Moderately } \\
\text { true }\end{array}$ & Exactly true
\end{tabular}

21. 4 __ Knowing to be "forever saved" help me to resolve difficult problems

22. _ _ _ _ In case of contrasts with unbelievers I can always obtain what I want

23. __ _ My faith helps me in life to reach my goals

24. _ _ _ _ The assurance of salvation helps me to face unexpected events

25. _ _ _ B B Because of my faith I know how to manage unexpected circumstances

26. _ _ _ I I can resolve the majority of problems if I pray and invest the necessary effort

27. _ _ _ I stay calm facing difficulties because I can trust in the assurance of salvation

28. _ _ _ _ In front of a problem God helps me to find several solutions

29. _ _ _ If I am in difficulties, God helps me to think of a solution

30.____ It doesn't matter what may happen, I can handle it because I have the assurance of salvation 


\section{Study of the relationship between faith and business:}

This study aims to investigate the connections between faith and business among the evangelical Christians entrepreneurs. Your participation is voluntary and your data will be maintained anonymous and confidential.

First of all we would like to ask some questions about you:

How old are you?_43

Gender: __ X_ Male __ Female

What is your status? (E. g., single, married, divorced, etc.) Married

What kind of job you do? Banker

Where are you born (city and country)? Wenzhou

For the next questions please choose a number 1-4 and write a number in every statement to identify how you agree with the statement.

\begin{tabular}{|cccc|}
1 & 2 & 3 & 4 \\
\hline Not at all true & Hardly true & $\begin{array}{c}\text { Moderately } \\
\text { true }\end{array}$ & Exactly true
\end{tabular}

31._3__ I can always manage to solve difficult problems if I try hard enough.

32. _ 3 __ If someone opposes me, I can find the means and ways to get what I want.

33. ___ It is easy for me to stick to my aims and accomplish my goals.

34. 2_ I I am confident that I could deal efficiently with unexpected events.

35. _ 1_ Thanks to my resourcefulness, I know how to handle unforeseen situations.

36. _ _ _ _ I can solve most problems if I invest the necessary effort.

37. 3 _ _ I can remain calm when facing difficulties because I can rely on my coping abilities.

38. _ 3_ When I am confronted with a problem, I can usually find several solutions.

39. _ _ _ I I I am in trouble, I can usually think of a solution.

40.___ I I I can usually handle whatever comes my way. 
For the next questions please choose a number 1-4 and write it in every statement to identify how much do you agree with the statement.

\begin{tabular}{|cccc|}
1 & 2 & 3 & 4 \\
\hline Not at all true & Hardly true & $\begin{array}{c}\text { Moderately } \\
\text { true }\end{array}$ & Exactly true
\end{tabular}
31. 4
Knowing to be "forever saved" help me to resolve difficult problems
32. _ _ _ In case of contrasts with unbelievers I can always obtain what I want
33. __ 3_ My faith helps me in life to reach my goals
34. 4___ The assurance of salvation helps me to face unexpected events
35. _ _ _ Because of my faith I know how to manage unexpected circumstances
36. _ 3 _ I can resolve the majority of problems if I pray and invest the necessary effort
37. 3 _ I I stay calm facing difficulties because I can trust in the assurance of salvation
38. _ _ _ _ In front of a problem God helps me to find several solutions
39. _ _ _ If I am in difficulties, God helps me to think of a solution
40. _ _ _ I _ It doesn't matter what may happen, I can handle it because I have the assurance of salvation

\section{Study of the relationship between faith and business:}

This study aims to investigate the connections between faith and business among the evangelical Christians entrepreneurs. Your participation is voluntary and your data will be maintained anonymous and confidential.

First of all we would like to ask some questions about you:

How old are you? 45

Gender:<smiles>[Y]C(C)C</smiles>
Female

What is your status? (E. g., single, married, divorced, etc.) married

What kind of job you do? boss of pharmacies and pastor

Where are you born (city and country)? Wenzhou

For the next questions please choose a number 1-4 and write a number in every statement to identify how you agree with the statement.

\begin{tabular}{|cccc|}
\hline 1 & 2 & 3 & 4 \\
\hline Not at all true & Hardly true & $\begin{array}{c}\text { Moderately } \\
\text { true }\end{array}$ & Exactly true
\end{tabular}

41._3__ I can always manage to solve difficult problems if I try hard enough.

42._2_ If someone opposes me, I can find the means and ways to get what I want.

43._3__ It is easy for me to stick to my aims and accomplish my goals.

44. 2___ I am confident that I could deal efficiently with unexpected events. 
45. 3

46. 4

47. 3

48. 2

49. 3

50. 2

Thanks to my resourcefulness, I know how to handle unforeseen situations.

I can solve most problems if I invest the necessary effort.

I can remain calm when facing difficulties because I can rely on my coping abilities.

When I am confronted with a problem, I can usually find several solutions.

If I am in trouble, I can usually think of a solution.

I can usually handle whatever comes my way.

For the next questions please choose a number 1-4 and write it in every statement to identify how much do you agree with the statement.

\begin{tabular}{|cccc|}
1 & 2 & 3 & 4 \\
\hline Not at all true & Hardly true & $\begin{array}{c}\text { Moderately } \\
\text { true }\end{array}$ & Exactly true
\end{tabular}
41. 3
Knowing to be "forever saved" help me to resolve difficult problems
42. -2 In case of contrasts with unbelievers I can always obtain what I want
43. -3
My faith helps me in life to reach my goals
44. 3
The assurance of salvation helps me to face unexpected events
45. 4
Because of my faith I know how to manage unexpected circumstances
46. 4 I can resolve the majority of problems if I pray and invest the necessary effort
47. 3 I stay calm facing difficulties because I can trust in the assurance of salvation
48. In front of a problem God helps me to find several solutions
49. 4 If I am in difficulties, God helps me to think of a solution
50.4 It doesn't matter what may happen, I can handle it because I have the assurance of salvation

\section{Study of the relationship between faith and business:}

This study aims to investigate the connections between faith and business among the evangelical Christians entrepreneurs. Your participation is voluntary and your data will be maintained anonymous and confidential.

First of all we would like to ask some questions about you:

How old are you?_28

Gender: Male__ _ _ Female

What is your status? (E. g., single, married, divorced, etc.) single

What kind of job you do? Buyer

Where are you born (city and country)? Shuzhou 
For the next questions please choose a number 1-4 and write a number in every statement to identify how you agree with the statement.

\begin{tabular}{|cccc|}
1 & 2 & 3 & 4 \\
\hline Not at all true & Hardly true & $\begin{array}{c}\text { Moderately } \\
\text { true }\end{array}$ & Exactly true
\end{tabular}

51.3__ I can always manage to solve difficult problems if I try hard enough.

52.2 If If someone opposes me, I can find the means and ways to get what I want.

53.3___ It is easy for me to stick to my aims and accomplish my goals.

54._3_ I I am confident that I could deal efficiently with unexpected events.

55._____ Thanks to my resourcefulness, I know how to handle unforeseen situations.

56. _ _ _ I I can solve most problems if I invest the necessary effort.

57. _ 3_ I can remain calm when facing difficulties because I can rely on my coping abilities.

58._____ When I am confronted with a problem, I can usually find several solutions.

59._3_ If I am in trouble, I can usually think of a solution.

60._____ I can usually handle whatever comes my way.

For the next questions please choose a number 1-4 and write it in every statement to identify how much do you agree with the statement.

\begin{tabular}{|cccc|}
1 & 2 & 3 & 4 \\
\hline Not at all true & Hardly true & Moderately \\
& & true & Exactly true
\end{tabular}

51._4_ Knowing to be "forever saved" help me to resolve difficult problems

52._3__ In case of contrasts with unbelievers I can always obtain what I want

53._3_ My faith helps me in life to reach my goals

54. 4_ The assurance of salvation helps me to face unexpected events

55. 4 ___ Because of my faith I know how to manage unexpected circumstances

56. 4 _ I can resolve the majority of problems if I pray and invest the necessary effort

57. 4 _ I stay calm facing difficulties because I can trust in the assurance of salvation

58. 4 __ In front of a problem God helps me to find several solutions

59._4_ If I am in difficulties, God helps me to think of a solution

60._4_ It doesn't matter what may happen, I can handle it because I have the assurance of salvation 


\section{Study of the relationship between faith and business:}

This study aims to investigate the connections between faith and business among the evangelical Christians entrepreneurs. Your participation is voluntary and your data will be maintained anonymous and confidential.

First of all we would like to ask some questions about you:

How old are you?_30_

Gender: __ X_ Male __ Female

What is your status? (E. g., single, married, divorced, etc.) married

What kind of job you do? employee of a travel agency

Where are you born (city and country)? Wenzhou

For the next questions please choose a number 1-4 and write a number in every statement to identify how you agree with the statement.

\begin{tabular}{|cccc|}
1 & 2 & 3 & 4 \\
\hline Not at all true & Hardly true & $\begin{array}{c}\text { Moderately } \\
\text { true }\end{array}$ & Exactly true
\end{tabular}

61.____ I can always manage to solve difficult problems if I try hard enough.

62. _ _ _ If If someone opposes me, I can find the means and ways to get what I want.

63. _ _ _ It is easy for me to stick to my aims and accomplish my goals.

64._2__ I am confident that I could deal efficiently with unexpected events.

65._2_ Thanks to my resourcefulness, I know how to handle unforeseen situations.

66. _ _ _ I I can solve most problems if I invest the necessary effort.

67. 3 _ _ I can remain calm when facing difficulties because I can rely on my coping abilities.

68. _ _ _ When I am confronted with a problem, I can usually find several solutions.

69.____ If I am in trouble, I can usually think of a solution.

70. _ _ I I I can usually handle whatever comes my way. 
For the next questions please choose a number 1-4 and write it in every statement to identify how much do you agree with the statement.

\begin{tabular}{|cccc|}
1 & 2 & 3 & 4 \\
\hline Not at all true & Hardly true & $\begin{array}{c}\text { Moderately } \\
\text { true }\end{array}$ & Exactly true
\end{tabular}
61._3
Knowing to be "forever saved" help me to resolve difficult problems
62. 2 In case of contrasts with unbelievers I can always obtain what I want
63. 3 My faith helps me in life to reach my goals
64. 4 The assurance of salvation helps me to face unexpected events
65. 4 Because of my faith I know how to manage unexpected circumstances
66. 4 I can resolve the majority of problems if I pray and invest the necessary effort
67. 3 I stay calm facing difficulties because I can trust in the assurance of salvation
68. 4 In front of a problem God helps me to find several solutions
69. 4 If I am in difficulties, God helps me to think of a solution
70. 4 It doesn't matter what may happen, I can handle it because I have the assurance of salvation

\section{关于信仰和生意之间的研究}

这次学术研究主要是针对于基督徒老板们做生意和信仰之间的紧密关系。你们可以自由 回答这些调查问卷，没有任何强制性，而且你们的信息将根据国家个人隐私法进行保 护。

个人信息:

几岁了? 26

性别: $x$ 男 女

你的生活状态? (单身, 已婚, 离异, 丧偶)__sposato

目前职业? commerciante

出生地方、城市? cina wenzhou3

接下来这些问题, 请选择 $1-4$ 之间, 然后根据个人的观点把相关答案填在空格上。

\begin{tabular}{|cccc|}
\hline 1 & 2 & 3 & 4 \\
\hline 完全不是 & 一点 & 相当 & 完全是
\end{tabular}

71._3_ 如果我认真面对总是能够解决重大困难的

72. 3 如果有人反对我，我能够找到解决的方法来到达我的目的

73._3_ 对我来说很容易坚持个人意志, 达到自己的目的

74. 3 _ 我很有信心有效的面对一些突发事件

75._3_ 我所拥有的资源足够可以面对不可预知的窘境 
76._4_ 只要用心就可以解决大部分问题

77._3_ 当遇到问题时, 会保持冷静, 相信自己有能力面对

78. _ 3 _ 当我有问题时, 总会找到很多解决方法

79. 3 3 当我在宭境时, 总是能想到一些东西来度过

80._3_ 不管遇到什么, 总是有能力去处理

接下来这些问题，请选择1-4之间，然后根据个人的观点把相关答案填在空格上。

\begin{tabular}{|cccc|}
1 & 2 & 3 & 4 \\
\hline 完全不是 & 一点 & 相当 & 完全是
\end{tabular}

71. 4 _ 当知道自己是 “得救的、有永生” ，会帮助我解决一些困难问题

72. 3 - 当和一些不信教的人有不同意见时, 我可以到达我的目的

73._4_ 我的信仰有助于我到达一些人生目标

74._4_ 在得救、永生的信念之下, 可帮助我面对一些突发事件

75._4_ 我的信仰可帮助解决一些未知害境

76._4_ 通过祷告和用心做事可以解决大部分问题

77._3_ 在得救、永生的信念之下会冷静的解决问题

78._4_ 面对问题相信上帝会帮我找到不同的解决方法

79._4_ 当我在困境时, 相信上帝会帮我度过的

80._ 4 _ 不管遇到什么, 我都相信有得救、永生和那解决问题的能力

\section{Studio del rapporto tra fede e business:}

Questo studio intende investigare le connessioni tra la fede ed il business tra i cristiani evangelici cinesi. La vostra partecipazione è volontaria e i vostri dati saranno mantenuti anonimi e riservati.

Prima di tutti vorremo chiederti alcune domande su di te:

Quanti anni hai?__26_

Genere: __ X_ Maschio __ Femmina

Qual è il tuo status? (E. g., single, sposato, divorziato, etc.) single

Che lavoro fai? impiegamo

Hai iniziato tu il business o lavori per altri?

Dove sei nato (paese e città)? cina, zhejiang 
Per le prossime domande, per favore scegli un numero 1-4 e scrivilo negli spazi bianchi per ciascuna affermazione al fine di indicare quanto condividi con quell'affermazione.

\begin{tabular}{|cccc|}
1 & 2 & 3 & 4 \\
\hline Per nulla vero & Poco vero & Abbastanza & Totalmente \\
& & vero & vero
\end{tabular}
81. 2
Riesco sempre a risolvere problemi difficili se ci provo abbastanza seriamente
82. 2 Se qualcuno mi contrasta, posso trovare il modo o il sistema di ottenere ciò che voglio
83. 2 Per me è facile attenermi alle mie intenzioni e raggiungere i miei obiettivi
84. 2 Ho fiducia di poter affrontare efficacemente eventi inattesi
85. Grazie alle mie risorse, so come gestire situazioni impreviste
86. 1 Posso risolvere la maggior parte dei problemi se ci metto il necessario impegno
87._____ Rimango calmo nell'affrontare le difficoltà perché posso confidare nelle mie capacità di fronteggiarle
88. 2 Quando mi trovo di fronte ad un problema, di solito trovo parecchie soluzioni
89. 2 Se sono in "panne", posso sempre pensare a qualcosa da mettere in atto
90. 2 Non importa quello che mi può capitare, di solito sono in grado di gestirlo

Per le prossime domande, per favore scegli un numero 1-4 e scrivi in ciascuna affermazione per indicare quanto condividi con quell'affermazione.

\begin{tabular}{|cccc|}
1 & 2 & 3 & 4 \\
\hline Per nulla vero & Poco vero & Abbastanza & Totalmente \\
& & vero & vero
\end{tabular}
81. 4 Sapere di essere "per sempre salvato" mi aiuta a risolvere problemi difficili
82. 3 In caso di contrasti con non credenti riesco a ottenere ciò che voglio
83. 4 La mia fede mi aiuta nella vita a raggiungere i miei obbiettivi
84.44 La certezza della salvezza mi aiuta ad affrontare eventi inattesi
$85 . \quad 4$ Grazie alla mia fede so come gestire situazioni impreviste
86. 3
87. 3 Posso risolvere la maggior parte dei problemi pregando ed impegnandomi Rimango calmo nell'affrontare le difficoltà perché posso confidare nella certezza della salvezza
88. 4 Di fronte ad un problema Dio mi aiuta a trovare parecchie soluzioni
89. 4 Se sono in difficoltà, Dio mi aiuta a pensare a qualcosa da mettere in atto 90.4 Non importa quello che mi può capitare, ho la certezza della salvezza e sono in grado di gestire la situazione 


\section{Studio del rapporto tra fede e business:}

Questo studio intende investigare le connessioni tra la fede ed il business tra i cristiani evangelici cinesi. La vostra partecipazione è volontaria e i vostri dati saranno mantenuti anonimi e riservati.

Prima di tutti vorremo chiederti alcune domande su di te:

Quanti anni hai?_23

Genere: __ X_Maschio __ Femmina

Qual è il tuo status? (E. g., single, sposato, divorziato, etc.) single

Che lavoro fai? commerciante

Hai iniziato tu il business o lavori per altri? per altri, genitori

Dove sei nato (paese e città)? Wenzhou cina

Per le prossime domande, per favore scegli un numero 1-4 e scrivilo negli spazi bianchi per ciascuna affermazione al fine di indicare quanto condividi con quell'affermazione.

\begin{tabular}{|cccc|}
1 & 2 & 3 & 4 \\
\hline Per nulla vero & Poco vero & Abbastanza & Totalmente \\
& & vero & vero
\end{tabular}

91._____ Riesco sempre a risolvere problemi difficili se ci provo abbastanza seriamente

92. __ _ _ Se qualcuno mi contrasta, posso trovare il modo o il sistema di ottenere ciò che voglio

93. _ _ _ Per me è facile attenermi alle mie intenzioni e raggiungere i miei obiettivi

94._____ Ho fiducia di poter affrontare efficacemente eventi inattesi

95. _ _ _ G Grazie alle mie risorse, so come gestire situazioni impreviste

96. _ _ _ Posso risolvere la maggior parte dei problemi se ci metto il necessario impegno

97. ___ R_ Rimango calmo nell'affrontare le difficoltà perché posso confidare nelle mie capacità di fronteggiarle

98. _ _ _ _ Quando mi trovo di fronte ad un problema, di solito trovo parecchie soluzioni

99. _ 3 __ Se sono in "panne", posso sempre pensare a qualcosa da mettere in atto

100. ___ _ _ Non importa quello che mi può capitare, di solito sono in grado di gestirlo 
Per le prossime domande, per favore scegli un numero 1-4 e scrivi in ciascuna affermazione per indicare quanto condividi con quell'affermazione.

\begin{tabular}{|cccc|}
1 & 2 & 3 & 4 \\
\hline Per nulla vero & Poco vero & Abbastanza & Totalmente \\
& & vero & vero
\end{tabular}

91._____ Sapere di essere "per sempre salvato" mi aiuta a risolvere problemi difficili

92. _ _ _ _ In caso di contrasti con non credenti riesco a ottenere ciò che voglio

93._____ La mia fede mi aiuta nella vita a raggiungere i miei obbiettivi

94. _ 3 _ _ La certezza della salvezza mi aiuta ad affrontare eventi inattesi

95. _ _ _ _ Grazie alla mia fede so come gestire situazioni impreviste

96. _ _ _ _ Posso risolvere la maggior parte dei problemi pregando ed impegnandomi

97._____ Rimango calmo nell'affrontare le difficoltà perché posso confidare nella certezza della salvezza

98. _ _ _ Di fronte ad un problema Dio mi aiuta a trovare parecchie soluzioni

99. _ _ _ _ Se sono in difficoltà, Dio mi aiuta a pensare a qualcosa da mettere in atto

Non importa quello che mi può capitare, ho la certezza della salvezza e sono in grado di

gestire la situazione

\section{Study of the relationship between faith and business:}

This study aims to investigate the connections between faith and business among the evangelical Christians entrepreneurs. Your participation is voluntary and your data will be maintained anonymous and confidential.

First of all we would like to ask some questions about you:

How old are you?_45

Gender:

X_Male Female

What is your status? (E. g., single, married, divorced, etc.) married

What kind of job you do? Boss of LED company

Where are you born (city and country)? Wenzhou

For the next questions please choose a number $1-4$ and write a number in every statement to identify how you agree with the statement.

\begin{tabular}{|cccc|}
1 & 2 & 3 & 4 \\
\hline Not at all true & Hardly true & Moderately & true
\end{tabular}

101. _ _ _ I can always manage to solve difficult problems if I try hard enough.

102. _ _ _ If If someone opposes me, I can find the means and ways to get what I want.

103. ___ _ It is easy for me to stick to my aims and accomplish my goals. 
104. _ _ _ I I am confident that I could deal efficiently with unexpected events.

105. 3_ T_ Thanks to my resourcefulness, I know how to handle unforeseen situations.

106. _ _ _ _ I can solve most problems if I invest the necessary effort.

107. _ _ _ _ I can remain calm when facing difficulties because I can rely on my coping abilities.

108. _ _ _ When I am confronted with a problem, I can usually find several solutions.

109. _ _ _ If I I am in trouble, I can usually think of a solution.

110. ___ _ I can usually handle whatever comes my way.

\section{Study of the relationship between faith and business:}

This study aims to investigate the connections between faith and business among the evangelical Christians entrepreneurs. Your participation is voluntary and your data will be maintained anonymous and confidential.

First of all we would like to ask some questions about you:

How old are you? _50

Gender: __ X_Male __ Female

What is your status? (E. g., single, married, divorced, etc.) ___ Married

What kind of job you do? ___ Pastor \& Project manager

Where are you born (city and country)? Wenzhou

For the next questions please choose a number 1-4 and write a number in every statement to identify how you agree with the statement.

\begin{tabular}{|cccc|}
1 & 2 & 3 & 4 \\
\hline Not at all true & Hardly true & $\begin{array}{c}\text { Moderately } \\
\text { true }\end{array}$ & Exactly true
\end{tabular}

111. _ 3__ I can always manage to solve difficult problems if I try hard enough.

112. _ _ _ If someone opposes me, I can find the means and ways to get what I want.

113. __ _ _ It is easy for me to stick to my aims and accomplish my goals.

114. 2_ I am confident that I could deal efficiently with unexpected events.

115. _ _ _ Thanks to my resourcefulness, I know how to handle unforeseen situations.

116. _ _ _ I can solve most problems if I invest the necessary effort.

117. _ _ _ I can remain calm when facing difficulties because I can rely on my coping abilities.

118. _ _ _ When I am confronted with a problem, I can usually find several solutions.

119. _ _ _ If I I am in trouble, I can usually think of a solution.

120. ___ I can usually handle whatever comes my way. 
For the next questions please choose a number 1-4 and write it in every statement to identify how much do you agree with the statement.

\begin{tabular}{|cccc|}
1 & 2 & 3 & 4 \\
\hline Not at all true & Hardly true & $\begin{array}{c}\text { Moderately } \\
\text { true }\end{array}$ & Exactly true
\end{tabular}

100. ___ Knowing to be "forever saved" help me to resolve difficult problems

101. _ _ _ In case of contrasts with unbelievers I can always obtain what I want

102. _ _ _ _ _ My faith helps me in life to reach my goals

103. _ _ _ The assurance of salvation helps me to face unexpected events

104. _ _ _ _ Because of my faith I know how to manage unexpected circumstances

105. _ _ _ I can resolve the majority of problems if I pray and invest the necessary effort

106. 3_ I stay calm facing difficulties because I can trust in the assurance of salvation

107. _ _ _ _ In front of a problem God helps me to find several solutions

108. _ _ _ If I am in difficulties, God helps me to think of a solution

109. _ _ _ It doesn't matter what may happen, I can handle it because I have the assurance of salvation 


\section{Study of the relationship between faith and business:}

This study aims to investigate the connections between faith and business among the evangelical Christians entrepreneurs. Your participation is voluntary and your data will be maintained anonymous and confidential.

First of all we would like to ask some questions about you:

How old are you?_45

Gender:_ X__ Male __ Female

What is your status? (E. g., single, married, divorced, etc.) married

What kind of job you do? manager of clothing store

Where are you born (city and country)? Wenzhou

For the next questions please choose a number 1-4 and write a number in every statement to identify how you agree with the statement.

\begin{tabular}{|cccc|}
1 & 2 & 3 & 4 \\
\hline Not at all true & Hardly true & $\begin{array}{c}\text { Moderately } \\
\text { true }\end{array}$ & Exactly true
\end{tabular}

121. 2 __ I can always manage to solve difficult problems if I try hard enough.

122. _ ____ If someone opposes me, I can find the means and ways to get what I want.

123. ___ _ It is easy for me to stick to my aims and accomplish my goals.

124. _ _ _ I I am confident that I could deal efficiently with unexpected events.

125. 2_ Thanks to my resourcefulness, I know how to handle unforeseen situations.

126. 2__ _ can solve most problems if I invest the necessary effort.

127. _ 2 2 can remain calm when facing difficulties because I can rely on my coping abilities.

128. 3_ When I am confronted with a problem, I can usually find several solutions.

129. _ 4 __ If I am in trouble, I can usually think of a solution.

130. ___ I I can usually handle whatever comes my way. 
For the next questions please choose a number 1-4 and write it in every statement to identify how much do you agree with the statement.

\begin{tabular}{|cccc|}
1 & 2 & 3 & 4 \\
\hline Not at all true & Hardly true & $\begin{array}{c}\text { Moderately } \\
\text { true }\end{array}$ & Exactly true
\end{tabular}

110. 2 Knnowing to be "forever saved" help me to resolve difficult problems

111. _ _ _ In case of contrasts with unbelievers I can always obtain what I want

112. __ _ _ My faith helps me in life to reach my goals

113. _ _ _ The assurance of salvation helps me to face unexpected events

114. 2_ 2_Because of my faith I know how to manage unexpected circumstances

115. 3_ _ I can resolve the majority of problems if I pray and invest the necessary effort

116. _ 3I stay calm facing difficulties because I can trust in the assurance of salvation

117. 4 __ In front of a problem God helps me to find several solutions

118. _ 4 __ If I am in difficulties, God helps me to think of a solution

119. _ _ _ It doesn't matter what may happen, I can handle it because I have the assurance of salvation

\section{Study of the relationship between faith and business:}

This study aims to investigate the connections between faith and business among the evangelical Christians entrepreneurs. Your participation is voluntary and your data will be maintained anonymous and confidential.

First of all we would like to ask some questions about you:

How old are you?_28

Gender: Male _ X_Female

What is your status? (E. g., single, married, divorced, etc.) married

What kind of job you do? Kindegarden Manager

Where are you born (city and country)? Wenzhou

For the next questions please choose a number 1-4 and write a number in every statement to identify how you agree with the statement.

\begin{tabular}{|cccc|}
\hline 1 & 2 & 3 & 4 \\
\hline Not at all true & Hardly true & $\begin{array}{c}\text { Moderately } \\
\text { true }\end{array}$ & Exactly true
\end{tabular}

131. _ 3__ I can always manage to solve difficult problems if I try hard enough.

132. _ _ _ If If someone opposes me, I can find the means and ways to get what I want.

133. _ _ _ It is easy for me to stick to my aims and accomplish my goals.

134. 2_ I am confident that I could deal efficiently with unexpected events.

135. 2_ Thanks to my resourcefulness, I know how to handle unforeseen situations.

136. $4 \ldots$ _ I can solve most problems if I invest the necessary effort. 
137. _ _ _ I can remain calm when facing difficulties because I can rely on my coping abilities.

138. _ _ _ W When I am confronted with a problem, I can usually find several solutions.

139. _ _ _ I I I am in trouble, I can usually think of a solution.

140. ___ _ I can usually handle whatever comes my way.

For the next questions please choose a number 1-4 and write it in every statement to identify how much do you agree with the statement.

\begin{tabular}{|cccc|}
1 & 2 & 3 & 4 \\
\hline Not at all true & Hardly true & $\begin{array}{c}\text { Moderately } \\
\text { true }\end{array}$ & Exactly true
\end{tabular}

120. 3_Knowing to be "forever saved" help me to resolve difficult problems

121. _ 3__ In case of contrasts with unbelievers I can always obtain what I want

122. ___ _ My faith helps me in life to reach my goals

123. _ _ _ The assurance of salvation helps me to face unexpected events

124. _ 3_Because of my faith I know how to manage unexpected circumstances

125. 4_ I can resolve the majority of problems if I pray and invest the necessary effort

126. 4 _ I stay calm facing difficulties because I can trust in the assurance of salvation

127. _ $4 \_$In front of a problem God helps me to find several solutions

128. _ _ _ _ If I am in difficulties, God helps me to think of a solution

129. _ _ _ It doesn't matter what may happen, I can handle it because I have the assurance of salvation 


\section{Study of the relationship between faith and business:}

This study aims to investigate the connections between faith and business among the evangelical Christians entrepreneurs. Your participation is voluntary and your data will be maintained anonymous and confidential.

First of all we would like to ask some questions about you:

How old are you?_47

Gender: Male __ X_Female

What is your status? (E. g., single, married, divorced, etc.) married

What kind of job you do? manager of several kindergarten

Where are you born (city and country)? Tangxia (Wenzhou)

For the next questions please choose a number $1-4$ and write a number in every statement to identify how you agree with the statement.

\begin{tabular}{|cccc|}
1 & 2 & 3 & 4 \\
\hline Not at all true & Hardly true & $\begin{array}{c}\text { Moderately } \\
\text { true }\end{array}$ & Exactly true
\end{tabular}

141. ___ _ I can always manage to solve difficult problems if I try hard enough.

142. _ _ _ I I I someone opposes me, I can find the means and ways to get what I want.

143. ___ _ It is easy for me to stick to my aims and accomplish my goals.

144. ___ _ I am confident that I could deal efficiently with unexpected events.

145. ___ _ Thanks to my resourcefulness, I know how to handle unforeseen situations.

146. _ _ _ _ I can solve most problems if I invest the necessary effort.

147. ___ I I can remain calm when facing difficulties because I can rely on my coping abilities.

148. _ _ W When I am confronted with a problem, I can usually find several solutions.

149. _ _ _ If I am in trouble, I can usually think of a solution.

150. ___ _ I can usually handle whatever comes my way.

For the next questions please choose a number 1-4 and write it in every statement to identify how much do you agree with the statement.

\begin{tabular}{|cccc|}
1 & 2 & 3 & 4 \\
\hline Not at all true & Hardly true & $\begin{array}{c}\text { Moderately } \\
\text { true }\end{array}$ & Exactly true
\end{tabular}

130. ___ Knowing to be "forever saved" help me to resolve difficult problems

131. _ _ _ _ In case of contrasts with unbelievers I can always obtain what I want

132. ___ _ My faith helps me in life to reach my goals

133. _ _ _ The assurance of salvation helps me to face unexpected events

134. _ _ _ _ Because of my faith I know how to manage unexpected circumstances

135. _ _ _ _ I can resolve the majority of problems if I pray and invest the necessary effort

136. _ _ _ I stay calm facing difficulties because I can trust in the assurance of salvation

137. _ _ _ _ In front of a problem God helps me to find several solutions

138. _ _ _ If I am in difficulties, God helps me to think of a solution

_ 4 __ It doesn't matter what may happen, I can handle it because I have the assurance of salvation 
For the next questions please choose a number 1-4 and write it in every statement to identify how much do you agree with the statement.

\begin{tabular}{|cccc|}
1 & 2 & 3 & 4 \\
\hline Not at all true & Hardly true & $\begin{array}{c}\text { Moderately } \\
\text { true }\end{array}$ & Exactly true
\end{tabular}

139. 3_Knowing to be "forever saved" help me to resolve difficult problems

140. 3 _ In case of contrasts with unbelievers I can always obtain what I want

141. 3___ My faith helps me in life to reach my goals

142. 3_ The assurance of salvation helps me to face unexpected events

143. 3__ Because of my faith I know how to manage unexpected circumstances

144. 3 __ I can resolve the majority of problems if I pray and invest the necessary effort

145. 3_ I I stay calm facing difficulties because I can trust in the assurance of salvation

146. $3 \_$In front of a problem God helps me to find several solutions

147. $3 \_$If I I am in difficulties, God helps me to think of a solution

148. 3__ It doesn't matter what may happen, I can handle it because I have the assurance of salvation

\section{Study of the relationship between faith and business:}

This study aims to investigate the connections between faith and business among the evangelical Christians entrepreneurs. Your participation is voluntary and your data will be maintained anonymous and confidential.

First of all we would like to ask some questions about you:

How old are you?_23

Gender: Female

What is your status? (E. g., single, married, divorced, etc.) Single

What kind of job you do? Administrator for Multiple businesses

Where are you born (city and country)? Wenzhou

For the next questions please choose a number 1-4 and write a number in every statement to identify how you agree with the statement.

\begin{tabular}{|cccc|}
\hline 1 & 2 & 3 & 4 \\
\hline Not at all true & Hardly true & $\begin{array}{c}\text { Moderately } \\
\text { true }\end{array}$ & Exactly true
\end{tabular}

151. _ _ _ I can always manage to solve difficult problems if I try hard enough.

152. _ _ _ If someone opposes me, I can find the means and ways to get what I want.

153. __ 4 _ It is easy for me to stick to my aims and accomplish my goals.

154. _ _ _ I I am confident that I could deal efficiently with unexpected events.

155. _ _ _ Thanks to my resourcefulness, I know how to handle unforeseen situations.

156. __ _ _ I can solve most problems if I invest the necessary effort. 
157. ___ _ I can remain calm when facing difficulties because I can rely on my coping abilities.

158. _ _ _ W When I am confronted with a problem, I can usually find several solutions.

159. _ _ _ If I am in trouble, I can usually think of a solution.

160. __ _ _ I can usually handle whatever comes my way.

For the next questions please choose a number 1-4 and write it in every statement to identify how much do you agree with the statement.

\begin{tabular}{|cccc|}
1 & 2 & 3 & 4 \\
\hline Not at all true & Hardly true & $\begin{array}{c}\text { Moderately } \\
\text { true }\end{array}$ & Exactly true
\end{tabular}

149. ___ Knowing to be "forever saved" help me to resolve difficult problems

150. _ _ _ In case of contrasts with unbelievers I can always obtain what I want

151. __ _ _ My faith helps me in life to reach my goals

152. _ _ _ The assurance of salvation helps me to face unexpected events

153. _ _ _ _ Because of my faith I know how to manage unexpected circumstances

154. __ _ _ I can resolve the majority of problems if I pray and invest the necessary effort

155. _ _ _ I I stay calm facing difficulties because I can trust in the assurance of salvation

156. _ _ _ In front of a problem God helps me to find several solutions

157. _ _ _ If I am in difficulties, God helps me to think of a solution

158. _ _ _ It doesn't matter what may happen, I can handle it because I have the assurance of salvation 


\section{Study of the relationship between faith and business:}

This study aims to investigate the connections between faith and business among the evangelical Christians entrepreneurs. Your participation is voluntary and your data will be maintained anonymous and confidential.

First of all we would like to ask some questions about you:

How old are you?_27

Gender: Male __ X_Female

What is your status? (E. g., single, married, divorced, etc.) single

What kind of job you do? manager of furnishing company

Where are you born (city and country)? Wenzhou

For the next questions please choose a number 1-4 and write a number in every statement to identify how you agree with the statement.

\begin{tabular}{|cccc|}
1 & 2 & 3 & 4 \\
\hline Not at all true & Hardly true & $\begin{array}{c}\text { Moderately } \\
\text { true }\end{array}$ & Exactly true
\end{tabular}

161. 2 __ I can always manage to solve difficult problems if I try hard enough.

162. _____ If someone opposes me, I can find the means and ways to get what I want.

163. ___ _ It is easy for me to stick to my aims and accomplish my goals.

164. _ _ _ I I am confident that I could deal efficiently with unexpected events.

165. 1_ Thanks to my resourcefulness, I know how to handle unforeseen situations.

166. _ 4_ I can solve most problems if I invest the necessary effort.

167. 2 2 I can remain calm when facing difficulties because I can rely on my coping abilities.

168. 2__ When I am confronted with a problem, I can usually find several solutions.

169._2__ If I am in trouble, I can usually think of a solution.

170. ___ I can usually handle whatever comes my way. 
For the next questions please choose a number 1-4 and write it in every statement to identify how much do you agree with the statement.

\begin{tabular}{|cccc|}
1 & 2 & 3 & 4 \\
\hline Not at all true & Hardly true & $\begin{array}{c}\text { Moderately } \\
\text { true }\end{array}$ & Exactly true
\end{tabular}

159. 3_Knowing to be "forever saved" help me to resolve difficult problems

160. ____ In case of contrasts with unbelievers I can always obtain what I want

161. ___ My faith helps me in life to reach my goals

162. _ _ _ The assurance of salvation helps me to face unexpected events

163. 4_ 4_Because of my faith I know how to manage unexpected circumstances

164. _ 4_I can resolve the majority of problems if I pray and invest the necessary effort

165. _ 3I stay calm facing difficulties because I can trust in the assurance of salvation

166. _ $4 \_$In front of a problem God helps me to find several solutions

167. ___ If I am in difficulties, God helps me to think of a solution

168. _ _ _ It doesn't matter what may happen, I can handle it because I have the assurance of salvation

\section{Study of the relationship between faith and business:}

This study aims to investigate the connections between faith and business among the evangelical

Christians entrepreneurs. Your participation is voluntary and your data will be maintained anonymous and confidential.

First of all we would like to ask some questions about you:

How old are you?_36

Gender: Male _ X__ Female

What is your status? (E. g., single, married, divorced, etc.) ___ Married

What kind of job you do? manager of a chemical factory

Where are you born (city and country)? Wenzhou

For the next questions please choose a number 1-4 and write a number in every statement to identify how you agree with the statement.

\begin{tabular}{|cccc|}
\hline 1 & 2 & 3 & 4 \\
\hline Not at all true & Hardly true & $\begin{array}{c}\text { Moderately } \\
\text { true }\end{array}$ & Exactly true
\end{tabular}

171. $3 \_$I can always manage to solve difficult problems if I try hard enough.

172. _____ If someone opposes me, I can find the means and ways to get what I want.

173. ___ _ It is easy for me to stick to my aims and accomplish my goals.

174. _ _ _ I am confident that I could deal efficiently with unexpected events.

175. 4__ Thanks to my resourcefulness, I know how to handle unforeseen situations.

176. _ $4 \_$I can solve most problems if I invest the necessary effort. 
177. _ _ _ _ I can remain calm when facing difficulties because I can rely on my coping abilities.

178. _ _ _ W When I am confronted with a problem, I can usually find several solutions.

179. 3_ _ If I am in trouble, I can usually think of a solution.

180. _ _ _ I can usually handle whatever comes my way.

For the next questions please choose a number 1-4 and write it in every statement to identify how much do you agree with the statement.

\begin{tabular}{|cccc|}
1 & 2 & 3 & 4 \\
\hline Not at all true & Hardly true & $\begin{array}{c}\text { Moderately } \\
\text { true }\end{array}$ & Exactly true
\end{tabular}

169. 4_K_ Knowing to be "forever saved" help me to resolve difficult problems

170. _ 4__ In case of contrasts with unbelievers I can always obtain what I want

171. ___ My faith helps me in life to reach my goals

172. _ _ _ _ The assurance of salvation helps me to face unexpected events

173. 4_Because of my faith I know how to manage unexpected circumstances

174. _ _ _ _ I can resolve the majority of problems if I pray and invest the necessary effort

175. __ _ _ I stay calm facing difficulties because I can trust in the assurance of salvation

176. _ _ _ _ In front of a problem God helps me to find several solutions

177. 4_ If I am in difficulties, God helps me to think of a solution

178. _ _ _ It doesn't matter what may happen, I can handle it because I have the assurance of salvation 


\section{Studio del rapporto tra fede e business:}

Questo studio intende investigare le connessioni tra la fede ed il business tra i cristiani evangelici cinesi. La vostra partecipazione è volontaria e i vostri dati saranno mantenuti anonimi e riservati.

Prima di tutti vorremo chiederti alcune domande su di te:

Quanti anni hai?27

Genere: __ __ Maschio __ Femmina

Qual è il tuo status? (E. g., single, sposato, divorziato, etc.) sposato

Che lavoro fai? _web designer

Hai iniziato tu il business o lavori per altri? __ per altri

Dove sei nato (paese e città)?_zhejiang cina

Per le prossime domande, per favore scegli un numero 1-4 e scrivilo negli spazi bianchi per ciascuna affermazione al fine di indicare quanto condividi con quell'affermazione.

\begin{tabular}{|cccc|}
1 & 2 & 3 & 4 \\
\hline Per nulla vero & Poco vero & Abbastanza & Totalmente \\
& & vero & vero
\end{tabular}

181. _____ Riesco sempre a risolvere problemi difficili se ci provo abbastanza seriamente

182. ___ _ _ Se qualcuno mi contrasta, posso trovare il modo o il sistema di ottenere ciò che voglio

183. ______Per me è facile attenermi alle mie intenzioni e raggiungere i miei obiettivi

184. ___ _ _ Ho fiducia di poter affrontare efficacemente eventi inattesi

185. _____ Grazie alle mie risorse, so come gestire situazioni impreviste

186. ___ _ _ Posso risolvere la maggior parte dei problemi se ci metto il necessario impegno

187. ___ _ _ Rimango calmo nell'affrontare le difficoltà perché posso confidare nelle mie capacità di fronteggiarle

188. ___ _ _ Quando mi trovo di fronte ad un problema, di solito trovo parecchie soluzioni

189. ___ _ _ Se sono in "panne", posso sempre pensare a qualcosa da mettere in atto

190. ___ _ _ Non importa quello che mi può capitare, di solito sono in grado di gestirlo 
Per le prossime domande, per favore scegli un numero 1-4 e scrivi in ciascuna affermazione per indicare quanto condividi con quell'affermazione.

\begin{tabular}{|cccc|}
1 & 2 & 3 & 4 \\
\hline Per nulla vero & Poco vero & Abbastanza & Totalmente \\
& & vero & vero
\end{tabular}

179. _ _ _ _ Sapere di essere "per sempre salvato" mi aiuta a risolvere problemi difficili

180. ___ _ _ In caso di contrasti con non credenti riesco a ottenere ciò che voglio

181. ___ _ _ La mia fede mi aiuta nella vita a raggiungere i miei obbiettivi

182. _ _ _ _ La certezza della salvezza mi aiuta ad affrontare eventi inattesi

183. __ _ _ Grazie alla mia fede so come gestire situazioni impreviste

184. ___ _ _ Posso risolvere la maggior parte dei problemi pregando ed impegnandomi

185. ___ _ _ Rimango calmo nell'affrontare le difficoltà perché posso confidare nella certezza della salvezza

186. _2___ Di fronte ad un problema Dio mi aiuta a trovare parecchie soluzioni

187. _____ Se sono in difficoltà, Dio mi aiuta a pensare a qualcosa da mettere in atto

188. _ _ ___ Non importa quello che mi può capitare, ho la certezza della salvezza e sono in grado di gestire la situazione

\section{Study of the relationship between faith and business:}

This study aims to investigate the connections between faith and business among the evangelical Christians entrepreneurs. Your participation is voluntary and your data will be maintained anonymous and confidential.

First of all we would like to ask some questions about you:

How old are you?_24

Gender: __ X_Male Female

What is your status? (E. g., single, married, divorced, etc.) Married

What kind of job you do? Manager of multiple businesses

Where are you born (city and country)? Wenzhou

For the next questions please choose a number 1-4 and write a number in every statement to identify how you agree with the statement.

\begin{tabular}{|cccc|}
1 & 2 & 3 & 4 \\
\hline Not at all true & Hardly true & $\begin{array}{c}\text { Moderately } \\
\text { true }\end{array}$ & Exactly true
\end{tabular}

191. 3 __ I can always manage to solve difficult problems if I try hard enough.

192. _____ If someone opposes me, I can find the means and ways to get what I want.

193. _ _ _ _ It is easy for me to stick to my aims and accomplish my goals.

194. _ _ _ I I am confident that I could deal efficiently with unexpected events.

195. _ 3_ Thanks to my resourcefulness, I know how to handle unforeseen situations. 
196.

197.

198. 2

199. 3

200.

4_I can solve most problems if I invest the necessary effort.

3 I can remain calm when facing difficulties because I can rely on my coping abilities. When I am confronted with a problem, I can usually find several solutions. If I am in trouble, I can usually think of a solution.

2__ I can usually handle whatever comes my way.

For the next questions please choose a number 1-4 and write it in every statement to identify how much do you agree with the statement.

\begin{tabular}{|cccc|}
1 & 2 & 3 & 4 \\
\hline Not at all true & Hardly true & $\begin{array}{c}\text { Moderately } \\
\text { true }\end{array}$ & Exactly true
\end{tabular}

189. 3 Knowing to be "forever saved" help me to resolve difficult problems

190. _ _ _ In case of contrasts with unbelievers I can always obtain what I want

191. _ _ _ My faith helps me in life to reach my goals

192. _ _ _ The assurance of salvation helps me to face unexpected events

193. 4_ 4 Because of my faith I know how to manage unexpected circumstances

194. 4_ _ I can resolve the majority of problems if I pray and invest the necessary effort

195. _ _ 3 I stay calm facing difficulties because I can trust in the assurance of salvation

196. $4 \ldots$ _ In front of a problem God helps me to find several solutions

197. _ 4 __ If I am in difficulties, God helps me to think of a solution

198. _ _ _ _ It doesn't matter what may happen, I can handle it because I have the assurance of salvation 


\section{Study of the relationship between faith and business:}

This study aims to investigate the connections between faith and business among the evangelical Christians entrepreneurs. Your participation is voluntary and your data will be maintained anonymous and confidential.

First of all we would like to ask some questions about you:

How old are you? _ 37

Gender: Male __ _ Female

What is your status? (E. g., single, married, divorced, etc.) married

What kind of job you do? manager of clothing store

Where are you born (city and country)? Wenzhou

For the next questions please choose a number 1-4 and write a number in every statement to identify how you agree with the statement.

\begin{tabular}{|cccc|}
1 & 2 & 3 & 4 \\
\hline Not at all true & Hardly true & $\begin{array}{c}\text { Moderately } \\
\text { true }\end{array}$ & Exactly true
\end{tabular}

201. 3__ I can always manage to solve difficult problems if I try hard enough.

202. _ ____ If someone opposes me, I can find the means and ways to get what I want.

203. _ _ _ _ It is easy for me to stick to my aims and accomplish my goals.

204. _ _ _ I I am confident that I could deal efficiently with unexpected events.

205. 3_ Thanks to my resourcefulness, I know how to handle unforeseen situations.

206. 3_ _ I can solve most problems if I invest the necessary effort.

207. _ 3I can remain calm when facing difficulties because I can rely on my coping abilities.

208. 3 _ 3When I am confronted with a problem, I can usually find several solutions.

209. _ _ _ If I I am in trouble, I can usually think of a solution.

210. ___ _ I can usually handle whatever comes my way. 
For the next questions please choose a number 1-4 and write it in every statement to identify how much do you agree with the statement.

\begin{tabular}{|cccc|}
1 & 2 & 3 & 4 \\
\hline Not at all true & Hardly true & $\begin{array}{c}\text { Moderately } \\
\text { true }\end{array}$ & Exactly true
\end{tabular}

199. _ _ _ K Knowing to be "forever saved" help me to resolve difficult problems

200. _ _ _ In case of contrasts with unbelievers I can always obtain what I want

201. 3__ My faith helps me in life to reach my goals

202. _ _ _ The assurance of salvation helps me to face unexpected events

203. _ _ _ _ Because of my faith I know how to manage unexpected circumstances

204. _ _ _ I can resolve the majority of problems if I pray and invest the necessary effort

205. _ _ _ I stay calm facing difficulties because I can trust in the assurance of salvation

206. _ 4 __ In front of a problem God helps me to find several solutions

207. _ _ _ If I I am in difficulties, God helps me to think of a solution

208. _ _ _ _ It doesn't matter what may happen, I can handle it because I have the assurance of salvation

\section{Study of the relationship between faith and business:}

This study aims to investigate the connections between faith and business among the evangelical

Christians entrepreneurs. Your participation is voluntary and your data will be maintained anonymous and confidential.

First of all we would like to ask some questions about you:

How old are you?_27

Gender:<smiles></smiles>
Female

What is your status? (E. g., single, married, divorced, etc.) single

What kind of job you do? commerciante

Where are you born (city and country)? Wenzhou

For the next questions please choose a number 1-4 and write a number in every statement to identify how you agree with the statement.

\begin{tabular}{|cccc|}
\hline 1 & 2 & 3 & 4 \\
\hline Not at all true & Hardly true & $\begin{array}{c}\text { Moderately } \\
\text { true }\end{array}$ & Exactly true
\end{tabular}

211. _ _ _ I I can always manage to solve difficult problems if I try hard enough.

212. _ _ _ If someone opposes me, I can find the means and ways to get what I want.

213. 2_ It is easy for me to stick to my aims and accomplish my goals.

214. 2_ I am confident that I could deal efficiently with unexpected events.

215. _ _ _ Thanks to my resourcefulness, I know how to handle unforeseen situations.

216. ___ _ I can solve most problems if I invest the necessary effort. 
217. _ _ _ I can remain calm when facing difficulties because I can rely on my coping abilities.

218. _ 3_When I am confronted with a problem, I can usually find several solutions.

219. 2_If I am in trouble, I can usually think of a solution.

220. ___ _ I can usually handle whatever comes my way.

For the next questions please choose a number 1-4 and write it in every statement to identify how much do you agree with the statement.

\begin{tabular}{|cccc|}
\hline 1 & 2 & 3 & 4 \\
\hline Not at all true & Hardly true & $\begin{array}{c}\text { Moderately } \\
\text { true }\end{array}$ & Exactly true
\end{tabular}

209. ___ Knowing to be "forever saved" help me to resolve difficult problems

210. _ _ _ _ In case of contrasts with unbelievers I can always obtain what I want

211 . _ 3_My faith helps me in life to reach my goals

212. 4_ 4 _ The assurance of salvation helps me to face unexpected events

213. _ _ _ _ Because of my faith I know how to manage unexpected circumstances

214. __ _ _ I can resolve the majority of problems if I pray and invest the necessary effort

215. _ _ _ I stay calm facing difficulties because I can trust in the assurance of salvation

216. _ 4_ In front of a problem God helps me to find several solutions

217. _ _ _ If I I am in difficulties, God helps me to think of a solution

218. _ _ _ It doesn't matter what may happen, I can handle it because I have the assurance of salvation 


\section{Study of the relationship between faith and business:}

This study aims to investigate the connections between faith and business among the evangelical Christians entrepreneurs. Your participation is voluntary and your data will be maintained anonymous and confidential.

First of all we would like to ask some questions about you:

How old are you?_28

Gender: __ X_ Male __ Female

What is your status? (E. g., single, married, divorced, etc.) sposato

What kind of job you do? Freelance

Where are you born (city and country)? Wenzhou

For the next questions please choose a number 1-4 and write a number in every statement to identify how you agree with the statement.

\begin{tabular}{|cccc|}
1 & 2 & 3 & 4 \\
\hline Not at all true & Hardly true & Moderately & true
\end{tabular}

221. ___ _ I can always manage to solve difficult problems if I try hard enough.

222. _ _ _ If someone opposes me, I can find the means and ways to get what I want.

223. 2 ___ It is easy for me to stick to my aims and accomplish my goals.

224. _ 3_ I I am confident that I could deal efficiently with unexpected events.

225. ___ Thanks to my resourcefulness, I know how to handle unforeseen situations.

226. _ _ _ I can solve most problems if I invest the necessary effort.

227. 3_ I can remain calm when facing difficulties because I can rely on my coping abilities.

228. _2__ When I am confronted with a problem, I can usually find several solutions.

229. _ _ _ If I am in trouble, I can usually think of a solution.

230. ___ I can usually handle whatever comes my way. 
For the next questions please choose a number 1-4 and write it in every statement to identify how much do you agree with the statement.

\begin{tabular}{|cccc|}
1 & 2 & 3 & 4 \\
\hline Not at all true & Hardly true & $\begin{array}{c}\text { Moderately } \\
\text { true }\end{array}$ & Exactly true
\end{tabular}

219. 3 K__ Knowing to be "forever saved" help me to resolve difficult problems

220. _ _ _ _ In case of contrasts with unbelievers I can always obtain what I want

221. ___ _ My faith helps me in life to reach my goals

222. _ _ _ T The assurance of salvation helps me to face unexpected events

223. 3_ 3_Because of my faith I know how to manage unexpected circumstances

$224 . \quad 3$ _ I can resolve the majority of problems if I pray and invest the necessary effort

225. _ _ 3I stay calm facing difficulties because I can trust in the assurance of salvation

226. _ 3 __ In front of a problem God helps me to find several solutions

227. _ _ _ If I am in difficulties, God helps me to think of a solution

228. _ _ _ It doesn't matter what may happen, I can handle it because I have the assurance of salvation

\section{关于信仰和生意之间的研究}

这次学术研究主要是针对于基督徒老板们做生意和信仰之间的紧密关系。你们可以自由 回答这些调查问卷, 没有任何强制性, 而且你们的信息将根据国家个人隐私法进行保 护。

个人信息:

几岁了? 34

性别:___ 男 — 女

你的生活状态? (单身, 已婚, 离异, 丧偶) sposato

目前职业? scarpe ingrosso

出生地方、城市? wenzhou

接下来这些问题, 请选择 $1-4$ 之间, 然后根据个人的观点把相关答案填在空格上。

\begin{tabular}{|cccc|}
1 & 2 & 3 & 4 \\
\hline 完全不是 & 一点 & 相当 & 完全是
\end{tabular}

231. 2 2_如果我认真面对总是能够解决重大困难的

232. 2_ 2 如果有人反对我，我能够找到解决的方法来到达我的目的

233. _ 2_对我来说很容易坚持个人意志, 达到自己的目的

234. 2 2 我很有信心有效的面对一些突发事件

235. 2 2_我所拥有的资源足够可以面对不可预知的窘境

236. 2 2 _ 只要用心就可以解决大部分问题

237. — 2 _ 当遇到问题时, 会保持冷静, 相信自己有能力面对 
238. — 2 _ 当我有问题时, 总会找到很多解决方法

239. 2_当我在窘境时, 总是能想到一些东西来度过

240. _ 2_ 不管遇到什么, 总是有能力去处理

接下来这些问题, 请选择1-4之间, 然后根据个人的观点把相关答案填在空格上。

\begin{tabular}{|cccc|}
1 & 2 & 3 & 4 \\
\hline 完全不是 & 一点 & 相当 & 完全是
\end{tabular}

229. 一 - _ 当知道自己是 “得救的、有永生” , 会帮助我解决一些困难问题

230. _ 2 _ 当和一些不信教的人有不同意见时, 我可以到达我的目的

231. _ - _ _ 我的信仰有助于我到达一些人生目标

232. — 4 _ 在得救、永生的信念之下, 可帮助我面对一些突发事件

233. _ - 4_我的信仰可帮助解决一些未知窘境

234. _ 4 _ 通过祷告和用心做事可以解决大部分问题

235. _ _ _ _ 在得救、永生的信念之下会冷静的解决问题

236. 4 _ 一面对问题相信上帝会帮我找到不同的解决方法

237. 一 _ _ 当我在困境时，相信上帝会帮我度过的

238. 4 _ _ 不管遇到什么, 我都相信有得救、永生和那解决问题的能力 


\section{Study of the relationship between faith and business:}

This study aims to investigate the connections between faith and business among the evangelical Christians entrepreneurs. Your participation is voluntary and your data will be maintained anonymous and confidential.

First of all we would like to ask some questions about you:

How old are you?_20

Gender: __ X_ Male __ Female

What is your status? (E. g., single, married, divorced, etc.) single

What kind of job you do? commerciante

Where are you born (city and country)? wenzhou

For the next questions please choose a number 1-4 and write a number in every statement to identify how you agree with the statement.

\begin{tabular}{|cccc|}
1 & 2 & 3 & 4 \\
\hline Not at all true & Hardly true & $\begin{array}{c}\text { Moderately } \\
\text { true }\end{array}$ & Exactly true
\end{tabular}

241. 2 __ I can always manage to solve difficult problems if I try hard enough.

242. _____ If someone opposes me, I can find the means and ways to get what I want.

243. ___ _ It is easy for me to stick to my aims and accomplish my goals.

244. _ _ _ I I am confident that I could deal efficiently with unexpected events.

245.

246. _ _ _ _ I can solve most problems if I invest the necessary effort.

247. __ _ I can remain calm when facing difficulties because I can rely on my coping abilities.

248. _ _ _ When I am confronted with a problem, I can usually find several solutions.

249.___ If I I am in trouble, I can usually think of a solution.

250. ___ I can usually handle whatever comes my way. 
For the next questions please choose a number 1-4 and write it in every statement to identify how much do you agree with the statement.

\begin{tabular}{|cccc|}
1 & 2 & 3 & 4 \\
\hline Not at all true & Hardly true & $\begin{array}{c}\text { Moderately } \\
\text { true }\end{array}$ & Exactly true
\end{tabular}

239._____ Knowing to be "forever saved" help me to resolve difficult problems

240. _ _ _ In case of contrasts with unbelievers I can always obtain what I want

241. ___ _ _ My faith helps me in life to reach my goals

242. _ _ _ _ The assurance of salvation helps me to face unexpected events

243. 2_ 2_Because of my faith I know how to manage unexpected circumstances

244. 2_ _ I can resolve the majority of problems if I pray and invest the necessary effort

245. _ _ _ I stay calm facing difficulties because I can trust in the assurance of salvation

246. __ _ _ In front of a problem God helps me to find several solutions

247. ___ If I am in difficulties, God helps me to think of a solution

248. _ _ _ It doesn't matter what may happen, I can handle it because I have the assurance of salvation

\section{Study of the relationship between faith and business:}

This study aims to investigate the connections between faith and business among the evangelical

Christians entrepreneurs. Your participation is voluntary and your data will be maintained anonymous and confidential.

First of all we would like to ask some questions about you:

How old are you?_23

Gender: Male_ _ _ Female

What is your status? (E. g., single, married, divorced, etc.) single

What kind of job you do? store manager

Where are you born (city and country)? Wenzhou

For the next questions please choose a number 1-4 and write a number in every statement to identify how you agree with the statement.

\begin{tabular}{|cccc|}
\hline 1 & 2 & 3 & 4 \\
\hline Not at all true & Hardly true & $\begin{array}{c}\text { Moderately } \\
\text { true }\end{array}$ & Exactly true
\end{tabular}

251. _ ___ I can always manage to solve difficult problems if I try hard enough.

252. _ ____ If someone opposes me, I can find the means and ways to get what I want.

253. _ ____ It is easy for me to stick to my aims and accomplish my goals.

254. _ 2__ I am confident that I could deal efficiently with unexpected events.

255. ____ Thanks to my resourcefulness, I know how to handle unforeseen situations.

256. _ $4 \_$_ I can solve most problems if I invest the necessary effort. 
257.____ I can remain calm when facing difficulties because I can rely on my coping abilities.

258. _ ____ When I am confronted with a problem, I can usually find several solutions.

259. _ _ _ If I am in trouble, I can usually think of a solution.

260. ____ I can usually handle whatever comes my way.

For the next questions please choose a number 1-4 and write it in every statement to identify how much do you agree with the statement.

\begin{tabular}{|cccc|}
1 & 2 & 3 & 4 \\
\hline Not at all true & Hardly true & $\begin{array}{c}\text { Moderately } \\
\text { true }\end{array}$ & Exactly true
\end{tabular}

249. ___ Knowing to be "forever saved" help me to resolve difficult problems

250. _ _ _ _ In case of contrasts with unbelievers I can always obtain what I want

251. ___ _ My faith helps me in life to reach my goals

252. _ _ _ The assurance of salvation helps me to face unexpected events

253. _ _ _ _ Because of my faith I know how to manage unexpected circumstances

254. __ _ _ I can resolve the majority of problems if I pray and invest the necessary effort

255. _ _ _ I I stay calm facing difficulties because I can trust in the assurance of salvation

256. _ _ _ _ In front of a problem God helps me to find several solutions

257. _ _ _ If I am in difficulties, God helps me to think of a solution

258. ___ _ It doesn't matter what may happen, I can handle it because I have the assurance of salvation 


\section{Study of the relationship between faith and business:}

This study aims to investigate the connections between faith and business among the evangelical Christians entrepreneurs. Your participation is voluntary and your data will be maintained anonymous and confidential.

First of all we would like to ask some questions about you:

How old are you?27

Gender:_ X__ Male __ Female

What is your status? (E. g., single, married, divorced, etc.) married

What kind of job you do? Worker

Where are you born (city and country)? Cina Zheijiang

For the next questions please choose a number 1-4 and write a number in every statement to identify how you agree with the statement.

\begin{tabular}{|cccc|}
1 & 2 & 3 & 4 \\
\hline Not at all true & Hardly true & $\begin{array}{c}\text { Moderately } \\
\text { true }\end{array}$ & Exactly true
\end{tabular}

261. ___ I can always manage to solve difficult problems if I try hard enough.

262. 3_ 3_If someone opposes me, I can find the means and ways to get what I want.

263. _ _ 4_t is easy for me to stick to my aims and accomplish my goals.

264. ___ I I am confident that I could deal efficiently with unexpected events.

265.

266. _ _ _ _ I can solve most problems if I invest the necessary effort.

267. ___ I can remain calm when facing difficulties because I can rely on my coping abilities.

268. 2_ 2_When I am confronted with a problem, I can usually find several solutions.

269. 3_ 3 If I am in trouble, I can usually think of a solution.

270. 2_I can usually handle whatever comes my way. 
For the next questions please choose a number 1-4 and write it in every statement to identify how much do you agree with the statement.

\begin{tabular}{|cccc|}
1 & 2 & 3 & 4 \\
\hline Not at all true & Hardly true & $\begin{array}{c}\text { Moderately } \\
\text { true }\end{array}$ & Exactly true
\end{tabular}

259. _ _ _ Knowing to be "forever saved" help me to resolve difficult problems

260. 2_ 2 In case of contrasts with unbelievers I can always obtain what I want

261. ___ _ My faith helps me in life to reach my goals

262. _ 4_ The assurance of salvation helps me to face unexpected events

263. _ _ 4Because of my faith I know how to manage unexpected circumstances

264. 3_ I can resolve the majority of problems if I pray and invest the necessary effort

$265 . \quad 3$ _ I stay calm facing difficulties because I can trust in the assurance of salvation

266. _ _ 4 In front of a problem God helps me to find several solutions

267. 4 L If I am in difficulties, God helps me to think of a solution

268. _ _ _ It doesn't matter what may happen, I can handle it because I have the assurance of salvation

\section{Study of the relationship between faith and business:}

This study aims to investigate the connections between faith and business among the evangelical Christians entrepreneurs. Your participation is voluntary and your data will be maintained anonymous and confidential.

First of all we would like to ask some questions about you:

How old are you?_32

Gender: Male ___ Female

What is your status? (E. g., single, married, divorced, etc.) married

What kind of job you do? manager of supermarket

Where are you born (city and country)? Wenzhou

For the next questions please choose a number 1-4 and write a number in every statement to identify how you agree with the statement.

\begin{tabular}{|cccc|}
\hline 1 & 2 & 3 & 4 \\
\hline Not at all true & Hardly true & $\begin{array}{c}\text { Moderately } \\
\text { true }\end{array}$ & Exactly true
\end{tabular}

271. 2__ I can always manage to solve difficult problems if I try hard enough.

272. _ ____ If someone opposes me, I can find the means and ways to get what I want.

273. ___ _ It is easy for me to stick to my aims and accomplish my goals.

274. ___ I I am confident that I could deal efficiently with unexpected events. 
275. 2_ 2_ Thanks to my resourcefulness, I know how to handle unforeseen situations.

276. $3 \_$I can solve most problems if I invest the necessary effort.

277. _ _ _ I can remain calm when facing difficulties because I can rely on my coping abilities.

278. _ _ _ When I am confronted with a problem, I can usually find several solutions.

279. _ _ _ If I am in trouble, I can usually think of a solution.

280. __ _ I can usually handle whatever comes my way.

For the next questions please choose a number 1-4 and write it in every statement to identify how much do you agree with the statement.

\begin{tabular}{|cccc|}
1 & 2 & 3 & 4 \\
\hline Not at all true & Hardly true & $\begin{array}{c}\text { Moderately } \\
\text { true }\end{array}$ & Exactly true
\end{tabular}

269. 4_Knowing to be "forever saved" help me to resolve difficult problems

270. _ _ _ _ In case of contrasts with unbelievers I can always obtain what I want

271. ___ _ My faith helps me in life to reach my goals

272. __ _ _ The assurance of salvation helps me to face unexpected events

273. 3_ 3_Because of my faith I know how to manage unexpected circumstances

274. _ 3_I can resolve the majority of problems if I pray and invest the necessary effort

275. _ 3I stay calm facing difficulties because I can trust in the assurance of salvation

276. 3__ In front of a problem God helps me to find several solutions

277. _ 4 __ If I am in difficulties, God helps me to think of a solution

278. ___ _ It doesn't matter what may happen, I can handle it because I have the assurance of salvation 


\section{Study of the relationship between faith and business:}

This study aims to investigate the connections between faith and business among the evangelical Christians entrepreneurs. Your participation is voluntary and your data will be maintained anonymous and confidential.

First of all we would like to ask some questions about you:

How old are you?_27

Gender: __ X_ Male __ Female

What is your status? (E. g., single, married, divorced, etc.) single

What kind of job you do? engeneer and store manager

Where are you born (city and country)? Tonglu

For the next questions please choose a number 1-4 and write a number in every statement to identify how you agree with the statement.

\begin{tabular}{|cccc|}
1 & 2 & 3 & 4 \\
\hline Not at all true & Hardly true & Moderately & true
\end{tabular}

281. ___ _ I can always manage to solve difficult problems if I try hard enough.

282. ___ _ If someone opposes me, I can find the means and ways to get what I want.

283. ___ _ _ It is easy for me to stick to my aims and accomplish my goals.

284. __ _ _ I am confident that I could deal efficiently with unexpected events.

285. ___ _ Thanks to my resourcefulness, I know how to handle unforeseen situations.

286. _ _ _ _ I can solve most problems if I invest the necessary effort.

287. _ _ _ _ I can remain calm when facing difficulties because I can rely on my coping abilities.

288. _ _ _ When I am confronted with a problem, I can usually find several solutions.

289.____ If I am in trouble, I can usually think of a solution.

290. ___ _ I can usually handle whatever comes my way. 
For the next questions please choose a number 1-4 and write it in every statement to identify how much do you agree with the statement.

\begin{tabular}{|cccc|}
1 & 2 & 3 & 4 \\
\hline Not at all true & Hardly true & $\begin{array}{c}\text { Moderately } \\
\text { true }\end{array}$ & Exactly true
\end{tabular}

279. ___ Knowing to be "forever saved" help me to resolve difficult problems

280. ___ _ In case of contrasts with unbelievers I can always obtain what I want

281. __ _ _ My faith helps me in life to reach my goals

282. _ _ _ _ The assurance of salvation helps me to face unexpected events

283. _ _ _ _ Because of my faith I know how to manage unexpected circumstances

284. _ _ _ _ I can resolve the majority of problems if I pray and invest the necessary effort

285. ___ _ I stay calm facing difficulties because I can trust in the assurance of salvation

286. _ _ _ _ In front of a problem God helps me to find several solutions

287. _ _ _ _ If I am in difficulties, God helps me to think of a solution

288. _ _ _ It doesn't matter what may happen, I can handle it because I have the assurance of salvation

\section{Study of the relationship between faith and business:}

This study aims to investigate the connections between faith and business among the evangelical Christians entrepreneurs. Your participation is voluntary and your data will be maintained anonymous and confidential.

First of all we would like to ask some questions about you:

How old are you? 40

Gender:<smiles>[Y][14CH3]</smiles>
Female

What is your status? (E. g., single, married, divorced, etc.) married

What kind of job you do? boss of multiple clothing stores

Where are you born (city and country)? Wenzhou

For the next questions please choose a number 1-4 and write a number in every statement to identify how you agree with the statement.

\begin{tabular}{|cccc|}
\hline 1 & 2 & 3 & 4 \\
\hline Not at all true & Hardly true & $\begin{array}{c}\text { Moderately } \\
\text { true }\end{array}$ & Exactly true
\end{tabular}

291. ___ _ I can always manage to solve difficult problems if I try hard enough.

292. _ _ _ _ If someone opposes me, I can find the means and ways to get what I want.

293. _ _ _ _ It is easy for me to stick to my aims and accomplish my goals.

294. _ _ _ _ I am confident that I could deal efficiently with unexpected events.

295. _ _ _ Thanks to my resourcefulness, I know how to handle unforeseen situations.

296. ___ _ I can solve most problems if I invest the necessary effort. 
297. _ _ _ I can remain calm when facing difficulties because I can rely on my coping abilities.

298. __ _ _ When I am confronted with a problem, I can usually find several solutions.

299. _ _ _ If I am in trouble, I can usually think of a solution.

300. 2_ _ I can usually handle whatever comes my way.

For the next questions please choose a number 1-4 and write it in every statement to identify how much do you agree with the statement.

\begin{tabular}{|cccc|}
1 & 2 & 3 & 4 \\
\hline Not at all true & Hardly true & $\begin{array}{c}\text { Moderately } \\
\text { true }\end{array}$ & Exactly true
\end{tabular}

289. ___ Knowing to be "forever saved" help me to resolve difficult problems

290. _ _ _ _ In case of contrasts with unbelievers I can always obtain what I want

291. ___ _ _ My faith helps me in life to reach my goals

292. _ _ _ The assurance of salvation helps me to face unexpected events

293. _ _ _ _ Because of my faith I know how to manage unexpected circumstances

294. ___ _ I can resolve the majority of problems if I pray and invest the necessary effort

295. ___ _ I stay calm facing difficulties because I can trust in the assurance of salvation

296. _ _ _ In front of a problem God helps me to find several solutions

297. _ _ _ If I am in difficulties, God helps me to think of a solution

298. _ _ _ It doesn't matter what may happen, I can handle it because I have the assurance of salvation 


\section{Study of the relationship between faith and business:}

This study aims to investigate the connections between faith and business among the evangelical Christians entrepreneurs. Your participation is voluntary and your data will be maintained anonymous and confidential.

First of all we would like to ask some questions about you:

How old are you?_26

Gender: ___ X_Male __ Female

What is your status? (E. g., single, married, divorced, etc.) married

What kind of job you do? pastor

Where are you born (city and country)? Pingshan

For the next questions please choose a number 1-4 and write a number in every statement to identify how you agree with the statement.

\begin{tabular}{|cccc|}
1 & 2 & 3 & 4 \\
\hline Not at all true & Hardly true & $\begin{array}{c}\text { Moderately } \\
\text { true }\end{array}$ & Exactly true
\end{tabular}

301. _ _ _ I can always manage to solve difficult problems if I try hard enough.

302. _ _ _ _ If someone opposes me, I can find the means and ways to get what I want.

303. ___ _ It is easy for me to stick to my aims and accomplish my goals.

304. _ _ _ I I am confident that I could deal efficiently with unexpected events.

305. _ _ _ Thanks to my resourcefulness, I know how to handle unforeseen situations.

306. ___ I I can solve most problems if I invest the necessary effort.

307. _ _ _ _ I can remain calm when facing difficulties because I can rely on my coping abilities.

308. _ _ _ When I am confronted with a problem, I can usually find several solutions.

309. _ _ _ If I I am in trouble, I can usually think of a solution.

310. ___ I can usually handle whatever comes my way. 
For the next questions please choose a number 1-4 and write it in every statement to identify how much do you agree with the statement.

\begin{tabular}{|cccc|}
1 & 2 & 3 & 4 \\
\hline Not at all true & Hardly true & $\begin{array}{c}\text { Moderately } \\
\text { true }\end{array}$ & Exactly true
\end{tabular}

299. ___ K__ Knowing to be "forever saved" help me to resolve difficult problems

300. _ _ _ _ In case of contrasts with unbelievers I can always obtain what I want

301. __ _ _ My faith helps me in life to reach my goals

302. _ _ _ _ The assurance of salvation helps me to face unexpected events

303. _ _ _ _ Because of my faith I know how to manage unexpected circumstances

304. __ _ _ I can resolve the majority of problems if I pray and invest the necessary effort

305. _ _ _ I stay calm facing difficulties because I can trust in the assurance of salvation

306. _ _ _ _ In front of a problem God helps me to find several solutions

307. _ _ _ If I I am in difficulties, God helps me to think of a solution

308. _ _ _ _ It doesn't matter what may happen, I can handle it because I have the assurance of salvation

\section{Study of the relationship between faith and business:}

This study aims to investigate the connections between faith and business among the evangelical Christians entrepreneurs. Your participation is voluntary and your data will be maintained anonymous and confidential.

First of all we would like to ask some questions about you:

How old are you?_46

Gender: Female

What is your status? (E. g., single, married, divorced, etc.) marred

What kind of job you do? pastor

Where are you born (city and country)? Qing Tian

For the next questions please choose a number 1-4 and write a number in every statement to identify how you agree with the statement.

\begin{tabular}{|cccc|}
\hline 1 & 2 & 3 & 4 \\
\hline Not at all true & Hardly true & $\begin{array}{c}\text { Moderately } \\
\text { true }\end{array}$ & Exactly true
\end{tabular}

311. _ ___ I can always manage to solve difficult problems if I try hard enough.

312. _____ If someone opposes me, I can find the means and ways to get what I want.

313. _____ It is easy for me to stick to my aims and accomplish my goals.

314. _ ___ I am confident that I could deal efficiently with unexpected events.

315. _ _ Thanks to my resourcefulness, I know how to handle unforeseen situations.

316. _ 1__ I can solve most problems if I invest the necessary effort. 
317. _2__ I can remain calm when facing difficulties because I can rely on my coping abilities.

318. _ ____ When I am confronted with a problem, I can usually find several solutions.

319. _ _ _ If I am in trouble, I can usually think of a solution.

320. ____ I can usually handle whatever comes my way.

For the next questions please choose a number 1-4 and write it in every statement to identify how much do you agree with the statement.

\begin{tabular}{|cccc|}
1 & 2 & 3 & 4 \\
\hline Not at all true & Hardly true & $\begin{array}{c}\text { Moderately } \\
\text { true }\end{array}$ & Exactly true
\end{tabular}

309. _ _ _ Knowing to be "forever saved" help me to resolve difficult problems

310. _ _ _ In case of contrasts with unbelievers I can always obtain what I want

311. ___ _ My faith helps me in life to reach my goals

312. _ _ _ The assurance of salvation helps me to face unexpected events

313. _ _ _ Because of my faith I know how to manage unexpected circumstances

314. __ _ I can resolve the majority of problems if I pray and invest the necessary effort

315. __ _ I I stay calm facing difficulties because I can trust in the assurance of salvation

316. _ _ _ In front of a problem God helps me to find several solutions

317. _ _ _ If I am in difficulties, God helps me to think of a solution

318. _ _ _ It doesn't matter what may happen, I can handle it because I have the assurance of salvation 


\section{Study of the relationship between faith and business:}

This study aims to investigate the connections between faith and business among the evangelical Christians entrepreneurs. Your participation is voluntary and your data will be maintained anonymous and confidential.

First of all we would like to ask some questions about you:

How old are you?_45

Gender: __ X_ Male __ Female

What is your status? (E. g., single, married, divorced, etc.) married

What kind of job you do? pastore

Where are you born (city and country)? Rui An (Wenzhou)

For the next questions please choose a number 1-4 and write a number in every statement to identify how you agree with the statement.

\begin{tabular}{|cccc|}
1 & 2 & 3 & 4 \\
\hline Not at all true & Hardly true & $\begin{array}{c}\text { Moderately } \\
\text { true }\end{array}$ & Exactly true
\end{tabular}

321. _ 3__ I can always manage to solve difficult problems if I try hard enough.

322. _____ If someone opposes me, I can find the means and ways to get what I want.

323. _ _ ___ It is easy for me to stick to my aims and accomplish my goals.

324. _ 3__ I am confident that I could deal efficiently with unexpected events.

325. ____ Thanks to my resourcefulness, I know how to handle unforeseen situations.

326. _ ___ I can solve most problems if I invest the necessary effort.

327. _ _ _ I I can remain calm when facing difficulties because I can rely on my coping abilities.

328. ____ When I am confronted with a problem, I can usually find several solutions.

329. _ _ _ If I am in trouble, I can usually think of a solution.

330. ____ I can usually handle whatever comes my way. 
For the next questions please choose a number 1-4 and write it in every statement to identify how much do you agree with the statement.

\begin{tabular}{|cccc|}
1 & 2 & 3 & 4 \\
\hline Not at all true & Hardly true & $\begin{array}{c}\text { Moderately } \\
\text { true }\end{array}$ & Exactly true
\end{tabular}

319. _ _ _ Knowing to be "forever saved" help me to resolve difficult problems

320. __ _ _ In case of contrasts with unbelievers I can always obtain what I want

321. ___ _ My faith helps me in life to reach my goals

322. _ _ _ _ The assurance of salvation helps me to face unexpected events

323. _ _ _ _ Because of my faith I know how to manage unexpected circumstances

324. _ _ _ I can resolve the majority of problems if I pray and invest the necessary effort

325. ___ _ I stay calm facing difficulties because I can trust in the assurance of salvation

326. __ _ In front of a problem God helps me to find several solutions

327. _ _ _ If I I am in difficulties, God helps me to think of a solution

328. _ _ _ _ It doesn't matter what may happen, I can handle it because I have the assurance of salvation

\section{关于信仰和生意之间的研究}

这次学术研究主要是针对于基督徒老板们做生意和信仰之间的紧密关系。你们可以自由 回答这些调查问卷，没有任何强制性，而且你们的信息将根据国家个人隐私法进行保 护。

个人信息:

几岁了? 30

性别: 男_x_女

你的生活状态? (单身, 已婚, 离异, 丧偶) single

目前职业?_PhD Student

出生地方、城市?_Baoding, Hebei Province

接下来这些问题, 请选择 $1-4$ 之间, 然后根据个人的观点把相关答案填在空格上。

\begin{tabular}{|cccc|}
1 & 2 & 3 & 4 \\
\hline 完全不是 & 一点 & 相当 & 完全是
\end{tabular}

331. _ 3 _ 如果我认真面对总是能够解决重大困难的

332. 2 - 如果有人反对我，我能够找到解决的方法来到达我的目的

333. _ - 3 _ 对我来说很容易坚持个人意志, 达到自己的目的

334. 3 我很有信心有效的面对一些突发事件

335. _ 3 - 我所拥有的资源足够可以面对不可预知的窘境

336. _ _ _ _ 只要用心就可以解决大部分问题

337. _ 3 _ 当遇到问题时, 会保持冷静, 相信自己有能力面对 
338. 一 2 _ 当我有问题时，总会找到很多解决方法

339. 一 - 4 当我在窘境时, 总是能想到一些东西来度过

340. _ 3 - 不管遇到什么, 总是有能力去处理

接下来这些问题, 请选择1-4之间, 然后根据个人的观点把相关答案填在空格上。

\begin{tabular}{|cccc|}
1 & 2 & 3 & 4 \\
\hline 完全不是 & 一点 & 相当 & 完全是
\end{tabular}

329. 一 - _ 当知道自己是 “得救的、有永生” ，会帮助我解决一些困难问题

330. - 2 — 当和一些不信教的人有不同意见时, 我可以到达我的目的

331. _ 2 _ 我的信仰有助于我到达一些人生目标

332. _ 3 _ 在得救、永生的信念之下，可帮助我面对一些突发事件

333. _ 3_ 我的信仰可帮助解决一些未知容境

334. _ 3 _ 通过祷告和用心做事可以解决大部分问题

335. _ - 4 在得救、永生的信念之下会冷静的解决问题

336. 一 - _ — 面对问题相信上帝会帮我找到不同的解决方法

337. - 4 _ 当我在困境时, 相信上帝会帮我度过的

4 _ 不管遇到什么, 我都相信有得救、永生和那解决问题的能力 


\section{Study of the relationship between faith and business:}

This study aims to investigate the connections between faith and business among the evangelical Christians entrepreneurs. Your participation is voluntary and your data will be maintained anonymous and confidential.

First of all we would like to ask some questions about you:

How old are you?_28

Gender: __ __ Male __ Female

What is your status? (E. g., single, married, divorced, etc.) single

What kind of job you do? architect

Where are you born (city and country)? Beijing

For the next questions please choose a number 1-4 and write a number in every statement to identify how you agree with the statement.

\begin{tabular}{|cccc|}
1 & 2 & 3 & 4 \\
\hline Not at all true & Hardly true & $\begin{array}{c}\text { Moderately } \\
\text { true }\end{array}$ & Exactly true
\end{tabular}

341. ___ _ I can always manage to solve difficult problems if I try hard enough.

342. __ _ _ If someone opposes me, I can find the means and ways to get what I want.

343. ___ _ It is easy for me to stick to my aims and accomplish my goals.

344. _ _ _ I I am confident that I could deal efficiently with unexpected events.

345. ___ Thanks to my resourcefulness, I know how to handle unforeseen situations.

346. ___ _ I can solve most problems if I invest the necessary effort.

347. ___ _ I can remain calm when facing difficulties because I can rely on my coping abilities.

348. _ _ _ When I am confronted with a problem, I can usually find several solutions.

349. __ _ _ If I am in trouble, I can usually think of a solution.

350. ___ I can usually handle whatever comes my way. 
For the next questions please choose a number 1-4 and write it in every statement to identify how much do you agree with the statement.

\begin{tabular}{|cccc|}
1 & 2 & 3 & 4 \\
\hline Not at all true & Hardly true & $\begin{array}{c}\text { Moderately } \\
\text { true }\end{array}$ & Exactly true
\end{tabular}

338. _ _ _ Knowing to be "forever saved" help me to resolve difficult problems

339. _ _ _ _ In case of contrasts with unbelievers I can always obtain what I want

340. _____ My faith helps me in life to reach my goals

341. _ 3__ The assurance of salvation helps me to face unexpected events

342. _ 3___Because of my faith I know how to manage unexpected circumstances

343. _ 3__ I can resolve the majority of problems if I pray and invest the necessary effort

344. _ 4 __ I stay calm facing difficulties because I can trust in the assurance of salvation

345. _ 4 __ In front of a problem God helps me to find several solutions

346. _ $4 \_$If I I am in difficulties, God helps me to think of a solution

347. _ 4 _ It doesn't matter what may happen, I can handle it because I have the assurance of salvation

\section{Studio del rapporto tra fede e business:}

Questo studio intende investigare le connessioni tra la fede ed il business tra i cristiani evangelici cinesi. La vostra partecipazione è volontaria e i vostri dati saranno mantenuti anonimi e riservati.

Prima di tutti vorremo chiederti alcune domande su di te:

Quanti anni hai? 26

Genere: _X_ Maschio ___ Femmina

Qual è il tuo status? (E. g., single, sposato, divorziato, etc.) sposato

Che lavoro fai? impiegato

Hai iniziato tu il business o lavori per altri? lavoro per altri

Dove sei nato (paese e città)? Wenzhou Cina

Per le prossime domande, per favore scegli un numero 1-4 e scrivilo negli spazi bianchi per ciascuna affermazione al fine di indicare quanto condividi con quell'affermazione.

\begin{tabular}{|cccc|}
1 & 2 & 3 & 4 \\
\hline Per nulla vero & Poco vero & Abbastanza & Totalmente \\
& & vero & vero
\end{tabular}

351. ___ _ Riesco sempre a risolvere problemi difficili se ci provo abbastanza seriamente

352. ___ _ _ Se qualcuno mi contrasta, posso trovare il modo o il sistema di ottenere ciò che voglio

353. ___ _ _ Per me è facile attenermi alle mie intenzioni e raggiungere i miei obiettivi

354. _ _ _ _ Ho fiducia di poter affrontare efficacemente eventi inattesi

355. ___ _ _ Grazie alle mie risorse, so come gestire situazioni impreviste 
356. ___ _ _ Posso risolvere la maggior parte dei problemi se ci metto il necessario impegno

357. ___ _ _ Rimango calmo nell'affrontare le difficoltà perché posso confidare nelle mie capacità di fronteggiarle

358. ___ _ _ Quando mi trovo di fronte ad un problema, di solito trovo parecchie soluzioni

359. __ _ _ Se sono in "panne", posso sempre pensare a qualcosa da mettere in atto

360. ___ _ _ Non importa quello che mi può capitare, di solito sono in grado di gestirlo

Per le prossime domande, per favore scegli un numero 1-4 e scrivi in ciascuna affermazione per indicare quanto condividi con quell'affermazione.

\begin{tabular}{|cccc|}
1 & 2 & 3 & 4 \\
\hline Per nulla vero & Poco vero & Abbastanza & Totalmente \\
& & vero & vero
\end{tabular}

348. _ _ _ _ Sapere di essere "per sempre salvato" mi aiuta a risolvere problemi difficili

349. ___ _ _ In caso di contrasti con non credenti riesco a ottenere ciò che voglio

350. __ _ _ La mia fede mi aiuta nella vita a raggiungere i miei obbiettivi

351. _ _ _ _ La certezza della salvezza mi aiuta ad affrontare eventi inattesi

352. ___ ___ Grazie alla mia fede so come gestire situazioni impreviste

353. _ _ _ _ Posso risolvere la maggior parte dei problemi pregando ed impegnandomi

354. ___ _ _ Rimango calmo nell'affrontare le difficoltà perché posso confidare nella certezza della salvezza

355. _ _ _ _ Di fronte ad un problema Dio mi aiuta a trovare parecchie soluzioni

356. _ _ _ _ Se sono in difficoltà, Dio mi aiuta a pensare a qualcosa da mettere in atto

357. ___ ___ Non importa quello che mi può capitare, ho la certezza della salvezza e sono in grado di gestire la situazione 


\section{关于信仰和生意之间的研究}

这次学术研究主要是针对于基督徒老板们做生意和信仰之间的紧密关系。你们可以自由 回答这些调查问卷, 没有任何强制性, 而且你们的信息将根据国家个人隐私法进行保 护。

个人信息:

几岁了?_28_

性别: X_— 男 — 女

你的生活状态? (单身, 已婚, 离异, 丧偶) sposato

目前职业? bigiotteria impiegato

出生地方、城市? wenzhou

接下来这些问题, 请选择1-4之间, 然后根据个人的观点把相关答案填在空格上。

\begin{tabular}{|cccc|}
1 & 2 & 3 & 4 \\
\hline 完全不是 & 一点 & 相当 & 完全是
\end{tabular}

361. - 1 - 如果我认真面对总是能够解决重大困难的

362. 一 1 — 如果有人反对我, 我能够找到解决的方法来到达我的目的

363. — 3 _ 对我来说很容易坚持个人意志, 达到自己的目的

364. _ 2 _ 我很有信心有效的面对一些突发事件

365. _ 3 _ 我所拥有的资源足够可以面对不可预知的窘境

366. _ 3_ 只要用心就可以解决大部分问题

367. _ _ _ 当遇到问题时, 会保持冷静, 相信自己有能力面对

368. — 2 _ 当我有问题时，总会找到很多解决方法

369. _ - _ 当我在窘境时, 总是能想到一些东西来度过

370. _ - 1_不管遇到什么，总是有能力去处理 
接下来这些问题, 请选择1-4之间, 然后根据个人的观点把相关答案填在空格上。

\begin{tabular}{|cccc|}
1 & 2 & 3 & 4 \\
\hline 完全不是 & 一点 & 相当 & 完全是
\end{tabular}

358. — 3 _ 当知道自己是 “得救的、有永生” ，会帮助我解决一些困难问题

359. - 1 — 当和一些不信教的人有不同意见时, 我可以到达我的目的

360. — - 4 我的信仰有助于我到达一些人生目标

361. 3 3 在得救、永生的信念之下, 可帮助我面对一些突发事件

362. 3 3_我的信仰可帮助解决一些未知蹇境

363. _ 3 _ 通过祷告和用心做事可以解决大部分问题

364. _ _ 3 _ 在得救、永生的信念之下会冷静的解决问题

365. — 3 _ 面对问题相信上帝会帮我找到不同的解决方法

366. 一 - — 当我在困境时，相信上帝会帮我度过的

367. _ - 4 不管遇到什么, 我都相信有得救、永生和那解决问题的能力 


\section{Study of the relationship between faith and business:}

This study aims to investigate the connections between faith and business among the evangelical Christians entrepreneurs. Your participation is voluntary and your data will be maintained anonymous and confidential.

First of all we would like to ask some questions about you:

How old are you?_41

Gender:_ X__ Male __ Female

What is your status? (E. g., single, married, divorced, etc.) married

What kind of job you do? manager of two factories for pharmaceutical products

Where are you born (city and country)? Wenzhou

For the next questions please choose a number 1-4 and write a number in every statement to identify how you agree with the statement.

\begin{tabular}{|cccc|}
1 & 2 & 3 & 4 \\
\hline Not at all true & Hardly true & $\begin{array}{c}\text { Moderately } \\
\text { true }\end{array}$ & Exactly true
\end{tabular}

371. _ _ _ _ I can always manage to solve difficult problems if I try hard enough.

372. _____ If someone opposes me, I can find the means and ways to get what I want.

373. _____ It is easy for me to stick to my aims and accomplish my goals.

374. ____ I am confident that I could deal efficiently with unexpected events.

375. 2__ Thanks to my resourcefulness, I know how to handle unforeseen situations.

376. _ _ _ I I can solve most problems if I invest the necessary effort.

377. _ _ _ I I can remain calm when facing difficulties because I can rely on my coping abilities.

378. _ ___ When I am confronted with a problem, I can usually find several solutions.

379._2__ If I am in trouble, I can usually think of a solution.

380 . ___ I I can usually handle whatever comes my way. 
For the next questions please choose a number 1-4 and write it in every statement to identify how much do you agree with the statement.

\begin{tabular}{|cccc|}
1 & 2 & 3 & 4 \\
\hline Not at all true & Hardly true & $\begin{array}{c}\text { Moderately } \\
\text { true }\end{array}$ & Exactly true
\end{tabular}

368. _ _ _ Knowing to be "forever saved" help me to resolve difficult problems

369. __ _ _ In case of contrasts with unbelievers I can always obtain what I want

370. __ _ _ My faith helps me in life to reach my goals

371. _ _ _ _ The assurance of salvation helps me to face unexpected events

372. _ _ _ _ Because of my faith I know how to manage unexpected circumstances

373. __ _ _ I can resolve the majority of problems if I pray and invest the necessary effort

374. __ _ _ I stay calm facing difficulties because I can trust in the assurance of salvation

375. _ _ _ _ In front of a problem God helps me to find several solutions

376. _ _ _ If I I am in difficulties, God helps me to think of a solution

377. _ _ _ _ It doesn't matter what may happen, I can handle it because I have the assurance of salvation

\section{Study of the relationship between faith and business:}

This study aims to investigate the connections between faith and business among the evangelical Christians entrepreneurs. Your participation is voluntary and your data will be maintained anonymous and confidential.

First of all we would like to ask some questions about you:

How old are you?_46

Gender: _ X__ Male __ Female

What is your status? (E. g., single, married, divorced, etc.) married

What kind of job you do? pastor and bar owner

Where are you born (city and country)? Wenzhou

For the next questions please choose a number 1-4 and write a number in every statement to identify how you agree with the statement.

\begin{tabular}{|cccc|}
1 & 2 & 3 & 4 \\
\hline Not at all true & Hardly true & $\begin{array}{c}\text { Moderately } \\
\text { true }\end{array}$ & Exactly true
\end{tabular}

381. ___ I I can always manage to solve difficult problems if I try hard enough.

382. __ _ _ If someone opposes me, I can find the means and ways to get what I want.

383. ___ _ It is easy for me to stick to my aims and accomplish my goals.

384. ___ _ I am confident that I could deal efficiently with unexpected events.

385. ___ Thanks to my resourcefulness, I know how to handle unforeseen situations.

386. ___ _ I can solve most problems if I invest the necessary effort. 
387. _ _ _ I can remain calm when facing difficulties because I can rely on my coping abilities.

388. _ _ _ _ When I am confronted with a problem, I can usually find several solutions.

389. _ _ _ If I am in trouble, I can usually think of a solution.

390. ___ _ _ I can usually handle whatever comes my way.

For the next questions please choose a number 1-4 and write it in every statement to identify how much do you agree with the statement.

\begin{tabular}{|cccc|}
1 & 2 & 3 & 4 \\
\hline Not at all true & Hardly true & $\begin{array}{c}\text { Moderately } \\
\text { true }\end{array}$ & Exactly true
\end{tabular}

378. ___ Knowing to be "forever saved" help me to resolve difficult problems

379. _ _ _ In case of contrasts with unbelievers I can always obtain what I want

380. ___ _ My faith helps me in life to reach my goals

381. _ _ _ _ The assurance of salvation helps me to face unexpected events

382. _ _ _ _ Because of my faith I know how to manage unexpected circumstances

383. _ _ _ _ I can resolve the majority of problems if I pray and invest the necessary effort

384. __ _ _ I stay calm facing difficulties because I can trust in the assurance of salvation

385. _ _ _ _ In front of a problem God helps me to find several solutions

386. ___ If I I am in difficulties, God helps me to think of a solution

387. ___ It doesn't matter what may happen, I can handle it because I have the assurance of salvation 


\section{Study of the relationship between faith and business:}

This study aims to investigate the connections between faith and business among the evangelical Christians entrepreneurs. Your participation is voluntary and your data will be maintained anonymous and confidential.

First of all we would like to ask some questions about you:

How old are you?_28

Gender: __ X_ Male __ Female

What is your status? (E. g., single, married, divorced, etc.) single

What kind of job you do? boss of clothing store

Where are you born (city and country)? Chong Qing

For the next questions please choose a number 1-4 and write a number in every statement to identify how you agree with the statement.

\begin{tabular}{|cccc|}
1 & 2 & 3 & 4 \\
\hline Not at all true & Hardly true & Moderately & true
\end{tabular}

391. _ 1__ I can always manage to solve difficult problems if I try hard enough.

392. __ _ _ If someone opposes me, I can find the means and ways to get what I want.

393. ___ _ It is easy for me to stick to my aims and accomplish my goals.

394. ___ _ I am confident that I could deal efficiently with unexpected events.

395. _ _ _ Thanks to my resourcefulness, I know how to handle unforeseen situations.

396. __ _ _ I can solve most problems if I invest the necessary effort.

397. __ _ _ I can remain calm when facing difficulties because I can rely on my coping abilities.

398. _ _ _ When I am confronted with a problem, I can usually find several solutions.

399. 3_ 3 If I am in trouble, I can usually think of a solution.

400. 1_ I can usually handle whatever comes my way. 
For the next questions please choose a number 1-4 and write it in every statement to identify how much do you agree with the statement.

\begin{tabular}{|cccc|}
1 & 2 & 3 & 4 \\
\hline Not at all true & Hardly true & $\begin{array}{c}\text { Moderately } \\
\text { true }\end{array}$ & Exactly true
\end{tabular}

388. _ _ K__ Knowing to be "forever saved" help me to resolve difficult problems

389. _ _ _ In case of contrasts with unbelievers I can always obtain what I want

390. __ _ _ My faith helps me in life to reach my goals

391. _ _ _ T The assurance of salvation helps me to face unexpected events

392. _ _ _ _ Because of my faith I know how to manage unexpected circumstances

393. _ _ _ I can resolve the majority of problems if I pray and invest the necessary effort

394. _ _ _ _ I stay calm facing difficulties because I can trust in the assurance of salvation

395. _ _ _ _ In front of a problem God helps me to find several solutions

396. _ _ _ If I I am in difficulties, God helps me to think of a solution

397. _ _ _ It doesn't matter what may happen, I can handle it because I have the assurance of salvation

\section{Study of the relationship between faith and business:}

This study aims to investigate the connections between faith and business among the evangelical

Christians entrepreneurs. Your participation is voluntary and your data will be maintained anonymous and confidential.

First of all we would like to ask some questions about you:

How old are you?_45

Gender: Male_F__ Female

What is your status? (E. g., single, married, divorced, etc.) married

What kind of job you do? Ass. Pres. And Entrepreneur

Where are you born (city and country)? Wenzhou

For the next questions please choose a number 1-4 and write a number in every statement to identify how you agree with the statement.

\begin{tabular}{|cccc|}
\hline 1 & 2 & 3 & 4 \\
\hline Not at all true & Hardly true & $\begin{array}{c}\text { Moderately } \\
\text { true }\end{array}$ & Exactly true
\end{tabular}

401. ___ _ I can always manage to solve difficult problems if I try hard enough.

402. _ _ _ _ If someone opposes me, I can find the means and ways to get what I want.

403. ___ _ It is easy for me to stick to my aims and accomplish my goals.

404. _ _ _ _ I am confident that I could deal efficiently with unexpected events.

405. _ _ _ Thanks to my resourcefulness, I know how to handle unforeseen situations.

406. ___ _ I can solve most problems if I invest the necessary effort. 
407. ___ _ I can remain calm when facing difficulties because I can rely on my coping abilities.

408. _ _ _ _ When I am confronted with a problem, I can usually find several solutions.

409. __ _ If I am in trouble, I can usually think of a solution.

410. ___ _ I can usually handle whatever comes my way.

For the next questions please choose a number 1-4 and write it in every statement to identify how much do you agree with the statement.

\begin{tabular}{|cccc|}
1 & 2 & 3 & 4 \\
\hline Not at all true & Hardly true & $\begin{array}{c}\text { Moderately } \\
\text { true }\end{array}$ & Exactly true
\end{tabular}

398. 2__ Knowing to be "forever saved" help me to resolve difficult problems

399. 2__ In case of contrasts with unbelievers I can always obtain what I want

400. _ _ _ _ My faith helps me in life to reach my goals

401. _ 3_ The assurance of salvation helps me to face unexpected events

402. _ _ _ _ Because of my faith I know how to manage unexpected circumstances

403. _ 3__ I can resolve the majority of problems if I pray and invest the necessary effort

404. _ 3__ I stay calm facing difficulties because I can trust in the assurance of salvation

405. _ _ _ In front of a problem God helps me to find several solutions

406. _ _ _ If I am in difficulties, God helps me to think of a solution

407. _ _ _ It doesn't matter what may happen, I can handle it because I have the assurance of salvation 


\section{Study of the relationship between faith and business:}

This study aims to investigate the connections between faith and business among the evangelical Christians entrepreneurs. Your participation is voluntary and your data will be maintained anonymous and confidential.

First of all we would like to ask some questions about you:

How old are you?_26

Gender: __ X_Male __ Female

What is your status? (E. g., single, married, divorced, etc.) single

What kind of job you do? factory manager

Where are you born (city and country)? Yun Nan, Cina

For the next questions please choose a number 1-4 and write a number in every statement to identify how you agree with the statement.

\begin{tabular}{|cccc|}
1 & 2 & 3 & 4 \\
\hline Not at all true & Hardly true & $\begin{array}{c}\text { Moderately } \\
\text { true }\end{array}$ & Exactly true
\end{tabular}

411. $1 \ldots$ I can always manage to solve difficult problems if I try hard enough.

412. _ ____ If someone opposes me, I can find the means and ways to get what I want.

413. ___ _ It is easy for me to stick to my aims and accomplish my goals.

414. _ _ _ I I am confident that I could deal efficiently with unexpected events.

415. 2_ Thanks to my resourcefulness, I know how to handle unforeseen situations.

416. $3 \_$I can solve most problems if I invest the necessary effort.

417. _ _ _ I can remain calm when facing difficulties because I can rely on my coping abilities.

418. _ _ _ When I am confronted with a problem, I can usually find several solutions.

419.___ _ If I am in trouble, I can usually think of a solution.

420. 2_ I can usually handle whatever comes my way. 
For the next questions please choose a number 1-4 and write it in every statement to identify how much do you agree with the statement.

\begin{tabular}{|cccc|}
1 & 2 & 3 & 4 \\
\hline Not at all true & Hardly true & $\begin{array}{c}\text { Moderately } \\
\text { true }\end{array}$ & Exactly true
\end{tabular}

408. 3_Knowing to be "forever saved" help me to resolve difficult problems

409. _ _ _ In case of contrasts with unbelievers I can always obtain what I want

410. __ _ _ My faith helps me in life to reach my goals

411. _ _ _ T The assurance of salvation helps me to face unexpected events

412. 4_ 4_Because of my faith I know how to manage unexpected circumstances

413. 4_ _ I can resolve the majority of problems if I pray and invest the necessary effort

414. 2__ I stay calm facing difficulties because I can trust in the assurance of salvation

415. _ 3__ In front of a problem God helps me to find several solutions

416. __ _ If I I am in difficulties, God helps me to think of a solution

417. _ _ _ It doesn't matter what may happen, I can handle it because I have the assurance of salvation 


\section{Studio del rapporto tra fede e business:}

Questo studio intende investigare le connessioni tra la fede ed il business tra i cristiani evangelici cinesi. La vostra partecipazione è volontaria e i vostri dati saranno mantenuti anonimi e riservati.

Prima di tutti vorremo chiederti alcune domande su di te:

Quanti anni hai?_26

Genere: _ X__ Maschio __ Femmina

Qual è il tuo status? (E. g., single, sposato, divorziato, etc.) single

Che lavoro fai? negoziante

Hai iniziato tu il business o lavori per altri? igenitori

Dove sei nato (paese e città)? wenzhou

Per le prossime domande, per favore scegli un numero 1-4 e scrivilo negli spazi bianchi per ciascuna affermazione al fine di indicare quanto condividi con quell'affermazione.

\begin{tabular}{|cccc|}
1 & 2 & 3 & 4 \\
\hline Per nulla vero & Poco vero & Abbastanza & Totalmente \\
& & vero & vero
\end{tabular}

421. _____ Riesco sempre a risolvere problemi difficili se ci provo abbastanza seriamente

422. ______ Se qualcuno mi contrasta, posso trovare il modo o il sistema di ottenere ciò che voglio

423. ___ _ _ Per me è facile attenermi alle mie intenzioni e raggiungere i miei obiettivi

424. _ _ _ Ho fiducia di poter affrontare efficacemente eventi inattesi

425. ______ Grazie alle mie risorse, so come gestire situazioni impreviste

426. ______ Posso risolvere la maggior parte dei problemi se ci metto il necessario impegno

427. ___ _ Rimango calmo nell'affrontare le difficoltà perché posso confidare nelle mie capacità di fronteggiarle

428. __ _ _ Quando mi trovo di fronte ad un problema, di solito trovo parecchie soluzioni

429. ______ Se sono in "panne", posso sempre pensare a qualcosa da mettere in atto

430. ______ Non importa quello che mi può capitare, di solito sono in grado di gestirlo 
Per le prossime domande, per favore scegli un numero 1-4 e scrivi in ciascuna affermazione per indicare quanto condividi con quell'affermazione.

\begin{tabular}{|cccc|}
1 & 2 & 3 & 4 \\
\hline Per nulla vero & Poco vero & Abbastanza & Totalmente \\
& & vero & vero
\end{tabular}

418. _ _ _ _ Sapere di essere "per sempre salvato" mi aiuta a risolvere problemi difficili

419. ___ _ In caso di contrasti con non credenti riesco a ottenere ciò che voglio

420. ___ _ _ La mia fede mi aiuta nella vita a raggiungere i miei obbiettivi

421. _ _ _ _ La certezza della salvezza mi aiuta ad affrontare eventi inattesi

422. ___ _ _ Grazie alla mia fede so come gestire situazioni impreviste

423. __ _ _ _ Posso risolvere la maggior parte dei problemi pregando ed impegnandomi

424. ___ _ _ Rimango calmo nell'affrontare le difficoltà perché posso confidare nella certezza della salvezza

425. _ _ _ _ Di fronte ad un problema Dio mi aiuta a trovare parecchie soluzioni

426. _ _ _ _ Se sono in difficoltà, Dio mi aiuta a pensare a qualcosa da mettere in atto

427. ___ _ _ Non importa quello che mi può capitare, ho la certezza della salvezza e sono in grado di gestire la situazione

\section{Study of the relationship between faith and business:}

This study aims to investigate the connections between faith and business among the evangelical Christians entrepreneurs. Your participation is voluntary and your data will be maintained anonymous and confidential.

First of all we would like to ask some questions about you:

How old are you?_46

Gender: _ X_ Male Female

What is your status? (E. g., single, married, divorced, etc.) married

What kind of job you do? entrepreneur and president of ass. Of businesses

Where are you born (city and country)? Wenzhou

For the next questions please choose a number 1-4 and write a number in every statement to identify how you agree with the statement.

\begin{tabular}{|cccc|}
1 & 2 & 3 & 4 \\
\hline Not at all true & Hardly true & $\begin{array}{c}\text { Moderately } \\
\text { true }\end{array}$ & Exactly true
\end{tabular}

431. _ _ _ I I can always manage to solve difficult problems if I try hard enough.

432. _ 2__ If someone opposes me, I can find the means and ways to get what I want.

433. _____ It is easy for me to stick to my aims and accomplish my goals. 
434. _ _ _ I I am confident that I could deal efficiently with unexpected events.

435. __ _ _ Thanks to my resourcefulness, I know how to handle unforeseen situations.

436. ___ _ I I can solve most problems if I invest the necessary effort.

437. ___ I can remain calm when facing difficulties because I can rely on my coping abilities.

438. _ _ _ When I am confronted with a problem, I can usually find several solutions.

439. _ _ _ _ If I am in trouble, I can usually think of a solution.

440. ___ _ I can usually handle whatever comes my way.

For the next questions please choose a number 1-4 and write it in every statement to identify how much do you agree with the statement.

\begin{tabular}{|cccc|}
1 & 2 & 3 & 4 \\
\hline Not at all true & Hardly true & $\begin{array}{c}\text { Moderately } \\
\text { true }\end{array}$ & Exactly true
\end{tabular}

428. ___ Knowing to be "forever saved" help me to resolve difficult problems

429. _ _ _ _ In case of contrasts with unbelievers I can always obtain what I want

430. _____ My faith helps me in life to reach my goals

431. _ 3__ The assurance of salvation helps me to face unexpected events

432. _ _ _ Because of my faith I know how to manage unexpected circumstances

433. _ _ _ _ I can resolve the majority of problems if I pray and invest the necessary effort

434. _ 3__ I stay calm facing difficulties because I can trust in the assurance of salvation

435. _ _ _ _ In front of a problem God helps me to find several solutions

436. _3_ If I am in difficulties, God helps me to think of a solution

437. _ ___ It doesn't matter what may happen, I can handle it because I have the assurance of salvation 


\section{Study of the relationship between faith and business:}

This study aims to investigate the connections between faith and business among the evangelical Christians entrepreneurs. Your participation is voluntary and your data will be maintained anonymous and confidential.

First of all we would like to ask some questions about you:

How old are you?_31

Gender: Male __ X_Female

What is your status? (E. g., single, married, divorced, etc.) married

What kind of job you do? sales manager

Where are you born (city and country)? Wenzhou

For the next questions please choose a number 1-4 and write a number in every statement to identify how you agree with the statement.

\begin{tabular}{|cccc|}
1 & 2 & 3 & 4 \\
\hline Not at all true & Hardly true & $\begin{array}{c}\text { Moderately } \\
\text { true }\end{array}$ & Exactly true
\end{tabular}

441. ___ _ I can always manage to solve difficult problems if I try hard enough.

442. _ _ _ If someone opposes me, I can find the means and ways to get what I want.

443. ___ _ _ It is easy for me to stick to my aims and accomplish my goals.

444. _ _ _ I I am confident that I could deal efficiently with unexpected events.

445. 2_ Thanks to my resourcefulness, I know how to handle unforeseen situations.

446. 3_ I can solve most problems if I invest the necessary effort.

447. __ _ _ I can remain calm when facing difficulties because I can rely on my coping abilities.

448. _ _ _ When I am confronted with a problem, I can usually find several solutions.

449. __ _ If I am in trouble, I can usually think of a solution.

450. 3_ I can usually handle whatever comes my way. 
For the next questions please choose a number 1-4 and write it in every statement to identify how much do you agree with the statement.

\begin{tabular}{|cccc|}
1 & 2 & 3 & 4 \\
\hline Not at all true & Hardly true & $\begin{array}{c}\text { Moderately } \\
\text { true }\end{array}$ & Exactly true
\end{tabular}

438. _ _ _ Knowing to be "forever saved" help me to resolve difficult problems

439. __ _ _ In case of contrasts with unbelievers I can always obtain what I want

440. ___ _ _ My faith helps me in life to reach my goals

441. _ 3_ The assurance of salvation helps me to face unexpected events

442. __ 4_Because of my faith I know how to manage unexpected circumstances

443. _ 3I can resolve the majority of problems if I pray and invest the necessary effort

444. _ _ 4 I stay calm facing difficulties because I can trust in the assurance of salvation

445. _ _ 3In front of a problem God helps me to find several solutions

446. $4 \mathrm{If} \mathrm{I}$ am in difficulties, God helps me to think of a solution

447. _ _ 4It doesn't matter what may happen, I can handle it because I have the assurance of salvation

\section{关于信仰和生意之间的研究}

这次学术研究主要是针对于基督徒老板们做生意和信仰之间的紧密关系。你们可以自由 回答这些调查问卷，没有任何强制性，而且你们的信息将根据国家个人隐私法进行保 护。

个人信息:

几岁了? 37

性别: _ _ X 男 — 女

你的生活状态? (单身, 已婚, 离异, 丧偶) ___ sposato

目前职业? commerciante

出生地方、城市? wenzhou

接下来这些问题, 请选择 $1-4$ 之间, 然后根据个人的观点把相关答案填在空格上。

\begin{tabular}{|cccc|}
1 & 2 & 3 & 4 \\
\hline 完全不是 & 一点 & 相当 & 完全是
\end{tabular}

451. 3 3_ 如果我认真面对总是能够解决重大困难的

452. _ 2 — 如果有人反对我，我能够找到解决的方法来到达我的目的

453. _ 3_ 对我来说很容易坚持个人意志, 达到自己的目的

454. _ 2 _ 我很有信心有效的面对一些突发事件

455. _ 1_ 我所拥有的资源足够可以面对不可预知的若境 
456. _ 3_ 只要用心就可以解决大部分问题

457. — 3 _ 当遇到问题时, 会保持冷静, 相信自己有能力面对

458. 一 3 _ 当我有问题时，总会找到很多解决方法

459. _ 3 _ 当我在宭境时, 总是能想到一些东西来度过

460. _ _ _ 不管遇到什么, 总是有能力去处理

接下来这些问题, 请选择1-4之间, 然后根据个人的观点把相关答案填在空格上。

\begin{tabular}{|cccc|}
\hline 1 & 2 & 3 & 4 \\
\hline 完全不是 & 一点 & 相当 & 完全是
\end{tabular}

448. 一 4 _ 当知道自己是 “得救的、有永生” ，会帮助我解决一些困难问题

449. 2 - 2 当和一些不信教的人有不同意见时, 我可以到达我的目的

450. _ 3 _ 我的信仰有助于我到达一些人生目标

451. - 3 _ 在得救、永生的信念之下，可帮助我面对一些突发事件

452. _ 2 _ 我的信仰可帮助解决一些未知若境

453. _ 3 _ 通过祷告和用心做事可以解决大部分问题

454. _ _ _ _ 在得救、永生的信念之下会冷静的解决问题

455. _ - 4 _ 面对问题相信上帝会帮我找到不同的解决方法

456. 4 - 当我在困境时，相信上帝会帮我度过的

457. _ - 4 不管遇到什么, 我都相信有得救、永生和那解决问题的能力 


\section{Study of the relationship between faith and business:}

This study aims to investigate the connections between faith and business among the evangelical Christians entrepreneurs. Your participation is voluntary and your data will be maintained anonymous and confidential.

First of all we would like to ask some questions about you:

How old are you?_47

Gender: __ X_Male __ Female

What is your status? (E. g., single, married, divorced, etc.) married

What kind of job you do? pastor and manager of chemical factory

Where are you born (city and country)? Wenzhou

For the next questions please choose a number 1-4 and write a number in every statement to identify how you agree with the statement.

\begin{tabular}{|cccc|}
1 & 2 & 3 & 4 \\
\hline Not at all true & Hardly true & $\begin{array}{c}\text { Moderately } \\
\text { true }\end{array}$ & Exactly true
\end{tabular}

461. _ ___ I can always manage to solve difficult problems if I try hard enough.

462. _____ If someone opposes me, I can find the means and ways to get what I want.

463. _ _ ___ It is easy for me to stick to my aims and accomplish my goals.

464. ____ I am confident that I could deal efficiently with unexpected events.

465. _ ___ Thanks to my resourcefulness, I know how to handle unforeseen situations.

466. _ 3__ I can solve most problems if I invest the necessary effort.

467. _ _ _ I I can remain calm when facing difficulties because I can rely on my coping abilities.

468. _2__When I am confronted with a problem, I can usually find several solutions.

469. _ ___ If I am in trouble, I can usually think of a solution.

470. ___ I I can usually handle whatever comes my way. 
For the next questions please choose a number 1-4 and write it in every statement to identify how much do you agree with the statement.

\begin{tabular}{|cccc|}
1 & 2 & 3 & 4 \\
\hline Not at all true & Hardly true & $\begin{array}{c}\text { Moderately } \\
\text { true }\end{array}$ & Exactly true
\end{tabular}

458. __ _ Knowing to be "forever saved" help me to resolve difficult problems

459. _ _ _ _ In case of contrasts with unbelievers I can always obtain what I want

460. ___ _ _ My faith helps me in life to reach my goals

461. _ _ _ _ The assurance of salvation helps me to face unexpected events

462. _ _ _ _ Because of my faith I know how to manage unexpected circumstances

463. _ _ _ I can resolve the majority of problems if I pray and invest the necessary effort

464. _ _ _ I stay calm facing difficulties because I can trust in the assurance of salvation

465. _ _ _ _ In front of a problem God helps me to find several solutions

466. __ _ If I I am in difficulties, God helps me to think of a solution

467. _ _ _ It doesn't matter what may happen, I can handle it because I have the assurance of salvation

\section{Study of the relationship between faith and business:}

This study aims to investigate the connections between faith and business among the evangelical Christians entrepreneurs. Your participation is voluntary and your data will be maintained anonymous and confidential.

First of all we would like to ask some questions about you:

How old are you? 44

Gender:

X_ Male Female

What is your status? (E. g., single, married, divorced, etc.) ___ Married

What kind of job you do? pastor

Where are you born (city and country)? Wenzhou

For the next questions please choose a number 1-4 and write a number in every statement to identify how you agree with the statement.

\begin{tabular}{|cccc|}
\hline 1 & 2 & 3 & 4 \\
\hline Not at all true & Hardly true & $\begin{array}{c}\text { Moderately } \\
\text { true }\end{array}$ & Exactly true
\end{tabular}

471. $3 \_$I can always manage to solve difficult problems if I try hard enough.

472. _____ If someone opposes me, I can find the means and ways to get what I want.

473. _ _ _ It is easy for me to stick to my aims and accomplish my goals.

474. ___ _ I l am confident that I could deal efficiently with unexpected events. 
475. 4___ Thanks to my resourcefulness, I know how to handle unforeseen situations.

476. _ 4 __ I can solve most problems if I invest the necessary effort.

477. _ _ _ _ I can remain calm when facing difficulties because I can rely on my coping abilities.

478. _ _ _ When I am confronted with a problem, I can usually find several solutions.

479. 3_ _ If I am in trouble, I can usually think of a solution.

480. _ 4 __ I can usually handle whatever comes my way.

For the next questions please choose a number 1-4 and write it in every statement to identify how much do you agree with the statement.

\begin{tabular}{|cccc|}
1 & 2 & 3 & 4 \\
\hline Not at all true & Hardly true & $\begin{array}{c}\text { Moderately } \\
\text { true }\end{array}$ & Exactly true
\end{tabular}

468. 4 ___ Knowing to be "forever saved" help me to resolve difficult problems

469. _ 4 __ In case of contrasts with unbelievers I can always obtain what I want

470. _ _ _ _ My faith helps me in life to reach my goals

471. _ _ _ _ The assurance of salvation helps me to face unexpected events

472. __ 4_Because of my faith I know how to manage unexpected circumstances

473. _ 4 __ I can resolve the majority of problems if I pray and invest the necessary effort

474. __ _ _ I stay calm facing difficulties because I can trust in the assurance of salvation

475. __ _ _ In front of a problem God helps me to find several solutions

476. 4_ If I am in difficulties, God helps me to think of a solution

477. _ _ _ It doesn't matter what may happen, I can handle it because I have the assurance of salvation 


\section{关于信仰和生意之间的研究}

这次学术研究主要是针对于基督徒老板们做生意和信仰之间的紧密关系。你们可以自由 回答这些调查问卷, 没有任何强制性, 而且你们的信息将根据国家个人隐私法进行保 护。

个人信息:

几岁了?_40_

性别: $\mathrm{x}$ 男 — 女

你的生活状态? (单身, 已婚, 离异, 丧偶) sposato

目前职业? sarto

出生地方、城市?_wenzhou

接下来这些问题, 请选择1-4之间, 然后根据个人的观点把相关答案填在空格上。

\begin{tabular}{|cccc|}
1 & 2 & 3 & 4 \\
\hline 完全不是 & 一点 & 相当 & 完全是
\end{tabular}

481. _ 3_ 如果我认真面对总是能够解决重大困难的

482. _ 2 — 如果有人反对我, 我能够找到解决的方法来到达我的目的

483. _ - _ _ 对我来说很容易坚持个人意志, 达到自己的目的

484. _ 3_ 我很有信心有效的面对一些突发事件

485. _ 1_ 我所拥有的资源足够可以面对不可预知的窘境

486. _ 3 _ _ 只要用心就可以解决大部分问题

487. _ 3 — 当遇到问题时, 会保持冷静, 相信自己有能力面对

488. 一 - _ 当我有问题时, 总会找到很多解决方法

489. _ - 3 _ 当我在若境时, 总是能想到一些东西来度过

490. 3 3 _ 不管遇到什么, 总是有能力去处理 
接下来这些问题, 请选择1-4之间, 然后根据个人的观点把相关答案填在空格上。

\begin{tabular}{|cccc|}
1 & 2 & 3 & 4 \\
\hline 完全不是 & 一点 & 相当 & 完全是
\end{tabular}

\section{关于信仰和生意之间的研究}

这次学术研究主要是针对于基督徒老板们做生意和信仰之间的紧密关系。你们可以自由 回答这些调查问卷, 没有任何强制性, 而且你们的信息将根据国家个人隐私法进行保 护。

个人信息:

几岁了?_44_

性别: X_男_— 女

你的生活状态? (单身, 已婚, 离异, 丧偶) married

目前职业? president of Chinese association

出生地方、城市? Wenzhou

接下来这些问题, 请选择1-4之间, 然后根据个人的观点把相关答案填在空格上。

\begin{tabular}{|cccc|}
1 & 2 & 3 & 4 \\
\hline 完全不是 & 一点 & 相当 & 完全是
\end{tabular}

1. 4

2. 4

3. -4

4. -3

5. -2

6. -4

7. 4

8. 3

9. -3

10. 3
如果我认真面对总是能够解决重大困难的 如果有人反对我, 我能够找到解决的方法来到达我的目的 对我来说很容易坚持个人意志, 达到自己的目的 我很有信心有效的面对一些突发事件 我所拥有的资源足够可以面对不可预知的窘境 只要用心就可以解决大部分问题 当遇到问题时, 会保持冷静, 相信自己有能力面对 当我有问题时, 总会找到很多解决方法 当我在若境时, 总是能想到一些东西来度过 不管遇到什么, 总是有能力去处理 


\section{关于信仰和生意之间的研究}

这次学术研究主要是针对于基督徒老板们做生意和信仰之间的紧密关系。你们可以自由 回答这些调查问卷, 没有任何强制性, 而且你们的信息将根据国家个人隐私法进行保 护。

个人信息:

几岁了?_45

性别: 男 _ X_— 女

你的生活状态? (单身, 已婚, 离异, 丧偶) married

目前职业? clothing store manager

出生地方、城市? Taiwan

接下来这些问题, 请选择1-4之间, 然后根据个人的观点把相关答案填在空格上。

\begin{tabular}{|cccc|}
1 & 2 & 3 & 4 \\
\hline 完全不是 & 一点 & 相当 & 完全是
\end{tabular}

1. - 4 如果我认真面对总是能够解决重大困难的

2. - 3 - 如果有人反对我, 我能够找到解决的方法来到达我的目的

3. - 3 - 对我来说很容易坚持个人意志, 达到自己的目的

4. - 4 _ 我很有信心有效的面对一些突发事件

5. - 3 我所拥有的资源足够可以面对不可预知的窘境

6. _ 3 _ 只要用心就可以解决大部分问题

7. _ _ _ 当遇到问题时, 会保持冷静, 相信自己有能力面对

8. - 3 _ 当我有问题时, 总会找到很多解决方法

9. - 3 - 当我在若境时, 总是能想到一些东西来度过

10. _ 4 _ 不管遇到什么, 总是有能力去处理 


\section{关于信仰和生意之间的研究}

这次学术研究主要是针对于基督徒老板们做生意和信仰之间的紧密关系。你们可以自由 回答这些调查问卷, 没有任何强制性, 而且你们的信息将根据国家个人隐私法进行保 护。

个人信息:

几岁了?_38_

性别: 男_

你的生活状态? (单身, 已婚, 离异, 丧偶) sposata

目前职业? restorante

出生地方、城市?_li shui qin tian

接下来这些问题, 请选择1-4之间, 然后根据个人的观点把相关答案填在空格上。

\begin{tabular}{|cccc|}
1 & 2 & 3 & 4 \\
\hline 完全不是 & 一点 & 相当 & 完全是
\end{tabular}

1. 4 如果我认真面对总是能够解决重大困难的

2. 2 如果有人反对我, 我能够找到解决的方法来到达我的目的

3. 1 _ 对我来说很容易坚持个人意志, 达到自己的目的

4. 2 我很有信心有效的面对一些突发事件

5. 3 我所拥有的资源足够可以面对不可预知的窘境

6. 4 _ 只要用心就可以解决大部分问题

7. 4 当遇到问题时, 会保持冷静, 相信自己有能力面对

8. 3 当我有问题时, 总会找到很多解决方法

9. 3 当我在宕境时, 总是能想到一些东西来度过

10. 4 _ 不管遇到什么, 总是有能力去处理 


\section{关于信仰和生意之间的研究}

这次学术研究主要是针对于基督徒老板们做生意和信仰之间的紧密关系。你们可以自由 回答这些调查问卷, 没有任何强制性, 而且你们的信息将根据国家个人隐私法进行保 护。

个人信息:

几岁了 26

性别: $\mathrm{x}$ 男 — 女

你的生活状态? (单身, 已婚, 离异, 丧偶) sposato

目前职业? imprenditore

出生地方、城市LISHUI

接下来这些问题, 请选择1-4之间, 然后根据个人的观点把相关答案填在空格上。

\begin{tabular}{|cccc|}
1 & 2 & 3 & 4 \\
\hline 完全不是 & 一点 & 相当 & 完全是
\end{tabular}

1. 4_ 如果我认真面对总是能够解决重大困难的

2. 4 - 如果有人反对我，我能够找到解决的方法来到达我的目的

3. - 2 - 对我来说很容易坚持个人意志, 达到自己的目的

4. _ 4_ 我很有信心有效的面对一些突发事件

5. 4 - 我所拥有的资源足够可以面对不可预知的窘境

6. _ 2 - 只要用心就可以解决大部分问题

7. 4 4 当遇到问题时, 会保持冷静, 相信自己有能力面对

8. - 3 - 当我有问题时, 总会找到很多解决方法

9. 3 - 3 当我在宕境时, 总是能想到一些东西来度过

10._3_ 不管遇到什么, 总是有能力去处理 


\section{Studio del rapporto tra fede e business:}

Questo studio intende investigare le connessioni tra la fede ed il business tra i cristiani evangelici cinesi. La vostra partecipazione è volontaria e i vostri dati saranno mantenuti anonimi e riservati.

Prima di tutti vorremo chiederti alcune domande su di te:

Quanti anni hai?_34_

Genere: __ X_Maschio __ Femmina

Qual è il tuo status? (E. g., single, sposato, divorziato, etc.) sposato

Che lavoro fai? Imprendtore

Hai iniziato tu il business o lavori per altri? Da solo

Dove sei nato (paese e città? Wenzhou

Per le prossime domande, per favore scegli un numero 1-4 e scrivilo negli spazi bianchi per ciascuna affermazione al fine di indicare quanto condividi con quell'affermazione.

\begin{tabular}{|cccc|}
1 & 2 & 3 & 4 \\
\hline Per nulla vero & Poco vero & Abbastanza & Totalmente \\
& & vero & vero
\end{tabular}

1. ___ _ _ Riesco sempre a risolvere problemi difficili se ci provo abbastanza seriamente

2. __ _ ___ Se qualcuno mi contrasta, posso trovare il modo o il sistema di ottenere ciò che voglio

3. _ _ _ Per me è facile attenermi alle mie intenzioni e raggiungere i miei obiettivi

4. _ 4 __ Ho fiducia di poter affrontare efficacemente eventi inattesi

5. _ _ _ G Grazie alle mie risorse, so come gestire situazioni impreviste

6. __ _ P Posso risolvere la maggior parte dei problemi se ci metto il necessario impegno

7. ___ Rimango calmo nell'affrontare le difficoltà perché posso confidare nelle mie capacità di fronteggiarle

8. _ _ _ _ Quando mi trovo di fronte ad un problema, di solito trovo parecchie soluzioni

9. _3_ Se sono in "panne", posso sempre pensare a qualcosa da mettere in atto

10. __ _ _ Non importa quello che mi può capitare, di solito sono in grado di gestirlo 


\section{关于信仰和生意之间的研究}

这次学术研究主要是针对于基督徒老板们做生意和信仰之间的紧密关系。你们可以自由 回答这些调查问卷, 没有任何强制性, 而且你们的信息将根据国家个人隐私法进行保 护。

个人信息:

几岁了?_26_

性别:_X_男_— 女

你的生活状态? (单身, 已婚, 离异, 丧偶) single

目前职业? addetto marketing

出生地方、城市? Zheijian

接下来这些问题, 请选择1-4之间, 然后根据个人的观点把相关答案填在空格上。

\begin{tabular}{|cccc|}
1 & 2 & 3 & 4 \\
\hline 完全不是 & 一点 & 相当 & 完全是
\end{tabular}

1. 3 如果我认真面对总是能够解决重大困难的

2. 3 如果有人反对我，我能够找到解决的方法来到达我的目的

3. 4 _ 对我来说很容易坚持个人意志, 达到自己的目的

4. 3_ 我很有信心有效的面对一些突发事件

5. 1_ 我所拥有的资源足够可以面对不可预知的窘境

6. 3_ 只要用心就可以解决大部分问题

7. 2_ 当遇到问题时, 会保持冷静, 相信自己有能力面对

8. 3 _ 当我有问题时, 总会找到很多解决方法

9. 2 _ 当我在若境时, 总是能想到一些东西来度过

10._3_ 不管遇到什么, 总是有能力去处理 


\section{关于信仰和生意之间的研究}

这次学术研究主要是针对于基督徒老板们做生意和信仰之间的紧密关系。你们可以自由 回答这些调查问卷, 没有任何强制性, 而且你们的信息将根据国家个人隐私法进行保 护。

个人信息:

几岁了?_32

性别: X_— 男 — 女

你的生活状态? (单身, 已婚, 离异, 丧偶) sposato

目前职业? barista

出生地方、城市? wenzhou

接下来这些问题, 请选择1-4之间, 然后根据个人的观点把相关答案填在空格上。

\begin{tabular}{|cccc|}
1 & 2 & 3 & 4 \\
\hline 完全不是 & 一点 & 相当 & 完全是
\end{tabular}

1. - 4 如果我认真面对总是能够解决重大困难的

2. - 4 一 如果有人反对我, 我能够找到解决的方法来到达我的目的

3. - 4 一 对我来说很容易坚持个人意志, 达到自己的目的

4. - 4 _ 我很有信心有效的面对一些突发事件

5. - 4 — 我所拥有的资源足够可以面对不可预知的窘境

6. _ - _ 只要用心就可以解决大部分问题

7. - 4 当遇到问题时, 会保持冷静, 相信自己有能力面对

8. - 4 — 当我有问题时, 总会找到很多解决方法

9. - 4 _ 当我在宕境时, 总是能想到一些东西来度过

10. _ 4 _ 不管遇到什么, 总是有能力去处理 


\section{关于信仰和生意之间的研究}

这次学术研究主要是针对于基督徒老板们做生意和信仰之间的紧密关系。你们可以自由 回答这些调查问卷, 没有任何强制性, 而且你们的信息将根据国家个人隐私法进行保 护。

个人信息:

几岁了? 45

性别: X_男_— 女

你的生活状态? (单身, 已婚, 离异, 丧偶) sposato

目前职业? president of association of network of entreprises

出生地方、城市? Zhejian

接下来这些问题, 请选择1-4之间, 然后根据个人的观点把相关答案填在空格上。

\begin{tabular}{|cccc|}
\hline 1 & 2 & 3 & 4 \\
\hline 完全不是 & 一点 & 相当 & 完全是
\end{tabular}

1. - 1 — 如果我认真面对总是能够解决重大困难的

2. 2 2 - 如果有人反对我, 我能够找到解决的方法来到达我的目的

3. - 3_ 对我来说很容易坚持个人意志, 达到自己的目的

4. 一 4 _ 我很有信心有效的面对一些突发事件

5. 2 2 - 我所拥有的资源足够可以面对不可预知的窘境

6. - 4 _ 只要用心就可以解决大部分问题

7. 一 - — 当遇到问题时, 会保持冷静, 相信自己有能力面对

8. - 3 — 当我有问题时, 总会找到很多解决方法

9. 一 4 _ 当我在若境时, 总是能想到一些东西来度过

10. _ 3 _ 不管遇到什么, 总是有能力去处理 


\section{关于信仰和生意之间的研究}

这次学术研究主要是针对于基督徒老板们做生意和信仰之间的紧密关系。你们可以自由 回答这些调查问卷, 没有任何强制性, 而且你们的信息将根据国家个人隐私法进行保 护。

个人信息:

几岁了?_46

性别: 男_—_ 女

你的生活状态? (单身, 已婚, 离异, 丧偶) sposata

目前职业? libera professionista

出生地方、城市? wenzhou

接下来这些问题, 请选择1-4之间, 然后根据个人的观点把相关答案填在空格上。

\begin{tabular}{|cccc|}
\hline 1 & 2 & 3 & 4 \\
\hline 完全不是 & 一点 & 相当 & 完全是
\end{tabular}

1. 3 - 3 如果我认真面对总是能够解决重大困难的

2. 2 2 如果有人反对我, 我能够找到解决的方法来到达我的目的

3. 2 2 - 对我来说很容易坚持个人意志, 达到自己的目的

4. _ 3 我很有信心有效的面对一些突发事件

5. 3 我所拥有的资源足够可以面对不可预知的窘境

6. _ _ 3 只要用心就可以解决大部分问题

7. —3 当遇到问题时, 会保持冷静, 相信自己有能力面对

8. _ _ 2 当我有问题时, 总会找到很多解决方法

9. 3 当我在若境时, 总是能想到一些东西来度过

10.__ 2 不管遇到什么, 总是有能力去处理 


\section{关于信仰和生意之间的研究}

这次学术研究主要是针对于基督徒老板们做生意和信仰之间的紧密关系。你们可以自由 回答这些调查问卷, 没有任何强制性, 而且你们的信息将根据国家个人隐私法进行保 护。

个人信息:

几岁了?_29_

性别: 男 X_ 女

你的生活状态? (单身, 已婚, 离异, 丧偶) married

目前职业? boss of furnishing company

出生地方、城市? Wenzhou

接下来这些问题, 请选择1-4之间, 然后根据个人的观点把相关答案填在空格上。

\begin{tabular}{|cccc|}
1 & 2 & 3 & 4 \\
\hline 完全不是 & 一点 & 相当 & 完全是
\end{tabular}

1. 3_ 如果我认真面对总是能够解决重大困难的

2. - 2 如果有人反对我, 我能够找到解决的方法来到达我的目的

3. - 3 _ 对我来说很容易坚持个人意志, 达到自己的目的

4. _3_ 我很有信心有效的面对一些突发事件

5._2_ 我所拥有的资源足够可以面对不可预知的窘境

6. _ - _ 只要用心就可以解决大部分问题

7. - 3 — 当遇到问题时, 会保持冷静, 相信自己有能力面对

8. - 3 — 当我有问题时, 总会找到很多解决方法

9. _ 2 _ 当我在若境时, 总是能想到一些东西来度过

10._2_ 不管遇到什么, 总是有能力去处理 


\section{关于信仰和生意之间的研究}

这次学术研究主要是针对于基督徒老板们做生意和信仰之间的紧密关系。你们可以自由 回答这些调查问卷, 没有任何强制性, 而且你们的信息将根据国家个人隐私法进行保 护。

个人信息:

几岁了?_26_

性别: X_—男_— 女

你的生活状态? (单身, 已婚, 离异, 丧偶) single

目前职业? sales manager and owner of clothing company

出生地方、城市? Nanjing

接下来这些问题, 请选择1-4之间, 然后根据个人的观点把相关答案填在空格上。

\begin{tabular}{|cccc|}
1 & 2 & 3 & 4 \\
\hline 完全不是 & 一点 & 相当 & 完全是
\end{tabular}

1. 4 _ 如果我认真面对总是能够解决重大困难的

2. - 3 — 如果有人反对我, 我能够找到解决的方法来到达我的目的

3. - 4 一 对我来说很容易坚持个人意志, 达到自己的目的

4. - 4 _ 我很有信心有效的面对一些突发事件

5. - 3 我所拥有的资源足够可以面对不可预知的窘境

6. _ - _ 只要用心就可以解决大部分问题

7. - 4 — 当遇到问题时, 会保持冷静, 相信自己有能力面对

8. - 3 — 当我有问题时, 总会找到很多解决方法

9. 一 4 _ 当我在若境时, 总是能想到一些东西来度过

10. _ 4 _ 不管遇到什么, 总是有能力去处理 


\section{关于信仰和生意之间的研究}

这次学术研究主要是针对于基督徒老板们做生意和信仰之间的紧密关系。你们可以自由 回答这些调查问卷, 没有任何强制性, 而且你们的信息将根据国家个人隐私法进行保 护。

个人信息:

几岁了?_19_

性别: 男 X_ 女

你的生活状态? (单身, 已婚, 离异, 丧偶) single

目前职业? psicologist

出生地方、城市? Heilongjiang

接下来这些问题, 请选择1-4之间, 然后根据个人的观点把相关答案填在空格上。

\begin{tabular}{|cccc|}
1 & 2 & 3 & 4 \\
\hline 完全不是 & 一点 & 相当 & 完全是
\end{tabular}

1. 4_ 如果我认真面对总是能够解决重大困难的

2. 4_ 如果有人反对我, 我能够找到解决的方法来到达我的目的

3. - 4 - 对我来说很容易坚持个人意志, 达到自己的目的

4. _ 3 _ 我很有信心有效的面对一些突发事件

5. 2 - _ 我所拥有的资源足够可以面对不可预知的窘境

6. 4 4 只要用心就可以解决大部分问题

7. 4 4 当遇到问题时, 会保持冷静, 相信自己有能力面对

8. _ 3 - 当我有问题时, 总会找到很多解决方法

9. 3 3 - 当我在宕境时, 总是能想到一些东西来度过

10. _ 3 - 不管遇到什么, 总是有能力去处理 


\section{关于信仰和生意之间的研究}

这次学术研究主要是针对于基督徒老板们做生意和信仰之间的紧密关系。你们可以自由 回答这些调查问卷，没有任何强制性，而且你们的信息将根据国家个人隐私法进行保 护。

个人信息:

几岁了?_25

性别:_X_男_— 女

你的生活状态? (单身, 已婚, 离异, 丧偶) married

目前职业? Bar owner

出生地方、城市? Wenzhou

接下来这些问题, 请选择1-4之间, 然后根据个人的观点把相关答案填在空格上。

\begin{tabular}{|cccc|}
1 & 2 & 3 & 4 \\
\hline 完全不是 & 一点 & 相当 & 完全是
\end{tabular}

1. - 3 _ 如果我认真面对总是能够解决重大困难的

2. - 2 - 如果有人反对我, 我能够找到解决的方法来到达我的目的

3. - 3 - 对我来说很容易坚持个人意志, 达到自己的目的

4. 2_—我很有信心有效的面对一些突发事件

5. _ 2 我所拥有的资源足够可以面对不可预知的窘境

6. _ 3 _ 只要用心就可以解决大部分问题

7. _ 2 — 当遇到问题时, 会保持冷静, 相信自己有能力面对

8. _ 2 当我有问题时, 总会找到很多解决方法

9. _ 2 _ 当我在若境时, 总是能想到一些东西来度过

10._3_ 不管遇到什么, 总是有能力去处理 


\section{关于信仰和生意之间的研究}

这次学术研究主要是针对于基督徒老板们做生意和信仰之间的紧密关系。你们可以自由 回答这些调查问卷, 没有任何强制性, 而且你们的信息将根据国家个人隐私法进行保 护。

个人信息:

几岁了?_34

性别: X_男_— 女

你的生活状态? (单身, 已婚, 离异, 丧偶) single

目前职业? restaurant owner

出生地方、城市? Chong Ching

接下来这些问题, 请选择1-4之间, 然后根据个人的观点把相关答案填在空格上。

\begin{tabular}{|cccc|}
1 & 2 & 3 & 4 \\
\hline 完全不是 & 一点 & 相当 & 完全是
\end{tabular}

1. - 4 如果我认真面对总是能够解决重大困难的

2. - 3 - 如果有人反对我，我能够找到解决的方法来到达我的目的

3. 3 3 - 对我来说很容易坚持个人意志, 达到自己的目的

4. - 4 _ 我很有信心有效的面对一些突发事件

5. 3 - _ 我所拥有的资源足够可以面对不可预知的窘境

6. _ 3 - 只要用心就可以解决大部分问题

7. _ 2 — 当遇到问题时, 会保持冷静, 相信自己有能力面对

8. - 3 — 当我有问题时, 总会找到很多解决方法

9. - 3 - 当我在宕境时, 总是能想到一些东西来度过

10._4_ 不管遇到什么, 总是有能力去处理 


\section{关于信仰和生意之间的研究}

这次学术研究主要是针对于基督徒老板们做生意和信仰之间的紧密关系。你们可以自由 回答这些调查问卷, 没有任何强制性, 而且你们的信息将根据国家个人隐私法进行保 护。

个人信息:

几岁了?_25

性别: X_男_— 女

你的生活状态? (单身, 已婚, 离异, 丧偶) single

目前职业? web manager

出生地方、城市? Hu Nan

接下来这些问题, 请选择1-4之间, 然后根据个人的观点把相关答案填在空格上。

\begin{tabular}{|cccc|}
1 & 2 & 3 & 4 \\
\hline 完全不是 & 一点 & 相当 & 完全是
\end{tabular}

1. 3 3 如果我认真面对总是能够解决重大困难的

2. - 3 - 如果有人反对我, 我能够找到解决的方法来到达我的目的

3. - 4 一 对我来说很容易坚持个人意志, 达到自己的目的

4. - 3 — 我很有信心有效的面对一些突发事件

5. _ 1_ 我所拥有的资源足够可以面对不可预知的窘境

6. _ 3 _ 只要用心就可以解决大部分问题

7. _ _ _ 当遇到问题时, 会保持冷静, 相信自己有能力面对

8. _ 3 _ 当我有问题时, 总会找到很多解决方法

9. - 2 _ 当我在若境时, 总是能想到一些东西来度过

10. _ 3 _ 不管遇到什么, 总是有能力去处理 


\section{关于信仰和生意之间的研究}

这次学术研究主要是针对于基督徒老板们做生意和信仰之间的紧密关系。你们可以自由 回答这些调查问卷, 没有任何强制性, 而且你们的信息将根据国家个人隐私法进行保 护。

个人信息:

几岁了?_28_

性别: X_男_— 女

你的生活状态? (单身, 已婚, 离异, 丧偶) single

目前职业? imprenditore

出生地方、城市? Hebei Cina

接下来这些问题, 请选择1-4之间, 然后根据个人的观点把相关答案填在空格上。

\begin{tabular}{|cccc|}
\hline 1 & 2 & 3 & 4 \\
\hline 完全不是 & 一点 & 相当 & 完全是
\end{tabular}

1. 3 3 如果我认真面对总是能够解决重大困难的

2. - 2 - 如果有人反对我, 我能够找到解决的方法来到达我的目的

3. - 3 — 对我来说很容易坚持个人意志, 达到自己的目的

4. - 3 _ 我很有信心有效的面对一些突发事件

5. 2 2 - 我所拥有的资源足够可以面对不可预知的窘境

6. _ - _ 只要用心就可以解决大部分问题

7. _ 3 - 当遇到问题时, 会保持冷静, 相信自己有能力面对

8. 3 - _ 当我有问题时, 总会找到很多解决方法

9. - 2 _ 当我在若境时, 总是能想到一些东西来度过

10. _ 2 _ 不管遇到什么, 总是有能力去处理 


\section{关于信仰和生意之间的研究}

这次学术研究主要是针对于基督徒老板们做生意和信仰之间的紧密关系。你们可以自由 回答这些调查问卷, 没有任何强制性, 而且你们的信息将根据国家个人隐私法进行保 护。

个人信息:

几岁了?_27_

性别: X_—男—— 女

你的生活状态? (单身, 已婚, 离异, 丧偶) single

目前职业? Restaurant owner

出生地方、城市? Beijing

接下来这些问题, 请选择1-4之间, 然后根据个人的观点把相关答案填在空格上。

\begin{tabular}{|cccc|}
1 & 2 & 3 & 4 \\
\hline 完全不是 & 一点 & 相当 & 完全是
\end{tabular}

1. - 1_ 如果我认真面对总是能够解决重大困难的

2. - 2 如果有人反对我, 我能够找到解决的方法来到达我的目的

3. - 3_ 对我来说很容易坚持个人意志, 达到自己的目的

4. - 4 _ 我很有信心有效的面对一些突发事件

5. 2 - - 我所拥有的资源足够可以面对不可预知的窘境

6. _ - _ 只要用心就可以解决大部分问题

7. — 4 当遇到问题时, 会保持冷静, 相信自己有能力面对

8. _ 3 — 当我有问题时, 总会找到很多解决方法

9. 一 4 _ 当我在若境时, 总是能想到一些东西来度过

10. _ 3 _ 不管遇到什么, 总是有能力去处理 


\section{关于信仰和生意之间的研究}

这次学术研究主要是针对于基督徒老板们做生意和信仰之间的紧密关系。你们可以自由 回答这些调查问卷, 没有任何强制性, 而且你们的信息将根据国家个人隐私法进行保 护。

个人信息:

几岁了?_43

性别: 男 X 一 女

你的生活状态? (单身, 已婚, 离异, 丧偶) Married

目前职业? factory owner

出生地方、城市? Tonglu

接下来这些问题, 请选择1-4之间, 然后根据个人的观点把相关答案填在空格上。

\begin{tabular}{|cccc|}
1 & 2 & 3 & 4 \\
\hline 完全不是 & 一点 & 相当 & 完全是
\end{tabular}

1. 3_ 如果我认真面对总是能够解决重大困难的

2. - 2 如果有人反对我, 我能够找到解决的方法来到达我的目的

3. - 3 _ 对我来说很容易坚持个人意志, 达到自己的目的

4. 3_ 我很有信心有效的面对一些突发事件

5. - 3 我所拥有的资源足够可以面对不可预知的窘境

6. _ - _ 只要用心就可以解决大部分问题

7. - 2 - 当遇到问题时, 会保持冷静, 相信自己有能力面对

8. 느 _ 当我有问题时, 总会找到很多解决方法

9. - 3 — 当我在宕境时, 总是能想到一些东西来度过

10._2_ 不管遇到什么, 总是有能力去处理 


\section{关于信仰和生意之间的研究}

这次学术研究主要是针对于基督徒老板们做生意和信仰之间的紧密关系。你们可以自由 回答这些调查问卷, 没有任何强制性, 而且你们的信息将根据国家个人隐私法进行保 护。

个人信息:

几岁了?_44

性别: 男 X_ 女

你的生活状态? (单身, 已婚, 离异, 丧偶) married

目前职业? manager of clothing factory

出生地方、城市? Tonglu

接下来这些问题, 请选择1-4之间, 然后根据个人的观点把相关答案填在空格上。

\begin{tabular}{|cccc|}
1 & 2 & 3 & 4 \\
\hline 完全不是 & 一点 & 相当 & 完全是
\end{tabular}

1. 3_ 如果我认真面对总是能够解决重大困难的

2. - 2 如果有人反对我, 我能够找到解决的方法来到达我的目的

3. - 3 _ 对我来说很容易坚持个人意志, 达到自己的目的

4. - 3 _ 我很有信心有效的面对一些突发事件

5. - 3 - 我所拥有的资源足够可以面对不可预知的窘境

6. _ - _ 只要用心就可以解决大部分问题

7. _ _ _ 当遇到问题时, 会保持冷静, 相信自己有能力面对

8. 一 2 — 当我有问题时, 总会找到很多解决方法

9. - 3 - 当我在若境时, 总是能想到一些东西来度过

10. _ 2 _ 不管遇到什么, 总是有能力去处理 


\section{关于信仰和生意之间的研究}

这次学术研究主要是针对于基督徒老板们做生意和信仰之间的紧密关系。你们可以自由 回答这些调查问卷, 没有任何强制性, 而且你们的信息将根据国家个人隐私法进行保 护。

个人信息:

几岁了?_28_

性别: 男 X_ 女

你的生活状态? (单身, 已婚, 离异, 丧偶) singola

目前职业? assistente alla clientela

出生地方、城市? milano

接下来这些问题, 请选择1-4之间, 然后根据个人的观点把相关答案填在空格上。

\begin{tabular}{|cccc|}
1 & 2 & 3 & 4 \\
\hline 完全不是 & 一点 & 相当 & 完全是
\end{tabular}

1. 3 _ 如果我认真面对总是能够解决重大困难的

2. - 3 - 如果有人反对我, 我能够找到解决的方法来到达我的目的

3. - 3_ 对我来说很容易坚持个人意志, 达到自己的目的

4. - 3 _ 我很有信心有效的面对一些突发事件

5. 2 - _ 我所拥有的资源足够可以面对不可预知的窘境

6. _ 3 _ 只要用心就可以解决大部分问题

7. _ _ _ 当遇到问题时, 会保持冷静, 相信自己有能力面对

8. 느 _ 当我有问题时, 总会找到很多解决方法

9. _ 2 当我在若境时, 总是能想到一些东西来度过

10._2_ 不管遇到什么, 总是有能力去处理 


\section{关于信仰和生意之间的研究}

这次学术研究主要是针对于基督徒老板们做生意和信仰之间的紧密关系。你们可以自由 回答这些调查问卷, 没有任何强制性, 而且你们的信息将根据国家个人隐私法进行保 护。

个人信息:

几岁了? 28

性别:_X_男_— 女

你的生活状态? (单身, 已婚, 离异, 丧偶) Sposato

目前职业? Project manager

出生地方、城市? Henan

接下来这些问题, 请选择1-4之间, 然后根据个人的观点把相关答案填在空格上。

\begin{tabular}{|cccc|}
1 & 2 & 3 & 4 \\
\hline 完全不是 & 一点 & 相当 & 完全是
\end{tabular}

1. - 4 如果我认真面对总是能够解决重大困难的

2. - 3 如果有人反对我, 我能够找到解决的方法来到达我的目的

3. 一 - _ 一 对我来说很容易坚持个人意志, 达到自己的目的

4. - 4 _ 我很有信心有效的面对一些突发事件

5. - 3 - 我所拥有的资源足够可以面对不可预知的窘境

6. _ - _ 只要用心就可以解决大部分问题

7. — - _ 当遇到问题时, 会保持冷静, 相信自己有能力面对

8. - 3 — 当我有问题时, 总会找到很多解决方法

9. 一 4 _ 当我在若境时, 总是能想到一些东西来度过

10. _ 4 _ 不管遇到什么, 总是有能力去处理 


\section{关于信仰和生意之间的研究}

这次学术研究主要是针对于基督徒老板们做生意和信仰之间的紧密关系。你们可以自由 回答这些调查问卷, 没有任何强制性, 而且你们的信息将根据国家个人隐私法进行保 护。

个人信息:

几岁了? 20_

性别: X_— 男 — 女

你的生活状态? (单身, 已婚, 离异, 丧偶) single

目前职业? job founder

出生地方、城市? Jilin

接下来这些问题, 请选择1-4之间, 然后根据个人的观点把相关答案填在空格上。

\begin{tabular}{|cccc|}
1 & 2 & 3 & 4 \\
\hline 完全不是 & 一点 & 相当 & 完全是
\end{tabular}

1. 3 - _ 如果我认真面对总是能够解决重大困难的

2. - 2 如果有人反对我, 我能够找到解决的方法来到达我的目的

3. - 3 _ 对我来说很容易坚持个人意志, 达到自己的目的

4. _ 3 _ 我很有信心有效的面对一些突发事件

5. 3 - 我所拥有的资源足够可以面对不可预知的窘境

6. _ - 4 只要用心就可以解决大部分问题

7. _ 2 — 当遇到问题时, 会保持冷静, 相信自己有能力面对

8. - 2 — 当我有问题时, 总会找到很多解决方法

9. - 3 — 当我在宕境时, 总是能想到一些东西来度过

10._2_ 不管遇到什么, 总是有能力去处理 


\section{关于信仰和生意之间的研究}

这次学术研究主要是针对于基督徒老板们做生意和信仰之间的紧密关系。你们可以自由 回答这些调查问卷, 没有任何强制性, 而且你们的信息将根据国家个人隐私法进行保 护。

个人信息:

几岁了?_26_

性别: — 男 _ X_女

你的生活状态? (单身, 已婚, 离异, 丧偶) single

目前职业? Banker

出生地方、城市? Taizhou

接下来这些问题, 请选择1-4之间, 然后根据个人的观点把相关答案填在空格上。

\begin{tabular}{|cccc|}
1 & 2 & 3 & 4 \\
\hline 完全不是 & 一点 & 相当 & 完全是
\end{tabular}

1. 3_ 如果我认真面对总是能够解决重大困难的

2. - 2 如果有人反对我, 我能够找到解决的方法来到达我的目的

3. - 3_ 对我来说很容易坚持个人意志, 达到自己的目的

4. - 2 — 我很有信心有效的面对一些突发事件

5. _ 2 我所拥有的资源足够可以面对不可预知的窘境

6. _ 3 _ 只要用心就可以解决大部分问题

7. - 2 - 当遇到问题时, 会保持冷静, 相信自己有能力面对

8. 一 2 — 当我有问题时, 总会找到很多解决方法

9. _ 2 — 当我在宕境时, 总是能想到一些东西来度过

10. 3 _ 不管遇到什么, 总是有能力去处理 


\section{关于信仰和生意之间的研究}

这次学术研究主要是针对于基督徒老板们做生意和信仰之间的紧密关系。你们可以自由 回答这些调查问卷, 没有任何强制性, 而且你们的信息将根据国家个人隐私法进行保 护。

个人信息:

几岁了_24

你的生活状态? (单身, 已婚, 离异, 丧偶) singola

目前职业? ristorante

出生地方、城市?_wenzhou

接下来这些问题, 请选择1-4之间, 然后根据个人的观点把相关答案填在空格上。

\begin{tabular}{|cccc|}
1 & 2 & 3 & 4 \\
\hline 完全不是 & 一点 & 相当 & 完全是
\end{tabular}

1. 3 - 3 如果我认真面对总是能够解决重大困难的

2. - 4 _ 如果有人反对我, 我能够找到解决的方法来到达我的目的

3. 4 _ 对我来说很容易坚持个人意志, 达到自己的目的

4. 2__ 我很有信心有效的面对一些突发事件

5. 2 _ 我所拥有的资源足够可以面对不可预知的窘境

6. 4 只要用心就可以解决大部分问题

7. 1_ 当遇到问题时, 会保持冷静, 相信自己有能力面对

8. - 2 — 当我有问题时, 总会找到很多解决方法

9. 3_— 当我在若境时, 总是能想到一些东西来度过

10._2_ 不管遇到什么, 总是有能力去处理 


\section{关于信仰和生意之间的研究}

这次学术研究主要是针对于基督徒老板们做生意和信仰之间的紧密关系。你们可以自由 回答这些调查问卷, 没有任何强制性, 而且你们的信息将根据国家个人隐私法进行保 护。

个人信息:

几岁了?_47

性别: X_—男—— 女

你的生活状态? (单身, 已婚, 离异, 丧偶) married

目前职业? Boss of Clothing factory

出生地方、城市? Tonglu

接下来这些问题, 请选择1-4之间, 然后根据个人的观点把相关答案填在空格上。

\begin{tabular}{|cccc|}
1 & 2 & 3 & 4 \\
\hline 完全不是 & 一点 & 相当 & 完全是
\end{tabular}

1. 3 如果我认真面对总是能够解决重大困难的

2. 2 如果有人反对我, 我能够找到解决的方法来到达我的目的

3. 3_— 对我来说很容易坚持个人意志, 达到自己的目的

4. - 2 — 我很有信心有效的面对一些突发事件

5. 2 2 我所拥有的资源足够可以面对不可预知的窘境

6. 3 3 - 只要用心就可以解决大部分问题

7. 2_— 当遇到问题时, 会保持冷静, 相信自己有能力面对

8. _2_ 当我有问题时, 总会找到很多解决方法

9. _ 2 — 当我在宕境时, 总是能想到一些东西来度过

10._3_ 不管遇到什么, 总是有能力去处理 


\section{关于信仰和生意之间的研究}

这次学术研究主要是针对于基督徒老板们做生意和信仰之间的紧密关系。你们可以自由 回答这些调查问卷, 没有任何强制性, 而且你们的信息将根据国家个人隐私法进行保 护。

个人信息:

几岁了?_47_

性别: X_— 男 — 女

你的生活状态? (单身, 已婚, 离异, 丧偶) sposato

目前职业? commerciante

出生地方、城市wenzhou

接下来这些问题, 请选择1-4之间, 然后根据个人的观点把相关答案填在空格上。

\begin{tabular}{|cccc|}
1 & 2 & 3 & 4 \\
\hline 完全不是 & 一点 & 相当 & 完全是
\end{tabular}

1. 3 - 3 如果我认真面对总是能够解决重大困难的

2. - 2 - 如果有人反对我, 我能够找到解决的方法来到达我的目的

3. - 3 _ 对我来说很容易坚持个人意志, 达到自己的目的

4. _ 2 - 我很有信心有效的面对一些突发事件

5. _ 2 - 我所拥有的资源足够可以面对不可预知的窘境

6. 3 3 - 只要用心就可以解决大部分问题

7. _ 2 — 当遇到问题时, 会保持冷静, 相信自己有能力面对

8. _ 2 - 当我有问题时, 总会找到很多解决方法

9. - 2 - 当我在宕境时, 总是能想到一些东西来度过

10. _ 3 _ 不管遇到什么, 总是有能力去处理 


\section{关于信仰和生意之间的研究}

这次学术研究主要是针对于基督徒老板们做生意和信仰之间的紧密关系。你们可以自由 回答这些调查问卷, 没有任何强制性, 而且你们的信息将根据国家个人隐私法进行保 护。

个人信息:

几岁了?_29_

性别:_X_男_— 女

你的生活状态? (单身, 已婚, 离异, 丧偶) single

目前职业? Restaurant owner

出生地方、城市? Beijing

接下来这些问题, 请选择1-4之间, 然后根据个人的观点把相关答案填在空格上。

\begin{tabular}{|cccc|}
1 & 2 & 3 & 4 \\
\hline 完全不是 & 一点 & 相当 & 完全是
\end{tabular}

1. 3 如果我认真面对总是能够解决重大困难的

2. 2_一如果有人反对我, 我能够找到解决的方法来到达我的目的

3. - 2 _ 对我来说很容易坚持个人意志, 达到自己的目的

4. _ 3 _ 我很有信心有效的面对一些突发事件

5. 3 _ 我所拥有的资源足够可以面对不可预知的窘境

6. _ - 3 只要用心就可以解决大部分问题

7. - 3 当遇到问题时, 会保持冷静, 相信自己有能力面对

8. - 2 — 当我有问题时, 总会找到很多解决方法

9. - 3 _ 当我在若境时, 总是能想到一些东西来度过

10._2_ 不管遇到什么, 总是有能力去处理 


\section{关于信仰和生意之间的研究}

这次学术研究主要是针对于基督徒老板们做生意和信仰之间的紧密关系。你们可以自由 回答这些调查问卷, 没有任何强制性, 而且你们的信息将根据国家个人隐私法进行保 护。

个人信息:

几岁了?_38_

性别: 男_X_ 女

你的生活状态? (单身, 已婚, 离异, 丧偶) divorziata

目前职业? ristoratrice

出生地方、城市? Wenzhou

接下来这些问题, 请选择1-4之间, 然后根据个人的观点把相关答案填在空格上。

\begin{tabular}{|cccc|}
1 & 2 & 3 & 4 \\
\hline 完全不是 & 一点 & 相当 & 完全是
\end{tabular}

1. - 4 _ 如果我认真面对总是能够解决重大困难的

2. - 3 如果有人反对我, 我能够找到解决的方法来到达我的目的

3. - 4 _ 对我来说很容易坚持个人意志, 达到自己的目的

4. - 4 _ 我很有信心有效的面对一些突发事件

5. - 4 _ 我所拥有的资源足够可以面对不可预知的窘境

6. _ - _ 只要用心就可以解决大部分问题

7. 一 - — 当遇到问题时, 会保持冷静, 相信自己有能力面对

8. - 4 _ 当我有问题时, 总会找到很多解决方法

9. - 3 - 当我在若境时, 总是能想到一些东西来度过

10. _ 4 _ 不管遇到什么, 总是有能力去处理 


\section{关于信仰和生意之间的研究}

这次学术研究主要是针对于基督徒老板们做生意和信仰之间的紧密关系。你们可以自由 回答这些调查问卷, 没有任何强制性, 而且你们的信息将根据国家个人隐私法进行保 护。

个人信息:

几岁了?_31_

性别:_X_男_— 女

你的生活状态? (单身, 已婚, 离异, 丧偶) sposato

目前职业? commerciante

出生地方、城市? Cina Wenzhou

接下来这些问题, 请选择1-4之间, 然后根据个人的观点把相关答案填在空格上。

\begin{tabular}{|cccc|}
1 & 2 & 3 & 4 \\
\hline 完全不是 & 一点 & 相当 & 完全是
\end{tabular}

1. _ - _ 如果我认真面对总是能够解决重大困难的

2. - 2 如果有人反对我, 我能够找到解决的方法来到达我的目的

3. - 2 _ 对我来说很容易坚持个人意志, 达到自己的目的

4. 느 - 我很有信心有效的面对一些突发事件

5. 3_ 我所拥有的资源足够可以面对不可预知的窘境

6. _2_ 只要用心就可以解决大部分问题

7. - 3 当遇到问题时, 会保持冷静, 相信自己有能力面对

8. 一 2 — 当我有问题时, 总会找到很多解决方法

9. - 3 — 当我在宕境时, 总是能想到一些东西来度过

10._1_ 不管遇到什么, 总是有能力去处理 


\section{关于信仰和生意之间的研究}

这次学术研究主要是针对于基督徒老板们做生意和信仰之间的紧密关系。你们可以自由 回答这些调查问卷, 没有任何强制性, 而且你们的信息将根据国家个人隐私法进行保 护。

个人信息:

几岁了?_56

性别: X_— 男 — 女

你的生活状态? (单身, 已婚, 离异, 丧偶) sposato

目前职业? ristorante (ora pensionato)

出生地方、城市? Wenzhou

接下来这些问题, 请选择1-4之间, 然后根据个人的观点把相关答案填在空格上。

\begin{tabular}{|cccc|}
1 & 2 & 3 & 4 \\
\hline 完全不是 & 一点 & 相当 & 完全是
\end{tabular}

1. 3 - 如果我认真面对总是能够解决重大困难的

2. - 2 - 如果有人反对我, 我能够找到解决的方法来到达我的目的

3. - 2 _ 对我来说很容易坚持个人意志, 达到自己的目的

4. - 3 _ 我很有信心有效的面对一些突发事件

5. 2 2 - 我所拥有的资源足够可以面对不可预知的窘境

6. 3 3 - 只要用心就可以解决大部分问题

7. 3 当遇到问题时, 会保持冷静, 相信自己有能力面对

8. _ 3 当我有问题时, 总会找到很多解决方法

9. 2 当我在若境时, 总是能想到一些东西来度过

10.__ 2 不管遇到什么, 总是有能力去处理 


\section{关于信仰和生意之间的研究}

这次学术研究主要是针对于基督徒老板们做生意和信仰之间的紧密关系。你们可以自由 回答这些调查问卷, 没有任何强制性, 而且你们的信息将根据国家个人隐私法进行保 护。

个人信息:

几岁了?_34_

性别: X_— 男 — 女

你的生活状态? (单身, 已婚, 离异, 丧偶) sposato

目前职业? tabaccaio

出生地方、城市? Zhejian

接下来这些问题, 请选择1-4之间, 然后根据个人的观点把相关答案填在空格上。

\begin{tabular}{|cccc|}
1 & 2 & 3 & 4 \\
\hline 完全不是 & 一点 & 相当 & 完全是
\end{tabular}

1. 3 _ 如果我认真面对总是能够解决重大困难的

2. 一 1 — 如果有人反对我, 我能够找到解决的方法来到达我的目的

3. - 3 _ 对我来说很容易坚持个人意志, 达到自己的目的

4. 2 2.5_ 我很有信心有效的面对一些突发事件

5. 2 2.5_ 我所拥有的资源足够可以面对不可预知的窘境

6. _ 3 _ 只要用心就可以解决大部分问题

7. - 3 — 当遇到问题时, 会保持冷静, 相信自己有能力面对

8. - 4 _ 当我有问题时, 总会找到很多解决方法

9. - 3 _ 当我在若境时, 总是能想到一些东西来度过

10._3_ 不管遇到什么, 总是有能力去处理 